UNIVERSITY OF ALBERTA

0004
$07693 \quad 13$ 


\section{Qx inbais

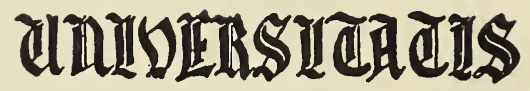

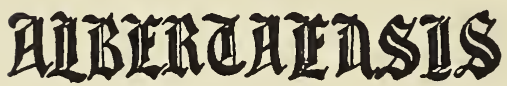

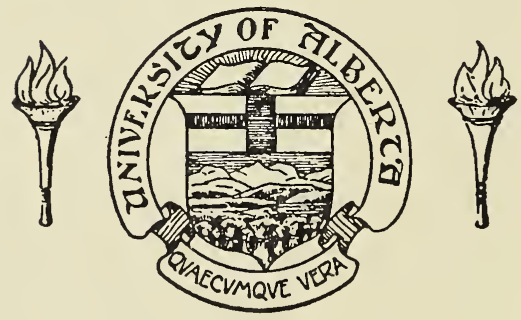


Digitized by the Internet Archive in 2018 with funding from University of Alberta Libraries 

MGGRAW-HILL PUBLIGATIONS IN THE A GRIGULTURAL SGIENGES

LEON J. COLE, Consulting Editor

ANIMAL NUTRITION 


\title{
MaGRAW-HILL PUBLICATIONS IN THE AGRICULTURAL SCIENCES
}

\author{
R. A. Brink, Consulting Editor
}

\author{
Adriance and Brison Propagation of Horticultural Plants \\ Brown - CotTon \\ Cruess - Commercial Fruit and Vegetable Products \\ Dickson. Diseases of Field Crops \\ Eckles, Combs, and Macy · Milk And Milk Products \\ Fawcett - Citrus Diseases \\ Fernald and Shepard - Applied Entomology \\ Gardner, Bradford, and Hooker . Fruit Production \\ Gustafson - Conservation of the Soll \\ Gustafson. Solls and Soll Management \\ Hayes and Garber - Breeding Crop Plants \\ Hayes and Immer Methods of Plant Breeding \\ Heald - Manual of Plant Diseases \\ Heald - Introduction to Plant Pathology \\ Herrington. Milk and Milk Processing \\ Hutcheson, Wolfe, and Kipps. Field Crops \\ Jenny FActors of SoIL Formation \\ Jull · Poultry Husbandry \\ Laurie and Ries. Floriculture \\ Leach - Insect Transmission of Plant Diseases \\ Little and Plastridge B Bovine Mastitis \\ Maynard · Animal Nutrition \\ Metcalf and Flint - Destructive and Useful Insects \\ Paterson-Statistical Technique in Agricultural Research \\ Peters. Livestock Production \\ Rather F Field CROPS \\ Rice - Breeding and Improvement of Farm Animals \\ Roadhouse and Henderson. The Market-milk Industry \\ Robbins, Crafts, and Raynor. WeEd Control \\ Schilletter and Richey. Textbook of General Horticulture \\ Thompson - Vegetable Crops \\ Waite P Poultry Science and Practice \\ Wilson - Grain Grops
}

The late Lcon J. Cole was Consulting Editor of this series from 1937 to 1948.

There are also the related series of McGraw-Hill Publications in the Botanical Sciences, of which Edmund W. Sinnott is Consulting Editor, and in the Zoological Sciences, of which A. Franklin Shull is Consulting Editor. Titles in the Agricultural Sciences were published in these series in the period 1917 to 1937. 


\title{
ANIMAL NUTRITION
}

BY

LEONARD A. MAYNARD, A.B., Ph.D., Sa.D.

Professor of Nutrition and Biochemistry and

Director of the School of Nutrition

Cornell University

Member, National Academy of Sciences

SEGOND EDITION

THIRD IMPRESSION

\author{
New York and London \\ MaGRAW-HILL BOOK COMPANY, ING。 \\ I 947
}




\section{ANIMAL NUTRITION}

Copyright, I 937, I947, BY THE MaGraw-Hill Book Company, Inc.

PRINTED IN THE UNITED STATES OF AMERICA

All rights reserved. This book, or parts thereof, may not be reproduced in any form without permission of the publishers. 


\section{PREFAGE TO THE SEGOND EDITION}

In the nine years since the first edition of this book appeared, striking advances, stimulated in many instances by the problems of the war emergency, have taken place in the field of nutrition. The discoveries with respect to vitamins have been particularly remarkable. Our knowledge of protein and mineral nutrition has also undergone a large development, and much new information has been gained regarding the nutritional roles of carbohydrates and fats as well. Thus a rather extensive revision of many sections of the text has been called for. In making these various changes and additions an effort has been made to keep the book close to its original size, and thus deletions of less important material have been made accordingly.

In making the revision an attempt has been made to cover the current literature through March, 1946. There has been only a limited opportunity, unfortunately, to take account of the results of the research which has been going on in foreign countries in the war years because the data have either remained unpublished or the journals containing them have not reached this country. For this reason, also, most of the new literature citations in the present revisions are to work carried out in the United States. It has been kept in mind that in listing papers as reference reading their availability in the libraries throughout the country is an important consideration. The student should not gain the idea thereby, however, that most of the new discoveries in the field of animal nutrition are being made in the United States. Such is far from the case.

The author wishes to acknowledge the many helpful suggestions for the revision of the text which he has received from teachers who have been using it in their classes. He is greatly indebted to his Cornell colleagues for active assistance, particularly to Professors J. K. Loosli and H. H. Williams who have aided in the preparation of the revision of several topics. His thanks are also due to Professors S. A. Asdell, LeRoy Barnes, K. C. Beeson, 
G. H. Ellis, W. A. Gortner, L. C. Norris, Fred Somers, and S. E. Smith who have read parts of the manuscript and made suggestions which have been incorporated. The painstaking technical assistance of Janet Eagle in compiling the literature citations, in the preparation of the indices, and in reading the proof is also gratefully acknowledged.

Leonard A. Maynard。

ITHACA, N. Y., April, 1946. 


\section{PREFACE TO THE FIRST EDITION}

The purpose of this book is to present the principles of nutrition and their applications in feeding practice. While these applications are made to farm animals primarily, consideration is also given to the broader relationships and significance of the basic principles. Much of the newer knowledge of nutrition, which has markedly improved the health and efficiency of both man and his animals, represents discoveries which have been made with the rat. The same underlying principles have found application in the conservation of wild life, the commercial rearing of fish and game, and even in the control or propagation of insects. Differences in anatomy and physiology and in food supply modify the application of the principles but do not destroy their basic usefulness. These facts are brought out in this book by using experiments with a variety of species as illustrations of the discussions presented.

Nutrition is a chemical process and its principles must be presented in chemical terms. It is assumed that the student has an elementary knowledge of organic chemistry and of physiology. The early chapters of this book provide a review and extension of this knowledge as related to those substances and processes with which nutrition deals. These discussions are limited to the essentials of the language in which the principles of nutrition must be presented.

In the discussion of growth, reproduction, lactation, and other body functions particular attention is given to the nutritive requirements of the various species of farm animals. But the major purpose is to teach how the facts of nutrition are being learned experimentally and how they find application in practice. A consideration of the detailed feeding practices which differ for the various species lies outside the scope of this book; but the discussions here included should provide a background for a better understanding of these practices as presented in the production courses for the various species. 
The knowledge of the principles of nutrition and of their application is far from complete. New discoveries are constantly being reported. In adding to our knowledge they inevitably cause some modification in the ideas previously held. Inevitably also, some of the reported discoveries prove to be only partially true. A textbook of nutrition must portray these developments, but it must avoid finality in matters which are in dispute or which require further testing as regards their practical applications. Such has been the aim in preparing this text.

Several considerations have governed the citations to the literature which have been made and the selection of general references included at the end of the various chapters. Some of the classical early contributions have been mentioned, and an attempt has been made to show very briefly the course of the development of the newer knowledge of nutrition by referring to typical studies which have marked its progress. Such a background is helpful for evaluating the significance of current contributions and for forecasting future developments. In discussing the very recent contributions to our knowledge citations are made to the experiments on which they are based in order that these publications may be consulted for more detailed information. In presenting current ideas which are in dispute, either as to fact or as to application, the literature which gives the divergent viewpoints is cited so that the student may have the opportunity to form his own judgment. The general references listed at the end of the different chapters furnish opportunity for collateral reading on the various topics presented. Providing the student with a bibliography of easily accessible sources has been a primary consideration in selecting these various references.

In preparing this text the author has been conscious of his temerity in undertaking the task. He has long felt the need for a textbook for his own classes, and this was the primary reason which led him to attempt the preparation of the present book. The material presented has been selected as a result of some twenty years' experience in teaching the principles of animal nutrition to undergraduate and graduate students at Cornell University. It is hoped that the book may be found useful by other teachers, although it is realized that courses covering the subject matter of animal nutrition are organized very differently at different institutions. The author will highly appreciate having 
his attention called to any errors found, and he will be glad to have criticisms and suggestions regarding the nature of the subject matter presented.

Through his long and close association with Professors C. M. McCay, F. B. Morrison, and S. A. Asdell, the author has obtained many ideas which have been incorporated in this book. $\mathrm{He}$ gratefully acknowledges his indebtedness to them. He is also indebted to Dr. LeRoy Barnes for assistance in the preparation of the discussion of electromagnetic radiation and of certain other topics of a physical nature. His thanks are due also to Drs. Mary Crowell, G. H. Ellis, George Davis, and E. W. Crampton, and to Russell Rasmussen for reading parts of the manuscript and for many helpful suggestions.

IтHACA, N. Y.,

LeOnard A. Maynard. August, 1937. 



\section{GONTENTS}

PAGE

Preface to the Second Edition . . . . . . . . . . v v

Preface to the First Edition . . . . . . . . . . . vii

\section{CHAPTER I}

The Expanding Field of Nutrition

Research an Essential Guide to Better Practice-Modern Knowledge Rests on Studies with Many Species and Many Basic Sciences-Importance of "Tracers"-Soil Factors in Nutrition-Economic Aspects-Productive Life the Goal-Need for Further Research.

\section{CHAPTER II}

The Animal Body and Its Food

Composition of the Animal Body-Water and Organic Substances-Minerals-Composition of the BloodComposition of Plants and Their Products-Organic Constituents-Mineral Matter-By-product Feeds.

\section{CHAPTER III}

Some Physiochemical Bases of Life Processes.

Surface Phenomena-Emulsions-Osmotic PressureColloidal State of Matter-Reaction Velocity - Catalysis -Biological Oxidation-reduction-Enzymes-Hydrogenion Concentration-pH Values-Buffer Action-Electromagnetic Radiation-The Spectrum-Absorption of Radiation-Emission Spectra-Isotopes-The Role of Water in the Animal Body-Properties and Functions of Water-"Free" and "Bound" Water-Metabolic Water-Factors Governing Water Excretion and Requirement-Insensible Perspiration-Water Requirements-The Determination of Water. 
CHAPTER IV

The Carbohydrates and Their Metabolism ....

Classification-Pentoses-Hexoses-Disaccharides-Trisaccharides-Polysaccharides-Starch-Glycogen-Cellulose-Pentosans-Hemicellulose, Lignin-Chemical Determination of Carbohydrates-Crude Fiber-Nitrogen-free Extract-Carbohydrate Metabolism-Digestion of Sugars and Starch-Digestion of Complex Polysaccharides-Factors Governing the Digestion of Crude Fiber-Action of Microorganisms-Influence of LigninBulk-Absorption and Storage of Carbohydrates-Transformation of Sugar into Fat-Tissue CarbohydratesCatabolism of Carbohydrates.

\section{CHAPTER V}

The Lipids and Their Metabolism . . . . . . . .

Classification-Fatty Acids-Structure of Fats-Melting Point-Iodine Number-Saponification Number-Reichert-Meissl Number-Oxidation of Fats-RancidityHydrogenation of Fats-Body Fats-Waxes-Phospholipids-Lecithin-Sterols-Choline-Cholesterol-Ergosterol-Determination of Lipids-Ether Extract-Lipid Metabolism-Digestion-Fecal Lipids-Metabolic FatAbsorption of Lipids-Fat Deposition-Fat and Water Relationships-Relation of Food Fat to Depot Fat-Soft Pork-Food Fat and Milk Fat-Catabolism of FatsKetosis-Acidosis-Formation of Fat from ProteinEssential Fatty Acids-Animal vs. Vegetable FatsNutritive Value of Fats as a Group-Fat Tolerance.

\section{CHAPTER VI}

The Proteins and Their Metabolism.

Elementary Composition of Proteins-Amino Acids and Their Distribution in Proteins-Structure of the Protein Molecule-Properties of Proteins-Chemical Determination-Crude and True Protein-Nonprotein-nitrogen Compounds-Amino Acids and Protein Quality-Essential and Nonessential Amino Acids-Synthesis of Non- 
essential Amino Acids-Adequacy of Amino-acid Mixtures for Optimum Nutrition-Biological Value-Determination of Amino Acids in Feeds-Crude vs. True Protein-Protein Metabolism-Products of Protein Digestion-Bacterial Action in the Digestive Tract-Fecal Nitrogen-Metabolic Nitrogen-Apparent and True Digestibility of Protein-Disposal of Absorbed Amino Acids - Protein Reserve-Protein Catabolism-Endogenous and Exogenous Catabolism-Minimum and Optimum Protein Intake.

\section{CHAPTER VII}

The Inorganic Elements And Their Metabolism . . 113

Essential Mineral Elements-Ash-Area Deficiencies and Excesses of Mineral Elements-General Functions of Mineral Elements-Calcium and Phosphorus-Interrelation with Vitamin D-Composition of Bone-Calcium and Phosphorus in Soft Tissues-In Blood-Absorption and Excretion of Calcium and Phosphorus-Deposition and Mobilization-Rickets-Osteomalacia-Calcium and Phosphorus Content of Feeds-Availability in FeedsPhosphorus Deficiency and Appetite-Calcium and Phosphorus Supplements-Defluorinated Phosphates-Magnesium - Symptoms of Deficiency - Calcium and Magnesium Interrelationships-Sodium-Potassium-Sodiumpotassium Ratio - Chlorine-Use of Common Salt-Iron - Hemoglobin Formation-Nutritional Anemia-Iron Nutrition in the Suckling-Iron Value of Foods-Functions of Copper-Deficiencies an Area Problem-Requirements and Feed Supply-Cobalt-Symptoms of Deficiency-Requirements and Content in Feeds-IodineThe Thyroid Gland-Goiter-Iodine Deficiency an Area Problem-Iodine Requirements-Iodine SupplementsIodized Milk and Eggs-Sulfur-Manganese-ZincAluminum-Silicon-Fluorine-T'oxicity of Fluorine and Its Practical Aspects-Selenium-Molybdenum-Nickel -Cobalt-Arsenic-Nitrites-Bromine-Acid-base Balance-Saline and Alkaline Waters-Complex Mineral Mixtures. 
The Vitamins

The Development of the Vitamin Concept-Fat-soluble and Water-soluble Vitamins-Vitamin A-Physiological Functions and Symptoms of Deficiency-Chemical Nature of Vitamin A and Carotene-Stability of Carotene and Vitamin A-Metabolism-Storage-Quantitative Determination of Vitamin A Value-Vitamin A Value of Feeds-Influence of Curing and Other Factors-Vitamin D-Physiological Functions and Symptoms of Deficiency - Interrelation with Radiant Energy - Chemistry-Multiple Nature-Assay-Distribution in Foods-Enrichment of Foods in Vitamin D-Sunlight and Vitamin D Nutrition-Overdosage with Vitamin D-Vitamin EPhysiological Functions and Symptoms of DeficiencyChemistry-Distribution in Foods-Vitamin K-Physiological Functions-Chemistry-Food Sources-Thiamine-Physiological Functions and Symptoms of Deficiency-Chemistry-Distribution in Foods-Riboflavin - Physiological Functions-Chemistry-Distribution in Foods-Nicotinic Acid-Functions and Symptoms of Deficiency-Chemistry-Food Sources-Interrelations with Amino-acid Metabolism-Vitamin $\mathrm{B}_{6}$-Functions and Symptoms of Deficiency-Chemistry-Food SourcesPantothenic Acid-Biotin-Choline-Inositol-Folic Acid-Other B-factors-Vitamin C-Functions and Symptoms of Deficiency-Chemistry-Food SourcesVitamin P-Synthesis of Vitamins in the Digestive Tract.

\section{CHAPTER IX}

Feeding Experiments. The Determination of DigestiBILITY

Comparative Feeding Trials-Feeding Trials with Laboratory Animals-Purified-diet Method-Synthetic Diets - Group Feeding vs. Individual Feeding-Controlled Feed Intakes-Paired Feeding-Slaughter Experiments -Financial Phases of Feeding Trials - Statistical Methods of Analysis of Data from Nutrition Experiments- 
The Determination of Digestibility-Methods of Collecting Feces-Example of a Digestion Trial-Enzymatic Method of Determining Protein Digestibility - Total Digestible Nutrients-Nutritive Ratio-Factors Affecting Digestibility - Influence of Feed Preparation on Digestibility-Significance of Digestion Trial Data.

\section{CHAPTER $\mathrm{X}$}

Nutritional Balances

Balance of Matter-Nitrogen Balance-Mineral Balances-Measurement of Gaseous Exchange-Respiration Apparatus-Respiratory Quotient-Nitrogen-carbon Balance-Kellner's Starch Values-Balance of EnergyUnits of Energy Value - Gross Energy or Heat of Combustion-Bomb Calorimeter-Metabolizable EnergyPhysiological Fuel Values-Heat Loss-Temperature Regulation-Critical Temperature-Animal Calorimeter -Respiration Calorimeter-Net-energy Values-Indirect Calorimetry-Respiration Apparatus-Insensible Loss in Weight as a Measure of Heat Production-Usefulness of Energy Studies-Advantages and Limitations of Balance Methods.

\section{CHAPTER XI}

Measures of Food Energy

Total Digestible Nutrients-Metabolizable EnergyPhysiological Fuel Values-Net Energy-Heat Increment - Specific Dynamic Effect-Net-energy Value and Body Function-Net Energy and Balance of Nutrients-Inconstancy of Net-energy Values-Other Measures of Food Energy - Bases of Feeding Standards-Usefulness of Feeding Standards.

\section{CHAPTER XII}

The Fasting Catabolism. Maintenance

Energy Catabolism of Fasting-Basal MetabolismUnits of Reference in Fasting Catabolism-Lability of 
Fasting Catabolism-Endogenous Nitrogen Metabolism -Relation to Energy Catabolism-Mineral Catabolism of Fasting-Maintenance Requirement for Food Energy - Basal Metabolism as a Measure of Energy Maintenance -Determination from Feeding Trials-Determination of Energy Equilibrium-Protein Requirement for Maintenance-Biological Value and Protein Requirement-Estimation of Protein Requirement from Endogenous Nitrogen-Nitrogen-balance Data as Measures-Determination from Feeding Trials-Constancy of Protein Maintenance Requirement-Mineral Requirements for Maintenance.

\section{CHAPTER XIII}

Growth

The Physiology of Growth-Nature of Growth-Cell as Unit - Growth of Body as a Whole-Growth of PartsMeasures of Growth-"Normal Growth"-Internal Secretions and Growth-Retardation of Growth-Accelerated Growth-Growth, Feed Efficiency and Carcass Quality-Rate of Growth and Productive Life-Energy Requirements for Growth-Factors Involved in Requirements-Estimation from Metabolism and Slaughter Data-Determination by Feeding Trials-Protein Requirements for Growth-Determination of Biological Value-Thomas-Mitchell Method-Supplementary Relations Among Proteins-Biological Values for Different Species-Protein Efficiency as Measured by Feeding Trials-Comparative Biological Value of Various Foods - Factors Governing the Protein Requirement-Estimation from Slaughter Data-Determination by Feeding Trials-Methods of Stating the Protein RequirementWool Production-Calcium, Phosphorus, and Vitamin D -Measures of Skeletal Growth-Optimum Bone Development - Calcium and Phosphorus Requirements from Balance Studies-From Growth and Bone Data-Requirements Stated as a Percentage of the Total RationRequirements for Vitamin D-Meeting the Requirements of Bone-forming Nutrients in Practice-Requirements 
for Iron-Salt-Iodine-Vitamin A RequirementsThiamine-Riboflavin-Nicotinic Acid-Other B-factors.

\section{CHAPTER XIV}

REPRODUCTION

Physiology of Reproduction-Ovulation and Fertilization -Fetal Growth-Energy Requirements-Fat Metabolism in Reproduction-Protein Requirements-Effects of Calcium and Phosphorus Deficiencies-Calcium and Phosphorus Requirements - Requirements for Vitamin D -Iron-Iodine-Vitamin A-Vitamin E-Other Vitamins-Nutrition and Diseases of Reproduction-Egg Production-Nutritive Requirements-Protein-Calcium, Phosphorus and Vitamin D-Other MineralsOther Vitamins.

\section{CHAPTER XV}

LACTATION

Physiology of Lactation-Mammary Glands-Hormonal Control-Thyroid Gland and Milk Secretion-Synthetic Estrogens and Lactation-Course of Milk SecretionMilk of Different Species-The Composition of Blood and Milk-Mechanism of Milk Secretion-Blood Changes in Relation to Secretion-Secretion of Lactose-Fat-Variations in Fat Percentage-Relation to Blood Composition -Influence of Nature of Ration-Secretion of ProteinMinerals-Pigments-Nature of Colostrum-Abnormal Milk Constituents - Variations in Milk CompositionEstimation of Energy Requirements from Metabolism Studies-Determination by Feeding Trials-Importance of Food Fat in Lactation-Protein Requirement-Protein Requirement as Measured by Feeding Trials-Estimation from Nitrogen-balance Data-Protein Allowances for Milking Cows in Practice-Cycle of Calcium and Phosphorus Metabolism-Effects of Calcium and Phosphorus Deficiencies-Requirements-Salt-Vitamin A Value of Milk-Vitamin A Requirements-Vitamin DVitamin D Milk--Thiamine-Riboflavin-Other Bvitamins-Vitamin 8 . 


\section{CHAPTER XVI}

Work Production

Nutrients Involved in Muscle Activity-Chemistry of Muscle Action-Fuel of Muscular Activity-Units of Work and Power-Efficiency of Muscle Work-Measurement of Energy Expended-Factors Affecting Work Efficiency-Energy Requirements for Work-Protein Requirements-Mineral Requirements-Vitamin Requirements.

List of Visual Aids . . . . . . . . . . . . . . . 465

Author Index . . . . . . . . . . . . . . 469

Subject Index . . . . . . . . . . . . . 479 


\section{ANIMAL NUTRITION}

\section{CHAPTER I \\ THE EXPANDING FIELD OF NUTRITION}

The great French chemist, Lavoisier, ${ }^{1}$ is frequently referred to as the founder of the science of nutrition. He established the chemical basis of nutrition in his famous respiration experiments carried out before the French Revolution. His studies led him to state, "La vie est une fonction chimique." Thereafter, chemistry became an important tool in nutrition studies. Through its application in physiological studies the old idea that the nutritive value of food resided in a single "aliment" was proved wrong in the first quarter of the nineteenth century. The need for protein, fat, and carbohydrates became recognized. For the remainder of the century, nutritional science and practice were concerned primarily with these nutrients and a few mineral elements. The large expansion in the nutrition field has occurred during the last 40 years with the discovery of the vitamins, of the role of amino acids, and of several more essential mineral elements. Today we know that the body needs some 40 different nutrients, in contrast to the three recognized a century ago.

While much of our current knowledge has resulted from direct attacks on evident nutritional and health problems of animals and man, equally important discoveries have come from more basic studies of the functioning of the animal organism, of the physiological and biochemical changes involved, and of the effects of

1 Antoine Lavoisier (1743-1794) introduced the balance and thermometer into nutrition studies. He discovered that combustion was an oxidation, and he showed that respiration in the body involved the combination of carbon and hydrogen with oxygen from inspired air and that the quantities of oxygen absorbed and carbon dioxide given off depended on the food intake and the work done. With Laplace, he designed a calorimeter by means of which it was demonstrated that respiration is the essential source of body heat. The science of nutrition was undoubtedly set back many years when Lavoisier's career was ended by the guillotine. 
various dietary variables. In many instances, under inspired leadership, research has shown the way to better practice before the need for it was recognized. An outstanding example of such a contribution is the feeding experiment with single plants planned by Babcock ${ }^{1}$ and carried out at the Wisconsin Experiment Station over 25 years ago.

Babcock, the chemist, recognized that when cows were being fed a combination of several feeds from different plant sources there was no way of knowing what particular contribution each was making to the animals' needs. He conceived the idea of trying out rations made up entirely from a single plant. This proposal seemed decidedly impractical to animal husbandmen who, in those days, thought more of their cows than of the possible value of such an experiment. Eventually Babcock was given the use of two cows, but, when one died after three months, the experiment was abandoned lest another valuable animal be lost also. Later, his idea was carried out in an extensive experiment by his younger colleagues, Hart and Humphrey, with the later cooperation of McCollum and Steenbock. Five-month-old heifer calves were selected. Four were placed on a ration made entirely from the wheat plant, four on a similar ration from the oat plant, and four on a ration from the corn plant. Another four received a ration of feeds from all three plants. These rations were made up to be alike as regards their contents of all the organic nutrients then known to be essential, and salt was fed in addition.

In the course of the experiment, striking differences developed between the group on the corn plant and the one on wheat. At the end of a year, similar gains in weight had been made, but the corn-fed animals were much the sleeker and more vigorous. When the animals were bred, remarkable differences occurred in the outcome. Each of the corn-fed group produced a normal calf which developed into a vigorous animal, while all of the calves from the wheat group either were dead at birth or died soon after. The corn-fed group produced three times as much milk in the month following calving as did the other group. The later

1 Stephen M. Babcock (1843-1931), who is most widely known for his invention, the Babcock test, made many pioneer contributions in the fields of dairy chemistry and animal nutrition. Following 6 years at the New York Experiment Station, he served for 25 years as chemist and assistant director at the Wisconsin Experiment Station. 
results continued to be strikingly in favor of the corn plant. Exhaustive chemical studies of the feeds and excreta of the cows and of the tissues of the calves which died or were killed for autopsy failed to find any explanation of the results. It was concluded that the wheat plant contained something toxic or, perhaps, that it lacked something supplied by corn. It was years before new discoveries provided the true answer.

This experiment made it clear that there were marked differences in nutritive values which could not be detected by any chemical means available at the time and that the current scientific bases for formulating rations were seriously inadequate. More important, the experiment led to the conviction that simplified diets must be used for the solution of nutrition problems. It stimulated the use of the purified-diet method (Sec. 205) which resulted in the discovery of the first vitamin (Sec. 154) in 1913 and which has been so largely responsible for the newer knowledge of nutrition. The report of this Wisconsin experiment ${ }^{1}$ is well worth reading by every student. He should enjoy forming his own opinion, in the light of modern knowledge, as to just what was wrong with the wheat ration. The far-reaching influence of this experiment should convince even the most practical-minded person that no one is wise enough to predict in advance what research is of practical value and what is not. Fundamental facts provide the only adequate bases for meeting current practical problems as well as for advancing nutritional science.

The modern discoveries in nutrition have resulted from studies with a wide variety of species. The contributions of the laboratory rat to our knowledge of vitamins, amino acids, and minerals have becn enormous. The discovery of insulin and of the role of nicotinic acid in the prevention and cure of pellagra exemplifies the debt that we owe to the dog. Guinea-pig experiments showed us the specific cause of scurvy and how to prevent it. 'The pioneer work that led to the discovery of thiamine was carried out with the chick, and this species has continued to help solve many puzzles in the field of vitamins. Monkeys, mice, and hamsters all have contributions to their credit. Even the lower forms, particularly bacteria, have played a large role in the discovery

${ }^{1}$ Hart, F. B., E. V. McCollum, H. Steenbock, and G. C. Humphrey, Physiological effect on growth and reproduction of rations balanced from restricted sources, Wis. Agr. Expt. Sta. Research Bull. 17, 1911. 
of growth factors, in the assay of our foods for various nutrients, and in explaining how these nutrients function in metabolism. Today the nutritional scientist realizes that basic or pilot experiments with one of these various species, selected in accordance with the objective of the study, provide the best approach for the solution of many of the problems in the nutrition of man and farm animals.

The expanding developments in the field of nutrition have resulted from the application of the knowledge and techniques of many different sciences. The physiologist and biochemist have long worked as a team in studying the body's need for food and how this food is metabolized. But the advancement in many areas was slow until the aid of scientists in other fields was obtained. The identification of the various vitamins lagged until the organic chemist became interested in their isolation and synthesis. Thanks to his efforts, commercial sources of many of them have become available both for further experimental work and also for use in feeding practice. The physicist has given us $\mathrm{X}$ rays, the spectrograph, isotopes, and other tools and has shown us how they can be used for the advancement of nutrition. The geneticist has discovered breed differences in nutritive requirements and in the efficiency of food utilization. He has even developed new strains of certain lower forms that will detect specific vitamin and aminoacid deficiencies in our foods. The microbiologist has assisted greatly in the recent discoveries of the nutritional roles that bacteria play in the rumen of the cow and sheep and in the intestine of other species. Microbiological methods have greatly speeded up the development of our knowledge regarding the vitamin and amino-acid content of foods.

The significance of these contributions from the various fields of science will become apparent in the discussions in the succeeding chapters. The modern student of nutrition must have an appreciation of the important relations of these basic sciences to the solution of the problems of the expanding field. He must have a real working knowledge of chemistry and physiology, particularly, if he is to understand present-day developments and apply them in feeding practice. Such a knowledge will also help him to evaluate the significance of new facts as they are discovered and enable him to modify his practice accordingly.

The essentiality of several nutrients has been a very recent 
discovery because they are needed in traces only. Here we think first of the vitamins, but $0.1 \mathrm{mg}$. of cobalt per day makes the difference between life and death in a sheep. A lack of that minute amount was responsible for tremendous livestock losses in certain parts of the world before their specific cause was discovered. We express protein requirements in pounds or grams, but a few milligrams or micrograms of certain other nutrients are just as important for health and production.

Studies of some of these "trace" mineral elements have shown that the character of the soil on which we grow our food crops plays an important role in determining their nutritive value. We have also learned that varieties of the same crop differ in nutritional quality and that various cultural factors have an influence here also. Thus, animal and human nutrition ties back into agriculture and to the soil, stressing the importance of yields of nutrients as distinguished from the consideration of tons or bushels per acre alone.

We have learned that the soil may contribute toxic elements to our food supply as well as essential ones. Some of the vitamins, as well as the minerals, that are essential in small amounts may prove harmful at higher intakes. Poor nutrition can result from too much as well as too little. Further, a suitable balance between certain nutrients is important.

The recent developments have served to stress the interrelationships between human and animal nutrition. Superficially, the rations of man and animals have little in common sinee the kinds of food eaten are so different. Yet the essential constituents of these rations, that is, the elements recpuired for arlequate nutrition, are largely the same whatever the species. The general principles of nutrition are identical. Both man and animals draw upon the same basic food supply the products of the soil. In the war emergency and its aftermath we have become conscious of the fact that while animals concentrate the nutrients of food crops into more nutritious and palatable forms for the human diet, they waste basic food resoures in the process. Inimal production had to be curtailed aceordingly, particularly in luropean countries, to conserve human food.

The most successful human diet, however, in terms of the optimum nutrition of a people, is one that contains liberal amount of animal products. There is a real nutritional justification for 
an animal industry, though its extent may be governed by economic considerations. Recent studies have shown that how animals are fed affects the nutritive value, as well as the palatability, of their products eaten by man. This aspect cannot be neglected by an industry that exists primarily to provide human food. The producer of milk, meat, and eggs needs to know something about their nutritive values. This is another example of the interrelationships between human and animal nutrition that the student should keep in mind.

Despite the large advances that typify the expanding field of nutrition, there are many "unknowns" for further study. It is doubtful whether all the essentials of an adequate diet for any species have been discovered. Certainly much more needs to be learned regarding the quantitative requirements of our farm animals for some of the more recently discovered nutrients. This fact is evident in the recently published reports, cited at the end of this chapter and referred to specifically later, setting forth recommended nutrient allowances for farm animals. Much more information is also needed about the quantitative occurrence of the recently discovered nutrients in our foodstuffs.

Most of our present knowledge of nutrition requirements has been gained from comparatively short-time studies. As higher and higher productive performance is sought in our farm animals, we recognize the limitations of our measures of adequate nutrition from the standpoint of productive life. The rearing of breeding stock, milk-producing animals, and laying hens represents an initial cost which, for greatest return, must be spread over a long period of profitable production. The desirability of rapid growth, not only to bring animals into production as soon as possible but also to develop the highest producers, has been a dominant idea in current nutrition thought. Recent discoveries in nutrition have resulted in feeding practices which have markedly accelerated the growth rate. At the same time, however, an increasing appreciation has developed that a large number of animals, which are highly promising from the standpoint of growth performance, fail to come into profitable production or have an abnormally short productive life. The large turnover of cows is a serious problem in the dairy business. Along with the factors of inheritance and of disease, the nutritional aspect deserves further study. There is need for a reconsideration of the nutrition of the animal 
from birth, with profitable productive life rather than rate of growth as the dominant viewpoint.

In a very thought-provoking article McCay and Crowell ${ }^{1}$ have challenged the current view that the most rapid growth, as measured by increase in weight and size, is the ideal for maximum health and long life, and they have cited evidence obtained with various species in support of their thesis. Clearly, increase in weight and size is a very inadequate measure of the complete development of the organism. It is possible that in stressing this general measure we have neglected factors vital to the correlated and optimum growth of the diverse organs and glands upon which later production and longevity depend. The enhanced growth in weight and size which has resulted from large intakes of recently discovered dietary essentials may be accentuating the limiting effect of as yet unidentified factors required for complete development and continued function. There may well be no conflict between rapid growth and length of productive life, provided the growth obtained is complete and correlated in all its aspects. But we may have no adequate knowledge at the present time of how to measure this growth and thus may be providing a nutrition which is far from optimum to achieve it.

The nutrition worker who is a true scientist recognizes the limitations of present knowledge. He realizes that findings which have later proved to be inadequate have been responsible for practical recommendations which did not prove effective. He is becoming more conservative accordingly. But overenthusiasm or error has characterized many of the popular articles in the field of nutrition and some of those who have food products for sale seem to have no inhibitions at all. It is not surprising that the layman is puzzled by what he reads and that reasoning or actual experience may convince him that the ficld is overexpanded. There has been an overexploitation of present knowledge, but the need for research to fill in the many gaps in this knowledge cannot be denied, and the accomplishments of the recent decades make it evident that further intensive studies will prove highly beneficial to human and animal welfare. There should be a curtailment of premature conclusions and recommendations for practice and an expansion of critical research by competent workers

1 McCay, C. M., and Mary F. Crowell, Prolonging the life span, Sci. Monthly, 39, 405-414, 1934. 
who have the patience to carry through the long-time experiments demanded for the complete solution of current problems.

From the discussions that follow the student will become conscious of the many gaps, and even of some contradictions, in present knowledge. Such a situation exists in every scientific field as one approaches its borders; but these borders are being constantly extended by research and the new ground gained is being consolidated. Continued activities in these directions are particularly needed in the field of nutrition. In the words of Professor Hart of the University of Wisconsin, we should "chart all the factors in nutrition, organic and inorganic, and study their distribution, physiology, pathology, and interplay. Put the need for these factors on a quantitative basis with optimum allowance for the complete cycle of the animal's life." Thus will the field of nutrition continue to expand for the benefit of the livestock industry and human welfare.

\section{Selected Literature}

Beadle, G. W.: Biochemical genetics, Chem. Rev., 37, 15-96, 1945.

Food and Agriculture Organization of the United Nations: Report of the first session of the Quebec conference, 1945. Washington, D.C., 1946.

Leitch, I., AND W. Godden: The efficiency of farm animals in the conversion of feedingstuffs to food for man, Imp. Bur. Animal Nutr. Tech. Communication, 14, 1941.

McCay, C. M.: Seven centuries of scientific nutrition, J. Am. Dietetic Assoc., 15, 648-658, 1939.

MaYnard, L. A.: The physiological approach to livestock nutrition problems, J. Animal Sci., 1, 179-188, 1942.

- Food production for better health and longer life, in Implications of nutrition and public health in the post-war period, pp. 5-19, Children's Fund of Michigan, Detroit, 1945.

— - The role and efficiency of animals in utilizing feed to produce human food, J. Nutr., 32, 345-360, 1946.

Michaud, L., and C. A. Elvehjem: The nutritional requirements of the dog, Nutrition Abstracts \& Revs., 13, 323-331, 1944.

Mitchell, H. H.: Adaptation to undernutrition, J. Am. Dietetic Assoc., 20, $511-515,1944$.

National Research Council, Committee on Animal Nutrition: Reports on recommended nutrient allowances for domestic animals. I. Recommended nutrient allowances for poultry, 1944; II. Recommended nutrient allowances for swine, 1944; III. Recommended nutrient allowances for dairy cattle, 1945; IV. Recommended nutrient allowances for beef cattle, 1945; V. Recommended nutrient allowances for sheep, 1945. 


\section{CHAPTER II}

\section{THE ANIMAL BODY AND ITS FOOD}

Nutrition involves various chemical and physiological activities which transform food elements into body elements. At the outset, therefore, a brief consideration of the chemical composition of the animal body in relation to the composition of its food is useful to give a general picture of the nutrition process, the detailed aspects of which are presented in later chapters.

\section{COMPOSITION OF THE ANIMAL BODY}

Over 75 years ago the famous English scientists, Lawes and Gilbert ${ }^{1}$ performed the pioneer and laborious task of analyzing the entire bodies of farm animals. Since that time, many similar studies have been made by other workers, with the result that we have a large body of data regarding the composition of various species at different ages and in varying states of nutrition. From these data the figures given in Table I have been assembled to provide a general picture of the gross composition of mature animals in a good state of nutrition and to show that different species are very similar in this respect.

1. Water and Organic Substances.- The data in Table I, given in round numbers, are subject to large variations according to age and nutritional state, as well as to differences among individuals. On a percentage basis, the water content show's a large decrease with age in early life. In the case of cattle, for example, the water content is approximately 95 per cent for the cmbryo shortly after conception, 75 to 80 per cent at birth, 66 to 72 per

${ }^{1}$ Agricultural science owes a tremendous debt to John B. Lawes (1814 1900) and Joseph II. Gillert (1817-1901) for their pioneer work in the fields of agronomy and animal mutrition, begun in 1813 and continued for over half a century. The experiment station which they foumled at Rothamsted, England, rapidly gained fame throughout the world, and it remains today an outstanding eenter of research in the plant scionces. Their studies of the composition of the animal body are publisherl under the title: Experimental encuiry into the composition of the animals fed and slaughtered as human food, Trans. Roy. Soc. (London) 2, 493-680, 1859. 
cent at five months, and 50 to 60 per cent in the mature animal. The variations for a given age are due primarily to the nutritional state as reflected in the store of fat. Very fat animals have less than 50 per cent of water at maturity. The percentage of fat normally increases with age, but it is highly variable at all times depending upon the level of food intake. Its variation affects the percentages of the other constituents, and this is particularly true for water. The Missouri workers, for example, found a thin steer to contain 18 per cent of fat and 57 per cent of water, in contrast to 41 per cent of fat and 42 per cent of water for a very fat animal.

In view of the wide differences in fat content which may occur, much less variable figures for the other constituents are obtained by expressing them on a fat-free (protoplasmic) basis. On this basis the gross composition of the mature animal body, less the contents of the digestive tract, is represented by the following

Table I.-Percentage Gross Composition of the Animal Body ${ }^{1}$

\begin{tabular}{|c|c|c|c|c|}
\hline Species & Water & Protein & Fat & $\begin{array}{c}\text { Mineral } \\
\text { matter }\end{array}$ \\
\hline Steer............... & 55 & 17 & 23 & 4.6 \\
\hline $\operatorname{Hog} \ldots \ldots \ldots \ldots \ldots$ & 58 & 15 & 24 & 2.8 \\
\hline Sheep............... & 60 & 16 & 20 & 3.4 \\
\hline 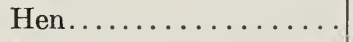 & 56 & 21 & 19 & 3.2 \\
\hline Mare............... & 60 & 17 & 17 & 4.5 \\
\hline $\operatorname{Man} . . . \ldots \ldots \ldots \ldots$ & 59 & 18 & 18 & 4.3 \\
\hline
\end{tabular}

1 Less contents of digestive tract.

approximate figures: water, 75 per cent; protein, 20 per cent; and mineral matter, 5 per cent. These figures are subject to little variation after the animal is nearly full grown, though there is a slight decrease in water throughout life.

The data of Table I do not reveal the very small amount of carbohydrate which is present in the body. Though occurring as much less than 1 per cent at any given moment, it is constantly being formed and broken down in metabolism and thus performs a multitude of vital functions. The only species differences shown in the table which may be considered significant are certain ones for mineral matter, reflecting differences in size of skeleton.

The chemical groups which make up the gross composition of 
the body are not evenly distributed throughout the various organs and tissues but are more or less localized according to their functions. Water is an essential constituent of every part of the body, but its quantitative distribution varies greatly in different parts. Blood plasma contains 90 to 92 per cent, muscle 72 to 78 per cent, bone approximately 40 per cent, and the enamel of the teeth 5 per cent.

Proteins are present in every cell and, as such, are the principal constituent, other than water, of the organs and soft structures of the body such as the muscles, tendons, and connective tissues. Most of the fat is localized in the adipose tissue, or fat depots, which occur under the skin, around the intestines, around the kidneys, and other organs; but it is also present in the muscles, bones, and elsewhere. In fact every cell contains substances classed with the fats. The small amount of carbohydrate present in the body is found principally in the liver, muscles, and blood.

2. Mineral Composition.- The mineral matter of the body comprises a large number of elements present in varying amounts in different parts, according to the functions they perform. The percentages of the principal mineral constituents of the body are indicated by the following data:

\begin{tabular}{|c|c|c|c|}
\hline Element & Per cent & Element & Per cent \\
\hline Calcium........... & 1.33 & Chlorine..... & 0.11 \\
\hline Phosphorus.......... & 0.74 & Magnesium... & 0.041 \\
\hline Sodium. ........... & 0.16 & Sulfur...... & 0.15 \\
\hline Potassium.......... & 0.19 & & \\
\hline
\end{tabular}

These data are averages of analyses of eighteen steers of varying ages, as reported by Hogan and Nierman. ${ }^{1}$ They are expressed as a percentage of the entire body less the contents of the digestive tract. It is noted that, aside from calcium, the elements occur as fractions of a per cent only. Despite their small amounts, they are absolutely essential to life.

Calcium, the mineral occurring in largest amounts in the body, is present almost entirely in the bones and teeth as phosphate and carbonate. The phosphorus which is combined with alcium to

1 Hogan, A. G., and J. I. Nurman, Studies in animal mutrition. VI. The distribution of the mineral elements in the animal body as influenced by age and condition, Mo. Agr. Expt. Sta. Research Bull. 107, 1927. 
form the skeleton accounts for approximately 80 per cent of the body supply. The remainder is widely distributed in combination with certain proteins and fats and as inorganic salts. Sulfur occurs throughout the body as a part of the protein molecule. Sodium, potassium, and chlorine are present almost entirely as inorganic salts in the various fluids. Most of the magnesium is present in the bones, but it is also found widely distributed elsewhere in the body. Iron is an essential constituent of the hemoglobin of the blood and occurs in lesser amounts throughout the organs and other tissues.

In addition to the elements listed in the table, there are many others which are present in smaller amounts, some of which are known to be necessary for life. Iodine, iron, copper, zinc, manganese, cobalt, and probably fluorine are essential body constituents. Boron, silicon, bromine, aluminum, nickel, and arsenic are additional elements which have been reported as normally occurring in the body, though they have no known function. Certain other mineral elements have been detected spectroscopically.

3. The Blood.-From the standpoint of nutrition, the composition of the blood is of special importance in that it is the medium by which the nutrients are carried to the various parts of the body and by which the waste products of metabolism are removed. The blood makes up from 5 to 10 per cent of the body weight depending upon the species and nutritive state. The figure for birds is higher than for mammals. The blood volume is related primarily to the active tissues of the body. Thus the larger the amount of adipose tissue the lower is the percentage of blood for the body as a whole. For example, it has been shown in the case of the hibernating woodchuck that the figure for blood percentage increases as it uses up its fat reserve.

The corpuscles make up from 30 to 45 per cent of the blood, depending upon the species. This percentage value is called the hematocrit. The solid matter of the red corpuscles consists almost entirely of the iron-containing protein, hemoglobin. In certain lower forms, however, the protein of the corpuscles contains an element other than iron as its respiratory pigment. The Pinna squamosa, a shellfish, has a protein called pinnaglobulin which contains manganese. Lobsters, crabs, and snails have the coppercontaining hemocyanin.

The plasma contains 10 per cent of solids, more than half of 
which are proteins. The remainder consists principally of various fatty substances, sugar, nonprotein-nitrogen compounds, and inorganic salts. The principal inorganic elements are sodium and chlorine, with potassium, calcium, magnesium, phosphorus, and others occurring in much smaller amounts. Most of the sodium and chlorine are combined together, but various other combinations of these and other elements occur, such as sodium bicarbonate, disodium phosphate, and potassium chloride.

\section{COMPOSITION OF PLANTS AND THEIR PRODUCTS}

Food must supply nutrients which can be used to build and renew the components of the body and to form its products such as milk, eggs, and wool, and it must furnish energy for the processes involved. After weaning, most of our farm animals obtain all of their food supply from plants. While there are certain animal species which are entirely carnivorous, the plant kingdom is the original and essential source of all animal life, because plants are able to utilize the energy of the sun to build substances which will nourish the animal. Plants make use of carbon dioxide, water, nitrates, and other mineral salts to form carbohydrates, fats, and proteins which the animals must have to build their bodies and which are broken down in life processes. Thus plants store and animals dissipate energy.

4. Plants and Their Parts.--Plants contain the same substances that are found in the animal body, but the relative amounts present are very different. Plants also show much larger differences in composition among species than do animals. The composition of certain typical plants and plant products is given in Table II. These data are presented for the purpose of comparing them with the data previously given for the animal body (Table I) and of illustrating certain useful generalizations regarding differences in composition among plants and their various products.

The analyses of three green plants are given to show the general composition of the living plants at the stage when vegetative growth is practically eompleted but before the seed has matured. These data reveal the fact that the principal constituent of living plants is water even as is true of the animal body. 'This water eontent decreases as the seed is matured. The striking difference in the eomposition of plants and animals is the fact that the dry matter of plants consists principally of carbohydrate. 
Table II.-Percentage Composition of Typical Plants and Their Products ${ }^{1}$

\begin{tabular}{|c|c|c|c|c|c|c|c|}
\hline Plants & Water & $\begin{array}{l}\text { Pro- } \\
\text { tein }\end{array}$ & Fat & $\begin{array}{l}\text { Carbo- } \\
\text { hy- } \\
\text { drates }\end{array}$ & $\begin{array}{c}\text { Min- } \\
\text { eral } \\
\text { mat- } \\
\text { ter }\end{array}$ & $\begin{array}{l}\text { Cal- } \\
\text { cium }\end{array}$ & $\begin{array}{l}\text { Phos- } \\
\text { phorus }\end{array}$ \\
\hline \multicolumn{8}{|l|}{ Green plants: } \\
\hline Corn. . . . . . & 73.1 & 2.1 & 0.7 & 22.8 & 1.3 & & \\
\hline Alfalfa........... & 74.1 & 4.4 & 0.8 & 18.2 & 2.5 & & \\
\hline Timothy ........... & 67.9 & 2.7 & 0.9 & 26.5 & 2.0 & & \\
\hline \multicolumn{8}{|l|}{ Dried plant products: } \\
\hline Corn stover. . . . . . & 9.4 & 5.9 & 1.6 & 77.3 & 5.8 & 0.46 & 0.09 \\
\hline Corn grain......... & 12.8 & 9.6 & 3.9 & 72.3 & 1.4 & 0.01 & 0.28 \\
\hline Soybean......... & 9.8 & 36.9 & 17.2 & 30.8 & 5.3 & 0.20 & 0.60 \\
\hline Alfalfa leaves...... & 11.0 & 21.9 & 3.0 & 53.9 & 10.2 & 2.25 & 0.23 \\
\hline Alfalfa stems...... & 11.4 & 10.0 & 1.2 & 70.8 & 6.6 & 0.79 & 0.14 \\
\hline
\end{tabular}

1 These data are taken from Appendix Table I in "Feeds and feeding," 20th ed., by F. B. Morrison, by permission of the Morrison Publishing Company, Ithaca, N.Y. The figures for alfalfa and timothy are the averages for plants in bloom, while those for corn represent its composition in the dough-to-glazing stage.

This constituent serves as both structural and reserve material, while in animals protein comprises the structure of the soft tissues and fat is the reserve. Thus, although the animal body contains only a trace of carbohydrate, this nutrient is the principal constituent of the food of most species. It serves as a source of energy, either currently, or as a reserve in the form of fat, into which it is readily transformed.

The data for dried plant products, representing the moisture basis to which they are reduced after curing for storage, are given to bring out certain generalizations regarding differences in composition among the various parts of the plant. The figures for corn stover and corn grain provide a comparison between the vegetative portion of the plant and its seed. The data for the soybean illustrate some characteristics of legume seeds and those for the alfalfa products bring out certain differences between leaves and stems.

Protein is primarily a constituent of active tissues and thus leaves are much richer in this nutrient than are stems, as the data for alfalfa show. Leafy, legume hays such as alfalfa and the clovers always contain more protein than the grass hays such as timothy. As the plant matures, there is a movement of protein 
from the vegetative parts to the seed to provide for the requirements of growth during germination. Thus, at maturity, the seed contains a higher percentage of protein than the rest of the plant, as is indicated by the figures for corn grain and corn stover.

Fat is also higher in the leaves than in the stems and generally is highest in the seeds where it serves as a condensed reserve of energy for later germination. In most seeds, of which corn and other cereals are examples, the principal store of energy is in the form of carbohydrates, but oil-bearing seeds, such as the soybean, cottonseed, and flax, contain their reserve primarily as fat, as their name implies. These seeds are used as commercial sources of oil, leaving oil meals as by-products for animal feeding. Oilbearing seeds are also much higher in protein than are the cereal seeds.

In all plant products, with the exception of the oil-bearing seeds, carbohydrate is the principal constituent, even as it is in the plant as a whole. The nature of this carbohydrate differs markedly according to whether it is serving as a reserve or structural element. In seeds, it occurs principally as starch which is the reserve carbohydrate, while, in stems and to a much lesser extent in leaves, a considerable proportion of it is present as cellulose, the principal structural carbohydrate. The outer coats of seeds also contain cellulose as a structural and protective element. Since cellulose and related compounds, classed by the nutrition chemist as crude fiber (Sec. 40), are much less digestible than starch, the various parts of plants differ markedly in nutritive value according to their digestibility. Feeds which are high in cellulose and related compounds and thus of low digestibility, such as hay, straw, and silage, are classed as roughages. The term, concentrates, is used to denote those low in cellulose and highly digestible. Here are included the seeds and most of their by-products.

5. Mineral Matter.-The amount of mineral matter in plants is highly variable in different species as well as in the different plant parts. From the standpoint of animal nutrition, we are particularly interested in the fact that the percentage distribution of the mineral elements of plants differs markedly from that in animals. To illustrate this fact for the dried plant products, data for calcium and phosphorus, the elements which make up over 70 per cent of body ash, are given in Table II. With the exception of the legumes which are always rich in calcium, these ele- 
ments make up a rather small part of the ash of plants. Both are exceeded by potassium, an element in which we are much less interested in animal nutrition. Calcium is primarily associated with the vegetative portion of the plant, and the leaf is richer than the stem. Without exception, seeds are low in calcium compared to the other parts of the plant, though oil-bearing seeds are higher than others. In contrast to calcium, phosphorus is richer in the seeds than in the rest of the plant. Leaves are richer than stems. The calcium and phosphorus content of the vegetative part of the plant is markedly influenced by soil factors. This is discussed later (Sec. 114).

Table III.-Percentage Distribution of Nutrients in the Parts of the Wheat Kernel

\begin{tabular}{c|c|c|c|c|c|c}
\hline $\begin{array}{c}\text { Part of wheat } \\
\text { kernel }\end{array}$ & $\begin{array}{c}\text { Pro- } \\
\text { tein }\end{array}$ & Fat & $\begin{array}{c}\text { Starch, } \\
\text { sugar, } \\
\text { etc. }\end{array}$ & $\begin{array}{c}\text { Cellulose, } \\
\text { pentosans, } \\
\text { etc. }\end{array}$ & Ash & $\begin{array}{c}\text { Undeter- } \\
\text { mined }\end{array}$ \\
\hline Whole kernel....... & 11.3 & 2.2 & 66.4 & 8.0 & 2.0 & 10.1 \\
Endosperm........ & 11.2 & 1.2 & 81.4 & 2.1 & 0.4 & 3.7 \\
Seed coats......... & 17.6 & 8.3 & 7.0 & 43.9 & 8.6 & 14.6 \\
Embryo............ & 40.3 & 13.5 & 24.3 & 1.7 & 4.8 & 15.4 \\
\hline
\end{tabular}

6. By-product Feeds.-The feeds of animals obtained from plants consist not only of forage crops, seeds, and roots but also of by-products arising from the processing of various plant materials, notably seeds, in the manufacture of products used for human food and for industrial purposes. The bran and middlings which arise from flour milling, gluten feed which is a by-product of cornstarch manufacture, and the meals which are the residues of the pressing of oil from oil-bearing seeds are all familiar examples of the very large number of by-product feeds. Their composition is usually very different from that of the seed or other material from which they arise. This is illustrated by the figures in Table III which are taken in a condensed form from data presented by Osborne and Mendel. ${ }^{1}$ While these data must be considered as

1 Osborne, Thomas B., and Lafayette B. Mendel, The nutritive value of the wheat kernel and its milling products, J. Biol. Chem., 37, 557-601, 1919. Osborne (1859-1929), chemist of Connecticut Agricultural Experiment Station at New Haven, and Mendel (1872-1935), professor of physiological chemistry in Yale University, collaborated in nutrition research for over 20 years. Their outstanding discoveries, particularly in the fields 
approximate only in view of the rather large percentage of undetermined material, they serve to show the large differences in composition among the different parts. The endosperm consists very largely of starch, the reserve material, and contains very little of the less digestible carbohydrates. In contrast, the seed coats are characterized by a high content of cellulose and related compounds which provide the needed protective qualities. They are also richer in protein, fat, and mineral matter than the endosperm, or the seed as a whole. The embryo is especially rich, compared to the other parts, in protein and fat and is lowest of all in cellulose. Most of the vitamin content of the entire kernel is found in the seed coats and embryo.

Thus the milling of wheat leaves for animals a feed which is richer in protein, fat, mineral matter, and vitamins than the entire kernel, but which is somewhat less digestible because of the larger amount of the higher carbohydrates. It is the endosperm which provides the patent flour for human food. A yield of approximately 70 per cent is obtained, which means that a portion of the endosperm is left behind with the seed coats and embryo which constitute the by-products of the milling process.

While wheat by-products have a high feeding value, this is by no means true for all by-product feeds. Oat mill by-product, for example, which is the residue from oatmeal production, contains less than half as much protein and over twice as much fiber as the seed itself, because it consists mostly of the hull. It is therefore of low digestibility and nutritive value. On the other hand, the pressing or solvent extraction of soybeans, cottonseed, and flaxseed to obtain their oils for human food or industrial use provides products that are highly digestible and of special value for their protein content.

Similarly, many important feeds, used mostly in swine and poultry rations, result from the processing of animal products. Here are included tankage, meat scraps, fish meal, milk byproducts, and many others.

of proteins and vitamins, which are frequently reforrect to in this book, assure them lasting recognition as pioneers in developing the newer knowledge of nutrition. In addition to their joint work, Osborne became the leading authority of the world on the vegetable proteins, while Mendel made many important contributions on various aspects of nutritional physiology and was an inspiring teacher to a host of students who are now carrying on his work in many lahoratories. 
A knowledge of the processes from which by-product feeds arise and thus of their make-up in terms of the different parts of the original material is a very helpful guide to their composition and feeding value. This subject is covered very thoroughly in the textbook by Morrison. ${ }^{1}$

\section{Selected Literature}

Accessory Food Factors Committee: Nutritive values of wartime foods, Medical Research Council War Memorandum No. 14, 1945.

Bureau of Human Nutrition and Home Economics and National Research Council: Tables of food composition in terms of eleven nutrients, U.S. Dept. Agr. Misc. Pub. No. 572, 1945.

Callow, E. H.: The food value of beef from steers and heifers, and its relation to dressing-out percentage, J. Agr. Sci., 34, 177-189, 1944.

Ellis, N. R., W. R. Kauffman, and C. O. Miller: Composition of the principal feedstuffs used for livestock, U.S. Dept. Agr., Yearbook of Agriculture, 1939, pp. 1065-1074.

Hopper, T. H.: Methods of estimating the physical and chemical composition of cattle, J. Agr. Res., 68, 239-268, 1944.

McComas, E. W., and T. E. Woodward: Nutritive values of miscellaneous feeds, U.S. Dept. Agr., Yearbook of Agriculture, 1939, pp. 1017-1064.

Mrtchell, H. H., and associates: The chemical composition of the adult human body and its bearing on the biochemistry of growth, J. Biol. Chem., 158, 625-637, 1945.

1 F. B. Morrison, Feeds and feeding, 20th ed., Morrison Publishing Company, Ithaca, N.Y., 1936. 


\section{CHAPTER III}

\section{SOME PHYSICOCHEMICAL BASES OF LIFE PROCESSES}

While most biological reactions can be duplicated in the test tube, the living organism can perform quickly and easily reactions which in the test tube require prolonged intervals or special conditions, such as high temperature. For example, it takes a 30 per cent solution of hydrochloric acid $5 \mathrm{hr}$. at a temperature above $100^{\circ} \mathrm{C}$. to hydrolyze protein, whereas enzymatic hydrolysis in the digestive tract will accomplish the same result in less than half the time at a temperature of $37^{\circ} \mathrm{C}$. and in a nearly neutral medium. The body tissues would be destroyed by the strong reagents and the high temperatures of the test tube. Although much remains to be learned as to how biological reactions take place, it is recognized that they are assisted by various physicochemical phenomena which play special roles in life processes. An understanding of certain of these phenomena is helpful in explaining various nutrition processes.

7. Surface Phenomena.-Each cell is separated from its medium and from other cells by a membrane, and the nucleus within the cell is surrounded by a membrane. At these surface boundaries many of the important reactions, both physical and chemical, occur, such as the formation of cartilage and bone which takes place at the boundary between the cell nucleus and its cytoplasm.

The molecules or particles of a liquid have a pronounced attraction for each other. At the surface this cohesive attraction is unbalanced, which means that work must be done on a molecule to take it from a position within the body of the liquid to a position in the surface. 'Thus there is resident in every unit area of surface a certain amount of potential energy which is known as the surface energy per unit area. The surface energy per unit area is equal to what is known as the surface tension. Since the potential energy of any system always tends toward a minimum, the surface area tends to become as small as possible, as is exemplified by the spherical form of a drop. Again, since the surface energy 
tends to become a minimum, any substances present which will lower the surface energy will tend to become concentrated at the surface and this phenomenon is known as adsorption.

8. Emulsions.-An emulsion is a suspension of two immiscible liquids in each other, which are held in a more or less permanent suspension by some substance acting as a film or an emulsifying agent. Oil and water, which are immiscible, can be shaken into an emulsion which is fairly permanent by the use of an appropriate emulsifying agent. Fat exists in milk in the form of an emulsion. Emulsification of two liquids may result in a semisolid state, as exemplified by such products as mayonnaise, lanolin which is wool fat with 25 per cent of water added, and the solid alcohol sold under the name of Sterno. The phenomenon is due to surface-tension relations, for the emulsifying substance is a surface-tension reducing agent. Emulsification results in an increase in surface and thus facilitates surface reactions. The bile salts act as the agents in the emulsification of fat in the intestine, whereby a greater surface is afforded for the action of the fatdigesting enzyme.

9. Osmotic Pressure.-If a solution and the pure solvent are placed in contact a homogeneous solution results under the action of diffusion. If, however, the solution and solvent are separated by a semipermeable membrane, i.e., one through which the solvent

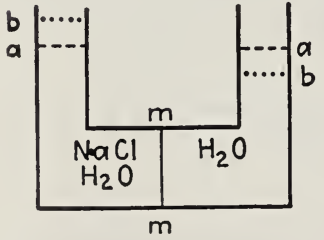

Fig. 1,-Osmotic pressure. can pass but the solute cannot, a special phenomenon arises which is illustrated in Fig. 1. The vessel consists of two compartments separated by a membrane $\mathrm{mm}$ through which water can pass but dissolved sodium chloride cannot. Water is placed in one compartment and a solution of sodium chloride in the other, so that both are at the same level, designated as $a$. Under these conditions, water diffuses through into the salt solution, and the level in this compartment rises while it falls in the other, the final levels being indicated by $b$. This takes place in opposition to the hydrostatic pressure, represented by the differences in level of the two columns, under the influence of a force which is called osmotic pressure. This pressure is determined by the number of particles in solution, whether molecules or ions. Thus, for a given solution, the higher the concentration the greater the osmotic pres- 
sure; and, at the same concentration of solute, solutions of highly ionized substances have greater osmotic pressures than solutions of weakly ionized substances.

Since all body fluids contain dissolved substances, they all exhibit osmotic pressure. This pressure is subject to variation according to the kind and concentration of the particles dissolved, and thus osmotic relationships play an important role in physiological processes. If the content of a cell has a lower osmotic pressure than its liquid medium, water tends to pass out of the cell and it shrinks, if the situation is reversed, the cell swells and may burst. For example, when a red corpuscle is placed in a solution of much lower osmotic pressure, it sivells and bursts with the liberation of hemoglobin, the red coloring matter of the blood. The phenomenon is called hemolysis. Solutions which are alike as regards osmotic pressure are said to be isotonic, while the terms, hypertonic and hypotonic, denote solutions of higher and lower pressure, respectively. A physiological salt solution is one containing 0.85 per cent of sodium chloride, a concentration which is isotonic with blood and other tissue fluids. Substances which are injected into the blood or tissues are placed in such a solution so that osmotic relations will not be disturbed.

10. The Colloidal State of Matter.-If common salt is dissolved in water, the dissolved particles are of molecular size and cannot be seen even through the ultramicroscope. The solution is clear and no settling occurs. If, on the other hand, fine sand is shaken with water a suspension is formed in which the suspended particles of sand are many, many times larger than the molecules of the dissolved salt, and the particles gradually settle out. While both the dissolving of the salt and the suspension of the sand are purely physical phenomena, the condition of the distributed or dispersed particles and their subsequent behavior are very different because of the wide difference in their size. An intermediate condition can occur in which the particles dispersed are larger than molecules, but smaller than those of the suspension described. This condition is referred to as the colloidal state of matter. The particles are large enough to be seen by the ultramicroscope, but not large enough to settle out. A colloidal solution has many properties which are very different from those exhibited by a true solution such as one of salt and water, and these properties are very important in biology. 
The essential characteristic of a colloidal solution is particle size. There is no one size, however, which defines the colloidal state. Colloidal solutions may grade into true solutions on the one hand and into suspensions on the other, and the same substance may exist either in a true solution or in the colloidal form depending upon how the solution is prepared. Colloidal properties are exhibited, however, only within a certain range of particle size. The colloidal state of matter has been arbitrarily defined as one in which the size of the particles dispersed lies within the range, $1 \mathrm{~m} \mu$ to $100 \mathrm{~m} \mu$.

11. Properties of Colloidal Solutions.-In a colloidal system the distributed particles are spoken of as the disperse or internal phase, while the solvent is called the dispersion medium or external phase. Some substances, such as kaolin and various metals, consist of pure solids when in the colloid state and are called suspensoids or lyophobic colloidal substances, in contrast to certain others designated as lyophilic, because, in aqueous solution, they have an attraction for the water such that the disperse phase may contain large quantities. Most of the colloidal substances which are important in physiology, are of the lyophilic type. Many lyophilic colloidal solutions solidify without the separation of water. This is called gelling. The protoplasm of cells of higher animals is a gel and its movements and other activities are due to adsorption and loss of water, actions which are influenced by the salts in the cell fluid and the reaction of the latter. Gelling helps explain permeability. Thus the nutrition of the cell and its aggregates is a function of the above phenomena.

Substances in the colloidal state are only slightly ionized and thus are only slightly reactive chemically. While chemical combinations thus occur, physical combinations are considered by most authorities to be of much more importance. Physical combinations take place through adsorption, a property which is exhibited to a high degree because of the large surface of the colloid particle. Owing to the large size of the particles dispersed and their lack of ionization, colloid solutions exhibit little osmotic pressure. Substances in the colloidal state diffuse slowly and are unable to pass through a parchment membrane. This property is taken advantage of to separate them from substances of smaller particle size, such as salts, in a solution. The process is called dialysis.

Most colloidal substances are electrically charged. Placing 
colloidal solutions in an electric field shows that in some the dispersed particles are electropositive, while in others they are electronegative. The reaction of the dispersing medium plays a role; for example, proteins are positive in acid solution, negative in alkaline solution.

12. Reaction Velocity, Catalysis.-The rate of any chemical reaction is proportional to the product of the active masses of the reacting substances. This is the law of mass action. The reaction velocity also increases with rise in temperature. More important is the influence of catalysis. A catalyst is a substance which alters the speed of a chemical reaction without being used up in the process. Most catalysts accelerate, but negative catalysis is known. In general, the velocity of catalytic reactions is proportional to the amount of catalyst present, provided the reacting substances are present in relatively large amounts.

13. Enzymes.-An enzyme is a catalyst produced by a living cell. Enzymatic activity is an important reason why living tissues can perform reactions much more readily than can be done in the test tube. The roles which enzymes play in the body in digestion and in other processes are familiar to all. Little was known about their specific nature until Sumner isolated in a crystalline state the enzyme, urease (Fig. 2), in 1926, and established its protein nature. Since that time many others have been isolated.

One important characteristic of enzymes is their power. For example, the enzyme catalase will decompose four to five million molecules of hydrogen peroxide per minute. Another important property is their specificily. A given enzyme can catalyze one particular reaction only. They are characterized also by being effective only in a narrow $\mathrm{pH}$ range (Sec. 16). For example, the optimum pH range for pepsin is 1.8 to 2.0 and the outside limits of its activity are $\mathrm{pH} 1$ and $\mathrm{pH}$ 3. The specific metabolic need for several of the vitamins rests upon their functioning as components of enzyme systems (Chap. VIII).

14. Biological Oxidation-reduction. - The animal body derives its energy from the oxidation of the end products of food that are absorbed after undergoing digestive breakdown in the alimentary tract. The food metabolites sugars, amino acids, and fatty acids are combined with oxygen in the various tissue cells to yield carbon dioxide, water, and energy. This process is known as biological or physiological oxidation. 


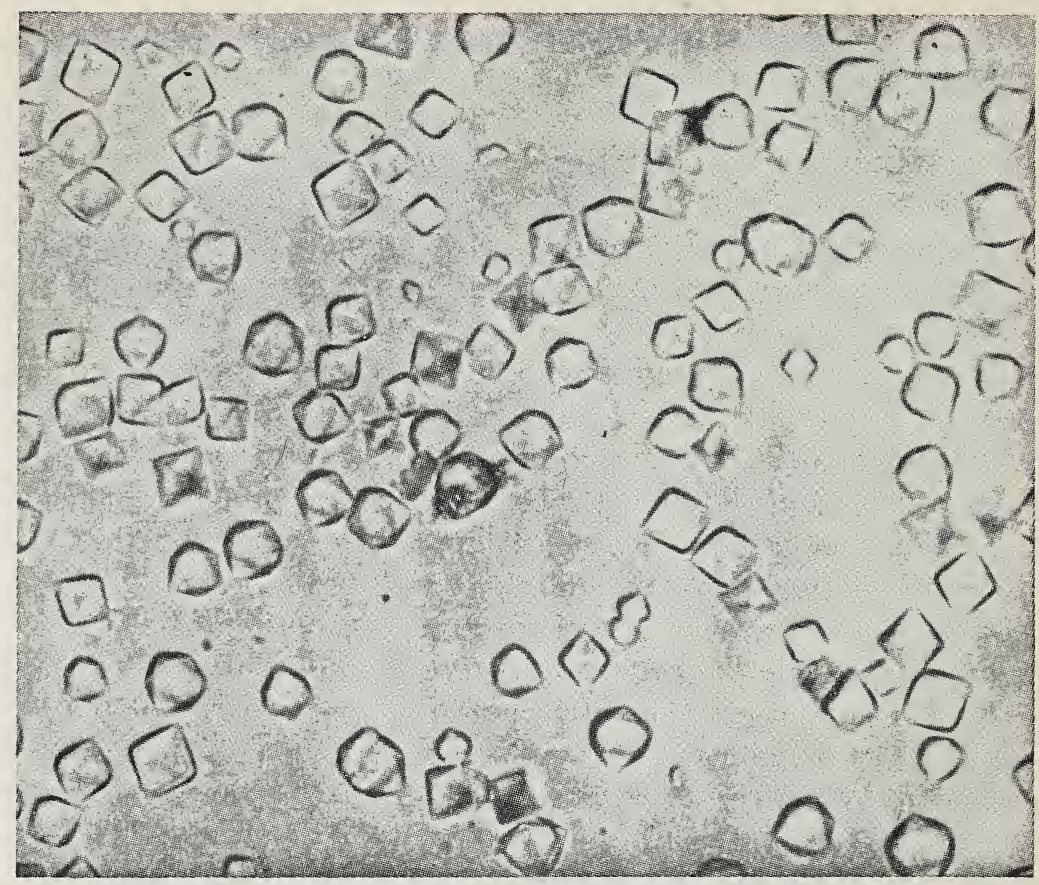

Fig. 2.-Crystalline urease. (Courtesy of J. B. Sumner, Cornell University.)

With every oxidation there takes place a simultaneous reduction. Oxidation-reduction processes, fundamentally, are similar whether living or nonliving systems are involved. Oxidation of a molecule involves the combination with oxygen or the removal of hydrogen or, specifically, the loss of electrons. From the viewpoint of physical chemistry, oxidation occurs when there is a loss of electrons, and reduction takes place when there is a gain of electrons. Therefore, during oxidation, electrons are transferred from the substance being oxidized to the substance that is reduced.

Substances that may be oxidized with ease at low temperature inside the body cannot be oxidized with molecular oxygen under similar conditions outside the body. It is apparent, therefore, that the body possesses catalytic systems capable of promoting such reactions under the comparatively mild conditions existing during biological oxidations.

The process of oxidation occurring in cells is exceedingly complex and involves, in many cases, a series of chain reactions that 
are controlled at each stage by a specific enzyme or oxidationreduction carrier in such a way that the energy is not liberated in a single explosive reaction and dissipated immediately as heat, but is liberated gradually or parceled out in such manner as to be physiologically utilizable.

The present view, based on experimental work, postulates that the tissues contain enzymes that activate the hydrogen of the substance to be metabolized. They are called dehydrogenases and are specific for the particular substrate or metabolite on which they act. Also present in the tissues are enzymes, called oxidases, that activate molecular oxygen. In addition to the foregoing, the tissues contain other biocatalysts that act as mediators or carriers and have the unique ability to undergo reversible oxidationreduction. They change easily from the oxidized form to the reduced form and back again and thus function to transfer the hydrogen or electrons from the metabolite to the oxygen. Thus, the oxidation of food substances in the tissues is not a single-stage process but a series or chain of separate but interdependent (linked) chemical reactions, involving not only molecular oxygen and activation of the metabolite but substances that act as carriers or bridges by virtue of their ability to be reversibly oxidized or reduced.

15. Hydrogen-ion Concentration.- Since most of the reactions which occur in the body take place in water solutions, the ions of water have a special significance in physiology. It is well understood that the acidity or basicity of a solution is due to hydrogen or hydroxyl ions. According to the theory of Arrhenius ${ }^{1}$ their presence and activity are due to the ionization of compounds containing them, and the greater the degree of ionization the greater is the activity, as shown by conductivity measurements. The purest water that can be prepared shows a slight but definite conductivity. According to the theory, this means that there is some dissociation:

$$
\mathrm{H}_{2} \mathrm{O} \longrightarrow \mathrm{H}^{+}+\mathrm{OH}^{-}
$$

1 Svante Arrhenius (1859-1927) was a Swedish scientist, one of the founders of the modern physical rhemistry. Recent researeh has eaused physiont chemists to modify his conception in so far as degree of dissociation is concerned and to explain differences in conductivity on other grounds. They speak of activity instead of dissociation and of hydrogen-ion activity instead of hydrogen-ion eoncentration. This modification does not interfere with the application of the hydrogen-ion concept in physiology. 
It is possible through conductivity measurements to calculate the number of ions actually dissociated. It has been found that the concentration of each.ion, expressed in mols per liter is 1 in $10,000,000$ or $1 \times 10^{-7}$, an expression which is more easily visualized by writing it as a fraction, $1 / 10^{7}$. It is also known that the concentration of hydrogen ions $\left[\mathrm{H}^{+}\right]^{1}$ times the concentration of hydroxyl ions $\left[\mathrm{OH}^{-}\right]^{1}$ equals a constant $K$, which is $10^{-14}$ at $25^{\circ} \mathrm{C}$. At neutrality $\left[\mathrm{H}^{+}\right]$is $10^{-7}$ and $\left[\mathrm{OH}^{-}\right]$is $10^{-7}$. According to the law of mass action, if the concentration of either ion is increased the other must diminish correspondingly:

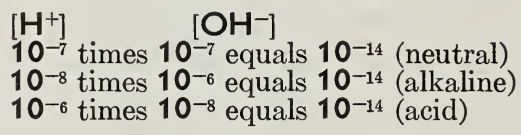

Thus the measurement of the concentration of one ion will tell us whether the solution is acid or alkaline and the degree. This is what is done where reaction is expressed as the $\left[\mathrm{H}^{+}\right]$and the solution is acid or alkaline according as $\left[\mathrm{H}^{+}\right]$is greater or less than $10^{-7}$. Concentrations lying between those represented by integral powers of 10 are expressed by coefficients, for example the $\left[\mathrm{H}^{+}\right]$of saliva is approximately $2 \times 10^{-8}$ (slightly alkaline).

16. $\mathrm{pH}$ Values.-Fortunately, we have a simpler method of expressing $\left[\mathrm{H}^{+}\right]$than the one just described, thanks to the suggestion of Sorenson that the negative exponent be used directly. The value so used is called the hydrogen-ion exponent or $p H$ value. It bears the following relation to $\left[\mathrm{H}^{+}\right]$:

$$
\mathrm{pH}=\log \frac{1}{\left[\mathrm{H}^{+}\right]}
$$

A pH of 7 represents neutrality, a value below 7 denotes an acid solution and one above 7 , an alkaline solution. Decimals take the place of the coefficients used in the expression of $\left[\mathrm{H}^{+}\right]$. For example, a $\mathrm{pH}$ value of 5.6 denotes an acidity greater than 6 but less than 5 .

It is essential to remember that the $\mathrm{pH}$ scale is logarithmic. A solution with a $\mathrm{pH}$ of 6 has 10 times as many hydrogen ions as one with a $\mathrm{pH}$ of 7 , and a $\mathrm{pH}$ of 5 represents a concentration which is 100 times that of $\mathrm{pH} 7$. The difference between $\mathrm{pH} 5.0$ and 5.1 is many times greater than that between 5.9 and 6.0 .

1 The brackets indicate "concentration" of the ion whose symbol is enclosed in them. 
Expressing acidity and alkalinity as a $\mathrm{pH}$ value differentiates between strong and weak acids and bases. A $N / 10$ hydrochloric acid and $N / 10$ acetic acid solution have the same strength in terms of titratable acidity. But hydrochloric acid is a strong and acetic a weak acid. Though they both show the same number of hydrogen ions on titration, hydrochloric acid has many more dissociated or active at any moment. $\mathrm{pH}$ measures this actual acidity as distinguished from the titratable acidity. A $N / 10$ solution of hydrochloric acid has a $\mathrm{pH}$ value of 1.09 , while a $N / 10$ solution of acetic acid has a value of 2.85 which indicates a much weaker acid in terms of hydrogen-ion concentration. The reactions of the biological organism to acids and bases are controlled by the actual acidity and thus a measure of the hydrogen-ion concentration is more useful than titratable acidity.

The determination of hydrogen-ion concentration can be carried out colorimetrically by the use of standard solutions and indicators which change color at different concentrations of the ion. It is also made directly by the use of a glass or hydrogen electrode. These methods are described in textbooks of physical and physiological chemistry.

17. Buffer Action.-The $\mathrm{pH}$ of the blood varies between 7.35 and 7.43. The range 7.0 to 8.0 is the extreme compatible with life. Yet the blood constantly receives large amounts of acid, such as $\mathrm{H}_{2} \mathrm{SO}_{4}$ and $\mathrm{H}_{3} \mathrm{PO}_{4}$, from protein breakdown. In order to holds its $\mathrm{pH}$ constant under these conditions, the blood contains substances called buffers the action of which may be illustrated as follows:

$\begin{aligned} & \mathrm{NaHCO}_{3} \\ & \begin{array}{l}\text { (slightly } \\ \text { alkaline) }\end{array} \text { (strong } \\ & \text { acid) }\end{aligned} \quad \begin{gathered}\mathrm{HaA} \\ \text { (neutral } \\ \text { salt) }\end{gathered}+\underset{\text { acid) }}{\mathrm{H}_{2} \mathrm{CO}_{3}}$

The buffer, $\mathrm{NaHCO}_{3}$, reacts with the strong acid to produce an acid of low hydrogen-ion concentration. Buffers are substances which prevent sudden or great changes in hydrogen-ion concentration when acid or alkali is added to a system. All biological reactions take place in a buffered medium because sudden or large changes in acidity or alkalinity are incompatible with life.

18. Electromagnetic Radiation.-When one turns on his radio, he is not likely to think of the similarity between the process of sending and receiving the program which he selects and the process of turning on an electric light whereby its filament becomes 
luminous. Yet both processes involve the transfer of energy through space in the form of waves, and the mechanism is the same in both cases. The physicist classes both as electromagnetic radiation. In the same class belong the light rays which are responsible for photosynthesis, the ultraviolet rays which produce vitamin $\mathrm{D}$ in our bodies and in our foods, the $\mathrm{X}$ rays which have manifold uses in physiology and medicine, and many others. Thus the student of nutrition must know something about the nature of this electromagnetic radiation and about the language which the physicist uses in describing it.

When energy is being liberated from the radio sending station, periodic electrical and magnetic disturbances are set up in space surrounding the station and travel away as waves at a velocity which is slightly less than $3 \times 10^{10} \mathrm{~cm}$. per second. It is believed that all the other rays previously mentioned are identical in nature with radio waves and that they travel with the same velocity. All differ, however, in wave lengths and in the frequency of the vibration associated with the wave motion. What is meant by wave length can be pictured by thinking of water waves and the distance from the crest of one to the crest of the next. Velocity, wave length, and frequency bear the following simple relation to each other:

$$
c=\nu \lambda
$$

in which $c$ is the velocity, $\nu$ (nu) the frequency, and $\lambda$ (lambda) the wave length. Since the velocity is constant for all forms of radiation, frequency and wave length must vary inversely with each other. The relationship is like that between the steps of a boy and a man walking together. The boy takes shorter steps and thus more per unit of time to keep pace with the man.

19. The Spectrum.-The physicist has studied electromagnetic radiation ranging in wave length from about $10^{5}$ down to $10^{-5} \mathrm{~cm}$. This range is conventionally divided into several loosely defined divisions according to the methods of production and of studying the radiation, giving what is called the electromagnetic spectrum illustrated in Fig. 3. The conventional divisions are given at the top and the wave lengths at various points are indicated at the bottom. Since the differences in wave length are so great from one end of the spectrum to the other, it is convenient to use more than one unit in expressing the wave length over the entire 
range. For the shortest, such as the gamma and $\mathrm{X}$ rays, the angstrom unit $(\AA$.) is commonly employed. As the waves become longer the millimicron or millimu $(\mathrm{m} \mu)$ comes into use, and, for those which are still longer, the $\mathrm{mu}$ or micron and finally the

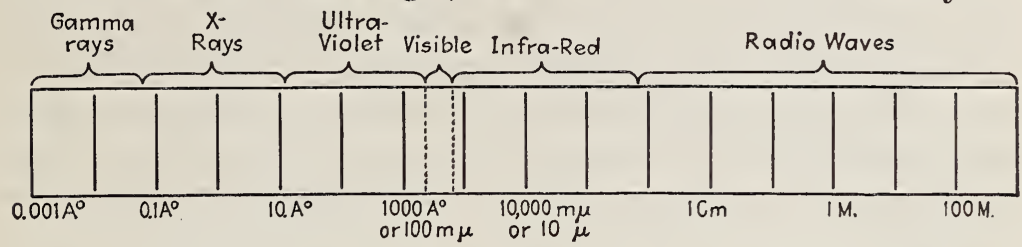

FIG. 3.-Spectrum of electromagnetic radiation. (Courtesy of L. L. Barnes, Cornell University.)

centimeter and meter are employed. The rays which are commonly met in nutrition studies are expressed in either angstrom units or millimu. The lengths represented by these units are as follows:

$$
\AA .=0.1 \mathrm{~m} \mu=0.0001 \mu=0.00000001 \mathrm{~cm} .\left(10^{-8} \mathrm{~cm} \text {. }\right)
$$

It is noted that visible light occupies a very small part of the electromagnetic spectrum. It comprises the wave lengths lying between approximately $4000 \AA .(400 \mathrm{~m} \mu)$ and $8000 \AA$. $(800 \mathrm{~m} \mu)$ of which the shortest are the violet and the longest the red rays. In addition to visible light, the ultraviolet and $\mathrm{X}$ rays are the ones in which we are most interested from the standpoint of nutritional physiology. The infrared waves are also called heat waves because they exhibit a heating effect which can be detected by placing a blackened thermometer in their path. This effect is taken advantage of in the treatment of certain diseases. All of these various radiations represented in the spectrum are commonly included under the term light, though the human eye is sensitive to only a narrow range.

No single source of electromagnetic radiation will provide rays of all lengths. The radiation which reaches us from the sun lies principally in the visible range and in certain portions of the ultraviolet and infrared. Various artificial sources are used to produce wave lengths lying in specific ranges. Utraviolet rays are commonly obtained from the carbon are or a mereury-vapor lamp. $X$ rays result when high-speed electrons (athode rays) strike a solid metal target. Radio waves are produced by vacuum tube oseillators and gamma rays by the spontaneous or artificial disintegration of atomic nuclei. 
20. Absorption of Radiation.--In considering the effect of radiation on biological processes, it is important to bear in mind that it is only those wave lengths, absorbed by the medium, which produce any change in it. For example, it is the light which is absorbed by water, not that which passes through, which raises the temperature. Since matter is made up of atoms which consist of electrical charges, it is not difficult to understand that radiation resulting from electrical and magnetic disturbances may in turn cause disturbances in the atoms of matter on which it falls.

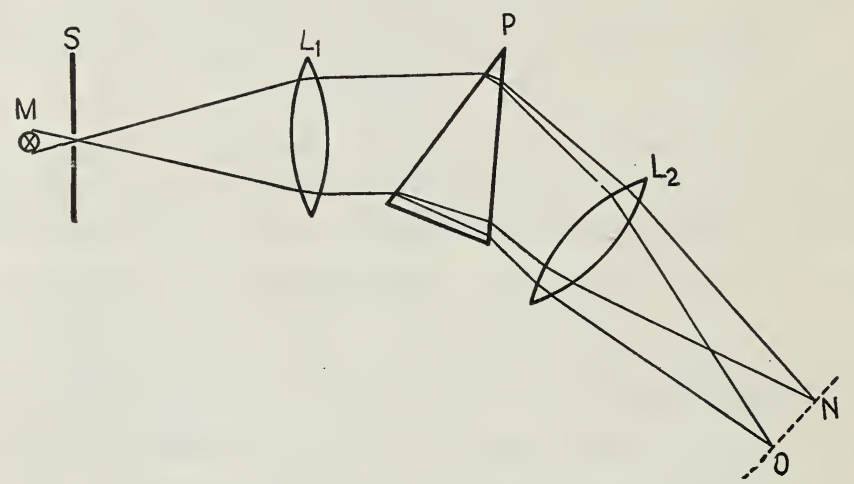

FIG. 4.-The spectrograph. (Courtesy of L. L. Barnes, Cornell University.)

When radiant energy is absorbed by matter, various processes may occur, such as a rise in temperature, the removal of an electron from an atom and various other changes in the structure of the molecules of the substance. These processes involve the transfer of energy from the radiation to the absorbing substance. A given change in the absorbing substance may require a definite amount of energy and this fact determines what wave lengths are effective in bringing about a given change and thus what ones are absorbed in the process. The formation of vitamin $\mathrm{D}$ from ergosterol (Sec. 163) by ultraviolet light is an example of a molecular change resulting from the absorption of radiation.

A substance may absorb radiant energy over a wide range of wave lengths, or it may absorb only a very narrow band of radiation. The wave lengths absorbed by a given substance can be determined by a spectrograph such as is illustrated diagrammatically in Fig. 4. A source of light is employed which emits a continuous spectrum, i.e., a source which emits light of all possible wave lengths over a certain selected range, such as $300 \mathrm{~m} \mu$ 
to $800 \mathrm{~m} \mu$. When such a source $M$ is placed in front of the slit $S$ of a spectrograph, the lens $L_{1}$ makes its rays parallel. The prism $P$ refracts the rays, the shorter wave lengths being changed in direction more than the longer ones. As these refracted rays pass through lens $L_{2}$, there will result a broad band of light between $N$ and $O$, the wave lengths becoming shorter and shorter from $N$ to $O$. If now we introduce some substance into the path of the light between $M$ and $S$ and if this substance absorbs light of some wave length intermediate between that falling at $N$ and that falling at $O$, then there will be a region between $N$ and $O$ which is not illuminated so strongly as it was before the substance was introduced. If a photographic plate is placed in the position NO the characteristic absorption spectrum of the substance is recorded on the plate. If absorption spectra for light of wave lengths lying in the visible range are being studied, glass lenses and a glass prism may be used, but, for work in the ultraviolet, too much of the radiation is absorbed by the glass itself, and thus quartz must be substituted.

Absorption spectra have proven very useful in identifying complex organic compounds and in studying their structure. As is discussed in Chap. VIII, they have contributed largely to our knowledge of the chemical nature of certain vitamins and have also provided methods for their assay. The photoelectric colorimeter is a crude type of absorption spectrometer in which a filter is used to provide a band of wave lengths in the spectrum, the absorption of which is a function of the number of absorbing molecules in the path of the light.

Emission spectra, including X-ray spectra, are used for analysis of atomic constituents of substances important in nutrition, notably the trace mineral elements.

21. Isotopes as "Tracers" in Metabolism.-The use of isotopes of elements, either the less abundant naturally occurring, stable ones, such as heavy hydrogen, or radioactive isotopes obtained by nuclear reactions, represents a contribution of modern physies to biology which has become an important tool in nutrition studies. For example, heavy hydrogen, $\mathrm{H}^{2}$, can be introduced into a fat and the course of that fat traced in metabolism by appropriate methods for detecting the isotope. Similarly, heavy nitrogen, $\mathrm{N}^{15}$, can be employed to study the metabolism of specific amino acids. Radioactive phosphorus, $P^{32}$, produced by the cyclotron, aan be 
introduced into various compounds and their course followed in absorption, deposition in the body, and excretion. Experiments carried out by the use of isotopes have revolutionized many of our ideas regarding the metabolism of fats, proteins, and minerals referred to in later chapters. The experimental techniques and accomplishments are very interestingly set forth in the book by Schoenheimer. ${ }^{1}$

\section{THE ROLE OF WATER IN THE ANIMAL BODY}

It has been mentioned that water makes up over 50 per cent of the composition of the body and that many tissues contain 70 to 90 per cent of this substance. In fact one may consider the living elements of the body as water inhabitants even as are the true aquatic species. This water is not simply an inert material or merely a solvent but is an active and structural constituent. If a frog's egg weighing a few milligrams is placed in sterile filtered water, a tadpole weighing several grams results. The tadpole contains less dry matter than the original egg, for a part of it has been used to furnish energy for the developmental process. The increase in weight is due to the taking up of water which has become an essential part of the organism. The vital role of water in the body is indicated by Rubner's ${ }^{2}$ observation that the body can lose practically all of its fat and over half of its protein and yet live, while a loss of one-tenth of its water results in death. Adolph ${ }^{3}$ in an excellent review of water metabolism has pointed out that water ranks far above every other substance in the body as regards rate of turnover, whether the comparison is made absolutely in gram molecules per day or relatively in per cent of the body content. Its consideration provides an appropriate introduction to nutritional physiology.

22. Properties and Functions of Water.-Water is the ideal dis- persing medium because of its solvent and ionizing powers which

1 Schoenhemer, Rudolph, The dynamic state of body constituents, Harvard University Press, Cambridge, Mass., 1942.

2 Max Rubner (1854-1932), a pupil of Voit, served for over 40 years at the University of Berlin, first as professor of hygiene and later of physiology. He made many pioneer contributions to the science of nutrition, particularly in the field of energy metabolism, as later discussions show.

${ }^{3}$ Adolph, Edward F., The metabolism and distribution of water in body and tissues, Physiol. Rev., 13, 336-371, 1933. 
facilitate cell reactions, and because of its high specific heat which enables it to absorb the heat of these reactions with a minimum rise in temperature. Cannon ${ }^{1}$ has pointed out that: "The heat produced in maximal muscular effort continued for 20 minutes would be so great that if it were not promptly dissipated it would cause albuminous substances of the body to become stiff like a hard boiled egg." The latent heat of vaporization of water also plays an important role in regulating body temperature. Other properties of large significance in physiology are the high surface tension, the tendency to form hydrates, and the high dielectric constant of water.

The manifold functions of water in connection with the transportation of metabolic products, with secretion and excretion, and with many other body processes are obvious. It plays many special roles also. As synovial fluid, it lubricates the joints, and, as cerebrospinal fluid, it acts as a water cushion for the nervous system. In the ear, it transports sounds, and, in the eye, it is concerned with sight.

23. Metabolic Water.-Most of the water which is utilized by the animal body is ingested, either as such or as a component of the food. There is a further available source which is provided by metabolic processes and which is thus called metabolic water. When the carbohydrate, glucose, is burned to furnish energy for body processes, carbon dioxide and water result:

\section{$\mathrm{C}_{6} \mathrm{H}_{12} \mathrm{O}_{6}+6 \mathrm{O}_{2} \longrightarrow 6 \mathrm{CO}_{2}+6 \mathrm{H}_{2} \mathrm{O}$}

By calculations from this equation, it can be shown that the metabolism of glucose yields 60 per cent of its weight as water. This figure can be taken as an approximate one for all carbohydrates. Similarly, the metabolism of protein produces approximately 42 per cent of its weight as water, while in the case of fat the figure is over 100 per cent. Metabolic water is also produced by the dehydration synthesis of body proteins, fats, and carbohydrates. Under certain physiological conditions, metabolie water plays an important role in the animal economy. It suffices to meet the needs of hibernating animals. These animals metabolize their reserves of carbohydrate and fat to provide energy for their

1 Walter B. Cannon was professor of physiology at Harvard Medieal School. The quotation is from his book, "The Wisdom of the Body," W. W. Norton \& Company, Inc., New York, 1932. 
vital processes, and this metabolism produces enough water to balance that lost by respiration and evaporation. The various roles of metabolic water in the vital processes of plants and animals have been discussed in a very interesting way by Babcock. ${ }^{1}$

24. Factors Governing Water Excretion and Requirement.The body's need for water is governed by many factors. Approximately 75 per cent of the tissue formed during growth is water, and, in the mature animal, such special processes as milk and egg production require water in accordance with the amount of the product being formed. Aside from these needs for the formation of tissue and products, there are large requirements for water to balance that lost by excretion through the gut, kidneys, lungs, and skin. These losses are related to body size, and, in rats, a voluntary intake of $800 \mathrm{ml}$. daily per square meter of body surface has been noted. But the losses are conditioned by body processes and are thus highly variable according to the diet, nature of the metabolic end products, and other factors. The losses through the gut vary with the species, as is evident from the fact that the feces of sheep are drier than those of cattle. A laxative diet increases the fecal loss.

Water is excreted in the urine as a solvent for catabolic products which leave the body through this channel, viz., minerals and nitrogenous end products such as urea. The higher the proportions of minerals and protein in the diet, the larger is the excretion of water in the urine and the larger the requirement accordingly. Another reason why a high protein diet increases the water requirement is that less metabolic water is formed in its catabolism than is the case for fat or carbohydrate. In certain pathological conditions excess water is retained in the tissues, body cavities, and elsewhere, causing edema.

There are marked species differences in water excretion according to the nature of the nitrogenous end products. In mammals the principal end product of protein catabolism is urea which is soluble in water and toxic to the tissues in concentrated solution. Thus much water is required to dilute it to a harmless concentration, remove it from the tissues, and excrete it. Uric acid, the principal nitrogenous end product in birds, is excreted in a nearly solid form with a minimum loss of water. Further, the break-

1 BАвсоск, S. M., Metabolic water: its production and role in vital phenomena, Wis. Agr. Expt. Sta. Research Bull. 22, 1912. 
down of protein to uric acid provides more metabolic water than does its catabolism to urea. Thus, other conditions being equal, birds have a lower water requirement than mammals and are much less sensitive to the temporary deprivation of it. Mammals will live longer without food than without water, and the consumption of food, especially protein food, without water hastens death as the result of the accumulation of toxic end products. Birds, snakes, and insects survive much longer under these conditions. Clothes moths, which contain 50 per cent of water in their bodies, live throughout their cycle on food containing 10 per cent or less of this compound. They excrete uric acid, and thus the small amount of water obtained as a component of their food, plus their metabolic water, suffices.

Expired air always contains more water than inspired air, and this loss is greatly increased by physical activity and other factors which speed up pulmonary exchange. Perspiration losses through the sweat glands represent an evaporation of water for the dissipation of heat in the regulation of body temperature (Sec. 230). They increase with muscle activity and temperature. In most animals the sweat glands are few or absent. Under these conditions, the lungs play an important role in the dissipation of heat. The constantly occurring excretion of water vapor through the lungs and skin is largely responsible for the body losses referred to as insensible perspiration (Sec. 235) which represents the difference between the gascous intake and outgo. These losses are of considerable magnitude and are related to the environmental temperature and humidity and to the nature of the metabolism including water intake.

Babcock cites the ability of the camel to accomplish long journeys with little water as illustrating the application of various factors which economize water requirement. This animal eats mostly carbohydrate food under these conditions and thus produces little urea for excretion. It depends upon fat stored in its hump for a part of its energy requirement, and the metabolism of this fat in turn provides a maximum amount of metabolic water. Evaporation from the skin is reduced by a thick coat of hair, and the feces are dry. These factors appear to be more important than the water-holding capacity of its stomach, the popular explanation. Fasting greatly decreases the need for water. Dogs have been found to ingest only one-fourth as much 
water on days when no food was given compared to the amount taken on an adequate diet.

25. Water Requirements. - It is evident that the body must receive sufficient water to balance its losses in addition to the amount required for the formation of new tissue or products; but it is also clear that the requirement will vary widely according to the magnitude of the various factors which govern the losses, and that there are marked species differences as well. Thus the determination of the water requirements for a given species and set of conditions is of limited value for any general recommendations. Leitch and Thomson ${ }^{1}$ have recently issued an excellent review of factors governing water intake and of the data dealing with the requirements of various classes of stock.

Fortunately, except under pathological conditions, there are no deleterious effects from an excessive consumption of water. Thus the requirements can best be taken care of in practice by making sure that the animals have the opportunity to consume all they desire at frequent intervals. The importance of frequent access to water for animals having a high requirement has been clearly shown in studies with milking cows. These animals need 4 to $5 \mathrm{lb}$. of water for each pound of milk produced. They will consume more when watered twice a day than once a day, and still more if water is before them at all times, and they will produce more milk where they have the latter, free access to water.

26. The Determination of Water.-The water present in a biological material is commonly determined by drying it to constant weight at the temperature of boiling water, and this is a satisfactory procedure for most routine analyses. Not all the water, however, at least in certain materials, is removed by this procedure. The unremoved portion represents water existing in films which has a very low vapor pressure even at $100^{\circ} \mathrm{C}$. Thus a refined method involves drying in partial vacuum. Strictly speaking, no figures for moisture content can be considered as absolute values since their magnitude is influenced by the three variables involved in the determination-temperature, pressure, and time. When the dried material is to be used for subsequent determinations with which previous oxidation might interfere, the drying is carried out in an inert gas such as nitrogen. Certain

1 Leiтch, I., and J. S. Thomson, The water economy of farm animals, Nutrition Abstracts \& Revs., 14, 197-223, 1944. 
materials must be dried at a temperature below $100^{\circ} \mathrm{C}$. to avoid alterations in some of their constituents. Other special procedures are required for certain products.

\section{Selected Literature}

DugGar, Benjamin M.: Biological effects of radiation, vols. I, II, MeGrawHill Book Company, Inc., New York, 1936.

Gortner, Ross A.: Outlines of biochemistry, John Wiley \& Sons, Inc., New York, 1929.

Loofbourow, J. R.: Borderline problems in biology and physics, Rev. Modern Phys., 12, 267-358, 1940.

Sumner, J. B., and G. F. Somers: Chemistry and methods of enzymes; Academic Press, Inc., New York, 1943.

West, E. S.: Physical chemistry for students of biochemistry and medicine, The Macmillan Company, New York, 1944. 


\section{CHAPTER IV}

\section{THE CARBOHYDRATES AND THEIR METABOLISM}

The group of foodstuffs called carbohydrates includes the sugars, starch, cellulose, gums, and related substances. Though none of these substances, with the exception of a small amount of sugar and glycogen, occurs as a constituent of the animal body, they form the largest part of its food. This follows from the fact that carbohydrates make up three-fourths of the dry weight of the plant world upon which animal life primarily depends for its food supply. The carbohydrates in the plants arise by means of photosynthesis, the most important chemical reaction in nature. The reaction involves the formation of intermediate products, but it may be simply represented as follows:

$$
6 \mathrm{CO}_{2}+6 \mathrm{H}_{2} \mathrm{O}+673 \mathrm{Cal} . \longrightarrow \underset{\text { glucose }}{\mathrm{C}_{6} \mathrm{H}_{12} \mathrm{O}_{6}}+6 \mathrm{O}_{2}
$$

The carbohydrates of the plant are in turn used by the animal as a source of energy for its life processes, and, thus, all animal life also is dependent upon the process of photosynthesis.

27. Classification of Carbohydrates.-The carbohydrates owe their name to the fact that they contain carbon, combined with hydrogen and oxygen which are usually in the same ratio as in water. Chemically they are polyhydroxy aldehydes and ketones, or substances which yield them on hydrolysis. An abbreviated classification, which includes the members in which we are particularly interested in nutrition, is presented in Table IV.

It is noted that the various members of a given subgroup have the same empirical formula. They have, however, different structural formulas and exhibit different degrees of optical activity. This ability to rotate the plane of polarized light is an important distinguishing feature of the sugars, many of which are stereoisomers of each other. In addition to the compounds falling under the classification given in Table IV, certain related substances or groups, such as uronic acids, hemicelluloses, polyuronides and lignin, require consideration in this chapter. 
Table IV.-Classification of Carbohydrates

I. Monosaccharides

1. Pentoses, $\mathrm{C}_{5} \mathrm{H}_{10} \mathrm{O}_{5}$

Arabinose

Xylose

Ribose

2. Hexoses, $\mathrm{C}_{6} \dot{\mathrm{H}}_{12} \mathrm{O}_{6}$

Glucose

Fructose

Galactose

Mannose

II. Disaccharides, $\mathrm{C}_{12} \mathrm{H}_{22} \mathrm{O}_{11}$

Sucrose

Maltose

Lactose
III. Trisaccharides, $\mathrm{C}_{18} \mathrm{H}_{32} \mathrm{O}_{16}$ Raffinose

IV. Polysaccharides

1. Pentosans, $\left(\mathrm{C}_{5} \mathrm{H}_{8} \mathrm{O}_{4}\right) x$ Araban

Xylan

2. Hexosans, $\left(\mathrm{C}_{6} \mathrm{H}_{10} \mathrm{O}_{5}\right) x$ Dextrin

Starch

Cellulose

Glycogen

Inulin

3. Mixed polysaccharides

Gums

Mucilages

\section{THE CHEMISTRY OF THE CARBOHYDRATES}

Only a few of the monosaccharides occur free in nature. Most of them are obtained as hydrolytic or fermentation products of more complex plant constituents. They are often called the simple sugars. All are soluble in water. They are classified into subgroups on the basis of the number of carbon atoms in the chain. There are trioses, tetroses, and others, as well as the pentoses and hexoses given in the table.

28. Pentoses.-The pentose sugars have been found as such in small amounts in certain plants, but they occur primarily in a polymerized form in the pentosans. Upon the hydrolysis of hay, oat hulls, corn cobs, and many woods, xylose is produced. Arabinose is obtained from gum arabic and other gums. Ribose is found in some nucleic acids (Sec. 87) and in the vitamin riboflavin (Sec. 179).

29. Hexoses.-The hexoses comprise a large group of sugars, several of which play a significant role in nutrition either as components of foods or as products of metabolism in the body. (Of those occurring in combined form, galactose is of special importance in nutrition. Glucose and fructose are the only ones which oceur free in nature. The hexoses are divided into aldoses and ketoses according to whether they contain aldehyde or ketone groups. Thus glucose is an aldo-sugar, while fructose is a ketosugar. 'The general formulas for the two classes of hexoses are as follows: 


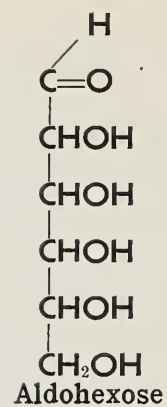

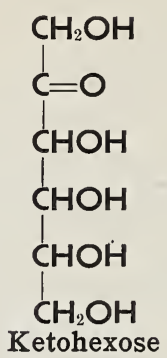

It is noted that each has five hydroxyl groups. The number of stereoisomers which can occur among the sugars is evident from these formulas. The formula for aldohexose has 4 asymmetric carbon atoms and thus 16 stereoisomers are theoretically possible. Of these, 4 optically active forms are known to occur in nature, and the others have been prepared in the laboratory. Eight stereoisomers of ketohexoses are theoretically possible of which two have been found in nature. The physiologically important hexoses are glucose, fructose, galactose, and mannose.

The 16 stereoisomeric aldohexoses consist of 8 pairs of mirror images of each other, viz., $d$-glucose and $l$-glucose, $d$-galactose and $l$-galactose, and 6 other pairs. Similarly, the 8 ketohexoses occur as 4 pairs of mirror images. The letter prefixes denote a conventional basic structural configuration and not direction of rotation. $d$-Glucose is dextrorotatory, but $d$-fructose is levorotatory. This usage of the letters, which seems to be fixed, is unfortunate because it results in confusion. For a more complete discussion of stereoisomerism in the sugars, the student is referred to a textbook of physiological chemistry.

Sugars containing an aldehyde or ketone group have a reducing power which classes them as reducing sugars. For example, when they are boiled with an alkaline solution of copper sulfate, such as Fehling solution, the cupric ion is reduced to a cuprous ion present as the oxide, a brick-red precipitate. This is an important reaction which is made use of for both qualitative tests and quantitative determinations. The reaction is not specific, however, because it is given by other reducing substances.

The glucose which occurs in nature has the $d$ configuration, and it has a specific rotation of $+52.5^{\circ}$ which accounts for its other name, dextrose. 
Glucose is found widely distributed, though in small amounts, in fruits and plant juices and also in honey. It is obtained commercially by the hydrolysis of cornstarch, which is a product of the same process which yields corn-gluten feed and meal for animal feeding. Glucose is of special interest in nutrition, because it is the principal end product of the digestion of higher carbohydrates, the form in which the nutrients circulate in the blood and the form in which they are utilized to furnish energy. It has a sweet taste but is not so sweet as cane sugar. It is fermented by yeast to form ethyl alcohol and carbon dioxide, and it also undergoes an acid fermentation. Glucose is a reducing sugar.

Galactose is an aldohexose which occurs in milk sugar in combination with glucose. It is a reducing sugar and has a specific rotation of $+80^{\circ}$. Certain compounds of galactose, namely, galactosides, occur in the brain and nervous tissue.

Mannose is an aldohexose occurring in mannans, a group of polysaccharides widely distributed in plants. It has a specific rotation of $+14.6^{\circ}$.

Fructose is the only important ketohexose. It occurs free along with glucose in fruits and honey and in combined form in higher carbohydrates. Fructose has a specific rotation of $-92^{\circ}$, which accounts for its other name, levulose. It is sweeter than sucrose and readily undergoes fermentation.

30. Disaccharides. - The disaccharides derive their name from the fact that they are combinations of two molecules of monosaccharides. Their general formula, $\mathrm{C}_{12} \mathrm{H}_{22} \mathrm{O}_{11}$, indicates that one molecule of water is eliminated in the combination. They are soluble in water, though in varying degrees.

Sucrose is made up of a combination of one molecule of d-glueose and one of $d$-fructose. It oceurs in sugar cane and sugar bects and thus is the sugar used on the table and in cooking. It oecurs also in ripe fruits, in tree sap (whence maple sugar) and elsewhere in nature. Sucrose has a specific rotation of $+67^{\circ}$, but it is not a reducing sugar. On hydrolysis with the enzyme, sucrase, or with dilute acids, sucrose is split into its constituent monosaceharides. The resulting sugar mixture is levorotatory. Since the hydrolysis

$$
\underset{\text { sucrose }}{\mathrm{C}_{12} \mathrm{H}_{22} \mathrm{O}_{11}}+\mathrm{H}_{2} \mathrm{O} \longrightarrow \underset{\substack{\text { glucose } \\ \text { Invert sugar }}}{\mathrm{C}_{6} \mathrm{H}_{12} \mathrm{O}_{6}}+\underset{\text { fructose }}{\mathrm{C}_{6} \mathrm{H}_{12} \mathrm{O}_{6}}
$$


thus results in a change from a dextro- to a levorotation the process is called inversion and the mixture of glucose and fructose is called invert sugar.

Maltose consists of two molecules of $d$-glucose joined together, as is evident on its hydrolysis by maltase or by acids. It derives its name from the fact that it is produced from starch by the action of malt which contains the starch-hydrolyzing enzyme, diastase. Maltose is a reducing sugar and is strongly dextrorotatory $\left(136^{\circ}\right)$.

Lactose is the sugar of milk and consists of one molecule of glucose and one molecule of galactose, which are produced by hydrolysis with lactase or acids. It is a reducing sugar with a specific rotation of $+55^{\circ}$, and it is only one-sixth as sweet as sucrose. Lactose is of special interest in nutrition, because it makes up nearly half of the solids of milk, nature's food for the young, and because it does not occur in nature except as a product of the mammary gland. This sugar has several physiological properties distinguishing it from others. It is less likely than glucose or sucrose to undergo acid fermentation in the stomach, a process which may result in irritation. Lactose promotes acidity in the intestine, favoring the development of desirable types of bacteria, the acidophilic organisms, and opposing the growth of the undesirable putrefactive bacteria. Several studies have shown that this sugar favors calcium and phosphorus assimilation, probably by increasing their absorption. Lactose is more slowly absorbed than other sugars which results in certain physiological advantages, but it also means that large intakes are likely to cause diarrhea.

31. Trisaccharides.-The trisaccharides consist of three monosaccharides, as the name indicates. Raffinose is a trisaccharide which occurs in sugar beets, cottonseed, and elsewhere, and which is composed of glucose, galactose and fructose. On hydrolysis it first yields fructose and the disaccharide, melibiose. The latter, which is isomeric with lactose, is next broken up into glucose and galactose.

32. Polysaccharides.-The polysaccharides are complex carbohydrates which are polymerized anhydrides of a large but undetermined number of the simple sugars, as their empirical formulas indicate. The various subgroups are rather ill-defined, and there is a lack of agreement as regards their classification. They are of high molecular weight, are unreactive, and form colloidal solu- 
tions for the most part. Upon hydrolysis by acids and enzymes, they are broken down into various intermediate products and finally into their constituent monosaccharides. Quantitatively, they are the most important nutrients in feeds of plant origin.

33. Starch.-The reserve material of most plants consists primarily of starch. When this polysaccharide is hydrolyzed with acids or enzymes it is changed into dextrin, maltose, and finally into glucose. In the ripening of fruits, there is a change of starch into sugars. The starches of different plants differ as regards the size and shape of their grains. These properties furnish a means of microscopic identification. Strictly speaking, the various starches are not pure carbohydrates because they contain minute amounts of acid radicals, which are sometimes fatty acids and which sometimes contain phosphorus. Starch gives a characteristic blue color with iodine.

In certain plants, notably the Jerusalem artichoke, inulin replaces starch as the reserve material. Inulin is a polysaccharide which yields fructose on hydrolysis.

34. Glycogen.-The small amount of carbohydrate reserve in the animal body exists in the liver and muscles in the form of glycogen, which resembles starch in certain properties as well as in function. It is therefore frequently called "animal starch." Glycogen is present in lower as well as in higher animal life. Toward the end of the larval period, it makes up 33 per cent of the dry weight of bee larvae. It is also present in yeasts and certain other fungi. Differing from starch, glycogen is soluble in water and gives a brown to red color with iodine, but both yield glucose as the sole end product on hydrolysis.

35. Dextrin.-This is an ill-defined group of intermediate compounds resulting from the hydrolysis and digestion of starch, and they are also produced from starch by the action of heat. They occur temporarily in both plants and animals as a result of metabolic processes and are particularly abundant in germinating seeds. The dextrins are much more soluble than the starches, and their molecules are certainly much smaller. Like lactose. dextrin furnishes a favorable medium for the development of acidophilic organisms in the digestive tract.

36. Cellulose. The term cellulose is applied to a group of polysaccharides which are more resistant to chemical reagents than is starch. Weak acids and alkalies have little effect on 
cellulose, but it can be hydrolyzed by strong acids to glucose. It is dissolved by an ammoniacal copper solution-Schweitzer's reagent. It is not acted upon by any enzyme secreted by mammalian tissues, but bacteria break it down. These are properties which have an important bearing on its usefulness in nutrition. There are many different celluloses in which the number of polymerized glucose molecules has been variously determined to range from 900 to 2000 .

Cellulose occurs in a nearly pure form in cotton, a simple cellulose. As the framework of plants and the protective coating of their seeds, it occurs combined with various aromatic derivatives, notably lignin.

37. Pentosans.-This group of polysaccharides differs from cellulose in yielding pentose sugars on complete hydrolysis with acids, and most of the group, at least, are much less resistant to acids and alkalies. The pentosans make up about 20 per cent of the complex carbohydrates in hays and occur in lesser proportions in various concentrates, such as the oil meals. When pentosans are boiled with hydrochloric acid, furfural, an aldehyde is produced. This reaction is the basis of the quantitative determination of pentosans, and it is used in the commercial production of furfural from oat hulls and corn cobs.

38. Hemicellulose.-The term hemicellulose is used by the plant chemist to denote a group of substances, including pentosans and certain hexosans, which are much less resistant to chemical agents than is cellulose. This group is commonly defined as carbohydrate substances that are insoluble in boiling water but soluble in dilute alkali and hydrolyzed by dilute acids to simple sugars and frequently to uronic acids, notably glucuronic and galacturonic. In the latter case, the substances are referred to as polyuronides. Glucuronic, and probably galacturonic acid, also serves as a detoxicating agent in the body for such substances as phenols by forming harmless conjugation products that are excreted. Glucuronic acid is definitely known to be produced in body metabolism for this purpose. The hemicelluloses are widely distributed in forage crops and in certain other feeds. Their recognition as a group is important in considering the digestibility of the higher carbohydrates (Sec. 43).

39. Lignin.- The woody parts of plants, such as cobs, hulls, and the fibrous portions of roots, stems, and leaves contain a com- 
plex, indigestible substance called lignin. The chemical structure of lignin remains uncertain. It contains carbon, hydrogen, and oxygen, but the proportion of carbon is much higher than in carbohydrates. Methoxy groups occur to the extent of 15 per cent or more of the molecule as a whole. The compound contains a polyhydroxy aromatic nucleus and occurs in different degrees of condensation according to the age of the tissue and other factors. Lignin is discussed along with the carbohydrates because it occurs in intimate association with cellulose and is included with the carbohydrates in the conventional methods of feed analysis. Its recognition as a separate entity is important because of its dominant influence on the degree of digestibility of many feeds. An excellent review of the literature on the nature and occurrence, chemistry and formation of lignin has recently been made by Hibbert. ${ }^{1}$

40. The Chemical Determination of Carbohydrates.-The analysis of feeds for all the individual carbohydrates would obviously be a tremendous task, particularly as the procedures for some of the higher ones are long and difficult. Thus, in the routine analysis of feedingstuffs the carbohydrates are determined as two groups; crude fiber and nitrogen-free extract (N.F.E.). The separation is obtained by a chemical method devised over 75 years ago by Henneberg and Stohmann ${ }^{2}$ and known as the Weende method after the name of their experiment station. After the removal of the water and fatty material from a given sample of feed, it is boiled for $30 \mathrm{~min}$. with weak sulfuric acid ( 1.25 per cent) and then for the same time with alkali of the same strength. This procedure removes the proteins, sugars, and starch, leaving as a residue most of the cellulose and other complex polysaccharides along with some mineral material. The losis on ignition of this dried residue is taken as the crude fiber. Since the crude fiber consists primarily of cellulose and other polysaccharides which serve as the structural and protective parts of plants, it is evidently

1 Hibmert, Harold, Lignin, Ann. Rev. Biochem., 11, 183 202, 1942.

${ }^{2}$ Wilhelm Henneberg (1825-1890) and Friedrich Stolmmmn (1832-1897) were pioneer German workers in the nutrition of farm animals. Their work inclucled respiration studies, digestion trials, and chemienl analyses of feeds and animal tissues. Their early studies, including their work on crude fiber, are reported in their two-volume publication: Beiträge zur Begründung ciner rationellen Fütterung der Wiederkäuer, vols. 1, 11, Schwetschke u. Sohn, Brunswick, 1860, 1865. 
higher in hay and similar roughages than in the grains, and it is higher in those seed by-products which consist largely of the outer coatings, such as wheat bran or oat hulls, than in the seed as a whole.

The nitrogen-free extract, which comprises the sugars, starch, and a large part of the material classed as hemicellulose, is determined by difference. It is represented by the figure obtained when the sum of the water, ash, protein, fat, and crude fiber of a feed is subtracted from 100. Since the figure is determined by difference instead of directly, it includes the cumulative errors of the other determinations and thus is not an exact value. The total error here involved is not a serious one from the standpoint of routine feed analysis and of the use of the value in practice, and thus the indirect procedure is employed in place of the more timeconsuming direct determination of the various sugars and starch. Primarily because it contains the starch, nitrogen-free extract makes up the principal constituent of most feeds of plant origin.

Though the Weende method is an empirical one which does not provide any sharp separation into chemical groups, it is useful because it is a simple procedure which makes a distinction between the more digestible and the less digestible carbohydrates. The distinction is by no means absolute, for crude fiber undergoes a very considerable breakdown in the digestive tract of Herbivora under the action of microorganisms, particularly in ruminants, and it does not remain entirely unattacked in Omnivora (Sec. 43). Further, the nitrogen-free extract includes pentosans and small amounts of other complex polysaccharides which are by no means completely digestible. On the other hand, lignin, which is practically indigestible by all species, is partially removed by the alkali of the Weende method.

\section{Lignin and Cellulose Content as Indicators of Digestibility.} - The knowledge that the partition of the higher carbohydrates into crude fiber and N.F.E. provides only an approximate distinc-tion between the more and the less digestible constituents has led several investigators to test out methods that might provide a more useful partition in this respect. Particular attention has been given to cellulose and lignin. Crampton and Maynard have proposed a procedure for partitioning the carbohydrate of feeds into cellulose, lignin, and other carbohydrates in a study in which the limitations of the Weende method are clearly revealed. More 
work needs to be done, however, on the analytical procedures. As they are improved they should find increased use, in place of the crude-fiber method, for the evaluation of the usefulness of the carbohydrate fraction of feeds, particularly in experimental studies. Here the methods just published by Ellis and associates ${ }^{1}$ appear especially promising.

\section{CARBOHYDRATE METABOLISM}

From the standpoint of nutrition, two processes are essential for life - the assimilation of food and the removal of waste products. The food consists of complex chemical units, such as proteins and fats; the waste products are simple compounds, such as carbon dioxide and water. The sum of the changes which food undergoes in its conversion to excretory products is called metabolism. Some reserve this term for the changes which occur in the absorbed food and which are involved in the breakdown of body tissues, processes which are also referred to as intermediary metabolism. These various metabolic changes are governed by physiological processes with which the student is assumed to be familiar in a general way from a previous study of physiology. Thus in the dis zussions to follow for the carbohydrates and other nutrients these changes as a whole are traced only in outline, as a background for a detailed consideration of certain features which from the standpoint of nutrition require a more extended discussion than they receive in an elementary course in physiology.

42. The Digestion of Sugars and Starch.-The previous discussion of the hydrolysis of compound sugars and stareh has indicated the processes by which these arbohydrate groups are broken down to the simple sugars under the action of specific enzymes secreted into the digestive tract. Since starch predominates in most rations, the principal cond product is glucose. Where milk is included in the ration, as is always the case for the suckling, galactose is also formed; and fructose is a digestion product of feeds containing sucrose, such as sugar beets. These

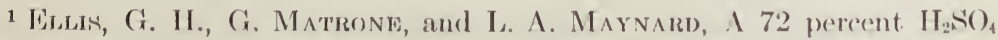
method for the determination of lignin and its use in animal nutrition studies, J. Animal Sci., 5, 285-297, 1946.

Matrone, (i., G. H. Fuls, and I. A. Maynar1), A modified NormanJenkins method for the determination of collulose and its use in the evaluation of fecdstuffs, J. Animal S'ci., 5, 306-312, 1916. 
digestive processes are common to all animal species including man, and their physiology requires no special discussion from the standpoint of nutrition. The breakdown of the higher carbohydrates, however, presents certain features, variable with the species, which have important bearings on the nutritive value of the ration as a whole and which need more extended consideration.

43. The Digestion of Complex Polysaccharides. - The breakdown of cellulose and similar compounds is accomplished, not by enzymes secreted into the digestive tract but rather by enzymes of symbiotic microorganisms. Of these organisms, bacteria are the most important. This symbiotic relationship occurs widely in animals which live on food of plant origin, but it is developed to the highest degree in ruminants since the rumen provides both the capacity and other factors which are most favorable to its activity. The symbiosis takes place also in the intestine. In the nonruminant Herbivora the caecum is the principal seat of action, but the colon is also concerned to an important degree. In the Omnivora, symbiosis occurs both in the caecum and colon, but the extent of the action is much less than in Herbivora. Cellulosesplitting microorganisms also play a helpful role in digestion in certain insects. Lignin is very resistant to microbiological attack and is, therefore, the least digestible of the polysaccharides. Cellulose is much more readily broken down, and the hemicelluloses, as a group, are the most digestible of the three.

Nearly 80 years ago Grouven suggested that the breakdown of cellulose resulted in the production of certain acids and gases. The experimental evidence for this viewpoint now appears convincing. The gases produced in the microbiological breakdown of the complex polysaccharides are methane and carbon dioxide, and the acids are acetic, lactic, propionic, butyric, isobutyric, and others. In fact the process is not limited to carbohydrates that cannot undergo enzymic digestion. Starch and sugars are also attacked by bacteria to a certain extent, particularly in ruminants.

Since in Herbivora 20 per cent or more of the ration may consist of substances that can yield only fermentation products on digestion, an important question arises as to the nutritive value of these products compared to those coming from enzymic digestion. Obviously, the gaseous products have no nutritive value. Thus, the fraction that is dissipated in this form is lost, although it is measured as digestible material since it does not appear in the 
feces. Most of the acids produced, however, have been shown to be glycogen-formers (Sec. 46) and thus have the same usefulness in metabolism as the glucose derived from starch. It is evident that because of the gaseous losses, the products of cellulose breakdown should not be expected to provide as much absorbable energy per unit of carbohydrate digested as the enzymic digestion product of starch. The significance of this question is discussed later after energy metabolism has been considered.

When cattle and sheep are pastured on alfalfa or clover, the rumen frequently becomes extended with gas, causing bloat. This is a serious trouble, not only in terms of the losses which result, but also because the likelihood of its occurrence restricts the use of these valuable feeds. Neither the specific physiological cause nor reliable methods of prevention are known. The subject has been authoritatively reviewed by Cole and associates. ${ }^{1}$

44. Factors Governing the Digestion of Crude Fiber.-The quantitative relations involved in the microbiotic decomposition of carbohydrates vary according to the kind and number of the microorganisms present, which in turn are under the influence of the character of the food. It has been shown, for example, that the addition of easily digestible carbohydrates such as starch, cane sugar, or molasses to the ration of cattle reduces the digestibility of the fiber, and this observation has been explained on the ground that the bacteria attack the simpler carbohydrates by preference. It is clear that such a shift in substance attacked would lower the nutritive value of the entire carbohydrate portion of the ration, in that less crude fiber would be digested and more of the absorbable sugar would be lost as gases. An illustration is here furnished of one of the factors which may influence carbohydrate digestion, especially in Herbivora, viz., the nature of the microbiotic action.

The differences in the extent of crude-fiber digestion in the various animal species are readily explainable on the basis of the varying opportunities presented for the action of microorganisms. Ruminants are able to digest at least 50 per cent of the crucle fiber of most feeds and other Herbivora can do nearly as well, in contrast to the Omnivora which have only a limited ability to digest the complex polysaccharides. Studies by Mitchell and

${ }^{1}$ Cose, H. H., and associates, A review of bloat in ruminants, J. Animal Sci., 4, 183-236, 1945. 
Hamilton ${ }^{1}$ have shown that the fiber of oat hulls and alfalfa hay was only 2 per cent digested by swine. Pure cellulose was digested to the extent of 3.5 per cent on the average. Some studies with Carnivora, such as dogs, have given entirely negative results, while other investigations have shown that limited amounts of the higher polysaccharides may be digested by this species. The differences in the results obtained may be due to differences in bacterial flora in the experimental animals. Fiber digestion occurs to a certain extent in the caeca of fowls. These species differences explain why hay and other roughages can form such a large part of the feed of horses and cows and yet be useful in only very limited amounts in the rations of pigs and chickens.

For a given species and animal, there are differences in the degree of the breakdown of crude fiber from different sources which are intimately associated with its chemical and physical nature. The complex polysaccharides of mature plants are less well digested than they are in young, growing plants. The crude fiber of growing pasture grass, fresh or dried, is more digestible than that of hay. Early-cut hay is more digestible than hay cut in late bloom or in seed. The difference is due to both chemical and physical structure and particularly to the presence of certain substances, notably lignin, which are deposited in the cell wall with age. The lignin is not only indigestible itself but it also lowers the digestibility of the cellulose and other complex carbohydrates.

Differences in crude-fiber digestibility have an influence on the digestibility of all nutrients because intact fiber hinders the action of the digesting enzymes on the other nutrients. This is true not only for the various plant parts, such as the stems and seeds with their protective coatings, but it is also true for each cell with its fibrous membrane. Only the tenderest of these membranes are permeable to the enzymes without previous decomposition or rupture. Of course, cellulose-splitting organisms are not the only factors here involved in the destruction of protective coatings, for the cell membrane can be ruptured by the mechanical processes of digestion or softened and disintegrated by chemical action in the

${ }^{1}$ Mitchell, H. H., and T. S. Hamilton, True and apparent digestibility of oat hulls and alfalfa meal by swine, with special reference to the ability of swine to digest cellulose and crude fiber, J. Agr. Research, 47, 425-435, 1933. 
digestive tract. But microbiotic action plays a very large role in connection with the fibrous rations of Herbivora, and, thus, the nature and amount of the crude fiber present are important factors governing the extent of the digestibility of the various nutrients in the ration.

The literature relative to the digestion of crude fiber in various species has been reviewed in a thorough manner by Mangold. ${ }^{1}$

45. Bulk.-Crude-fiber content is an important factor governing the bulk of a ration, whatever may be the significance implied in the rather variable usage of this term. As used in connection with a grain mixture the term refers to the weight of a given volume of the feed. For example, oats which weigh approximately $1 \mathrm{lb}$. to the quart are bulky in contrast to corn meal which weighs $1 \frac{1}{2} \mathrm{lb}$. on the same basis. The bulky concentrates are in general those which are high in crude fiber, although the air spaces between the particles also contribute to bulk. For the ration as a whole, increasing the roughage portion with its highfiber content increases its bulk. The importance of making up a concentrate mixture so that it will have a certain amount of bulk is stressed by many authorities in order to avoid the formation of a doughlike mass in the stomach which is not readily attacked by the digestive juices. The physiological evidence for this point of view, however, is not entirely conclusive.

Bulk is also considered important from the standpoint that a certain distention of the digestive tract is desirable for the tract's most effective functioning, particularly in the elimination of the feed residues. Of course, this distention can be brought about by a large intake of any kind of food, but it is particularly accomplished for the tract as a whole by indigestible material such as crude fiber. In fact, in human nutrition the term, roughage, is used synonymously with bulk to denote the indigestible portion

1 Mangond, Eunest, The digestion and utilization of (rude fiber, Nutrition Abstracts of Revs., 3, 647-656, 1934. Ernest Mangold was professot of animal physiology and director of the 'Tierphysiologisehen Instituts der Isandwirtschaftlichen Hochschule at, Berlin. He is the anthor of a very comprehensive and authoritative work: "Handbuch der Einährme und des Stoffwechscels der Laudwirtschaftlichen Nut»ticre, Grundlagen der lï̈t termastehre," published in four volumes by J. Springer, Berlin, 1929-1932. These volumes constitute an invaluable soure of information for students of animal physiology and nutrition. 
of the diet. Procter and Wright ${ }^{1}$ have advanced the view that water-absorbing capacity is the property of a feed most important in determining its bulk in the digestive tract. Some fibrous materials, such as agar, absorb large quantities of water, while others, such as regenerated cellulose, do not. Linseed-oil meal which is much lower in fiber than wheat bran absorbs three times as much water and, thus, is a more bulky feed in the digestive tract according to Procter and Wright.

The influence of bulk in promoting the elimination of feed residues is essentially a laxative effect. It is recognized that feeds high in crude fiber tend to be laxative and that a fiber which readily absorbs water and swells is more laxative than one that does not, at least for certain species. A nonfibrous feed which absorbs a large amount of water is less effective, because it is largely digested and thus does not reach the portion of the tract occupied primarily by feed residues. Of course, bulk is not the sole cause of laxative effect, for many feeds are laxative because of specific chemical substances contained in them which promote peristalsis. In certain species including man, large intakes of fiber cause intestinal irritation and other gastrointestinal troubles.

The degree of bulk which is desirable naturally depends upon the species, in view of their variability as regards size and anatomy of their digestive tracts. It is also dependent upon the level of production sought. Too much bulk lessens the consumption of digestible nutrients, and, thus, the intake of bulky material of low digestibility must be limited. Though alfalfa may be ideal as a sole ration from the standpoint of promoting the normal activity of the digestive tract, high-producing cows cannot consume enough of it to meet their needs for nutrients. On the other hand, a high intake of a ration too low in bulk may result in indigestion and in the animal going "off feed." In this connection, it is interesting to note that Mead and Goss ${ }^{2}$ have reared heifers on a roughage-free diet from birth to over 18 months of age. The animals were normal in size for the breed and showed no abnormalities other than frequent bloating and lack of regular rumination. With the exception of crude fiber, they digested the nutrients

1 Procter, Frank, and N. C. Wright, Bulk in animal feeding, J. Agr. Sci., 17, 392-406, 1927.

2 Mead, S. W., and Harold Goss, Ruminant digestion without roughage, J. Dairy Sci., 18, 163-170, 1935. 
of their ration as well as did animals reared on the same ration plus wood pulp as an artificial roughage.

Powell ${ }^{1}$ has reported that when the entire roughage component of the ration of cows was fed in a finely ground state, the fat content of the milk was markedly lowered. In repeating certain phases of Powell's study, Loosli and coworkers ${ }^{2}$ found that when the roughage intake was cut to less than half the normal amount and the grain increased accordingly, there was a significant drop in the production of milk and fat. The explanation for both of these findings appears to lie in changes in rumen processes. Clearly, the question of the optimum amount and physical state of the roughage component of the ration needs further study.

\section{Absorption, Transport, and Storage of Carbohydrates.-A} recent physiological finding that may have considerable nutritional significance is that some absorption takes place from the rumen. Some of the acids, notably acetic, that result from carbohydrate fermentation are here absorbed, and there is evidence that glucose also can pass into the blood stream from the rumen.

In all species the intestine is, at least, the principal scat of carbohydrate absorption. Hexose sugars and acids resulting from carbohydrate fermentation are absorbed and transported to the liver where they are converted into glycogen, which in turn is gradually reconverted into glucose, the form in which all carbohydrates serve the body. While the liver is by far the largest single storehouse of glyeogen, the latter is found in limitedamomt in practically all tissues, notably in the muscles. In fact, the total found in all muscles may exceed that present in the liver. The main purpose of this glycogen is to provide an easily available source of energy-producing material for use as needed. 'Thus each tissue may have a small store, but the liver contains the main supply which, when thrown into the general cireulation as sugar, becomes available for use by any tissue in the body.

The glycogenic function of the liver provides a merhanism whereby the blood-sugar level may be held within the comparattively narrow limits compatible with normal metabolism. 'The blood of cows and sheep contains from 40 to $60 \mathrm{mg}$. of silgar per

1 Pownds, E. B3., One rause of fat variation in milk, Proc. Am. Soc. A uimal P'roduction, 1938, p. 40-47.

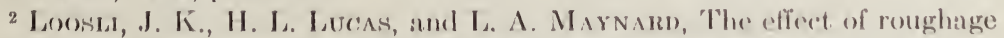
intake on the fat eontent of milk, o. Dairy Sci., 28, 1.17-153, 1915. 
$100 \mathrm{ml}$. In the case of man and the dog, the usual range is 70 to $90 \mathrm{mg}$. Similar values are obtained for the pig on the average, but much greater variations have been reported. Birds have higher blood-sugar values than do mammals, but cold-blooded animals show very low figures, such as $20 \mathrm{mg}$. commonly found for the frog.

The temporary storage of glycogen following carbohydrate absorption prevents hyperglycemia, i.e., a blood-sugar level above the normal range; and the later release of this glycogen as glucose to balance the withdrawal of sugar from the blood by the tissues prevents the opposite, hypoglycemia. This glycogenic function of the liver is under the control of certain hormones. If this control fails, either hyperglycemia or hypoglycemia may result.

47. Transformation of Sugar into Fat.- The ability of the liver and other tissues to store sugar as glycogen is limited, and, thus, when the carbohydrate intake regularly exceeds the current need of the body for energy purposes, sugar is transformed into fat. This process takes place on a large scale in the fattening of animals, since their food consists principally of carbohydrates. This formation of body fat from carbohydrate food was first demonstrated by Lawes and Gilbert ${ }^{1}$ by means of a slaughter experiment. They chose pigs from the same litter and of the same size. Some of these animals were slaughtered at the start and analyzed as controls, while the others were killed after being fed for an extended period on a low-fat ration of known composition. The data obtained from the analysis of these animals, compared with the data from the controls, showed that the pigs had stored more fat than could have resulted from all of the fat and protein fed and, therefore, that a part of their fat must have been formed from carbohydrates. The formation of milk fat from carbohydrate was demonstrated by Jordan and coworkers ${ }^{2}$ in a somewhat

${ }^{1}$ See footnote, p. 9.

2 Jordan, W. H., and C. G. Jenter, The source of milk fat, N.Y. Agr. Expt. Sta. Bull. 132, 1897; Jordan, W. H., C. G. Jenter, and F. D. Fuller, The food source of milk fat; with studies on the nutrition of milch cows, ibid., 197, 1901. Whitman H. Jordan (1851-1931), following service at the Connecticut, Pennsylvania, and Maine Agricultural experiment stations, was director of the New York experiment station at Geneva for 25 years. As one of the pioneers in the development of experiment station work, he championed the view that the maintaining of rigidly scientific investigation was the most useful function of these stations. 
similar way by feeding a ration low in fat and showing that the milk fat exceeded that which could have come from the total protein and fat in the food, while the weight and appearance of the animal indicated that the milk fat could not have been made at the expense of body fat.

The formation of fat from carbohydrate is also readily demonstrated by means of the carbon balance (Sec. 224) and by the measurement of gaseous exchange (Sec. 222). The transformation consists of many intermediary steps involving the breakdown of the glucose molecule into simple units and the synthesis of glycerol and fatty acids from these units. The exact mechanism is unknown. While this formation of fat from sugar takes place very readily, it is doubtful whether the reverse process occurs at all. It is recognized that glycerol can be changed into glucose, but the transformation of fatty acids into carbohydrate has not been proved and is denied by many.

48. The Formation of Tissue Carbohydrates. - Small amounts of carbohydrates and their derivatives occur as structural elements in certain tissues. Pentoses are constituents of cell nucleic acids, and galactose exists in combination with lipids in nerrous tissue. Various carbohydrate groups occur in many conjugated proteins, and cartilage, bones, and tendons contain an amino polysaccharide. The synthesis of these carbohydrate-containing structural elements and their subsequent catabolism represent a phase of carbohydrate metabolism which is little understood.

The formation of lactose in milk secretion represents a special carbohydrate synthesis which takes place on a largescale (sere. 334).

49. The Catabolism of Carbohydrates. Glucose is oxidized to furnish energy for body processes, notahly muscular activity, and, under certain conditions, it ma bo oxidized merely to lumish heat. While it is clear that the end products are carbon dioxicle and water, there is a chain of intermediate reactions which ale not completely understood. The process has been particularly studied in connection with muscle contraction. In the breakdown of muscle glycogen, lactic acid is formed and oxidized to carbon dioxide and water, but there are several intermediary products and side reactions, as is detailed later (Sec. 306).

While the normal end products of carbohydrate metaholism are carbon dioxicleand water which are exereted through the lumgs, skin, and urine, in diabetes there is a lature of this metabolism 
whereby the glucose content of the blood is greatly increased and the sugar is excreted in the urine. Normally the urine contains only traces of sugars, and the occurrence of a measurable amount is called glycosuria. In diabetes the body tissues waste away, the alkali reserve of the blood is decreased by the acidosis, and the body is poisoned by the accumulated, incompletely catabolized products. This disease is very common in man, and it occurs occasionally in dogs, but it is very rare in farm animals.

\section{Selected Literature}

Browne, C. A.: The origin and application of the term, nitrogen-free extract, in the valuation of feedingstuffs, J. Assoc. Off. Agr. Chem. 23, 102-108, 1940.

Cori, Carl F., and G. T. Cori: Carbohydrate metabolism, Ann. Rev. Biochem., 2, 129-146; 3, 151-174; 4, 183-198, 1933-1935.

Fraps, G. S.: Digestibility by chickens of the constituents of the nitrogenfree extract of feeds, Texas Agr. Expt. Sta. Bull. 437, 1931.

Fürth, Otto, and Paul Engel: Über die Verwertung der Pentosane im tierischen Organismus, Biochem. Z., 237, 159-188, 1931.

Koenler, Alfred E., Ione Rapp, and Elsie Hill: The nutritive value of lactose in man, J. Nutrition, 9, 715-724, 1935.

McAnally, R. A., and A. T. Phillipson: Absorption of volatile acids from the rumen of the sheep, J. Physiol., 101, 13P-14P, 1942.

McCance, R. A., and R. D. Lawrgnce: The carbohydrate content of foods, Med. Research Council, Special Rept. Ser. 135, 1935.

Miller, Edwin C.: Plant physiology, 1st ed., McGraw-Hill Book Company, Inc., New York, 1931.

Morris, L., R. B. Thompson, and V. G. Heller: Crude fiber in chicken rations, Poultry Sci., 11, 219-225, 1932.

Norman, A. G.: The biochemistry of cellulose, the polyuronides, lignin, etc., The Clarendon Press, Oxford, 1937.

Patton, A. R., and L. Greseker: Seasonal changes in the lignin and cellulose content of some Montana grasses, J. Animal Sci., 1, 22-26, 1942.

Phillips, E. F.: The utilization of carbohydrates by honeybees, J. Agr. Research, 35, 385-428, 1927.

Rettger, L. F., and H. A. Cheplin: A treatise on the transformation of the intestinal flora, with special reference to the implantation of Bacillus acidophilus, Yale University Press, New Haven, 1921.

Williams, Ray D., William H. Olmisted, C. H. Hamann, J. A. Fiorito, and Dовотиу Duckies: The effect of cellulose, hemicellulose and lignin on the weight of the stool: A contribution to the study of laxation in man, $J$. Nutrition, 11, 433-449, 1936. 


\section{CHAPTER V}

\section{THE LIPIDS AND THEIR METABOLISM}

Plant and animal materials contain a group of substances, insoluble in water but soluble in ether, chloroform, and benzene, which are most commonly referred to as lipids or lipides. The group includes the fats and several closely related or associated compounds, such as the phosphatides, sterols, and others. From the standpoint of the amounts present in the animal body and its food, the fats are by far the most important members of the group, but several of the other lipids play very significant roles in nutrition and in physiology. As an example, one may cite ergosterol which is a mother substance of vitamin D.

50. Classification of Lipids.-In using the term lipids to designate this group of physiologically important compounds, the nomenclature and classification suggested by Bloor ${ }^{1}$ are followed (Table V). The term, lipoids, is used instead of lipids by some writers, but this usage is confusing because the same term is also used by others to denote certain members only. Sometimes the

\section{Table V.-Classification of the Lipids}

Simple Lipids.-Esters of the fatty acids with various alcohols

Fats-esters of the fatty acids with glycerol *

Waxes-esters of the fatty acids with alcohols other than glycerol

Compound Lipids.-Esters of the fatty acids containing groups in addition to an alcohol and fatty acid

Phospholipids-substituted fats containing phosphoric acid and nitrogen-lecilhin, cephalin, sphingomyelin

Glycolipids-compounds of the fatty acids with a carbohydrate and containing nitrogen but no phosphoric acid-cercbrosides

Aminolipids, sulfolipids, ete-groups which are at present not sufficiontly well characterized for classification

Derived Lipids. - Substances derived from the above groups by hydrolysis

Fatty acids of various series

Sterols-mostly large molecular alcohols, found in nature combined with the fatty acids, and which are soluble in the fat solvents

* Commonly called triglycerides or neutral fats.

1 Bloor, W. R., Biochemistry of the fats, Chem. Rev., 2, 243-300, 19251926. 
term fat is employed to include the group as a whole. In addition to their distinctive properties as regards solubility, the lipids are characterized by being esterlike combinations of fatty acids or by being capable of forming such combinations, and they are substances which can perform useful functions in living organisms. These characterizations serve to exclude organic compounds which qualify as regards solubility but which have no biochemical or physiological relationships to the true members of the group.

51. The Fatty Acids. - Since the fatty acids are constituents of most of the other lipids, it is helpful to take them up first. A list of those which commonly occur in plant and animal fats is given in Table VI. Melting points are listed for those which are solid

Table VI.-Fatty Acids Commonly Found in Lipids

\begin{tabular}{|c|c|c|}
\hline Acids & Formula & $\begin{array}{l}\text { Melting point, } \\
{ }^{\circ} \mathrm{C}\end{array}$ \\
\hline 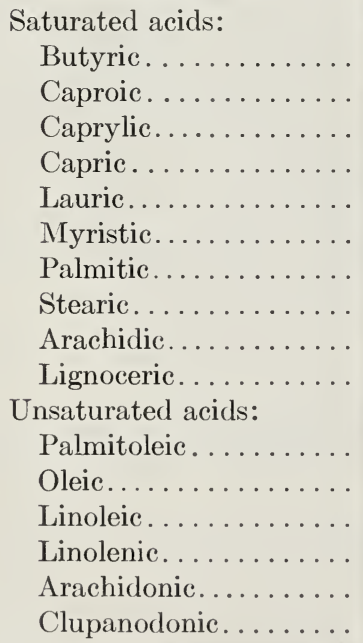 & $\begin{array}{l}\mathrm{C}_{3} \mathrm{H}_{7} \mathrm{COOH} \\
\mathrm{C}_{5} \mathrm{H}_{11} \mathrm{COOH} \\
\mathrm{C}_{7} \mathrm{H}_{15} \mathrm{COOH} \\
\mathrm{C}_{9} \mathrm{H}_{19} \mathrm{COOH} \\
\mathrm{C}_{11} \mathrm{H}_{23} \mathrm{COOH} \\
\mathrm{C}_{13} \mathrm{H}_{27} \mathrm{COOH} \\
\mathrm{C}_{15} \mathrm{H}_{31} \mathrm{COOH} \\
\mathrm{C}_{17} \mathrm{H}_{35} \mathrm{COOH} \\
\mathrm{C}_{19} \mathrm{H}_{39} \mathrm{COOH} \\
\mathrm{C}_{23} \mathrm{H}_{47} \mathrm{COOH} \\
\mathrm{C}_{15} \mathrm{H}_{29} \mathrm{COOH} \\
\mathrm{C}_{17} \mathrm{H}_{33} \mathrm{COOH} \\
\mathrm{C}_{17} \mathrm{H}_{31} \mathrm{COOH} \\
\mathrm{C}_{17} \mathrm{H}_{29} \mathrm{COOH} \\
\mathrm{C}_{19} \mathrm{H}_{31} \mathrm{COOH} \\
\mathrm{C}_{21} \mathrm{H}_{33} \mathrm{COOH}\end{array}$ & $\begin{array}{c}\text { Liquid } \\
\text { Liquid } \\
16 \\
31 \\
44 \\
54 \\
63 \\
70 \\
76 \\
86\end{array}$ \\
\hline
\end{tabular}

above $15^{\circ} \mathrm{C}$. All of the acids listed have an even number of carbon atoms since, with a few exceptions, these are the only ones which occur in nature. The saturated acids have the general formula, $\mathrm{C}_{n} \mathrm{H}_{2 n}^{\prime} \mathrm{O}_{2}$, and the melting point rises throughout the series. Butyric acid occurs in milk fat. The acids from caproic to myristic are present in only a few fats, including the fat of milk and the oil of the cocoanut and related plants. Palmitic and 
stearic acids are widely distributed in plant and animal fats generally. Arachidic and lignoceric acids occur in peanut and certain other vegetable oils. The first four acids listed in the table are classed as volatile since they can be distilled with steam.

The unsaturated acids contain one or more pairs of carbon atoms united by more than one bond. Palmitoleic acid, containing one double bond, occurs in fish oils and also in the body fat of higher animals. Oleic acid, which also has one double bond, is widely distributed in animal and plant fats. Linoleic, also called linolic acid, having two double bonds and linolenic acid with three double bonds are found in the cottonseed, linseed, soybean, and other oilbearing seeds, as well as in certain animal fats. Arachidonic acid has four double bonds and is found in limited amounts in the fat of various animal tissues. Clupanodonic acid is a highly unsaturated acid occurring in fish oils. These double bonds are reflected in the formulas for the acids, in the smaller number of hydrogen atoms relative to the carbon atoms present. Unsaturated acids have lower melting points and are more reactive than the saturated acids of the same number of carbon atoms. It is noted, for example, that stearic acid melts at $70^{\circ} \mathrm{C}$., whereas oleic, linoleic, and linolenic are liquid at room temperature, although all have 18 carbon atoms. These characteristics are important in physiology because they influence the properties of the fats and other lipids in which the fatty acids are combined.

\section{THE FATS AND WAXES}

52. The Structure of Fats.-The chemical nature of the fats was established in 1814 by the brilliant work of the French chemist, Chevreul. They are esters formed by the union of the trihydroxy alcohol, glycerol, with three molecules of fatty acids. Three molecules of water must be split out, and thus a dehydrating agent is required. Using $R-C(O) H$ as the general formula for a fatty acid, the formation of a fat may be illustrated as follows:

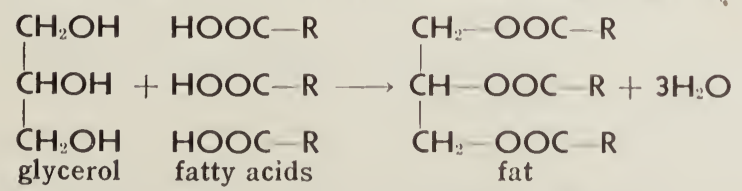

The fatty acids may be alike or different. For example, glycerol may combine with three molecules of palmitic acid to form 
tripalmitin, or it may combine with one molecule each of oleic, palmitic, and stearic acids to form palmito-oleo-stearin. The reaction shown above is a reversible one in that fats may be split into glycerol and fatty acids under the action of dilute mineral acids, enzymes, or steam. The process is essentially a hydrolysis. Enzymatic hydrolysis occurs in digestion. While the term fat is employed for all triglycerides, the term oil is used in industrial classifications to denote those which are liquid below $20^{\circ} \mathrm{C}$. Most vegetable fats fall into the latter class.

The fats which occur in nature consist of triglycerides containing different fatty acids in varying proportions. The principal fatty-acid constituents of most animal fats are palmitic, stearic, and oleic acids, but several others occur in lesser amounts. The fatty-acid distribution in some typical plant and animal fats is illustrated by the data given in Table VII. Considerable variaTable VII.-Percentage of Fatty Acids and Physical and Chemical Constants of Some Common Fats

\begin{tabular}{|c|c|c|c|c|c|c|}
\hline & $\begin{array}{c}\text { Butter- } \\
\text { fat }\end{array}$ & Lard & $\begin{array}{c}\text { Cocoa- } \\
\text { nut } \\
\text { fat }\end{array}$ & $\begin{array}{c}\text { Soy- } \\
\text { bean } \\
\text { fat }\end{array}$ & $\begin{array}{c}\text { Corn } \\
\text { fat }\end{array}$ & $\begin{array}{c}\text { Cotton- } \\
\text { seed } \\
\text { fat }\end{array}$ \\
\hline \multicolumn{7}{|l|}{ I. Saturated acids: } \\
\hline Butyric.......... & 3 & & & & & \\
\hline Caproic......... & 1 & & & & & \\
\hline Caprylic........ & 2 & & 8 & & & \\
\hline Capric.......... & 2 & & 7 & & & \\
\hline Lauric. . . . . . . . . & 7 & $\ldots$ & 48 & & & \\
\hline Myristic......... & 23 & 1 & 17 & - & & 1 \\
\hline Palmitic........ & 19 & 25 & 9 & 7 & 7 & 19 \\
\hline Stearic.......... & 11 & 13 & 2 & 4 & 3 & 2 \\
\hline Arachidic ....... & $\ldots \ldots$ & 1 & & 1 & 1 & 1 \\
\hline \multicolumn{7}{|l|}{ II. Unsaturated acids: } \\
\hline Oleic........... & 27 & 54 & 6 & 33 & 43 & 33 \\
\hline Linoleic. . . . . . . . . & 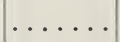 & 7 & 3 & 51 & 39 & 39 \\
\hline Linolenic......... & & $\ldots \ldots$ & $\ldots \ldots$ & 2 & & \\
\hline Melting point, ${ }^{\circ} \mathrm{C} \ldots \ldots$ & $28-36$ & $35-45$ & $20-25$ & Liquid a & at ordina & ry temp. \\
\hline Iodine no............ & $26-38$ & $40-70$ & $8-10$ & $130-137 \mid$ & $|105-125|$ & $100-115$ \\
\hline Saponification no...... & $220-241$ & $193-120$ & $250-260$ & $190-194$ & $87-93$ & $190-200$ \\
\hline Reichert-Meissl no..... & $23-33$ & & 6-8 & & & \\
\hline
\end{tabular}

tions among samples of a given fat are to be expected. This is particularly true for the animal fats because their composition is influenced by the diet of the animal. At least some of the fats 
shown in the table contain small amounts of acids for which no values are given. The fatty-acid make-up of a fat determines its specific chemical and physical properties. Certain constants used for measuring these properties are listed in the last lines of the table. These constants are given as a range since they reflect the variation in fatty-acid distribution. Some samples will fall outside the ranges given.

53. Melting Point.- Since a naturally occurring fat consists of a more or less variable mixture of glycerides, its melting point is variable and not sharp. Nevertheless the determination provides a useful measure of hardness. For the fats which are liquid at ordinary temperatures, the solidifying point rather than the melting point is generally used as the measure. Although rariable according to the make-up of the fat, the temperature of solidification is always lower than that of melting. While the presence of acids of a low molecular weight tends to make for a low melting point, the degree of unsaturation is also an important factor influencing this constant. This is readily evident by comparing the amounts of unsaturated acids in soybean and corn fats, which are liquid at ordinary temperatures and solidify between -5 and $-10^{\circ} \mathrm{C}$., with the amounts in cocoanut fat, which molts at $20^{\circ} \mathrm{C}$. or above. Though cocoanut fat has much smaller amounts of unsaturated acids than lard, it melts at a lower temperature because of its high content of acids of low molecular weight.

54. Iodine Number.-An unsaturated fat easily unites with iodine, two atoms of this element being added for each double bond. Thus the iodine number is a measure of the degree of unsaturation. It is defined as the number of grams of iodine absorbed by 100 grams of fat, and it is the most useful single measure of the character of fat. The value of $130 \mathrm{for}$ soybean oil, which reflects its high degree of unsaturation, may be contrasted with the figure of 8 for cocoanut oil.

55. Saponification Number.-When a fat is boiled with alkali, such as sodium hydroxide, it is split inte glycerol and the alkali salt of the fatty acids. These alkali salts are called soaps and the process is called saponification. The process oceurs in digestion under the action of the sodium salts in the hile. The amount of alkali required to saponify a given amount of fat is a measure of the length of the fatty-acid chains present; for the smaller the fatty-acid molecules the greater is the number of these molecules 
per gram of fat and, thus, the larger the amount of alkali required for saponification. This measure is called the saponification number. As an illustration, butterfat with its large percentage of the lower fatty acids has a much higher saponification number than corn oil which contains mostly acids with 18 carbon atoms. Saponification splits a mixture of lipids into a saponifiable fraction which consists principally of fatty acids, and an unsaponifiable fraction or residue which contains the sterols. All naturally occurring fats, such as those listed in Table VII contain some unsaponifiable materials.

56. Reichert-Meissl Number.-The determination of the amount of soluble, volatile fatty acids present is a useful measure of the character of butterfat and for detecting adulteration in it, since the large percentages of these acids in butterfat are a distinctive feature. This measure is called the Reichert-Meissl number. The fatty-acid distribution given in Table VII shows why cocoanut fat is the only one, aside from butter, which gives a value of any size. It is also evident that butterfat and cocoanut fat are easily distinguishable by this constant.

Other commonly employed constants are the refractive index which measures hardness, and the acid number which measures the amount of free fatty acids.

57. Oxidation of Fats. - Fats are readily oxidized at the double bond, and, as this occurs, the fat becomes more viscous or harder. This reaction takes place in the drying of paints, involving oxidation of the highly unsaturated acids in the linseed oil which commonly is the carrier of the pigment. Vegetable oils are classified on the basis of their drying properties as nondrying, semidrying, or drying oils. The last include the oils which are highly unsaturated. The rapid oxidation of a highly unsaturated fat generates much heat. Herein lies the cause of the spontaneous combustion of oily rags.

58. Rancidity.-Both oxidative and hydrolytic changes are responsible for the development of rancidity in different fats. Various decomposition products result. Peroxides are formed as intermediate compounds and hence the peroxide number is used as a measure of rancidity. 'The changes occur especially in the presence of heat, light, and moisture. Certain substances called prooxidants, such as copper and iron salts, catalyze the process that is thus referred to as autoxidation. Ultraviolet light is par- 
ticularly effective in hastening this process. On the other hand, many other compounds, referred to as antioxidants, retard the development of rancidity. Many vegetable oils have natural antioxidants present, while animal fats, particularly when refined, have little such activity. Vitamin $\mathrm{E}$ is a very effective antioxidant.

Since rancid fats have disagreeable flavors and odors, their acceptability as foods is always impaired even though their nutritive value may not be affected. The deterioration in stored grains, and particularly in meals, which may result from fat hydrolysis and subsequent changes has been reviewed by a committee of the National Research Council. ${ }^{1}$

59. Hydrogenation of Fats.-Double bonds will take on hydrogen as well as oxygen, though less readily. A catalyst is required. This process of hydrogenation produces a saturated and thus a hard fat, out of an unsaturated, soft one. This saturation of the double bonds makes the fat less reactive and thus tends to prevent the oxidative changes of rancidity. Thus hydrogenation is used for improving the keeping qualities of certain fats, especially vegetable oils, used for food, resulting in such products as Crisco. The oils are not completely hydrogenated because if this were done the products would be too hard for convenient use. Completely hydrogenated cottonseed oil melts around $62^{\circ} \mathrm{C}$. and gives no iodine number, whereas the partially hydrogenated products used in cooking melt between 35 and $43^{\circ} \mathrm{C}$. and have an iodine number of 60 to 75 .

60. Body Fats.-Terroine ${ }^{2}$ classified the body lipids into two groups: the "constant element" and the "variable element." Terroine's distinction was based upon the fact that during periods of inadequate food intake the variable clement is drawn upon to furnish energy for body processes, while the constant element remains intact to preserve the essential structures of the body. While this concept has been modified by reeont discoveries as to the dynamic state of fat (Sec. 71) it remains a useful one. The constant element represents the part which is essential as a con-

1 Jones, D. B., and associates, The effect of storage of grains on their nutritive value, Nall. Research Comncil Reprint and Cire. Series No. 116, 1943.

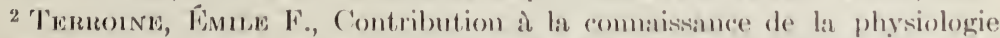
dess substances grasses et lipoüliques, Amu. sci. mal. \%ool. 4 (10), 5-397, 1920 . Terroine was director of the Institut de Physiologie (ienerale at the ITniversity of Strashourg. He has made many outstanding contributions in the fields of energy and protein metabolism and in comparative physiology. 
stituent of functioning cells, and consists primarily of phospholipids and sterols. The variable element is the much larger group and represents the fat which has been deposited as an energy reserve. This depot fat consists principally of triglycerides of palmitic, stearic, and oleic acids, with much smaller amounts of various others. The fatty-acid distribution varies with the species. Coldblooded animals have softer, and thus more unsaturated, fats than warm-blooded animals. In general, Carnivora have softer fats than Herbivora. Terroine has given a detailed discussion of these species differences. For a given animal, there are also certain differences according to the location of the fat depot. Although a given species tends to deposit a fat of constant composition, the nature of the diet has a marked influence, as is discussed later.

61. Waxes.- When a fatty acid combines with one of the higher monohydroxy alcohols, a wax results. For example, palmitic acid is combined with myricyl alcohol, $\mathrm{C}_{30} \mathrm{H}_{61} \mathrm{OH}$, in beeswax and with cetyl alcohol, $\mathrm{C}_{16} \mathrm{H}_{33} \mathrm{OH}$, in spermaceti. Waxes have high melting points and are difficult to saponify and thus not readily digested. They occur as secretions or excretions in many animals, particularly insects, and in many forms of plant life, particularly as protective coatings.

\section{COMPOUND LIPIDS}

62. Phosopholipids.-As their name indicates, the phospholipids, also called phosphatides and phospholipins, are lipids containing phosphorus. They are present in every plant and animal cell and very evidently play a fundamental role in cellular structure and activity. All of them on hydrolysis yield fatty acids and phosphoric acid, and most of them yield glycerol and a nitrogenous base. One group of phospholipids are called lecithins, the general formula for which is given below:
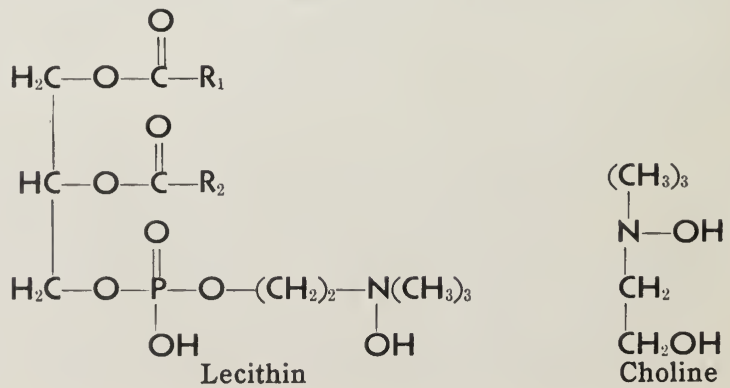
$R_{1}$ and $R_{2}$ represent the residues of the molecules of fatty acids. Thus the lecithins may be considered as fats in which one of the fatty acids has been replaced by phosphoric acid and the nitrogenous base, choline. The various members of the group contain different combinations of fatty acids. Though lecithins which contain two saturated acids are known, most of them contain at least one unsaturated acid and several contain two. Eggs and liver are particularly rich in lecithins.

The cephalins are phospholipids which are similar to the lecithins with the exeeption that they contain amino-ethyl alcohol (hydroxy-ethyl amine) in place of choline. Recently a new type of cephalin, containing the amino acid, serine, has been identified. Inositol (Sec. 195) is a constituent of certain compounds of the cephalin group. The sphingomyelins yield, on hydrolysis, fatty acids, choline, phosphoric acid, and the complex nitrogenous base, sphingosine. They contain no glycerol.

Because of their preponderance of unsaturated fatty acids, the phospholipids of animal tissues are in general much more unsaturated than is the case for the neutral fats. This has naturally led to the view that the functions of the phospholipids are associated in some way with their high degree of unsaturation, a property which would tend to make them more reactive than the triglycerides. It appears significant that fatty acids in active tissues are present principally as phospholipids while the inactive adipose tissues consist primarily of neutral fat. According to the commonly accepted concept of fat metabolism, neutral fats undergo desaturation and are then changed to phospholipids, as preliminary steps in their oxidation. The phospholipids adsorb relatively larger amounts of water than do neutral fats and thus they are more readily dispersed in the body fluids. This has suggested that they are the form in which fats are transported in the blood and other fluids.

Phospholipids are found in both the seeds and leaves of plants. In the seeds they probably represent reserve material, since they disappear during germination, but, in the leaves, they are evidently an integral part of the protoplasm.

The glycolipids derive their name from the fact that they contain a carbohydrate group, which is galactose. They also contain a fatty acid and sphingosine. They are found particularly in the brain and thus are frequently called ceretrosides. 
63. Choline.-This compound, having the formula shown on page 64, has recently become of special interest in nutrition as a result of the discovery, as reviewed by Griffith, ${ }^{1}$ that in its absence from the diet of rats, fatty livers and kidney injury result. These findings have been noted also in other species. They reflect the further finding that in choline deficiency there is a decrease in the synthesis of phospholipids in the liver and kidneys. A deleterious effect on growth has been noted in chickens. Though the relationship is not clear, choline deficiency in the chick or turkey poult leads to perosis or "slipped tendon," a trouble in which a lack of manganese is also concerned (Sec. 139).

Choline is generally classed with the vitamins (Sec. 194). It is not a dietary essential in the same sense as most of the others because the body can synthesize it from certain other dietary constituents, notably methionine (Sec. 82), which contain "labile" methyl groups. The process is called transmethylation. Choline deficiency has been produced experimentally in poultry.

\section{THE STEROLS}

The sterols are alcohols of high molecular weight. They are the unsaponifiable constituents of lipids. In animal and plant tissues, they occur both free and combined with fatty acids as esters.

64. Cholesterol.-The most important sterol in animal tissues is cholesterol, and it is doubtless an essential cell constituent. This sterol has the formula, $\mathrm{C}_{27} \mathrm{H}_{45} \mathrm{OH}$, and contains one double bond. It occurs in both the free and combined state in the blood. Though this sterol is being constantly formed and destroyed in the body, its functions remain little known, despite much study. It probably originates in the cells in which it is found. In the blood the fatty acids combined with cholesterol are very unsaturated, and thus it is suggested that the acids so combined may have an activity comparable to those present in phospholipids, with the limitation that cholesterol esters are more difficult to saponify. Clearly they serve for the transport of cholesterol.

Coprosterol, $\mathrm{C}_{27} \mathrm{H}_{47} \mathrm{OH}$, is a sterol found in the feces which is a product of the reducing action of bacteria in the lower intestine.

${ }^{1}$ Griffith, W. H., The nutritional importance of choline (editorial review), J. Nutrition, 22, 239-253, 1941. 
65. Phytosterols.-The sterols of plants are called phytosterois, of which there are several; for example, sitosterol, present in corn. They are probably end products of plant metabolism. Ergosterol, $\mathrm{C}_{28} \mathrm{H}_{43} \mathrm{OH}$, is a plant sterol of outstanding interest because it is a provitamin of vitamin D (Sec. 163).

The sterols belong to the unsaponifiable fraction of lipids. While this fraction is relatively small in most animal and vegetable fats, some fish-liver oils are very rich in it, notably the liver oil of certain sharks which contains 90 per cent of unsaponifiable matter. No sterols found in plants are appreciably absorbed into the animal body, but cholesterol is readily absorbed from animal products.

66. The Determination of Lipids.-In routine feed analysis, the lipids are determined as ether extract. The feed is dried to a moisture-free basis and then extracted for $16 \mathrm{hr}$. with anhydrous ethyl ether. The extract is weighed after the evaporation of the ether. In addition to lipids, ether extracts plant pigments, such as chlorophyll, xanthophyll, and carotene, and traces of various other substances. Ether also removes certain essential oils which are nonlipid products consisting primarily of aromatic esters, aldehydes, and ethers. Thus the use of the term, ether extract, as a synonym for fat, in speaking of the nutrient composition of feeds and rations, is not strictly accurate. In certain leafy materials, the amount of ether extract other than ester's of fatty acids may represent 25 to $40^{\circ}$ per cent of the total. In those foods, however, which we recognize to be the chief sources of dictary fat, namely seeds and animal products, the ether extract consists very largely of triglycerides.

There are special methods for the determination of the various members of the lipids and such determinations are essential for many studies of fat metabolism. The reader is referred to a textbook of physiological chemistry for a discussion of these methods.

\section{LIPID METABOLISM}

Though, following the nursing stage, the lipids make up only a small part of the diet of most animals, the metabolism of fat is of great importance in mutrition, both because of the vital roles played by specific lipids and also because of the extensive fat formation which occurs in the body in fat deposition, in the secretion of milk, and in other functions. Lipids occur as essential 
constituents in every cell in the body. While the depot fat serves primarily as a source of energy, that deposited under the skin serves also as a nonconducting layer which prevents the too rapid escape of body heat and that around the viscera and certain other organs performs a supporting function.

67. The Digestion of Lipids. - Since the lipids of most feeds consist to a very large extent of triglycerides, the products of lipid digestion are essentially the fatty acids and glycerol resulting from the hydrolytic action of the intestinal lipase, which is aided by the saponifying and emulsifying action of the bile. To the extent that compound lipids are present, there arise in addition small amounts of other products such as phosphoric acid and nitrogen bases, but the free sterols are not acted upon in the digestive tract. The sterol esters may be hydrolyzed, setting free their fatty acids. From a quantitative standpoint these free and combined sterols are a negligible part of the ration. Of the plant pigments which make up a sizable fraction of the ether extract of certain feeds, notably leafy material, some, such as chlorophyll, are destroyed in the digestive tract while others are not attacked.

68. Fecal Lipids. - The ether extract of the feces consists of digestible fats which have escaped the action of the digestive juices, lipids which are not absorbable such as plant sterols, and nonlipid material of food origin such as pigments. It is recognized that the feces may also contain metabolic fat, which is ether-soluble fecal material of body origin such as the residues of digestive juices, as distinguished from undigested or unabsorbed food lipids. The ether extract of the feces of Carnivora and Omnivora shows that the lipids of the rations commonly fed these species are nearly completely digested. It is considered that a sizable portion of this extract represents metabolic fat, though the question has been extensively studied only in the dog. In the case of Herbivora, fat digestion is much less complete, owing primarily to the protective action of undigested cellulose surrounding the fat, which serves as a barrier against digestive action in general. The ether extract of the food of Herbivora also contains relatively more nonabsorbable material such as pigments.

Several recent studies have dealt with the question of the relation of melting point and degree of saturation to the digestibility of fats, but the data as a whole are not sufficiently in agreement 
to provide a definite answer. Very few experiments have been carried out with farm animals.

69. The Absorption of Lipids.-Bile appears to be the most important single factor in fat absorption. This importance of bile resides in its ability to form water-soluble complexes of the fatty acids and cholesterol which are then readily absorbed. During absorption the fatty acids are converted to lecithin, most of which is in turn changed to neutral fat. This fat and the remaining lecithin enter the general circulation through the thoracic duct, by way of the liver, and through other channels. The absorption of fat results in a rise in the blood lipids which is particularly marked in Carnivora and Omnivora following a meal rich in fat. In Herbivora on their customary rations, no rise is detectable because of the low fat intake and its gradual digestion and absorption. The alimentary fat which is poured into the blood during absorption gradually disappears into the tissues, whence it is used to build structural tissue, deposited as a reserve of energy, or used currently for energy purposes.

70. Fat Deposition.- The depot fat is formed not only from ingested fat but also from carbohydrates (Sec. 47) and sometimes from protein. Approximately 50 per cent of the adipose tissue is

Table VIII.-Composition and Physical Constants of Fat Deposits IN THE STEER ${ }^{1}$

\begin{tabular}{|c|c|c|c|c|c|}
\hline Samples & $\begin{array}{l}\text { Water, } \\
\text { per cent }\end{array}$ & $\begin{array}{l}\text { Nitro- } \\
\text { gen, per } \\
\text { cent }\end{array}$ & $\begin{array}{c}\text { Iodine } \\
\text { value }\end{array}$ & $\begin{array}{l}\text { Melting } \\
\text { point, } \\
{ }^{\circ} \mathrm{C} .\end{array}$ & $\begin{array}{l}\text { Saponi- } \\
\text { fication } \\
\text { number }\end{array}$ \\
\hline Kidney fat. . . . . . . . . . & 4.5 & 0.18 & 40.8 & 45.0 & 197 \\
\hline 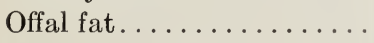 & 9.5 & 0.27 & 38.4 & 45.2 & 196 \\
\hline Loin fat. . . . . . . & 9.1 & 0.40 & ᄂ 43.6 & 42.0 & 193 \\
\hline Inside chuck fat. . . & 11.2 & 0.31 & $\sim 46.9$ & 40.5 & 198 \\
\hline Rib fat........... & 10.7 & 0.45 & $\backslash 45.2$ & 40.3 & 199 \\
\hline Round and rump fat. . & 14.4 & 0.62 & 346.3 & 39.6 & 194 \\
\hline Outside rump fat..... & 10.9 & 0.40 & । 49.3 & 35.2 & 196 \\
\hline
\end{tabular}

1 These data are taken in a condensed form from Table $57 \mathrm{in}$ : Trowbridis, P. F., C. R. Moulton, and L. D. Haigu, Composition of the beef animal and energy cost of fattening, Mo. Agr. Expt. Sta. Res. Bull. 30, 1919.

found under the skin, i.e., subcutaneous fat. The balance is located around certain organs, notably the kidneys, in the membranes surrounding the intestines, in the muscles, and elsewhere. 
The Danish scientists, Henriques and Hansen, ${ }^{1}$ were pioneers in the study of fat deposition. One of their articles, published in 1901 , reports a study of the kind of fat deposited in various portions of the body of the dog. The data in Table VIII give the composition and physical constants of the fat deposited in various parts of the steer. The different deposits contain a variable amount of water which usually does not exceed 20 per cent. The nitrogen is present as protein in connective tissue. Deposited fat may contain from 1 to 4 per cent of protein. It also contains 0.1 to 0.2 per cent of mineral matter. The physical constants show that the character of the fat differs somewhat in different locations.

Since adipose tissue always contains some water, it is evident that fat deposition involves a deposition of water also. With a ration rich in fat, there is some retention of water in all tissues including the blood. Fat deposits are considered to be water-inoil emulsions, in which albumin, lecithin, or soaps act as the emulsifying agent. When the depots are called upon to furnish energy, there may be a retention of water in place of the fat. This has been clearly shown for the human subject by Newburgh and Johnston. ${ }^{2}$ By taking account of the water intake and outgo, as well as the energy metabolism, they found that obese individuals frequently maintained or even increased their weight temporarily on a reducing diet, because water was being stored despite the fact that depot fat was being used up. Particularly striking is the observation of Trowbridge ${ }^{3}$ that the kidney fat of a steer on a submaintenance ration for 11 months contained 81.4 per cent of water, 9.6 per cent of protein, and only 4.6 per cent of fat, whereas for a check animal the figures were 5.5, 1.7, and 93.1 per cent, respectively. These observations illustrate the limitations of the weight measure as the sole criterion of nutritive state in maintenance or in fattening. The fat-water relationships in adipose tissue may have a bearing on the amount of "shrink" in animals rapidly fattened for market.

71. Dynamic State of Body Fat. - The modern discoveries made

1 Henriques, V., and C. Hansen, Vergleichende Untersuchungen über die chemische Zusammensetzung des thierischen Fettes, Skand. Arch. Physiol., 11, 151-165, 1901 .

${ }^{2}$ Newburgh, L. H., and M. W. Johnston, Endogenous obesity - a misconception, J. Am. Dietetic Assoc., 5, 275-285, 1930.

3 Trowbridge, P. F., The resorption of fat, Proc. Am. Soc. Animal Nutrition, 1910, pp. 13-20. 
by the use of isotopes (Sec. 21) have shown that the fats in the body are in a constant state of flux. Fatty acids from the depots are being constantly mobilized and transported. Absorbed fatty acids merge with these from the depots. Some of the acids of this pool are constantly being converted into others. Some are degraded, while others are combined with glycerol and transported back to the depots. All of these reactions are so balanced that mixtures of fatty acids in the depots, blood, and organs tend to remain qualitatively and quantitatively constant. The studies that have established this new knowledge are interestingly reviewed by Schoenheimer. ${ }^{1}$

72. Relation of Food Fat to Depot Fat.-The nature of the depot fat is markedly influenced, however, by the character of its food source. This is of large practical importance, since the degree of hardness of this fat is a considerable factor in the market value of the carcasses of meat animals. This is particularly true for hogs as indicated by the "soft pork" problem. The influence of the kind of fat fed upon the character of the body fat is strikingly shown by the following data obtained by Anderson and Mendel ${ }^{2}$ with rats in which the oils listed furnished 60 per cent of the energy intake.

\begin{tabular}{|c|c|c|}
\hline Food fat & $\begin{array}{c}\text { Iodine number } \\
\text { of food fat }\end{array}$ & $\begin{array}{c}\text { Iorline number } \\
\text { of body fat }\end{array}$ \\
\hline Soybean oil........... & 132 & 123 \\
\hline Corn oil. . . . . . . . & 124 & 114 \\
\hline Cottonseed oil. ....... & 108 & 107 \\
\hline Peanut oil. . . . . . . . & 102 & 98 \\
\hline Lard . . . . . . . . . . & 63 & 72 \\
\hline Butterfat........ & 36 & 56 \\
\hline Cocoanut oil.......... & 8 & 35 \\
\hline
\end{tabular}

Anderson and Mendel found that the iodine numbers of body fat deposited from various carbohydrates and proteins fell approximately within the range 55 to 70 . This range, representing fat synthesized within the body, was thus considered to typify

1 Somonnmimer, Romolph, The dymamic state of bolly constituents, Harvard University Press, Cambridge, 1942.

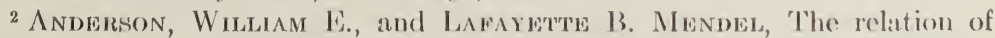
diet $t_{0}$ the quality of the fat produced in the animal body, J. Biol. (Yhem., 76, 729-747, 1928. 
the normal depot fat of the rat. Taking this range as a base line, the data for the various oils given above show the striking influence of large intakes of fats differing widely as regards degree of saturation from that normally deposited. It is noted; however, that the extremes exhibited by the food fats are never reached by the body fats, reflecting the capacity of the organism, in depositing ingested fat, to modify the latter where it is widely different from the normal deposit. Whether this is accomplished by pref'erential catabolism or by saturation or by desaturation prior to deposition cannot be stated. The data given illustrate the fact that carbohydrates produce a less unsaturated and thus a harder body fat than do most fats found in feeds of vegetable origin.

Many experiments have shown that fat deposition in the hog follows the same principles illustrated above for the rat. The data in Table IX from the work of Ellis and Isbell ${ }^{1}$ demonstrate

Table IX.-Influence on Hog Carcass of Adding Various Oils to a Basal Ration of Corn and Tankage

\begin{tabular}{|c|c|c|c|c|c|c|}
\hline \multirow[b]{2}{*}{ Oil supplement } & \multirow[b]{2}{*}{$\begin{array}{l}\text { Firm- } \\
\text { ness } \\
\text { grade }^{1}\end{array}$} & \multirow[b]{2}{*}{$\begin{array}{l}\text { Melt- } \\
\text { ing } \\
\text { point, } \\
{ }^{\circ} \mathrm{C} \text {. }\end{array}$} & \multirow[b]{2}{*}{$\begin{array}{l}\text { Iodine } \\
\text { number }\end{array}$} & \multicolumn{3}{|c|}{ Fatty Acids } \\
\hline & & & & $\begin{array}{c}\text { Oleic, } \\
\%\end{array}$ & $\begin{array}{l}\text { Lino- } \\
\text { leic, } \\
\%\end{array}$ & $\begin{array}{c}\text { Total } \\
\text { satu- } \\
\text { rated, } \\
\%\end{array}$ \\
\hline Peanut oil, $4.1 \% \ldots$ & MS & 34.3 & 72.4 & 47.9 & 13.8 & 32.5 \\
\hline Cottonseed oil, $4.1 \%$. & $\mathrm{H}$ & 45.3 & 64.4 & 35.9 & 15.7 & 43.0 \\
\hline Soybean oil, $4.1 \% \ldots$ & MS & 31.2 & 75.7 & 43.3 & 18.6 & 33.8 \\
\hline Corn oil, $4.1 \% \ldots \ldots$ & MS & 36.3 & 76.3 & 45.0 & 16.8 & 33.0 \\
\hline Corn oil, $11.5 \% \ldots$ & $\mathrm{O}$ & 24.5 & 97.2 & 41.4 & 31.4 & 23.1 \\
\hline
\end{tabular}

${ }^{1} \mathrm{H}=$ hard, $\mathrm{MS}=$ medium soft, $\mathrm{O}=$ oily.

the effect of adding various oils to a ration of corn and tankage, which by itself produces a firm fat in hogs. The percentage of fat in these rations is much smaller than that used in obtaining the data previously cited for the rat, and thus the effects are less marked. It is noted, however, that the ration containing cottonseed oil, having the lowest iodine number of the oils used, was the

1 Ellis, N. R., and H. S. Isbell, Soft pork studies. II. The influence of the character of the ration upon the composition of the body fat of hogs; III. The effect of food fat upon body fat, as shown by the separation of the individual fatty acids of the body fat, J. Biol. Chem., 69, 219-248, 1926. 
only one which produced a carcass graded as hard. . This grade is reflected in a high melting point, a relatively low iodine number, and the highest percentage of saturated fatty acids. All of the other oils, when added at the same level as the cottonseed, produced medium-soft carcasses, readily explainable by the constants and fatty-acid distribution of their fats. Increasing the level of corn oil produced an oily carcass with fat which melted at room temperature and which consisted of unsaturated acids to the extent of 73 per cent.

The data in Table IX explain why soybeans and peanuts, feeds rich in highly unsaturated fats, can be used in only a limited way

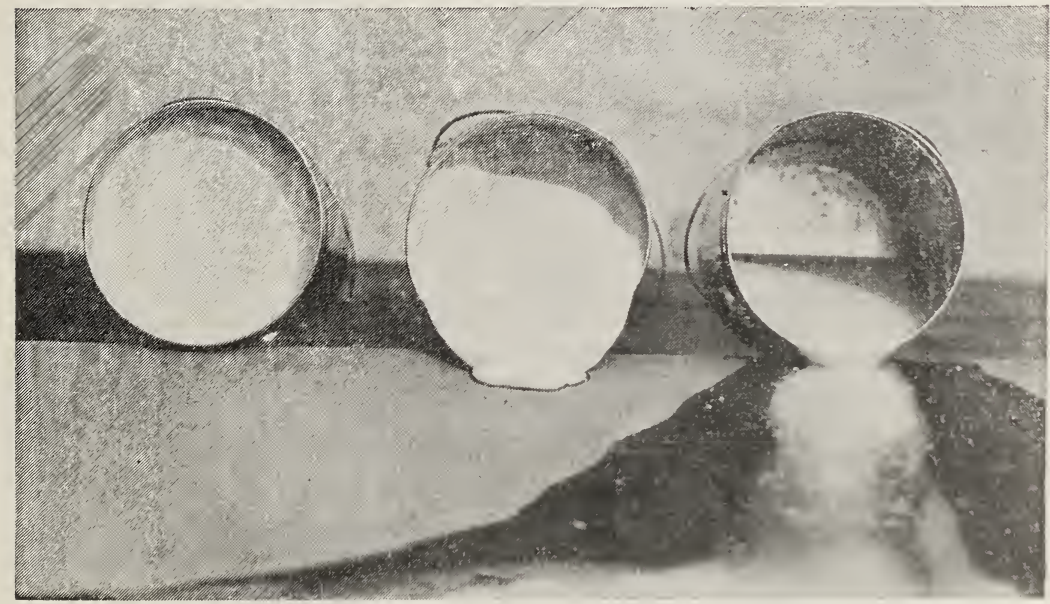

Fig. 5.-Lard from hard, soft, and oily carcasses. (Taken from O. G. Hankins, N. R. Ellis, and J. H. Zeller, Some results of soft pork investigations. II, ('.S. Dent. Agr. Bull. 1492, 1928.)

for fattening hogs without producing soft pork (Fig. 5). With both hogs and cattle fed the usual fattening rations, the deposited fat becomes harder with age, owing to an increased rate of deposition which results in relatively more of this fat being formed from carbohydrate.

Deposits of soft fat can be modified by a change in diet. When, after a period on feeds rich in unsaturated fat, a ration which will produce a hard fat is given, the deposited fat gradually becomes harder. Ellis ${ }^{1}$ has described such a change in hogs, which results

${ }^{1}$ LuLis, N. R., Changes in quantity and composition of fat in hogs fed at peanut ration followed by a corn ration, U.S. I)ept. Agr. T'ech. Bull. 36s, 1933. (See also earlier papers cited.) 
when a ration containing peanuts is followed by corn and nonsoftening supplements. The process is called "hardening off" and is taken advantage of in feeding practice in finishing hogs for market. Anderson and Mendel ${ }^{1}$ have shown that the process takes place more rapidly where the animal is fasted for a period before the hardening ration is given. The recent discoveries regarding the dynamic state of fat explain why this process occurs.

73. Food Fat and Milk Fat.-The character of the food fat has the same influence on the nature of the milk fat as it does on the depot fat. This is shown in Fig. 6, which presents data taken from the work of Maynard, McCay, and Madsen. ${ }^{2}$ In this ex-

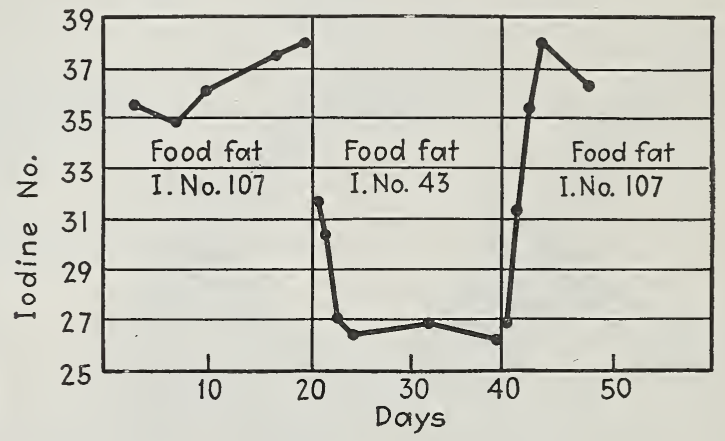

Fig. 6. - The iodine number of milk fat as influenced by food fats of high and low degrees of unsaturation.

periment, a ration containing approximately 3.5 per cent of fat on a dry-matter basis was used. In the first and third periods the grain mixture was selected to have a high iodine number, primarily by the inclusion of ground flaxseed, while in the middle period the iodine number was reduced to a low value by the omission of the flaxseed and the inclusion of cocoanut-oil meal. The curve shows that a change in the iodine number of the food fat from 107 to 43 resulted, in the first 24 hours, in a drop in the value for milk fat from 38 to 32 , with a later drop to approximately 26 as the minimum. The restoration of the food fat of high iodine number resulted in a quick rise in the milk-fat value to its level during the

1 Anderson and Mendel, loc. cit.

${ }^{2}$ Maynard, I. A., C. M. McCay, and L. L. Madsen, The influence of food fat of varying degrees of unsaturation upon blood lipids and milk fat, J. Dairy Sci., 19, 49-53, 1936. 
first period. These rapid and large changes with a ration which contained only about 3.5 per cent of fat are striking indeed.

In contrast to the marked influence on depot fat and milk, changes in the character of the food fat of the laying hen are not reflected to any extent in the fat of the eggs produced.

74. The Catabolism of Fats.-The ultimate catabolic products of fat are normally carbon dioxide and water. Our knowledge of the various stages of the catabolic process is very incomplete. According to the widely accepted theory of Leathes and Raper, the triglycerides, prior to their oxidation, are desaturated and then changed to the more reactive phospholipids, these processes taking place in the liver. Presumably, hydrolysis precedes oxidation with the formation of fatty acids and glycerol, whence the metabolism of the glycerol can follow the same course as the carbohydrates (Sec. 46).

The present physiological evidence is not adequate to provide a clear understanding of the changes that the fatty acids undergo in their oxidation. An important physiological abnormality here concerned is the accumulation of the ketone bodies, viz., hydroxybutyric acid, ketobutyric acid (acetoacetic acid), and acetone, into which the latter acid is in part converted. Whether the production of these ketone bodies is a metabolic abnormality in itself or whether they are normal intermediates that accumulate because of a condition that prevents their further oxidation remains unsettled. It seems clear, however, that the accumulation is related to some corresponding failure of carbohydrate metabolism.

The normal end products of fat metabolism are carbon dioxide and water which are excreted throughout the lungs, kidneys, and skin as is the case for carbohydrates.

75. Ketosis.-The important result of this accumulation of ketone bodies is the production of a condition known as ketosis. As the bodies accumulate in the blood, acetonemia results and they spill over into the urine producing acetomuria, thus providing clinical symptoms of the metabolic failure. Since two of the ketone bodies are rather strong acids, their excessive production uses up the alkali reserve of the blood, producing aridosis. The carbon-dioxide transporting power of the blood is lessened and cellular oxidation is decreased. This is a serious condition which in extreme cases results in coma and death.

Ketosis is the physiological condition responsible for two serious 
livestock troubles-acetonemia in dairy cattle and "pregnancy disease" in sheep. In both species high blood and urine ketone levels, a low blood sugar, and a depleted glycogen reserve, accompanied by a lack of appetite, occur. In view of these clinical findings, a dietary cause has long been considered a possibility, but experiments thus far have failed to show how the troubles can be prevented or cured by an appropriate selection of the ration fed. Vitamins A and D and those of the B group have all proved ineffective. Although the effective clinical treatment is glucose injection, the feeding of molasses or glucose itself does not prevent or cure the trouble. Since ketosis is aggravated by partial or complete fasting and has in fact been produced experimentally by withholding food, a relatively high nutrient intake prior to and following parturition seems indicated as a possible means of reducing the occurrence of the trouble. Carnivora are little susceptible to the disturbance of fat metabolism which results in acidosis, and the same is apparently true for the hog.

76. Formation of Fat from Protein.-The previous discussion of fat deposition has indicated that ingested protein can be transformed into body fat. It is known that the nonnitrogenous residue of certain amino acids can be changed into glucose. Since glucose is readily changed into fat, the possibility of the formation of fat from protein is generally accepted. Clearly it is a process which occurs much less commonly, as well as less efficiently, than the change of carbohydrate into fat.

77. Essential Fatty Acids.-Despite the fact that certain lipids are essential constituents of animal tissues, the knowledge that carbohydrates are readily changed into fat and that such essential lipid constituents as phospholipids and cholesterol can be made in the body naturally led to the view that lipids as such are not required in the diet. This viewpoint was changed some 15 years ago by the studies of Burr and Burr. ${ }^{1}$ These investigators found that, with a diet almost entirely devoid of fat, rats developed a scaly condition of the skin and a necrosis of the tail, accompanied by failure of growth and eventual death. The addition of small amounts of pure linoleic acid was strikingly effective in preventing

${ }^{1}$ Burr, George O., and Mildred M. Burr, A new deficiency disease produced by the rigid exclusion of fat from the diet, J. Biol. Chem., 82, 345367,1929 ; On the nature and role of the fatty acids essential in nutrition, ibid., 86, 587-621, 1930. 
or curing these conditions, but saturated acids were ineffective. Later, arachidonic and linolenic acids were each found partially effective in correcting the troubles. These two, along with linoleic, are commonly referred to as the essential fatty acids since they cannot be synthesized in the body from carbohydrates or fats in general. But, clearly, linoleic acid is the one of primary importance in the diet since, apparently, the others can be manufactured from it. Linoleic acid is also essential for reproduction and normal lactation in the rat.

Unsaturated fatty-acid deficiency has also been described in mice, but there is little direct proof that the acids are required in the diets of other species. There is some evidence for a requirement by man. Dogs on a low-fat diet develop skin lesions curable by lard which is rich in the unsaturated acids. Attempts to demonstrate a need for the acids in the rations of pigs and chickens have failed, very possibly because the diets used were not sufficiently low in the acids in question.

On the basis of rat experiments it has been suggested that any need for linoleic acid can be met by an amount in the diet that will supply 1 per cent of the total caloric intake. Fortunately, the acid is widely distributed among feed fats. For example, soybean oil, cottonseed oil, peanut oil, and various animal fats are excellent sources. In view of the nature and amounts of fat that are commonly found in the rations of farm animals, it seems probable that any needs they may have would thus be supplied. But this is a matter that nceds further study, particularly if the wartime trend to the increased use of solvent extraction in manufacturing by-product feeds continues.

78. Animal vs. Vegetable Fats.- Certain fats, notably milk fat, are nutritionally more valuable than others because of their content of fat-soluble vitamins. But there is no clear evidence that, as sources of fatty acids, animal fats in general are superior to vegetable fats. Linoleic acid occurs liberally in specific fats of both groups. Phospholipids, which supply choline, are found in both animal and vegetable fats. Despite much study no proof has been produced that the unique fatty acid distribution in milk fat gives it a physiological advantage over other fats in a mixed diet. On the basis of rat experiments there is evidence that in the early weeks of life, when lactose is the sole carbohydrate ingested, butterfat is superior to veretable oils in promoting grow th; 
but even in this special case the evidence has been challenged. Data have also been reported indicating that butterfat and other animal fats are superior to certain vegetable oils as supplements to skim milk for calves, but here again later studies suggest that these findings were owing to causes other than any chemical differences existing among the fats tested.

79. Special Nutritive Value of Fats as a Group.--So far as we know at present lipids are not specifically required in the diet except as a source of the essential fatty acids and of choline. Even here the requirements remain uncertain, in almost all cases, for farm animals. There is evidence, however, that the desirable intake of fat is not measurable- solely by a need for these specific compounds. Fat promotes the absorption of both vitamin $\mathrm{A}$ and carotene, particularly the latter. Russell and coworkers ${ }^{1}$ found that the absorption of carotene by hens, for example, was about 60 per cent of the intake in a ration containing approximately 4 per cent of fat, in contrast to a 20 per cent absorption on a ration extracted to .07 per cent of this nutrient. Fat also plays a role in the absorption of calcium. Fats supply two and one-quarter times as much energy as do carbohydrates. Thus, the higher the fat content of the ration, the greater energy value per pound. This fact is sometimes lost sight of.

While carbohydrates alone can supply the energy needs of the body, it is evident that under certain conditions, at least, these needs can be more efficiently met by supplying a part of the food energy in the more condensed form of fat. In the case of man at hard work, a liberal intake of fat is recognized as desirable, at least for the purpose of ensuring adequate energy consumption without excessive bulk. There is some evidence that this is true also in the case of hens in heavy egg production.

In reviewing the various experiments with rats, Mendel and Anderson ${ }^{2}$ stated that an abundant intake of fat is much more effective for storing fat than an equicaloric intake of carbohydrates. Ellis and Zeller ${ }^{3}$ were not able to confirm this observation in the

1 Russell, W. C., M. W. Taylor, H. A. Walker, and L. J. Polskin, The absorption and retention of carotene and vitamin A by hens on normal and low fat rations, J. Nutrition, 24, 199-211, 1942.

2 Mendel, Lafayette B., and W. E. Anderson, Some relations of diet to fat deposition in the body, Yale J. Biol. Med., 3, 107-137, 1930.

${ }^{3}$ LLLIs, N. R., and J. H. Zeller, with the technical assistance of S. J. 
case of hogs. They found no apparent disadvantage from reducing the ether extract of the ration to 0.5 per cent. Robison ${ }^{1}$ on the other hand has recently reported that increasing the percentage of fat in hog rations increased without exception the rapidity of gain and the amount of gain per unit of feed. With the exception of one out of nine comparisons the feed savings were greater than could be accounted for by their higher energy value. As is discussed later (Sec. 345), certain levels of fat are important in the dairy ration from the standpoint of maximum milk production.

An explanation of the recent findings showing a greater than expected value of fat as a source of energy may lie in the results of Forbes and others. ${ }^{2}$ These results showed that with equicaloric diets the inclusion of fat results in a decreased heat increment (Sec. 241). With fewer calories thus lost as heat, more should be available for production. The foregoing discussions in this and preceding sections have indicated that much more needs to be learned regarding the special roles lipids may play in the diet. Studies are particularly needed on farm animals because commonly little or no attention is given to the fat component of their rations.

80. Fat Tolerance in Farm Animals.-It is a common belief that the Herbivora have a low tolerance for fat, but the experimental evidence on this question is scanty. Certainly the suckling is able to handle a relatively large amount of fat, since milk contains from 25 to 40 per cent of this nutrient on a dry-matter basis. Here we are reminded, however, that Holstein milk is more suitable for raising dairy calves than milk higher in fat. Beyond the milk-feeding stage, Herbivora receive in their normal rations only a small fraction of the fat which they consume as sucklings. While it is probable that certain levels may be expected to cause digestive disturbances and perhaps metabolic disturbances also, it seems unlikely that there need be any concern regarding such effects from any fat level occurring in the commonly fed rations. In fact, milking cows have heen fed experimentally for several DАнL, Soft pork studies. IV. The influence of a ration low in fat upon the composition of the body fat of hogs, J. Biol. Chem., 89, 185-197, 1930.

1 Robison, W. I., Fat in rations for swine, Ohio Expt. Sta. Bimonthly Bull., 28, 203-208, 1943.

${ }^{2}$ Forbes, E. B., and associates, Relation of fat to economy of food utilization. II. By the mature albino rat, J. Nutrition, 31, 213-227, 1946 (see also earlier papers cited). 
weeks, without any signs of trouble, on rations containing three times as much fat as they normally receive.

Certainly the pig can tolerate rather high intakes of fat, and here no difficulty will arise with the usual feeds, except in respect to soft pork. Hens readily digest rations containing a percentage of fat representing a higher level than found in the commonly fed rations.

\section{Selected Literature}

Anonymous: An effect of different carbohydrates and fats on B-vitamin requirements of the rat, Nutrition Revs., 3, 332-335, 1945.

Bhattacharya, Ramkanta, and T. P. Hilditch: The body fats of the pig. I. Influence of the ingested fat on the component fatty acids, Biochem. $J ., 25,1954-1964,1931$.

BoER, J., and B. C. P. JANSEN: Investigations on the nutritive value of butter compared with that of other fats to which varying amounts of vitamin A and vitamin D have been added, Arch. Neérland. Physiol., 26, 1-177, 1942.

Boutwell, R. K., and associates: Studies on the interrelation of fats, carbohydrates and B-vitamins in rat nutrition, Arch. Biochem., 7, 143-157, 1945.

Brown, E. F, and W. R. BLoor: The nutritive value of the fatty acids of butter including their effect on the utilization of carotene, $J$. Nutrition, 29, 349-360, 1945.

Brown, J. B., and C. C. Sheldon: The occurrence of highly unsaturated fatty acids in the oils of some common fowls and in animal fats, $J . A m$. Chem. Soc., 56, 2149-2151, 1934.

Burr, G. O.: Significance of the essential fatty acids, Federation Proc., 1, 224-233, 1942.

, and R. H. Barnes: Fat metabolism, Ann. Rev. Biochem., 12, 157$182,1943$.

Committee on Fats: A report on margarine, Natl. Research Council Reprint and Circ. Series No. 118, 1943.

Forbes, E. B., and associates: Relation of fat to economy of food utilization. II. By the mature albino rat, J. Nutrition, 31, 213-227, 1946.

Forbes, R. M.: Ketosis in ruminants, Cornell Vet., 33, 27-47, 1943.

Henry, K. M., and associates: Comparison of the growth-promoting value for rats of butter fat, of margarine fat and of vegetable oils, J. Dairy Research, 14, 45-58, 1945.

Hoagland, R., and G. G. Snider: Nutritive properties of lard and other shortenings, U. S. Dept. Agr. Tech. Bull. 821, 1942.

KaUCHER, M., and associates: The distribution of lipids in animal tissues, Arch. Biochem., 3, 203-215, 1943.

Mattil, K. F., and J. W. Higgins: The relationship of glyceride structure to fat digestibility, J. Nutrition, 29, 255-260, 1945.

McHenry, E. W., and J. M. Patterson: Lipotropic factors, Physiol. Revs., 24, 128-167, 1944. 
MurLin, John R.: The conversion of fat to carbohydrate in the germinating castor bean. I. The respiratory metabolism, J. Gen. Physiol., 17, 283$302,1933$.

Quackenbush, F. W., F. A. Kummerow, and H. Steenbock: The effectiveness of linoleic, arachidonic and linolenic acids in reproduction and lactation, J. Nutrition, 24, 213-224, 1942.

Sampson, J., V. M. Hanawalt, and R. Graham: Ketosis in swine, Cornell Vet., 33, 355-359, 1943.

SHAw, J. C., and associates: Studies on ketosis in dairy cattle. VI. Is ketosis in dairy cattle due to a vitamin A deficiency? J. Am. Vet. Med. Assoc., 106, 285-291, 1945 (see earlier papers in this series).

Shorland, F. B., and P. B. D. De LaMare: Studies on the fats of the bacon pig with reference to carcass quality. The effect of diet on the component fatty acids of the back fat, J. Agr. Sci., 35, 33-38, 1945.

DU Vigneaud, V., and associates: The utilization of the methyl group of methionine in the biological synthesis of choline and creatine, J. Biol. Chem., 140, 625-641, 1941. 


\section{CHAPTER VI}

\section{THE PROTEINS AND THEIR METABOLISM}

Since protein is the principal constituent of the organs and soft structures of the animal body, a liberal and continuous supply is needed in the food throughout life for growth and repair, and thus the transformation of food protein into body protein is a very important part of the nutrition process. The term protein is a collective one which embraces an enormous group of closely related but physiologically distinct members. Plant proteins differ from each other and from animal proteins; each animal species has its own specific proteins and a given animal contains many different ones in its organs, fluids, and other tissues. In fact no two proteins seem to be exactly alike in their physiological behavior. This physiological specificity makes protein nutrition a rather complicated but nevertheless an extremely interesting subject of study.

81. Elementary Composition of Proteins.-In common with the fats and carbohydrates, the proteins contain carbon, hydrogen, and oxygen. In addition they contain a large and fairly constant percentage of nitrogen. Most of them also contain sulfur and a few contain phosphorus and iron. The range of elementary composition of the more typical proteins is as follows:

Per Cent

\begin{tabular}{|c|c|}
\hline Cark & 51.0 to 55.0 \\
\hline Hydrogen. . & 6.5 to 7.3 \\
\hline Nitrogen... & 15.5 to 18 \\
\hline Oxygen. . & 21.5 to 2 \\
\hline Sulfur. . . & 0.3 to \\
\hline Phosphorus. & 0.0 to \\
\hline
\end{tabular}

They are complex substances, colloidal in nature and of high molecular weight. The various proteins cannot be identified or distinguished from each other by any simple chemical method, and thus their classification is based primarily on physical properties. The classification generally used is the one recommended 
jointly by the American Physiological Society and the American Society of Biological Chemists. ${ }^{1}$

82. Amino Acids.-An essential distinguishing feature of all proteins is recognized to be the kind and amounts of the amino acids present. These amino acids are obtained as the hydrolytic end products when proteins are boiled for many hours with strong acids or when they are acted upon by certain enzymes. They are also the end products of protein digestion and the building stones from which body protein is made, as well as intermediary products in protein catabolism. Thus our study of protein nutrition deals primarily with amino acids.

The amino acids which have been identified in plant and animal proteins are classified according to the series of organic compounds in which they belong, and those in the aliphatic series are further classified according to the number of amino groups and carboxyl groups present. The classification of those which have received special attention in nutrition studies follows:

I. Aliphatic Amino Acids

A. Monoamino-monocarboxylic acids<smiles>NCC(=O)O</smiles>

Glycine, $\mathrm{C}_{2} \mathrm{H}_{5} \mathrm{NO}_{2}$

Amino-acetic acid<smiles>NC(CO)C(=O)O</smiles>

Serine, $\mathrm{C}_{3} \mathrm{H}_{7} \mathrm{NO}_{3}$ $\alpha$-Amino- $\beta$-hydroxypropionic acid<smiles>CC(C)CC(N)C(=O)O</smiles>

Leucine, $\mathrm{C}_{6} \mathrm{H}_{13} \mathrm{NO}_{2}$

$\alpha$-Amino- $\gamma$-methyl-valeric acid<smiles>CCCCC(N)C(=O)O</smiles>

Norleucine, $\mathrm{C}_{6} \mathrm{H}_{13} \mathrm{NO}_{2}$ $\alpha$-Amino-caproic acid<smiles>CC(N)C(=O)O</smiles>

Alanine, $\mathrm{C}_{3} \mathrm{H}_{7} \mathrm{NO}_{2}$ $\alpha$-Amino-propionic acid<smiles>CC(C)C(N)C(C(=O)O)[N+](=O)[O-]</smiles>
$\alpha$-Amino- $\beta$-methyl-butyric acid<smiles>CCC(C)C(N)C(=O)O</smiles>

Isoleucine, $\mathrm{C}_{6} \mathrm{H}_{13} \mathrm{NO}_{2}$

$\alpha$-Amino- $\beta$-methyl-valeric acid

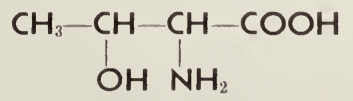

Threonine, $\mathrm{C}_{4} \mathrm{H}_{9} \mathrm{NO}_{3}$ $\alpha$-Amino- $\beta$-hydroxybutyric acid

1 Joint Recommendations of the Physiologieal and Biochemical Committees on Protein Nomenclature. J. Biol. Chem., 4, XIAVIII-I.I, 1908. 
B. Monoamino-dicarboxylic acids<smiles>NC(CC(=O)O)C(=O)O</smiles>

Aspartic acid, $\mathrm{C}_{4} \mathrm{H}_{7} \mathrm{NO}_{4}$

Amino-succinic acid<smiles>NC(CCC(=O)O)C(=O)O</smiles>

Glutamic acid, $\mathrm{C}_{5} \mathrm{H}_{9} \mathrm{NO}_{4}$ $\alpha$-Amino-glutaric acid<smiles>NC(CC(=O)O)C(O)C(=O)O</smiles>

Hydroxyglutamic acid, ${ }^{*} \mathrm{C}_{5} \mathrm{H}_{9} \mathrm{NO}_{5}$ $\alpha$-Amino- $\beta$-hydroxyglutaric acid

C. Diamino-monocarboxylic acids<smiles>N=C(N)NCCCC(N)C(=O)O</smiles>

Arginine, $\mathrm{C}_{6} \mathrm{H}_{14} \mathrm{~N}_{4} \mathrm{O}_{2}$ $\alpha$-Amino- $\delta$-guanidine-valeric acid<smiles>NCCCCC(N)C(=O)O</smiles>

Lysine, $\mathrm{C}_{6} \mathrm{H}_{14} \mathrm{~N}_{2} \mathrm{O}_{2}$ $\alpha-\epsilon$-Diamino-caproic acid<smiles>NC(=O)NCCCC(N)C(=O)O</smiles>

D. sulfur-containing amino acids<smiles>NC(CSSCC(N)C(=O)O)C(=O)O</smiles>

Cystine, $\mathrm{C}_{6} \mathrm{H}_{12} \mathrm{~N}_{2} \mathrm{O}_{4} \mathrm{~S}_{2}$

$\operatorname{Di}(\alpha$-amino- $\beta$-thio-propionic acid)<smiles>CSCCC(N)C(=O)O</smiles>

Methionine, $\mathrm{C}_{5} \mathrm{H}_{11} \mathrm{NO}_{2} \mathrm{~S}$ $\alpha$-Amino- $\gamma$-methylthiolbutyric acid

* Recent studies have cast doubt on the existence of this acid in natural products. 
II. Aromatic Amino Acids
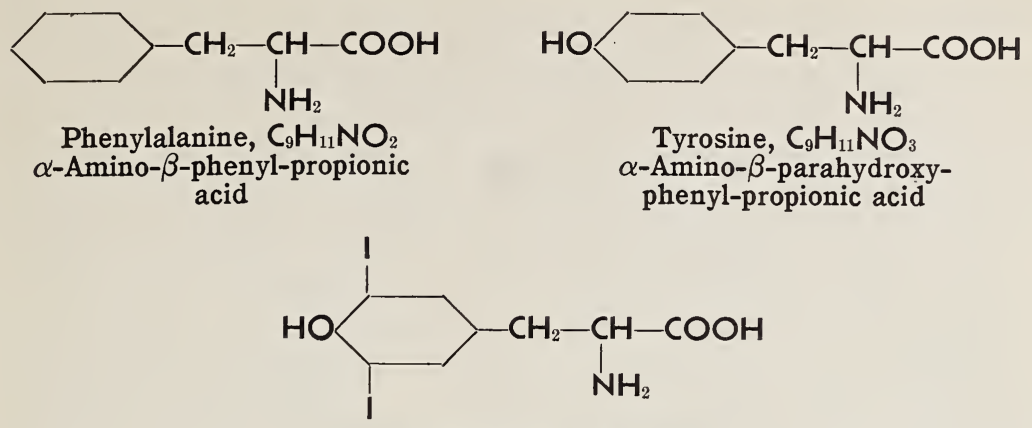

Iodogorgoic acid, $\mathrm{C}_{9} \mathrm{H}_{9} \mathrm{NO}_{3} \mathrm{I}_{2}$ 3,5-Diiodo-tyrosine<smiles>NC(CC1CC(I)C(OC2CC(I)C(I)C(I)C2)C(I)C1)C(=O)O</smiles>

Thyroxin, $\mathrm{C}_{15} \mathrm{H}_{11} \mathrm{NO}_{4} \mathrm{I}_{4}$

$\left(3,5,3^{\prime}, 5^{\prime}\right.$-Tetraiodo-4'-hydroxy-diphenyl-ether) alanine

III. Heterocyclic Amino Acids<smiles>NC(Cc1cnc[nH]1)C(=O)O</smiles>

Histidine, $\mathrm{C}_{6} \mathrm{H}_{9} \mathrm{~N}_{3} \mathrm{O}_{2}$ $\alpha$-Amino- $\beta$-imidazole-propionic acid<smiles>O=C(O)C1CC(O)CN1</smiles>

Hydroxyproline, $\mathrm{C}_{5} \mathrm{H}_{9} \mathrm{NO}_{3}$ $\delta$-Hydroxypyrrolidine- $\alpha$-carboxylic acid<smiles>O=C(O)C1CCCN1</smiles>

Proline, $\mathrm{C}_{5} \mathrm{H}_{9} \mathrm{NO}_{2}$

Pyrrolidine- $\alpha$-carboxylic acid<smiles>NC(Cc1c[nH]c2ccccc12)C(=O)O</smiles>

Tryptophane, $\mathrm{C}_{11} \mathrm{H}_{12} \mathrm{~N}_{2} \mathrm{O}_{2}$ $\alpha$-Amino- $\beta$-indolepropionic acid

83. Amino-acid Distribution in Proteins.-The amino acids are present in widely varying amounts in different proteins, and one or more of them may be entirely absent from many of the proteins.

For many years following the recognition of the nutritional importance of the amino acids, attempts to obtain quantitative 
data on their distribution in various proteins met with very limited success. During the past three years, new techniques that have supplemented and, in fact, largely supplanted the chemical procedures previously used have practically solved the analytical problems involved. Microbiological methods have proved particularly useful here as has been the case for the assay of vitamins. These methods depend upon the use of a microorganism that requires for its growth the nutrient to be determined. For example, Lactobacillus arabinosus $17-5$ requires nine amino acids for its growth. Any one of them can thus be determined in a protein hydrolysate by adding an aliquot of it to a nutrient medium that is complete for this organism, except for the amino acid in question. The quantitative metabolic response of the organism measures the amount of the amino acid supplied by the hydrolysate. Several other organisms have been found equally useful for specific amino acids. Methods based on the use of isotopes have also been developed.

The study by Brand and coworkers ${ }^{1}$ is a fine example of how these new techniques can provide complete and accurate data on the amino-acid composition of proteins. Specimen papers from other laboratories are listed at the end of this chapter. Many more are to be found in the current literature. In Table $\mathrm{X}$ data showing figures obtained on the amino-acid composition of glycinin by the newer techniques are listed along with those found in the early literature. This table was compiled by H. B. Vickery in 1945 for a report of the Committee on Protein Foods of the Food and Nutrition Board of the National Research Council. From such studies now being reported a large body of data is accumulating on the amino-acid distribution in the principal proteins of the body and of foods.

All of the amino acids, with the exception of glycine, are optically active in nature. Most of them aresoluble in water. Since amino acids have both amino groups and carboxyl groups, they are considered to be amphoteric electrolytes, reacting as acids in the presence of bases and as bases in the presence of acids. Different amino acids have different isoelectric points.

84. The Structure of the Protein Molecule.-Our knowledge of the structure of proteins is due primarily to the work of Emil

${ }^{1}$ Brand, Erwin, and associates, The empirical formula of $\beta$-lactoglobulin, J. Am. Chem. Soc., 67, 1524-1532, 1945. 
Table X.-Percentage of Amino-Acid Constituents of Glycinin * (All values corrected for ash and moisture content of preparation.)

\begin{tabular}{|c|c|c|c|c|}
\hline & $\begin{array}{l}\text { Early } \\
\text { literature }\end{array}$ & M. S. Dunn & $\begin{array}{l}\text { Merck and Co. } \\
\text { (J. C. Woodruff) }\end{array}$ & $\begin{array}{c}\text { Other } \\
\text { observations }\end{array}$ \\
\hline 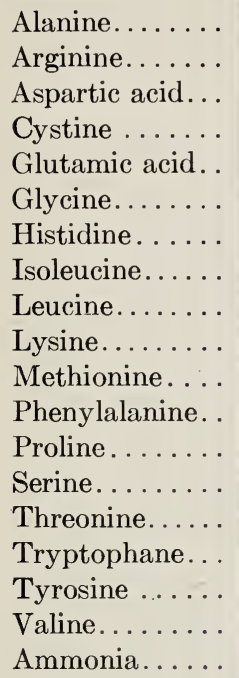 & $\begin{array}{r}5.12 \dagger \\
3.89 \dagger \\
0.74 \S \\
19.46 \dagger \\
0.97 \dagger \\
1.39 \dagger \\
\\
8.45 \dagger \\
2.71 \dagger \\
1.84 * * \\
3.86 \dagger \\
3.78 \dagger \\
\end{array}$ & $\begin{array}{c}23.3 \\
3.99 \\
2.18 \\
7.05 \\
8.49 \\
6.52 \\
1.19 \\
5.96\end{array}$ & $\begin{array}{l}2.2 \\
5.4 \\
8.3 \\
5.8 \\
1.14 \\
6.4\end{array}$ & $\begin{array}{l}9.4 \ddagger \\
21.0 \| \\
2.08 \text { 『 }\end{array}$ \\
\hline
\end{tabular}

* Compiled by H. B. Vickery.

† Osbgrne and Clapp, Am. J. Physiol., 19, 468 (1907).

$\ddagger$ Jones and Moeller, J. Biol. Chem., 79, 429 (1928).

§ Csonka AND Jones, J. Agr. Res., 46, 51 (1933).

\| Oucotт, J. Biol. Chem., 153, 71 (1944).

If Vickery and Winternitz, J. Biol. Chem., 156, 211 (1944).

** Baernstein, J. Biol. Chem., 97, 663 (1932).

it Horn And Jones, J. Biol. Chem., 157, 153 (1945).

¥ Personal letter from J. L. Stokes dated Sept. 26, 1945 (3.4\% on dry basis).

Fischer who devised methods for uniting amino acids through their amino and carboxyl groups, with the elimination of water. As an example, the union of two molecules of glycine to form the dipeptide, glycyl-glycine may be represented as follows:
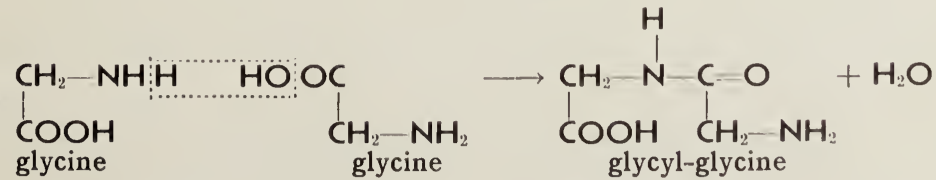

Fischer succeeded in hooking together as many as 18 amino acids, and the complex synthetic polypeptides thus formed were found 
to have many properties in common with the proteins. Thus, on the basis of his and later work, it is considered that proteins are anhydrides of amino acids and that the principal linkage existing between the amino acids in the protein molecule is through the amino group of one acid and the carboxyl group of another. This type of union $(-\mathrm{NH}-\mathrm{C}=\mathrm{O})$ is referred to as the peptide

\section{linkage.}

It is assumed that the proteins occurring in nature are built up from their constituent amino acids, but we have no knowledge as to the exact process. In the case of plants, including the lower forms such as yeast and bacteria, nitrates and ammonium salts are used as the initial nitrogenous compounds for protein synthesis. In the case of animals, however, the constituent amino acids must be available, with the exception of some which can be synthesized in the body from simpler compounds, as is discussed later. The lower forms of animal life may have a greater ability to synthesize amino acids, but the evidence here is not conclusive.

85. Properties of Proteins.-Proteins can combine chemically with both acids and bases. This is explained on the basis that they are amphoteric substances by virtue of containing free amino and carboxyl groups. Each protein has its characteristic isoelectric point at which the tendencies to acidic and basic dissociations are equal, and, at this point, the protein is most readily precipitated by salt solutions and by alcohol. This property is taken advantage of in the separation and purification of proteins.

In addition to forming chemical combinations, proteins in solution have colloidal properties. They do not pass through the membranes or gels which are used as the criteria for separating out colloidal particles, and many workers hold the view that proteins can bind ions physically by adsorption as well as uniting with them chemically.

The different proteins vary as regards their solubility in water and various aqueous solutions, but none of them is soluble in the common fat solvents such as ethyl ether and petroleum ether. They can be precipitated from solution by a large variety of substances, including various neutral salts, such as sodium sulfate and magnesium sulfate. Large amounts of these salts are required to cause the proteins to precipitate, and the process is referred to as salting out. Salts of heavy metals are good precipi- 
tants and so are strong mineral acids. Phosphotungstic acid, trichloracetic acid, and tannic acid are reagents commonly used in the laboratory for precipitating proteins.

The coagulation of protein probably involves a dehydration. It can be brought about by heat and by alcohol. In digestion it occurs as a result of enzymatic action. Proteins are such labile substances that their nutritive value may be altered by physical agents. Heat improves the nutritive value of the proteins of certain feeds but has the opposite effect in other cases (Sec. 284). Jones and associates ${ }^{1}$ have reviewed evidence suggesting that certain changes taking place in the protein of stored grains may lessen its nutritive value.

86. The Chemical Determination of Protein.-The direct determination of the various proteins which are present in a feed or tissue is an impracticable procedure. Thus the chemist takes advantage of the fact that nitrogen occurs in the different proteins in a fairly constant percentage-16 per cent on the average (Sec. 81). He analyzes for nitrogen and multiplies the result by the factor $6.25(100 \div 16)$. The sample is digested with sulfuric acid and a catalyst until all the organic matter is destroyed. This procedure changes the nitrogen into the form of ammonium sulfate. The digest is distilled with sodium hydroxide and the ammonia is driven over into standard acid and titrated, whereby the nitrogen present in the sample is determined. While the average factor, 6.25 , is applied to feeds in general, specific factors may be used in the case of products for which the protein and nitrogen relations are definitely known. For example, it has been found that the combined proteins of milk contain approximately 15.7 per cent of nitrogen on the average and hence the factor 6.38 is used. Wheat flour protein, on the other hand, contains 17.5 per cent nitrogen and thus the factor is 5.71. Specific factors are also employed for certain animal tissues. Jones ${ }^{2}$ has published specific factors for 121 different proteins and foods.

The estimation of protein content from an analysis for nitrogen assumes that all of the nitrogen in the substance analyzed is in the form of protein. This is not strictly true for any feedstuff, and

1 Jones, D. B., and associates, The effect of storage of grains on their nutritive value, Natl. Research Council Reprint and Circ. Series No. 116, 1943.

${ }^{2}$ Jones, D). Breesw, Factors for converting percentages of nitrogen in foods and feeds into percentages of proteins, U. S. Dept. Agr. Circ. 183, 1931. 
there are certain ones which contain a considerable amount of nitrogen in compounds other than protein. This fact was recognized by the early workers in animal nutrition and methods were accordingly proposed for determining the true protein as distinguished from the crude protein obtained by multiplying the total nitrogen by a factor. True protein as obtained by the Stutzer method is the insoluble residue resulting from the boiling of the feed with water and the addition of copper hydrate. The nitrogen is then determined in the residue and multiplied by 6.25 . The method assumes that the nonprotein compounds are watersoluble and that any protein so dissolved is precipitated by the boiling and by the copper hydroxide. The early workers recognized that the method was a conventional one and recent studies have emphasized its limitations. The distinction between crude and true protein, however, has largely lost its significance in so far as the protein values of feeds are concerned, for reasons which are detailed later (Sec. 93).

87. Nonprotein-nitrogen Compounds.-The nonprotein compounds occurring in feeds include: amides, amino acids, nitrogenous glucosides and fats, alkaloids, ammonium salts, and others. Of these, the amides and the amino acids are the only ones which occur to any considerable extent, and they are present in large amounts in only a few of the common feeds. They seem to be especially abundant where growth is rapid, and thus they may make up as much as one-third of the total nitrogen in pasture grass and soiling crops. The developing seed is high in nonprotein nitrogen at the start but low at maturity. A large part of the nitrogen in silage crops occurs in this form, due in part to their immaturity at harvest and in part to the fermentation processes which take place. Certain roots apparently have a considerable portion of their nitrogen stored in forms other than protein. Mature hays and the commonly fed concentrate mixtures of seeds and their by-products contain relatively little nonprotein nitrogen.

In addition to the nonprotein-nitrogen compounds which occur in feeds, there are a number which are important in nutrition, either as intermediary or end products of protein metabolism or as essential and active constituents of various tissues and secretions.

Asparagine and glutamine are amides found in the free state in plants. They are the forms in which their corresponding amino 
acids, aspartic and glutamic, respectively, occur to a considerable extent in the protein molecule. Urea, the diamide of carbonic acid, is the principal end product of nitrogen metabolism in mammals and in most fishes.

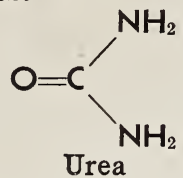

There are many different nucleic acids in nucleoproteins, distinguished by their hydrolytic products. The nucleic-acid molecule contains phosphoric acid, pentoses, purine bases, and pyrimidine bases. These bases are heterocylic compounds containing nitrogen.

Uric acid is the principal end product of purine catabolism in man and of protein catabolism in birds and reptiles. Uric acid and urates are the principal nitrogenous excretory products in insects.

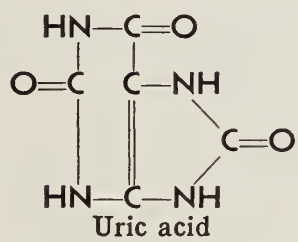

In mammals other than man and the monkey, the principal end product of purine catabolism is not uric acid but its oxidation product, allantoin, $\mathrm{C}_{4} \mathrm{H}_{6} \mathrm{~N}_{4} \mathrm{O}_{3}$.

Hippuric acid occurs in considerable amounts in the urine of all herbivorous animals and normally in much lesser amounts in the urine of other animals including man. It is a combination of benzoic acid and the amino acid, glycocoll or glycine, and thus is named benzoyl-glycine.

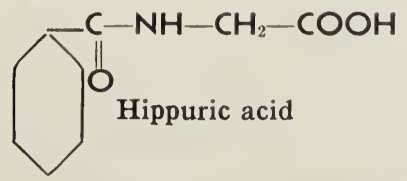

It is classed as a detoxication product in that benzoic acid, which cannot be utilized by the body and is in fact harmful, is transformed, by pairing it with glycine, into a harmless product which is readily excreted. The rations of herbivorous animals normally contain much larger amounts of hippuric-acid precursors, such as 
benzoic acid and various related aromatic compounds, than is the case for Omnivora. In all species there are considerable variations in hippuric-acid excretion according to the nature of the feed.

Creatine, methylguanidine acetic acid, occurs widely in the animal body, especially in muscle. It is excreted as its anhydride, creatinine, which is thus a normal constituent of urine. Creatinine excretion is a measure of the basal nitrogen catabolism, as is discussed later (Sec. 250). The relation between these two compounds is indicated by their formulas:<smiles>N=C(N)N</smiles>
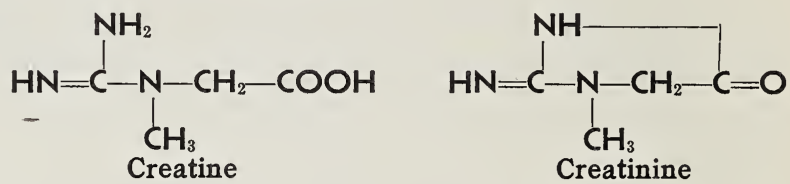

Creatine occurs in muscle as an easily hydrolyzable phosphate, phosphocreatine or phosphagen, which is decomposed in muscle activity (Sec. 366).

Glutathione, is a tripeptide of cysteine, glutamic acid, and glycine, which plays a role in physiological oxidations.

\section{AMINO ACIDS AND PROTEIN QUALITY}

The recognition that the nitrogen present in the body had its origin in nitrogen compounds present in the food dates primarily from the work of Magendie ${ }^{1}$ published in 1816. After it became established that proteins were the nitrogen compounds essentially concerned, Magendie produced the first evidence that all proteins were not of equal value. In his famous "gelatin report" published in 1841, he showed that gelatin would not take the place of meat protein in the diet. Thirty-five years later Escher, in an experiment with dogs, reported that the deficiency of gelatin could be made good by the addition of tyrosine. This finding was a forerunner of the modern concept of the essential role of amino acids in protein nutrition, a concept which did not become recognized until 40 years after the initial observation of Escher. In

${ }^{1}$ François Magendie (1783-1855), the great French physiologist, is recognized as the founder of the modern experimental method in animal feeding experiments. He employed diets of pure carbohydrates and fats to prove that food nitrogen is essential. These studies were published under the title: Sur les propriétés nutritives des substances qui ne contiennent pas d'azote, Ann. chim. phys., 1st ser., 3, 66-77, 1816. 
1914 Osborne and Mendel $^{1}$ showed that certain proteins which resulted in nutritive failure in rats when used alone were rendered satisfactory by the addition of missing amino acids. These fundamental results, quickly followed by many others, including comparisons of different protein sources with chickens and hogs, led to the realization that the value of a given protein in nutrition is governed by its amino-acid make-up, because the body is unable to synthesize many of the amino acids which are present in its proteins and thus the protein in the food must be of a nature which will supply them.

88. Essential and Nonessential Amino Acids.-Experiments have established a list of amino acids which the body cannot synthesize adequately and which are thus designated as essential amino acids. They have also established another list of acids classified as unessential, since the body can manufacture them.

The great advances in this field have resulted from the pioneer work of W. C. Rose of the University of Illinois, a pupil of Mendel. In 1930 he began a brilliant series of studies, using a new technique that has given us specific information as to the amino acids that must be present in the diet. Using diets otherwise adequate for the normal growth of rats, in which the sole source of nitrogen was supplied by amino acids, the effect of the addition or removal of 22 of the acids was studied. Thus, the Illinois workers were able to classify them as shown in Table XI. It is noted that 10 are listed as essential and 12 nonessential. A summary of these pioneer studies which are published in several different papers is to be found in a review article by Rose. ${ }^{2}$

Arginine represents a special case in that growth can take place in its absence but not at a normal rate. This means that this acid can be synthesized in the body but not sufficiently rapidly to meet fully the demands of normal growth. Dr. Rose has defined an essential amino acid as one which camnot be synthesized at a sufficiently rapid rate to eause normal growth.

While additional amino acids may occur in plant or animal proteins, it is clear from these Illinois investigations that all which are dietary essentials for the growth of rats are known. The amino

1 Osborne, Thomas B., and Ianayejte B. Mender, Amino acids in nutrition and growth, J. Biol. Chem., 17, 325 349, 1914.

${ }^{2}$ Rose, W. C., The nutritive signifieance of the amino acids, Physiol. Revs., 18, $109-136,1938$. 
acids, thyroxine and iodogorgoic acid, listed on page 85 but not included in Table XI, are derivatives of the nonessential acids alanine and tyrosine respectively.

\begin{tabular}{cl} 
Table Xi.-Classification of the Amino Acids with \\
Respect to Their & Growth Effects ${ }^{1}$ \\
Essential & \multicolumn{1}{c}{ Nonessential } \\
Lysine & Glycine \\
Tryptophane & Alanine \\
Histidine & Serine \\
Leucine & Norleucine \\
Isoleucine & Aspartic acid \\
Phenylalanine & Citrulline \\
Threonine & Tyrosine \\
Methionine & Proline \\
Valine & Hydroxyproline \\
Arginine & Glutamic acid \\
& Hydroxyglutamic acid \\
& Cystine
\end{tabular}

${ }^{1}$ As reported by W. C. Rose at the annual meeting of the Federation of American Societies for Experimental Biology, Memphis, Tenn., April, 1937.

The findings apply to other species also. The Illinois workers found that, aside from arginine, the adult dog requires the same amino acids as the growing rat. No real exception is here involved because the rat does not require arginine except for rapid growth. The evidence in the case of the dog has been confirmed by others in showing that at least 9 amino acids are essential for plasmaprotein production. The same acids are also required by the growing chick, according to the results of Almquist and Grau, ${ }^{1}$ and of Hegsted. ${ }^{2}$ (Glycine is needed in addition for rapid growth, and tris appears to be true also for glutamic acid.

The needs of man for amino acids are now under study by Holt and associates of Johns Hopkins University, as well as by Rose and his coworkers. ${ }^{3}$ The latter are now repeating with human subjects

1 Almquist, H. J., and C. R. Grau, The amino acid requirements of the chick, J. Nutrition, 28, 325-331, 1944.

${ }^{2}$ Hegsted, D. Mark, Growth in chicks fed amino acids. J. Biol. Chem., 156, 247-252, 1944.

${ }^{3}$ Rose, William C., William J. Haines, and Julius E. Johnson, The role of the amino acids in human nutrition, J. Biol. Chem., 146, 683-684, 1942.

Rose, William C., William J. Haines, Julius E. Johnson, and DonALD T. WARNER, Further experiments on the role of the amino acids in human nutrition, $J$. Biol. Chem., 148, 457-458, 1943. 
their studies made with rats, using nitrogen balance as the measure. The use of amino acids as the sole source of nitrogen for man obviously involves experiments of much greater magnitude and difficulty than ever before attempted in this field. To date this epoch-making study as briefly reported by the Illinois workers has shown that eight of the amino acids needed by the growing rat are needed also by the human adult. Arginine is not needed, as was to be expected, since this acid is not required for adult rats or dogs either. Surprisingly, neither is histidine needed. The finding seems conclusive, but no explanation as to why the human differs in this respect has thus far been found.

No studies of this character have been made with pigs. But it is reasonable to believe that their requirements are similar to those of the other species discussed. There is ample evidence from experiments with different high-protein feeds as to the general importance of their amino-acid make-up. The situation is very different, however, in the case of cattle and sheep because of the microbiological synthesis of amino acids in the rumen, as is discussed later (Sec. 94). Such evidence as is available regarding their practical importance in ruminant nutrition is discussed in the chapters dealing with growth and lactation.

It should be emphasized that the identical needs for amino acids that have been established for the species discussed are qualitative only. Studies thus far indicate that the quantitative requirements per unit of body weight or of growth tissue formed vary greatly among species, in the case of at least some of the essential amino acids. This is not unexpected since species differ in their protein make-up. For a similar reason, the proportions in which the amino acids are required by a given species may vary according to the protein product being formed, for example, growth tissue, or eggs in the case of poultry. In fact, the qualitative requirements for milk and egg production may not be identical with those for the growth of the species concerned. This is a question that has not been studied.

In the course of his studies with rats Rose investigated the nutritive value of the optical isomers of the essential amino acids. He found that only the naturally occurring forms of valine, leucine, isoleucine, lysine, and threonine were utilized, whereas both isomers of methionine, tryptophane, and phenylalanine were effective. In the case of tryptophane the finding for the rat does 
not hold for the chick. These results have significance in connection with the possible use of synthetic amino acids as supplements to deficient rations.

89. Synthesis of Nonessential Amino Acids.-It should be understood that the terms essential and nonessential refer to a need in the diet. Clearly, all the amino acids that comprise body proteins are physiologically essential. Those which are not required in the diet are thus nonessential because they can be synthesized in the body. One of the reactions by which this synthesis occurs is transamination. In this process keto acids, some of them originating from carbohydrates, are changed to amino acids by replacing the oxygen atom of the ketone group with ammonia. The latter, however, must be transferred from a $-\mathrm{CH}\left(\mathrm{NH}_{2}\right)$ group of one of the dicarboxylic amino acids.

Some of the amino acids are made directly from others. Thus, cystine is formed from methionine. This mode of formation of cystine illustrates the fact that the physiological need for nonessential amino acids cannot be supplied entirely independent of the diet. In the absence of cystine, for example, the diet must contain enough methionine to meet body needs for both. Almquist ${ }^{1}$ has found that this does not occur in the commonly fed chick rations and thus that cystine content as well as methionine content is important in practice. He lists the following six amino acids as being of practical importance in selecting chick rations: arginine, lysine, methionine, cystine, tryptophane, and glycine. The list includes the nonessential acid, cystine, for reasons previously mentioned, but excludes eight of the essential acids because his studies indicate that they are always supplied adequately on rations that are satisfactory in other respects. There is no justification for assuming that these distinctions would hold for other species for which quantitative requirements are different. We do, however, make similar distinctions among the essential mineral elements (Sec. 102) and vitamins (Chap. VIII).

It has been shown experimentally that some of the essential amino acids can be synthesized in the body if appropriate precursors are present. Thus, arginine can be made from citrulline in the case of mammals, methionine can be made from homocystine, and choline by methylation, and several others from their

${ }_{1}^{1}$ Almquist, H. J., Protein and amino-acid requirements of chickens; Proc. Animal Nutrition Conf., Cornell University, 1945. 
corresponding $\alpha$-keto or $\alpha$-hydroxy acids. But these findings are not of practical importance because they involve precursors that are not normal dietary constituents.

90. Are Amino-acid Mixtures Adequate for Optimum Protein Nutrition? - It has been repeatedly observed that the growth rate obtained in experimental animals on amino-acid mixtures is not so rapid as when protein of high biological value is employed. Both Woolley ${ }^{1}$ and Womack and Rose ${ }^{2}$ have very recently reported evidence that certain intact proteins contain a growth factor apparently different from any of the amino acids obtained on their hydrolysis. Woolley found that a concentrate of strepogenin, a peptide-like bacterial growth factor present in casein but destroyed by acid hydrolysis, was an effective supplement to a casein digest. These brief reports clearly suggest that the nutritional properties of protein do not reside solely in the amino acids resulting from their hydrolysis. It can be expected that further contributions to this highly important question will rapidly result from experiments now in progress.

91. Essential Amino Acids and Protein Quality.-The discovery that many of the amino acids composing body proteins must be supplied as such by food protein explains why different foods and rations of the same protein content have different protein values in nutrition, i.e., they differ in protein quality.

In actual feeding practice, no ration ever contains only one protein, but consists of a mixture of many. No ration is ever likely to be entirely lacking in an essential amino acid, but different rations differ widely in the quantitative relations of their amino acids. Thus the ration which has the highest protein quality is the one which supplies all the amino acids needed in proportions most nearly like those in which they exist in the protein to be formed (growth tissue, milk, eggs, wool). Such a ration will meet the protein needs of the body with a minimum intake of food protein. On the other hand, certain rations may be so deficient in one or more essential amino acids that they will not provide adequate protein nutrition no matter how much is fed.

${ }^{1}$ Woolley, D. W., Observations on the growth-stimulating action of certain proteins added to protein-free diets compounded with amino acids, J. Biol. Chem., 159, 753-754, 1945.

${ }^{2}$ Wомаск, M., and W. C. Rost, Evidence for the existence of an unidentified growth stimulant in proteins, J. Biol. Chem., 162, 735-736, 1946. 
The amino acids which remain unused in the formation of body protein are not wasted as food because they can serve as a source of energy, but they are wasted in so far as the specific function of protein is concerned.

Since the body contains many different proteins having somewhat different amino-acid relations, the usefulness of the food protein may depend in part on the purpose for which it is fed. It has been noted, for example, that fewer amino acids are needed for maintenance than for rapid growth.

92. The Determination of Amino Acids in Feeds.- Since feeds differ in protein value according to the kinds and amounts of essential amino acids present, it obviously would be highly useful to have a simple and accurate method of analyzing feeds for amino acids, to provide data for computing rations.

Early attempts to apply the Van Slyke method, previously employed for pure proteins, to feeding stuffs were later largely abandoned as the unreliability of the data obtained became evident. The problem of determining amino-acid content is obviously much more difficult in the case of a feed than for a pure protein because of the large amounts of other substances present. Their removal without loss or destruction of the amino acids constitutes the chief difficulty. With the development of the new techniques applicable to pure proteins (Sec. 83), there has been a large revival of studies on feeding stuffs. Papers reporting the results obtained by these techniques are now appearing in the literature. For example, Almquist ${ }^{1}$ has reported data for some 20 poultry feeds and Stokes and associates ${ }^{2}$ have published figures on various feeding stuffs. At present, however, we must look largely to other methods for data on the biological value of the protein of feeds. Such methods are discussed later (Sec. 278).

93. Crude vs. True Protein.- The recognition that the value of feed for protein nutrition is determined primarily by its aminoacid content has caused the distinction between crude and true protein to lose the significance formerly attributed to it. According to the concept of true protein, any uncombined amino acids present in a feed are eliminated from consideration; yet they are

${ }^{1}$ Loc. cit.

${ }^{2}$ Sтокеs, J. L., and associates, Microbiological methods for the determination of rmino acids. II. A uniform assay for ten essential amino acids, J. Biol. Chem., 160, 35-49, 1945. 
just as valuable as though actually a part of a protein molecule. Hart and Bentley ${ }^{1}$ found for various seeds, hay, and green forage that the nitrogen classed as nonprotein by the Stutzer procedure was largely comprised of free amino acids and peptides. Certainly a determination of protein which does not include these acids and peptides is not a true measure of the value of a feed in protein nutrition. Further, true protein itself does not have the certain and fixed nutritive value originally conceived for it. Its value is dependent upon the kinds and amounts of amino acids contained in it. Finally there is now clear evidence, as is referred to later (Sec. 94), that, in addition to the amino acids, there are certain other nonprotein-nitrogen compounds eliminated in the detelmination of true protein, which are useful for meeting the protein needs of ruminants.

In view of all these considerations, a distinction between crude and true protein of feeds, particularly as conceived of by the Stutzer method, seems no longer worth while. In this book, unless otherwise specifically stated, the term protein is used without qualifying adjective to express the value obtained by multiplying the total nitrogen by 6.25 (or some other stated factor). It should be borne in mind that the value so expressed includes other nitrogen compounds besides protein and that a more exact measure of the value of feed nitrogen for protein nutrition must at present be a biologiral rather than a chemical one.

In calculating rations it is the common British practice to give the nonprotein nitrogen a 50 per cent value. Thus they use a value termed protein equivalent, obtained as follows:

Protein equivalent $=\frac{\text { digest ible crude protein }+ \text { digestible true protein }}{2}$

\section{PROTEIN METABOLISM}

As a result of the action of the various proteolytic enzymes secreted into the stomach and intestines, the food proteins are hydrolyzed through various intermediary stages to their ronstituent amino acids. The latter are thus the principal end products of protein digestion, but a small amount of ammonia may also be produced as a result of the splitting off of free amino groups from

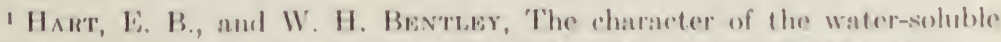
nitrogen of semene common feedingstulfs, J. Biol. Chem., 22, $177-153,1915$. 
the protein molecule, or from some of its intermediary hydrolytic products, or from amides.

94. Protein Synthesis in the Rumen.-In the discussion of carbohydrate metabolism, it was pointed out that bacteria and other microorganisms play a large role in the breakdown of complex carbohydrates in the digestive tract, especially in the ruminants. This bacterial growth has a significance as regards protein metabolism as well. As the bacteria multiply, they synthesize protein to construct their own bodies, obtaining the raw material from the ingested food. For this purpose they can utilize amides, ammonium salts, and even nitrates, as well as protein itself. Bacterial protein so formed in the rumen may be digested later in the stomach and intestine. To the extent that this occurs, there may be available for absorption a different mixture of amino acids than would have resulted from the digestion of the food protein alone, and, in so far as the bacterial protein is formed from the simpler nitrogen compounds which the animal body cannot utilize, a distinct gain in amino acids available to the body may result.

The concept that microorganisms play a useful role in protein metabolism was put forward long before the specific importance of amino acids was appreciated. From a study of cellulose digestion Zuntz, ${ }^{1}$ in 1891, expressed the view that rumen bacteria use by preference amides, amino acids, and ammonium salts instead of protein. Other studies led to the belief that the protein supplied by a given ration was augmented as a result of the formation of protein in the bodies of bacteria and protozoa which were later digested. These early observations were followed by many experiments indicating that the protein requirements of animals, especially Herbivora, could be met in part by such nonproteinnitrogen compounds as asparagine, urea, and even ammonium salts, and these findings were frequently explained on the basis that microorganisms intervened to transform these simple compounds into protein which was later digested and thus served the body.

${ }^{1}$ Nathan Zuntz (1847-1920) was a pioneer in the field of basal metabolism and in respiration studies with farm animals. He developed the first portable respiration apparatus. Trained as a physician, he early forsook medicine to become a teacher and investigator in physiology, first at Bonn and later at Berlin. He devoted himself particularly to work with farm animals and to basic problems related to their nutrition. His publications, numbering over 400 , deal with a wide variety of physiological problems. 
The many contradictory findings reported kept the question open for nearly 50 years after the initial observations of Zuntz. In 1937 Fingerling and coworkers ${ }^{1}$ produced clear evidence from nitrogen-balance studies with calves that urea can be utilized to supply a part of the protein needs for growth. Shortly thereafter, convincing growth studies were published in both Great Britain and the United States, and other evidence followed rapidly. The utilization of urea by growing sheep was established by Harris and Mitchell, ${ }^{2}$ and its usefulness for milk production was proven by Rupel and associates ${ }^{3}$ and by others. Studies also showed that urea could be utilized by calves as early as two months of age. These various results came just in time to find application in the United States during the Second World War. Because of the shortage of high-protein concentrates, urea was included in many commercial dairy feeds with generally satisfactory results.

Specific evidence that bacterial synthesis in the rumen is responsible for this utilization of urea in the nutrition of sheep and cattle has come from rumen-fistula studies. The nature of the ration influences the extent of this synthetic activity, and readily utilizable carbohydrates such as starch or molasses must be present to provide energy for bacterial growth. Urea cannot provide the sole source of nitrogen in the ration. The presence of protein promotes the activity of the bacteria as well as supplying amino acids that supplement those of the bacterial protein. The qualitative aspects are important here, as is evident from the findings of Loosli and Harris ${ }^{4}$ that the addition of methionine improves the utilization of urea by lambs.

The urea fed is not completely utilized. Twenty-five per cent or more may pass through in the feces. An excessive intake of urea is poisonous because of the ammonia produced from it in the rumen. The studies by Rupel and associates previously cited indicated that urea should not be fed at a greater rate than 1 per

1 Fingerling, G., and coworkers, Ersatz des Nahrungseiweisses durch Harnstoff beim wachsenden Rinde, Landw. Vers.-Sta., 128, 221-235, 1937.

${ }^{2}$ Harris, L. E., and II. H. Mitchell, The value of urea in the synthesis of protein in the paunch of the ruminant, J. Nutrition, 22, 183-196, 1941.

${ }^{3}$ Rupel, I. W., G. Bonstedt, and E. B. Hart, The comparative value of urea and linseed meal for milk production, J. Dairy Sci., 26, 647-66.t, 1943.

${ }^{4}$ LoosL, J. K., and L. F. HARRIs, Methionine increases the value of urea for lambs, J. Animal Sci. 4, 435-437, 1945. 
cent of the total dry matter of the ration or 3 per cent of the concentrate mixture. In the case of the latter, this maximum would provide approximately one-third of the total nitrogen in the form of urea.

Nitrogen-balance studies with rats and chickens have revealed no advantage from the addition of urea to low-protein rations, as is to be expected in view of the nature of their digestive tract. The caecum of the horse should provide some opportunity for the bacterial synthesis of protein, but specific studies have not been reported for this species. The fact that microbiological synthesis of protein in the rumen can help supply the quantitative needs of cows and sheep suggests also that their qualitative dietary needs for amino acids are influenced as well. Such an effect could help explain why studies thus far made with ruminants have failed to demonstrate an importance of protein quality at all comparable to that found with hogs and chickens. The findings as to synthetic activity in the rumen should not, however, be interpreted to mean that the amino-acid make-up of the ration is entirely without importance in the case of ruminants. In fact, there is positive evidence that this is not the case, as is discussed in later chapters.

95. Fecal Nitrogen.-The nitrogenous compounds excreted in the feces consist in part of undigested or unabsorbed food nitrogen and in part of another fraction, called metabolic nitrogen. This metabolic fraction comprises substances originating in the body, such as residues of the bile and other digestive juices, epithelial cells abraded from the alimentary tract by the food passing through it, and bacterial residues. Strictly speaking, however, the nitrogen in bacterial residues must be considered to have come originally, in part at least, from the food. The existence of this fecal metabolic nitrogen, as distinguished from undigested nitrogen, is shown by the fact that the feces excreted on a nitrogen-free diet always contain nitrogen compounds. The reason for making the distinction is that the two fractions have different origins and that the distinction is made use of in measuring the biological value of proteins in nutrition (Sec. 278).

While the amount of the undigested fraction is determined by the digestibility of the nitrogenous portion of the ration, the size of the metabolic fraction is independent of this factor and is governed in part by the total amount of dry matter consumed and 
in part by body size. That metabolic nitrogen output increases with the level of food intake is easily understandable from the fact that the higher the intake, the greater the secretion of digestive juices and the greater the wear and tear on the lining of the tract. The output per unit of dry-matter intake is apparently increased as the proportion of roughage increases in the diet, but the protein level has practically no influence. Data obtained by Mitchell indicate that on rations containing minimum amounts of roughage the output of metabolic nitrogen is approximately $0.2 \mathrm{~g}$. per $100 \mathrm{~g}$. of dry matter consumed.

The influence of body size is shown by observations that at the same level of food intake the larger animal excretes more metabolic nitrogen. This effect is explainable on the basis that some of the nitrogenous constituents of the bile, and possibly of other digestive secretions, represent true excretions of body metabolism unrelated to food intake. One would expect these excretions to be proportional to body size. The relative influence of food intake and of body size upon the amount of metabolic nitrogen has been critically studied by Schneider ${ }^{1}$ working in Mitchell's laboratory, and this investigator presents an extensive review of the subject. While the preponderance of the evidence indicates that food intake has the predominant influence, some workers have come to the opposite conclusion.

It is evident that, at a given level of food intake, the higher the digestibility of its protein, the larger is the proportion of the total fecal nitrogen which is represented by the metabolic fraction. In the case of a man eating a highly digestible dict, the fecal nitrogen is principally metabolic. At the other extreme, the metabolic nitrogen may be only a small fraction of the total fecal output in the case of Herbivora consuming a ration of low protein digestibility. To the extent that the metabolic nitrogen is a function of total food intake, lowering the proportion of protein in the ration results in a decrease in the undigested nitrogen relative to the total fecal output.

Various methods have been used for separating the metabolic from the undigested nitrogen in the feces. 'The one most commonly employed involves the digestion of the feces by a pepsin

I Schneider, Burch Hart, The relationship of the metabolic nitrogen of the faeces to body weight and to food intake for rats, Biochem. J., 28, $360364,1934$. 
solution acidified with hydrochloric acid. Sometimes a subsequent digestion with trypsin is used. The basis of the method is that the procedure will digest the nitrogenous compounds of metabolic origin but not break down the undigested fraction since the latter has previously resisted a similar action in the body. The method is open to criticism from several points of view and various studies have shown it to be inaccurate. The output of metabolic nitrogen can be determined with a nitrogen-free ration or with rations containing small amounts of proteins which are known to be practically 100 per cent digested. Figures so obtained for the metabolic nitrogen per unit of dry-matter intake are used to calculate the metabolic fraction produced from rations which result in the excretion of undigested nitrogen as well, notably in the Thomas-Mitchell method of determining the biological value of proteins (Sec. 278).

In 1927 Titus $^{1}$ introduced a technique with steers, involving the plotting of the total nitrogen intake as a function of the total nitrogen excretion, with rations of varying protein content but of constant total food intake. He extrapolated the straight line thus obtained to the point of zero protein intake to arrive at the estimated metabolic nitrogen excretion for the food intake in question. Bosshardt and Barnes ${ }^{2}$ have recently employed this procedure with mice and consider that it gives, for this species at least, more reliable indices of the metabolic nitrogen under conditions of protein feeding than those obtained with protein-free or protein-low diets.

96. Apparent and True Digestibility of Protein.-The recognition that the fecal nitrogen consisted in part of compounds other than those coming from the food early led to the proposal to determine the true digestibility of protein by considering only the undigested fraction, as distinguished from apparent digestibility which was based on the total output. The previous discussion has indicated that there is no accurate method for quantitatively determining the two fractions. While such a distinction is desirable in certain experimental work, it does not have any important significance in feeding practice. The excreted metabolic

1 Titus, H. W., The nitrogen metabolism of steers on rations containing alfalfa as the sole source of the nitrogen, $J$. Agr. Research, 34, 49-58, 1927.

${ }^{2}$ Bosshard, D. K., and R. H. Barnes, The determination of metabolic fecal nitrogen and protein digestibility, J. Nutrition, 31, 13-21, 1946. 
nitrogen represents a loss which must be taken account of and assessed against some body process. Although it is independent of the nitrogen component of the food, it is related to the food intake as a whole and it is a loss which occurs in the course of the digestion of this food. It is more appropriately assessed against digestion than against any other body function. Thus the figures for the digestibility of protein commonly determined and employed represent apparent digestibility, though generally spoken of without this qualifying term.

97. The Disposal of Absorbed Amino Acids.-The nitrogenous digestion products enter the blood stream mainly, at least, as amino acids. Small amounts of ammonia and of the simpler peptides are also absorbable. The absorption of amino acids causes their level in the blood to rise temporarily, but they are rapidly removed from the circulating fluid by the various tissues of the body and they are held for a time in the tissues in a very loosely combined or in a free state. Subsequently they are disposed of in the following ways:

1. They may be synthesized into tissue proteins and other nitrogen-containing tissue constituents. Such a synthesis includes the formation of the protein and other nitrogenous compounds of secretions, notably of milk. It also involves the replacement of tissues used up in the "wear and tear" of body processes.

2. They may be deaminized and the nonnitrogenous residue converted into glucose and glycogen, for use currently as a source of energy, or perhaps even into fat, to be held as reserve for future energy needs.

The mechanism of protein synthesis from amino acids is unknown. In vitro, it can be accomplished by the same enzymes which hydrolyze protein, and thus the synthesis is sometimes considered as a reverse phase of proteolysis. But the conditions under which it can be made to take place in vitro are vastly different from those which are met in the body, and thus the actual body process is far from being explained. In the adult animal which is producing no special nitrogenous product, such as milk, eggs, wool, or even a fetus, the need for protein synthesis is limited almost entirely to the requirements for the replacement of worn-out tissues; for, differing from the case for carbohydrates and fat, protein, as such, cannot be stored by the adult, organism except to a very limited extent. Thus any excess of amino acids under- 
goes deaminization. Not only is this true for the absorbed amino acids as a whole, but it is true also for specific ones present in an excess relative to others which are essential for protein synthesis. Thus, in rations containing protein of low biological value, an extensive deaminization of absorbed amino acids inevitably occurs, irrespective of whether the needs for protein synthesis are completely met.

This deaminization occurs in the liver and kidneys and perhaps elsewhere. It involves the splitting off of ammonia, either by oxidation or by hydrolysis, as is indicated by the following equation for the oxidative procedure.
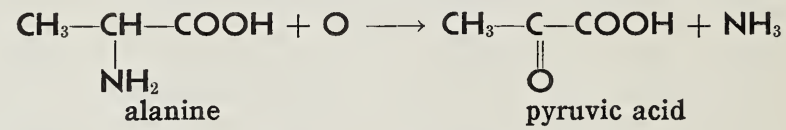

98. Protein Reserve; Plasma Proteins.-The previous statement that the adult organism cannot store protein requires qualification. During a period of inadequate protein nutrition, protoplasm may be broken down to meet certain other nitrogen needs of the body, and it may also be broken down to supply energy after a prolonged period of inadequate food intake. With the restoration of an adequate diet, additional protein will be retained in the adult body until the losses are made good. Further, exercise can result in increased muscle size in the adult, and this must mean some increase in protein content. In addition to these special cases of protein retention, it is recognized that a liberal protein intake regularly tends to result in a small increase in the body which is variously referred to as protein reserve or deposit protein, and by other terms. On the other hand, the increment thus built up tends to disappear on a low-protein diet. The proof of the existence of this protein reserve rests upon nitrogen-balance studies (Sec. 220).

While this protein store is not at all comparable in magnitude to the fat depots, it is more important currently because it is the source from which plasma proteins, as well as hemoglobin, are manufactured. The principal proteins of the blood plasma are serum albumin, serum globulin, and fibrinogen. Each has specific functions and must be constantly regenerated from the protein reserve. When this reserve becomes depleted in anemia, through fasting, or as a consequence of a diet low in protein, hypoprotein- 
emia results. Thus, a low plasma-protein level, not attributable to specific disease, is indicative of inadequate protein nutrition. Since antibodies are produced from serum globulin, however, protein undernutrition that results in hypoproteinemia is linked with the occurrence of infectious diseases. This link has been definitely established experimentally, resulting in the conclusion that adequate protein nutrition is important from the standpoint of resistance to infection.

The interrelationships between the protein reserve, hemoglobin, and the plasma proteins have been clearly set forth by Whipple. ${ }^{1}$ A diagram reproduced from this article is given in Fig. 7 .

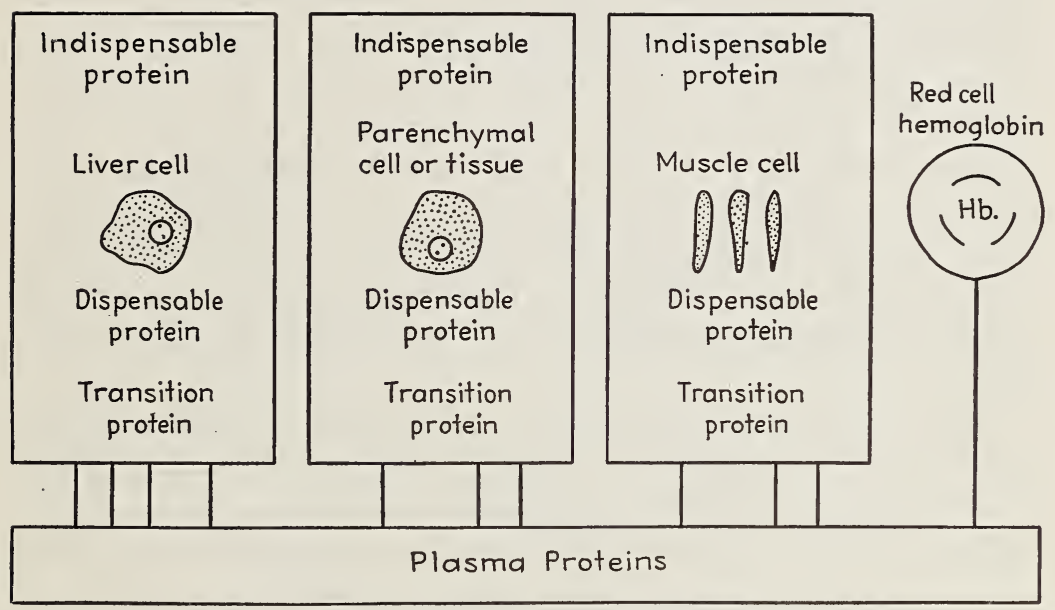

FIG. 7.-Dynamic equilibrium of body proteins. (From G. H. Whipple, Am. J. Med. Sci., 203, 477-489, 1942.)

99. Protein Catabolism.-When the tissues break down, the protein molecules are apparently hydrolyzed into their constituent amino acids by a process analogous to digestion. These amino acids next undergo deaminization, presumably in the same way as do some of the absorbed amino acids. The ammonia is converted into urea, mainly in the liver, and then excreted in the urine. The nonnitrogenous residue serves as a source of energy, thus being broken down to carbon dioxide and water and so excreted. In addition to urea, the urine contains several nitrog-

${ }^{1}$ Whipple, George H., Hemoglobin and plasma preteins: Their production, utilization and interrelation, Am. J. Mcd. Sci., 203, 477-489, 1942. 
enous catabolic products such as uric acid, ammonium salts, creatinine, hippuric acid, and others. These have been described previously (Sec. 87).

100. Endogenous and Exogenous Catabolism.-In 1905 Folin ${ }^{1}$ put forth the theory that there are two forms of protein catabolism, essentially independent and quite different from each other; a variable one which he called exogenous, dependent on the level of protein consumed, and a constant type, the endogenous catabolism, related to body size and other body factors. According to this theory the endogenous catabolism represents metabolic processes which are the essential characteristic of living cells, exemplified by the nitrogen excretion on a nitrogen-free, otherwise adequate, diet. It reflects metabolic processes which are essential to life, and the end products thus excreted tend to be constant, unaffected by the character or amount of the food protein. The endogenous nitrogen excreted represents the loss which must be made good by dietary protein in order to maintain the integrity of the nitrogenous tissues of the body. The exogenous catabolism, on the other hand, reflects the breakdown of absorbed dietary nitrogen compounds which are not synthesized into body protein.

This theory of Folin was early challenged by certain workers, and the arguments against its validity have recently been reviewed by Borsook and Dubnoff. ${ }^{2}$ Particularly significant are the studies by Schoenheimer demonstrating that the proteins of the body are not static but are in a dynamic state of equilibrium. By the use of amino acids synthesized with heavy nitrogen he has traced the metabolism of various acids throughout the body and has shown that, like fats, body proteins are constantly being broken down and resynthesized. Similarly, amino acids are being deaminized and reformed. Thus, the nitrogen excreted in the urine is the excess from a balanced state, not merely the result of a minimum "wear and tear" protein catabolism or of the deaminization of a surplus of ingested amino acids. Thus any sharp distinction between endogenous and exogenous nitrogen, as set forth by Folin, is no longer valid. The question remains open, however,

${ }^{1}$ Folin, Orto, A theory of protein metabolism, Am. J. Physiol., 13, 117$138,1905$.

${ }^{2}$ Borsook, H., and J. W. Dubnoff, The metabolism of proteins and amino acids, Ann. Rev. Biochem., 12, 183-189, 1943. 
as to whether the dynamic state significantly changes the end results of catabolism.

This question is an important one for students of nutrition because one method of arriving at the maintenance requirement of protein (Sec. 259), and also the most widely used method of determining the biological value of proteins (Sec. 278), assume the reality of Folin's endogenous catabolism. In this connection Mitchell, ${ }^{1}$ who has been largely responsible for developing both of these methods, has made the following statement:

There is nothing in Schoenheimer's work that denies the existence of a constant type of catabolism of nitrogen-containing compounds in the tissues; in fact, his beautiful analysis of the creatine-creatinine reaction illustrates this very thing. The term endogenous catabolism is still applicable since its independence of the protein intake implies its restriction to functional tissue constituents. Also, there is still a variable catabolism of nitrogenous substances, the rate of which is determined by the magnitude of the supply of dietary amino acids, regardless of whether this catabolism involves tissue constituents or dietary amino acids, and regardless of the proportions in which tissue and dietary constituents are involved. While the term exogenous, in its original meaning, is not descriptive of this phase of nitrogen catabolism, it may still be applicable in so far as the speed of the catabolism is set by the magnitude of the exogenous supply of nitrogen. For these reasons, the theory of protein metabolism upon which the calculation of the biological values of proteins rests is still sound, and hence biological values so calculated still carry their original meaning.

101. Minimum and Optimum Protein Intake.-The question as to whether a level of protein in excess of the minimum required to meet the protein needs of the body is advantageous or disadvantageous has been long debated in the field of human nutrition, and it has implications for animals also. Under the influence of Liebig, ${ }^{2}$ who erroneously believed that protein was broken down

1 Mitchels, H. H., Biological methods of measuring the protein values of feeds, J. Animal Sci., 2, 263-277, 1943.

2 Justus von Jiebig (1803-1873) was the foremost organic chemist of his time and is frequently spoken of as the founder of agricultural chemistry. He was the father of the modern methods of organic analysis, and with him began the accumulation of knowledge regarding the composition of foods, tissues, feces and urine not available to earlier nutrition workers. He wrote several books dealing with the relations of organic chemistry to agriculture and to animal economy which are well worth reading by the modern student. 
to furnish the energy for muscular work, the importance of large intakes of proteins was greatly overemphasized for many years following the middle of the last century. Gradually, as a result of research, the pendulum swung to the other extreme marked by the publication in 1904 by Chittenden ${ }^{1}$ of experiments supporting the view that minimum intakes favored health and bodily vigor. Chittenden's views were by no means universally accepted, and, today, most authorities favor intakes in excess of what may be considered the minimum requirements.

We have seen that a liberal protein intake tends to cause a high level of "deposit protein" in the tissues. The desirability of maintaining the protein reserves has been discussed (Sec. 98). The theory of optimum protein nutrition has been particularly applied to the dairy cow on the basis of experiments suggesting that raising the protein level stimulates the mammary glands. But there are many negative experiments also. Critical proof that the feeding of protein in excess of that covering all requirements of the body will, by its presence or catabolism, stimulate production must be considered to be lacking.

On the other side, it is recognized that protein in excess of what the body can use tends to be wasted in so far as its specific function as protein is concerned, since it cannot be stored in any but very limited amounts but must be catabolized. Further, there are those who feel that excess protein is definitely harmful, stating that its catabolism and the excretion of urea place an unnecessary and undesirable burden on the body, particularly on the kidneys. There are many experiments showing the harmful effect of the excessive feeding of specific amino acids. On the other hand, there is ample evidence that the body can metabolize rather high levels of proteins in complete diets for long periods without deleterious effects on production or on the body itself.

Some of the differences of opinion relative to the optimum level of protein intake have doubtless arisen from failure to recognize the bearing of variations in protein quality. The minimum intake

1 Russell H. Chittenden (1856-1943) served for 40 years as professor of physiological chemistry at Yale University where he made many outstanding contributions to the modern science of nutrition and inspired a host of students who have continued his work. An account of his protein studies is given in his book "Physiological Economy in Nutrition," Frederick A. Stokes Company, New York, 1904. 
which proves adequate for a specific combination of proteins will neither be adequate nor optimum for a combination of lower biological value. It is now apparent that some of the superior results reported for high-protein diets in the earlier literature were owing to the presence of unrecognized B-vitamins in the animal sources used, which were not adequately supplied in the basal ration.

It seems clear that, at least during the growth period, the body can function normally over a rather wide range of protein intake above the minimum, except where certain diseases are present. Since marked differences in quality exist among commonly fed rations, at least for certain species, the intake in practice should be more liberal than the experimentally determined minimum with a specific combination. There is also evidence (Sec. 243) that a certain level is desirable from the standpoint of the most effective use of the ration as a whole. But that there are stimulating or other definite, though intangible, beneficial effects from a luxus consumption appears very doubtful.

\section{Selected Literature}

Archibald, J. G.: Feeding urea to dairy cows, Mass. Agr. Expt. Sta. Bull. $406,1943$.

Baumgarten, W., A. N. Mather, and I. Stone: Essential amino acid composition of feed materials, Cereal Chem., 23, 135-155, 1946.

BLock, R. J., and D. Bolling: The amino acid composition of proteins and foods, Charles C. Thomas, Publisher, Springfield, Ill., 1945.

Burroughs, E. W., H. S. Burroughs, and H. H. Mitchell: The independence of the endogenous and the exogenous metabolism of nitrogen, J. Nutrition, 19, 271-283, 1940.

(AnNon, P. R.: Protein metabolism and aequired immunity, J. Am. Dietetic Assoc., 20, 77-80, 1944.

('munAlt, A. ('.: Protein metabolism in the plant, Yale University P'ress, New Haven, 1939.

Dunn, M. S., S. M. SHANkman, and M. N. CAmen: Investigations of amino acids, peptides and proteins. XXV. The determination of histidine in protein hydrolysates with Lactobacillus fermenti 36, J. Biol. Chem., 161, $6699678,1945$.

Lvans, R. J., and J. L. ST. Jonn: Listimation of the relative nutritive value of vegetable proteins hy two chemical methods, J. Nutrition, 30, 209-217, 1945 .

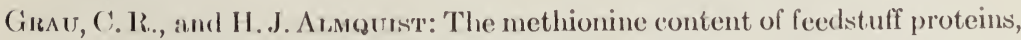
Arch. Biochem., 6, 287-294, 1915. 
Harris, L. E., and H. H. Mitchell: The value of urea in the synthesis of protein in the paunch of the ruminant. II. In growth, J. Nutrition, 22, 183-196, 1941.

Hart, E. B., and associates: The utilization of simple nitrogenous compounds such as urea and ammonium bicarbonate by growing calves, J. Dairy Sci., 22, 785-798, 1939.

Luck, J. Murray: Liver proteins. I. The question of protein storage, $J$. Biol. Chem., 115, 491-510, 1936.

MAdDEN, S. C., and associates: Ten amino acids essential for plasma protein production effective orally or intravenously, J. Expt. Med., 77, 277-295, 1943.

Mitchell, H. H.: The effect of the proportions of fat and carbohydrate in the diet upon the excretion of metabolic nitrogen in the feces, J. Biol. Chem., 105, 537-546, 1934.

Newburgh, L. H., and A. C. Cur tis: Production of renal injury in the white rat by the protein of the diet. Dependence of the injury on the duration of feeding, and on the amount and kind of protein, Arch. Internal Med., 42, 801-821, 1928.

Osborne, Thomas B., Lafayette Mendel, Edwards A. Park, and MilTON C. Winternitz: Physiological effects of diets unusually rich in protein or inorganic salts, J. Biol. Chem., 71, 317-350, 1927.

Owen, E. C., J. A. B. Smith, and N. C. Wright: Urea as a partial protein substitute in the feeding of dairy cattle, Biochem. J., 37, 44-53, 1943.

Rose, W. C., and E. E. RICE: The significance of the amino acids in canine nutrition, Science, 90, 186-187, 1939.

Schneider, Burch H.: The subdivision of the metabolic nitrogen in the feces of the rat, swine and man, J. Biol. Chem., 109, 249-278, 1935.

Slonaker, James R.: The effect of different percents of protein in the diet. I. Growth, Am. J. Physiol., 96, 547-556, 1931.

Smith, J. A. B., and F. Baker: The utilization of urea in the bovine rumen. IV. The isolation of the synthesized material and correlation between protein synthesis and microbial activities, Biochem. J., 38, 496--505, 1944 (and earlier papers).

Stewart, James: A study of nitrogen metabolism in sheep on high-protein diets, J. Agr. Sci., 20, 1-17, 1930.

Tolstoi, EDward: The effect of an exclusive meat diet lasting one year on the carbohydrate tolerance of two men, J. Biol. Chem., 83, 747-752, 1929.

Vickery, Hubert Bradford, and Richard Block: The basic amino acids of wool, J. Biol. Chem., 86, 107-111, 1930.

- and Carl L. A. Schmidt: The history of the discovery of the amino acids, Chem. Rev., 9, 169-318, 1931.

Woodman, H. E., and R. E. Evans: Nutrition of the bacon pig. XI. The minimum level of protein intake consistent with quick growth and satisfactory carcass quality, J. Agr. Sci., 35, 133-149, 1945. 


\section{CHAPTER VII \\ THE INORGANIC ELEMENTS AND THEIR METABOLISM}

The discussion in Chap. II has indicated that the body contains a large number of mineral elements which occur both in combination with each other and in combination with the organic constituents. While the physiological importance of some of them was early recognized, our specific knowledge of their nutritional significance is due primarily to research carried out during the last 35 years.

102. Essential Mineral Elements.-Today we recognize that the following mineral elements perform essential functions in the body and thus must be present in the food: calcium, phosphorus, sodium, potassium, chlorine, magnesium, iron, sulfur, iodine, manganese, copper, cobalt, and zinc. The proof that each of these elements is essential rests upon experiments with one or more species. All elements have not been tested with all species, but it is highly probable that there is no exception to the need for all of them by all higher animals. The question as to whether fluorine should be included in the list of essential minerals is discussed later (Sec. 146). There are at least a dozen more elements, such as silicon, boron, bromine, arsenic, and others, which regularly occur in the animal body. Some may perform essential functions as yet undiscovered. It is reasonable to believe, however, that most of them are found in the body merely because they are present in the food and thus are retained in part instead of being excreted.

Nevertheless, a possible need for some of these elements must be recognized. The recent discovery that one-tenth of a milligram of cobalt daily can restore to health sheep that otherwise die on pasture in certain areas of the world, despite failure to prove the element essential in small animal experiments with specifically purified diets, is a case in point. This finding for cobalt has also served to disprove the earlier viewpoint that, even if some of these elements, thus far not proven essential, are actually needed in 
traces, their universal presence in feeds should take care of this need. Clearly, more study is needed of some of the elements not included in the essential list. We must also recognize that elements may be essential, yet harmful in excess. This is true even of common salt. Even small amounts of copper and iodine are toxic, though needed in traces. Others that have no known useful function sometimes occur in natural feeds in toxic amounts, for example, selenium and molybdenum.

An excellent summary of the present knowledge of various trace elements that are essential or harmful to health is to be found in a series of papers presented at a symposium held by the Nutrition Society of Great Britain. ${ }^{1}$ Another review which deals particularly with mineral deficiencies and excesses in pasture herbage is that of Russell. ${ }^{2}$

The proof that a given element is essential depends upon feeding a ration so low in that element that structural or functional injury results. It is not possible to prepare any ration absolutely free from any mineral element, and thus proof of the need of those which may be required only in traces is difficult or impossible to establish. This explains why many remain in the doubtful column.

103. Area Deficiencies and Excesses of Mineral Elements.-In the case of several of the essential minerals, the initial knowledge of their need and of the symptoms resulting from their deficiency in the ration was gained by observations with grazing animals. Thus, phosphorus deficiency was first established as a result of the correlation of the symptoms with the low-phosphorus content in the herbage resulting from a corresponding deficiency in the soil. A pioneer study here is the one by Theiler and associates. ${ }^{3}$ They showed that large losses which occurred in both growing and adult cattle on the range were owing to a very low content of the element in the herbage as a result of a deficiency in the soil, a situation that has since been noted in other parts of the world including various areas in the United States. This and similar observations

${ }^{1}$ Various authors, Trace elements in relation to health, Proc. Nutrition Soc., 1, 176-225, 1944.

${ }^{2}$ Russell, F. C., Minerals in pasture deficiencies and excesses in relation to animal health, Imp. Bur. Animal Nutr. Tech. Commun., 15, 1944.

${ }^{3}$ Theiler, Arnold, H. H. Green, and P. J. du Toit, Phosphorus in the live stock industry, J. Dept. Agr., Union S. Africa, 8, 460-504, 1924. 
have led to surveys of the occurrence of animal troubles that might be correlated with specific soil deficiencies. Beeson ${ }^{1}$ of the U.S. Plant, Soil, and Nutrition Laboratory has reviewed the world-wide literature dealing with this general subject. Very recently Beeson ${ }^{2}$ has also reported a study of the occurrence of diseases in the United States resulting from deficiencies or excesses of minerals in the soil. A map from this publication is reproduced in Fig. 8.

104. Ash.-The mineral elements as a group are determined in a feed or animal tissue by burning off the organic matter and weighing the residue, which is called ash. Such a determination tells nothing about the specific elements present and the ash may include carbon from organic matter as carbonate when baseforming minerals are in excess. The determination is used in the conventional feed analysis to provide a figure which can be added in with others to arrive at the nitrogen-free extract by difference (Sec. 40). The ash may be used as a starting point for the determination of the percentages of the specific elements present, the information in which we are interested from the standpoint of mineral nutrition. But it must be remembered that an analysis of the ash tells us nothing as to the combination in which a given mineral occurs either in a body tissue or in a feed. When the organic matter is oxidized the minerals present in organic combination are changed to an inorganic form. Many of the minerals in the body function primarily as specific organic and inorganic combinations, and, in the case of the food also, the combination is important in so far as the usefulness of certain elements are concerned. For example, the primary need for sulfur in the food is as a constituent of the amino acids, cystine and methionine. No information as to the amount of the element so combined is furnished by determining the sulfur content of the ash of the ration. Thus the nutrition chemist must resort to special methods which give him specific information as to the forms in which certain mineral elements occur in the body tissues and in foods, rather than relying on a determination of the ash and its ingredients.

1 Begson, Kennetu C., 'The mineral composition of erops, with particular reference to the soils in which they were grown. A review and compilation, U.S. Depl. Agr. Misc. Pub. No. 369, 1941. (164 pp.)

${ }^{2}$ Befson, Kennetu C., The occurrence of mineral nutritional diseases of plants and animals in the United States, Soil Sci., 60, 9-13, 1945. 


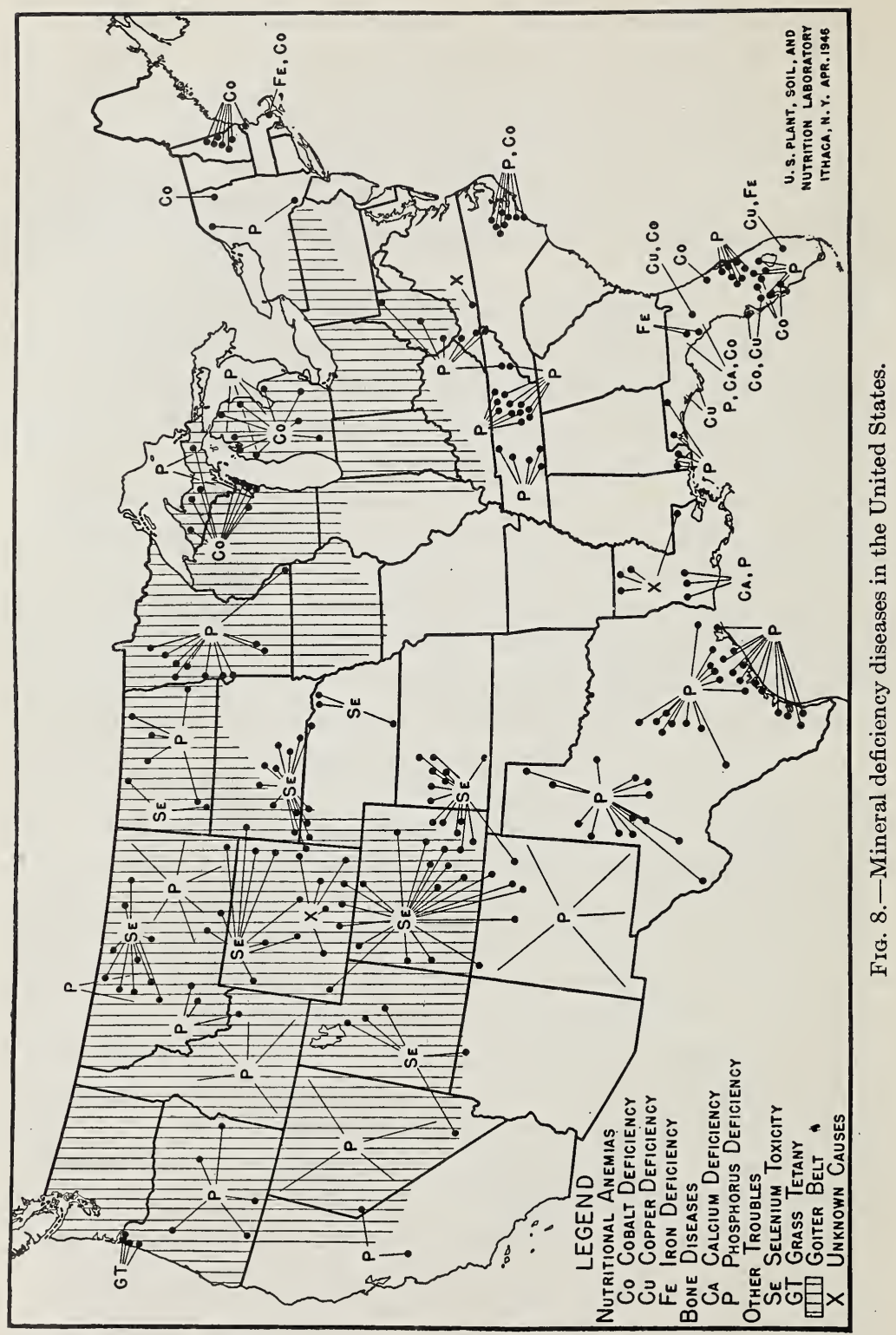


105. General Functions of Mineral Elements. - The essential elements serve the body in many different ways. As constituents of the bones and teeth, they give rigidity and strength to the skeletal structures. They are also constituents of the organic compounds, such as protein and lipids, which make up the muscles, organs, blood cells, and other soft tissues of the body. Further, they serve a variety of functions as soluble salts in the blood and other body fluids. Here they are concerned in the maintenance of osmotic relations and acid-base equilibrium and exert characteristic effects on the irritability of muscles and nerves. Many of their vital functions are due to an ionic interrelationship which finds expression in the terms "antagonistic action" and "balanced solution." For example, a certain balance between calcium, sodium, and potassium in the fluid which bathes the heart muscle is essential for the normal relaxation and contraction which constitute its beating. In addition to these general functions in which several minerals may take part, each one has various specific roles.

\section{CALCIUM AND PHOSPHORUS}

Over 70 per cent of the ash of the body consists of calcium and phosphorus. These two elements are discussed together because they are closely associated with each other in metabolism. They occur in the body combined with each other for the most part, and an inadequate supply of either in the diet limits the nutritive value of both. As early as 1842, it became recognized through the work of Chossat ${ }^{1}$ with pigeons that poor bone developed on a diet low in calcium. When fed wheat alone, the birds died after 10 months, and, on autopsy, the bones were found very much depleted. Calcium carbonate prevented the trouble. Chossat used chickens, rabbits, frogs, eels, lizards, and turtles in later studies. During the next 20 years, studies in both France and Germany showed that skeletal development in various species of farm animals was dependent upon the supply of calcium and phosphorus in the ration and that the deficiencies could be corrected by feeding bone meal and other sources of the minerals. Early in the present century, experimental work in this field became particularly active, and, with the discovery of vitamin D in 1922, a great impetus was given to studies of the metabolic processes involved.

1 Chossat, M., Note sur le système osseux, Compt. rend. acad. sci., 14, 451-454, 1842. 
106. Interrelation of Calcium, Phosphorus, and Vitamin D.Adequate calcium and phosphorus nutrition is dependent upon three factors; a sufficient supply of each element, a suitable ratio between them, and the presence of vitamin D. These factors are interrelated. While an adequate supply of the elements is the first essential, they are more effectively utilized when they are present in a certain ratio to each other. A ration containing 10 parts of calcium to 1 of phosphorus will not provide for efficient assimilation even though the phosphorus is present in what is normally a sufficient amount. The same is true where this relation between the elements is reversed. While the desirable calciumphosphorus ratio has been defined as one lying between $2: 1$ and $1: 2$, adequate nutrition is possible outside of these limits. The optimum ratio varies somewhat according to the levels of the elements. With plenty of vitamin $\mathrm{D}$ in the ration, the ratio becomes of less importance, and more efficient utilization is made of the amounts of the elements present. In the entire absence of the vitamin, assimilation is poor even though the other factors are optimum. The relative importance of these various factors differs considerably in different species and according to the physiological function in question. In the present discussion only incidental mention is made of vitamin $\mathrm{D}$ since the role of this nutrient is taken up later in Chap. VIII.

107. The Composition of Bone.-Approximately 99 per cent of the calcium and 80 per cent of the phosphorus of the body are present in the bones and teeth. Though somewhat variable according to age, state of nutrition, and species, normal adult bone may be considered to have the following approximate composition: water, 45 per cent; ash, 25 per cent; protein, 20 per cent; and fat, 10 per cent. The organic matrix of bone in which the mineral salts are deposited consists of a mixture of proteins, of which the principal one is ossein. The water content of bone decreases with age, and the fat is variable according to the nutritive state since the bone marrow serves as a fat depot, and thus ash content is expressed most frequently on the basis of the moisture-free, fat-free bone. In mammals the ash is made up approximately as follows: calcium, 36 per cent; phosphorus, 17 per cent; carbon dioxide, 5.5 per cent; and magnesium, 0.8 per cent. There are small amounts of several other minerals.

Assuming that the carbon dioxide is present as calcium car- 
bonate and the magnesium as phosphate, it may be calculated that the ash is made up of approximately 85 per cent of tricalcium phosphate, 14 per cent of calcium carbonate, and 1 per cent of magnesium phosphate. The chemical make-up is more complicated, however, than this implies. Bone gives an X-ray diffraction pattern similar to that of the mineral, apatite, the unit of structure of which contains $\mathrm{Ca}_{10}\left(\mathrm{PO}_{4}\right)_{6} \mathrm{~F}_{2}$. Substitutions, such as $(\mathrm{OH})^{-}$for $\mathrm{F}^{-}$and $\mathrm{Mg}^{++}$for $\mathrm{Ca}^{++}$, can occur in part in the apatite lattice without producing significant changes in the diffraction pattern. Recent evidence ${ }^{1}$ based on careful chemical and X-ray studies of tricalcium phosphate shows that it also has an apatite structure closely resembling bone. This suggests that bone may be a hydrated tricalcium phosphate type of compound containing sodium, magnesium, and carbonate substitutions.

There is little variation in the elementary composition of bone ash. The calcium and phosphorus always occur in approximately a $2: 1$ ratio, although slight variations with age and diet may occur. Magnesium is somewhat higher than normal in rachitic bone and much lower in magnesium deficiency (Sec. 119). The phosphatecarbonate ratio decreases with age and is lower in rickets. Since bone ash consists almost entirely of calcium and phosphorus salts and since the relative amounts of these elements show little variation, the ash content of bone is commonly used as the measure of its state of calcium and phosphorus nutrition.

Teeth are similar to bone in chemical composition but characteristic differences exist between the enamel, dentine, and pulp. The enamel is the hardest substance in the body and has the lowest water content, approximately 5 per cent. It contains only 3.5 per cent of organic matter.

108. Calcium and Phosphorus in Soft Tissues.- The 1 per cent of body calcium which occurs outside the bones is widely distributed throughout the organs and tissues, where it exists, at least in part, in the colloidal state. The large amounts of phosphorus which are found elsewhere than in the bones are present mostly in organic combinations such as phosphoprotein, nucleoprotein, phospholipid, phosphocreatine, hexose phosphate, and others. The discussions of these compounds in earlier chapters have indicated their distribution and functions and serve to show the

1 Hendricks, S. B., and W. L. HnLl, The inorganic constitution of bone, Science, 96, 255-257, 1942. 
many roles which phosphorus plays in the organism other than as a structural element in bone. Phosphorus makes up 0.15 to 0.2 per cent of the soft tissues of the body.

109. Calcium and Phosphorus in Blood.-The blood cells are almost or entirely devoid of calcium, but the serum, in health, contains from 9 to $12 \mathrm{mg}$. per $100 \mathrm{ml}$. in most species. In the laying hen, a much higher level occurs during egg production. Two types of serum calcium are distinguished, diffusible and nondiffusible, differentiated by a membrane impermeable to colloids. The nondiffusible calcium is bound to protein. The diffusible fraction, which makes up 60 per cent or more of the total, is present largely as compounds of phosphate and bicarbonate and is the part which is of principal significance in calcium and phosphorus nutrition. The level of diffusible calcium is not necessarily higher, however, in active metabolism. In addition to its function in bone deposition, the serum calcium is essential for the clotting of the blood and is concerned in the maintenance of acid-base equilibrium. It also plays a role in the physiological balance of basic ions (Sec. 151).

While the primary source of blood calcium is obviously the food, its level is not readily influenced by the dietary intake but is primarily controlled by a hormone from the parathyroid glands. As need arises, this hormone maintains the level in the blood by mobilizing calcium from the bones (Sec. 111). If the parathyroids are removed or fail to function, the blood level drops and tetany occurs. This is a hyperirritability of the neuromuscular system which in severe cases results in convulsions. If the glands are abnormally active, as occurs in certain diseases, an excessive mobilization of calcium takes place with a consequent demineralization of the bones. There is an excessive loss of calcium from the body as a result of an increased excretion in the urine. Blood calcium is low in "milk fever." It may be low in rickets, particularly if accompanied by tetany.

Whole blood contains from 35 to $45 \mathrm{mg}$. of phosphorus per $100 \mathrm{ml}$. , most of which is in the cells. The element occurs in a variety of forms, principally organic combinations. From the standpoint of mineral nutrition, our main interest lies in the inorganic phosphorus which occurs in the plasma, although it is evident that an interchange of phosphate between organic and inorganic forms continually occurs. In health its level generally lies between 
4 and $9 \mathrm{mg}$. per $100 \mathrm{ml}$., depending upon the age and species. The level is higher at birth than at maturity, the most rapid decline occurring early in life. The maintenance of the inorganic phosphorus level of the blood is governed by the factors which promote calcium and phosphorus assimilation. A low level occurs commonly in rickets.

The calcium and phosphorus levels in the blood are important indicators of the state of nutrition of these elements; but, in this connection, it is important to remember that their levels represent a balance between several opposing factors: absorption, excretion, deposition, and mobilization. Normal levels do not guarantee a normal state of bone nutrition.

110. Absorption and Excretion of Calcium and Phosphorus.The nutrition of calcium and phosphorus is dependent in the first place upon their absorption and in the second place upon their deposition in the bones. The state of their nutrition is best measured either by balance studies (Sec. 221) which determine the difference between the intake and the outgo in the feces and urine, or by chemical, histological, or X-ray studies of the bones. The absorption of these elements cannot be measured in the same way as is done for organic nutrients because the feces are one of the paths of outgo of the portion which has been absorbed and metabolized, as well as of the portion which escapes absorption. Using special techniques, the process has been studied by taking advantage of the fact that absorption and excretion occur at different places in the intestinal tract. The measurement of the distribution of the minerals between the urine and feces, and the determination of their concentrations in the blood are also useful in studying absorption.

It is clear that the absorption of both calcium and phosphorus is favored by factors which operate to hold them in solution. An acid medium tends to prevent the formation of the insoluble and thus unabsorbable tricalcium phosphate. Lactose, which promotes an acid reaction in the digestive tract, favors absorption, and assimilation is thereby improved. Certain factors influence the absorption of one element but not the other. Large intakes of iron, aluminum, and magnesium interfere with the absorption of phosphorus by forming insoluble phosphates. An experimentally produced "beryllium rickets" is due to the effect of the beryllium in rendering phosphorus insoluble. Fatty acids may 
form insoluble calcium soaps which are assimilated with difficulty, yet a certain amount of fat seems to favor the absorption of this element. A great excess of either calcium or phosphorus interferes with the absorption of the other, a fact which helps to explain why a certain ratio between them in the diet is desirable for their best assimilation. With a large excess of either element, the other one tends to become tied up as the insoluble tricalcium phosphate.

Many studies have been made of the influence of crude fiber on the absorption of calcium and phosphorus, with rather conflicting results. In general, the direct addition of cellulose to diets has had little influence, while diets naturally high in fiber appear to have a more marked effect. It is probable that in the latter case the effect is an indirect one, whereby the minerals existing in cells surrounded by fiber which is not digested are thus kept from contact with the absorbing membranes. This is an important practical question, particularly as regards calcium, since the only vegetable foods which are rich in this element are also high in fiber. Where crude fiber or other substances cause a rnarked laxative effect absorption is reduced.

The measurement of absorption is of limited value because of the fact that absorbed calcium and phosphorus may be promptly excreted unless conditions are favorable for their deposition in the bones. It has been shown, for example, that though the feeding of a mineral acid will increase absorption all of the increase may be rapidly excreted. Thus the nutritionist is more interested in the net absorption, the amount which actually remains in the body as shown by a balance experiment. At best, a large wastage of calcium and phosphorus is involved in their adequate nutrition.

Approximately 75 per cent of the excreted calcium is found in the feces. The figure is somewhat variable according to the diet and other factors, and it is higher in the young than in the adult. Phosphorus is excreted principally in the feces in Herbivora, principally in the urine in Carnivora, and about equally divided between the two channels in man. The distribution between feces and urine can be shown by injecting a salt of the element into the blood stream and noting the increased output in the two channels. A variety of phosphorus compounds, chiefly phosphates, occur' in the urine, of which approximately 6 per cent are in organic form. 


\section{Deposition and Mobilization of Calcium and Phosphorus.-} The bones serve not only as structural elements but also as storehouses of calcium and phosphorus which may be mobilized at times when the assimilation of these minerals is inadequate to meet body needs. Thus the mineral metabolism of bone involves not only the deposition of calcium and phosphorus during growth but also processes of storage and mobilization which occur throughout life. As an aid to an understanding of how these various

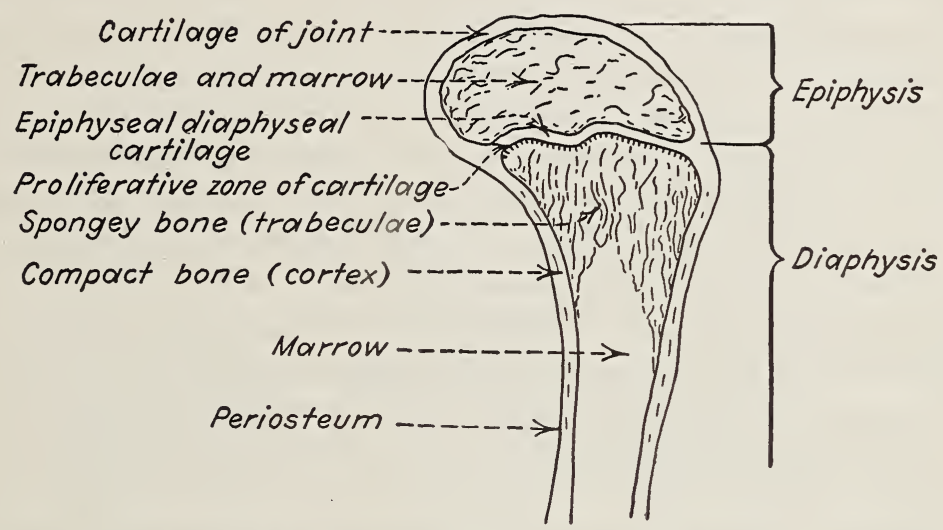

Fig. 9.-Diagram of a longitudinal section of a growing bone. (Courtesy of Katharine Hummel, Cornell University.)

processes take place, a diagram of a longitudinal section of bone is given in Fig. 9.

The growth of bone in length takes place at the junction of the epiphysis and diaphysis. The cartilage in between is a temporary formation which grows by the multiplication of its own cells and continues to be replaced at both surfaces by calcified bone. When the cartilage ceases to regenerate and is entirely replaced by bone itself, the epiphysis unites with the diaphysis and growth ceases. This is referred to as the closing of the epiphyses. In the process of ossification, cartilage is converted into osscin and then calcified. The zone where this is taking place is referred to as the proliferation zone of cartilage or the zone of provisional calcification. It is the area which is examined in the "line test" (Sec. 164) used as a measure of the state of calcium and phosphorus nutrition. Bone formation also occurs under the periosteum. At first the only bone formed is of the spongy type. An internal reconstruction is 
responsible for the formation of the more complex structure called compact bone.

As distinguished from the shaft, the trabeculae are lacelike structures in which a reserve of calcium and phosphorus is deposited for mobilization to meet needs not currently supplied by the diet. This function of the trabeculae has been clearly portrayed by the detailed studies of Bauer, Aub, and Albright. ${ }^{1}$ These structures are located close to the epiphyseal ends of the bones where the blood supply is greatest. They provide the calcium mobilized by the parathyroid to maintain the level in the blood. During heavy lactation, they are drawn upon to meet a part of the requirements for the minerals secreted in the milk (Sec. 353). They also may be drawn upon in pregnancy and, perhaps, during periods of rapid growth for the building of the structural portion of the bone. This depletion of the trabeculae involves no physiological harm, and their mineral content is readily restored with an adequate diet during periods when the body needs for calcium are less, for example, during the dry period for the dairy cow. But, if they are not restored, the shaft of the bone may be eventually attacked with serious consequences as is described later.

Like the structure of bone itself, the physicochemical changes involved in the deposition of its calcium salts remain a puzzle, despite much study. It is clear that sufficient concentrations of diffusible calcium and inorganic phosphates are prerequisites. It is considered that the blood, and thus the fluid bathing the bone, is supersaturated with tricalcium phosphate and that deposition in the bone involves a precipitation of this salt. But ossification is not an inert process of precipitation or else it could occur anywhere in the body. The tricalcium phosphate does not precipitate out in the fluid media but only in active bone and cartilage. It appears that some vital factor of the bony tissue itself must be involved. Robison ${ }^{2}$ has produced important evidence that a phosphatase, occurring only in active bone or cartilage, hydrolyzes organic phosphates in the blood cells thus providing an

1 Bauer, Walter, J. C. Aub, and Fuller Albright, Studies of calcium and phosphorus metabolism. V. A study of the bone trabeculae as a readily available reserve supply of calcium, $J$. Exptl. Med., 49, 145-161, 1929.

${ }^{2}$ Robison, RoBert, The significance of phosphoric acid ester in metabolism, New York University Press, New York, 1932. 
increased concentration of inorganic phosphate ion which causes precipitation to be initiated. In his publication this investigator has reviewed various theories of calcification.

112. Rickets. - It is evident from the previous discussion that a failure of normal calcium and phosphorus nutrition may occur at any time of life when the supply of the elements and the factors concerned in their assimilation, notably vitamin $\mathrm{D}$, are not adequate to meet functional needs. In the adult the failure is reflected in a negative balance of the minerals, and, in growth, the balance data show inadequate retention. At both stages there is a decreased ash content of the bones. Their consequent weakening may eventually result in certain external symptoms, such as lameness and fractures, which are alike at all ages, though, during the formative stage, abnormalities of growth which result in misshapen bones are the more common. There are, however, marked differences in the bone pathology, particularly histological, according to the stage of bone development and also according to the specific nutritional deficiency primarily concerned. Therefore, various terms are used to designate different failures of calcium and phosphorus nutrition. Unfortunately there is a lack of uniformity in the use of these terms.

In its broadest sense, rickets represents a disturbance of the mineral metabolism in such a way that the calcification of the growing bone does not take place normally. This is the sense in which the term is used in this book. The cause of the failure lies primarily in the fluid which bathes the bone, rather than in the bone itself, and thus rickets may be considered essentially as a disordered condition of the blood. There is a lowering of the level of inorganic phosphorus or calcium or both and an increase in phosphatase, in the plasma. The blood picture varies according to the specific dietary deficiency involved. Some authorities limit the use of the term rickets, or true rickets, to the specific bone pathology found in very early growth, involving changes which are produced experimentally on a low-phosphorus high-calcium diet deficient in vitamin $\mathrm{D}$ and which are accompanied by a low blood phosphorus. There is a widening of the epiphysealdiaphyseal cartilage, an excessive production of osteoid tissue which accounts for the enlargement of the ends of the long bones, and other characteristic histological changes. But bone abnormalities can develop at any time during growth. 'They can oceur at 
any time because of a lack of calcium as well as of phosphorus and of the vitamin, and the blood picture may vary as regards the mineral relations. Though the specific bone pathology may differ, the broad definition of rickets includes all of these nutritive failures, recognizing, however, that tetany may also occur if the blood calcium becomes very low. Frequently the terms, lowphosphorus rickets and low-calcium rickets, are used where a distinction is made.

The failure of bone nutrition during growth results not only in an arrest of its normal development but also in various structural

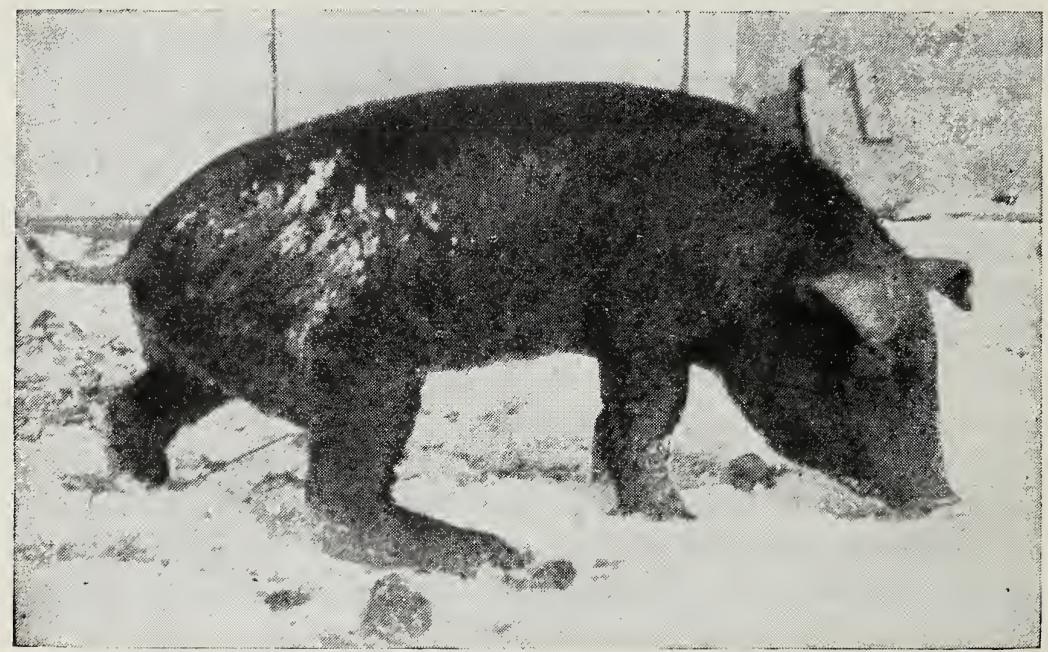

Fig. 10.-An extreme case of rickets caused by a ration low in calcium.

abnormalities. There is an enlargement of the ends of the bones which shows itself in a beading of the ribs and certain other bones. In severe and prolonged failure of adequate nutrition, the tension of the muscles pulls the weakened bones out of shape and the weight of the body causes the leg bones to buckle and even to fracture. Such a condition is illustrated in Fig. 10. Rapid growth accelerates the development of rickets, probably caused in part by the demands of muscle formation for phosphorus.

Rickets is very common in calves and pigs. In calves its occurrence is revealed in decreased growth, stiffness of gait, enlarged and painful joints, arching of the back, and, as an extreme symptom, the birth of weak or deformed calves. A low- 
blood calcium appears to be a more marked and regular finding than low phosphorus. In swine, retarded growth, enlarged joints, and bone deformities which may produce posterior paralysis are the most evident physical symptoms. In pigs low-blood phosphorus is a characteristic finding, but, on low-calcium rations, the blood calcium may be low also. In lambs enlarged joints which are frequently painful, stiffness and irregular gait are common. The occurrence of the disease in this species has been described by Duckworth and associates. ${ }^{1}$ Rickets has also been reported in horses, dogs, and several other species. In all of them retardation of growth, inadequate calcification, and bone malformations result.

113. Osteomalacia.-The term osteomalacia is commonly used to denote a failure of calcium and phosphorus nutrition in the adult bone, and it is so used in this book. A mobilization of calcium and phosphorus salts from the bones of the adult, exceeding the reserve supply present in the trabeculae, results in a breakdown of the structural portion. This excessive mobilization may be caused by an overfunctioning of the parathyroid or by some other pathological condition, but it is caused most frequently by a continued body demand for calcium and phosphorus which is greatly in excess of the supply being assimilated. Most of the acute cases occur during pregnancy and lactation when, owing to an inadequate diet, excessive demands are made upon bones already depleted. Any adult animal which continually fails to receive calcium and phosphorus nutrition adequate for its needs must gradually deplete its bones. Whether this occurs to the point where the bones break down or production becomes lessened depends upon the extent of the deficiency.

A striking depletion of the bones which resulted in broken pelves in dairy cows continuously fed on calcium-deficient roughages has been described by Becker, Neal, and Shealy. ${ }^{2}$ A similar condition caused by phosphorus deficiency has been reported from South Africa and elsewhere. Osteomalacia in horses on a low-

1 Duckworth, J., W. Godden and W. Thomson, The relation between rates of growth and rickets in sheep on diets deficient in vitamin D., J. Agr. Sci., 33, 190-196, 1943.

2 Becken, R. B., W. M. Nent, and A. T. Shenty, Effect of calciumdeficient roughages upon milk production and welfare of dairy cows, Fla. Agr. Kixpl. Sla. Tech. Bull. 262, 1933. 
calcium high-phosphorus ration has been reported by Philippine workers. ${ }^{1}$ The trouble has been reported in sheep, beef cattle, swine, and other species. A characteristic feature of the trouble is a negative calcium and phosphorus balance. The blood may be low in one or both of the minerals. If very low in calcium, there may be tetany also. Provided it is not too far advanced, osteomalacia responds to treatment by correcting the dietary deficiency which is responsible for the inadequate calcium and phosphorus nutrition of the bones. Clearly the necessity of giving attention to bone nutrition does not end with the close of the growth period. An active metabolism continues throughout life, and, for a normal productive life of breeding stock and lactating animals, this nutrition must be such as to insure that the bones do not become depleted, even though acute symptoms of osteomalacia do not occur.

Like rickets, osteomalacia is a term used in somewhat different senses by different authorities. In reading accounts of investigations dealing with either of these troubles, it is important to note how the terms are being used. Osteoporosis is another term that has a rather variable meaning. Those who consider the lowphosphorus variety as the only true rickets employ it to denote the histology where low calcium is primarily involved. Aphosphoresis and acalciosis denote, respectively, a condition due to a lack of phosphorus and a condition due to a lack of calcium. The role of vitamin $\mathrm{D}$ in these variously named troubles is discussed later (Sec. 161).

114. The Calcium and Phosphorus Content of Feeds.-The different concentrates and roughages vary widely in their content of calcium and phosphorus. Certain combinations furnish a sufficient supply of these minerals while others are deficient. Thus an important aid in providing for adequate calcium and phosphorus nutrition is a general knowledge of the composition of the common feeds. This knowledge enables the feeder to consider minerals, as well as protein and total digestible nutrients, in making up his rations and provides him with the information for determining when supplementary sources of these elements are needed.

The relative amounts of calcium in certain typical feeds are

${ }^{1}$ Kinter, J. H., and R. L. Holt, Equine osteomalacia, Philippine J. Sci., $49,1-89,1932$. Sumulong, Manuel D., Observations on the bones of native horses affected with osteomalacia; ibid., 53, 141-158, 1934. 
shown in Fig. 11. For comparative purposes the values for skim milk and corn silage are given on a dry basis. The cereal seeds are all low in calcium. Legume seeds, notably soybeans, are higher, and the same is true for the oil meals. All seeds and their products, however, must be classed as poor sources of calcium in terms of the requirement of the animal body: Grass hays, such as timothy, are also poor in contrast to legume hays which are rich. On a dry basis, skim milk exceeds the best hays in calcium content. Much richer than any of the feeds shown in the chart, however, are the animal by-products containing bone, such as tankage, meat scrap, and fish meal. A 60 per cent protein tankage will furnish four or five times as much calcium as will legume hay or skim milk and twenty times as much as will vegetable protein con-

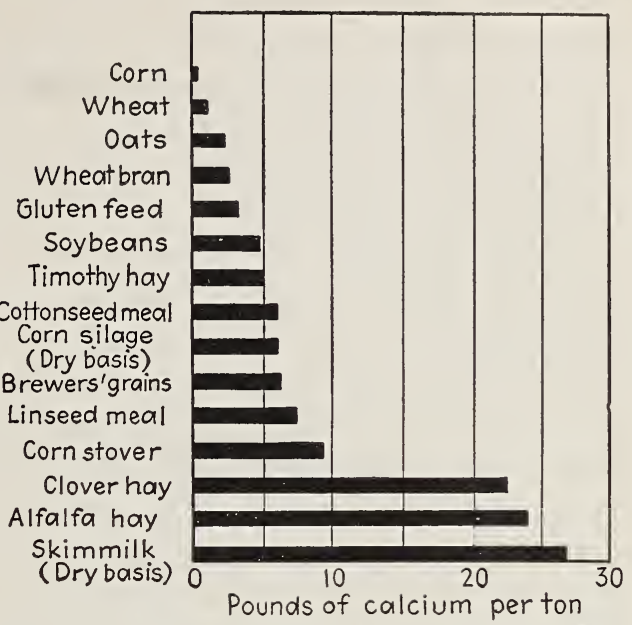

FIG. 11.-Calcium content of common feedstuffs.

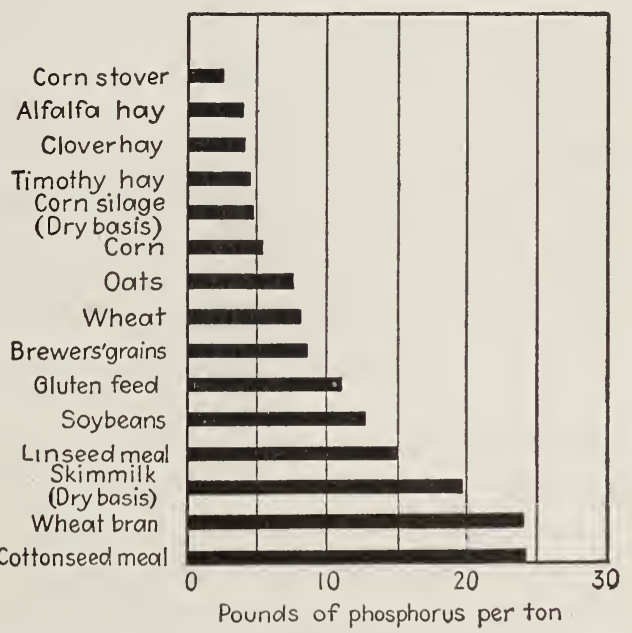
centrates such as the Fig. 12.-Phosphorus content of common feedstuffs. oil meals.

As is shown in Fig. 12, these same feeds present a very different picture in phosphorus content. Here the seeds are uniformly higher than the roughages, and seed by-products, such as wheat bran and the oil meals, are especially rich in phosphorus. Skim 
milk is the only feed included in the charts which can be classed as rich in both calcium and phosphorus. The bone-carrying animal by-products are also very rich in both elements. Tankage supplies more than twice as much phosphorus as any feed shown in Fig. 12. The milled flours are lower in both calcium and phosphorus than the whole seeds.

While the data presented in Figs. 11 and 12 are useful to show the differences between the various kinds of feeds, they must not be considered to be exact values, because the calcium and phosphorus contents of feeds, especially the roughages, are variable according to the nature of the soil on which they are grown, the fertilizer used, and the water relations. Timothy hay grown on fertile soil may contain two or three times as much calcium as that grown on a worn-out acid soil. On the other hand, legume hays require a soil rich in lime for satisfactory growth, and thus, while they show some variation according to soil, they can always be relied upon as rich sources of calcium. All hays are highly variable in phosphorus content according to the supply available in the soil and to other factors. In a study of fifty samples of timothy hay grown on different soils in central New York, the calcium ranged from 0.14 to 0.34 per cent and the phosphorus, from 0.13 to 0.29 per cent. Thus, the feeder must know something about the mineral content of his roughage in order to tell the exact conditions under which he needs a mineral supplement. General statements that one type of hay always needs a supplement, while another type never does, cannot always hold. Pasture grass is subject to even larger variations than dry roughage because the species of the grasses is a large factor and because climatic conditions also play a role.

115. Availability of Calcium and Phosphorus of Feeds.-The possibility that the availability of calcium and phosphorus may vary considerably according to their chemical combination or physical association with other compounds in feeds must be recognized. There is little specific knowledge on this point, however.

Much research has centered around the question of the availability of phosphorus present as phytin or phytic acid. The latter compound is an acid hexaphosphoric acid ester of inositol (Sec. 195). It occurs as salts of calcium, magnesium, etc., the complex being referred to as phytin. Half or more of the phosphorus of 
most mature seeds and their products, notably wheat bran which is a rich source, is so combined. Thus, the question of its availability is an important one in animal nutrition.

Several experiments, but by no means all, have shown that with rations containing phosphorus largely in the form of phytin, the calcium and phosphorus utilization is impaired. The specific reason is still a matter of debate. It is agreed that the phytin complex is subject to breakdown in the digestive tract under the action of the enzyme, phytase. According to one theory that has considerable experimental support, the phytic acid that occurs in seeds is not completely neutralized by calcium and magnesium, and, thus, when made soluble by enzyme action, the unneutralized acid precipitates calcium, rendering it unabsorbable. There are other experiments that suggest that the phosphorus is in part unavailable owing to the incomplete breakdown of the phytin in the digestive tract, particularly in foods and feeds subjected to heat that destroys phytase. Some doubt has been thrown on the adequacy of this explanation by failure to find phytase in some of the feeds in question and by the demonstration of its presence in the intestinal mucosa of some species. Very recent studies by Singsen and Mitchell ${ }^{1}$ with poultry and by Boutwell and associates ${ }^{2}$ with rats have shown that vitamin $\mathrm{D}$ is definitely concerned in the utilization of phytin phosphorus. The latter paper also reviews earlier work indicating that wheat bran provides a satisfactory source of phosphorus for swine and cattle, at least under practical conditions, with sunlight available. In the case of man, the evidence seems clear that phytin phosphorus is a less satisfactory source. Some of the papers dealing with this unsettled problem are listed at the end of this chapter.

The availability of the calcium of certain leafy materials is impaired by the presence of oxalic acid. The acid precipitates the calcium and prevents its absorption. In the case of spinach, for example, there is usually enough oxalic acid present to render all of its calcium unavailable and a part of that of the rest of the diet as well. On the other hand, the calcium of kale, which contains practically no oxalic acid, is nearly as well assimilated as that of

1 Singsen, E. P., and H. H. Mitcuelu, Soy bean meal chick rations need no inorganic phosphorus supplement, Poultry Sci., 23, 152-153, 1944.

${ }^{2}$ Boutwert, R. K., and associates, The availability of wheat bran phosphorus for the rat, J. Nutrition, 31, 193-202, 1946. 
milk. This problem has been studied in detail by Kohman ${ }^{1}$ who gives a table listing the oxalic-acid content of many vegetables and fruits.

Little is known about the oxalic content of animal feeds. It has been reported that decalcification has been noted in sheep grazed on feed containing oxalic acid. In a limited study with cattle, however, it has been concluded that the ingestion of soluble oxalates has no deleterious effect on calcium absorption. The

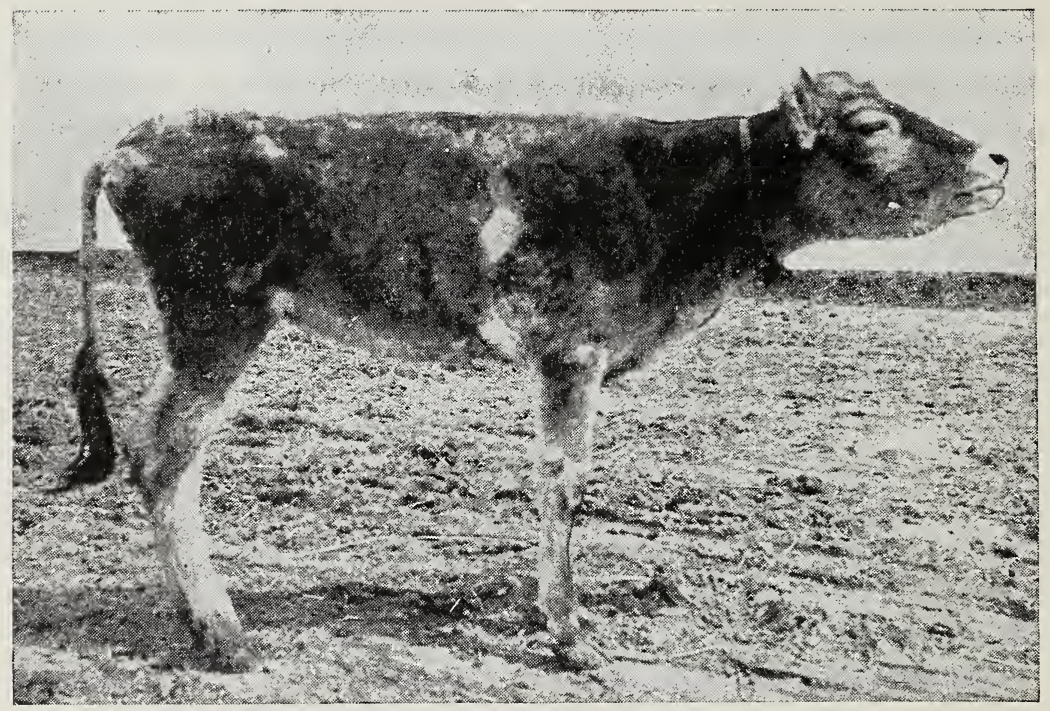

FIG. 13.- "Wood-chewing" calf which developed this depraved appetite while on a ration of grain and poor hay, a ration low in phosphorus and vitamin D.

finding was explained on the basis of oxalic-acid breakdown in the rumen. Both the oxalic-acid content of animal feeds and its significance in the metabolism of different species need further study.

116. Phosphorus Deficiency and Appetite.-A deficiency of phosphorus has a specific effect in causing a loss of appetite, and even a depraved appetite, frequently referred to as "pica," which is exhibited in the eating of bones, wood, clothing, and other materials to which the animal may have access. The animal becomes very emaciated. This condition, which is illustrated in Fig. 13,

${ }^{1}$ Konman, E. F., Oxalic acid in foods and its behaviour and fate in the diet, J. Nutrition, 18, 233-244, 1939. 
is most frequently met in grazing animals in areas where the soil, and thus the forage, is very low in phosphorus. It may also occur in barn feeding and here a lack of vitamin D may also be involved. Very large losses have occurred among grazing animals in different parts of the world as a result of this severe phosphorus deficiency, even where the forage was abundant and nutritionally adequate in other respects. Many of the deaths have resulted from diseases to which the weakened animals become especially susceptible, notably from infections contracted by eating decaying bones of animals which had died. Bone meal or other rich sources of phosphorus are now being effectively used to prevent these losses.

The fact that phosphorus deficiency results in a severe emaciation has raised the question as to whether there is a poorer utilization of the small amount of food consumed. In studying this question with dairy cattle, Riddell, Hughes, and Fitch ${ }^{1}$ found no decrease in digestibility, but there was evidence of a higher energy metabolism. From a critical experiment with beef heifers, Kleiber, Goss, and Guilbert ${ }^{2}$ concluded that loss of appetite was the main factor but that there was a slightly lower efficiency of energy utilization.

117. Calcium and Phosphorus Supplements.-In selecting rations for their calcium and phosphorus content, consideration should first be given to supplying the minerals, in so far as possible, by choosing those feeding stuffs that are rich in the elements needed. However, the farmer must build his rations around the available feeding stuffs on his own farm, and it may not be practicable for him to make up his rations so that they will be rich in the needed minerals. Wherever it is not practicable or possible to provide for adequate mineral nutrition by an appropriate combination of the feeding stuffs available, mineral supplements should be used.

The qualities which determine the feeding value of a supplement are: content of calcium and phosphorus, fineness of division,

${ }^{1}$ Riddeli, W. H., J. S. Hughes, and J. B. Fitch, The relation of phosphorus deficiency to the utilization of feed in dairy cattle, Kans. Agr. Expt. Sta. T'ech. Bull. 36, 1934.

${ }^{2}$ Klember, Max, Harold Goss, and H. R. Gulbert, Phosphorus deficiency metabolism and food utilization in beef heifers, J. Nutrition, 12, $121-153,1936$. 
and freedom from harmful impurities. The analyses of commonly available calcium and phosphorus supplements are given in Table XII. The chemical composition of these supplements varies according to the purity of the.raw material and the method of processing. Standard products should have a composition approximating that represented by the figures given in the table. The figure for ground limestone is representative of the highcalcium products available. Dolomitic limestones have much smaller and variable contents of calcium.

Many studies have shown that the minerals of these supplements are readily utilizable by both animal and man. Assuming that no harmful substances are present in the supplements and that the latter are in a suitable physical condition, all may be considered to be of equal value per unit of calcium and phosphorus

Table XII.-Percentage Composition of Calcium and Phosphorus Supplements

\begin{tabular}{|c|c|c|}
\hline Supplements & Calcium & Phosphorus \\
\hline Raw bone meal. . & 22.5 & 10.5 \\
\hline Steamed bone meal........ & 31.3 & 14.4 \\
\hline Dicalcium phosphate......... & 23.5 & 18.7 \\
\hline Spent bone black............. & 22.0 & 10.9 \\
\hline Ground limestone $\ldots \ldots \ldots \ldots$ & 38.5 & \\
\hline Oyster shells.................. & 37.9 & \\
\hline
\end{tabular}

present. While the minerals must be in solution in order to be absorbed, the factors which determine solubility in the intestine are more important than the form ingested. It is evident, however, from the investigation of Deobald and associates ${ }^{1}$ with chicks, that the calcium of highly insoluble, complex iron-calcium silicates is not utilized. While much of the phosphorus in the body is in organic compounds, inorganic phosphorus can be utilized in their synthesis. There is no special virtue in the so-called organic sources of calcium and phosphorus.

118. Defluorinated Phosphates.-The supplements listed in Table XII do not include any of the "defluorinated phosphates" that came into use during wartime, because of their variable

${ }^{1}$ Deobald, H. J., C. A. Elvehjem, E. B. Hart, and J. G. Halpin, Availability of calcium salts for bone formation and rickets prevention in chicks, Poultry Sci., 15, 42-47, 1936. 
nature. Rock phosphate and its products are harmful owing to their fluorine content (Sec. 143). Processes have been developed for removing this fluorine to the extent that the products can be used without harm. But the latter is not true for all that have been offered for animal feeding. The maximum fluorine content that may be considered safe for different species is discussed later (Sec. 145).

Various defluorinated phosphates have been tested experimentally with rats, chickens, pigs, and calves. Several have been found satisfactory, although in general the calcium and phosphorus available have been found somewhat less than in the case of bone meal. In fact, a few products have been noted to have a very low availability. The temperature to which the defluorinated process is carried out and the amounts of iron and aluminum present seem to be the governing factors in the availability of the minerals. Much information along these lines is to be found in the recently published collaborators' studies. ${ }^{1}$ The fluorine hazard in the use of these products has been reviewed by Mitchell. ${ }^{2}$

It is expected that current commercial developments will result in the improvement and standardization of defluorinated products for use as mineral supplements.

\section{MAGNESIUM}

Though present in the body in a much smaller amount, the magnesium is closely associated with calcium and phosphorus, both in its distribution and in its metabolism. Approximately 70 per cent of the body supply is in the skeleton, the remainder being found widely distributed in the various fluids. Blood serum contains 1 to $3 \mathrm{mg}$. of the element per $100 \mathrm{ml}$. and its level tends to vary with the phosphorus content. 'The considerable percentage which is found elsewhere than in the bones indicates

1 BrRI), H. R., and associates: Nutritive evaluation of defluorinated phosphates and other phosphorus supplements. II. Defluorinated phosphates as phosphorus supplements for chicks, .J. Assoc. Official Agr. Chem., 28, 118-129, 1945; Euss, N. R. and associates: III. Utilization experiments with rats, ibid., $129-142$.

${ }^{2}$ Mi'crits, H. H., The use of phosphorus containing substitutes for bone meal in livestock feeding, with particular reference to the fluorine hazard, Natl. Rescarch Council, Committee on Animal Nutrition Report No. 10, 1943. 
that its distribution in the body as a whole follows that of phosphorus rather than of calcium. In fact, though the calcium content of the entire body is many times that of magnesium, the soft tissues actually contain much more of the latter. Like calcium and phosphorus, magnesium is excreted in both the urine and feces. The major output is found in the feces.

119. Symptoms of Magnesium Deficiency.-Our knowledge that magnesium is an essential element dates from the work of Kruse, Orent, and McCollum. ${ }^{1}$ Lowering its content in the diet to 1.8 parts per million resulted, in rats, in vasodilation, hyperirritability, convulsions, and death. In the main the same symptoms occurred in dogs. A characteristic blood finding was a lowered magnesium content but normal calcium and phosphorus. This picture led the investigators to call the trouble "magnesium tetany," thus distinguishing it from the usual tetany in which a low blood calcium is characteristic.

A tetany in calves, characterized by a low blood magnesium with normal calcium and phosphorus, was reported by Duncan, Huffman, and Robinson ${ }^{2}$. of the Michigan Experiment Station. The calves were reared for extended periods, either on milk alone, a food which is rather low in magnesium, or on milk plus special supplements which contained little or none of the element. These observations were confirmed by other workers using purified diets very low in the element. In calves showing the typical symptoms, the magnesium in the blood serum is frequently as low as $0.1 \mathrm{mg}$. per $100 \mathrm{ml}$. compared with a normal of around $2.5 \mathrm{mg}$. The bones become depleted of magnesium and calcification is decreased. Animals that die of tetany frequently reveal pathological calcifications in the vascular system.

These findings with calves have focused attention on a disease of cattle called "grass tetany" or "grass staggers." This disease has been reported particularly from Holland and also from New Zealand as a sickness that occurs in fresh cows within a week or two after they are turned out to pasture. It has been compre-

${ }^{1}$ Kruse, H. D., E. R. Orent, and E. V. McCollum, Studies on magnesium deficiency in animals. I. Symptomatology resulting from magnesium deprivation, J. Biol. Chem., 96, 519-539, 1932; III. Chemical changes in the blood following magnesium deprivation, ibid., 100, 603-643, 1933.

${ }^{2}$ Duncan, C. W., C. F. Huffman, and C. S. Robinson, Magnesium studies in calves. I. Tetany produced by a ration of milk or milk with various supplements, J. Biol. Chem., 108, 35-44, 1935. 
hensively studied by Sjollema. ${ }^{1}$ The physical symptoms are similar to those of magnesium tetany. There is a similar frequency of fatal outcome and the blood magnesium is low. It has been reported from New Zealand that animals affected by grass staggers and showing a low magnesium in the blood respond to treatment with salts of the element. It remains uncertain, however, as to whether all the troubles referred to as grass tetany or grass staggers represent an uncomplicated magnesium deficiency.

There is a marked seasonal variation in the magnesium level in the blood of cows and calves, the lowest level occurring during the pasture season - the period when most of the acute troubles occur. But wide variations in the blood magnesium have been noted in animals showing no physical symptoms, and relations to feed supply have not been clearly established. The fact that the tetany can be experimentally produced in calves on milk diets supplemented with iron and copper, but not on grain mixtures of similar magnesium content, indicates that the dietary relationship is not a simple one.

On the basis of studies by Huffman and associates, ${ }^{2}$ the magnesium allowance has been placed at $0.6 \mathrm{~g}$. for $100 \mathrm{lb}$. body weight. This figure applies to the element as supplied in mineral feeds in view of evidence that the requirement is higher when it is supplied as salts of magnesium. The allowance corresponds to approximately 0.06 per cent of the dry ration. The chick allowance has been set at 0.04 per cent of the feed. The specific needs of other animals are unknown. Since most of the commonly fed roughages and concentrates contain at least 0.1 per cent of magnesium and many have three to four times this figure, deficiencies under the usual conditions of feeding practice seem unlikely.

Magnesium is recognized to be concerned in several specific body functions. It activates the enzyme, phosphatase, and it plays a role in carbohydrate metabolism. The element is essential for the proper formation of both the teeth and their supporting structures. It has been ascribed a helpful role in rickets by

1 Sjollema, B., On the nature and therapy of grass staggers, Vet. Record, n.s., 10, 425-431, 450-453, 1930.

${ }^{2}$ Hufrman, C. F., C. L. Conley, C. C. Lightfoot, and C. W. Duncan, Magnesium studies in calves. II. The effect of magnesium salts and various natural feeds upon the magnesium content of the blood plasma, J. Nutrition, 22, 609-20, 1941. 
some investigators and a harmful role by others. There is a possibility that it exerts a variable effect here, depending upon the level fed and the accompanying calcium and phosphorus relations.

120. Calcium and Magnesium Interrelationships.-In the nutrition of farm animals, much attention has been given to the question of the possible deleterious effects of excessive magnesium intakes in view of its high level in certain waters and in relation to the use of dolomitic limestone as a calcium supplement. Early observations that the injection of magnesium salts exerted certain inhibitory effects on body functions were extended by Loeb and especially by Meltzer and Auer ${ }^{1}$ in showing that calcium antagonized these inhibitory effects. A year later Mendel and Benedict ${ }^{2}$ reported that injecting calcium increased the urinary output of magnesium and, more important, that the injection of magnesium caused large urinary losses of calcium as an accompaniment of the pathological symptoms. Later workers found that magnesium interfered with calcification in vitro, an effect which was overcome by adding phosphorus. These various observations naturally raised the question as to whether a high dietary intake of magnesium had a deleterious effect on calcium assimilation, and some positive evidence for this view was suggested by early work.

It has become apparent, however, from several carefully controlled studies with different species that, when the magnesium is ingested instead of injected, there is a much smaller loss of calcium or no loss at all, due to a selective absorption which prevents most of the magnesium from entering the blood stream. It also appears that the extent of the absorption and thus of the deleterious effect on calcium retention is governed by the amount of calcium and phosphorus, particularly the latter, in the ration. When these two elements are present in liberal amounts the harmful effect of the magnesium is slight or nil. Palmer, Eckles, and Schutte ${ }^{3}$ for example, have shown that the ingestion of magnesium sulfate by cattle on a low-phosphorus diet results in serious and

${ }^{1}$ Meltzer, S. J., and J. Auer, The antagonistic action of calcium upon the inhibitory effect of magnesium, Am. J. Physiol., 21, 400-419, 1908.

${ }^{2}$ Mendel, Lafayette B., and S. R. Benedict, The paths of excretion for inorganic compounds. IV. The excretion of magnesium; V. The excretion of calcium, Am. J. Physiol., 25, 1-22, 23-33, 1909.

${ }^{3}$ Palmer, L. S., C. H. Eckles, and D. J. Schutte, Magnesium sulfate as a factor in the retention of calcium and phosphorus in cattle, Proc. Soc. Exptl. Biol. Med., 26, 58-62, 1928. 
continuous losses of calcium which are overcome by increasing the phosphorus content of the ration.

Experiments with pigs, chickens, and rats, using rations liberal in phosphorus, have shown that dolomitic limestone is a satisfactory source of calcium for bone formation despite its magnesium content. Thus it appears that, provided both calcium and phosphorus are plentifully supplied, the ingestion of at least a moderate excess of magnesium, either in a mineral supplement or in water or other foods, will not markedly disturb calcium retention, though it may tend to increase the requirements for calcium and phosphorus in the ration. Further studies of this question may be worth while, and certainly it should be remembered that a magnesian limestone is of value as a calcium supplement only in proportion to its content of this element and that magnesium is at best simply inert material.

Further evidence of the interrelationship between calcium and magnesium is presented by Tufts and Greenberg ${ }^{1}$ who showed that a larger amount of magnesium is required to prevent the symptoms of deficiency of this element as the calcium intake is increased.

\section{SODIUM, POTASSIUM, AND CHLORINE}

In contrast to the minerals previously discussed which are found principally in the bones, sodium, potassium, and chlorine occur almost entirely in the fluids and soft tissues of the body, where they serve to maintain osmotic pressure and acid-base equilibrium and where they play important roles in water metabolism.

121. Sodium. - The body contains approximately 0.2 per cent of sodium. It occurs primarily in the extracellular fluids, in contrast to potassium, which is found largely within the cells. Sodium makes up 93 per cent of the bases of blood serum, and thus it is the predominant basic element, concerned in neutrality regulation. The element seems to be absent from blood cells, but it does oceur in considerable amounts in the muscles, where it is associated in some unknown way with their contraction. The need for sodium becomes readily evident in the retarded growth that results on diets low in the element. A lack of sodium also lowers the utiliza-

1 Tunts, Elama V., and 1) magnesium deficiency, Proc. Soc. Exptl. Biol. Med., 34, 292-294, 1936. 
tion of digested protein and energy and prevents reproduction. In laying hens, a deficiency results in lowered production, loss of weight, and cannibalism.

Sodium salts are readily absorbed and circulate throughout the entire body. Since the element is not stored appreciably, any excess intake is rapidly excreted. Normally over 90 per cent of the excretion takes place through the kidneys as chlorides and phosphates. There is some loss in the perspiration, which, at hard work, particularly in warm weather, may represent by far the major portion of the total excretion.

122. Potassium.- In contrast to sodium, the potassium of the body exists primarily as a cellular constituent. Human-blood cells, for example, contain over twenty times as much of the element as does the plasma. Potassium plays a vital but little understood role in muscle where its content is six times that of sodium. While blood plasma contains many times as much sodium as potassium, in milk the reverse is true. The reason for the very different distribution throughout the body of these two elements which are so closely related chemically is a mystery.

Though it can be readily demonstrated by growth and reproduction experiments that potassium is an essential mineral, all foods, particularly plant products, are so rich in it that there is never any deficiency in the diet. The element, like sodium, is readily absorbed and the excess over body needs is immediately excreted. This excretion normally takes place in the urine to the extent of 90 per cent, but profuse sweating diverts a large portion through this channel.

Sodium-potassium Ratio.- The fact that plant products contain many times as much potassium as of sodium early raised the question as to the significance of the sodium-potassium ratio in the diet. In 1873 Bunge, ${ }^{1}$ on the basis of rather meager data, evolved the theory that an excessive intake of potassium impoverished the organism of sodium and chlorine. This theory was extended to explain the apparently larger requirement of Herbivora

1 Gustave von Bunge (1844-1920), trained both in chemistry and in medicine, had a long and outstanding career as a teacher and investigator, serving for many years as professor of physiological chemistry at Basel. He made many contributions to the knowledge of the nutrition of minerals, notably iron, and wrote a textbook, "Physiologie des Menschen," which contains a wealth of information for the modern student. 
than of other species for common salt, as being due to the great excess of potassium relative to sodium in leafy materials. Pasture grass, for example, may contain eighteen times as much potassium as sodium. This attractive theory, which has continued to receive attention, has been supported by the results of some of the later studies, while, in others, the findings have been entirely negative. The more reliable evidence indicates that, though a high-potassium intake may result in an initial increased excretion of sodium from the body, some adjustment rapidly occurs whereby this increased loss is stopped. Experiments with cows given free access to salt have not shown any relation between the amount of salt eaten and the variations in the potassium intake.

123. Chlorine.-Differing from sodium and potassium, chlorine is found in large concentrations both within and without the cells of the body tissues. Blood cells contain about one-half as much as the plasma. Approximately 15 to 20 per cent of the chlorine of the body appears to be in organic combination. The chlorides of the blood, principally sodium chloride, make up two-thirds of its acidic ions. This indicates their large role in acid-base relations. The gastric secretion contains chlorine as free acid and in the form of salts. The body has a certain capacity to store chlorine in the skin and subcutaneous tissues. Its excretion follows that of sodium and potassium.

124. The Use of Common Salt.-The age-old practice of including common salt in the diets of both man and animals means that most of the sodium and chlorine is both ingested and excreted in this form. Since salt serves as a condiment as well as a nutrient, the intake tends to be highly variable and frequently in excess of needs. Its use as a condiment has physiological support in evidence that it stimulates salivary secretion and promotes the action of diastatic enzymes. When the intake is at a minimum, the body makes an adjustment whereby the output of sodium and chlorine in the urine nearly ceases. The same is true for potassium. In contrast, large intakes involve a correspondingly large excretion, the water requirement being increased accordingly. The kidney is the regulating organ which, through its secretory acitivity, controls the concentration of electrolytes in the blood.

In 1905 Babcock ${ }^{1}$ reported a long-time study of the role of salt

1 Bancock, S. M., 'The addition of salt to the ration of dairy cows, $W$ is. Agr. Expt. Sta. Ann. Rept. 22, $129-156,1905$. 
in the dairy ration. He found that cows receiving no salt exhibited an abnormal appetite for it after two or three weeks but that a much longer time elapsed, even a year, before any ill effect on health was noted. Eventually there was a loss of appetite, an unthrifty condition, and a marked decline in weight and milk yield. These symptoms appeared first in the higher producers, and the breakdown most frequently occurred at calving or shortly after at the height of milk flow. The feeding of salt produced rapid recoveries in animals showing acute symptoms. The long period which elapsed before health was affected by salt deprivation illustrates the ability of the body to husband its supply of sodium and chlorine, reducing their excretion to a minimum, when the intakes are very small. Babcock expressed the view that dry cows and steers would suffer no great inconvenience if given no salt except that contained in a normal ration. In such a case, however, their feed consumption would probably decline.

The human kidney may excrete as little as $1 \mathrm{~g}$. or as much as $40 \mathrm{~g}$. of sodium chloride per day depending on the intake. Given normal kidneys and an appropriate water intake, large amounts can be excreted without harm. Excessive intakes, however, result in water retention in the body causing edema. Among farm animals, chickens have been considered to have a low tolerance for salt, yet Mitchell and coworkers ${ }^{1}$ found that they could be reared from nine to twenty-one weeks of age on rations containing 8 per cent of salt. Farm animals have died, however, from consuming salt when given free access to it following a long period of salt deprivation or partial starvation. The tolerance of the animal body for potassium is apparently somewhat less than for sodium.

The salt requirement is greatly increased under conditions which cause heavy sweating because of the large loss in this secretion. Miners have been noted to lose $2 \frac{1}{2} \mathrm{~kg}$. of sweat per hour, containing $2 \mathrm{~g}$. of sodium chloride. If large amounts of water are drunk under these conditions, cramps result. The cramps disappear on drinking water containing salt. On a low-salt diet, however, the body gradually makes an adjustment whereby the concentration in the sweat, as well as in the urine, is gradually decreased. Equilibrium between intake and outgo is thus established at a much lower level than is possible initially.

${ }^{1}$ Mitchell, H. H., L. E. Card, and G. G. Carman, The toxicity of salt for chickens, Ill. Agr. Expt. Sta. Bull. 279, 1926. 


\section{IRON}

Although the body contains only about 0.004 per cent of iron, this element plays a central role in life processes. As a constituent of the respiratory pigment, hemoglobin, iron is essential for the functioning of every organ and tissue of the body. It occurs as an iron-porphyrin nucleus, known as hematin, not only in hemoglobin but also in proteins that are components of cytochrome, peroxidase, and catalase. Thus, iron is a constituent of oxygen carriers and of oxidizing catalysts or enzymes. Most of the iron present in the body is in the form of hemoglobin. In addition to small amounts in other active forms distributed throughout the body, a variable store is located in the liver and, secondarily, in the spleen and kidneys. Since the red cells and their hemoglobin are constantly being destroyed and replaced, iron obviously undergoes a very active metabolism. Its synthesis into hemoglobin occurs throughout life as well as during the growing period when the total blood supply is being augmented.

125. Hemoglobin Formation.-The blood cells which contain the hemoglobin are formed in the bone marrow. It is considered that these red corpuscles are destroyed after an average life of four to six weeks. In the course of their destruction, the hematin of the hemoglobin is split into an iron compound and bilirubin and other pigments which are carried to the liver and secreted in the bile. Iron released by the normal blood-cell destruction can be used again to form hemoglobin, practically without loss. In certain diseases, however, this destruction may be accelerated and iron formed by toxic destruction cannot be reutilized. If the cells are not renewed so rapidly as destroyed, or, if the increase in the number of cells which are required to enlarge the blood supply with growth does not occur, ancmia results. The condition of the blood in this respect is commonly determined by measuring its hemoglobin content. The normal content of hemoglobin for most mammals lies within the range, 10 to $15 \mathrm{~g}$. per $100 \mathrm{ml}$. of blood. In severe anemia the value may drop to one-half or even one-third of the normal.

The physiologist distinguishes several different types of anemia. The importance of iron as a factor varies with the type. In pernicious anemia, also called primary anemia, there is no lack of iron or failure of hemoglobin formation but rather a lack of an 
organic substance essential to stimulate the production of the red corpuscles. The active substance is present in liver and thus pernicious anemia sufferers can be kept alive by the consumption of liver or of liver extract, but no real cure results, for the substance must be supplied constantly. An extract of stomach tissue is also effective and a combination of liver and stomach extracts is more effective than liver alone. In pernicious anemia there is a lack of hydrochloric acid in the gastric juice, and a gastric disturbance is considered a primary cause of the trouble. For their discoveries leading to this knowledge of the cause and treatment of pernicious anemia, which previously proved fatal to man in about three years, Whipple, Minot, and Murphy received the Nobel prize in medicine. This type of anemia is not known to occur in farm animals.

Secondary anemias are due to a loss of blood as in hemorrhage, or to accelerated blood destruction in various diseases. Both mineral and organic factors are concerned in blood regeneration in these anemias. They can be cured only by eliminating the cause. There are also hereditary anemias, such as "sickle-cell anemia" in man, and other types identified in animals.

126. Nutritional Anemia.-While nutrition is concerned in the treatment of the previously described anemias, the term nutritional anemia refers to those caused primarily by a lack of a specific nutrient. Iron is the nutrient most commonly involved, but anemia also results from a deficiency of copper and of certain vitamins, as is discussed later. Iron-deficiency anemia may occur at any time of life when the available supply of the mineral becomes deficient relative to the needs for hemoglobin formation. It is particularly likely to develop in certain species during the suckling period, since milk is very low in iron. Our knowledge of iron nutrition during this period is due particularly to the early work of Bunge and Abderhalden. A comparison of the mineral constituents of milk and of the newborn showed that, while the other constituents were in similar concentrations, the percentage of iron in the milk ash was only one-sixth of the figure for the iron in the ash of the newborn. It was also found that there was a much larger percentage of iron present at birth than later in life. The explanation was therefore made that nature provides for the iron requirements of the suckling largely by means of a store in its body at birth which may be drawn upon for blood formation 
and other essential functions during the period when milk is normally the principal or sole food. Bunge found that the guinea pig, which normally commences to eat leafy material within a day after birth, is born without any special store of iron.

This provision of nature for iron nutrition in the suckling does not always prove adequate. The store in the newborn is influenced by the diet of the mother during gestation. If the birth occurs prematurely there is a smaller store because most of the storage occurs late in gestation. If the number of young born is larger than usual for the species, for example, twins in humans and extra large litters in hogs, the individual's supply tends to be smaller. Even if the store is normal, a long nursing period without supplementary iron-rich food may exhaust it. The reserve of the human young is usually exhausted before the end of the sixth month. These factors are responsible for many cases of nutritional anemia in babies. In farm animals, the trouble occurs as a practical problem only in the case of pigs. In both species the anemia can be prevented by the feeding of iron and a trace of copper to the sucklings. It does no good to feed the mineral to the lactating mother, for the iron content of milk cannot be increased in this way. A detailed description of this anemia in suckling pigs and its treatment is given later (Sec. 299).

While anemia has been produced experimentally in lambs and calves by restricting them to a milk diet, in practice the disease is not met in them because they early begin to eat supplementary food which supplies the needed iron. Iron-deficiency anemia can occur beyond the suckling stage, at any time of life when the supply of iron in the food is inadequate to meet the needs for hemoglobin formation. These needs are greatly enlarged during gestation and egg production. In the case of farm animals, however, the commonly fed rations are so rich in iron that the deficiency troubles do not occur except in very special situations. Such a situation exists in Florida where the soil is very poor in both iron and copper. Cattle receiving a ration consisting mostly or entirely of grass forages grown on this soil become anemic but respond to the iron and copper treatment. Anemia has been reported in range animals in certain other parts of the world, but further proof is needed that a lack of iron is the sole cause. In these same Florida areas anemia has been reported to occur in 
the human population as a result of a low content of iron in the foods grown on the iron-low soils.

Recent work has emphasized the ability of the body to store iron in excess of current needs when the food is rich in the element. The color of the blood and specifically its hemoglobin content are measures of the state of iron nutrition. The anemia caused by iron deficiency is of the microcytic hypochromic type, i.e., the cells are subnormal in size and hemoglobin content. Thus this anemia is readily differentiated from the macrocytic hyperchromic type which responds to "folic acid" (Sec. 196).

127. The Iron Value of Foods.-Aside from milk, most of the feeds for animals contain very liberal amounts of iron relative to the need by the body. Leafy materials are rich sources and so are many seeds. Since most of the iron in cereal seeds is in the outer coatings and germ, milling results in increasing the supply to animals, but in decreasing it in so far as man is concerned. The availability of iron differs according to its food source.

Many of the determinations of available iron have been made by the use of $a, \alpha$-dipyridyl reagent that reacts only with ionized iron. Using this method, hematin iron has been found completely unavailable in contrast to the high availability of the iron of inorganic salts. The iron of seeds, especially legumes, appears to be more available than that of leafy materials. Many other foods have been thus classified. Biological methods, however, which use hemoglobin regeneration as the measure, have frequently failed to check the results of the chemical procedure. Thus, until further studies are made, quantitative statements as to the relative value of the iron in different foods seems of questionable value. A biological finding of special interest is that the presence of phytic acid in a food interferes with the absorption of iron because of its precipitation as phytate.

In so far as farm animals, including chickens, are concerned, their usual rations are so rich in iron that they can normally be counted upon to supply enough even though its availability is low. Aside from the special situations previously referred to, the addition of iron salts to the rations of various species has failed to result in any evident benefit, and a marked excess may be definitely deleterious. Too much iron in the diet interferes with phosphorus absorption by forming an insoluble phosphate and rickets may thus result on a diet otherwise adequate. 


\section{COPPER}

As a result of a series of studies beginning in 1925, Hart and associates at the University of Wisconsin discovered that a small amount of copper is necessary, along with iron, for hemoglobin formation. It is not a constituent of hemoglobin, but it does occur as hemocuprin in blood cells. In certain invertebrates copper is present in hemocyanin that functions as an oxygen carrier. A store of copper is normally present in the liver and spleen.

128. Specific Functions of Copper.-The role of copper in hemoglobin formation is incompletely understood. In its absence, dietary iron is absorbed and deposited in the liver and elsewhere, but normal blood regeneration does not occur, and anemia results. When copper is added to the diet, hemoglobin synthesis is resumed. It is quite probable that its role in blood formation is secondary to its effects on cells, in general, as a component of enzyme complexes. As such, it functions in oxidation-reduction systems. For example, it is a constituent of the cytochrome oxidase of heart and liver tissues and of ascorbic acid oxidase.

129. Copper Deficiencies as Area Problems.-More than a decade before the role of copper in hemoglobin formation was discovered, investigators in northern Europe were studying possible mineral deficiencies in the forage in areas where a wasting disease of cattle, called lechsucht, was common. In 1933 Sjollema established its cause as a copper deficiency by finding marked differences in the copper content of the forage in "healthy" and "sick" areas and by curing the trouble with copper therapy. Recently Sjollema has shown that in affected cows and goats the copper content of the blood falls to one-third of the normal concentration of $100 \mu \mathrm{g}$. per cent. The copper content of the liver, spleen, and hair was also decreased. It has also been established that a disease of lambs, referred to as enzootic alaxia or "swayback," and by other names, and characterized by nervous symptoms, is caused by a deficiency of copper. The disease has been reported from several countries, and its prevention has been accomplished by feeding copper to the pregnant ewe. A chronic copper deficiency resulting from a low content in the herbage has also been reported responsible for a trouble in grazing cattle in Australia, known as "falling disease." This disease is characterized by staggering, falling, and instantaneous death. 
It is apparent that these various troubles have certain symptoms in common and others that differ. Further study of the dietary relationships and specific pathology of each is needed. It is quite possible that more than one deficiency is involved in some cases. Marked success has been achieved, however, in lessening the incidence of all of them by the feeding of copper salts and also by fertilization of the soil with this mineral. The occurrence of these various troubles has been reviewed by Underwood. ${ }^{1}$ Papers reporting detailed studies of each are listed at the end of this chapter. It is evident that they reflect a role of copper which is much more basic than its function in blood regeneration. Surprisingly, anemia is not stressed as a characteristic of these diseases.

Similar troubles have not been reported in the United States, although there is evidence, based upon the response of anemic animals, that a copper deficiency occurs in certain areas, notably in Florida.

130. Requirements and Feed Supply.-On the basis of studies with men, dogs, and rats, the copper requirement for the prevention of anemia is considered to be about one-tenth that of iron. Such an intake provides the amount of copper that is needed along with iron to prevent anemia in suckling pigs (Sec. 299). The studies of the copper content of the herbage in "healthy" and "sick" areas suggest that a level of 7.5 p.p.m. is adequate. An intake of $5 \mathrm{mg}$. of copper daily for pregnant ewes to prevent troubles in their lambs has been suggested. A comparison of the data for copper content of the commonly fed concentrates and roughages with the estimated needs, as set forth above, clearly suggests that rations satisfactory in other respects should provide an adequate supply. A need for a copper supplement is not indicated except in the special-area situations discussed. Further studies are called for, however, to ascertain whether these severe area symptoms reflect a deficiency that is actually much more widespread in a form too mild to be definitely recognized. More specific information on copper requirements is needed, particularly since high intakes are toxic.

${ }^{1}$ Underwood, E. J., The significance of the "trace elements" in nutrition, Nutrition Abstracts \& Revs., 9, 515-534, 1940. 


\section{COBALT}

Cobalt is the latest addition to the list of mineral elements that are recognized to be essential for animal growth and health. The knowledge of its essential role developed as a result of long-time studies of certain peculiar wasting diseases of grazing animals, known by different names in different areas throughout the world, but having similar symptoms that suggested a common cause. Each disease was early recognized to be limited to certain areas of the country in question, and prevention and cure by transferring the animals from "sick" to "healthy" areas was successfully practiced long before anything definite was known about the cause. The discovery of a lack of cobalt, resulting from its deficiency in the soil and thus in the herbage grazed, was reported independently in 1935 by Filmer and Underwood and by Marston and Lines, working in Australia. The history of the various area troubles and of the experimental studies carried out to establish their cause have been reviewed by Marston ${ }^{1}$ and by Underwood. ${ }^{2}$

Following the reports from Australia, cobalt-deficient areas were established in Florida, Western Canada, Michigan, Wisconsin, and New Hampshire. Papers reporting some of these studies are cited at the end of this chapter. Other areas are suspected. According to the reports from Canada and New Hampshire, cobalt deficiency can occur on dry, winter rations as well as on pasture. Sheep and cattle are the only animals thus far found to be affected.

131. Symptoms of Cobalt Deficiency.-The symptoms are similar to those of general malnutrition. The animals become listless, lose appetite and weight, become weak and anemic, and finally die. A depraved appetite is frequently noted. While post-mortem examinations reveal a low cobalt content in various organs compared to the normal, response to cobalt feeding is the only clear evidence in the live animal that a lack of the element is the cause of the physical symptoms noted. In fact, some of the reports of cobalt deficiency are unconvincing because the troubles occurred on rations obviously deficient in other respects and because other nutrients were used along with cobalt to bring about

1 Marston, Hedley R., Ruminant nutrition, Ann. Rev. Biochem., 8, $557-573,1939$.

2 UNDERWOOD, E. J., loc. cit. 
a "cure." Seasonal occurrences of the symptoms and spontaneous recoveries also complicate the picture.

Attempts to produce the deficiency experimentally with diets adequate in all other respects have failed. Extensive attempts have been made with rats, guinea pigs, and rabbits. The latter species, for example, has grown satisfactorily for a year without deficiency symptoms on a diet containing less than one-fifth the concentration of cobalt required to maintain health in a sheep. Clearly, there are marked differences in quantitative requirements among species. In fact, it has been suggested, but without any adequate proof, that a need for cobalt is limited to ruminants. Certainly our knowledge of the functions of cobalt, of the specific signs of its deficiency, and of the extent of the occurrence of the trouble uncomplicated by other deficiencies would be greatly advanced by studies of the experimentally produced disease.

132. Cobalt Requirements and Content in Feeds.-The evidence as to the quantitative needs for cobalt rests on studies of its content in the herbage where troubles occur. It has been reported that the dry matter of grass of healthy areas contains around 0.1 p.p.m. of cobalt on the average compared with figures from 0.04-0.07 p.p.m. for "sick" areas. Assuming that 0.1 p.p.m. may be considered as the requirement, this would indicate a daily intake of approximately $0.1 \mathrm{mg}$. per $100 \mathrm{lb}$. body weight. Such a minute intake as this has actually restored sick animals to health.

Aside from the pasture grass and roughages produced in the areas where cobalt deficiency has been definitely identified, feeds in general appear to contain more than the 0.1 p.p.m. of cobalt that is considered essential. This is not true, however, in the case of milk and certain samples of corn and possibly other grains. Analytical data obtained by reliable methods are far too few to provide any adequate picture of the cobalt content of our feed supplies. Further studies are urgently needed both of the roughages and concentrates grown in different areas because the soilcrop relationship is a direct one. Further studies are also needed to ascertain whether cobalt-deficiency troubles occur more widely than is indicated by the specific areas identified. In these areas more critical studies are needed as to the extent of the troubles and of other deficiencies that may, be contributing factors. In the meantime, when the general symptoms for which cobalt de- 
ficiency may be responsible occur, the feeding of a cobalt salt is indicated, along with any other measures needed to make the ration complete in all respects. There seems to be no justification, on the basis of present evidence, for the addition of cobalt supplements to rations generally where no need has been demonstrated.

\section{IODINE}

The mature animal body is estimated to contain less than 0.00004 per cent of iodine, but, if this minute amount is not maintained through the food, disaster results. More than half of this iodine is in the thyroid gland, and it is in connection with the functioning of this gland that the body's need for iodine occurs.

133. The Thyroid Gland.-This gland consists of two parts lying on each side of the trachea at its upper end. In the case of an adult man it weighs about $1 \mathrm{oz}$. It produces an internal secretion which contains the hormone thyroxine, isolated by Kendall in 1914 as a crystalline product containing about 65 per cent of iodine. Thyroxine is an iodine-containing amino acid present as the protein, thyroglobulin. Diiodotyrosine is also present in the gland. The removal of the thyroid early in life results in all species in a stunting of physical, mental, and sexual development. In adult animals the hair and skin show premature aging, and mental and physical sluggishness may develop. In all cases there is a lowered basal metabolism (Sec. 247). It is probable that the primary function of the thyroid gland is to control the metabolic rate through the output of its hormone and that the more evident effects of thyroid deficiency are a result of a failure of this control. Most of the iodine that occurs in the tissues and fluids of the body other than the thyroid is probably in thyroxine serving its function in the control of metabolism.

Goiter is an enlargement of the thyroid gland. Medical men recognize two types: simple or endemic goiter which is caused primarily by a lack of iodine, and exophthalmic goiter which involves other structures of the body besides the thyroid gland. Simple goiter is much the more common type, and it is the one with which we are concerned in nutrition. It develops as a result of a failure of the thyroid tissue to supply enough secretion, owing either to a reduced supply of iodine for its manufacture or to an increased demand for the secretion by the body. It is a compensatory hypertrophy, that is, an enlargement involving the 
formation of more tissue in an effort to supply more secretion. The demand for thyroxine varies in accordance with the activity of the body functions it controls, and thus, given a fairly constant supply of iodine in the diet, simple goiter is most likely to develop during periods of greatly increased need.. In the human these critical periods are pregnancy and puberty. In farm animals, however, goiter usually shows itself in the young at birth as a result of a deficiency of iodine in the rations of the mother during gestation. The young thus affected are born weak or dead (Fig. 14). On a deficient diet the mother is not able to supply the

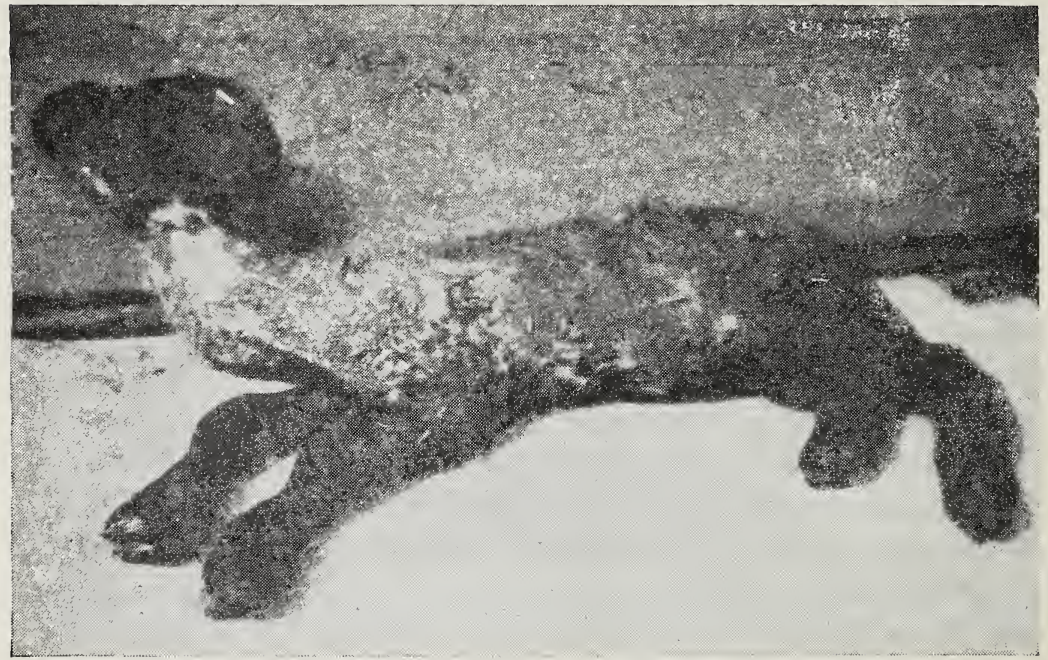

FIg 14.-Goiter in a newborn lamb. (Courtesy of C. C. Culbertson of the Iowa Experiment Station.)

fetus with enough iodine. The danger is thus increased in the case of multiple births.

In calves, lambs, and kids the enlargement of the gland is very evident in the newborn. In pigs the most outstanding symptom of the deficiency is hairlessness. They are bloated and have thick skins and puffy necks. In foals the only symptom may be extreme weakness at birth, resulting in an inability to stand and suck. A limited amount of data indicates that "navel ill" in foals may be lessened by feeding iodine to brood mares, but further evidence is required. Birds and fish as well as mammals have enlarged thyroids as a result of iodine deficiency. Animals born alive with a well-developed goitrous condition usually fail to survive or 
remain weaklings. No treatment has been found particularly effective. Studies of goiter troubles in humans have clearly established that, while iodine is effective as a preventive, it may be harmful rather than beneficial as a treatment after the goiter has developed. While the nutritionist is concerned with prevention, treatment belongs entirely to the field of medicine.

Though a lack of iodine is the primary cause of simple goiter, it is recognized that other factors may contribute, notably the high-calcium content of the water in many goitrous regions. In addition, it is recognized that there may be specific goitrogenic and antigoitrogenic substances in certain foods. Thus, cabbage has been considered to promote goiter production in man and there is evidence, as produced especially by Wilgus and associates, ${ }^{1}$ that soybean meal has a similar effect in poultry, stepping up the iodine requirement accordingly. On the other hand, certain foods have been classed as antigoitrogenic, and certain specific substances, such as thiourea and thiouracil, are known to lower thyroid activity.

134. Iodine Deficiency an Area Problem.-The need for additional iodine in the rations of farm animals, as well as of humans, exists primarily in certain areas where the soil and thus the water and food crops are low in this element. There are various regions throughout the world where goiter troubles of varying degrees are very common in all species unless additional iodine is fed, and there are others where the trouble is entirely unknown. In the United States, the goiter areas are primarily in the Northwest and in the Great Lake region. It is estimated that, before iodine feeding was practiced in Montana, goiter caused an annual loss of many thousand pigs. Records from other areas show that serious losses in the sheep and cattle industries occurred which were largely prevented following the discovery of the lack of iodine as the causative factor. There are borderline regions in which goiter occurs only occasionally. When the usual iodine intake is little above the minimum requirement, an enlarged physiological demand by an individual may be responsible for the occasional troubles. A barely sufficient intake may be changed to an inadequate one by a change in the make-up of the ration.

Hundreds of years before iodine was discovered, people living

1 Wugus, H. S., Jr., and associates, The goitrogenicity of soybeatns, $J$. Nutrition, 22, 43-52, 1941. 
in goitrous areas learned the usefulness of certain products, now known to be rich in iodine, as a preventive of goiter. The value of sea salt in comparison with certain inland deposits was early recognized. Our real understanding of the problem is very recent as indicated by the fact that the discovery by Baumann of iodine in the thyroid gland was not made until 1896.

135. Iodine Requirements.-We do not have specific knowledge of the minimum iodine requirements of the various species, but we do know the levels that are at least high enough to prevent goiter. Since goiter troubles in farm animals are associated primarily with reproduction, their specific needs for iodine are discussed in Chap. XIV. Although it appears that these needs must be greatest during reproduction, iodine is obviously required throughout life to keep the thyroid gland functioning normally. The appearance of goiter may result as an advanced stage of deficiency. On this basis the continued feeding of an additional supply might be considered desirable in areas of severe iodine deficiency. There is some evidence from certain areas that additional iodine improves growth in various species, but this evidence is not entirely convincing. It has also been reported that, with sows fed in dry lot in an area, borderline with respect to the occurrence of goiter, additional iodine lessens the number of pigs dead at birth or which die in the first week, although there was little physical evidence of iodine deficiency. Recommendations for year-round feeding are usually put on an insurance basis or are suggested as the simplest way of making certain that the needs of breeding stock are taken care of in areas where goiter is very common. In an extensive experiment as to the value of iodine for livestock in central Pennsylvania, Forbes and coworkers ${ }^{1}$ found no beneficial effects on the growth of dairy calves, lambs, pigs, or chickens, or on the incidence of abortion in dairy cattle or on egg production in pullets.

136. Iodine Supplements.-Where the occurrence of goiter shows that attention to iodine nutrition is needed, the most practical method is the use of some special source such as iodized salt or sodium or potassium iodide. None of the common feedstuffs, with the exception of fish meal made from saltwater fish, can be

${ }^{1}$ Forbes, E. B., G. M. Karns, S. I. Bechdel, P. S. Williams, T. B. Keith, E. W. Callenbach, and R. R. Murphy, The value of iodine for livestock in central Pennsylvania, J. Agr. Research, 45, 111-128, 1932. 
relied upon to be rich in iodine. Dried kelp, a sea plant, is rich in the element, and so is cod-liver oil. While special advantages are sometimes claimed for organic sources of iodine, the preponderance of the evidence indicates that the cheaper inorganic iodides are equally satisfactory. When massive doses of iodine are given as a therapeutic agent, an organic source has the advantage of slower absorption and less risk of harm from overdosage, but, in the amounts needed to prevent goiter, this is not a factor. Iodized salt loses its iodine rather readily under certain conditions because of the catalytic action of impurities present. Thus, after storage it may be an unreliable source of iodine unless stabilized. Processes have recently been developed for accomplishing this stabilization. Iodized salt in mixed feeds is less subject to deterioration because the presence of proteins and unsaturated fats tends to stabilize the iodine.

Any required addition of iodine need not be supplied every day, because the thyroid has a considerable capacity to store the element. This is illustrated by the fact that goiter has been prevented in children in goitrous areas by feeding sodium iodide periodically for a month and repeating twice yearly.

137. Iodized Milk and Iodized Eggs.-Large intakes of iodine by the dairy cow result in an increased content in the milk, and the same is true for the hen in egg production. It has been proposed that special sources of iodine should be fed to cows and hens in order to produce iodized milk and eggs for human consumption for the prevention of goiter. This is not a new idea, for the textbook of Gorup-Besanez published in 1878 records the feeding of iodine to llamas in South America and the use of the iodine-containing milk as medicine. Such a practice does not seem desirable today from either the human or animal standpoint. The iodine secreted in milk and eggs is no more effective than iodized salt. Only a small and variable percentage of the iodine fed to the animal appears in the product, and thus this method of providing it to those who need it is more expensive and much less certain as regards the amount supplied than is direct administration. Medical authorities agree that the fortification of foods other than salt with iodine is unnecessary and may endanger public health. As far as the animals are concerned, the continuous feeding of the rather large intakes of iodine required to result in a 
substantial enrichment in their products is a practice which may result in definite harm, for the danger of overdosage is a real one. For example, an intake of $0.05 \mathrm{gm}$. of potassium iodide daily has been shown to depress weight and cause irregularities of reproduction in ewes.

\section{SULFUR}

The body contains approximately 0.15 per cent of sulfur. This element occurs almost entirely in organic compounds, notably in proteins in which it is present as the sulfur-containing amino acids, eystine and methionine. Wool contains approximately 4 per cent of sulfur. The element occurs also in a number of special compounds such as glutathione (Sec. 87) and others. All of these compounds are doubtless derived from proteins or the sulfurcontaining amino acids. This fact indicates that meeting the sulfur needs of the body is primarily a matter of amino-acid nutrition. Since hair and wool are rich in sulfur-containing proteins, the influence of cystine and other sulfur compounds, as supplements to commonly fed rations, has been studied from the standpoint of the growth of these epidermal tissues, with generally negative results (Sec. 289). Free sulfur or inorganic sulfate in the diet has little if any value in nutrition, and excessive intakes of the free form are definitely toxic. The blood contains small amounts of sulfates. Thiocyanate ions are also present in blood, as well as in saliva and other secretions. An interesting study of sulfur balance in the hen has been reported by Holman and associates. ${ }^{1}$

Both the feces and urine are paths of sulfur excretion. In the urine three forms occur: inorganic sulfates, the principal fraction, which represent the final stage of oxidation of organic sulfur; ethereal sulfur which is present in complex detoxication products; and neutral sulfur which occurs as cystine, taurine, thiosulfates, and other compounds. Since excreted sulfur arises primarily from protein catabolism, there is a rather constant ratio between it and the nitrogen in the urine. There is evidence that the excretion of neutral sulfur is proportional to the basal metabolism.

${ }^{1}$ Holman, Ralph T., M. Wight Taylor, and Walter C. Russell, The sulfur balance of the nonlaying, molting and laying hen, J. Nutrition, 29, 277-282, 1945. 


\section{MANGANESE}

Manganese occurs in the body. principally in the liver, but it is also present in appreciable amounts in various other organs and in the skin, muscle, and bones. Despite the very small total supply in the body, this element has several essential functions and its consideration is of practical importance in animal nutrition.

138. Functions in Grow.th and Reproduction.-The identification of manganese as an essential element resulted initially from studies by Orent and McCollum with rats, which revealed its role in reproduction. On a manganese-low diet, sexual maturity is delayed, and ovulation is irregular. If conception occurs, the young are born weak or dead and their bodies contain less than half as much manganese as those born from mothers normally fed. In the male a diet devoid of the element causes a degeneration of the germinal epithelium. It has been shown experimentally that reproduction in pigs is interfered with on a manganese-low diet. Such a diet also results in a slower rate of growth in laboratory animals, chickens, and perhaps others.

139. Manganese and Bone Development.--In 1935 Wilgus and associates reported evidence that manganese is markedly effective in reducing the incidence of perosis, or "slipped tendon," a. malformation of the leg bones of growing chicks, thus providing the first specific information regarding the prevention of a long-known and serious trouble in practice. Their work was confirmed by others, and further studies showed that a shortening of the leg bones was involved. Definite changes in the physical and chemical structure of the bones were noted. Manganese did not always prove 100 per cent effective, however, and support was thus furnished for an earlier view that some organic factor was also involved. In 1940 clear evidence was produced that choline, in addition to manganese, is necessary to prevent perosis in birds. Just how choline acts is not clear, but its action has no apparent connection with its role in fat metabolism (Sec. 63). It appears from present studies that biotin deficiency is also concerned (Sec. 191). The high calcium and phosphorus rations normally fed to poultry are a contributing cause of the occurrence of perosis. They also aggravate the effect of a low manganese intake on growth.

Bone malformations, grossly most evident as crooked front legs, have also been produced in rabbits by feeding a diet low in man- 
ganese, (as are illustrated in Fig. 15. ) The humeri are shorter than normal and lower in ash, density, and in breaking strength. There are also marked histological changes. Reports have also been published attributing the occurrence of lameness and crooked legs in pigs to a manganese-deficient ration, but in view of other work, it appears that further studies are needed with this species before definite conclusions can be drawn. In the studies where the crooked legs were noted, the ration was high in calcium and phos-

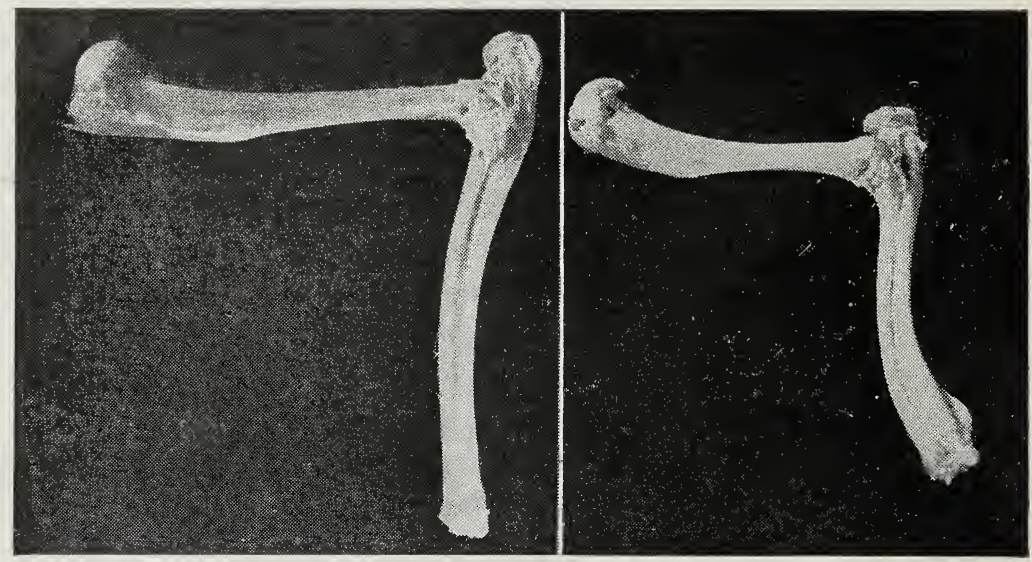

FIg. 15.-Front leg bones from a control (left) and a manganese-deficient (right) rabbit. Note the bending of the radius and ulna and the shortness of the bones of the manganese-deficient rabbit. (Courtesy of S. E. Smith.)

phorus. In rats fed a manganese-low diet, bone changes appear in the second generation.

Just how manganese functions in bone formation is not clear. It is reasonable to believe that the mineral is concerned in enzyme systems, and there is some evidence associating it with phosphatase activity.

140. Requirements and Feed Supplies.-Quantitative requirements for farm animals have been established only in the case of poultry. The needed allowance has been set at $25 \mathrm{mg}$. per pound of feed for chicks and $15 \mathrm{mg}$. for hens. These levels have been set high enough to meet the situation when the ration is very high in calcium and phosphorus also, as a result of the liberal inclusion of bone-carrying feeds. The needs of pigs are certainly much lower, and probably this is true also for other farm animals. On the basis of data as to the manganese content of the commonly 
used feeding stuffs it is evident that no manganese supplements are called for, except possibly for poultry. In the latter case it has become common practice to add such a supplement to commercially mixed rations, presumably as an insurance measure.

\section{ZINC}

Though the total amount is very small, zinc is rather widely distributed in the various tissues of the body, notably in the bones, hair, liver, pancreas, kidney, and muscles. The early studies of Bertrand, indicating that this element plays an essential role, have been recently confirmed and extended by others in experiments with both rats and mice. On a nearly zinc-free diet growth is retarded; and the development of the fur of rats is interfered with, according to Stirn, Elvehjem, and Hart. ${ }^{1}$ Continued feeding of relatively large intakes of zinc results in a markedly increased store of the element in the body which gradually disappears after the feeding is stopped. On a zinc-deficient diet its content in the bones, teeth, and blood is lowered. The main path of excretion is the feces. Zinc has been found in both human and cow's milk, and colostrum has been reported much richer than milk itself. It is a constituent of the enzyme, carbonic anhydrase, and undoubtedly plays a role in other enzyme systems. Thus, it may be considered an essential dietary constituent for man and other animals besides those specifically studied. The metabolism of zinc has recently been reviewed. ${ }^{2}$

Zinc is widely distributed in the vegetable kingdom. The amounts present in the common foods of animals and man are greatly in excess of any probable need by the body, and thus, in practice, the question of a zinc requirement calls for no consideration.

\section{ALUMINUM AND SILICON}

141. Aluminum.-All plants and animals contain traces of aluminum. Thus far no evidence has been produced that it is an essential constituent of body tissues, and its presence is explainable on the basis that it is passively taken up and retained owing to its universal presence in foods.

${ }^{1}$ Stirn, F. E., C. A. Elvehuem, and E. B. Hart, The indispensability of zine in the nutrition of the rat, J. Biol. Chem., 109, 347-359, 1935.

${ }^{2}$ Anonymous, Metabolism of zinc, Nutrition Revs., 1, 411-413, 1943. 
In view of the widespread use of aluminum cooking utensils, much recent research has been devoted to possible toxic effects of the element. Much higher levels than occur in foods or waters have been continuously fed to rats, dogs, pigs, and man without observable harm. Since toxic effects have been reported from the injection of aluminum salts, it seems probable that the lack of harmful effect from rather large intakes in the food is due to a low degree of absorption. It is clear, however, that aluminum may interfere with the absorption of phosphorus. Intakes which are large enough to combine with a substantial part of the phosphorus of the diet render the latter unabsorbable and result in a lowering of the plasma phosphate, a decrease in bone ash, and rickets. Such an effect is not to be feared from natural foods, since they contain, at most, only a few parts per million of the element.

142. Silicon.-All animal tissues which have been examined have been found to contain silicon in varying amounts. It is present in the blood serum of farm animals as 1 to $2 \mathrm{mg}$. per $100 \mathrm{ml}$. Wool contains from 0.02 to 0.08 per cent, but this variation apparently has no relation to wool quality and no definite correlation with intake. Silica constitutes up to 77 per cent of the ash of feathers and may help maintain their rigidity. No one has been able to demonstrate that the element plays any essential role in the body, and thus its occurrence is generally regarded merely as an accumulation resulting from its universal occurrence in foods, particularly those of vegetable origin.

Mature roughages are especially rich in silicon since their cellulose is infiltrated with the element. Samples of timothy hay have been reported to contain as much as 0.7 per cent. The mineral metabolism studies of Forbes and Beegle ${ }^{1}$ revealed an extensive metabolism of silicon in the dairy cow. In many instances the intakes equaled those of sodium, chlorine, and phosphorus. Most of the ingested element was recovered in the feces, but the balance studies recorded some storage in almost all cases, frequently 3 to $5 \mathrm{~g}$. daily. Only very small amounts were found in the urine, the feces being by far the principal channel of excretion.

${ }^{1}$ Forbes, E. B., and F. M. BeEgLe, The mineral metabolism of the milch cow, Ohio Agr. Expt. Sta. Bull. 295, 1916. 


\section{FLUORINE}

While fluorine is found in various other parts of the body, notably in the hair, its regular occurrence in the teeth and bones to the extent of 0.02 to 0.05 per cent is of primary interest to the nutritionist. Here it exists in an apatite form as an integral part of the structure. Although this regular occurrence and certain specific evidence discussed later suggest that fluorine may be an essential dietary constituent in minute amounts, its primary significance in animal nutrition is concerned with definitely harmful effects resulting from excessive intake.

143. The Toxicity of Fluorine.-In large doses fluorine is an acute poison. The harmful effects that are of practical importance in livestock feeding, however, are the result of the continuous ingestion of comparatively minute amounts in fluoride-containing water or in rations supplemented with mineral phosphates high in the element. The most evident effects are on the bones and teeth in which excess fluorine gradually accumulates.

The bones lose their normal color and luster, become thickened and softened, and the breaking strength is decreased. Bony outgrowths from the surface, called exostoses, occur. The fluorine content of the bone increases many times, and its magnesium content also increases, but there is a decrease in carbonate. The total ash content is lowered by high levels of intake. There are also characteristic histological changes. The effects upon the teeth are similar though they manifest themselves somewhat differently, particularly in certain species. In the rat the enamel loses its glistening yellow color and becomes chalky and brittle. The permanently growing incisors do not wear away normally and either the upper or lower incisors become elongated. These changes are illustrated in Fig. 16, which also shows the thickening of the skull bones resulting from fluorine feeding. In hogs and cattle, defects in the enamel are produced and the teeth become soft and worn down until in some cases the pulp cavities are exposed. The teeth become sensitive to cold water, and food consumption is interfered with.

In children an excessive fluorine intake is responsible for the development of mottled enamel. This condition is characterized by the presence of chalky-white patches on the surface of the teeth. Frequently the entire tooth surface is dull white in color, 
and the enamel becomes pitted and may chip off. Secondarily the teeth may become stained showing a coloration which varies from yellow to black. Mottled teeth are structurally weak owing to an interference with the normal development of the enamel. Mottling is chiefly a defect of the permanent teeth which results during their formation. Normally formed teeth do not become

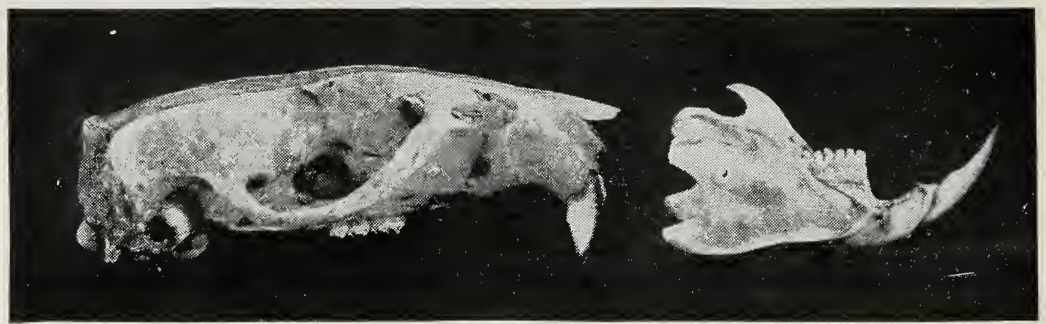

$A$

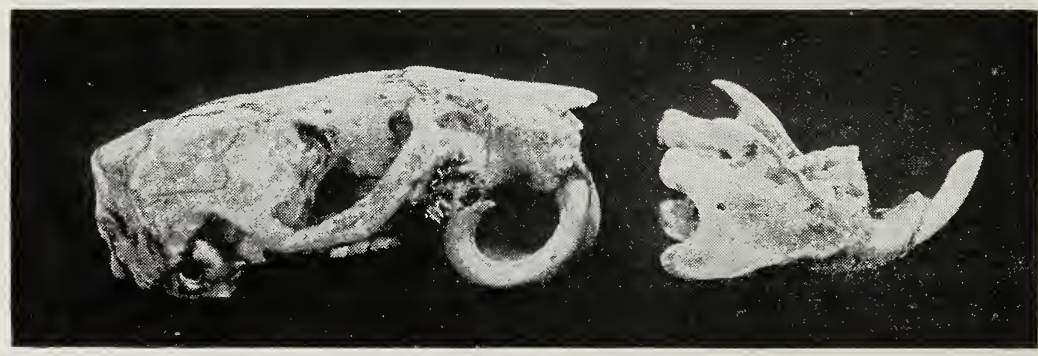

$B$

Fig. 16.--Skulls of rats fed on diets with and without fluorine. $A$, normal skull. $B$, thickened skull with elongated and chalky upper incisors caused by excessive fluorine intake.

mottled later. In the permanently growing teeth of the rat, however, bleaching may be produced at any time during life. The fact that mottled enamel will occur in children who regularly drink water containing as little as 1 p.p.m. of fluorine illustrates how small an amount may cause injury. Mottled enamel has also been reported to occur in cattle in areas where the water is high in fluorine.

While injuries to the bones and teeth are the initial or the most evident effects of fluorine, higher intakes or long-continued feeding interfere with food consumption, growth, and milk production. Of course, the wearing down of the teeth interferes with food consumption and this, in turn, with growth and production. There are generalized toxic effects, however, reflected in degenerative 
changes in various organs and soft tissues. The form in which fluorine is fed has an influence on its toxicity. Sodium fluoride is more toxic than calcium fluoride and certain other insoluble products. There are species differences in susceptibility. The chicken will tolerate a considerably higher level than other farm animals.

Fluorine is a cumulative poison. Short-time experiments in which no harmful effect is noted are not reliable measures of the safety of a given level in feeding practice. At first the fluorine merely accumulates in the bones and teeth without evident harm, and considerable time elapses before structural injury becomes evident. The avidity of the bones and teeth for fluorine tends to protect the soft tissues against excessive concentrations. As the bones become saturated, however, the greater part of the absorbed fluorine is free to produce its general toxic effects on the organs and soft tissues. Phillips, Hart, and Bohistedt ${ }^{1}$ found that, while the deleterious effects of higher levels were evident much earlier, an intake of rock phosphate which provided approximately 0.008 per cent of the total dry matter fed to dairy cows had a marked effect on production only after three years of feeding. Reproduction was affected in these animals. Thus the level of fluorine is most critical in connection with the long-time feeding of breeding stock and milk-producing animals.

144. Safe Levels of Fluorine Intake.-It is evident that the safe level varies with the species, the duration of the feeding period, and the source of the fluorine. From a study of the literature it appears that the upper limit of safety in the case of cattle, sheep, and hogs is represented by a level of 0.01 per cent of the element in the dry matter of the total ration. In the case of chickens this maximum safe level is around 0.035 per cent. Somewhat higher levels are safe for short periods. On the other hand, the permissible levels which may be considered definitely safe under all conditions for long-time feeding lie much below those mentioned above. This matter has been carefully considered by the Committee on Animal Nutrition of the National Research Council, and their recommendations are embodied in a report by Mitchell. ${ }^{2}$

1 Phillips, P. H., E. B. Hart, and G. Bohstedt, Chronic toxicosis in dairy cows due to the ingestion of fluorine, Wis. Agr. Expt. Sta. Research Bull. 123, 1934

2 Mrtchels, H. H., The fluorine problem in livestock feeding, Natl. Research Council Reprint and Circ. Series No. 113, 1942. 
This report tentatively fixes the levels in the total ration as 0.003 per cent for cattle, sheep, and swine and 0.015 per cent for chickens; or, for the concentrate mixtures of sheep and cattle, 0.006 and 0.004 per cent respectively. An excellent general review of the fluorine, with citations of the principal contributions in the field, is to be found in this report by Mitchell.

145. Practical Aspects of Fluorine Toxicity.-Aside from the special situation in areas where the water is high in fluorine, our practical interest in this fluorine problem from the standpoint of farm animals lies in the fact that certain mineral supplements may contain excessive amounts. Rock phosphate contains 3.5 to 4 per cent of fluorine, and thus even 1 per cent of it in the concentrate mixture would provide an intake approximately ten times the permissible level previously mentioned. Products made from rock, such as acid phosphate and dicalcium phosphate, as normally manufactured, are also far too high in fluorine for safe use. In fact, it was the employment of rock phosphate and its products as mineral supplements that first demonstrated the fluorine problem in feeding practice. As has previously been mentioned (Sec. 118), processes have now been developed for defluorinating rock phosphate and its products to make them safe for animal feeding. The term defluorinated is not, however, sufficient evidence in itself that the product is safe to feed. Its guaranteed fluorine minimum must be considered in relation to the permissible levels.

Bone meal, the most commonly used calcium and phosphorus supplement, contains 0.03 to 0.04 per cent of fluorine, an amount that is below the permissible level when the product is fed as 1 per cent of the concentrate mixture of cattle or sheep. Despite its widespread use over many years in experimental studies as well as in practice, no evidence of fluorine injury from the use of bone meal as a mineral supplement has been noted. The Association of American Feed Control Officials, Inc. has set forth in its Official Publication for 1946 the following tentative regulations regarding the fluorine content of mineral substances:

The fluorine content of any mineral or mineral mixtures that are to be used directly for the feeding of domestic animals shall not exceed 0.30 per cent for cattle; 0.35 per cent for sheep; 0.45 per cent for swine, and 0.60 per cent for poultry.

Rock phosphate or other fluorine bearing ingredients may be used only 
in such limited amounts in feeding stuffs so that they will not raise the fluorine of the total concentration of the (grain) ration above the following amounts; for cattle 0.009 per cent of fluorine; for sheep 0.010 per cent of fluorine; for swine 0.014 per cent of fluorine; and for poultry 0.035 per cent of fluorine.

These allowable levels are considerably above the permissible levels of the report of the National Research Council (Sec. 144).

While fluorine occurs in most of the common feedstuffs, in general, the level does not exceed 1 or 2 p.p.m. Considerably higher values have been reported for certain fish meals, as is to be expected in view of their bone content. The question as to whether phosphate manuring constitutes a hazard by reason of an increased fluorine content in the crops so fertilized has been answered in the negative. The use of fluorine insecticides appears to be hazardous in so far as human nutrition is concerned and a similar problem may be created by the use of these insecticides on crops eaten by animals.

146. Is Fluorine an Essential Element?-Evidence that, despite its harmful effects at higher intakes, the ingestion of minimum amounts of fluorine may be distinctly beneficial has come from observations with respect to tooth decay in man and experimental animals. It has been definitely shown by both epidemiological and experimental studies that where the water supply contains 1 to 2 p.p.m., in contrast to lower levels, the incidence of dental caries is decreased. Additions to the diet have also been found effective. Whether the effect is brought about through metabolic changes, through bacteriostatic action in the mouth, or by other means remains uncertain. Optimism regarding the long-time beneficial effects of fluorine in preventing tooth decay should be tempered by the fact that the margin between the observed beneficial level and the definitely harmful level is very narrow. There is still a question as to whether a level which proves protective initially may become harmful in later life on continuous ingestion.

The question as to whether fluorine is an essential dietary constituent has been investigated with rats, using diets designed to be as low as possible in the element. The early studies produced entirely negative results. Very recently McClendon and Foster ${ }^{1}$ have briefly reported positive findings in generation studies using

1 McClendon, J. F., and WM. C. Foster, The necessity of fluorine in the diet. II. Federation P'roc., 4, 159, 1945; Am. J. Med. Sci., 210, 131-132, 1945. 
diets apparently much lower in fluorine than those previously employed. Excessive tooth decay and reproductive failure resulted. Such findings provide evidence that fluorine, in minute amounts, is an essential dietary constituent and not merely a toxic substance which, like some other poisons, exerts a beneficial effect on some tissues when ingested at a very low level. From the practical standpoint, however, at least in animal feeding, its harmful effect is the important consideration.

\section{OTHER TOXIC MINERALS}

147. Selenium.-This element has recently been found to be responsible for a peculiar disease of livestock which has long been

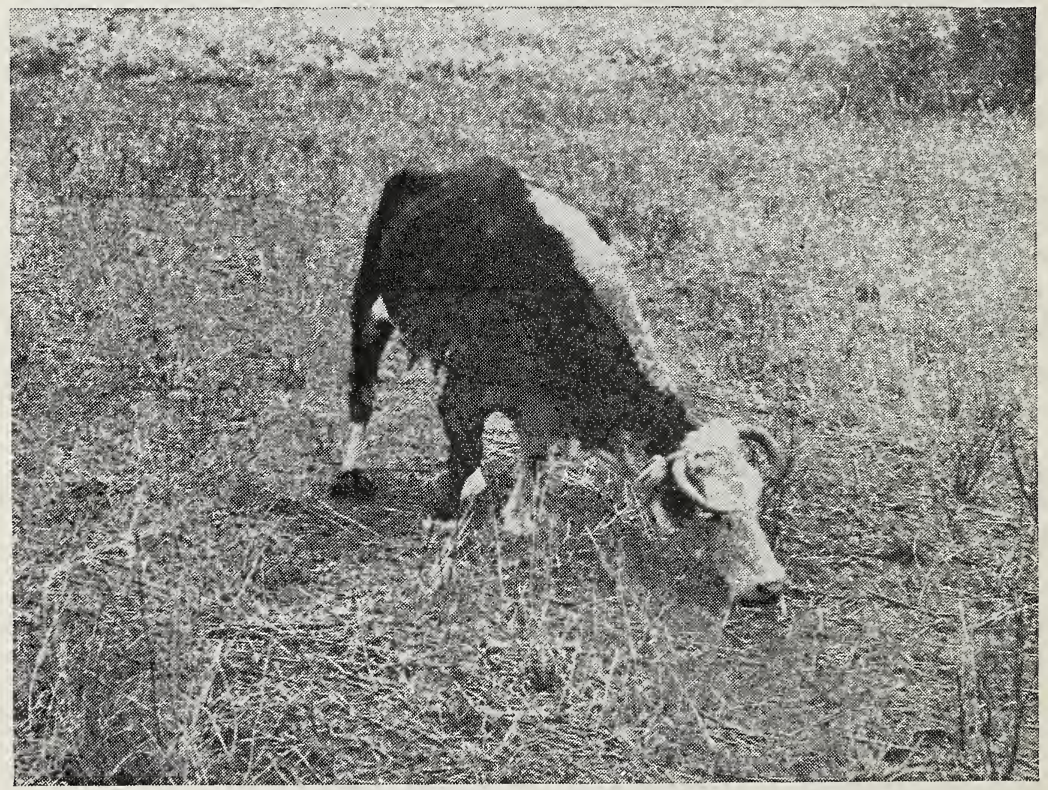

FIg. 17.-Selenium poisoning. (Courtesy of A. A. Beath, University of Wyoming.)

known to exist in certain regions of the world. In the United States, it occurs in some areas of the plains region, notably South Dakota, and is known locally as "alkali disease" or "blind staggers." In chronic cases there is a loss of hair from the mane and tail in horses and from the tail in cattle and a general loss of hair in swine. The hoofs slough off, lameness occurs, food consumption decreases, and death may occur by starvation. These 
external symptoms are accompanied by marked pathological changes which are revealed on autopsy.

As a result of studies begun in 1929, Franke, chemist of the South Dakota Experiment Station, traced the cause of the disease to crops grown in localized soil areas. This finding led to a cooperative study with the U.S. Department of Agriculture which resulted in the discovery of selenium as the specific factor. Various food crops may contain toxic levels of the element as a result of the amounts present in the soil in the areas in question. The soil may contain as much as 40 p.p.m., but any soil which contains more than 0.5 p.p.m. is potentially dangerous. Both the forage and the grains contain toxic levels. Different plants vary greatly in the amounts they take up, but the concentration in the plant is generally much greater than in the soil. On a soil containing 9 p.p.m. of selenium certain crops have been found to contain as much as 1200 p.p.m. Chronic toxicity is caused by rations containing as little as 8.5 p.p.m. of selenium. Acute cases of poisoning have been reported from levels of 500 to 1000 p.p.m. Young animals are especially susceptible, and growth is retarded with levels too low to cause other evident symptoms. This selenium injury is not limited to animals, for human cases have also been reported. White flour milled from wheats grown in a seleniferous area may contain toxic levels.

No practical method has been found of eliminating this selenium injury, either by dietary means or by soil treatment, although arsenic ingestion has been found experimentally to counteract the toxic effects. In areas where it occurs, toxic levels in the food crops are so general that there is no safe food supply. There seems to be no solution other than to abandon the area. Certainly a livestock industry cannot flourish, and the production of food crops constitutes a menace to both animals and man. The milk and eggs from cows and hens fed rations containing selenium contain the element.

During the past 10 years a large number of studies have been published dealing with the occurrence of selenium in soils and crops and its metabolism and pathological effects in animals. These studies have been comprehensively reviewed by Moxon and Rhian ${ }^{1}$ of the South Dakota Experiment Station.

${ }^{1}$ Moxon, Alvin L., and Morris Rhian, Selenium poisoning, Physiol. Revs., 23, 305-337, 1943. 
148. Molybdenum.-A trouble in cattle referred to as teartness, and known for over a hundred years to be definitely associated with certain pasture areas in England and not with others, has been established by Ferguson and associates as a molybdenum toxicity. The trouble affects ruminants, particularly calves and cows in milk. The physical symptoms are extreme diarrhea with consequent loss in weight and milk yield. Molybdenum was discovered to be the cause by analyses of the forage from unhealthy and normal areas and by feeding experiments. The trouble is found where the herbage contains 0.003 per cent or more of the element. Copper sulfate is effective in curing the diarrhea. No certain evidence of the occurrence of this trouble elsewhere has been reported. In investigating the possibility that molybdenum might be an essential element in traces, Wisconsin workers found that a diet containing as little as $0.005 \mathrm{mg}$. per day was satisfactory for rat growth.

149. Arsenic.-This element is found in small amounts in the blood, skin, hair, hoofs, milk, and elsewhere. No evidence that even traces of it are essential in the diet has been found, despite considerable study. Its toxic effects are well recognized, and forages contaminated with spray residues must be avoided accordingly.

150. Nitrites.- In 1937 Newsom and coworkers of Colorado reviewed a series of reported cases of acute symptoms and death in cattle following the ingestion of oat hay or straw and referred to as oat-hay poisoning. The physical symptoms noted were trembling, staggering gait, rapid respiration, and prostration. Detailed studies of cases in Wyoming were later reported by Bradley and coworkers. ${ }^{1}$ Among the post-mortem findings recorded was the significant one that most of the hemoglobin had been converted to methemoglobin, explaining the physical symptoms noted. Chemical analyses of fifteen samples of oat hay and straw fed where deaths had occurred revealed a potassium nitrate content of 2.2 to 7.3 per cent, whereas other oat hay contained only a trace. Since nitrite, rather than nitrate, was known to form methemoglobin, and since there was no nitrite present in the hay, Bradley and coworkers concluded that the nitrate must have been converted into nitrite in the digestive tract. Support

1 Bradley, W. B., H. F. Eppson, and O. A. Beath, Livestock poisoning by oat hay and other plants containing nitrate, Wyoming Agr. Expt. Sta. Bull. 241, 1940. 
for their conclusion is to be found in earlier studies by Seekles and Sjollema who introduced potassium nitrate into the rumen of cattle and got symptoms of nitrite poisoning as indicated by the formation of methemoglobin.

Limited observations by the Wyoming workers suggest that horses and sheep, as well as cattle, may occasionally suffer from oat-hay poisoning. Other plants, such as certain weeds, wheat, barley, and cane sorghum, sometimes contain enough nitrate to cause the characteristic trouble. It is apparent that the troubles are limited to certain areas, with some evidence that they occur year after year in these areas. It appears that oat-hay poisoning is of most concern in the case of ruminants because of the special opportunity for chemical changes provided by their digestive tracts. Robinson of New Zealand has reported a special case of nitrite poisoning in pigs resulting from the formation of nitrite from nitrate in the cooking of the mangels fed. On the basis of present evidence, there appears to be no reason for concern regarding the possibility that nitrate fertilization may produce crops that are toxic.

\section{OTHER MINERALS}

The recent findings of the large importance of traces of boron in plant growth have stimulated a study of its possible role in animal nutrition. In comprehensive experiments by different workers, however, diets supplying as little boron as $0.16 \mathrm{mg}$. per kilogram body weight have had no deleterious effects on growth, reproduction, or lactation in rats.

Nickel has been identified in various tissues of the body, but despite considerable study no proof has been obtained that it is useful for any body function. Some studies of cobalt deficiency have suggested that nickel may have a useful role in curing the trouble when the cobalt intake is inadequate. The observations thus far reported are not convincing.

\section{SOME PHYSIOLOGICAL EFFECTS OF MINERALS AS A GROUP}

The previous discussions have shown that with certain mineral elements their quantitative relationships to each other are important as well as their absolute amounts in the diet. There are physiological effects resulting from the relations among the min- 
erals as a group, or from their intakes as a whole, which also require brief consideration.

151. Acid-base Balance in the Ration.-It has been noted that the $\mathrm{pH}$ of the blood and other body fluids must be held in a very narrow range for health and normal function. In contrast, the food ingested may exhibit wide ranges of potential acidity or alkalinity depending upon the amounts of the various mineral elements present. Thus the question of the influence of the acidbase balance, more specifically designated as acid-, alkali-ash value, of the diet upon metabolism has received much study. This balance is determined by calculating the equivalent in normal acid of the acid-forming minerals, chlorine, phosphorus, and sulfur, and figuring the equivalent in normal alkali of the base-forming elements, sodium, potassium, calcium, and magnesium. Calculated in this way the potential acidity of wheat exceeds its potential alkalinity by the equivalent of $12 \mathrm{ml}$. of normal acid per $100 \mathrm{~g}$. It is an acid-forming food. On the other hand, alfalfa has a net potential alkalinity of $93 \mathrm{ml}$. and is, therefore, a base-forming food. In general, seeds and their by-products are acid-forming, while roughages are base-forming. High-protein diets tend to be acid-forming owing especially to the sulfur present. The acid-, alkali-ash value of a ration can be calculated from the figures for its ingredients.

In figuring this value, no account is taken of organic acids. Citrus fruits contain considerable amounts of these acids, and they are base-forming foods. Organic acids are not taken into consideration, because, for the most part, they are oxidized or otherwise metabolized in the body and thus do not function as acids in the fluids.

It is recognized that highly acid-forming diets decrease the alkali reserve of the blood and may result in the excretion of fixed bases, even from the bones. It has been shown, however, that the body is able to tolerate a moderate excess of acid-forming elements without harm. In farm animals most of the experiments in which this question has been studied by the ingestion of mineral acids have indicated that the animals have effective means of taking care of them. The production of ammonia from urea provides a particularly effective agency for the neutralization of acid without increasing protein catabolism or loss of fixed base. The urine of Herbivora is generally alkaline, reflecting the fact that 
their ration is usually base-forming. The urine of Carnivora is commonly acid, and that of Omnivora is either acid or alkaline depending on the nature of the diet.

The feeding of large amounts of silage which has developed a high acidity does not cause any serious physiological disturbance because the acidity is owing to organic acids which for the most part are readily oxidized.

In the case of silage preserved with mineral acids, however, as is the case with the A.I.V. process and with the use of phosphoric acid, the situation is different. Particularly when such silages are fed for several months with little or no other roughages, the protective mechanism of the body may not suffice. It has thus become common practice to add calcium carbonate as a neutralizer where A.I.V. silage is thus fed. In the case of phosphoric-acid silage, the need for neutralization is somewhat less, but the addition of the carbonate is recommended here where hay which is part legume is not fed also. Legume hay has a higher net alkaliash value than grass hays. Of course, the amount of acid added to the silage and the character of the crop, whether legume or nonlegume, are also factors governing the need for neutralization. This general problem is reviewed in connection with the studies reported by Lepard and associates. ${ }^{1}$

152. Saline and Alkaline Waters.-The water supplies for animals in certain regions have such high concentrations of various salts as to interfere with growth, lactation, and reproduction. This problem has been critically studied by Heller ${ }^{2}$ and the studies have produced some very valuable data on the tolerance of animals to specific salts and to large intakes of minerals in general. The waters studied were heavily saturated with chlorides and sulfates of sodium, calcium, and magnesium and contained minor quantities of carbonates, bicarbonates, and other ions. It was found that the damage depended more on the total amount of salts present than on any specific one, thus representing an osmotic effect rather than an injury from any particular ion. The maximum concentration of soluble salts which could be safely tolerated

1 LePARD, O. L., and associates, The effect of phosphoric acid silage on the acid-base balance in dairy cows, J. Dairy Sci., 23, 1013-1022, 1940.

${ }^{2}$ Helser, V. G., Saline and alkaline drinking waters, J. Nutrition, 5, 421-429, 1932; 'The effect of saline and alkaline waters on domestic animals, Okla. Agr. Lixpt. Sta. Bull. 217, 1933. 
appeared to lie between 1.5 and 1.7 per cent. Alkalies were more injurious than neutral salts. Chlorides were less harmful than sulfates, and organic salts less harmful than inorganic. Magnesium chloride was more injurious than the calcium or sodium salt. Sheep were more resistant to injury than cattle and cattle more than hogs. More recent studies by Heller have indicated that the cause of the injury is not due to any influence on the $\mathrm{pH}$ of the intestinal tract, digestibility, or nitrogen retention.

153. Complex Mineral Mixtures.-So far as is now known, except in special situations, the only supplementary minerals that are ever needed in the commonly fed rations of farm animals, beyond the suckling stage, are salt, calcium, phosphorus, and iodine. There are many proprietary mineral mixtures on the market which contain a large number of other minerals such as potassium, magnesium, iron, sulfur, and copper. It is a waste to feed unneeded minerals and several cases of harmful effects of excessive intake of essential elements have been mentioned in previous discussions. It is both good economy and good nutrition to limit any intake of supplemental minerals to those which are actually deficient in the ration being fed. Commonly salt is the only supplement needed. The writer believes that complex mineral mixtures have no place in scientific feeding, particularly when they contain purgatives, worm remedies, and tonics and are thus sold as "shot-gun" prescriptions for all ills, nutritional and otherwise.

\section{Selected Literature}

Allcroft, W. M., and H. H. Green: Seasonal hypomagnesaemia of the bovine, without clinical symptoms, J. Comp. Path. Therap., 51, 176-191, 1938.

Barrentine, B. F., L. A. Maynard, and J. K. Loosli: The availability of the calcium and phosphorus of defluorinated rock phosphate for the rat, J. Nutrition, 27, 35-42, 1944.

BaUdisch, Oskar: The importance of trace elements in biological activity, Am. Scientist, 31, 211-240, 1943.

Bennetts, H. W., and A. B. Beck: Enzootic ataxia and copper deficiency in Western Australia, Australia, Council Sci. Ind. Research Bull. 147, 1942.

- , R. HarLeY, and S. T. Evans: Copper deficiency of cattle and the fatal termination "falling disease," J. Dept. Agr. W. Australia, 19, 2d. ser., 96-104, 1942.

Black, W. H., L. H. Tash, J. M. Jones, and R. J. Kleberg: Effects of phosphorus supplements on cattle grazing on range deficient in this mineral, U.S. Dept. Agr. Tech. Bull. 856, 1943. 
Bowstead, J. E., J. P. Sackville, and R. D. Sinclair: The development of cobalt deficiency in sheep, Scientific Agr., 22, 314-325, 1942.

Cunningham, I. J.: Grass staggers and magnesium metabolism, New Zealand J. Sci. Tech., 18, 424-428, 1936.

Edgar, Grahame: Experiments on copper storage in the liver of sheep. I. The effect of increased iron, cobalt and manganese intake, Austrialan Vet. $J ., 18,28-31,1942$.

Forbes, E. B., and M. Helen Keith: Phosphorus compounds in animal metabolism, Ohio Agr. Expt. Sta. Tech. Bull. 5, 1914.

- , and S. R. Johnson: Phosphorus deficiency among cattle in Pennsylvania, Pa. Agr. Expt. Sta. Bull. 371, 1939.

Henry, K. M., and S. K. Kon: The retention of calcium and phosphorus by the rat from wholemeal bread, with and without added calcium, and from white bread fortified with calcium and vitamin $\mathrm{B}_{1}$, Biochem. J., 39, 117-122, 1945.

Hove, E., C. A. Elvehjem, and E. B. Hart: Arsenic in the nutrition of the rat, Am. J. Physiol., 124, 205-212, 1938.

Johnson, S. R.: Studies with swine on rations extremely low in manganese, J. Animal Sci., 2, 14-22, 1943.

- : Studies with swine on low-manganese rations of natural foodstuffs, $J$. Animal Sci., 3, 136-142, 1944.

Keener, H. A., G. P. Percival, and K. S. Morrow: Cobalt treatment of a nutritional disease in New Hampshire dairy cattle, N.H. Agr. Expt. Sta. Circ. 68, 1944.

Kегтн, T. B., and associates: Nutritional deficiencies of a concentrate mixture composed of corn, tankage, soybean oilmeal, and alfalfa meal for growing pigs, J. Animal Sci., 1, 121-125, 1942.

Lintzel, W., and T. RAdefF: Über den Eisengehalt and Eisenansatz neugeborener und saugender Tiere (nach Versuchen an Kaninchen, Meerschweinchen, Ratte, Hund, Katze, Schwein, Ziege, Rind), Arch. Tierernähr. Tierzucht, 6, 313-358, 1931.

Lyon, C. B., and K. C. Beeson: Manganese and ascorbic acid formation, J. Amer. Soc. Agron., 35, 166-167, 1943.

McCance, R. A.: The ionizable and available iron in foods, J: Soc. Chem. Ind. (London), Chem. and Ind., 58, 528-530, 1939.

- , and E. M. Widdowson: Mineral metabolism on dephytinized bread, $J$. Physiol., 101, 304-313, 1942; The absorption and excretion of zinc, Biochem. J., 36, 692-696, 1942.

- - C. N. Edgecombe, and E. M. Widdowson: Phytic acid and iron absorption, Lancet CCXLV, 126-128, 1943.

MCCAY, C. M., and associates: The calcium and phosphorus content of the body of the brook trout in relation to age, growth and food, J. Biol. Chem., 114, 259-263, 1936.

Maynard, L. A.: Relation of soil and plant deficiencies and of toxic constituents in soils to animal nutrition, Ann. Rev. Biochem., 10, 449-470, 1941. , S. A. GoldBers, and R. C. Miller: A study of the dietary relationships and the pathology of "stiffness" in swine, Cornell Univ. Agr. Expt. Sta. Mem., 86, 1925. 
Mitchell, H. H., and F. J. McClure: Mineral nutrition of farm animals, Natl. Research Council Bull. 99, 1937.

Moxon, A. L., and associates: Growth of steers on seleniferous range, $J$. Animal Sci., 3, 299-309, 1944.

Nicholson, L. W., and W. R. Brenemare: Goiterogenic diets and their effects on thyroid hyperplasia and vital organs of chicks, Poultry Sci., 24, 426-433, 1945.

Orent-Keiles, E., and E. V. McCollum: Potassium in animal nutrition, J. Biol. Chem., 140, 337-352, 1941.

PARKs, R. Q., and associates: Quantitative chemical microdetermination of twelve elements in plant tissue, Ind. and Eng. Chem., 15, 527-533, 1943.

Patтon, A. R.: Silicon content of wool in relation to dietary silicon, Ark. Agr. Expt. Sta. Bull. 375, 1939.

Peirce, A. W.: Chronic fluorine intoxication in domestic animals, Nutrition Abstracts \& Revs., 9, 253-261, 1939.

Schaible, P. J., Selma L. Bandemer, and J. A. Davidson: The manganese content of feedstuffs and its relation to poultry nutrition, Mich. Agr. Expt. Sta. Tech. Bull. 159, 1938.

Schultze, M. O.: Metallic elements and blood formation. Physiol. Revs., 20, $37-67,1940$.

Shrewsbury, C. L., J. D. Hatfield, L. P. Doyle, and F. N. Andrews: Some effects of fluorine in the nutrition of sheep, Indiana Agr. Expt. Sta. Bull. 499, 1944.

Smith, M. C., E. M. Lantz, and H. V. Smith: The cause of mottled enamel, a defect of human teeth, Ariz. Agr. Expt. Sta. Tech. Bull. 32, 1931.

Spitzer, Robert R., and PaUl H. Phillips: Enzymatic relationships in the utilization of soybean oil meal phosphorus by the rat, J. Nutrition, 30, 183-192, 1945.

Talapatra, S. K., S. C. Ray, N. D. Kehar, and K. C. Sen: Oxalic acid in feeding stuffs and its significance in calcium assimilation, Science and Culture, 8, 209-213, 1942.

Theiler, Arnold: The osteodystrophic diseases of domesticated animals. (1) The structure of bone; atrophy; osteoporosis; osteomyelitis. (2) Rickets and osteomalacia, Vet. J., 90, 143-175, 1934. (3) The osteodystrophia fibrosa, ibid., pp. 183-206, 1934.

Wachtel, L. W., C. A. Elvenjem, and E. B. Hart: Studies on the physiology of manganese in the rat, Am. J. Physiol., 140, 72-82, 1943. 


\section{CHAPTER VIII}

\section{THE VITAMINS}

Over one hundred years ago Prout ${ }^{1}$ stated that there were three great staminal or proximate principles - a saccharine principle, an oily principle, and an albuminous principle-which provided the essential nutritive constituents of all organized bodies. Until early in the present century these principles, which later became known as the carbohydrates, fats, and proteins, were considered to be adequate to meet all the nutritive needs of the body other than its mineral requirements. Then came the discovery that there were other organic dietary essentials, previously unrecognized because needed in only minute amounts, which were not supplied by the early known principles. These are the nutrients which we class as vitamins. Knowledge as to the chemical nature of these dietary essentials lagged far behind the discovery of their nutritional importance, and thus, in the absence of any chemical basis for classifying them, they were grouped together and the term vitamine, coined by Funk in 1912 to designate a single one, was taken over to cover the group. From a physiological and nutritional standpoint, there are many advantages in considering the vitamins as a group, but it should be borne in mind that most of them are unrelated chemically and that the group name has no chemical significance.

In the 30 years since the first vitamin was discovered, our knowledge in this field has greatly advanced. New ones have been reported from time to time, their physiological functions have been worked out, and the chemical nature of most of them has been established. At the same time, the subject has become more complicated each year, not only because of the increasing body of information, but also because of the mass of conflicting or

1 Prout, Wiluiam, Chemistry, meteorology and the function of digestion, Bridgewater 'Treatise, William Pickering, London, 1834. Prout (1785-1850), an English physician, was a profound student of the relations of chemistry to physiology. He discovered hydrochloric acid in the gast:ic juice, showed that the snake excretes its nitrogen as uric acid, and demonstrated that the developing chick takes calcium from the shell to build its bones. 
unconfirmed data which is characteristic of a rapidly developing, new field of knowledge. There are some 15 vitamins for which the information is sufficiently complete and definite that their existence is generally accepted. There are several others which have been proposed as the result of various experiments. It is unlikely that all of them are distinct essentials. On the other hand, the probability that there are still undiscovered vitamins must be recognized. A textbook on nutrition can deal only with those which are well established by a substantial amount of generally accepted evidence. For a knowledge of the status of the many others which have been proposed, the student must consult the voluminous literature in this field, and, as is true for an up-todate knowledge of the subject of vitamins in general, he must follow the new contributions as they appear in the various journals. He will find this no easy task, and he will also come to realize that complete knowledge of the subject of the vitamins lies far in the future.

A generally recognized vitamin is one that has been proven an essential dietary constituent for one or more species. Some vitamins are metabolic essentials, but not dietary essentials, for certain species, because they can be synthesized readily from other food or metabolic constituents. Thus, while vitamin $\mathrm{C}$ has been proven a metabolic essential for many species, it is a dietary essential only in the case of man, guinea pigs, and monkeys, because the other animals are able to provide their needs through synthesis. Various B-vitamins are essential for normal ruminant metabolism and yet are not needed in the food because of bacterial synthesis in the rumen. While metabolic needs are similar, dietary needs for the vitamins differ widely among species. No generalizations can, therefore, be made regarding the nutritive requirements of farm animals for the vitamins as a group. Neither can generalizations be made with respect to feed sources. Each vitamin has a somewhat different distribution from the others, in terms of the materials which make up the food supply. Our knowledge here must be specific even as is the case for the requirements of the different animals.

The vitamins now recognized as distinct dietary essentials are differentiated chemically and on the basis of their physiological functions, particularly as indicated by the metabolic and other symptoms of their deficiency. Chemical evidence is required to 
make certain that a distinct essential is being dealt with, but in the case of several of the vitamins there are different, though closely related, chemical compounds that have the same physiological effects. Thus, there are some 10 sterols that have vitamin $\mathrm{D}$ activity.

154. Development of the Vitamin Concept.-Though the incidence of some of them has doubtless increased in modern times owing to changes in dietary habits, the specific diseases, which we now know to be due to the absence of the recently discovered vitamins, date far back in history. Scurvy has been a scourge of various peoples at least since the time of Hippocrates (400 B.c.), while beriberi was apparently known to the Chinese hundreds of years earlier. Though the specific evidence is comparatively recent, it is clear that, by the trial-and-error method, various individuals and peoples gradually learned that certain of these troubles were associated in some way with the nature of the diet and that specific foods were helpful in their treatment. The very early use by the Chinese of substances rich in vitamin A as remedies for night blindness, now known to be caused by a lack of this vitamin, is evident from the recent studies of these old remedies. In 1747, Lind, a British naval surgeon, showed that the juice of citrus fruits was a cure for scurvy. Cod-liver oil was used as a specific for rickets long before anything was known about the cause of this disease.

During the nineteenth century, many isolated observations were made which gradually led up to the discovery of vitamins as the causes of these disorders now called deficiency diseases. Prior to 1816 , Magendie ${ }^{1}$ observed in a dog what was undoubtedly xerophthalmia, in an experiment constituting a forerunner of the purified-diet method which was responsible 100 years later for the discovery of vitamin A. In the latter part of the century, several men made observations which led them to suggest that there were other dietary essentials besides the early recognized proximate principles, but these unorthodox suggestions at first received little attention. In 1881, Lunin reported studies made in Bunge's laboratory showing that mice would not grow on an artificial mixture made up of the proximate principles of milk. $\mathrm{He}$ expressed the view that there might be "unknown substances"

1 Magendie, François, Sur les propriétés nutritives des substances qui ne contiennent pas d'azote, Ann. chim. phys., 3, 66-77, 1816. 
essential for life in addition to proteins, fats, carbohydrates, and salts.

During the last decade of the century, Eijkmann, a physician working in the Dutch East Indies, was led to study polyneuritis in birds in view of its similarity to beriberi in man. He found that the disease was caused by an exclusive diet of polished rice and cured by adding the polishings. He also noted that beriberi in prisoners eating polished rice tended to disappear when a less highly milled product was fed. In these various studies, published in 1897, he was clearly dealing with the factor which later became known as vitamin B. The studies of Eijkmann were extended by Grijns, another Dutch scientist who made important contributions to the early knowledge of vitamins. Prior to the work of Eijkmann, Takaki, director-general of the Japanese Navy, sent two ships in 1887 on a nine-month voyage to test the effect of dietary additions on the incidence of beriberi. Of the crew which received mostly polished rice and dried fish, 60 per cent developed the disease, while in the other ship where this diet was supplemented with more meat, vegetables, and milk only 14 cases occurred among the 276 men. At that time the beneficial effect was erroneously ascribed to the larger amount of protein in the diet.

With the opening of the twentieth century, the earlier work of Lunin with artificial diets was repeated by others, notably by Pekelharing of the University of Utrecht who was familiar with the course of the studies in the Dutch East Indies and by Hopkins in England. Again it was concluded that the proximate principles would not suffice. As stated by Hopkins in 1906: "No animal can live on a mixture of pure protein, fat, and carbohydrate, and, even when the necessary inorganic material is carefully supplied, the animal still cannot flourish. The animal body is adjusted to live either upon plant tissues or other animals, and these contain countless substances other than protein, carbohydrate and fats." He coined the term accessory food factors for these substances.

From 1907 to 1913, Holst and Frölich of the University of Christiana carried out their classic investigation on scurvy. They were directed to investigate scurvy in Norwegian sailors. They showed that guinea pigs developed this disease on cereals and bread and that it was cured by small amounts of fresh cabbage or carrots. They concluded that scurvy was due to the 
absence of a specific chemical factor, which was destroyed by cooking. They demonstrated a relationship between human and guinea-pig scurvy.

Following work published in 1909 by Stepp showing the necessity of some constituent contained in the lipid fraction of certain natural foods, definite proof of the existence and specific physiological function of vitamin A was furnished in 1913 by the independent investigations of McCollum and Davis ${ }^{1}$ and of Osborne and Mendel. ${ }^{2}$ This specific knowledge resulted from carefully controlled experiments by the purified-diet method (Sec. 205). Dating from 1913, the extension of the knowledge of vitamins proceeded very rapidly.

In this brief statement of the historical background of the vitamin concept, only a few of the men concerned in its development have been mentioned. The discussion suffices to show that many scientists throughout the world contributed and that it is impossible to name any one person or group as the discoverer of this farreaching concept. Such is the often-repeated story in scientific investigations. Links in the chain of facts are supplied and gradually put together by various workers over a period years. Finally some one man may complete the chain, and a discovery is announced; but he may deserve no more, and sometimes even less, credit than others who made the previous observations which he used and extended in making the final contribution.

155. Fat-soluble and Water-soluble Vitamins.-McCollum proposed the names fat-soluble $A$ for the factor found in butter and water-soluble $B$ for the one concerned with beriberi as descriptive terms, since the first was extractable from foods with fat solvents and the second with water. On a similar basis, the antiscorbutic vitamin was later called water-soluble C. Though these descriptive adjectives were eventually given up they are still frequently used as general terms in classifying the vitamins. Thus the fat-soluble vitamins include $\Lambda, D, F$, and $K$, while the members of the $\mathrm{B}$ complex, $\mathrm{C}$, and certain others are classed as water soluble.

In the present chapter, these various vitamins are discussed as

1 McCollum, F. V., and Marguerite Davis, Necessity of certain lipins in the diet during growth, J. Biol. Chem., 15, 167-175, 1913.

${ }^{2}$ Osmorne, Thomas B., and Ianayette B. Mendel, The influence of butter-fat on growth, J. Biol. Chem., 16, 423-437, 1913. 
regards their physiological effects, chemical nature and properties, and distribution in feeds. The specific requirements for growth, lactation, and other body functions are discussed in later chapters. Principal attention is given to those vitamins that have been demonstrated to be of practical importance in the feeding of farm animals.

\section{VITAMIN A}

All animals require a dietary source of vitamin A. The vitamin does not occur as such in plant products but rather as its precursor, carotene. This compound is commonly spoken of as provitamin $A$ because the body can transform it into the active vitamin. This is the way in which the vitamin A needs of farm animals are met, for the most part, because their rations consist mainly or entirely of foods of plant origin. The combined potency of a feed, represented by its vitamin $\mathrm{A}$ and carotene content, is referred to as its vitamin A value.

156. Physiological Function and Symptoms of Deficiency.Vitamin A is combined with a protein in visual purple, a compound that breaks down in the physiological process of sight, as a result of a photochemical reaction. A deficiency of the vitamin, in terms of the needs for the resynthesis of visual purple, results in night blindness, which is a symptom in all animals. The deficiency first manifests itself as a slow dark adaptation. In man the measurement of this physiological response after exposure of the eye to a calibrated source of light is used in estimating quantitative needs of the vitamin.

There are various other eye symptoms that vary markedly among species, some of which represent secondary infections. Xerophthalmia, an advanced stage of vitamin A deficiency noted particularly in children and rats, is characterized by a dry condition of the cornea and conjunctiva, cloudiness, and ulceration. It is not a common symptom in other animals, although corneal changes occur. Copious lacrimation is a more prominent eye symptom in cows (Fig. 18). In the case of chickens, on the other hand, the secretions of the tear glands dry up, and an infection may then occur, resulting in a discharge that causes the lids to stick together. In young calves severe vitamin A deficiency may result in blindness, caused by stenosis of the foramen and constriction of the optic nerve. 
Wolbach and Howe ${ }^{1}$ are responsible for discovering a generalized effect of the absence of the vitamin. They found that the normal epithelium in various locations throughout the body became replaced by a stratified, keratinizing epithelium. This effect has been noted in the respiratory, alimentary, reproductive,

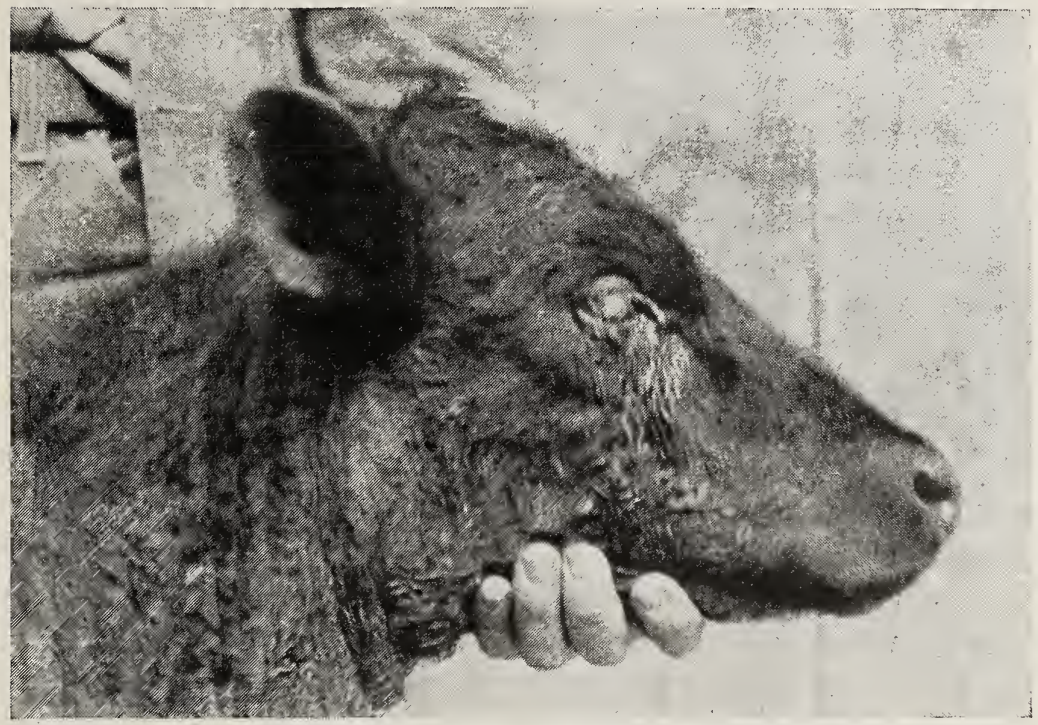

Fig. 18. - Advanced state of eye lesion in vitamin A deficiency. (Courtesy of G. H. Hart, California Experimental Station.)

and genitourinary tracts, as well as in the eye. This keratinization lowers the resistance of the epithelial tissues to the entrance of infective organisms. Thus respiratory troubles, such as colds and sinus infections, tend to be more severe in vitamin $\mathrm{A}$ deficiency. The same is true for certain gastrointestinal and kidney troubles. The formation of kidney and bladder stones is favored because the damaged epithelium interferes with the normal secretion and elimination of the urine. Xerophthalmia follows an injury to the epithelium of the eye. While a bacterial invasion has been frequently noted here, there is disagreement as to its being necessarily involved.

The recognition that certain infections were more common in

1 Wolbach, S. B., and P. R. Howe, Tissue changes following deprivation of fat-soluble A vitamin, J. Exptl. Med., 42, 753-777, 1925; Vitamin A deficiency in the guinea-pig, Arch. Path. Lab. Med., 5, 239-253, 1928. 
vitamin A deficiency led to the proposal that it be called the antiinfective vitamin. Further studies have shown that this term is not justified. It would appear that a diet adequate in the vitamin is desirable to help maintain what may be considered the normal powers of resistance, but the early idea that additional intakes would largely obviate specific infections which enter through the epithelium has proved false. Aside from its curative effect on xerophthalmia, there is no evidence that the administration of the vitamin after an infection has become established will shorten its course or lessen its severity.

These observations do not mean that this keratinization of the epithelium is of little importance. There are many troubles, noninfective in character, which increase following its occurrence. This is true for certain gastrointestinal disturbances such as diarrhea. There is a specific interference with reproduction caused by this altered epithelium which is of great importance, as is discussed later (Sec. 316). Keratinization is also responsible for certain skin troubles, such as dryness, occlusion of the hair follicles, and eruptions.

A lack of vitamin A results in the development of certain nervous disorders exemplified by a lack of coordination, a staggering gait, and spasms. These are prominent symptoms in cattle, sheep, and swine. There are degenerative changes in the nerves. Whether these changes are secondary to skeletal deformities remains a disputed question.

In vitamin A deficiency there is a lowering of the normal level of the vitamin and of carotene in the blood. Determinations of these levels are thus employed in studies of vitamin A nutrition and in estimating requirements. Variations in these levels caused by factors other than diet make interpretations difficult in the individual.

A lack of vitamin A is responsible for certain injuries to the teeth involving pathological changes in the odontoblasts and pulp. It also results in a loss of appetite which is doubtless one cause of the growth failure.

157. Chemical Nature of Vitamin A and Carotene.-Chemical isolation and identification early became a goal of vitamin research because of the recognized importance of working with pure substances of known composition, rather than with concentrates containing many other chemical compounds besides the vitamin 
under study. In view of the enormous difficulties involved in isolating substances which are complex in nature, present in only minute amounts, and rather unstable, it is not surprising that our knowledge of the chemical nature of the vitamins has lagged far behind their discovery. Remarkable progress has been made during the last 15 years with the result that today we have fairly complete information regarding a number of these essentials.

Vitamin .A is a nearly colorless substance having the formula, $\mathrm{C}_{20} \mathrm{H}_{30} \mathrm{O}$. It does not occur as such in plant materials, but rather as its precursors, certain carotenoid pigments which are converted into the vitamin in the animal body. The development of the knowledge as to the relationship between vitamin A and carotene and as to their chemical nature represents a highly interesting chapter of vitamin research, which illustrates the course of such studies.

In 1914 McCollum and Davis found that the vitamin was contained in the unsaponifiable fraction of milk fat and later studies confirmed its identity as an unsaponifiable constituent extractable by lipid solvents. In 1919 Steenbock called attention to the fact that among vegetable foods vitamin A potency was associated in a rather remarkable way with yellow color, and, shortly thereafter, he and his associates published many data demonstrating this association. They went so far as to suggest that carotene was the source of the vitamin. This view was not accepted by other workers, and Steenbock came to recognize that the vitamin was not carotene itself because certain potent sources of the vitamin were colorless. It was 10 years before the riddle was solved.

In the meantime studies in various laboratories gradually built up the body of information which provided the answer. Drummond and his associates used an old color reaction for cod-liver oil as a basis for developing a test which provided a method for the detection and estimation of vitamin $\mathrm{A}$. The test involved the production of a brilliant blue color by arsenic trichloride. Later the test was modificd by Carr and Price by the substitution of antimony trichloride for the arsenic compound and the test is known today as the Carr-Price reaction. The spectrograph (Sec. 20) also came into use for studying the nature of the vitamin, and its content in fish-liver oils was found to be correlated with a selective absorption with a maximum at $328 \mathrm{~m} \mu$. Both the color 
reaction and the absorption spectrum proved very useful in the later studies which resulted in the identification of the vitamin and in demonstrating its relationship to carotene.

Renewed beliefs in this relationship caused von Euler and associates ${ }^{1}$ in Stockholm to conduct carotene-feeding experiments. They obtained a definite growth response when the pigment was added to a vitamin $\mathrm{A}$ deficient diet, and their results were quickly confirmed by several others. In 1930 Moore ${ }^{2}$ produced proof that the animal body transformed carotene into vitamin $\mathrm{A}$. $\mathrm{He}$ fed rats on a diet which resulted in the symptoms of deficiency. Some of the animals were then killed, and their livers found devoid of $\mathrm{A}$. The rest of the animals were fed carotene with a resulting disappearance of the deficiency symptoms, and, on autopsy, their livers were found rich in the vitamin. Moore summarized the information as follows:

Carotene

Synthesized in plant

Orange red in color

No selective absorption in vicinity of $3280 \AA$ A.

Greenish blue color with antimony trichloride, with maximum at $5900 \AA$ A.
Vitamin A

Stored in animal

Almost colorless

Marked absorption in 3280 Å.

Vivid blue color with antimony trichloride, showing maxima at 5270 and $6060 \AA$.

Meanwhile halibut-liver oil had been found an especially concentrated source of the vitamin, and fractionation methods were applied to it to isolate the active substance. These methods brought success by 1932 in the isolation, by Karrer and his associates in Switzerland and by Drummond and his coworkers in England, of a very active fraction which was identified as an unsaturated alcohol having the formula, $\mathrm{C}_{20} \mathrm{H}_{30} \mathrm{O}$. Karrer proposed the structural formula given on page 185 which shows the compound to have a $\beta$-ionone ring and an unsaturated side chain.

There followed the brilliant researches by Karrer, by Kuhn in Germany, and by others which established the chemical structure of the highly complex hydrocarbon, carotene, which was previously known to have the empirical formula, $\mathrm{C}_{40} \mathrm{H}_{56}$. Several

1 von Euler, Beth, Hans von Euler, and Harry Hellström, A-vitaminwirkungen der Lipochrome, Biochem. Z., 203, 370-384, 1928.

${ }^{2}$ Moore, Thомаs, Vitamin A and carotene. I. The association of vitamin A activity with carotene in the carrot root, Biochem. J., 23, 803-811, 1929. 
SEc. 157]
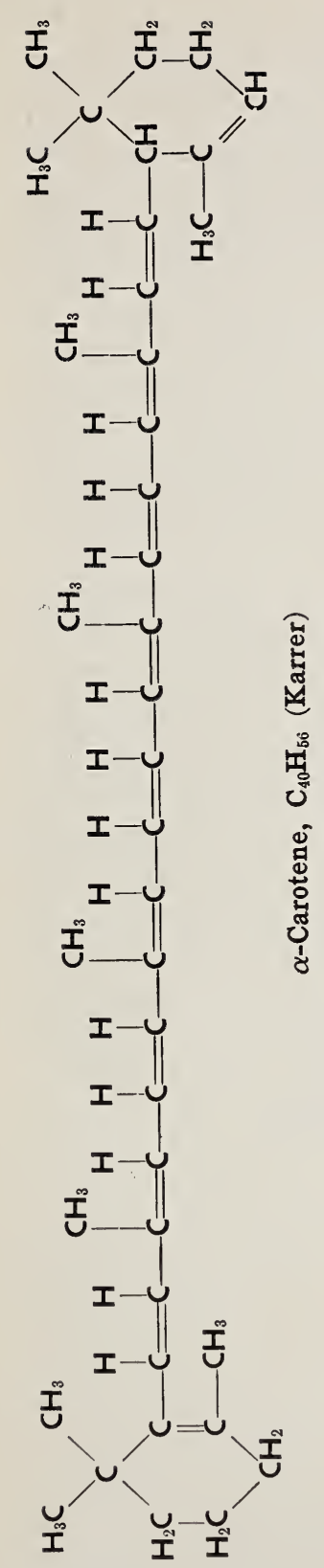

THE VITAMINS

185

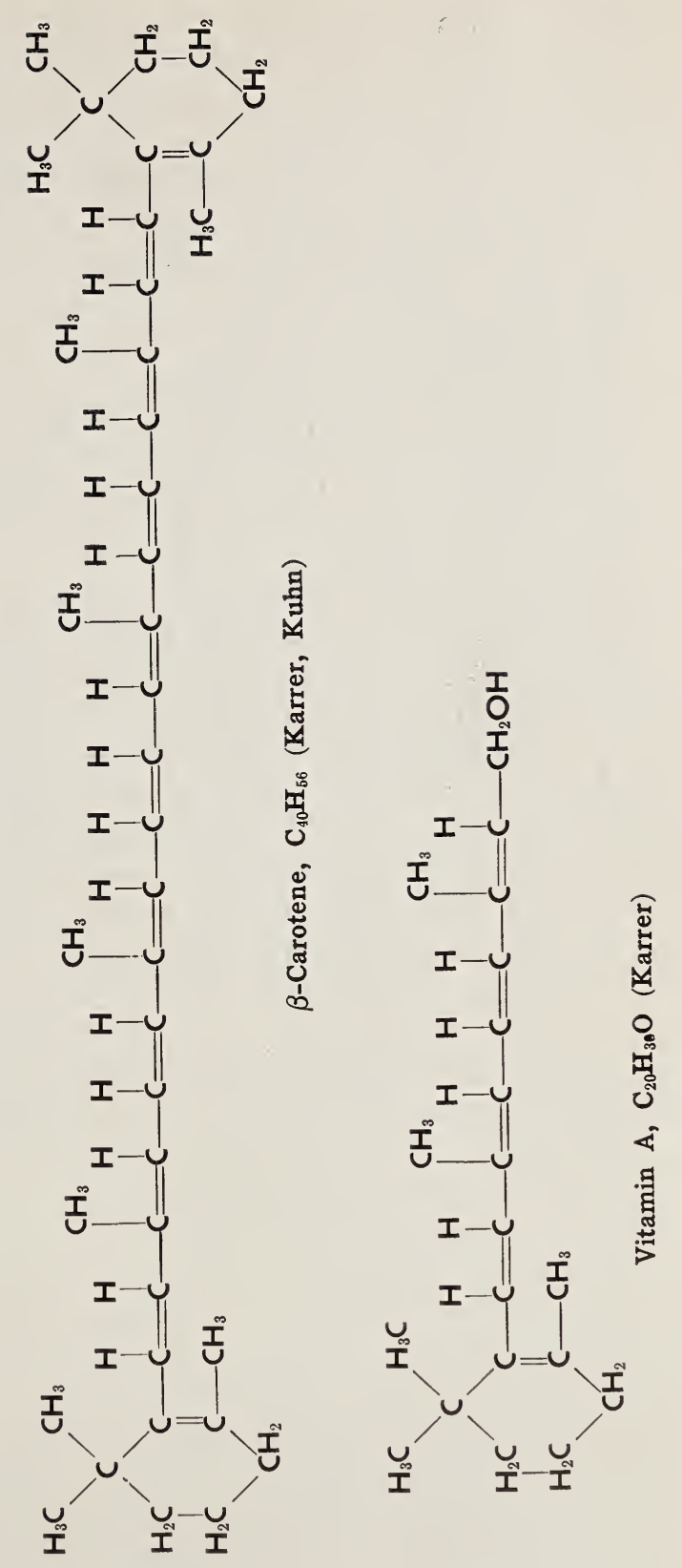


isomeric forms of carotene were isolated and their structural formulas worked out. All were reddish-yellow crystalline compounds which differed, however, as regards optical activity and the wave length at which maximum color absorption occurred. It is now recognized that there are four different carotenes which have vitamin A activity, viz., $\alpha$-, $\beta-\gamma-$, and hydroxy- $\beta$-carotene. The last one is also called cryptoxanthine and is the form found in yellow corn. Most of the carotene of other feeds is in the $\beta$-form.

The formulas shown on page 185 reveal that vitamin A contains a $\beta$-ionone ring and that $\beta$-carotene contains two of these rings while $\alpha$-carotene contains only one. Thus $\beta$-carotene can yield two molecules of vitamin A while the other carotenes can yield only one, giving the $\beta$-form approximately twice the vitamin A potency of the others.

Vitamin A exists only in the animal kingdom. Here it occurs both as the free alcohol and also as esters of the higher fatty acids and is related to unsaturated acids. Very recently it has been discovered that there is another form of vitamin $A$, referred to as $\mathrm{A}_{2}$ to distinguish it from the common form, $A_{1}$, previously described. $\mathrm{A}_{2}$, which was isolated from fresh-water fish, has not been crystallized, but it is distinguished from $\mathrm{A}_{1}$ by its maximum absorption at 345 to $350 \mathrm{~m} \mu$ in contrast to 325 to $328 \mathrm{~m} \mu$ for $\mathrm{A}_{1}$.

Differing from the nutrients previously considered, the vitamins as a class are susceptible to destruction in varying degrees by certain physical and chemical agents which may become operative in the course of some of the processes to which feeds are subjected. The same is true during storage under certain conditions. The different vitamins vary greatly in their susceptibility to the action of these agents. Both carotene and vitamin $\mathrm{A}$ are destroyed by oxidation, and this is the most common cause of any depreciation which may occur in the potency of sources of them. The process is accelerated at high temperatures, but heat without oxygen has a minor effect. Butter exposed in thin layers in air at $50^{\circ} \mathrm{C}$. loses all its vitamin A potency in six hours, but, in the absence of air, there is little destruction at $120^{\circ} \mathrm{C}$. over the same period. Codliver oil in a tightly corked bottle has shown activity after 31 years, but it may lose all of its potency in a few weeks when incorporated in a feed mixture stored under the usual conditions.

This latter fact has an important practical bearing. Neither proprietary nor home-mixed feeds can be relied upon to contain 
the vitamin A potency originally present in the cod-liver oil or similar products included as an ingredient. The distribution of the oil over the other constituents provides a large surface for oxidative action, and this process is accelerated by the presence of prooxidants (Sec. 58) in any rancid fats present in the feed. Such fats in the oil itself are of course particularly operative. Certain metals also, such as iron, catalyze the destructive action. Carotene appears to be less rapidly destroyed than the vitamin itself, but, when dissolved in oil and added to a feed stored at room temperature, losses as high as 68 per cent have been reported after 16 weeks. With both carotene and the vitamin, the nature of the associated substances has a marked influence on the rate of destruction. In all cases the action is retarded by storage at low temperature. Large losses in vitamin value as a result of oxidation take place in the curing of roughages and in certain other feed-preservation processes. The presence of prooxidants and antioxidants in the plant tissues plays a role in the extensiveness of the destruction. Corn has been reported to lose as much as 60 per cent of its vitamin A value on seven months' storage.

The cooking processes commonly used in human food preparation do not cause much destruction of the vitamin potency. Hydrogenation of fats lessens their vitamin A value, and thus the commercial products prepared for culinary purposes commonly contain none of the vitamin, though it may have been present in the original material. Saponification does not destroy the vitamin if oxidation is avoided.

158. Metabolism of Carotene and Vitamin A.-The absorption of vitamin A, and particularly of carotene, varies according to the nature of the diet, especially its fat content, and the species. There is evidence that some of the carotene ingested is destroyed in the intestine and that this destruction is lessened by the presence of antioxidants such as vitamin $\mathrm{E}$ in the feed. Absorbed carotene is converted into vitamin $\mathrm{A}$ in the liver, but the extent of the conversion varies with the species. The rat is the best converter. The cow makes only a limited conversion, as is evident from the carotene secreted in the milk and from the relation of this carotene secretion to its supply in the feed. All these variables affecting carotene absorption and conversion greatly complicate the problem of measuring the true vitamin $A$ value of feeds and rations for different species (Sec. 160). 
Both vitamin $\mathrm{A}$ and carotene can be stored in the animal body, and, in those species in which the conversion is only partial, a large storage of carotene occurs on diets rich in the pigment. The extensive and thorough studies of Guilbert and Hart ${ }^{1}$ with cattle have contributed a large amount of information along these lines. The total storage of carotene and vitamin $\mathrm{A}$ in the liver and depot fat of cows which had access to a carotene-rich ration throughout life was estimated to be 0.6 to $0.7 \mathrm{~g}$. for the younger animals and up to $3.6 \mathrm{~g}$. in aged cows. From 67 to 93 per cent of the storage was in the liver. In this organ most of the storage was in the form of the vitamin itself, while in the fat depots carotene predominated. A cow whose reserves were depleted was fed approximately $15 \mathrm{~g}$. of carotene in freshly cut alfalfa during a period of 13 days and stored about $400 \mathrm{mg}$. It is evident that the rate of storage with a high intake can greatly exceed the rate of depletion on a vitamin-deficient diet. Guilbert and Hart found that over 200 days elapsed before the livers of animals which had previously received feeds rich in carotene were completely depleted of the vitamin and its precursor. In studies with rats, Davies and Moore ${ }^{2}$ have shown that the adult is able to store, with massive doses, enough vitamin A in its liver to supply its theoretical requirement for a century but that these superfluous stores are eliminated at a very rapid rate until a state of stable storage is reached.

The storage of vitamin A or its precursor or both appears to be a function of all species. It has a large practical importance in nutrition because it provides a means whereby reserves can serve during periods of dietary scarcity, and it eliminates the necessity of a constant daily supply of the vitamin or its precursor in the diet. A quantity sufficient to protect a rat for several months can be given in a single dose. Animals on good pasture can store extensive reserves to help meet their needs during the winter feeding period when their rations may be deficient. This large capacity to store the vitamin must be taken account of in studies of

${ }^{1}$ Guilbert, H. R. and G. H. HART, Storage of vitamin A in cattle, $J$. Nutrition, 8, 25-44, 1934; Minimum vitamin A requirements with particular reference to cattle, ibid., 10, 409-427, 1935.

${ }^{2}$ Davies, Alan W., and Thomas Moore, Vitamin A and carotene. XII. The elimination of vitamin A from the livers of rats previously given massive doses of vitamin A concentrate, Biochem. J., 29, 147-150, 1935. 
requirements in order to make sure that intakes that appear adequate for a given function are not being supplemented by reserves stored up prior to the period of observation.

Among cattle there are marked breed differences as regards ability to convert carotene into the vitamin. This is reflected in the difference in color of the depot fat and milk fat between Holsteins and Jerseys. The bearing of this on the vitamin potency of the milk produced is discussed later (Sec. 357).

159. Quantitative Determination of Vitamin A Value.-The improvement and standardization of methods for the quantitative estimation of the vitamin A value of foods constitute a very active field of research at the present time. Biological, chemical, and physical methods are being employed. Since the procedures are constantly being modified, the description of the methods in use will be limited to a statement of the principles involved.

The biological method measures the total potency whether owing to the vitamin itself or to its precursor or to both, while certain others determine only one of these substances. The food to be tested is fed at several levels to different groups of young rats, as a supplement to a vitamin A-free diet which has caused growth to cease. The growth response is then compared with that produced in a similar group of rats receiving as a supplement a standard source of the vitamin, such as $\beta$-carotene or a "reference cod-liver oil." In this way the amount of the feed under test which gives the same response as the standard supplement is determined and the potency is expressed in units per gram. The International unit (I.U.) is officially defined as the potency equivalent to $0.6 \mu \mathrm{g}$. of pure $\beta$-carotene. Under the same test conditions $1 \mu \mathrm{g}$. of pure crystalline vitamin $\mathrm{A}$ has been found equivalent to approximately 4 I.U.; i.e., $0.6 \mu \mathrm{g}$. of $\beta$-carotene is equivalent to $0.25 \mu \mathrm{g}$. of vitamin $\mathrm{A}$. This relationship is somewhat different from that indicated by the chemical evidence that $\beta$-carotene hydrolyzes into two molecules of vitamin A.

Vitamin A as such can be determined spectrophotometrically in fish oils, calculating I.U. from the extinction coefficient ( $E$ value) at $3280 \AA$. It can also be determined colorimetrically by the Carr-Price reaction (Sec. 157). Carotene content can be estimated colorimetrically or spectrophotometrically, but difficult problems arise here in extracting from the plant products the solution to be tested. $\beta$-carotene must be freed from other pig- 
ments, and if other active carotenes are present, they must be separately evaluated. Thus, each plant product presents a special problem. Failure to recognize this fact has resulted in some unreliable values in the literature. Special problems are met in applying the colorimetric or spectrophotometric procedure to butter, which contains both vitamin $\mathrm{A}$ and carotene and also added coloring material. Details cannot be here given, either as to these various procedures or their limitations. Pertinent studies are cited at the end of this chapter.

The rat-assay method overvalues the actual vitamin A potency of a food that contains much of this potency in the form of carotene because the rat utilizes carotene to a greater degree than do other species. It is recognized in human nutrition, for example, that 1 I.U. supplied as carotene is only about half as valuable as 1 I.U. of the vitamin itself, though both are equal by definition, as determined with the rat. Thus it is considered that the adult needs about 3000 I.U. as vitamin A, or 6000 I.U. as carotene, daily, and the recommended dietary allowance of 5000 I.U., set up by the National Research Council, assumes that approximately twothirds will be supplied by carotene and one-third by the vitamin itself. In the case of cows, Guilbert found that it took approximately twice as many I.U. of carotene as of vitamin A to prevent night blindness in cattle and that the ratio was wider at the higher levels needed for storage and reproduction. The pig and sheep also utilize carotene less efficiently than does the rat.

The errors here involved in using rat-assay values, or in applying the relationship found in the rat assay to determining the vitamin A values of plant products fed to farm animals, are obvious. For this reason it is becoming an increasing practice to state animal requirements both as carotene and as vitamin $\mathrm{A}$ and to express the carotene and vitamin A content of feeds separately, both in $\mu \mathrm{g}$. This enables one to calculate how the needs of a given species can be met in terms of a specific feed supply, as is illustrated in later chapters where requirements are discussed.

160. Vitamin A Value of Feeds.-The richest sources of vitamin A are the fish oils. Some swordfish-liver oils contain as many as 200,000 units of vitamin A per gram. Halibut-liver oil may run as high as 70,000 units. Thus both are many times more potent than cod-liver oils. Products from the same species, however, may be highly variable in potency, and thus, in their manufacture 
for use as vitamin A supplements, they are subjected to a biological assay in order that the user may be assured of a certain minumum potency. Among the common foods of animal origin, milk fat, egg yolk, and liver are rated as rich sources, but this is not the case if the animal from which they come has been receiving an A-deficient diet for an extended period. Since the vitamin is present in the fat, skim milk contains very little.

In the nutrition of farm animals, we are primarily interested in the potency of plant products. Though the yellow color is masked by chlorophyll, all green parts of growing plants are rich in carotene and thus have a high vitamin A value. Good pasture always provides a liberal supply, and the kind of pasture plant, whether grass or legume, appears to be of minor importance. At maturity, however, leaves contain much more than stems, and thus legume hay is much richer in vitamin content than timothy or other grasses. With all hays and other forage, the vitamin value decreases after the bloom stage, and much of the carotene is destroyed by oxidation in the process of field curing. Russell ${ }^{1}$ found that there may be a loss 'of more than 80 per cent of the carotene of alfalfa during the first $24 \mathrm{hr}$. of the curing process. It occurs chiefly during the hours of daylight, owing to photochemical activation of the destructive process. Hays which are cut in the bloom stage or earlier and cured without exposure to rain or to too much sun retain a considerable proportion of their carotene content, while those which are cut in the seed stage and exposed to rain and to the sun for extended periods lose it almost entirely. Under similar conditions of curing, alfalfa and other legume hays are much richer than grass hays because of their leafy nature, but a poor grade of alfalfa may have less than a good grade of timothy.

In the artificial curing of hay with a "hay drier," there is only a slight loss of carotene because of the rapidity of the process. Russell and coworkers found the machine-dried product to have two to ten times the value of field-cured alfalfa. Severe heating of hay in the mow or stack reduces the vitamin content, and there is a gradual loss in storage so that old hay is poorer than new. Owing to their higher initial content machine-dried hays are subject to larger percentage losses than field-cured. Losses as

1 Russeld, WALTER ( $\%$, The effect, of the euring process upon the vitamin $\Lambda$ and D content of alfalfa, J. Biol. Chem., 85, 289-297, 1929. 
high as 60 per cent have been reported from July to November, but they were found much smaller during the colder months. Temperature is the major factor causing variations in loss during storage.

The degree of greenness in a roughage is a good index of its carotene content. The data in Table XIII are useful to indicate

\section{Table XiII.-Eistimated Carotene Content of Feeds in Relation} to Appearance and Methods of Conservation *

\begin{tabular}{|c|c|}
\hline Feedstuff & $\begin{array}{c}\text { Carotene } \\
\text {-mg. per } \\
\text { pound }\end{array}$ \\
\hline Fresh green legumes and grasses, immature ............ & 15 to 40 \\
\hline 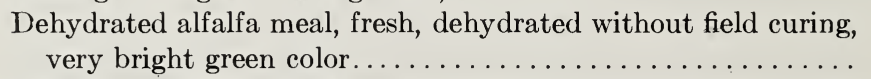 & 110 to 135 \\
\hline $\begin{array}{l}\text { Dehydrated alfalfa meal after considerable time in storage, bright } \\
\text { green color } \ldots \ldots \ldots \ldots \ldots \ldots \ldots \ldots \ldots \ldots \ldots \ldots \ldots \ldots \ldots \ldots \ldots \ldots\end{array}$ & 50 to 70 \\
\hline Alfalfa leaf meal, bright green color . . . . . . . . . . . . & 60 to 80 \\
\hline $\begin{array}{l}\text { Legume hays, including alfalfa, very quickly cured with minimum } \\
\text { sun exposure, bright green color, leafy } \ldots \ldots \ldots \ldots \ldots \ldots \ldots\end{array}$ & 35 to 40 \\
\hline Legume hays, including alfalfa, good green color, leafy . . . . . . & 18 to 27 \\
\hline $\begin{array}{l}\text { Legume hays, including alfalfa, partly bleached, moderate } \\
\text { amount of green color } \ldots \ldots \ldots \ldots \ldots \ldots \ldots \ldots \ldots \ldots \ldots \ldots\end{array}$ & 9 to \\
\hline $\begin{array}{l}\text { Legume hays, including alfalfa, badly bleached or discolored, } \\
\text { traces of green color } \ldots \ldots \ldots \ldots \ldots \ldots \ldots \ldots \ldots \ldots \ldots \ldots\end{array}$ & 4 to \\
\hline $\begin{array}{l}\text { Nonlegume hays, including timothy, cereal, and prairie hays, } \\
\text { well cured, good green color } \ldots \ldots \ldots \ldots \ldots \ldots \ldots\end{array}$ & 9 to \\
\hline Nonlegume hays, average quality, bleached, some green color. . & 4 to \\
\hline Legume silage $\ldots \ldots \ldots \ldots \ldots \ldots \ldots \ldots \ldots \ldots \ldots$ & 5 to 20 \\
\hline Corn and sorghum silages, medium to good green color........ & 2 to 10 \\
\hline $\begin{array}{l}\text { Grains, mill feeds, protein concentrates, and by-product concen- } \\
\text { trates, except yellow corn and its by-products............ }\end{array}$ & 0.01 to 0.2 \\
\hline
\end{tabular}

* Compiled by H. R. Guilbert, University of California, and reproduced by his permission.

the order of the differences found among various roughages differing as to color, kind, and other factors. Published average values as to carotene content can serve only as approximate guides in feeding practice because of the many factors affecting the actual potency of individual samples as fed.

Aside from yellow corn and its by-products practically all of the concentrates used in feeding animals are devoid of the vitamin or nearly so. The potency of yellow corn is only about one-eighth that of good roughage. Roots and tubers as a class supply prac- 
tically no vitamin A, but carrots are a very rich source and so are sweet potatoes, as might be expected from their yellow color. Pumpkins and squash also supply considerable amounts. The green leafy vegetables used in human nutrition are rich.

Tankage, meat scraps, and similar animal by-products have little if any vitamin A potency. Certain fish meals are fair sources, but variation in the raw material, and in the methods of processing which may entirely destroy any potency originally present, make generalizations here of no value.

\section{VITAMIN D}

Only a few years after vitamin A was discovered, it became clear, through the work of Mellanby in England with dogs, that a dietary deficiency was concerned in rickets. The proof that it was due to a distinct vitamin was furnished by McCollum and associates ${ }^{1}$ in 1922 . This proof was obtained by oxidizing codliver oil until vitamin A was destroyed, as shown by the inability of the oil to cure xerophthalmia, and then by demonstrating that the oxidized oil was still effective in curing rickets.

161. Physiological Functions and Symptoms of Deficiency.In view of the circumstances of the discovery of vitamin $\mathrm{D}$ as well as the fact that cod-liver oil had long been known to be effective in the cure of rickets, the term, antirachitic factor, naturally arose. It. is evident from previous discussions (Sec. 112) that, however the term is defined, rickets is a disturbance of calcium and phosphorus metabolism and that the mineral relations in the diet as well as the vitamin are involved. There can be no calcification without calcium and phosphorus. On the other hand, the vitamin has a nutritional significance in addition to its relation to this disturbance of bone growth.

Undoubtedly vitamin $\mathrm{D}$ is always required for the normal calcification of the growing bone, but the amount needed varies with the mineral relations in the diet and also with the species. More is required when the amount of either element or the ratio between them is suboptimum. But no amount will compensate

1 McCollum, E. V., Nina Simmonds, J. E. Becker, and P. G. Shipley, Studies on experimental rickets. XXI. An experimental demonstration of the existence of a vitamin which promotes calcium deposition, J. Biol. Chem., 53, 293-321, 1922. 
for severe deficiencies of either mineral. Theiler, ${ }^{1}$ for example, has shown that rickets develops in calves on a low-phosphorus ration despite a very large supply of $\mathrm{D}$ in the form of radiant energy (Sec. 162). The species differences are illustrated by the fact that with adequate intakes of calcium and phosphorus a ration which contains only enough vitamin $\mathrm{D}$ to produce normal bone in the rat or pig will very quickly cause the development of rickets in chicks. Surprisingly, the human baby is more like the bird in this respect than the other mammals mentioned. Turkeys and pheasants have higher requirements than chicks. The effect of a lack of vitamin D and calcium on bone structure in young cattle is strikingly illustrated in Fig. 19.

The necessity of vitamin $\mathrm{D}$ for normal calcification during growth has been demonstrated for many different species. The physical symptoms and bone and blood changes characteristic of inadequate calcification have been described (Sec. 112). The role of vitamin $\mathrm{D}$ in the adult appears much less important except during reproduction and lactation. Congenital malformations in the newborn result from extreme deficiencies in the diet of the mother during gestation, and the mother's skeleton is injured as well. While there is no large transfer to the fetus, a liberal intake during gestation does provide a sufficient store in the newborn to help prevent early rickets. For example, newborn lambs can be provided enough in this way to meet their needs for six weeks.

A lack of the antirachitic factor decreases egg production and hatchability, and the few eggs laid have thin shells and are easily broken. The vitamin content of the eggs produced is influenced by the amount present in the diet of the hen (Sec. 324). In view of the intense calcium and phosphorus metabolism that takes place in lactation, one would expect vitamin $\mathrm{D}$ to play a large role in milk secretion. This is not true in the case of the cow, as is discussed later (Sec. 359). It has proven valuable in the case of human lactation, however. Other species have been little studied. Apparently the vitamin is not readily secreted into milk, for massive doses in the feed are required to influence its concentration in this secretion. Ordinary levels of cod-liver oil are ineffective for this purpose.

1 Theiler, Arnold, The osteodystrophic diseases of domesticated animals. I. The structure of the bone; atrophy; osteoporosis; osteomyelitis, Vet. $J$., 90, 143-158, 1934. 
It is evident that the body has some ability to store the vitamin, though to a much lesser extent than is the case for vitamin A. The principal store of vitamin D occurs in the liver, but it is also found in the blood, lungs, kidneys, and elsewhere.

There is no satisfactory information at the present time as to just how and where vitamin $\mathrm{D}$ functions in aiding calcium and

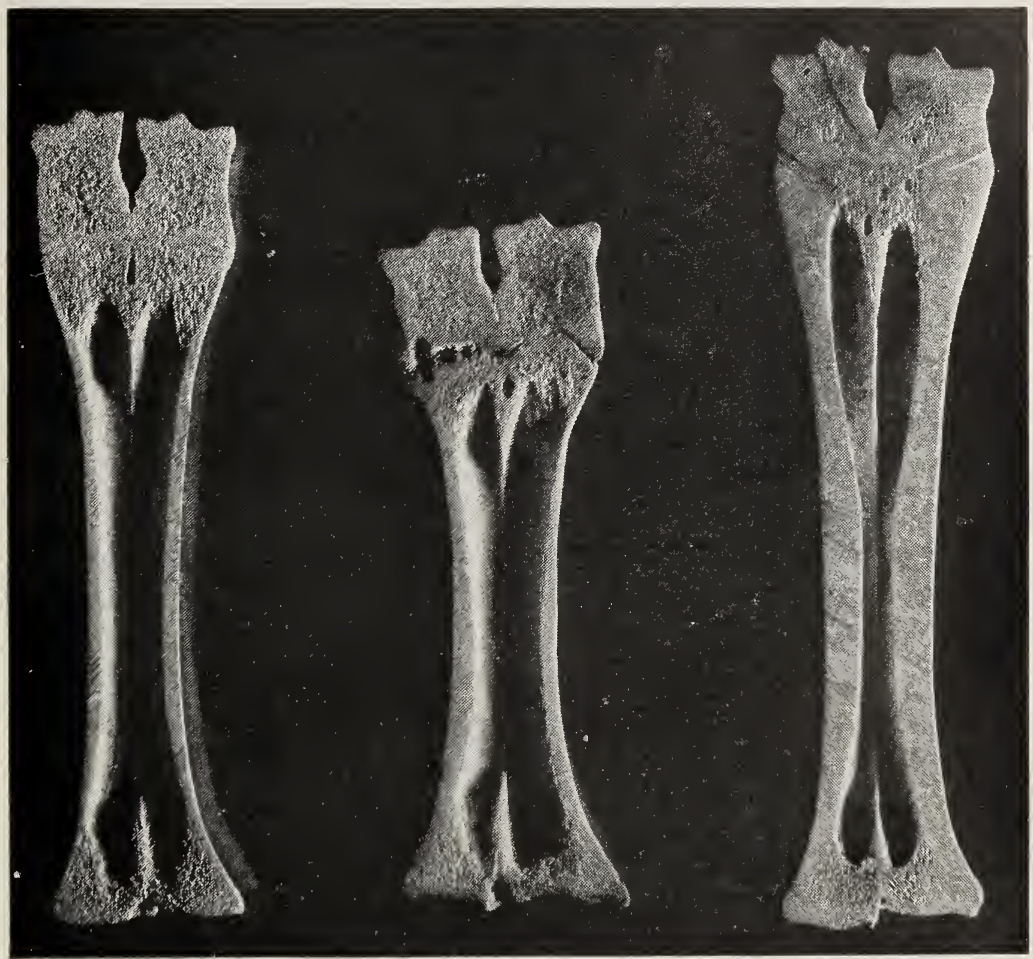

FIG. 19.-Effect of a deficiency of vitamin D and calcium on bone development in young cattle.

The bone on the right is from a normal animal; the other two from affected animals. Note the differences in thickness of walls and density. (From T. W. Gullickson, L. S. Palmer and W. L. Boyd. A rickets-like disease in young cattle. Minn. Agr. Expt. Sta. Tech. Bull. 105, 1935.)

phosphorus metabolism. It was early noted that in rickets the $\mathrm{pH}$ of the intestinal contents and of the feces was more alkaline than normal and that this condition was corrected by the ingestion of vitamin D. 'This observation, in view of the recognized effect of an acid reaction in promoting calcium and phosphorus absorption, led to the view that the vitamin functioned by increasing 
absorption. Later, more specific evidence has strengthened the belief that the vitamin either increases absorption or decreases reexcretion. But many feel that this is, at least, not the full explanation. Other possibilities are that the vitamin functions in an enzyme system in bone deposition or that it influences the phosphorus or calcium levels in the blood. The whole subject needs further investigation.

162. Vitamin D and Radiant Energy.-While the value of sunlight in the treatment of rickets had been known for many years prior to the discovery of vitamin $\mathrm{D}$, it was not until $\mathrm{X}$-ray methods of diagnosis became available that positive proof was obtained of a specific effect on bone calcification. Using these methods Huldschinsky ${ }^{1}$ demonstrated in 1919 that ultraviolet light caused the deposition of calcium salts in the bones of rachitic children and thereby cured the disease. Later work showed that sunlight was also effective.

When it became evident that both ultraviolet light and a factor present in cod-liver oil produced an identical effect in the healing of rickets, the question naturally arose as to why two such apparently unrelated factors could produce the same specific results. The answer was not long in coming. Following the studies of Goldblatt and Soames showing that the livers of irradiated rats possessed antirachitic properties, Hess of Columbia University and Steenbock of Wisconsin, independently and almost simultaneously, announced in 1924 that food materials which were ineffective in preventing rickets could be made antirachitic by exposing them to ultraviolet light. The original announcements were published in detail by Hess and Weinstock, ${ }^{2}$ by Steenbock and Black ${ }^{3}$ and by Steenbock and Nelson. ${ }^{4}$ Several other papers quickly followed showing that a great variety of edible materials

${ }^{1}$ Huldschinsky, K., Heilung von Rachitis durch künstliche Höhensonne, Deut. med. Wochschr., 45, 712-713, 1919.

${ }^{2}$ Hess, A. F. and Mildred Weinstock, Antirachitic properties imparted to inert fluids and to green vegetables by ultra-violet irradiation, J. Biol. Chem., 62, 301-313, 1924.

${ }^{3}$ Steenbock, Harry, and Archie Black, Fat-soluble vitamins. XVII. The induction of growth-promoting and calcifying properties in a ration by exposure to ultra-violet light, J. Biol. Chem., 61, 405-422, 1924.

${ }^{4}$ Steenbock, Harry, and M. T. Nelson, Fat-soluble vitamins. XIX. The induction of calcifying properties in a rickets-producing ration by radiant energy, J. Biol. Chem., 62, 209-216, 1924. 
could be activated, that the same short-wave lengths were here concerned as were effective in irradiating the body, and that the active substance was in the unsaponifiable fraction. These observations provided the working hypothesis that radiant energy cured rickets because it activated some precursor in the body to provide the active agent, that by similar action it produced in certain foods a similar agent which became effective upon ingestion, and that certain substances such as cod-liver oil naturally possessed this agent. Leads were thus provided for an attack on the problem of the chemical nature of the antirachitic factor.

163. Chemistry of Vitamin D.-The knowledge that the active substance in materials made antirachitic by irradiation was in the nonsaponifiable fraction led to experiments with various sterols which resulted in the initial conclusion that cholesterol was the specific one activated. Later studies showing that irradiated ergosterol was much more active were responsible for the view that the activity of cholesterol was due to ergosterol as a contaminant. Several different kinds of evidence from various laboratories led to the conviction by 1928 that ergosterol was the precursor which became vitamin $\mathrm{D}$ through a molecular rearrangement brought about by the action of radiant energy. Attention was next directed to the very difficult task of isolating the active substance present in the resinous gum which resulted from the most effective irradiation of the crystalline ergosterol. Success was achieved by 1932. A group of English workers isolated from the mixture of sterols, which resulted from irradiation of ergosterol, a highly active crystalline substance which they named calciferol, and an essentially identical substance was simultaneously obtained by Windaus and associates in Germany. Calciferol, designated $\mathrm{D}_{2}$, melts at 114 to $117^{\circ} \mathrm{C}$. and is isomeric with ergosterol, which melts at $166^{\circ} \mathrm{C}$. Ergosterol has three double bonds while calciferol has four. Thus irradiation results in breaking one of the carbonto-carbon linkages.

Further studies with different species and different sources of the vitamin led to proof that the original idea as to the activity of irradiated cholesterol was also correct. The active compound was isolated from fish-liver oil, and also prepared by irradiating 7-dehydrocholesterol. It was designated $\mathrm{D}_{3}$. Its formula is shown along with that of $\mathrm{D}_{2}$. Later other active compounds were discovered, and now it is known that there are at least 10 sterol 
<smiles>CC(C)C(C)C=CC(C)C1CCC2=CC=C3CC(O)CC3CCC2CC1</smiles>

Calciferol (vitamin $\mathrm{D}_{2}$ ), $\mathrm{C}_{28} \mathrm{H}_{44} \mathrm{O}$ An active product of ergosterol

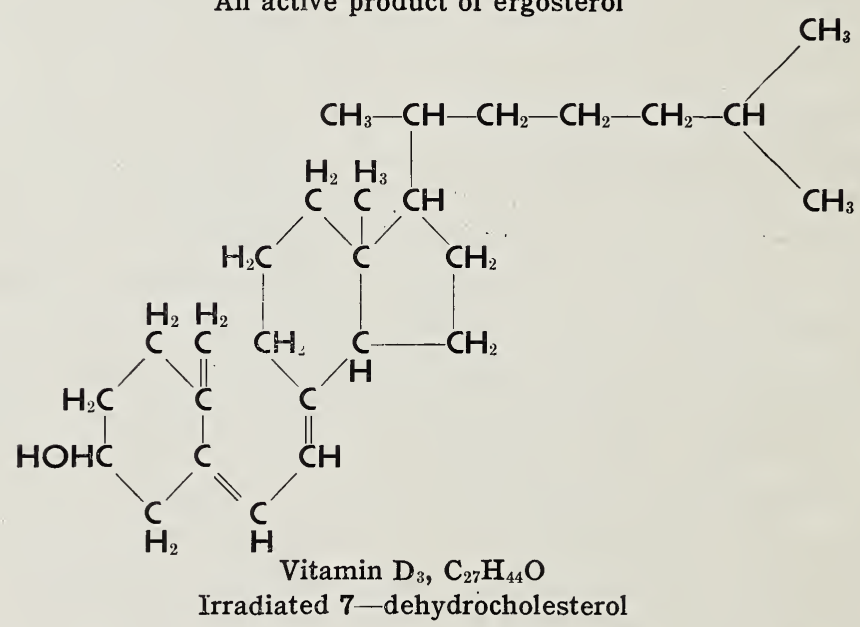

derivatives that have vitamin $\mathrm{D}$ activity. Thus one speaks of the "multiple nature" of this vitamin. Only $\mathrm{D}_{2}$ and $\mathrm{D}_{3}$ are important, however, in terms of the normal food supply.

Vitamin $\mathrm{D}_{2}$ is the form found in plant products, such as hay, after irradiation, in yeasts and thus in vitamin $\mathrm{D}$ milk produced by yeast feeding (Sec. 360). Vitamin $D_{3}$ is the animal form found in fish oils, irradiated milk, and in the body after irradiation. Both have the same antirachitic value for the rat, but $\mathrm{D}_{3}$ is much more effective for the chick. They also differ in their activity for turkeys. Marked differences between them have not been established for other animals or for man. 
Under most conditions, both forms of vitamin D are much more stable than vitamin A. It has recently been found, however, that when fish-oil concentrates or activated animal sterols are combined with minerals, particularly calcium carbonate, as a premix for storage and later inclusion in poultry feeds, over half of the vitamin $\mathrm{D}$ activity is destroyed in less than a month, and nearly all in four months. Industrial practices are being changed accordingly. These findings emphasize the importance of a study of other conditions under which the vitamin may be less stable than previously thought.

164. Vitamin D Assay.-The antirachitic value of a food can be measured either by chemical analysis of the bones or by X-ray methods or by the "line test." The latter, originally developed by McCollum and associates, ${ }^{1}$ is the one at present recommended by the U.S. Pharmacopoeial Vitamin Advisory Board. The deposition of calcium salts in the metaphyses of the distal ends of the radii and ulnae of growing rats is measured by the extent of the staining of sections by silver nitrate. Standard rats are first made rachitic on a basal ration, and then the substance to be tested is added in graded amounts to different groups and the calcification compared with that obtained in a group receiving a reference cod-liver oil of known potency. For the details of the test, the student is referred to the most recent announcement of the advisory board.

Vitamin D potency is expressed in rat units per gram. The U.S.P. unit, which is also the International unit, is the activity of $1 \mathrm{mg}$. of the International standard solution of irradiated ergosterol, prepared under conditions defined by the League of Nations Health Organization. Since the two principal forms of vitamin D differ markedly, per rat unit, in their antirachitic potency for poultry, a chick-assay procedure is used to evaluate sources for use in poultry rations. The method is detailed in the official publication of the Association of American Feed Control Officials. $^{2}$ One A.O.A.C. chick unit is defined in this publication as being "equal in biological activity for the chick to one unit of

1 McColtum, E. V., and associates, Studies on experimental rickets. XVI. A delicate biological test for calcium-depositing substances, J. Biol. Chem., 51, 41-49, 1922.

${ }^{2}$ Anonymous, Official publication, pp. 76-77, Association American Feed Control Officials, Inc., College Park, Md., 1946. 
vitamin D in U.S.P. Reference Cod-Liver Oil in this method of assay."

165. Vitamin D in Foods. - Of all the vitamins, the antirachitic has the most limited distribution in natural foods. Among animal products, eggs, especially the yolks, are a very good source, particularly where the diet of the hen is rich. Milk contains a variable amount in its fat fraction ( 5 to 40 U.S.P. units in cow's milk per quart), but neither cow's nor human milk contains enough to protect the baby against rickets. Other animal products are poor, as is to be expected from the fact that the storage of the vitamin in animal tissues is very limited. Certain fish meals, depending upon the nature of the raw material and its processing, contain fair amounts of the antirachitic factor.

Seeds and their by-products are practically devoid of the vitamin. So are growing crops, including pasture grass. During the sun-curing of roughages, however, vitamin $\mathrm{D}$ is formed under the action of radiant energy upon ergosterol or some other provitamin, and the principal source of the antirachitic factor in the rations of farm animals is thus provided. Legume hay which is cured in such a way as to preserve most of its leaves and green color contains considerable amounts. Alfalfa, for example, will range from 300 to 1000 I.U. per pound. Timothy and other grass hay contain less. Stemmy hay, lacking in leaves and color, which has been exposed to a minimum of sunlight may contain none, whether legume or nonlegume. Artificially dried hay contains much less than that which has been properly sun-cured. Corn silage contains a demonstrable amount of the vitamin, primarily in the portions, such as the tassels, silk, and leaves, which are dried in the field.

Cod- and certain other fish-liver oils, as well as certain fish-body oils, are rich sources of vitamin D and thus are used in both human and animal nutrition to supplement the common foods which are deficient. More commonly, however, the much more concentrated products mentioned in the following paragraph are employed.

166. Enrichment of Foods in Vitamin D.-Steenbock patented his discovery that certain foods could be enriched in the antirachitic factor by irradiation with ultraviolet light, assigning the patent to the University of Wisconsin. The process has found wide application and has proved an outstanding contribution to better nutrition. Activation is dependent upon the presence of a 
provitamin in the substance in question, and thus certain materials develop a high potency on irradiation, while others acquire little or none. The most potent products are obtained by irradiating the sterols that are subject to activation. Thus, irradiated ergosterol is produced and sold for human use in a variety of forms under the trade name "viosterol." Irradiated animal sterols and activated 7-dehydrocholesterol are the products most frequently used in poultry feeds in view of the superior value of the $\mathrm{D}_{3}$ form of the vitamin for this species. Yeast is rich in ergosterol, and thus its irradiation results in a potent source that is used for other farm animals. Milk, which normally is not a rich source of the vitamin, can be irradiated to contain 400 U.S.P. units per quart, a level also obtainable by feeding irradiated yeast (Sec. $360)$.

Foods can also be enriched in the antirachitic factor by adding to them one of the concentrated sources previously mentioned. This is another way in which vitamin $\mathrm{D}$ milk is produced.

167. Sunlight and Vitamin D Nutrition.-The previous statements that most of the commonly used feeds contain little or no vitamin $D$ suggest that there must be a widespread need for supplements of the vitamin in feeding farm animals. This would be true were it not for the sun, which by irradiation produces the factor from precursors present in the body. In sunlight, nature has provided for the deficiencies in most of her food products. The skin and sebaceous secretions contain the provitamin, and thus the activated substance is produced on and in the skin from which it is absorbed. That this absorption can take place is clear from the fact that rickets can be successfully treated by rubbing cod-liver oil on the skin. Animals also ingest some of the activated material present in the skin secretions in the process of licking the body. Irradiation is less effective on dark pigmented skin. This has been shown to be true for white and black breeds of hogs as well as for people. Irradiation is more effective on exposed skin than through a heavy coat of hair.

The effectiveness of the sunlight is dependent upon the lengths and intensity of the ultraviolet rays which reach the body. It is ineffective through ordinary window glass because the latter does not allow sufficiently short wave lengths to pass through. The radiations which reach the earth contain only a small part of the ultraviolet range which has an antirachitic effect. The shortest 
wave length which ever reaches the earth is $290 \mathrm{~m} \mu$, shorter ones being absorbed by the atmosphere. This shortest available wave length reaches the earth only in summer and only in the tropics. The greater the distance the rays have to travel, the longer is the minimum wave length which reaches the earth and the lesser the intensity of the effective radiations. Thus sunlight is more potent in the tropics than in the Temperate or Arctic zone, more potent in summer than in winter, more potent at noon than in the morning or evening, and more potent at high altitudes. These variations are of large importance in vitamin $\mathrm{D}$ nutrition. Animals which are on pasture during the summer never suffer from the lack of the antirachitic factor even though their diet is practically devoid of it. In the wintertime the story is different. At best, the animals are outside only a part of the time, there are generally fewer sunny days, and the sunlight which actually reaches the animal is much less effective than in summer. Under most conditions of practice in the latitude of the northern United States, it is unsafe to rely on exposure to sunlight to provide the antirachitic factor during the winter months, as has been definitely proven for pigs and calves.

Fortunately, especially for city dwellers, it is not necessary for the body to be in the direct sunlight in order that activation may take place. It can occur in the shadow on sunny days. "Skyshine" from the northern sky on bright days may be one-half to two-thirds as potent as direct sunlight. Rays reflected from snow and water are more potent than when direct. Clouds, smoke, and dust, however, greatly cut down the effectiveness of the light. The dust and smoke of cities are responsible for the much greater incidence of rickets in city children than occurs in the country.

168. Overdosage with Vitamin D.-Experiments with massive doses of irradiated ergosterol have shown that a condition of "hypervitaminosis" can be produced characterized by hypercalcemia, the widespread deposition of calcium salts in the arteries and various organs and tissues, other pathological changes, and even death. Fortunately the range between the body requirements and the harmful dose is rather wide. There need be no fear from intakes of the vitamin which represent the maximum ever needed for normal calcification, but, since harm can result from overdosage, it is important to bear in mind that excessive intakes 
may be injurious rather than beneficial. Harm can also result from overirradiation of the body.

\section{VITAMIN E}

As a result of the stimulus to experimentation with purified diets which followed the discovery of the first vitamin, it was frequently observed that on certain diets, which were satisfactory for growth and health, rats failed to reproduce. Studies of the cause of this failure resulted in the discovery, in the early twenties, by Evans of the University of California, Mattill of the University of Rochester, Sure of the University of Arkansas, and their associates that there is a specific dietary factor, later called vitamin E, essential for reproduction in the rat. Since that time much has been learned about its chemical nature and distribution in foods, but despite many studies the knowledge as to its physiological functions and need by various species remains in a very unsatisfactory state. Specific information regarding its significance in farm animal nutrition is especially limited.

169. Physiological Functions and Symptoms of Deficiency.--It has been definitely proved that vitamin $\mathrm{E}$ is essential for normal reproduction in the rat, both male and female. When the factor is absent from the diet of the female, death and resorption of the fetuses result. In the male, degenerative changes in the testes are produced. The injury of the male causes permanent sterility, while in the female later pregnancies are successful if the vitamin is supplied. If the deficiency in the female is not so great as to cause fetal death, it may nevertheless result in paralysis in the suckling young toward the end of the nursing period. In the mouse, fetal death and resorption result from the deficiency, but, differing from the rat, no injury is caused in the male.

Many attempts to relate vitamin $\mathrm{E}$ to similar reproductive failures in other species have resulted in negative or contradictory results. The early reports by Vogt-Moller and Bay in Denmark that vitamin $\mathrm{E}$ therapy was useful in treating reproductive failures in cattle and swine have not been borne out by later studies. Extensive experiments in the United States have failed to connect a deficiency of vitamin $\mathrm{E}$ with reproductive failure in cattle, sheep, or goats, or to demonstrate that the reproductive performance on commonly fed rations can be improved by feeding concentrated 
sources of the vitamin. Of particular interest is the study reported by Salisbury ${ }^{1}$ of the performance of bulls used for artificial insemination, involving the collection of over 1250 semen samples and the insemination of over 8200 cows. Bulls fed wheat-germ oil, a vitamin $\mathrm{E}$ concentrate, showed no superiority in fertility over those receiving the same ration without the concentrate. Nor did studies of the semen volume and quantity or of other possible variables reveal any advantage for the vitamin.

Muscular dystrophy has been experimentally produced in various species with E-deficient diets and prevented by addition of the vitamin. The external symptoms of muscle weakness and paralysis are reflected in degenerative histological changes. Of special interest in this connection is the report by Willman and associates ${ }^{2}$ of success in the prevention and even in the cure, by the use of sources of vitamin E, of "stiff-lamb disease," a trouble of sporadic occurrence in suckling lambs that are raised in dry lot.

Several studies have shown that a deficiency of vitamin $\mathrm{E}$ in the diet of the chick results in nutritional encephalomacia, characterized by an incoordinated gait, prostration, and brain lesions. "Exudative diathesis" is another deficiency symptom in the chick, the exudate appearing in various subcutaneous tissues and sometimes in the musculature. Dam ${ }^{3}$ has recently reported, however, that these chick symptoms can be developed or suppressed by changing dietary factors other than vitamin $\mathrm{E}$, thus casting doubt on their specific significance.

Several papers have indicated that vitamin E may play a role that is interrelated with that of other vitamins, such as its effect in decreasing intestinal destruction of carotene (Sec. 158).

Mason ${ }^{4}$ has presented a very interesting review of the changing concepts regarding vitamin $\mathrm{E}$ that have resulted from the many studies over the past 20 years. In this paper he develops the idea that most of the changes considered to result from a deficiency

${ }^{1}$ Salisbury, G. W., A controlled experiment in feeding wheat germ oil as a supplement to the normal ration of bulls used for artificial insemination, J. Dairy Sci. 27, 551-562, 1944.

${ }^{2}$ Willman, J. P., et al., Prevention and cure of muscular stiffness ("stifflamb" disease) in lambs, J. Animal Sci., 4, 128-32, 1945.

${ }^{3}$ Dam, Henrik, Studies on vitamin E deficiency in chicks, $J$. Nutrition, 27, 193-211, 1944.

${ }^{4}$ MASON, KarL E., Changing concepts of the antisterility vitamin (vitamin E), Yale J. Biol. and Med., 14, 605-617, 1942. 
of the vitamin can be classed as injuries to either the vascular system or to muscle.

The rat has a large ability to store vitamin $\mathrm{E}$ in its tissues. This is shown by the fact that females born of mothers whose diets contained a liberal supply frequently have enough in their bodies at birth to carry them through a first pregnancy. Rats reared on natural foods rich in the factor and then placed on a deficient diet may produce three or four litters before exhausting their reserves. The vitamin $\mathrm{E}$ content of the body tissues can also be demonstrated by feeding these tissues to females which have failed as a result of a deficiency and noting the recovery that occurs. Storage doubtless complicates a study of questions now at issue as to the functions of the vitamin and its need by various species.

170. Chemistry of Vitamin E.-The vitamin is found in the nonsaponifiable fraction of fats and oils, as is the case also with vitamin D. In 1936 Evans and associates isolated from wheat germ an alcohol having vitamin $\mathrm{E}$ activity, for which the term $\alpha$-tocopherol was proposed. Two years later its structure, characterized by a chromane nucleus, was identified.

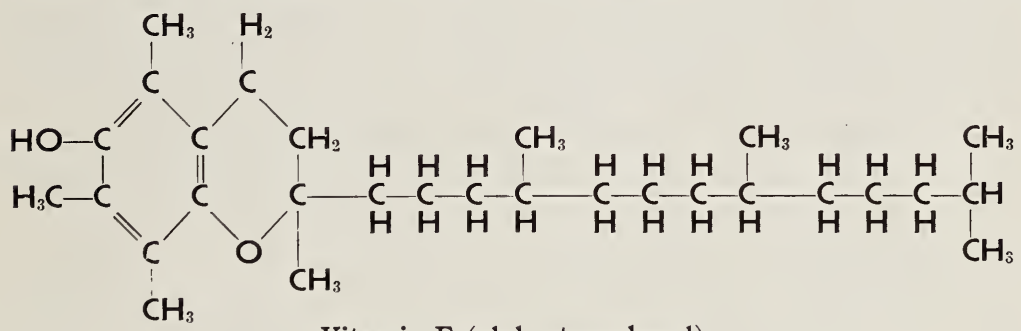

Vitamin E (alpha-tocopherol)

Later, the two naturally occurring isomeric forms, $\beta$ and $\gamma$, were found to be active also. Several active synthetic products have also been produced. Thus, vitamin E, like several others, has a multiple nature. The $\alpha$-form is approximately twice as active as the $\beta$ - and four times as active as the $\gamma$-form. The tocopherols are extremely resistant to heat but readily oxidized. They are destroyed by rancid fats.

171. Vitamin E in Foods.-Vitamin E is widely distributed in the common foods. Green forage and other leafy materials are excellent sources. Alfalfa, spinach, lettuce, watercress, and the like are especially rich. The vitamin is abundant in cereal grains and other seeds especially in the germ. It is also present in 
various animal products. Wheat-germ oil is the most concentrated source, but cottonseed oil and various other vegetable oils are also rich in vitamin $\mathrm{E}$. Milk is relatively poor in the vitamin, but egg yolk is rich, if the hen's diet contains the vitamin liberally. The wide distribution of the vitamin bears out the experimental findings previously mentioned, indicating that any need by farm animals should usually be met by the commonly fed rations.

Vitamin E content is determined by noting the ability of graded amounts of the test feed to cause the birth of a normal litter from females of proven fertility which show failure during gestation on a vitamin E-free ration.

\section{VITAMIN $\mathrm{K}$}

In 1929, Henrik Dam of Denmark fed chickens a synthetic diet in an attempt to determine whether they were able to synthesize cholesterol. He noted that the chickens that were kept on an ether-extracted diet became anemic and developed subcutaneous and intermuscular hemorrhages. This was the first observation of the symptoms that we now know to be attributable to vitamin $K$ deficiency. Since the factor was found to be concerned with blood coagulation, the Danish workers (Dam and Shønheyder) proposed the name vitamin $K$ from the Danish word for coagulation.

172. Physiological Functions and Symptoms of Deficiency.When vitamin $K$ is deficient, the coagulation time of the blood is increased and the prothrombin level is decreased. The function of the vitamin is to maintain this level, by means of its influence on prothrombin formation that takes place in the liver. The adequacy of vitamin $\mathrm{K}$ is determined by measuring the clotting time of the blood. Where the time is prolonged, either a decreased absorption or a decreased utilization of the vitamin is indicated.

Vitamin $\mathrm{K}$ bears an interesting relation to "hemorrhagic sweet clover disease." This disease has been responsible for large animal losses. Recent studies have shown that the spoiled sweet clover contains dicumarol that decreases the blood prothrombin, resulting in the hemorrhages that are characteristic of the disease. Vitamin $\mathrm{K}$ has proved helpful in treatment. These findings have resulted from a series of brilliant studies by Link and associates of the University of Wisconsin, as summarized in a recent review. ${ }^{1}$

- Anonymous, The story of dicumarol, Nutrition Revs., 3, 55-59, 1945. 
Though originally discovered in chicks, the symptoms of $\mathrm{K}$ deficiency have been reported in other birds (geese, pigeons, and ducks) and also in mice, rats, rabbits, and man under special conditions. While the vitamin is needed for the physiological functioning of all species, a dietary deficiency is of minor importance for those species that have a marked bacterial action in the digestive tract because the vitamin is synthesized by bacteria, not only in the rumen but also in the lower intestine.

Intestinal synthesis is influenced by various conditions. Sulfonamides prevent intestinal synthesis, and under these conditions the addition of vitamin $\mathrm{K}$ to the diet corrects the deficiency that occurs. Possible reasons why chickens are more susceptible to dietary deficiency are less opportunity for intestinal synthesis and limited absorption from the lower part of the intestines in this species.

Vitamin $\mathrm{K}$ has been found to have a definite value in human therapy (1) as a preoperative and postoperative measure to prevent risk of bleeding, (2) in cases where absorption is impaired as in obstructive jaundice because bile is necessary for the absorption of $\mathrm{K}$, and (3) in hemorrhagic diseases of the newborn. The blood of infants at birth contains less than the usual amounts of prothrombin, and this deficiency increases for a time because the intestine of the newborn is sterile.

173. Chemistry of Vitamin K.- It is now recognized that there are several different compounds, similar in structure, that have vitamin $\mathrm{K}$ activity. In 1939 , as a result of the activities of several different workers, two such compounds were isolated as fatsoluble substances. The more active one, designated as $\mathrm{K}_{1}$, was isolated from alfalfa and found to have the following structure:

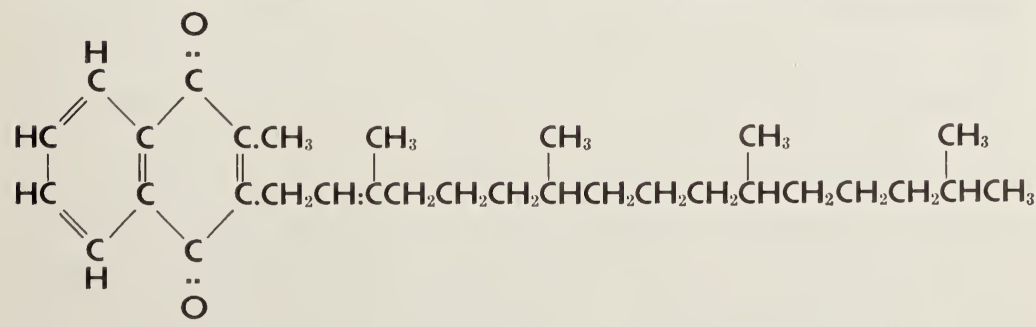

Vitamin $\mathrm{K}_{1}$ (2-methyl-3-phytyl-1,4-naphthoquinone)

The second compound, designated as $\mathrm{K}_{2}$, was isolated from fish meal. It contains the same quinone nucleus, but there are some 
differences in the side chain. More recently another active compound, $K_{3}$, was obtained from corn stigma. In addition, several synthetic naphthoquinones have been prepared that have vitamin $K$ activity. 2-Methyl-1,4-naphthoquinone is a synthetic product that is three times as active as $K_{1}$. Some of the synthetic products are water-soluble, in contrast to the natural products that caused the vitamin to be classed originally as fat-soluble.

174. Food Sources of Vitamin K. - So far as is known there is no need for giving consideration to the vitamin $\mathrm{K}$ content of the rations of farm animals, except in the case of poultry. Normally, rumen or intestinal synthesis should meet the needs in other species. All green, leafy materials are rich sources of the vitamin, and various other plant products contain substantial amounts. Liver, egg, and fish meal are good animal sources. Assay procedures have been worked out with chicks, using $1 \mu \mathrm{g}$. of $K_{1}$ as the unit.

\section{THIAMINE (VITAMIN $B_{1}$ )}

The early work of Eijkmann and others which established the fact that there is a specific dietary factor essential for the prevention of beriberi in man and polyneuritis in pigeons has been referred to. Further studies of this factor, which became known as water-soluble B and later simply as vitamin B, caused it to be recognized as essential for growth and for certain other physiological functions besides its antineuritic properties. As more critical investigations were made of its distribution in foods, chemical nature, and properties, the realization gradually developed, between 1925 and 1930, that vitamin B actually consisted of at least two factors differing as regards chemical nature and physiological effects. Thus what was formerly spoken of as vitamin B came to be called the vitamin $B$ complex or group. The term vitamin $B$ (or $B_{1}$ ) was reserved for the antineuritic factor. The name thiamine was introduced when its chemical nature was established (Sec. 176). The vitamin is required in the metabolism of all species of animals and in plant metabolism as well. Higher plants synthesize it, and so do many of the lower forms. All animals, however, must have a dietary source, unless it is synthesized for them by microorganisms in the digestive tract-as is the case with ruminants. 
175. Physiological Functions and Symptoms of Deficiency.Thiamine occurs as a pyrophosphate in the coenzyme cocarboxylase which is essential for the oxidative removal of pyruvic acid, an intermediate in carbohydrate metabolism. The impairment of this process as a result of thiamine deficiency explains the specific symptoms involved.

The classic diseases, beriberi in man and polyneuritis in birds, represent a late stage of the deficiency, resulting from a peripheral neuritis caused by the accumulation of intermediates of carbohydrate metabolism, as was first indicated by the studies of Peters and associates at Oxford. Other symptoms include a slowing of

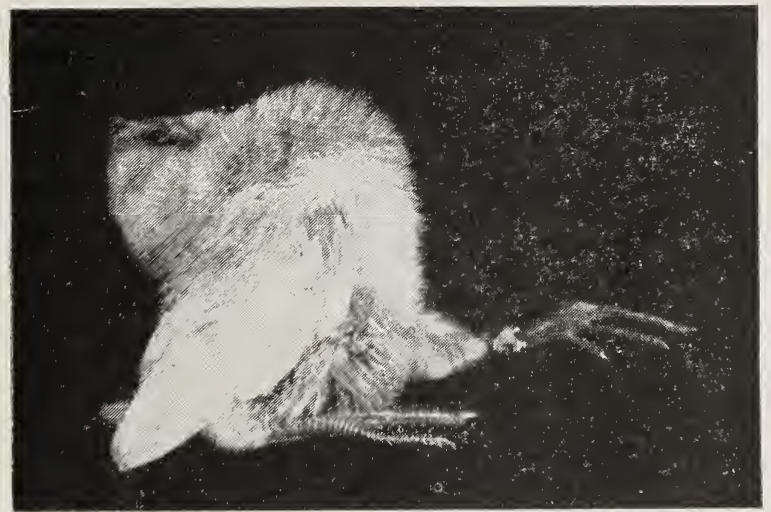

FIg. 20.-Polyneuritis. (Courtesy of L. C. Norris, Corneli University.)

the heart beat (bradycardia), enlargement of the heart, edema, gastrointestinal troubles, and lack of appetite (anorexia). Muscle weakness, easy fatigue, and hyperirritability are less specific symptoms. There is a very marked effect on growth that is the result, at least in part, of loss of appetite. In swine the deficiency reveals itself particularly in a decrease of appetite and body weight, vomiting, a slow pulse, subnormal body temperature, and postmortem heart changes. In chickens and turkeys there is a loss of appetite, emaciation, impairment of digestion, a general weakness, and frequent convulsions with polyneuritis as an extreme symptom (Fig. 20). This characteristic trouble will develop in 9 to 12 days in day-old chickens on a thiamine-deficient diet. Recovery is amazingly prompt when the vitamin is given. In foxes the 
deficiency causes a characteristic disease, chastek paralysis. Cattle and sheep do not require thiamine in their rations because the vitamin is synthesized adequately by microorganisms in the rumen. Carlström and Hjärre ${ }^{1}$ reported that a deficiency of vitamin $B_{1}$ is responsible for nervous symptoms in horses, including incoordination and paralysis of the hindquarters, but the ration fed was deficient in other B-factors, Later studies (Sec. 178) have indicated that the horse needs riboflavin specifically.

There is evidence that the symptoms of $B_{1}$ deficiency develop more quickly on a fat-free diet and that fat exerts a sparing action on the vitamin requirement. A lack of vitamin $\mathrm{B}_{1}$ causes reproductive failure in both sexes. There is a larger requirement for lactation than for growth because of the increased metabolism involved. Vitamin $B_{1}$ is secreted in milk but never in large amounts. The vitamin $B_{1}$ content of eggs can be altered by its level in the diet of the hen. The factor is stored in the body to only a limited extent. In the case of the pig, however, whose tissues, for some unexplained reason, contain several times as much thiamine as is the case with other species studied, there is a store that can meet body needs on a thiamine-deficient diet for nearly two months. ${ }^{2}$

176. Chemistry of Thiamine.-In 1926 the Dutch workers, Jansen and Donath, isolated vitamin B in crystalline form and reported an empirical formula containing carbon, hydrogen, oxygen, and nitrogen. Later Windaus and coworkers prepared a crystalline product which was found to contain sulfur as well as the elements reported by Jansen and Donath. Other workers confirmed the presence of this additional element, and it was later found also in the crystals of the Dutch workers. In 1936 synthesis of the vitamin was accomplished by Williams and Cline, ${ }^{3}$ and Williams ${ }^{4}$ established the following structure:

1 CARlström, B., and A. HJärRe, Durch B-Avitaminose verursachte Mangelkrankheiten bei Militärpferden, Tierernährung, 11, 121-129, 1939.

2 Heinemann, W. W., and associates, The relation of the amount of thiamine in the ration of the hog to the thiamine and riboflavin content of the J. Nutrition, 31, 107-125, 1946.

${ }^{3}$ Wrlliams, R. R., and J. K. Cline, Synthesis of vitamin $\mathrm{B}_{1}, J . A m$. Chem. Soc., 58, 1504-1505, 1936.

${ }^{4}$ Williams, R. R., Structure of vitamin $\mathrm{B}_{1}, J$. Am. Chem. Soc., 58, 1063$1064,1936$. 


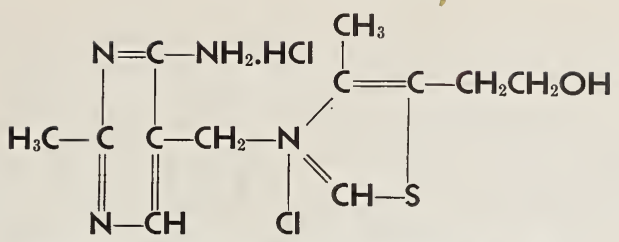

Thiamine hydrochloride (Williams, 1936)

It is noted that the vitamin consists of a molecule of pyrimidine and a molecule of thiazole. Thiamine is soluble in 70 per cent alcohol as well as water and is readily destroyed by heat, especially in the presence of alkali. In a dry state, it is stable at $100^{\circ} \mathrm{C}$. for several hours, but moisture greatly accelerates the destruction, and thus it is much less stable to heat in fresh than in dry foods. Autoclaving destroys vitamin $\mathrm{B}_{1}$, an observation which played an important role in the discovery that what was originally considered to be a single vitamin contains more than one factor.

177. Thiamine in Foods.-Brewer's yeast is the richest known source of vitamin $B_{1}$. The factor is present in liberal amounts in a wide variety of foods. Whole cereal grains are rich sources. Since the vitamin is present primarily in the germ and seed coats, by-products containing the latter are richer than the whole kernel, while highly milled flour is very deficient. Wheat germ ranks next to yeast. Lean pork, liver, kidney, and egg yolk are rich animal products. The content in lean pork can be doubled by increasing the thiamine intake of the pig. The content in hays decreases as the plant matures and is less in the cured than in the fresh product. The content is correlated with leafiness, greenness, and protein content. In general, good quality hay is a substantial source, and, in a dry climate, there is practically no loss in storage. Milk is not a rich source, and pasteurization for $30 \mathrm{~min}$. at $145^{\circ} \mathrm{F}$. destroys 25 per cent of its content.

The fact that thiamine is water-soluble as well as unstable to heat results in large losses in certain cooking operations to which foods are subjected. There should be little concern about any lack of vitamin $B$ in the rations of farm animals in view of the generous supply in most of the feeds used. Further, rumen synthesis makes the question of feed supply of little or no importance in the case of cattle and sheep.

Feeds are assayed for thiamine by various procedures. The biological method measures the growth response in rats caused by 
the test substance under standardized conditions. This procedure is time-consuming and costly. A standard chemical method is based on the fluorescence produced by thiochrome, a compound that is formed from thiamine on oxidation. A commonly used microbiological method is based on the need of the vitamin for the growth of the fungus Fhycomyces blakesleeanus. The basis of the method lies in the fact that the growth of the fungus is proportional to the amount of thiamine added over a low range of addition. A comparison of the amount of growth produced through the addition of known amounts of thiamine with the amount produced by the addition of specific amounts of the food to be tested provides a basis for estimating its vitamin content. There are other microbiological procedures. These various methods are constantly undergoing study for their improvement, and thus the student should consult the current literature for details regarding the procedure best suited to his purpose.

The official unit (I.U. and U.S.P.) is the biological activity of three $\mu \mathrm{g}$. of pure thiamine hydrochloride. Thus, $1 \mathrm{mg}$. of thiamine equals 333 I.U.

\section{RIBOFLAVIN}

Following the recognition that the original water-soluble B consisted of more than one factor, it was thought for a time that the effects not attributable to a lack of the antineuritic vitamin were owing to a deficiency of another single factor, designated $\mathrm{G}$ by some, and $\mathrm{B}_{2}$ by others. But soon it was learned that at least two factors were involved here also. Some confusing use of the letters followed. The situation became more complicated as evidence developed that there were more than two, and possibly several, factors concerned. Fortunately, one by one the different vitamins were identified chemically and given specific chemical names that have come into standard use.

The first factor identified was riboflavin. It is sometimes still referred to as $\mathrm{G}$ or $\mathrm{B}_{2}$. The vitamin is required in the metabolism of all animals but not required in the rations of cattle and sheep because of bacterial synthesis in the rumen.

178. Physiological Functions and Symptoms of Deficiency.Riboflavin functions in the body as a constituent of several enzyme systems. Warburg's yellow oxidation enzyme is a combination of riboflavin with a protein and phosphoric acid, which is essential 
for cell respiration. The vitamin is also a constituent of $d$-aminoacid oxidase and xanthine oxidase. A deficiency of this factor is reflected in a wide variety of symptoms somewhat variable with the species. A decreased growth rate is common, but not a specific symptom. The economy of food utilization is impaired.

In 1929 Norris and associates described a peculiar type of leg paralysis in chicks which they considered to be the result of a lack of an unidentified vitamin. This paralysis was later shown to be the most characteristic symptom of riboflavin deficiency in this species. The chicks are first noted to be walking on their hocks with their toes curled inward ("curled-toe paralysis"). The legs become paralyzed, but the birds may otherwise appear normal. Diarrhea is another common symptom in chicks. In laying birds, a deficiency of riboflavin results in low egg production and poor hatchability. A deficiency in swine causes stiffened limbs, skin eruptions and exudates over the back and sides, lens opacities, and cataracts. Cataracts are also found in rats.

Symptoms have not been noted in ruminants, apparently because rumen synthesis meets their needs. While experiments have suggested that some bacterial synthesis takes place in the digestive tract of horses, Pearson and associates ${ }^{1}$ have reported evidence, based on riboflavin excretion in the urine, that this species requires the vitamin in its ration. Recent field studies have also suggested that riboflavin deficiency may be concerned in periodic ophthalmia ("moon blindness") in horses.

In man there are both skin and eye symptoms. The skin becomes roughened, furrows appear around the mouth (cheilosis), and dermatitis occurs. A frequent but nonspecific eye symptom is "corneal vascularization," detectable by the biomicroscope.

179. Chemistry of Riboflavin.-Milk was early recognized to be an excellent source of the original vitamin $\mathrm{G}$, as measured by growth response. Observations that the growth effect exhibited by whey seemed to be associated with its greenish-yellow fluorescent pigment led to the isolation of this pigment, first called lactochrome and later lacloflavin (Fig. 21) as the biologically active material. A similar compound was also isolated as hepatoflavin from liver and as ovoflavin from eggs. Later riboflavin was synthesized, and evidence was obtained for its identity with the

1 Penrson, P. B., M. K. Sheymani, and H. S. Schmint, Riboflavin in the nutrition of the horse, Arch. Biochem., 3, 467-474, 1944. 


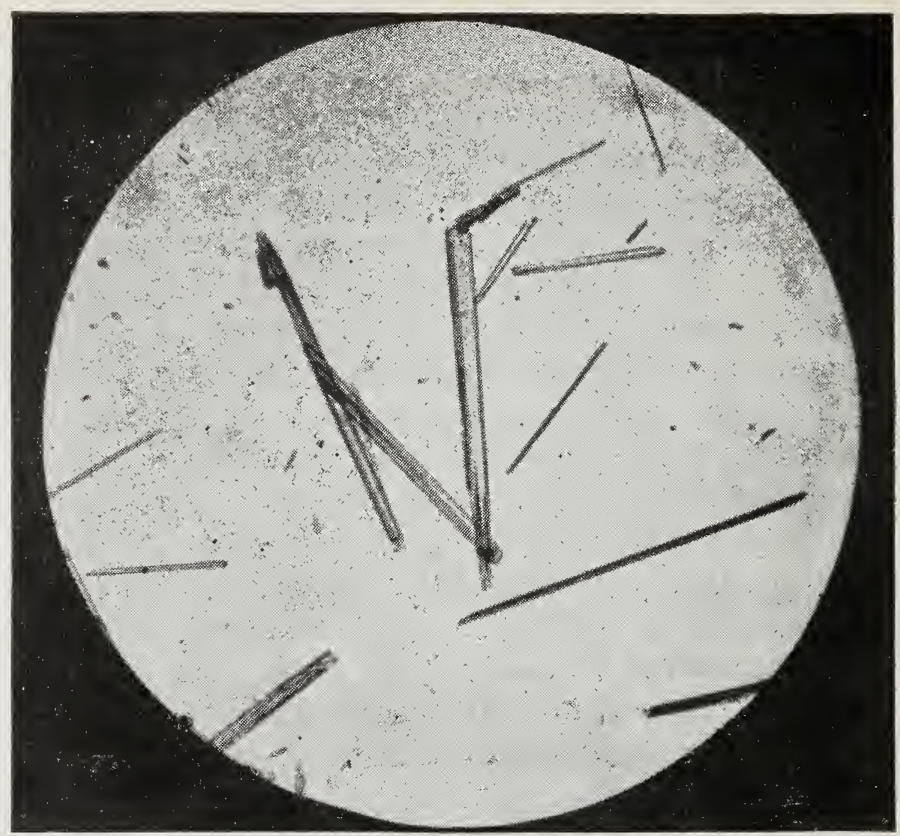

Fig. 21.-Crystalline lactoflavin. (Courtesy of George C. Supplee.)

naturally occurring products, both chemically and biologically. The advances here resulted particularly from the brilliant work of György, Kuhn and associates in Germany, Karrer and coworkers in Switzerland, and von Euler and associates in Sweden. It is now accepted that the biologically active substance has the following structural formula:

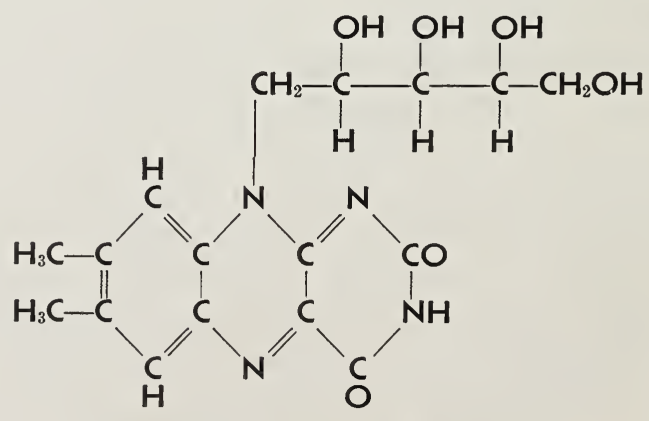

Riboflavin, $\mathrm{C}_{17} \mathrm{H}_{20} \mathrm{~N}_{4} \mathrm{O}_{6}$ 
The compound consists of a dimethyl isoalloxazine nucleus combined with ribose as a side chain. It may be obtained in the form of orange-yellow crystals that are soluble in water. The solution has a greenish-yellow fluorescence. Riboflavin is heat-stable in acid solution but readily destroyed in an alkaline medium. Visible light, particularly the blue and violet rays, readily destroys it.

180. Riboflavin in Foods.-Milk is a rich source of the vitamin, especially the skim milk or whey fractions. This is one of their very important values in rations for pigs and poultry. Alfalfa hay is rich in riboflavin, and other green leafy forages are important sources also. Cereals and their by-products have a rather low content, in contrast to their supply of thiamine. Oil meals are much better sources, as are also certain meat by-products. Riboflavin concentrates prepared from whey, yeast, and the byproducts of butyl alcohol fermentation are commonly used in poultry rations.

The riboflavin content of foods may be determined by rat or chick assays, but the more rapid microbiological or chemical methods are now more generally employed. The most commonly used microbiological method is based upon the growth response of Lactobacillus casei. There are various chemical methods that measure the fluorescence produced by riboflavin.

\section{NICOTINIC ACID (NIACIN)}

Our knowledge regarding nicotinic acid as a dietary essential grew out of the long-time search for a cure for pellagra, a disease that as late as 1935 was estimated to be taking several thousands of lives annually in our southern states. Outstanding pioneer studies covering several years were made by Goldberger of the U. S. Public Health Service, resulting in the conclusion in 1920 that the disease was caused by an ill-balanced diet. In 1925 he established significant resemblances between pellagra and black tongue in dogs, thus ushering in an era of research on the latter. In 1937 Elvehjem and coworker's ${ }^{1}$ at the University of Wisconsin made the dramatic discovery that nicotinic acid, a compound that had remained idle on the chemist's shelf for many years,

1 Elven.jem, C. A., and coworkers, Relation of nicotinic acid and nicotinic acid amide to canine black tongue, J. Am. Chem. Soc., 59, 1767-1768, 1937. 
would cure black tongue. Proof that it would also cure uncomplicated human pellagra quickly followed. We now know that it is a dietary essential for pigs, chickens, monkeys, and other species. It is synthesized in the rumen of cattle and sheep and also, apparently, in the digestive tract of the horse. Synthesis in the rat has also been demonstrated.

Niacin is a term that was adopted as a short name for this vitamin, particularly in view of the fact that the chemical name proved objectionable to the public as a name for a dietary essential.

181. Physiological Functions and Symptoms of Deficiency.In the body nicotinic acid functions as a component of two coenzymes - coenzyme I or cozymase, and coenzyme II. They are concerned with glycolysis and respiration. In a deficiency of the vitamin, a decreased content of cozymase has been demonstrated in liver and muscle tissue.

Pellagra in man is characterized by a fiery red tongue, ulcers of the mouth, dermatitis, loss of appetite, nausea, and other symptoms. Somewhat similar troubles are found in farm animals. The need of pigs for nicotinic acid and the symptoms resulting from its deficiency were first established by the studies of Chick and associates in England and by Hughes of California. Loss of weight, diarrhea, vomiting, and dermatitis are commonly occurring symptoms. The vitamin has been found helpful in the cure of some cases of necrotic enteritis, but it will not prevent the occurrence of the disease. Though chicks can apparently synthesize a part of the nicotinic acid required for their metabolism, a dietary need is clear. Its deficiency is characterized by poor growth, mouth symptoms somewhat similar to those of black tongue in dogs, poor feathering, and occasionally a scaly dermatitis. The vitamin is also a dietary essential for the adult fowl. In Fig. 22 the extreme physical symptoms of nicotinic acid deficiency in the pig and the results of nicotinic acid administration to such an animal are shown.

The synthesis of the vitamin in the rumen of cattle and sheep has been demonstrated, and deficiency symptoms in these species have not been produced. Pearson and associates ${ }^{1}$ found no difference in the blood level or urinary excretion of nicotinic acid in lambs fed a diet low in the vitamin compared with a normal

${ }^{1}$ Pearson, P. B., and associates, Studies on the metabolism of nicotinic acid in the sheep, J. Nutrition, 20, 551-563, 1940. 
diet. Pearson and Lueke ${ }^{1}$ have also shown that ponies receiving $0.1 \mathrm{mg}$. of nicotinic acid per kilogram body weight made normal growth and that the amount excreted in the urine and feces exceeds the intake under these conditions.

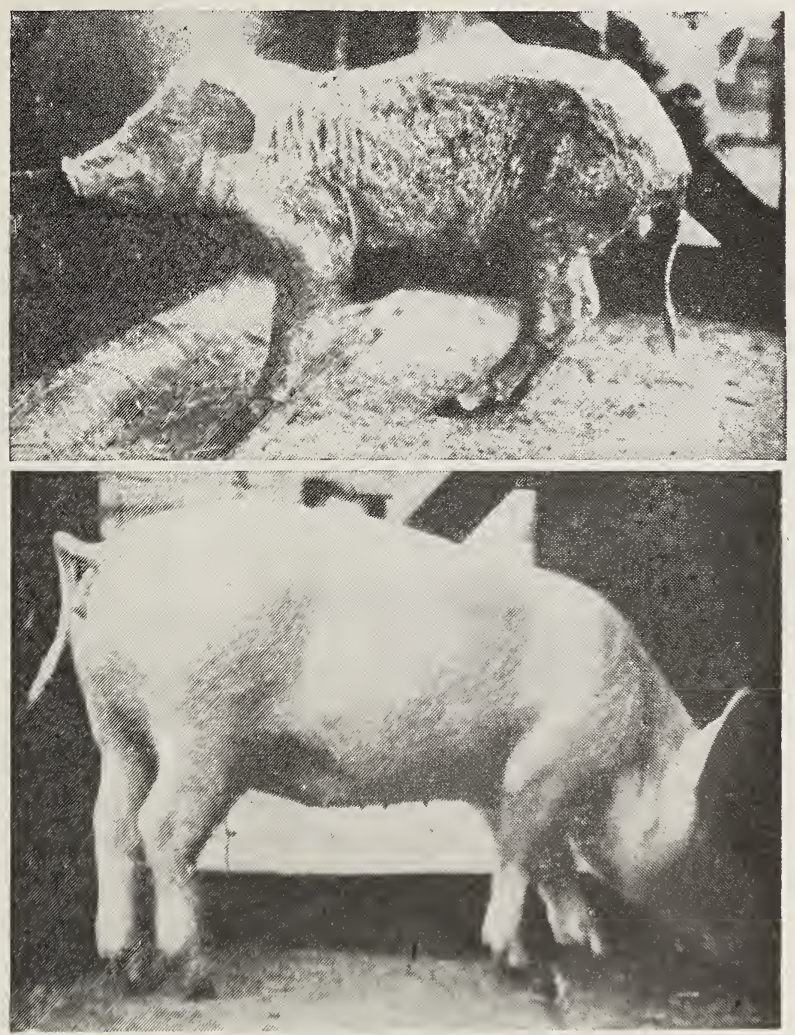

Fig. 22.-Fxtreme nicotinic acid deficiency and recovery. (The condition shown at the top was produced with a diet consisting largely of corn. Nicotinic acid administration resulted in the recovery shown at the bottom. (From an article by Chick and associates, Biochem. J., 32, 10-12, 1938.)

Certain nicotinic acid derivatives, the urinary excretion of which varies with the level of intake, are being studied as indicators of the nutritional status with respect to this vitamin. Physical symptoms and response to treatment, however, are much more useful criteria at present.

${ }^{1}$ Pearson, P. B., and R. W. Lueke, Studies on the metabolism of nicotinic acid in the horse, Arch. Biochem., 6, 63-68, 1945. 
182. Chemistry of Nicotinic Acid.-The structural formulas of nicotinic acid and the physiologically active nicotinic acid amide are shown below:

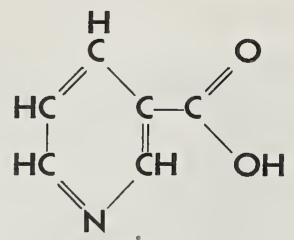

Nicotinic acid

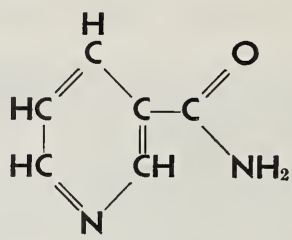

Nicotinic acid amide

The formulas reveal that the compounds are derivatives of pyridine. Coenzyme $\mathrm{I}$ is a diphosphopyridine nucleotide, and coenzyme II is a triphosphopyridine nucleotide. Nicotinic acid is a moderately sour, white crystalline substance, soluble in water and alcohol. It is quite resistant to heat and oxidation and is thus stable in foods.

183. Nicotinic Acid in Foods. - The vitamin has a wide distribution among feeds, and, thus, a deficiency in the commonly fed rations of farm animals that need this factor seems unlikely. This viewpoint is supported by experimental observations. Cereals and their by-products, except corn, are good sources. Peanut-oil meal is an excellent source, but other oil meals contain considerably less. Leafy materials, particularly alfalfa, are fair sources. The vitamin is contained in larger amounts in muscle and organ meats and fish, and, thus, animal by-products are generally good sources.

The dog is used in assaying for nicotinic acid biologically, but this is a long and expensive procedure. Thus, various chemical, colorimetric, and microbiological methods have been developed. The latter have proved of most general usefulness, notably the method of Krehl, Strong, and Elvehjem. ${ }^{1}$

184. Interrelationship between Nicotinic Acid and Amino-acid Metabolism.-The consumption of corn was early associated with the occurrence of pellagra. Even after the vitamin was discovered and its low content in corn established, evidence persisted that corn had some positive role in connection with the disease. Recent studies in Elvehjem's laboratory have suggested an explanation.

${ }^{1}$ Krehl, W. A., F. M. Strong, and C. A. Elvehjem, Determination of nicotinic acid: Modifications in the micro-biological method. Ind. and Eng. Chem. Anal. Ed., 15, 471-475, 1943. 
It was found that when corn grain replaced sucrose in a purified ration for dogs, the nicotinic-acid requirement was markedly increased. In rats, which normally do not require this vitamin, the workers produced a deficiency by adding corn to a low-protein diet. They, in turn, overcame the trouble by adding nicotinic acid or casein or tryptophane, an amino acid in which corn is deficient. Milk also helped to correct the deficiency, an observation which is in line with the evidence that milk is effective in curing pellagra, though rather low in nicotinic acid. Other protein sources were also found effective. The studies with rats are presented in two papers by Krehl and associates. ${ }^{1}$ Briggs ${ }^{2}$ has briefly announced similar findings with chickens. Evidence for a somewhat similar interrelationship has also been reported with pigs by Wintrobe and associates. ${ }^{3}$ On a purified ration containing only 10 per cent of protein in the form of casein but otherwise adequate, the omission of nicotinic acid produced the characteristic signs of its deficiency. When the casein content was stepped up to provide 26 per cent of protein, the deficiency symptoms were not produced. The investigators concluded that there was a close relationship between protein and nicotinic acid.

The mechanism of the interrelationships here described remains unknown. It illustrates one of the many factors that complicate the problem of establishing specific vitamin requirements for practical rations, as is discussed later in considering the intestinal synthesis of vitamins (Sec. 202).

\section{VITAMIN B $_{6} \quad$ (PYRIDOXINE)}

In 1934 György separated the nonthiamine part of the $B$ complex into riboflavin and a "complementary factor" that he named vitamin $\mathrm{B}_{6}$ and defined as the factor "responsible for the cure of a specific dermatitis developed by young rats on the vitamin-free diet supplemented with $B_{1}$ and riboflavin." The isolation of the

1 KreHL, W. A., and associates, Factors affecting the dietary niacin and tryptophane requirement in the growing rat, $J$. Nutrition, 31, 85-106, 1946; The effect of protein on the nicotinic acid and tryptophane requirement of the growing rat, J. Biol. Chem., 162, 403-411, 1946.

2 Brigas, G. M., Influence of gelatin and tryptophane on the nicotinic acid requirements of chicks, J. Biol. Chem., 161, 749-750, 1945.

${ }^{3}$ Wintrobe, M. M., and associates, Nicotinic acid and the level of protein intake in the nutrition of the pig, $J$. Nutrition, 30, 395-412, 1945. 
vitamin in crystalline form was first accomplished by Keresztesy and Stevens of Merck and Company in 1938. Lepkovsky, about the same time, reported the isolation of crystals of his "Factor I" which apparently was $B_{6}$. The structure of the vitamin was first explained by Kuhn and coworkers who gave the name adermin. These same workers, along with Harris and Folkers of Merck and Company, deserve credit for the synthesis of the vitamin. György proposed the name pyridoxine which has been largely adopted. The vitamin is a dietary essential for the rat, pig, chick, dog, and other species including microorganisms. It has been reported effective in curing certain skin lesions in man. Like the other B-factors previously discussed, it is synthesized in the rumen of cattle and sheep.

\section{Physiological Functions and Symptoms of Deficiency.-} As a result of the recent work of Gale and Epps in England and Gunsalus and coworkers of Cornell University, it has been shown that vitamin $\mathrm{B}_{6}$ is a precursor of codecarboxylase, the coenzyme of at least four decarboxylases; namely, those acting on tyrosine, lysine, arginine, and tryptophane. Its basic role in amino-acid metabolism (Sec. 97) is thus evident. Microorganisms that grow without vitamin $B_{6}$ have been shown to synthesize codecarboxylase directly.

The specific dermatitis (acrodynia) that characterizes pyridoxine deficiency in rats is not found in other species, but convulsions are a common symptom in all. In pigs the symptoms include a microcytic, hypochromic anemia, epileptic-like fits or convulsions, and slow growth. Also, a nerve degeneration is found on autopsy. In chicks, abnormal excitability, jerky, aimless movements, and, later, convulsions occur, followed by complete exhaustion. Slow growth and suppressed appetite are accompanying symptoms. No reports of symptoms of deficiency in cattle or sheep have appeared. The vitamin appears to be concerned in hemoglobin formation and may be of value in the treatment of certain types of anemia.

186. Chemistry of Vitamin $B_{6}$.-There are at least three compounds in food that have vitamin $B_{6}$ activity. They are pyridoxine and its derivatives, pyridoxamine and pyridoxal. Like nicotinic acid, all have a pyridine base. The formulas for the three compounds are given on page 221: 


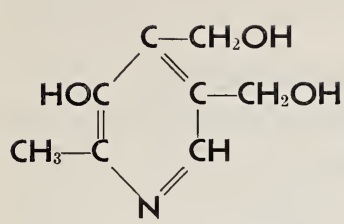

Pyridoxine

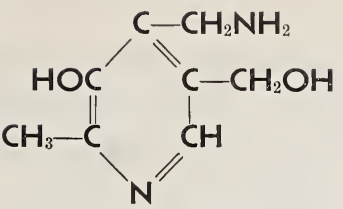

Pyridoxamine

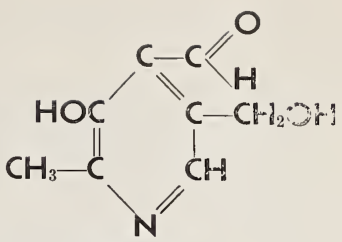

Pyridoxal

Pyridoxine was the compound first isolated. It is a white crystalline solid with a salty taste. It is water-soluble but fairly stable to heat. The other two compounds have the greater biological activity. Additional ones may be discovered.

187. Food Supply.--Most of the data on the vitamin $B_{6}$ content of foods were obtained before the two more active forms were discovered, and thus by methods which measured pyridoxine activity alone in some cases. The quantitative significance of published values is thus somewhat uncertain. It is apparent, however, that the vitamin is widely distributed in foods. Yeast, liver, milk, cereal grains and their by-products, and vegetable fats are excellent sources. Rice bran and polish are especially rich. Chick studies make it evident that the vitamin is not lacking in commonly fed rations. The same appears to be true for pigs, though less specific evidence is available.

Assays are carried out mostly by microbiological methods. Here it is essential either to use an organism that will respond to all three compounds or to use different organisms in separate tests. Thus, $L$. casei responds almost exclusively to pyridoxal, and $S$. faecalis primarily to pyridoxamine, while $S$. carlbergensis responds nearly equally to all three. The latter is true also for the X-ray mutant of Neurospora sitophila.

\section{PANTOTHENIC ACID}

In 1933 R. J. Williams and associates fractionated bios, a growth factor for yeast, and obtained a very potent acid fraction which they named pantothenic acid. When the chemical nature of this substance was definitely established, it became clear that it was the same factor concerned in a specific dermatitis condition in chicks, deseribed by various workers. Now it is known that pantothenic acid is a dietary essential also in rats, dogs, pigs, turkeys, and probably other species. It is synthesized in the rumen 
of the cow and sheep. There is some evidence that the horse may require it.

188. Physiological Functions and Symptoms of Deficiency.-The basic physiological role of pantothenic acid is not clearly established, but the diverse symptoms suggest it must play a fundamental role in cellular metabolism. A very long list of symptoms has been described in different species, as summarized by Williams. ${ }^{1}$ In chickens there is first a retardation of growth and feather development. Next, the dermatitis appears. The eyelids become granular and stick together, and scabs appear around the mouth, and vent and on the feet. Liver damage,

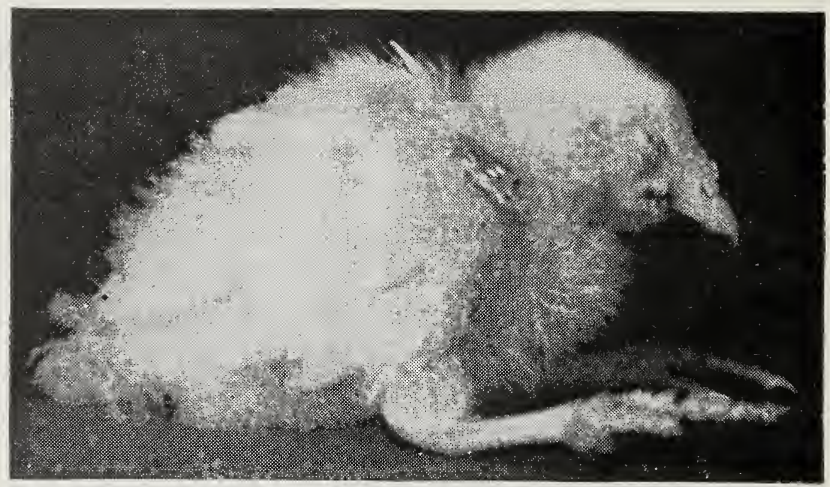

FIG. 23.-Pantothenic acid deficiency. (Courtesy of L. C. Norris, Cornell University.)

changes in the spinal cord, and several other post-mortem findings are to be noted. Hatchability is decreased in adult birds. The condition produced in chickens is shown in Fig. 23. Pigs suffering from pantothenic-acid deficiency have a scurfy skin and thin hair, a brownish secretion around the eyes, gastrointestinal troubles, slow growth, and a characteristic goose stepping. Nerve degeneration and organ changes are found on autopsy.

A lack of pantothenic acid has been found to result in a premature graying of the hair in piebald rats, foxes, and dogs. Administration of the vitamin restores the hair to its natural color. The effect is not specific because such a graying has been observed as a result of a deficiency of other factors. Neither pantothenic acid

${ }^{1}$ Williams, R. J., The chemistry and biochemistry of pantothenic acid, Advances in Enzymol., 3, 253-287, 1943. 
nor any other factor has been shown to be concerned in the graying of hair in man.

189. Chemistry of Pantothenic Acid.-This vitamin is a peptide of $\beta$-alanine and 2-4 dihydroxy-3,3-dimethyl butryic acid.

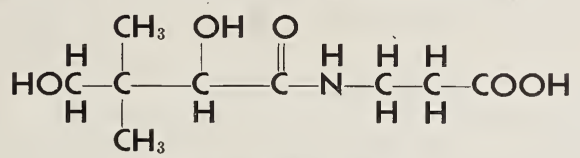

Pantothenic acid

It is obtained as its calcium salt, which is a white, relatively insoluble powder.

190. Pantothenic Acid in Foods.-The vitamin is widely distributed in foods of both animal and plant origin. A deficiency in the commonly fed rations of farm animals seems improbable. Alfalfa hay, peanut meal, cane molasses, yeast, rice bran, and wheat bran are especially rich in the factor. Cereal seeds and their by-products and many other feeds are good sources. Microbiological methods are used in assaying for the vitamin.

\section{BIOTIN}

The history of the discovery of the physiological significance of biotin is the history of the merging of three lines of investigation, for a long time apparently unrelated. It well illustrates how scientific information develops. In $1936 \mathrm{Kögl}$ and Tonnis in Germany announced the crystallization of a factor called biotin necessary for the growth of yeast. Later it was discovered to be identical with a growth factor, "Coenzyme R," found essential in 1933 for the growth of nodule bacteria. In 1927 Boas in England had reported that the feeding of Chinese egg white to rats produced a typical dermatitis. Parsons of Wisconsin studied this "egg-white injury" in detail for several years, finding that there was a "protective factor" in certain foods, notably liver and kidney. In the meantime, György studied the chemistry of this protective factor and in 1937 applied the term "Factor $H$ " to it.

In 1938 György and du Vigneaud teamed up on the problem and in 1940 announced that vitamin $H$ and biotin were identical, and they gave further proof later. Next it was announced by Eakin and by György and Fakin that egg-white injury resulted from its rendering dietary biotin unavailable, owing to a specific constituent, "avid-albumin" or "avidin." At the same time R. J. Wil- 
liams announced the isolation from egg white of a substance rendering biotin inactive for yeast growth. Du Vigneaud isolated the vitamin in 1941 and determined its structure in 1942. Harris and coworkers of Merck and Company synthesized it in 1943. Thus a new vitamin was discovered, essential for both animals and lower plants. It is required in the diet of rats, poultry, dogs, rabbits, monkeys, and probably other species.

191. Physiological Functions and Symptoms of Deficiency.The basic physiological function of biotin remains uncertain. Symptoms that have been reported in various species are dermatitis, pale and dry skin, muscle weakness and pain, and retarded growth. In chickens the characteristic symptoms are poor growth and dermatitis. The nature of the latter is somewhat similar to the condition produced by pantothenic acid deficiency. The vitamin has also been found useful along with manganese and choline in preventing perosis (Sec. 139). In the mature fowl hatchability is decreased by its deficiency. Turkeys and ducks also require the vitamin. The factor appears to be concerned with an ascending paralysis in dogs. Paralysis is one of the symptoms noted in rats also.

The experimental production of biotin deficiency in pigs by feeding desiccated egg white has very recently been reported by Cunha, Lindley, and Ensminger. ${ }^{1}$ The symptoms reported for the pig are spasticity of the hind legs, cracks in the feet, and a dermatitis characterized by dryness, roughness, and a brownish exudate.

192. Chemistry of Biotin.-As determined by isolation and by synthesis, biotin is 2-keto-3,4-imadazilido-2-tetrahydrothiophenevaleric acid.

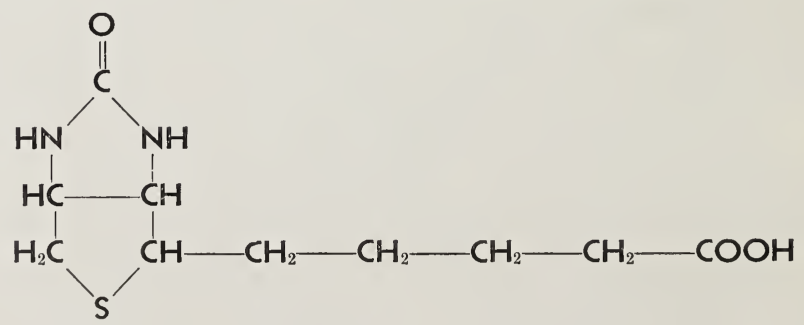

Biotin

1 Cunha, T. J., D. C. Lindley, and M. E. Ensminger, Biotin deficiency syndrome in pigs fed desiccated egg white, J. Animal Sci., 5, 219-225, 1946. 
It is a crystalline compound, very stable chemically, but soluble in alcohol and water. Structurally related compounds have been found to have biotin activity for the growth of microorganisms, and thus there may be more than one compound that has activity in animal nutrition.

193. Biotin in Foods. - The vitamin appears to be widely distributed in human foods, but animal feeds have been little studied. Liver, kidney, yeast, milk, and egg yolk are especially rich. Most of the severe deficiency symptoms in animals have been experimentally produced by diets high in egg white that greatly steps up the requirement. There is no present evidence that commonly fed rations of poultry, or of any other farm animal that may need the vitamin, are likely to be deficient. Various microbiological methods are used for the assay of biotin.

\section{OTHER VITAMINS OF THE B GROUP}

There are other factors, commonly included in the B group, that have been shown to be dietary essentials for one or more species. No extended discussion of them seems worth while in this text because their need in the rations of farm animals other than poultry has not been demonstrated, because many of the data regarding them are so uncertain, and because very active current research is constantly changing and augmenting present information. The student must follow the current literature to get any adequate picture of the status of this information.

194. Choline. - The chemistry and physiological functions of this substance, which is commonly classed with the B-vitamins, have previously been discussed briefly in connection with the lipids in which it occurs (Sec. 63). While choline or some metabolic precursor would appear to be a physiological need generally, a dietary need has not been demonstrated for farm animals except poultry. Here the requirement, which may be met in other ways than by choline itself (Sec. 63), is considered to be around $0.7 \mathrm{~g}$. for chicks and $0.9 \mathrm{~g}$. for turkey poults, per pound of feed. There is no clear evidence at present that practical poultry rations need an additional supply. It also seems improbable that the commonly fed rations of other farm animals are inadequate in choline to meet any need that may exist, but more specific information should be obtained. 
195. Inositol.-This compound occurs in plant products in the organic phosphorus compound, phytin (Sec. 115). It has the following formula.

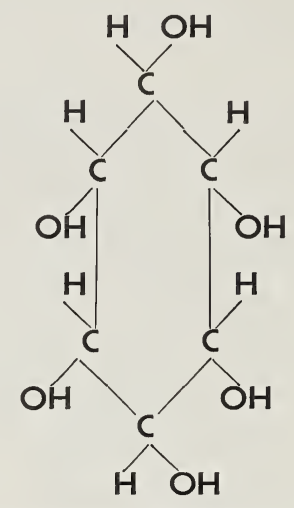

Inositol, $\mathrm{C}_{6} \mathrm{H}_{12} \mathrm{O}_{6}$

In 1940 Woolley showed that inositol could prevent and cure a characteristic alopecia in mice. Evidence for its usefulness in certain restricted diets fed to the cotton rat as well as the ordinary rat, hamsters, and chickens has also been reported. Less specific evidence for its usefulness as a supplement to restricted rations fed other laboratory animals has been noted. The various experiments have been critically reviewed by Woolley. ${ }^{1}$ He also cites others in which symptoms have not been observed with diets nearly devoid of inositol and in which its synthesis by the body has been demonstrated, reaching the conclusion that there is no unanimity of opinion as to whether this factor should be considered a dietary essential. If needed by farm animals, commonly fed rations should supply an abundance.

196. "Folic Acid" and Related Factors.-During the past several years many new names have appeared in the literature for various unidentified substances considered to be new vitamins on the basis of their essentiality for the growth of certain microorganisms or for the growth and hemoglobin production in various species of animals, notably chicks, monkeys, and rats. The names, such as "factor U," "vitamin M," "vitamin $B_{c}$," " $B_{c}$ conjugate," "L. Casei factor," "S. Lactis $R$ factor," and others, were coined

1 Woolley, D. W., The nutritional significance of inositol, J. Nutrition, 28, 305-323, 1944. 
on the basis of the source of the identified substance or of the species for which it was found active. Gradually evidence accumulated that some of them, at least, had similar physiological effects and thus must be related chemically, if they were not actually identical. Thus, the term folic acid came into popular use as a group name, although there was no general agreement as to which of the various proposed factors should be included in the group. This was not surprising since none of them had been isolated, except in the form of concentrates, and thus it was impossible to decide what ones were entitled to be considered as distinct entities.

Very recently the situation has greatly changed. The crystallization of vitamin $\mathrm{B}_{\mathrm{c}}$ was accomplished, and the structure and synthesis of the $L$. Casei factor were worked out. It has now become apparent that these factors and also the $S$. Lactis $R$ factor have a common chemical nucleus but differ with respect to attached groups. A similar relationship has been postulated for some of the others previously listed. The field is developing so rapidly that any attempt to summarize the present knowledge, as this text is written, is not worth while. The student must follow the current literature to read the story as it unfolds in this fascinating new chapter on vitamin nutrition. The synthetic L. Casei factor has already been found useful in treating macrocytic anemias in man. Aside from its use with the chick, the importance of this and related factors in farm animal nutrition remains to be studied.

The chemical name "pteroyl glutamic acid" has been proposed for the synthetic $L$. Casei factor, based on the fact that it contains a pteridine (2-amino-4-hydroxypteridine-6-carboxylic acid), paraamino benzoic acid, and glutamic acid. Whether the popular term "folic acid" will persist and what it will designate remain to be seen.

197. Other Factors.-Para-amino benzoic acid has been reported as effective in preventing graying of the hair and in promoting growth in chicks and lactation in rats. Clear evidence is still lacking that the compound acts specifically in producing any of these effects. It is known to be concerned, however, in the growth of certain microorganisms, and thus to play an indirect role in animal nutrition by stimulating the production of other Bfactors in the intestine. It is a constituent of "folic acid." 
The grass juice factor, announced several years ago as essential for the growth of guinea pigs, rats, and chicks, and so named because it was extracted from grass and found in milk from cows on green pastures, still remains of uncertain identity. Contrary to what was expected, no role in herbivorous animals has been demonstrated for this factor.

Other proposed factors of uncertain identity at present are: $\mathrm{B}_{10}, \mathrm{~B}_{11}$, Factor $\mathrm{S}$, Factor R, pigmentation factor, and others.

\section{VITAMIN C (ASCORBIC ACID)}

Ascorbic acid is the vitamin that was designated as watersoluble $C$, or the antiscorbutic factor, 30 years ago. The metabolic need appears to be a general one among species, but a dietary need is limited to man, the guinea pig, and the monkey. Some question remains, however, as to whether it is always synthesized adequately in the metabolism of other species. This question applies particularly to farm animals.

198. Physiological Functions and Symptoms of Deficiency.The most clearly established functional roles of vitamin $\mathrm{C}$ are exhibited in connection with the formation and maintenance of intracellular material in the bones as well as in the soft tissues. A deficiency for this purpose results in the well-known symptoms of scurvy, such as swollen, bleeding, and ulcerated gums, loosening of teeth, weak bones, and fragility of the capillaries with resulting hemorrhages throughout the body.

In a deficiency of the vitamin its content in the blood plasma is lowered, and thus blood level is used as a measure of nutritional status. The urine excretion is also used as a diagnostic measure, involving the so-called saturation technique. This technique is based on the fact that when the body is depleted an intake results first in storage and then in excretion. The intake which will keep the tissues saturated as indicated by the urinary output represents the maximum which could be considered of any value to the body.

199. Chemistry of Vitamin C.-Credit for the isolation of the compound we now call ascorbic acid is due to King of the United States and Szent-Györgyi of Hungary. The vitamin occurs in two forms, a reduced form that is readily oxidized to a dehydro form, as shown on page 229 . 

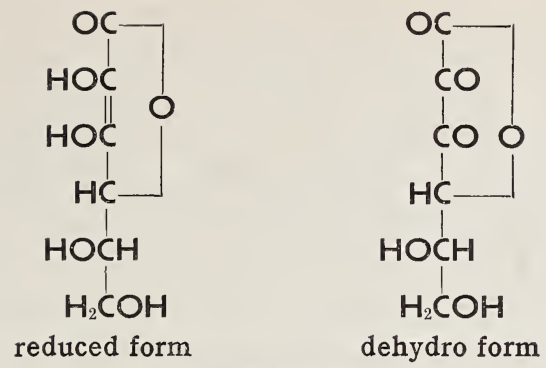

Ascorbic acid

Both forms are biologically active. In foods the reduced form greatly predominates, but it may reversibly oxidize to the dehydro form. The latter can be further oxidized to diketogulonic acid, an inactive compound. This reaction is irreversible. This change takes place readily, and thus the vitamin is very susceptible to destruction through oxidation, a change that is accelerated by heat. The vitamin is more stable in an acid than an alkaline medium. It is not found in dried foods and is markedly destroyed by cooking, particularly where the $\mathrm{pH}$ is alkaline. Cooking losses also result because of its solubility. There are also losses in storage, particularly in certain foods.

200. Vitamin $\mathrm{C}$ in Foods. - The guinea-pig assay provides the most reliable information as to the biological activity of sources of vitamin $\mathrm{C}$, but it is a laborious and time-consuming procedure. Most of our knowledge of the ascorbic acid content of foods has been obtained by chemical methods, involving the reduction of the dye 2,6-dichlorophenol-indophenol with the reduced form of vitamin $\mathrm{C}$, and measurement by titration or colorimetry. Special procedures are required where the oxidized form is also present. The largest problem involved, particularly in the case of certain foods, is in getting an extract that contains all of the vitamin and yet is free from substances that affect titration on the one hand or the color reading on the other. The vitamin ( value of a food is commonly expressed in milligrams. One I.U. is the activity of $0.05 \mathrm{mg}$. of ascorbic acid. Citrus fruits, tomatoes, green leafy vegetables, potatoes, and certain other fruits and vegetables are the principal food sources. Milk is a substantial source as drawn, but much of the vitamin value is lost in pasteurization.

201. Is Vitamin C a Dietary Need for Farm Animals? While it is recognized that ascorbic acid is synthesized in the metabolism 
of farm animals, some recent reports suggest that there may be special conditions in which this synthesis may not be adequate to meet body needs. Phillips and associates at the University of Wisconsin have reported that on a vitamin A-deficient ration the blood level of vitamin $\mathrm{C}$ may be low also. They noted that the concentration of ascorbic acid was low in the blood of "hard to settle" cows, and in bull semen of low potency. Somewhat similar findings have been reported for horses. Other workers have not been successful in confirming these findings, at least under other conditions. Thus their practical significance remains in doubt, but well worthy of further study.

The Wisconsin workers have also reported that the ascorbic acid level of the blood of the calf falls off after birth and that the administration of the vitamin during the early days of the calf's life helps prevent scours and navel ills. It was found that the administration must be by injection after two weeks, apparently because the ingested vitamin is destroyed in the rumen as soon as the later begins to function. This same Wisconsin report suggested that the administration of nicotinic acid to newborn calves also helped control scours. Workers at Cornell, Ohio, and Michigan have not been able to confirm these findings, particularly under practical conditions. On the other hand, a surprising occurrence of scurvy in dairy cows has been reported from Michigan. Further studies in this general field are clearly needed.

In purified diet studies with chicks a beneficial effect on growth rate has sometimes been noted from feeding ascorbic acid. It has been suggested that under these conditions the vitamin may serve as an antioxidant or detoxifying agent, or in connection with the intestinal synthesis of other factors, rather than as an antiscorbutic:

Literature dealing with these various observations is cited at the end of this chapter. It is evident that the field is one that needs much more exploration and controlled study before conclusions, particularly those applicable to practice, can be reached.

\section{VITAMIN P (CITRIN)}

In 1936 Szent-Györgyi announced that there is a substance in citrus fruits, different from vitamin $\mathrm{C}$, that is essential to prevent fragility of the capillaries. The substance was designated as vitamin $P$ or citrin. Certain capillary resistance tests have been de- 
vised to measure its biological effect in man and guinea pigs. The chemical nature of the substance or substances that are involved has not been definitely determined. Despite much study, the evidence as to whether vitamin $\mathrm{P}$ is entitled to be classed as a vitamin remains in doubt. The similarity of its reported physiological effects and occurrence in foods to those of vitamin $\mathrm{C}$ greatly complicates the problem. No work with this substance has been carried out with farm animals. Much of the literature dealing with this proposed vitamin is cited in a recent paper by Scarborough ${ }^{1}$ that reports studies on its chemical nature and distribution in foods.

\section{SYNTHESIS OF VITAMINS IN THE DIGESTIVE TRACT}

Previous discussions have indicated that all of the B-vitamins, as well as vitamin $\mathrm{K}$, are synthesized by microorganisms in the rumen. Reference has also been made to the occurrence of intestinal synthesis of some of them. Recent studies have served to emphasize the nutritional importance of these microbiological activities.

It is well recognized that the nature and activity of the microflora in the digestive tract are influenced by the character of the diet. Vitamin formation is thus influenced, as has been established particularly in connection with intestinal synthesis. The questions involved would seem to be of large possible importance in the case of ruminants, since it is commonly assumed that no account need be taken of the content of these rations in the B-vitamins because of rumen synthesis. But direct proof is lacking that the assumption always holds. A few observations have been reported indicating that the rumen synthesis of at least some of the Bvitamins is influenced by the nature of the rations, especially the kind of carbohydrate present, but quantitatively significant data are difficult to obtain because soluble constituents in the rumen may pass on rapidly, as well as be subject to absorption. Even less is known as to what may be taking place in the caeca of nonruminant Herbivora.

202. Intestinal Synthesis.-Much more has been learned about intestinal synthesis in rats and chicks. Here purified diets can

1 Scarborough, H., Observations on the nature of vitamin $\mathrm{P}$ and the vitamin $\mathrm{P}$ potency of certain foodstuffs, Biochem. J., 39, 271-278, 1945. 
be effectively employed, and the feeding of sulfa drugs to alter the microflora has proved a very useful technique. It has been found, for example, that while the rat does not normally need a dietary source of folic acid or biotin, deficiency symptoms are produced by feeding sulfa drugs. This indicates that body needs for these vitamins are ordinarily met by intestinal synthesis. There is evidence that some of various undifferentiated antianemic factors related to folic acid may promote the bacterial synthesis of each other. Further, the present confusion regarding some of them may arise from the fact that under certain dietary conditions they are synthesized adequately in the intestine and under others, not. Alterations in the intestinal microflora is one of the probable explanations for the recently discovered interrelationships between nicotinic acid and amino-acid metabolism (Sec. 184). A high-sucrose diet lessens the synthesis of this vitamin.

The intestinal synthesis of thiamine and riboflavin has been demonstrated. In the case of riboflavin, at least, the amount thus produced may be of real nutritional importance. Certain carbohydrates, notably lactose, promote this synthesis. On the other hand, a high-lactose diet may decrease the formation of other factors. Fat has also been demonstrated to exert an influence on intestinal synthesis. The probable role of para-amino benzoic acid has been noted.

These various observations, and others like them that might be mentioned, cannot be translated into recommendations for practice at the present time, particularly as far as farm animals are concerned. Generalizations are of little value because a diet of a given make-up may promote the synthesis of one vitamin but decrease that of another, while a shift in its make-up may reverse its specific effects. Further, results obtained with purified diets containing large amounts of pure nutrients may be quite different from those obtained with rations consumed in practice.

The findings do have an important significance, however. They show that its content of specific nutrients as fed is not the whole story in evaluating the nutritive value of a diet. Intestinal synthesis may make an important contribution. There may well be metabolic essentials, at present undiscovered because of adequate intestinal synthesis, which may be later recognized as dietary essentials with certain food combinations. The findings help ex- 
plain some of the rather wide discrepancies which are to be noted in studies of vitamin requirements and in biological assays where different basal diets are used. There are many findings reported in the earlier literature, obtained by feeding different combinations of B-vitamins and explained on the basis of metabolic interrelationships or antagonisms. The explanation for some of these findings at least may well lie in the intestine.

In some ways these new findings with respect to intestinal synthesis complicate the problem of applying vitamin knowledge to feeding practice. But the complexity will be resolved as further knowledge is gained. Such has been the case of vitamin puzzles in the past. A recognition of the important relations which may exist between the nutrition of an animal and the nutrition of the microorganisms inhabiting its digestive tract is essential for future research which should result in better and more economical feeding practice. The findings with laboratory animals should certainly stimulate studies with farm animals, particularly to get a better understanding of what happens in that big vitamin factory, the rumen.

\section{Vitamin A}

\section{Selected Literature}

Anonymous: Vitamin A deficiency and the requirements of human adults, (Report of Vitamin $\Lambda$ Subcommittee of Accessory Food Factors Committee), Nature, 156, 11-12, 1945.

Batchelder, E. L., and J. C. Eввs: Some observations of dark adaptation in man and their bearing on the problem of human requirement for vitamin A, J. Nutrition, 27, 295-302, 1914.

BraUde, R., and associates: Vitamin A studies with rats and pigs, Biochem. $J$., 35, 693-707, 1941.

Fraps, G. S., and W. W. Meinke: Digestibility by rats of $\alpha-, \beta$-, and neo- $\beta$ carotenes in vegetables, Arch. Biochem., 6, 323-327, 1945.

HAIG, C., and A. J. РАтек, Jr.: The relation between dark adaptation and the level of vitamin $\Lambda$ in the blool, $J$. Clin. Investigation, 21, 377-383, 1942.

Moore, L. A.: Some ocular changes and deficiency manifestations in mature cows fed a ration deficient in vitamin $\Lambda$, J. Dairy Sci., 24, 893-902, $19+1$.

- , and M. H. Berry: Vitamin $\Lambda$ and carotene content of the blood plasma of dairy calves from birth up to four months of age, J. Inairy Sci., 28, $821-826,1945$.

Moone, 'T., and Y. L. WANG: Hypervitaminosis A, Biochem. J., 39, 222-22S. 1945.

Osen, B. I., and associates: Determination of vitamin $A$, I nd. and Eing. Chem., 17, $559-562,1945$. 
Pavcek, P. L., E. J. Herbst, and C. A. Elvehjem: The nutritional value of telang livers, J. Nutrition, 30, 1-9, 1945.

Sutton, T. S., and P. A. Soldner: Seasonal variations in the blood plasma carotene and vitamin A of adult dairy cattle, J. Dairy Sci., 28, 859-867, 1945.

Wadgh, R. K., S. M. Hauge, and J. H. Hilton: Carotene losses in freshly cut plant tissues, J. Dairy Sci., 27, 585-590, 1944.

ZscheiLe, F. P., and associates: Determination of vitamin A and carotenoids in butterfat, Ind. and Eng. Chem., 16, 190-193, 1944.

\section{Vitamin D}

Duckworth, J., W. Godden, and W. Thomson: The relation between rates of growth and rickets in sheep on diets deficient in vitamin D, J. Agr. Sci., 33, 190-196, 1943.

Fitch, L. W. N., and T. K. Ewer: The value of vitamin D and bone-flour in the prevention of rickets in sheep in New Zealand, Australian Vet. J., 20, 220-226, 1944.

Johnson, D. W., and L. S. PALMer: Individual and breed variations in pigs on rations devoid of vitamin D, J. Agr. Research, 58, 929-939, 1939; Meeting the vitamin $\mathrm{D}$ requirement of pigs with alfalfa hay and winter sunshine, J. Agr. Research, 63, 639-648, 1941.

JoNES, J. H.: The production of hypercalcemia with small amounts of vitamin D, J. Nutrition, 28, 7-16, 1944.

Krauss, W. E., and C. E. Knoop: Effectiveness of ultraviolet light applied to the head or back regions of calves, J. Dairy Sci., 21, 705-712, 1938.

Wilson, D. C.: Potency of vitamins $\mathrm{D}_{2}$ and $\mathrm{D}_{3}$ in osteomalacia and late rickets, Lancet, CCXXXVIII, 961-962, 1940.

\section{Vitamin $\mathrm{E}$}

Mason, K. E.: Criteria of response in the bio-assay of vitamin E, J. Nutrition, 23, 59-70, 1942.

Thomas, B. H., W. F. LaGrange, and C. C. Culbertson: Effect of liberal wheat germ oil feeding on the reproduction of several breeds of sheep, J. Animal Sci., 1, 61, 1942.

\section{Vitamin $\mathbf{K}$}

DAм, H.: Vitamin K, its chemistry and physiology, Advances in Enzymol., 2, $285-324,1942$.

McELroy, L. W., and H. Goss: A quantitative study of vitamins in the rumen contents of sheep and cows fed vitamin-low diets. I. Riboflavin and vitamin K, J. Nutrition, 20, 527-540, 1940.

Overman, R. S., and associates: Studies on the hemorrhagic sweet clover disease. IX. The effect of diet and vitamin $\mathrm{K}$ on the hypoprothrombinemia induced by $3,3^{\prime}$-methylenebis (4-hydroxycoumarin) in the rat, J. Nutrition, 23, 589-602, 1942.

\section{Thiamine}

LARDINoIs, C. C., and associates: Rumen synthesis of the vitamin B complex as influenced by ration composition, J. Dairy Sci., 27, 579-583, 1944. 
Miller, R. C., and associates: The influence of the thiamine intake of the pig on the thiamine content of pork with observations on the riboflavin content of pork, J. Nutrition, 26, 261-274, 1943.

NaJjar, V. A., and L. E. Holt, Jr.: The biosynthesis of thiamine in man and its implications in human nutrition, $J . A m$. Med. Assoc., 123, 683-684, 1943.

Pence, J. W., and associates: The thiamine content of pig blood, J. Biol. Chem., 158, 647-651, 1945.

Wintrobe, M. M., and associates: A study of thiamine deficiency in swine, Johns Hopkins Hosp. Bull., 71, 141-162, 1942.

, and associates: Absence of nerve degeneration in chronic thiamine deficiency in pigs, $J$. Nutrition, 28, 283-288, 1944.

\section{Riboflavin}

Bethke, R. M., and P. R. REcond: The relation of riboflavin to growth and curled-toe paralysis in chicks, Poultry Sci., 21, 147-154, 1942.

Daniel, L., and L. C. Norris: Riboflavin content of milk and milk products, Food Research, 9, 312-318, 1944.

NaJjar, V. A., and associates: The biosynthesis of riboflavin in man, J. Am. Med. Assoc., 126, 357-358, 1944.

Peterson, W. J., F. M. Haig, and A. O. Shaw: Destruction of riboflavin in milk by sunlight, J. Am. Chem. Soc., 66, 662-663, 1944.

Wintrobe, M. M., and associates: Riboflavin deficiency in swine with special reference to the occurrence of cataracts, Johns Hopkins Hosp. Bull., 75, 102-114, 1944.

\section{Nicotinic Acid}

Birch, T. W., H. Chick, and C. J. Martin: Experiments with pigs on a pellagra-producing diet, Biochem. $J ., 31,2065-2079,1937$.

Elvenjem, C. A., and L. J. Tepley: The structure and estimation of natural products functionally related to nicotinic acid, Chem. Revs., 33, 185208, 1943.

Hughes, E. H.: The vitamin-B complex as related to growth and metabolism in the pig, Hilgardia, 11, 595-612, 1938.

\section{Pyridoxine}

Bellamy, W. D., W. W. Umbreit, and I. C. Gunsalus: The function of pyridoxine: Conversion of members of the vitamin $\mathrm{B}_{6}$ group into code carboxylase, J. Biol. Chem., 160, 461-472, 1945.

Foluis, R. H., Jr., and M. M. Wintroвe: A comparison of the effects of pyridoxine and pantothenic acid deficiencies on the nervous tissues of swine, J. Exptl. Med., 81, 539-552, 1945.

Hochbert, M., I). Melnick, and B. I. Oser: On the stability of pyridoxine, J. Biol. Chem., 155, 129-136, 1944.

McElrox, L. W., and H. Goss: $\Lambda$ quantitative study of vitanins in the rumen contents of sheep and cows fed vitamin-low diets. II. Vitamin $B_{6}$ (pyridoxine), J. Nutrition, 20, 541-550, 1940. 
MeLnick, D., and associates: The multiple nature of vitamin $\mathrm{B}_{6}$. Critique of methods for the determination of the complex and its components, J. Biol. Chem., 160, 1-14, 1945.

Wintrobe, M. M., and associates: Pyridoxine deficiency in swine, with particular reference to anemia, epileptiform convulsions and fatty liver, Johns Hopkins Hosp. Bull., 72, 1-25, 1943.

\section{Pantothenic Acid}

Bauernfeind, J. C., L. C. Norris, and G. F. Heuser: The pantothenic acid content of feedstuffs as determined by microbiological assay, Poultry Sci., 21, 136-141, 1942.

McElroy, L. W., and H. Goss: A quantitative study of vitamins in the rumen content of sheep and cows fed vitamin-low diets: IV. Pantothenic acid, J. Nutrition, 21, 405-409, 1941.

Silber, R. H.: Studies of pantothenic acid deficiency in dogs, J. Nutrition, 27, 425-433, 1944.

Wintrobe, M. MI., and associates: Pantothenic acid deficiency in swine, with particular reference to the effects on growth and on the alimentary tract, Johns Hopkins Hosp. Bull., 73, 313-341, 1943.

\section{Biotin}

Anonymous: Lysozyme, avidin, and biotin, Nutrition Revs., 3, 200-201, 1945. György, P., and C. S. Rose: A further note on the identity of vitamin H with biotin, Science, 92, 609, 1940.

Hegsted, D. M., and associates: Biotin in chick nutrition, $J$. Nutrition, 23, 175-179, 1942.

DU Vigneaud, V., and associates Or the identity of vitamin $\mathrm{H}$ with biotin, Science, 92, 62-63, 1940.

\section{Other Vitamins of the B Group}

Anonymous: Choline in animal and human nutrition, Nutrition Revs., 2, 314316, 1944.

Anonymous: Para-aminobenzoic acid and antagonism to sulfonamides and Marfanil, Nutrition Revs., 3, 152-154, 1945.

Briggs, G. M., Jr., and associates: Studies on two chemically unidentified water-soluble vitamins necessary for the chick, J. Biol. Chem., 148, 163$172,1942$.

Daniel, L. J., and associates: Studies on the formation of folic acid by incubating lactobacillus casei factor and pyracin with chick liver, J. Biol. Chem., 160, 265-271, 1945.

Frost, D. V., and associates: Adequacy of the known synthetic vitamins for normal feathering and pigmentation in chicks, Proc. Soc. Exptl. Biol. Med., 61, 65-69, 1946.

Hegsted, D. M., and associates: Inositol in chick nutrition, Proc. Soc. Exptl. Biol. Med., 47, 376-377, 1941.

Hill, F. W., L. C. Norris, and G. F. Heuser: Studies of unidentified vitamins required by the chick, $J$. Nutrition, 28, 175-188, 1944. 
LANGTron, W. C., and associates: Nutritional cytopenia (vitamin M deficiency) in the monkey, J. Exptl. Med., 68, 923-940, 1938.

Norris, L. C., and G. F. Heuser: Water soluble vitamins, Ann. Rev. Biochem., 14, 469-524, 1945.

Rhian, M. A., R. J. Evans, and J. L. St. John: The choline content of feeds, J. Nutrition, 25, 1-5, 1943.

\section{Ascorbic Acid}

Briggs, G. M., Jr., and associates: Effect of ascorbic acid on chick growth when added to purified rations, Proc. Soc. Exptl. Biol. Med., 55, 130-134, 1944.

Farmer, C. J.: Some aspects of vitamin C metabolism, Federation Proc., 3, 179-188, 1944 .

Lundquist, N. S., and P. H. Phillips: Some dietary factors essential for the growing calf, J. Dairy Sci., 26, 1023-1030, 1943.

Moore, L. A., and J. W. CotTer: The relationship between a low carotene intake and urinary excretion of ascorbic acid in dairy cattle, J. Dairy Sci., 28, 495-506, 1945.

VAVICH, M. G., and associates: Utilization and excretion of ingested ascorbic acid by the dairy cow, J. Dairy Sci., 28, 759-770, 1945.

\section{Miscellaneous and General Papers}

Briggs, G. M., Jr.: Observations on an unidentified feather pigment factor necessary for chickens fed purified diets, Poultry Sci., 25, 41-46, 1946.

Ellis, N. R., and L. L. Madsen: The vitamin content of animal feedstuffs, U.S. Dept. Agr., Animal Husbandry Div. Mimeo. Paper 61, 1943.

Kon, S. K.: Synthesis of vitamins by micro-organisms of the alimentary tract, Proc. Nutrition Soc., 3, 217-238, 1945.

Lowry, O. H., and O. A. BEssey: Microchemical methods for nutrition studies, Federation Proc., 4, 268-271, 1945.

Norton, C. L., and associates: Controlled experiments on the value of supplementary vitamins for young dairy calves, J. Dairy Sci., 29, 231-238, 1946.

SchweigerT, B. S., and associates: Intestinal synthesis of $\mathrm{B}$ vitamins by the rat, Arch. Biochem., 6, 403-410, 1945.

TAtum, E. L.: Biochemistry of fungi, Ann. Rev. Biochem., 13, 667-704, 1944.

Wolbach, S. B., and O. A. Bessey: Tissue changes in vitamin deficiencies, Physiol. Revs., 22, 233-289, 1942. 


\section{CHAPTER IX}

\section{FEEDING EXPERIMENTS. THE DETERMINATION OF DIGESTIBILITY}

Our previous discussion has considered the different nutrients which are required by the animal body and the metabolic changes which they undergo in serving its various functions. A knowledge of the quantitative needs of the body for these nutrients and of the relative value of feeds as sources of them is the basis of scientific feeding, a knowledge which has been gained gradually by means of research and experience over many years. An understanding of the methods by which it has been attained, and which are still being employed to augment it, is essential for the student of nutrition.

\section{FEEDING EXPERIMENTS}

Trial and experience were the means by which the art of feeding animals was originally developed. With the establishment of specific agencies to augment this knowledge, such as the agricultural experiment station, the feeding-trial method naturally was adopted as the means by which current practices could be critically tested and improved with the aid of the underlying sciences. A feeding trial with the species in question still remains the most useful method of obtaining results which have a direct application to feeding practice. But the method has a broader usefulness than this, as is indicated by the fact that feeding experiments with laboratory animals provide fundamental data which find application in human nutrition as well as in the feeding of farm animals. Feeding trials take many forms, a fact which must be appreciated if the results are to be interpreted correctly.

203. Comparative Feeding Trials.-In its simplest form, a feeding trial is a record of the results produced in terms of growth, milk production, or other function from a given feed or ration. Two or more rations may be compared with each other on this basis. Additional records as to the feed eaten provide a compari- 
son of the relative amounts of the rations required to produce a unit of product, and, by the use of cost figures, the results may be put on a money basis. The records here obtained tell us nothing as to why one ration proved better than another, unless the poorer one was so unpalatable as to be little consumed or unless it caused absolute harm. As a further step in the interest of more specific information, individual feeds may be compared as a part of rations the other ingredients of which are held constant. Here is an example which shows that fish meal is a better protein supplement for hogs than linseed meal:

\begin{tabular}{|c|c|c|}
\hline & $\begin{array}{c}\text { Average } \\
\text { daily gain, } \\
\text { lb. }\end{array}$ & $\begin{array}{l}\text { Feed required for } \\
100 \mathrm{lb} \text {. gain, lb. }\end{array}$ \\
\hline 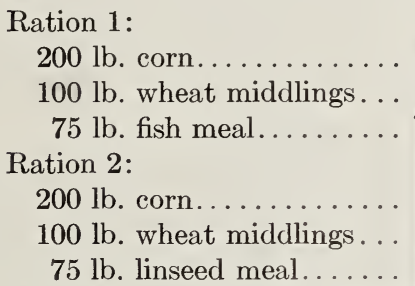 & 1.2 & 390 \\
\hline
\end{tabular}

This experiment gives us a specific answer as to the comparative over-all effect of these two feeds but it tells nothing as to why the fish meal was better. Was it the result of the higher percentage of protein in the fish product or a higher biological value of this protein? Was the large amount of calcium supplied by the fish meal in contrast to the very small amount present in the oil meal a factor, or did certain vitamins present in the one but not the other play a role?

It is important to know the specific nutritive quality which makes one feed better than another. For example, if the superiority of the fish-meal ration resulted cntircly from the extra calcium supplied, the addition of ground limestone to the linseed-meal ration would provide a cheaper method of getting the same results. The comparison of two feeds with respect to a specific nutrient such as calcium or protein requires that all other nutritive factors be held alike and adequate in the two rations. This can never be achicved absolutely, but feeding trials can be set up in such a way 
as to give most of the specific information desired, as is illustrated in connection with later discussions.

204. Feeding Trials with Laboratory Animals.-Today many of the problems of nutrition are being studied with small animals, such as the rat. The processes of growth, reproduction, and lactation can be effectively investigated and the value of various feeds for these various functions determined. The much smaller cost in terms of animals, feed, and labor, and the much shorter time involved for a given experiment, in view of the short life cycle of the laboratory animal, are important advantages. The influence of individual variability, a serious disturbing factor in large-animal experimentation, can be reduced to a minimum by the use of animals of similar genetic and nutritional history, by the employment of large numbers, and by close environmental control. Slaughter for chemical and histological examination, a desirable feature of many feeding trials, presents little difficulty with small animals, compared to the economic and other considerations involved in the case of farm animals.

The laboratory animal is thus highly useful for working out many of the fundamental principles of nutrition. The results obtained in feeding trials with the small animals, however, cannot be considered to have direct application to the various species of farm animals, because of the differences in physiology and other considerations. Even here studies with small animals serve as pilot experiments, by means of which much preliminary information can be obtained more quickly and at much less cost than with the large animals, and whereby it can be determined what ideas are of sufficient promise to justify the expense involved in giving them a final test with the large animals. The situation is analogous to that of an industry in which processes worked out in the laboratory are first tested on a semicommercial scale before being finally adopted. Of course, there are feeding problems which by their nature are susceptible to solution only by experiments with the farm animals themselves, but the animal industry owes much to experiments with the rat.

205. The Purified-diet Method.-An important feature of feeding trials which has been developed along with the use of laboratory animals is the employment of purified diets. These diets consist of purified sources of the various nutrients. For example, protein is supplied as casein, carbohydrates as starch and sucrose, 
fat as lard or some oil, minerals as chemically pure salts, and vitamins as the pure crystalline compounds. Such a diet makes it possible to include or withdraw a given nutrient with a minimum of disturbance of any of the other nutrient relations. The influence of different protein levels can be studied by including varying amounts of casein without any change in the rest of the ration, whereas the addition of the natural source of casein, viz., milk, would introduce many variables because it contains all of the other nutrients as well. Another protein such as zein of corn can be substituted for the casein and the relative value of the two determined. By similar procedures, the other nutrients can be subjected to specific study.

The extensive use of the purified-diet method has been a development of the last 30 years, but the idea was conceived more than a century ago, at least. As reported in 1816, Magendie fed diets of pure sugar and of pure fat to dogs to ascertain whether or not nitrogen was required in the food. Before the middle of the last century Boussingault, ${ }^{1}$ the famous French chemist, carried on nutrition studies with various species, involving the use of diets consisting in part of purified nutrients. As later attempts were made from time to time to use this method, the discouraging result occurred that the more completely the diet consisted of purified nutrients, the less satisfactory was the effect on the animal. It was this discouraging result, however, that led to the conclusion, toward the close of tha century, that there were dietary essentials unknown to the chemist and thus led to the later discovery of the vitamins and other previously unappreciated nutritive factors. There followed the intensive application of the purified-diet method by McCollum, by Osborne and Mendel, and by others, as a result of which an increasing knowledge as to essential constituents of a purified diet and new discoveries as to nutritional requirements simultaneously developed.

1 J. B. Boussingault (1802-187 $7^{\mathrm{j}}$ ), following a period of service as professor of chemistry at Lyons, France, founded the first Agricultural Experiment Station in 1836 at Pechelbronn. Here his pioneer studies on the nutrition of various species of animals extended over many years and became models for later investigators. Boussingault ranks as one of the foremost agricultural scientists of all time. His two-volume work, "Economie Rurale," published in 1843 and 1844, and dealing with soils, crops, and fertilizers as well as the nutrition of cattle, horses, hogs, and other animals, is mghly worth-wnile reading for the modern student. 
Thus the purified-diet method became responsible for much of our modern knowledge of nutrition, including the physiology of the vitamins, the establishment of differences in protein quality, and more exact information regarding many of the minerals. Studies of the role of an element needed by the body in small amounts can be effectively carried out only with basal diets which may be freed from it and to which it may be added in known amounts. This is only possible with purified diets because a diet cannot be prepared from natural foods which will be free from the element in question. The use of purified diets came to be known as the biological method for testing foods as to their content of vitamins (Sec. 159) and as to the quality of their protein (Sec. 91).

The purified-diet method has limitations that should be kept in mind. The ingredients of these diets cannot be considered pure in the absolute sense. Starch, for example, cannot be entirely freed from mineral matter without breaking down its structure. The essentiality of some mineral elements, needed only in traces, may remain undiscovered because of the impossibility of eliminating them entirely from the other ingredients of the experimental diet. Some of the recently discovered vitamins were identified as "impurities", in purified diets earlier assumed to consist only of known nutrients. Some of the constituents, notably protein, in purified diets are altered from their natural state in the process of purification. The kind of pure carbohydrate used affects the significance of the results in the case of certain vitamins because of the effects of various carbohydrates on vitamin synthesis in the alimentary tract (Sec. 202).

The purified-diet method has been developed to its highest degree of usefulness in the case of the rat, both because of the lesser problem involved in preparing purified nutrients on a small scale and also because of the years of experience with this species. The knowledge as to the rat's qualitative and quantitative needs is much greater accordingly, but it may not yet be complete in terms of successive generations. Lesser success has been achieved in the case of other laboratory animals, although the purified-diet method is proving useful in studying many problems with mice, guinea pigs, hamsters, and monkeys. Purified diets have also been used successfully in certain studies with chickens, pigs, calves, and sheep. The roughage factor presents a special problem in the case of ruminants. Papers illustrating the application of the 
purified-diet method to farm animals are listed at the end of this chapter.

206. Group Feeding vs. Individual Feeding.-Feed records are a desirable feature of all feeding trials. Even where the feed cost

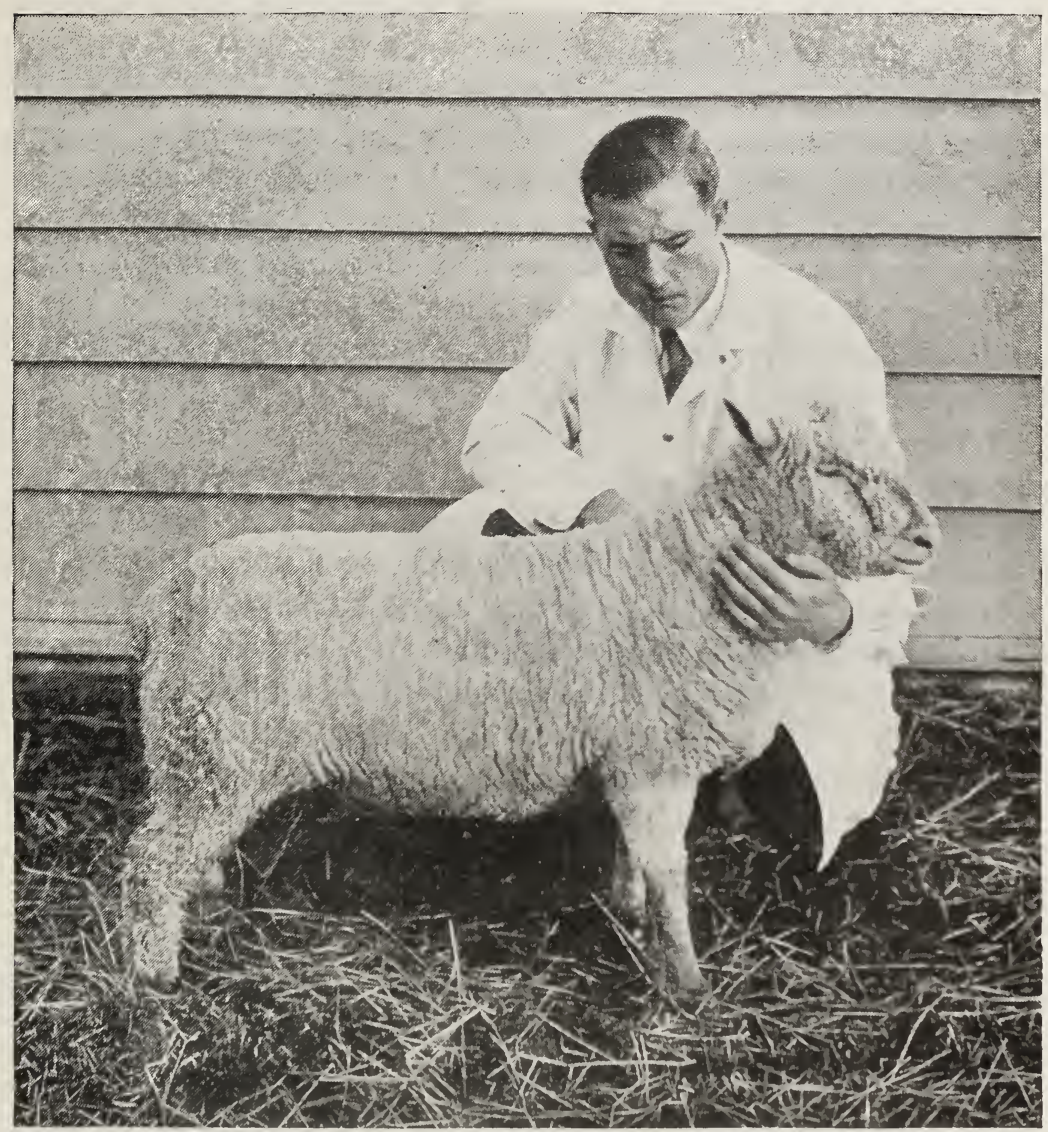

FI(x. 24. - This sheep was reared from weaning to maturity on a purified diet which it received for 15 months.

of the physiological performance is not of primary concern it is frequently essential from the standpoint of the interpretation of the results to have some record of the feed consumed. In many feeding experiments, particularly those with farm animals, the animals have been fed as a group. This is the simplest procedure from the standpoint of equipment needed and labor cost, but, in many experiments, it introduces complications in the interpreta- 
tion of results. Such complications arise when there is a wide variability in the individual behavior within the lot, as to both production and feed consumption. The difficulty is increased when an animal owing to accident or other unavoidable cause has to be removed from the lot. The performance of the individual can be eliminated from consideration, but the food which it ate cannot. Individual feeding eliminates these disadvantages. It makes possible the correlation of individual performance record with the food which the animal ate. It preserves the identity of the individual. Certain species, which are fed together in practice, may consume somewhat less when fed individually. Thus certain workers stress this "competition in the feed lot" as being of large practical importance in feeding trials with beef cattle, sheep, and hogs.

While there are types of feeding experiments in which feed records of the group as a whole are sufficient or in which they may be acceptable in the interest of economy and of the use of larger numbers of animals, individual records are highly desirable in studies where only small differences are to be expected and where quantitative data are of special importance. Individual records are much more useful from the standpoint of statistical treatment (Sec. 211). The relative advantages of group and individual feeding are discussed in various papers presented in a symposium before the American Society of Animal Production. ${ }^{1}$

207. Controlled Feed Intakes.-Early in their studies of protein quality Osborne and Mendel recognized that ad ibitum feeding frequently gave rise to variable results. They raised the fundamental question: "Does one animal grow because it eats more or the other fail because it eats less?" They experimented with various procedures of controlled feeding as a means of eliminating the uncertainties here involved. In one series of studies Osborne and Mendel ${ }^{2}$ kept the food intakes alike for each diet under study, in accordance with a prescribed schedule based upon a preliminary experiment. They were thus able to compare

${ }^{1}$ Carroll, W. E., Group feeding as a method of livestock experimentation, Proc. Am. Soc. Animal Production, 1930, pp. 34-44. LusH, JAY L., Interpreting the results of group feeding experiments, ibid., pp. 44-55. CRampton, E. W., Individual feeding for the comparative feeding trial, ibid., pp. 56-63.

2 Osborne, Thomas B., and Lafayette B. Mendel, A quantitative comparison of casein, lactalbumin, and edestin for growth or maintenance, $J$. Biol. Chem., 26, 1-23, 1916. 
the growth made on different diets consumed in the same amount. Recognizing that the more rapidly growing animals might be at a disadvantage under this system in view of their increasing maintenance requirement, they carried out another series in which the food intake was adjusted in accordance with increase in weight. In another experiment Osborne and Mendel ${ }^{1}$ allowed ad libitum feeding and selected for comparison the growth records of those animals which had consumed substantially the same amount of food under this system. The discussion presented in these papers clearly shows that a proper assessment of the effect of food consumption as such is a very important matter in any feeding experiment, and the papers are well worth reading by any student who is planning such an experiment. This early work by Osborne and Mendel was a forerunner of the paired-feeding method which is widely used today.

208. Paired Feeding.-In this method of comparing two rations the animals are selected by pairs, one animal of a given pair being placed on ration $A$ and the other being placed on ration $B$, and both animals being given exactly the same amount of food. The latter is accomplished by limiting the intakes of both to that of the animal consuming the lesser amount. The two animals of the pair are selected to be as nearly alike as possible in size, age, and previous history, but such equalities are not essential from pair to pair. The equalization of food intake is also limited to within the pair. This method is illustrated by the data presented in Table XIV, obtained in an experiment in which the two rations under comparison were alike with the exception of the phosphorus carrier. Both rations contained the same amount of phosphorus and in the same ratio to calcium. It is noted that for a given pair of rats the food intakes were substantially alike over the experimental period of 35 days. When it is desired to eompare three rations at the same time, the animals can be selected in trios. This may involve complications, however, in the equalization of food intake, complications which become increasingly troublesome in comparing more than three rations.

An important feature of a paired-feeding experiment is a statistical analysis of the data obtained, and the adaptability of

1 Osbonne, Thomas B., and Lanavette B. Mendel, The relative value of certain proteins and protein concentrates as supplements to corn gluten, J. Biol. Chem., 29, (69-92, 1917. 
the data to statistical treatment (Sec. 211) is a strong point in favor of the method. Other things being equal, the larger the number of pairs the greater the reliability of the results. The data given in Table XIV include only four of the six pairs actually used in the experiment. The statistical analysis of the complete data revealed no certain advantage for one phosphorus carrier over the other.

In 1921 Armsby suggested the paired-feeding method as a procedure to be used in cooperative experiments to determine the protein requirements of calves. During the last 10 years, the

Table XiV.-Data from a Paired-Feeding Experiment in Which Dicalcium Phosphate $(A)$ and Bone Meal $(B)$ Were Compared as Sources of Phosphorus for Bone Growth ${ }^{1}$

\begin{tabular}{|c|c|c|c|c|c|c|c|c|}
\hline & \multicolumn{2}{|c|}{ Pair 1} & \multicolumn{2}{|c|}{ Pair 2} & \multicolumn{2}{|c|}{ Pair 3} & \multicolumn{2}{|c|}{ Pair 4} \\
\hline & $A$ & $B$ & $A$ & $B$ & $A$ & $B$ & $A$ & $B$ \\
\hline Food & 253 & 253 & 255 & 254 & 252 & 252 & 224 & 228 \\
\hline Ash in bone, & 48.44 & 47.43 & 51.63 & 50.64 & 49.77 & 48.91 & 50.81 & 54.23 \\
\hline Ash in bone, mg. ... & 191.0 & 157.7 & 190.3 & 154.7 & 179.2 & 166.3 & 162.3 & 171.3 \\
\hline Calcium in bone, $\%$. & 19.81 & 16.04 & 18.59 & 18.20 & 17.78 & 17.63 & 18.20 & 19.26 \\
\hline $\begin{array}{r}\text { Phosphorus in bone, } \\
\% \ldots \ldots \ldots \ldots\end{array}$ & 9.9 & 8.5 & 9.3 & 9.2 & 8.9 & 8.8 & 9.0 & 9.6 \\
\hline
\end{tabular}

${ }^{1}$ From Rottensten, K. V., and L. A. Maynard, The assimilation of phosphorus from dicalcium phosphate, C.P., tricalcium phosphate, C.P., bone dicalcium phosphate and cooked bonemeal, J. Nutrition, 8, 715-730, 1934.

method has been employed to study a wide variety of problems by Mitchell who is a strong champion of it. A paper by Mitchell and Beadles ${ }^{1}$ gives an excellent description of the procedure and its application. A unique advantage claimed for the paired-feeding method is that it eliminates the confusing effects which may arise from a variable food intake, even though results are compared per unit of feed consumed.

A criticism advanced against the method is that limiting the food intake may defeat the very object of the experiment, since a frequent effect of a nutritionally deficient ration is to decrease food consumption, with the result that the full effect of the better ration cannot express itself and that the comparison is made at a

${ }^{1}$ Mitchell, H. H., and J. R. Beadles, The paired-feeding method in nutrition experiments and its application to the problem of cystine deficiencies in food proteins, J. Nutrition, 2, 225-243, 1930. 
restricted food intake instead of a normal one. The force of this criticism is dependent upon the nature of the experiment. In answer to this criticism, the proponents of the method, though granting that it is not suitable to every type of problem, state that if a given ration is nutritionally superior to another its superiority should in general be evident when comparable animals receive the same intake, even though it is restricted. As an exception to this general statement, however, it may be noted that the essentiality of arginine for normal growth in the rat (Sec. 88) would not have been discovered in an experiment in which the food intake was only sufficient to support slow growth. In practical tests in which palatability and level of food intake are important criteria of the relative value of the rations, equalized feeding would obviously defeat their purpose. One must be careful, however, about drawing conclusions that more fundamental differences exist where some physical factor concerned in palatability may have been solely responsible for the results obtained.

The method is not suitable for finding out how much superior one ration is to another for growth, because, as the animal on the superior ration increases in weight over its mate, its maintenance requirement becomes greater than that of its mate. Under these conditions, an equal food intake for both means that the larger animal must be using a larger proportion for maintenance, and less remains for growth promotion. Therefore, an absolute equality of food intake means that the quantities available for the specific function which is being used as the criterion in comparing the two rations are not equal. The faster-growing animal is penalized. In order to obtain quantitative data Mitchell and Hamilton ${ }^{1}$ have fed pairs of rats amounts that would support equal gains in weight, using the differences in amounts fed as the measure of the relative nutritive value of the two rations under comparison.

The paired-feeding method is a useful technique but requires judgment in its application and in the interpretation of the results obtained. It would appear to find its largest usefulness in comparisons in which food consumption is not markedly restricted by the conditions imposed, and in which the measure is in terms of the specific effect of the nutrient under study, as is illustrated in

1 Mitchela, H. H., and T. S. Hamiton, 'The balancing of rations with respect to protein, Proc. Am. Soc. Animal Production, 1935, p). 241-252. 
Table XIV, instead of the more general measure of increase in weight. Some of the limitations of the method are brought out in the recent studies by Barnes and coworkers, ${ }^{1}$ dealing with methods of measuring protein efficiency. There are many problems concerning which the use in separate experiments of both ad libitum feeding and controlled feeding will give much more information than either procedure alone. If the two give similar results, the validity of the conclusions is greatly enhanced thereby.

This discussion of paired feeding illustrates the fact that no single method is suitable for the solution of all types of nutrition problems, that the effective investigator must select his method in accordance with his problem, frequently employing more than one method, and, finally, that he must interpret his results with a full consideration of the advantages and limitations of the method used.

209. Slaughter Experiments.-In the previously discussed experiment presented in Table XIV, the relative value of the two mineral supplements was measured in terms of the calcium and phosphorus content of the bones, since the growth of the animals as a whole would not have given definite information as to bone development. Such a procedure, which involves the killing of the animals and the analysis of certain specific tissues or of the body as a whole, is commonly referred to as a slaughter experiment. In many feeding trials, it is desirable to obtain more specific information regarding the effect of a given ration than is furnished by the common measures of weight and size. For example, in studies of the protein requirement for growth or of the comparative value of 'different protein sources, it is important to know the specific effect in terms of protein tissue formed since the increase in the body as a whole is owing to water, fat, and minerals as well as protein, the relations of which may vary.

The introduction of the slaughter method by Lawes and Gilbert has been referred to. As now used it takes many forms according to the problem under investigation. To study the effect of a given diet on changes in body composition a group of like animals are selected and a part of them are slaughtered and analyzed at the start of the experiment. The others are fed a weighed and analyzed diet for a given period and then slaughtered and ana-

${ }^{1}$ Barnes, Richard H., and coworkers, Measurement of the growth promoting quality of dietary protein, Cereal Chem., 22, 273-286, 1945. 
lyzed. The difference in their composition from that of the check animals killed at the start reveals the effect of the diet fed. The use of the slaughter method for studying protein and energy requirements is illustrated by the work of Mitchell and Hamilton. ${ }^{1}$

A slaughter experiment requires much more time and labor than is involved in merely weighing or measuring the animals, and in many instances difficult problems are presented in the selection of representative samples of tissues and in their preparation for analysis. For each period of observation, a sufficiently large number of animals must be examined to minimize the rather large individual variability in composition. In general, small laboratory animals are much easier to work with than the larger farm animals. Because of the economic considerations involved, work with the latter must be limited for the most part to those animals for which a return can be obtained on the carcass after the desired samples for analysis have been taken. As regards farm animals, therefore, the slaughter method has found its greatest application in studying the nutrition of beef cattle, sheep, and swine. Slaughter data may also include various measures of market value, such as dressing percentages and quality of the carcass, and such measures are frequently used in meat-production experiments to study the influence of a given ration upon the quality of the product and upon its selling price.

An excellent discussion of procedures for the handling of tissues obtained in slaughter experiments is presented in the report of the Subcommittee on Animal Nutrition of the National Research Council. ${ }^{2}$

210. Financial Phases of Feeding Trials.-It is obvious that an essential practical consideration in evaluating a ration for farm animals is its cost in terms of the return obtained for the product. Thus, in many feeding trials, records are kept of feed and perhaps of other costs, and of the estimated or actual selling price of the product. Profit or loss per animal or per unit of feed thus becomes a measure of the nutritive value of the ration. While it is obvious that the financial phases of feeding operations cannot

1 Mitchell, H. H., and T. S. Hлmmton, Swine type studies. III. The energy and protein requirements of growing swine and the utilization of feed energy in growth, Ill. Agr. Expt. Sta. Bull. 323, 1929.

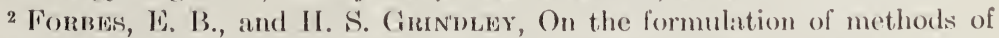
experimentation in animal production, Nall. Research Conncil Bull. 33, 1923. 
be neglected, the expression of the results in terms of dollars and cents, unless properly interpreted, may obscure rather than clarify the facts brought out by the experiment. Monetary statements are not experimental results. They are based upon factors which are not under experimental control, the same combination of which may never occur again. The relative prices of feeds, and the selling price of the product vary from time to time, in fact from day to day and from place to place, according to market conditions. Clearly the product obtained per unit of feed is a much more stable and useful measure. While financial statements of feeding trials are interesting to the reader, they provide no basic or generalized measure of nutritive value and relying upon them as a guide for practice may prove disastrous. In contrast, a statement of food consumed and product obtained provides the basic data to which the feeder can apply current prices and thus obtain a much more accurate picture of the probable financial outcome than is given by a statement of the financial results based on prices at the time and under the conditions of the experiment.

211. Statistical Methods of Analysis of Data from Nutrition Experiments.-In a feeding trial certain factors, such as the amounts and quantities of feed, the time and method of feeding, and the general care and management, can be definitely fixed. Certain other factors, inherent in the animals used, cannot be controlled. The object of a well-planned experiment is to reduce these uncontrollable factors to a minumum by giving attention, in the selection of the animals used, to genetic and nutritional history as well as to such factors as age, size, vigor, and the like. Even though this is effectively done there still remain inherent variables which cause two individuals to respond somewhat differently though treated exactly alike in an experiment. When treated differently, a part at least, of the difference in response is the result of the inherent variables and not the treatment.

The effect of the inherent variables cannot be measured, but the probability that the observed differences in experimental results could arise from the uncontrollable variables alone can be estimated and taken into account. This is done by a statistical analysis of the data obtained. Such an analysis helps the investigator to decide whether the results from a given comparison reflect a real difference in response to the two treatments, or 
whether they may have occurred simply because of inherent variations in the animals used. Statistical methods are also usefully employed in planning experiments in such a way as to make them most likely to give a definite answer to the question under study. They have become an essential tool of the investigator in nutrition, and some knowledge of them is helpful to all students in this field as an aid in the evaluation of published research. It is beyond the scope of this book to attempt any presentation of statistical methods, but, in the literature at the close of this chapter, several papers are cited which describe the procedures used and their usefulness in various types of research.

\section{THE DETERMINATION OF DIGESTIBILITY}

It is obviously impracticable to carry out feeding trials with all of the different feeds and combinations which are used in making rations; neither do these trials which measure only the final effect of the feed in terms of the function under study tell us much regarding the intermediate processes involved. There are other measures of nutritive value which give us more definite information as to why a particular result is obtained, and this information is useful both in experimental studies and in feeding practice. Chemical analysis is the starting point for determining the nutritive value of feeds, but the actual value of ingested nutrients is dependent upon the use which the body is able to make of them. The first consideration here is digestibility, since undigested nutrients do not get into the body proper.

Anatomical and physiological differences in the digestive tracts of various species are responsible for large variations among them in their ability to utilize different types of food in their nutrition. These variations are largest in the case of roughages, because of their content of complex polysaccharides. Different species of farm animals do not differ greatly in their ability to digest concentrates such as seeds and their by-products, since most of these feeds are low in crude fiber. Fortunately, for experimental work, digestion in the rat is similar to that in the hog. The ability of the ruminant to handle a large amount of roughage gives it a special place in agrieulture in that it can utilize the coarse products of the farm which find little outlet in other directions, whereas the hog competes more or less directly with man, or 
with the demands of industry, for most of its food. Because of its capacious digestive tract, the ruminant can consume a ration which it only partially digests and still get enough nutrients for rapid growth or other function, whereas the hog must have a highly digestible ration in order to eat enough to meet its needs for best performance. Thus, for economic reasons, the rations fed to cows, sheep, and even horses are commonly those which are less digested than those fed to hogs.

212. The Determination of Digestibility.-A digestion trial involves a record of the nutrients consumed and of the amounts of them voided in the feces. It is essential that the feces collected represent quantitatively the undigested residue of the measured amount of food consumed. Various methods are employed for this fecal collection. In the case of Omnivora and Carnivora some indigestible, easily distinguishable substance called a marker may be used. The marker is fed just before the beginning of the ingestion of the ration to be tested, and again at its close. The feces collection is begun when the first marker appears and ended with the appearance of the second. A satisfactory marker must be inert physiologically and contain no element under investigation. The less the substance diffuses the better. Carmine is a frequently used marker. Ferric oxide, chromic oxide, and soot have also been employed. No marker can be considered to provide unquestionable accuracy.

In the case of herbivorous animals with their much larger and more complicated digestive tracts the use of a marker is not a suitable method. For these species, and commonly for other farm animals also, the ration to be tested is fed in constant daily amounts for an extended period. After allowing a certain number of days to elapse as a preliminary period to free the digestive tract of any indigestible material coming from the feed consumed prior to the start of the constant intakes of the ration under study, the collection of the feces is begun and continued through the collection period. The length of the periods required to obtain reliable results depends upon the species, longer periods being necessary in the case of Herbivora, especially ruminants, than of other species. In general, the longer the period of collection, provided the stated amount of food continues to be consumed regularly and completely, the more accurate the results, since the effect of periodic fluctuations is minimized. 
213. Methods of Collecting Feces.-There are various methods used in the collection of the feces in a digestion trial. For laboratory animals, and also for sheep, hogs, and other animals of a similar size, metabolism cages have been devised which permit

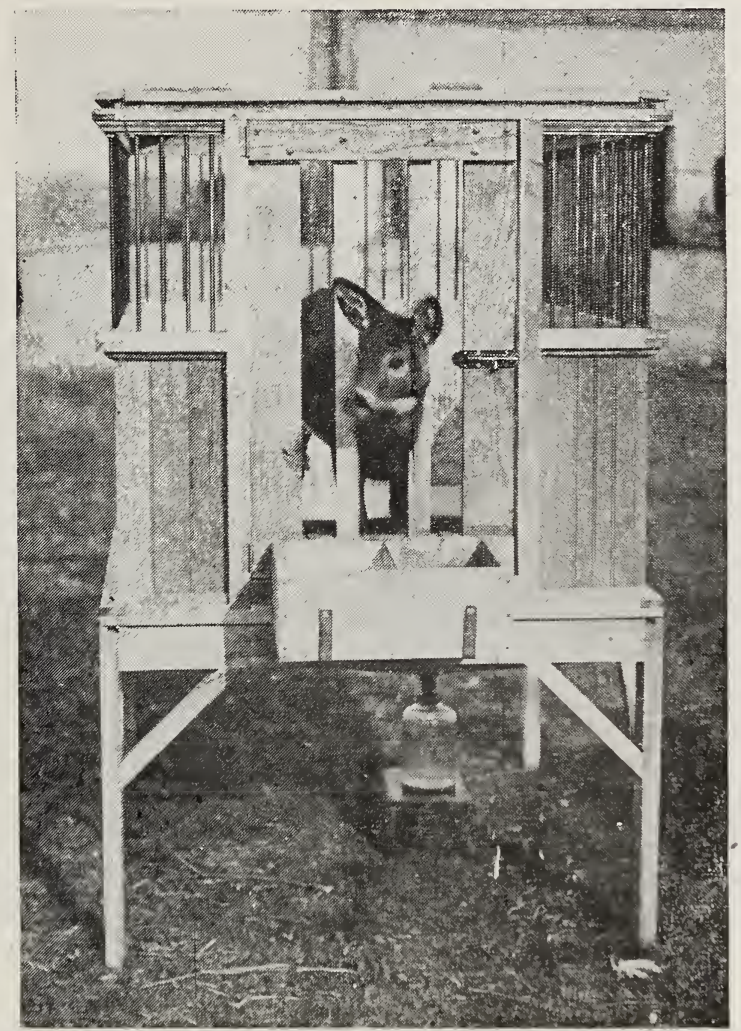

Fig. 25.-Metabolism cage for separation and collection of feces and urine. (From L. A. Maynard, Gardiner Bump, Robert Darrow, and J. C. Woodward, Food preferences and requirements of the white-tailed deer, N. Y. State Conservation Dept. \& N. Y. State College of Agr. Bull. 1, 1935).)

the accurate separation and collection of the excreta. Such a cage is shown in Fig. 25. The animal stands on an iron grid through which the excreta pass. The feces are separated out by a suitable screen and the urine passes through into the bottle shown underneath. The feedbox is outside the cage, and the animal may be stanchioned during feeding. Thus no feed is 
scattered into the feces, and any scattered outside can be collected and accounted for.

Collection bags or similar devices which can be attached to the animal are commonly employed for steers and wethers. A bag designed by Garrigus and Rusk of the University of Illinois for collecting the feces of steers on pasture is shown in Fig. 26. Such a bag cannot be used for female animals because of the problem of separating the feces from the urine. With dairy cows a commonly used procedure is to employ attendants who remain behind the

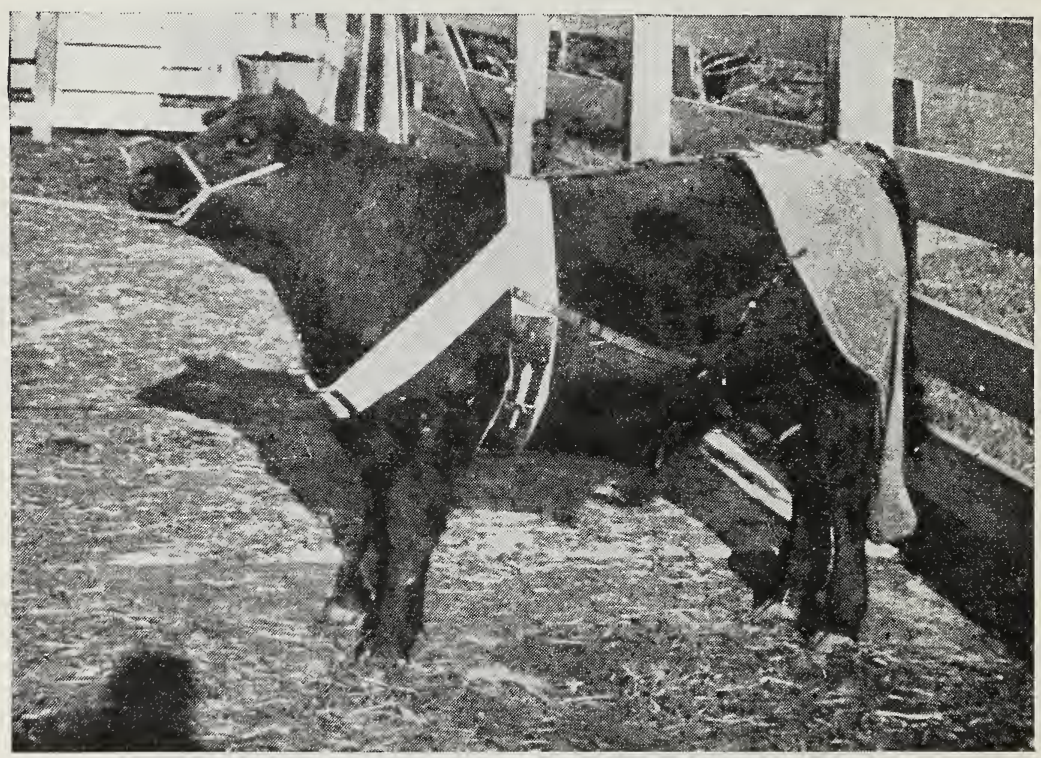

Fig. 26.-Harness and bag for collecting feces in a digestion trial.

animals constantly to collect the excreta as voided. This is an accurate but expensive method.

Ritzman and Colovos ${ }^{1}$ have described a device which provides for the automatic collection and separation of the solid and liquid excreta of cows. The excreta as voided pass down a chute behind the cow and fall on a broad belt moving uphill. The urine drains off the belt into a collecting pan, whereas the feces remain on the belt and are dumped into a can as the belt goes over a roller.

${ }^{1}$ Ritzman, E. G., and N. F. Colovos, An automatic method for collecting solid and liquid excreta from cows in digestion experiments, N.H. Agr. Expt. Sta. Tech. Bull. 52, 1932. 
Simpler equipment for separating urine and feces, utilizing a device originally designed by Møllgaard, is described by Forbes and associates. ${ }^{1}$

The determination of digestibility in poultry requires a special technique since the feces and urine are voided together, causing a mixing of the urinary and fecal nitrogen. The two forms of nitrogen can be separated by determining the ammonia and uric acid which represent the urinary output. The determination of digestibility is also carried out by the use of an operative technique which involves the formation of an artificial anus. Papers describing procedures for poultry are listed at the end of this chapter.

214. A Digestion Trial.-An example of the data obtained in a digestion trial is presented in Table XV. In obtaining the data for intake of nutrients, the feed intake was multiplied by figures for its percentage composition as determined by chemical analysis. Similarly, the data for excreted nutrients were calculated, and the digested nutrients obtained by subtraction. The final figures, expressed as percentages, are called digestion coefficients. In such a trial, several animals must be used and the results averaged to minimize the factor of individual variability.

It is noted that the mineral nutrients are not considered in Table XV. The discussion in Chap. VII has shown that some of the absorbed minerals are excreted through the gut. There is no method of separating such mineral material from the portion which originally failed of absorption. Since this is true and since the reexcreted portion may be a large as well as a variable part of the whole, it is impossible to arrive at a figure of any value for the digestibility of most of the mineral elements. Data for "digestible ash" which are frequently reported in connection with digestion trials have no real significance.

The digestibility of individual feeds may be determined in so far as they provide a satisfactory ration for the period of the test, when fed alone. The digestibility of concentrates by ruminants cannot be determined in this way because they do not furnish sufficient bulk; their coefficients can be obtained only by difference. In this procedure the digestibility of a roughage as a basal ration is first determined, and then the concentrate is added to

1 Forbes, Trnest B., and associates, The digestibility of rations by cattle and sheep, P'enn. Agr. Expt. Sta. Bull. 339, 1937. 
the roughage for a second test. By a consideration of differences between the figures obtained for the roughage alone and for the combination, coefficients for the digestibility of the concentrate are calculated. Such figures represent the net effect of the addition of the concentrate to the roughage, but they may not be exact for the concentrate because its addition may have influenced the digestibility of the basal ration. The frequent occurrence of impossible coefficients in data thus obtained testifies to this fact.

Table XV.-Digestibility of Dried Grass by a Dairy Cow ${ }^{1}$ (Data for a One-week Period)

\begin{tabular}{|c|c|c|c|c|}
\hline & \multirow{2}{*}{$\begin{array}{l}\text { Crude } \\
\text { protein }\end{array}$} & \multicolumn{2}{|c|}{ Carbohydrates } & \multirow{2}{*}{$\begin{array}{l}\text { Ether } \\
\text { extract }\end{array}$} \\
\hline & & Fiber & N.F.E. & \\
\hline $\begin{array}{l}\text { Intake of } 44,684 \text { g. dry matter, con- } \\
\text { taining, g. ................ } \\
\text { Output of } 11,609 \text { g. fecal dry matter, } \\
\text { containing, g. . . . . . . . . }\end{array}$ & $\begin{array}{r}10,216 \\
2,559\end{array}$ & $\begin{array}{l}8,255 \\
2,158\end{array}$ & $\begin{array}{r}20,823 \\
4,042\end{array}$ & $\begin{array}{r}1,697 \\
783\end{array}$ \\
\hline $\begin{array}{l}\text { Digested nutrients, g. . } \\
\text { Digested nutrients, \%. }\end{array}$ & $\begin{array}{r}7,657 \\
75\end{array}$ & $\begin{array}{r}6,097 \\
73.9\end{array}$ & $\begin{array}{r}16,781 \\
80.6\end{array}$ & $\begin{array}{r}914 \\
53.9\end{array}$ \\
\hline
\end{tabular}

1 These data are taken from Newlander, J. A., and C. H. Jones, The digestibility of artificially dried grass, Vt. Agr. Expt. Sta. Bull. 348, 1932.

215. The Enzymatic Method of Determining Protein Digestibility.-Waterman and associates designed a method for determining the digestibility of the proteins of foods in the laboratory by the use of a pepsin-hydrochloric-acid solution. This enzymatic method has proven useful for studying the relative digestibility of various sources of protein and for studying the influence of certain factors such as cooking on the digestion process. The method cannot be relied upon, however, to give the same results as are produced in vivo, for the conditions of the digestive tract cannot be duplicated in the test tube. This is particularly true for the roughages. When applied to hays and pasture grass, the enzymatic method has been found to give much higher values than are actually obtained with ruminants.

216. Total Digestible Nutrients.-As a general measure of the nutritive value of a feed, digestion coefficients are used to compute its content of total digestible nutrients (T.D.N.). The dried grass used in the digestion trial presented in Table XV had the following 
composition: crude protein, 20.11; crude fiber, 16.25; nitrogen-free extract, 40.99; ether extract, 3.34. The digestible nutrients are obtained from these data by multiplying them by the digestion coefficients given in the table, as is shown below:

\begin{tabular}{|c|c|c|c|}
\hline Nutrient & $\begin{array}{c}\text { Total } \\
\text { nutrients } \\
\text { in } 100 \mathrm{lb} . \text {, } \\
\text { lb. }\end{array}$ & $\begin{array}{c}\text { Digestion } \\
\text { coefficients, } \\
\text { per cent }\end{array}$ & $\begin{array}{c}\text { Digestible } \\
\text { nutrients, } \\
\text { lb. }\end{array}$ \\
\hline $\begin{array}{l}\text { Crude protein } . \ldots \ldots \ldots \ldots \ldots \ldots \\
\text { Crude fiber } . \ldots \ldots \ldots \ldots \ldots \ldots \\
\text { Nitrogen-free extract. } \ldots \ldots \ldots \ldots \\
\text { Ether extract } \ldots \ldots \ldots \ldots \ldots \ldots\end{array}$ & $\begin{array}{r}20.11 \\
16.25 \\
40.99 \\
3.34\end{array}$ & $\begin{array}{c}75 \\
73.9 \\
80.6 \\
53.9(\times 2.25)\end{array}$ & $\begin{array}{r}15.08 \\
12.01 \\
33.03 \\
4.04\end{array}$ \\
\hline Total digestible nutrients... & & & 64.16 \\
\hline
\end{tabular}

The digestible fat is multiplied by the factor 2.25 in arriving at the figure 4.04 , because it has that much more energy value than the other nutrients, as is explained later (Sec. 227). The usefulness of T.D.N. values in evaluating feeds and in formulating rations is also discussed later (Sec. 238).

Morrison ${ }^{1}$ has compiled the data from digestion experiments carried out with the various feeding stuffs used for farm animals, and thus constructed a table of average digestion coefficients. $\mathrm{He}$ has applied these coefficients to figures which he has compiled on the average composition of these feeding stuffs and thus computed their content of digestible nutrients. These data, representing an exceedingly time-consuming and invaluable piece of work, are given in Table $I$ in the appendix of his book. The values for digestible protein and total digestible nutrients are the ones commonly employed in the computation of rations for farm animals. The figures for concentrates can be considered to apply to all species. Those for roughages apply to cattle and sheep but are somewhat too high for the horse, and, of course, they do not hold for the pig. Morrison has compiled the available data on the digestibility of feeds by horses and swine and these data are also given in the appendix of his book.

217. Nutritive Ratio.- This is the ratio of the digestible protein, expressed as unity, to the sum of digestible carbohydrates and

${ }^{1}$ Morrison, F. B., Feeds and feeding, 20th ed., Morrison Publishing Company, Ithaca, N.Y. 
fat, the latter being multiplied by 2.25. The second factor of the ratio is calculated as follows:

\section{$\underline{(\text { digestible fat } \times 2.25)+\text { digestible N.F.E. }+ \text { digestible fiber }}$ digestible protein}

Based upon the data previously given for dried grass (Sec. 216) this calculation results in the figure 3.2 and the ratio is therefore $1: 3.2$. Such a ratio is called a narrow one because of the relatively large amount of protein in relation to the other nutrients; where the reverse is true we have a wide ratio.

218. Factors Affecting Digestibility.-The influence of crude fiber content on digestibility has been discussed (Sec. 44). The previous discussion of the digestibility of the carbohydrates also illustrates the fact that the nature of the nutrients themselves influences their digestibility. This is particularly true for the group comprising the ether extract. While in seeds and their by-products this extract consists almost entirely of readily digestible esters of fatty acids, the extract of roughages contains a high proportion of nonsaponifiable constituents as well as nonlipid substances.

Digestibility may be limited by a lack of time for complete digestive action on less easily digestible substances or by a lack of complete absorption. Such an effect is heightened by a rapid passage of the food through the tract. On the other hand, food may move so slowly through the intestines as to be excessively subject to wasteful fermentations. Lack of time for digestion or absorption may explain why, as the level of food intake increases above a certain value, the digestibility of all nutrients tends to decrease. Average digestion coefficients determined at or near maintenance are frequently found not to hold at the level of food intake required for liberal production. The early studies of Eckles ${ }^{1}$ showing digestibility in the dairy cow to be lower at full feed than at maintenance have been confirmed by later workers.

As the nutritive ratio becomes wider, the digestibility of all nutrients tends to be lower. This is particularly true for protein, and the effect here is readily explainable on the basis of output of metabolic nitrogen, since the protein coefficient determined represents the apparent digestibility (Sec. 96). Inasmuch as

${ }^{1}$ EckLes, C. H., Nutrients required for milk production, Mo. Agr. Expt. Sta. Research Bull. 7, 1913. 
the metabolic nitrogen is governed by total food intake and thus tends to remain constant although the percentage of protein in the food is lowered, the fecal nitrogen as a whole does not decrease proportionally with the decreased protein intake, even though the residual food nitrogen may. Thus the apparent digestibility of protein is lowered with a wide ratio even though the true value may not be. The lowering of the digestibility of nutrients, other than protein, with a ration having a wide nutritive ratio is less marked than for protein itself, and published data indicate that it occurs less consistently. In the case of ruminants, however, the addition of protein or of nitrogen compounds utilized by bacteria to a ration having a wide ratio definitely increases the breakdown of the higher carbohydrates, and this in turn makes other nutrients more digestible.

It is recognized that the digestibility of a mixture is not necessarily the average of the values for its constituents determined separately or indirectly. Each feed may exert an influence on the digestibility of the others. Although it is impossible to determine the specific factors involved in this associative digestibility, the previous discussion of the influence of crude-fiber content and of nutritive ratio makes it easy to understand that marked variations from computed averages may occur.

Influence of Feed Preparation on Digestibility.-Grinding grain usually does not increase digestibility in those animals which masticate their feed thoroughly, but seeds which escape mastication may remain largely undigested in passing through the tract. Sheep masticate their feed so effectively that there is no advantage in grinding grain for them, except in the case of very small and hard seeds. Cattle chew their grain less thoroughly and thus digest it somewhat better when it is ground. Grinding helps for very young animals before their teeth are developed and for old animals that have poor teeth. Digestibility in growing swine is only slightly increased by grinding, but the effect is more marked in older animals.

Differing from the case with grains, roughage is chewed by all animals sufficiently to break it up so that the digestive juices can penetrate it. 'There is no advantage in grinding or chopping hays which are of sufficiently good quality and palatability to be completely consumed without it. Grinding does, however, increase the consumption of coarse roughages and lessens the wastage 
which inevitably occurs when such roughages are fed uncut. This result is a distinct advantage in many feeding operations, but, with high-producing dairy cows where capacity to consume and digest food is a limiting factor, increasing the consumption of the less nutritious portion of the roughage may be definitely undesirable. It may be disadvantageous also for fattening calves.

Roughage should be coarsely ground or chopped rather than finely ground. The coarse product is more palatable and fine grinding may actually decrease digestibility. This has been shown to be true for alfalfa in studies with cattle at the Pennsylvania State College. A depression of rumination resulted which was the probable cause of the lower digestibility. From a practical standpoint, chopping or coarse grinding is preferable because it requires less power and is thus less expensive. Whether or not it pays to grind feeds under any conditions depends upon the gain in production relative to the cost of grinding.

Cooking feeds does not help digestibility in mature farm animals except in the case of a few feeds for swine and poultry. The digestibility of soybeans and soybean-oil meal by hogs and poultry is also improved by a thorough heat treatment, either in connection with oil removal or separately. The newborn calf develops the ability to digest uncooked starch very rapidly. A coefficient of digestibility of 90 per cent at four weeks of age has been reported. None of the various processes of fermenting, "predigesting," and malting which have been exploited as methods for getting more nutrient value from roughages and other fibrous feeds have been found to have any advantage when subjected to critical tests.

219. The Significance of Digestion-trial Data.-The previous discussion has indicated that a variety of factors influence the nature of the results obtained in a digestion trial. This fact must be borne in mind in interpreting the data and applying them to practice. The most significant data for practical application are obtained where the ration is fed at the level required for satisfactory production. This means both an adequate total intake and also an adequate protein content. A sufficient supply of other nutrients is also desirable because a deficiency of some of them may affect digestion processes even though there is no evident effect on production over the short period of the trial. These various considerations can be met in the case of mixed rations but not in 
the case of many individual feeds. The alternative in the latter case is to employ the indirect method, which, however, brings in other possible errors as has been discussed.

Digestion data measure the disappearance of the nutrient in passing through the tract in absorption. In the case of ruminants particularly, coefficients for the higher carbohydrates are always too high as a measure of absorbed nutrients, because of the gaseous losses. There are some gaseous losses from nitrogen-free extract also. A crude-fiber coefficient is subject to further question because a part of the undigested residues of this feed component may be sufficiently broken down to appear in the nitrogen-free extract of the feces instead of in the crude-fiber portion. In the case of the usual rations for Herbivora, fat-digestion coefficients are subject to rather large errors owing to various causes attributable principally to the ether-extract method. These errors are not of large significance, however, in terms of the digestibility of the ration as a whole because the ether-extract fraction represents such a small part of the total.

Despite these various limitations, digestion coefficients remain distinctly useful. A consideration of the limitations serves to emphasize the importance of proper planning of digestion trials and of the matters that should be borne in mind in interpreting the results. Much helpful information along these lines is to be found in the publications by Mitchell ${ }^{1}$ and by Forbes. ${ }^{2}$ The publication by Mitchell also discusses the relation between chemical composition and digestibility and considers the usefulness of formulas for calculating digestibility from its crude-fiber and protein content. Other studies dealing with this question are cited in the list of papers that follows.

\section{Selected Literature}

Axelsson, J.: Die Bestimmung des allgemeinen Nährwertes (Energiewertes) der Futtermittel nach der chemischen Zusammensetzung, Tierernährung 10, 238-248, 1938.

Cochran, W. G., K. M. Autrey, and C. Y. Cannon: A double change-over design for dairy cattle feeding experiments, J. Dairy Sci., 24, 937-951, 1941 .

1 Mitchell, H. H., The evaluation of feeds on the basis of digestible and metabolizable nutrients, J. Animal Sci., 1, 159-173, 1942.

${ }^{2}$ loc. cit. 
Crampton, E. W.: The design of animal husbandry experiments, J. Animal Sci., 1, 263-276, 1942.

- and J. M. BeLL: The digestibility of typical Eastern Canadian feeds by market bacon hogs, Sci. Agr., 25, 43-50, 1944.

Forbes, Ernest B., and associates: The digestibility of rations by cattle and sheep, Penn. Agr. Expt. Bull. 339, 1937.

- , and associates: Conditions affecting the digestibility and the metabolizable energy of feeds for cattle, Pa. Agr. Expt. Sta. Bull. 452, 1943.

Fraps, G. S.: Digestibility and production coefficients of poultry feeds, Tex. Agr. Expt. Sta. Bull. 372, 1928.

Gallup, W. D., and C. S. HobBs: The desiccation and analysis of feces in digestion experiments with steers, J. Animal Sci., 3, 326-332, 1944.

Garrigus, W. P. and H. H. Mitchell: The effect of grinding on the digestibility of corn by pigs and on its content of metabolizable energy, J. Agr. Research, 50, 731-735, 1935.

Haberland, H. F. O.: Die operative Technik des Tierexperimentes, Handbuch der biologischen Arbeitsmethoden, Abt. V, Teil 3C, Heft 1, Urban \& Schwarzenberg, Berlin, 1934.

Halnan, E. T.: Digestibility trials with poultry. XI. The digestibility and metabolizable energy of raw and cooked potatoes, potato flakes, dried potato slices, and dried potato shreds, J. Agr. Sci., 34, 139-154, 1944.

Hart, E. B., O. L. Kline, and G. C. Humphrey: The effect of artificial drying on the availability of the nutrients of alfalfa hay, J. Agr. Research, 45, 507-511, 1932.

Hayward, J. W., H. Steenbock, and G. Bohstedt: The effect of heat as used in the extraction of soy bean oil upon the nutritive value of the protein of soy bean oil meal, J. Nutrition, 11, 219-234, 1936.

Heller, V. G., L. Morris, and H. E. Shirley: A method of calculating coefficients of digestibility of poultry feeds, Poultry Sci., 10, 3-9, 1930.

Lancaster, R. J.: Metabolism trials with New Zealand feeding-stuffs. IV. The relative significance of lignin, cellulose and crude fibre in the evaluation of foods, New Zeal. J. Sci. Tech., 25, 137-153, 1943.

Loosur, J. K.: Feeding laboratory animals, Ann. N.Y. Acad. Sci., 46, 45-75, 1945.

Lucas, H. L.: A method of equalized feeding for studies with dairy cows, $J$. Dairy Sci., 26, 1011-1022, 1943.

McRoberts, V. F., and A. G. Hogan: Adequacy of simplified diets for the pig, J. Nutrition, 28, 165-174, 1944.

Mitcheld, H. H. A graphical presentation of the financial phases of feeding experiments, Ill. Agr. Expt. Sta. Bull. 234, 1921.

- Some essentials of a good nutrition experiment, J. Nutrition, 4, 525$538,1931$.

- , and H. S. Grindley: The element of uncertainty in the interpretation of feeding experiments, Ill. Agr. Expt. Sta. Bull. 165, 1913.

SEAth, D. M. A $2 \times 2$ factorial design for double reversal feeding experiments, J. Dairy Sci., 27, 159-164, 1944.

SNedecor, George W.: Statistical methods applied to experiments in agriculture and biology, Iowa State College Press, Ames, Iowa, 1946. 
Titus, Harry W.: Statistical method in planning and interpreting animal nutrition experiments, Poultry Sci., 13, 358-359, 1934.

-, Morley A. Jull, and Walter A. Hendricks: Growth of chickens as a function of feed consumption, J. Agr. Research, 48, 817-835, 1934.

- - , and John C. Hammond: A method of analyzing the data of chick nutrition experiments, Poultry Sci., 14, 164-173, 1935.

Watson, C. J., and associates: Digestibility studies with ruminants. VIII. Associative digestibility of hay and grains (see also earlier papers, this series), Sci. Agr., 22, 250-270, 1941; Digestibility studies with swine. I. The digestibility of grains and concentrates at different stages of the growing and fattening period, Sci. Agr., 23, 708-724, 1943. 


\section{CHAPTER $\mathrm{X}$}

\section{NUTRITIONAL BALANCES}

The physiologists of four centuries ago, though they knew nothing about respiration, recognized that there must be some other loss from the body besides those in the feces and urine. They referred to this loss as the insensible perspiration, by which they meant the invisible exhalations which are known today as carbon dioxide and water. Sanctorius, a professor in the Medical School at Padua, who died in 1616, spent much of his life trying to measure this insensible loss by weighing himself, his food, and his excreta. An old print shows Sanctorius eating while seated in a chair balanced on a steelyard. He weighed himself before eating, added a weight corresponding to the amount of food he proposed to eat and stopped eating when his chair dipped.

In making these various measurements, Sanctorius performed what may be termed the first balance experiment. Such an experiment, as we know it today, involves a quantitative accounting for the intake of a given nutrient in the food and for its outgo in the excreta, providing data for determining whether there is a gain or loss of this nutrient by the body. Such an experiment constitutes another method of measuring nutritive value and the state of nutrition of the body . It gives specific information comparable to that of a slaughter experiment, previously described, and has the obvious advantage that it can be carried out with the living animal. Balance measures are commonly divided into two classes: those which deal with substances that can be weighed or measured, the balance of matter; and those which include heat losses, the balance of energy. A distinction between matter and energy is untenable according to modern physics, but it remains useful for the present discussion.

\section{THE BALANCE OF MATTER}

Boussingault ${ }^{1}$ carried out the first real balance experiment in 1839. He measured the carbon; hydrogen, oxygen, nitrogen, and

${ }^{1}$ Boussingault, J. B., Analyses comparées des aliments consommés et des produits rendus par une vache laitière; recherches entreprises dans le 
ash in the food of a dairy cow receiving a ration that maintained her weight, and the outgo of these nutrients in the feces, urine, and milk. He recognized that he had not accounted for gaseous forms of the elements, and he used his data to estimate the atmospheric oxygen that was required by the cow. Later he made similar studies with a horse and other species. In our nutrition studies of today frequent use is made of the nitrogen balance, of various mineral balances, and, to a lesser extent, of the carbon balance.

220. The Nitrogen Balance.-A determination of the nitrogen in the food and excreta under controlled conditions provides a quantitative measure of the protein metabolism and specifically shows whether the body is gaining or losing protein. This is illustrated by the data in the following table, obtained with a steer receiving $8 \mathrm{lb}$. of clover hay daily:

\begin{tabular}{|c|c|c|}
\hline Average daily nitrogen & $\begin{array}{c}\text { Income, } \\
\mathrm{g} .\end{array}$ & $\begin{array}{c}\text { Outgo, } \\
\text { g. }\end{array}$ \\
\hline $\begin{array}{l}\text { In hay } \ldots \ldots \ldots \ldots \ldots \\
\text { In feces. } \ldots \ldots \ldots \ldots \ldots \\
\text { In urine } \ldots \ldots \ldots \ldots \ldots \ldots \\
\text { Lost from body } \ldots \ldots \ldots \ldots\end{array}$ & $\begin{array}{l}71.4 \\
\cdots \\
\cdots \\
15.5\end{array}$ & $\begin{array}{l}28.4 \\
58.5\end{array}$ \\
\hline 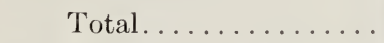 & 86.9 & 86.9 \\
\hline
\end{tabular}

It is noted that the daily nitrogen intake was $15.5 \mathrm{~g}$. less than the total outgo from the body and that the animal was thus in negative nitrogen balance. It was losing $96.9 \mathrm{~g}$. $(15.5 \times 6.25)$ of protein from its body daily, representing the amount by which the intake of protein fell short of meeting the needs of the animal for maintenance. Had the nitrogen intake equaled the outgo, the animal would have been in nitrogen equitibrium, the normal picture in the mature animal which is receiving an intake of protein adequate for its needs. An excess of intake over outgo would have represented a posilive nitrogen balance, involving a storage of protein in the body such as occurs in growth. Such a protein balance shows an increase in actual protein tissue, thus representing a more exact measure of growth than increase in weight which may result in a varying degree from fattening.

but d'examiner si les animaux herbivores empruntent de l'azote à l'atmosphère, Ann. chim. phys., 2d ser., 71, 113-127, 1839. 
The preceding example represents the simplest form of a nitrogen-balance experiment. The use of a ration consisting of several feeds may or may not require a record of the nitrogen intake from each, depending upon the feeding system and the objective sought. In a study of the protein metabolism in lactation, the nitrogen output in the milk must be accounted for. A determination of a nitrogen balance in a lactating cow shows whether the protein intake is adequate for the milk being produced or whether the milk protein is secreted in part at the expense of the body tissues of the animal. It is recognized that there are slight nitrogen losses in the skin excretions and in shed hair, and these are sometimes accounted for by analyzing the brushings from the animal. But this loss has been found so small that it is usually disregarded.

A nitrogen-balance experiment is carried out similarly to a digestion trial (Sec. 212) with the additional provision for the collection and analysis of the urine and of any product such as milk. For the determination of the balance, feces and urine can be collected together, and this is sometimes done since it is the simpler procedure and eliminates separate analyses. In most experiments, however, it is desired to know what part of the outgo is indigestible matter and what part represents a loss in metabolism, and, for this purpose, the collections must be made separately by one of the methods previously described (Sec. 213). The nitrogen-balance method is used to determine the protein requirements for various body functions, to study the quality or biological value of the protein supplied by different feeds and rations, and for other purposes. These various uses are described later (Secs. 278, 279), and reference is made to papers which give detailed procedures.

221. Mineral Balances.-The balance of any mineral element can be obtained in the same way as is done for nitrogen since the same paths of outgo are involved. In fact, balance studies of nitrogen and of several mineral elements are frequently carried out together in the same experiment. The most frequently determined mineral balances are those for calcium and phosphorus. They provide an accurate measure of bone development during growth, and of the adequacy of calcium and phosphorus nutrition for various body functions such as maintenance, pregnancy, and lactation. Their use is described later (Sec. 292). 
222. The Measurement of Gaseous Exchange.-In utilizing the balance method to determine the gain or loss of fat in the body and to study the value of any nutrient or ration for the production of energy, it is necessary to ascertain the intake and outgo of carbon. Since this element is eliminated in part in gaseous form, an accounting for such losses becomes essential. The amount of carbon lost through the lungs in respiration is obtained by a measurement of gaseous exchange, involving a determination of the oxygen consumed as well as the carbon dioxide eliminated. This measurement is an important feature also of the determination of the energy metabolism of the body since the production of energy is an oxidative process which involves the intake of oxygen, and the output of carbon dioxide and water. It is to Lavoisier that we owe the discovery of the true significance of respiration ${ }^{1}$ as an oxidation comparable to combustion outside the body.

The determination of gaseous exchange can be carried out either by placing the subject in a chamber, the atmosphere of which can be controlled and measured, or by the use of a facepiece which provides for the analysis of the inspired and expired air. The use of the chamber makes possible an accounting for the water lost as perspiration and for the intestinal gases produced (Sec. 43), as well as the pulmonary exchange. These gaseous losses resulting from fermentations are of sufficient magnitude in Herbivora, especially ruminants, to require that they be determined or calculated in arriving at a carbon or energy balance. The various devices which are used in either of these methods are referred to as respiration apparatus. The earliest forms consisted of closed chambers in which the subject was placed and in which the change in the composition of the air was determined. The limitation of this procedure, which failed to provide for any renewal of the air or removal of waste products during the course of the experiment, is obvious. Two types of apparatus were later devised to remedy this defect; the closed-circuit type designed by Regnault and Reiset and the open-circuit type developed by Pettenkofer.

The closed-circuit type derived its name from the fact that the same air is continuously circulated, with provision for the removal of the waste products and the addition of oxygen. This apparatus is illustrated diagrammatically in Fig. 27. It is noted

1 See footnote, p. 1. 


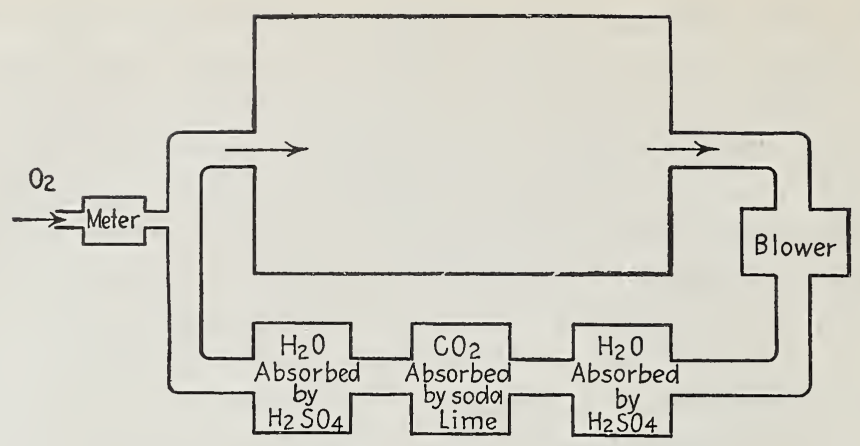

Fig. 27.-Closed-circuit respiration apparatus.

that the carbon dioxide and water are removed from the outgoing current bv absorbents. Their output is determined by recording the increase in weight of the absorbing vessels. The oxygen of the circulating air is renewed through a meter by means of which the volume added is recorded. The residual air at the close of the experiment is analyzed to take account of any changes in composition from that at the start. In this apparatus, the intestinal carbon dioxide is absorbed along with that from the lungs. The other intestinal gases, chiefly methane, can be determined in the residual air. Methane is determined by drawing the air sample over platinized kaolin, or a similar substance, at red heat. The methane is thus oxidized and determined from the carbon dioxide produced. Methane and other oxidizable gases present are thus referred to as combustible gases, a term which has special significance in connection with the energy balance (Sec. 231). Re. gnault and Reiset used their apparatus for studies with sheep, calves, hogs, and poultry. The same principle is employed in the apparatus designed for man by Atwater and Benedict, ${ }^{1}$ but

1 William Olin Atwater (1844-1907) served for 34 years as professor of chemistry at Wesleyan University, Middletown, Conn. The first agricultural experiment station in the United States was estabished at Middletown under his direction in 1875. It was later moved to New Haven. Atwater also served as the first chief of the Office of Experiment Stations of the U.S. Department of Agriculture. In 1892, with the assistance of E. B. Rosa, professor of physics at Wesleyan, Atwater began the construction of the first human-respiration calorimeter which he later employed in his pioneer studies of heat production in man, of energy requirements for various body functions and of the nutritive value of foods. In this work Francis Gano Benedict early became associated. Upon Atwater's death, the calorimeter 
the larger the animal the greater the difficulty and cost of constructing an airtight unit in which the temperature and humidity are well defined.

The open-circuit type differs from the one just described in that the circulating air is drawn from the atmosphere, and the outgoing air, or a measured fraction of it, is passed through the absorbents. When it is desired to account for the intestinal gases other than carbon dioxide, provision for their determination in the outgoing air as well as in the residual air of the chamber must be made. The Pettenkofer apparatus, originally designed for studies with men, was adapted for use with farm animals by later German

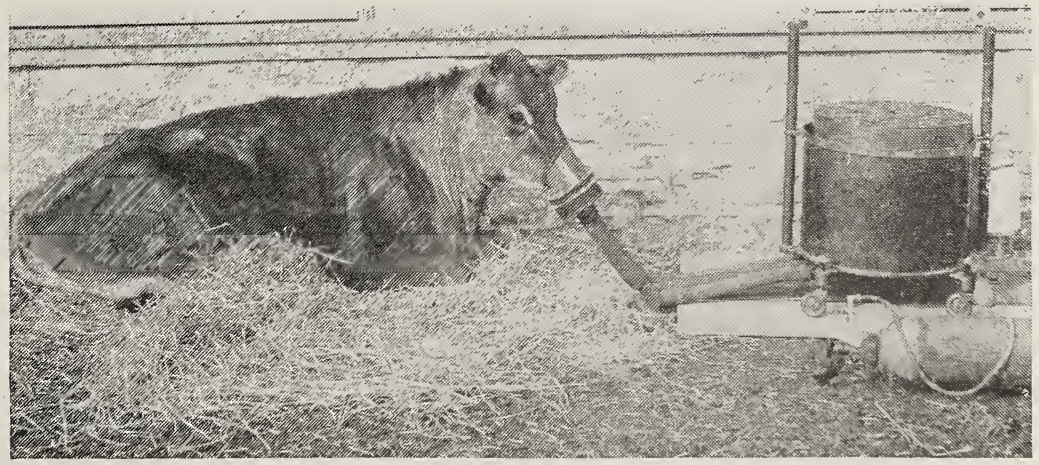

FIG. 28.-Apparatus for measuring pulmonary exchange.

(Courtesy of S. Brody, Missouri Agricultural Experiment Station.)

workers, a development with which the names of Henneberg and Stohmann, Kuhn, and later Kellner are especially associated.

In either the closed- or open-circuit type the chamber can be replaced by a facepiece or some other device for determining the pulmonary exchange only. Zuntz modified the Pettenkofer apparatus for use with the horse by eliminating the chamber and collecting the expired air by a tracheal canula, thus providing a portable device. Brody ${ }^{1}$ has described an airtight muzzle for farm animals (Fig. 28). When it is not desired to determine the

was moved to Boston and set up in the Nutrition Laboratory of the Carnegie Institution of Washington, where for 40 years Benedict and his associates have carried on outstanding studies of the energy metabolism in man and in various species of animals.

1 Brody, SAmues, Growth and development. XV. Energy and nitrogen metabolism during the first year of mostnatal life, Mo. Ayr. Expt. Sta. Research Bull. 143, 1930. 
losses in intestinal gases and in perspiration, the elimination of the chamber with its large volume of air has certain advantages, since short-time observations are thereby accurate and since changes can be traced sharply. For studies extending over several hours or days, the chamber type works better.

Modern respiration apparatus for farm animals include provisions for feeding and for the collection of the feces and urine, as well as for the determination of oxygen intake and of gaseous losses. They are described later (Sec. 234).

223. Respiratory Quotient.-The relation between the oxygen consumed and the carbon dioxide given off in respiration is expressed as the respiratory quotient, computed as follows:

$$
\frac{\text { Volume of } \mathrm{CO}_{2} \text { produced }}{\text { Volume of } \mathrm{O}_{2} \text { consumed }}=\text { respiratory quotient (R.Q.) }
$$

The numerical value of this quotient is dependent upon the chemical nature of the substance being oxidized within the body. The burning of a molecule of glucose, the form in which carbohydrates are catabolized, takes place according to the following equation:

$$
\mathrm{C}_{6} \mathrm{H}_{12} \mathrm{O}_{6}+6 \mathrm{O}_{2} \longrightarrow 6 \mathrm{CO}_{2}+6 \mathrm{H}_{2} \mathrm{O}
$$

Since the carbohydrate molecule contains hydrogen and oxygen in the proportion to form water, oxygen from the outside is required only for the oxidation of the carbon. One molecule of carbon dioxide is formed for each molecule of oxygen consumed, and, therefore, the respiratory quotient is 1.0. The fat molecule, on the other hand, does not contain nearly enough oxygen to take care of the hydrogen present, and thus a part of the oxygen used in burning fats appears as water. More oxygen is consumed, therefore, than is represented by the carbon dioxide given off and the R.Q. becomes less than 1.0. For most body and food fats, it is approximately 0.7 . Such is the case for triolein, for example, as shown by the following equation for its complete oxidation:

\section{$\mathrm{C}_{3} \mathrm{H}_{5}\left(\mathrm{OOCC}_{17} \mathrm{H}_{33}\right)_{3}+80 \mathrm{O}_{2} \longrightarrow 57 \mathrm{CO}_{2}+52 \mathrm{H}_{2} \mathrm{O}$}

For protein the basis for computing the respiratory quotient is less certain because the mode of its utilization in the body varies, because it is incompletely oxidized in catabolism, and because different ones vary in composition. The average figure commonly given for the R.Q. of protein is 0.8 .

The magnitude of the respiratory quotient gives an approximate idea of the kind of nutrient which is being burned in the 
body. The closer the quotient approaches unity, the larger is the proportion of carbohydrates being used, while values lying close to 0.7 indicate that fat predominates as the body fuel. The meaning of an intermediate value is less clear since the quotient for protein lies in between those for carbohydrate and fat, and since a determined quotient may represent the result of the burning of variable proportions of all three. Respiratory quotients larger than unity are sometimes obtained, and they are explainable either on the basis that carbon dioxide is temporarily being given off more rapidly than it is being produced or on the basis that carbohydrate is being converted into a fat in the body. The synthesis of oxygen-poor fats from the relatively oxygen-rich carbohydrates involves a liberation of carbon dioxide. Wierzuchowski and Ling ${ }^{1}$ report quotients of 1.4 and higher in rapidly fattening hogs, and they cite a quotient of similar magnitude obtained by Benedict for the goose. On the other hand, respiratory quotients below 0.7 have been observed in fasting, particularly in hibernating animals, and they may be the result of the conversion of fat into carbohydrate.

224. The Nitrogen-carbon Balance.-When carried out in conjunction with the nitrogen balance which measures changes in protein content, a carbon balance provides the additional data needed to obtain the gain or loss of fat. In thus measuring the changes in protein and fat content, an approximately complete picture of the influence of food upon the organic composition of the body is obtainable since its carbohydrate content is so small. Determinations are made of the carbon and nitrogen in the food, feces, and excreta and of the carbon in the gaseous output. Recognizing the limitations of his determinations of digestibility as measures of feed value, Henneberg, prior to 187 (), turned his attention to the nitrogen-carbon balance in farm animals, taking his cue from the work of Voit and associates with man. Later a respiration chamber for large animals was built at the Möckern Experiment Station under the direction of Gustav Kuhn, and studies were undertaken which were carried out for the most part by Kuhn's successor, (). Kellner. ${ }^{2}$

1 Wienzuchowski, M., and S. M. Lang, On fat production in a young hog, J. Biol. Chem., 64, 697 707, 1925.

${ }^{2}$ Oscar Kellner (1851-1911), following short periods of service in the agricultural experiment stations at. Proskan and Hohenhein and an extended 
As an example of a nitrogen-carbon balance, the data from one of Kellner's experiments ${ }^{1}$ are presented in a condensed form in Table XVI. It is noted that from the nitrogen balance the amount of carbon gained as protein is calculated and that this value subtracted from the total carbon gained gives a figure which represents that gained as fat, from which the amount of

Table XVI.-Example of a Nitrogen-Carbon Balance

\begin{tabular}{|c|c|c|c|c|}
\hline \multirow{2}{*}{ Item } & \multicolumn{2}{|c|}{ Nitrogen } & \multicolumn{2}{|c|}{ Carbon } \\
\hline & Intake, g. & Outgo, g. & Intake, $\mathrm{g}$. & Outgo, g. \\
\hline Feed ............ & 390.55 & $\ldots \ldots$ & 5668.2 & \\
\hline Feces............ & $\ldots \ldots$ & 105.69 & $\ldots \ldots$ & 1456.9 \\
\hline Urine ... . . . . . . . & $\ldots \ldots$ & 263.76 & $\ldots$ & 283.3 \\
\hline Gases............ & $\ldots \ldots$ & $\ldots \ldots$ & $\ldots \ldots$ & 3247.9 \\
\hline Gain to body...... & $\ldots \ldots$ & 21.10 & $\ldots \ldots$ & 680.1 \\
\hline Total. . & 390.55 & 390.55 & 5668.2 & 5668.2 \\
\hline
\end{tabular}

Based upon a content of $52.54^{1}$ per cent carbon and $16.67^{1}$ per cent nitrogen in fat-free, ash-free flesh, and of 76.5 per cent carbon in fat, the following calculations gave the protein and fat gained:

$21.1 \mathrm{~g}$. nitrogen gain divided by 0.1667 equaled $126.6 \mathrm{~g}$. protein gain.

$126.6 \mathrm{~g}$. protein times 0.5254 equaled $66.5 \mathrm{~g}$. carbon in protein.

$680.1 \mathrm{~g}$. carbon gain minus 66.5 equaled $613.6 \mathrm{~g}$. carbon gained as fat. 613.6 divided by 0.765 equaled $802.1 \mathrm{~g}$. fat gain.

${ }^{1}$ Figures used by later workers are slightly different.

fat can be computed. The computation is based upon the fact that the carbon content of the body exists almost entirely as protein and fat. It disregards the small amount of glycogen which is normally present, since it is considered that any changes in this constituent are so small as to be of very minor importance

period as professor of agricultural chemistry at the University of Tokyo, became director of the experiment station at Möckern in 1893. Here, he served until his death. His many accurately conducted respiration studies with farm animals made a large contribution to the fundamental knowledge of nutritional physiology and found practical application in his feeding standards. Kellner's textbook "Die Ernährung der landwirtschaftliche Nutztiere," the first edition of which was published in 1905 , contains an extensive account of his respiration studies and describes his feeding standards.

1 Kellner, O., and A. Kohler, Untersuchungen über den Stoff- und Energie-umsatz des erwachsenen Rindes der Erhaltungs- und Produktionsfütter, Landw. Vers. St., 53, 1-16, 1900. 
under normal feeding conditions. This is less true when the diet is such as to cause a loss, rather than a storage, of fat. For experiments over an extended period, disregarding the glycogen is of no concern, but, in experiments of only a few hours' duration, a considerable error may be introduced. The glycogen changes can be estimated by including determinations of hydrogen and oxygen in the balance data, a procedure which makes the experiment much more difficult and laborious. The most important use of the carbon- and nitrogen-balance method today is in connection with indirect calorimetry (Sec. 233).

225. Kellner's Starch Values.-Using the nitrogen-carbon-balance method, Kellner added pure carbohydrate, protein, and fat to a basal-maintenance ration and thus determined the relative amounts of these pure digestible nutrients required to produce a unit of body fat. When he tested feeding stuffs instead of pure nutrients, he found that the fat-producing power was less than calculated from their content of digestible nutrients and that the discrepancy was larger with those feeds high in fiber. He concluded, therefore, that some of the calculated fat-producing power was lost as a result of the "work of digestion" which increased with fiber content. Having determined the actual fat-producing power of a number of typical feeds, he worked out factors for estimating the loss which he ascribed to the work of digestion for feeds of varying fiber content. He thus obtained a basis for computing fat-producing power for a given feed from its content of digestible nutrients. He did not express this fat-producing power of the feed directly but rather in terms of the number of kilos of starch that would be required to produce the same amount of fat as $100 \mathrm{~kg}$. of the feed. Hence his values were ealled starch equivalenls or starch values. For example, the starch value of corn (maize) meal, $81.5 \mathrm{~kg}$., was the amount of starch which would produce as much fat as $100 \mathrm{~kg}$. of the meal. Expressed in pounds, the starch value of corn meal is thus 81.5 per $100 \mathrm{lb}$. of feed. In the appendix of his book, Kellner published such values for approximately 300 feeds, a few of which are listed below:

\begin{tabular}{|c|c|}
\hline Oats.... & 59.7 \\
\hline Wheat........ & 71.3 \\
\hline Linseed-oil meal. & 71.8 \\
\hline Wheat bran..... & 45.0 \\
\hline 'Timothy hay..... . . & 29.1 \\
\hline Oat straw $\ldots \ldots \ldots \ldots \ldots \ldots$ & 17.0 \\
\hline
\end{tabular}


Kellner's starch values became the basis of his feeding standard, and his system is still used for evaluating feeds and computing rations for animals in most European countries. Further reference is made to them later (Chap. XI).

\section{THE BALANCE OF ENERGY}

The largest purpose which food serves is the production of energy for body processes. Since all the organic nutrients can serve this purpose, energy value provides a common basis for expressing their nutritive value. The fact that all these nutrients, notably protein, may have specific and unique functions as well does not alter their common usefulness as sources of energy. This holds whether they are used for the purpose immediately upon absorption or whether they are built into body tissue; for the glycogen and fat of the body constitute reserves which can be used as needed, and, when these supplies are exhausted, the protein of structural tissues can be broken down to serve as energy. Thus a measure of the gain or loss of energy provides a useful measure of the state of nutrition of the body and of the relative value of various foods. It takes into account a further loss not measurable by the balances previously discussed, viz., the loss of heat.

226. Units of Energy Value.-Since all forms of energy are convertible into heat, it has been found convenient to express the energy changes of body processes in terms of heat units (calories). In this connection it is important to realize that it is not heat itself which the body uses. The body is not a heat engine (Sec. 366). The small calorie is defined as the amount of heat required to raise $1 \mathrm{~g}$. of water $1^{\circ} \mathrm{C}$. The large Calorie, or kilogram-calorie, written with a capital $\mathrm{C}$ to distinguish it from the small calorie, is the amount required to raise $1 \mathrm{~kg}$. of water $1^{\circ} \mathrm{C}$. It is the one commonly used in expressing the energy value of foods. A Therm is $1000 \mathrm{Cal}$. and is used as a matter of convenience where large values are involved. One Calorie equals approximately 4 British thermal units (B.t.u.). This unit is the amount of heat required to raise $1 \mathrm{lb}$. of water $1^{\circ} \mathrm{F}$.

227. Gross Energy, Heat of Combustion.-When a substance is completely burned to its ultimate oxidation products, viz., carbon dioxide, water, and other gases, the heat given off is consid- 
ered as its gross energy or heat of combustion. This measure is the starting point in determining the energy value of foods. The determination is carried out in a calorimeter, of which there are various types.

The bomb calorimeter consists essentially of a bomb in which the food is burned, enclosed in an insulated jacket containing water

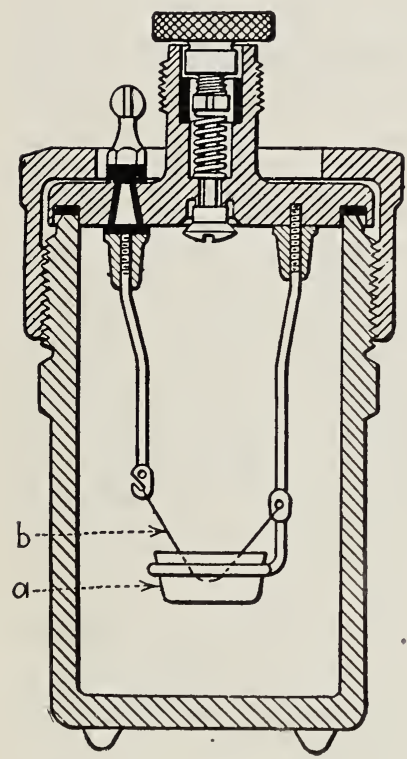

A

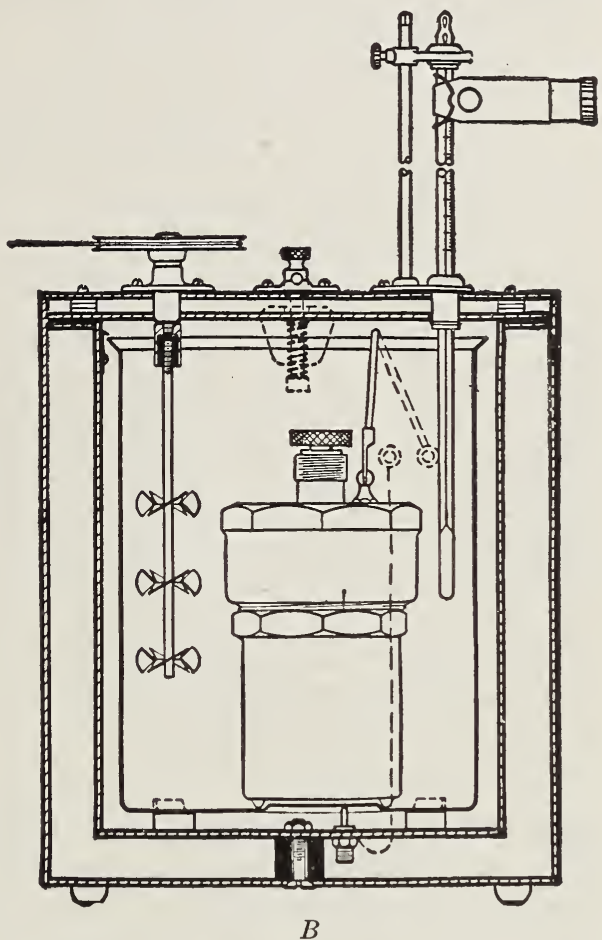

Fig. 29.-The Parr bomb calorimeter. $A$, cross section of bomb; $B$, cross section of calorimeter with bomb in place. (Reproduced by permission of the Parr Instrument Company, Moline, Ill.)

which surrounds the bomb and which thus provides the means of measuring the heat produced. The construction of the Parr oxygen calorimeter is illustrated in Fig. 29. In $A$, the bomb is shown in cross section. A weighed amount of substance to be tested is placed in the cup $a$ of the bomb, and the fuse wire $b$ connecting the two terminals is put in place. The cover is serewed on and the bomb charged with 25 to 30 atmospheres of oxygen. The bomb is then placed in the calorimeter jacket as shown in $B$, 
surrounded by a known volume of water. The stirrer is started, and, when the temperature becomes constant, the charge is ignited electrically and readings are taken on the thermometer to ascertain the maximum rise. This value multiplied by the sum of thermal capacity of the metal parts and the mass of water gives the number of calories produced by the burning of the sample. Various corrections are required for radiation, for the fuse wire, for acids produced and for other factors in arriving at

Table XVII.-Gross Energy Values or Heats of Combustion (Dry matter basis)

\begin{tabular}{|c|c|c|c|}
\hline Pure nutrients & $\begin{array}{l}\text { Cal. } \\
\text { per } \mathrm{g} .\end{array}$ & Feeding stuffs & $\begin{array}{l}\text { Cal. } \\
\text { per g. }\end{array}$ \\
\hline Glucose. & 3.76 & Corn meal. & 4.43 \\
\hline Sucrose.. & 3.96 & Oats...... & 4.68 \\
\hline Starch... & 4.23 & Soybeans.... & 5.52 \\
\hline Butterfat . & 9.21 & Wheat bran. . & 4.54 \\
\hline Lard ..... & 9.48 & Linseed-oil meal. . & 5.12 \\
\hline Seed fat. . & 9.33 & Timothy hay.... & 4.51 \\
\hline Casein............ & 5.86 & Clover hay ........... & 4.47 \\
\hline Elastin. . & 5.96 & Corn stover......... & 4.33 \\
\hline Gliadin. . & 5.74 & Oat straw.... & 4.43 \\
\hline
\end{tabular}

the final figure for the calorific value of the food. The radiation corrections are eliminated in the adiabatic type of bomb calorimeter.

The oxy-calorimeter, developed by Benedict and Fox, ${ }^{1}$ measures the volume of oxygen required to burn a known weight of food. This value is used to calculate the heat of combustion by the use of factors established with the bomb calorimeter.

The gross energy values of some pure nutrients and feeding stuffs are given in Table XVII.

It is noted that among the pure nutrients the fats have approximately twice the energy value of the carbohydrates and that the proteins occupy an intermediate position. These differences are governed by elementary composition, especially the relative amount of oxygen contained in the molecule, since heat is produced only from the oxidation which results from the union with oxygen from without (Sec. 223). In the case of carbohydrates,

1 Benedict, Francis G., and Edward L. Fox, The oxy-calorimeter, Ind. Eng. Chem., 17, 912-918, 1925. 
there is enough oxygen present in the molecule to take care of all the hydrogen present, and thus heat arises only from the oxidation of the carbon. In the case of fat, however, there is relatively much less oxygen present and relatively more atoms requiring oxygen from without, and the combustion involves the oxidation of hydrogen as well as carbon. The burning of $1 \mathrm{~g}$. of hydrogen produces over four times as much heat as is the case for carbon. These facts explain the much greater gross energy values for the fats compared with the carbohydrates. The heat produced in the burning of protein comes from the oxidation of both carbon and hydrogen, but the nitrogen present gives rise to no heat at all because it is set free as such in its gaseous form. No oxidation of it has taken place, and thus no heat is produced.

These differences in elementary composition also explain the differences which occur among members of the three classes of nutrients. In both starch and glucose, for example, the hydrogen is taken care of by the oxygen in the molecule, but there is relatively more carbon in $1 \mathrm{~g}$. of starch than in $1 \mathrm{~g}$. of glucose, and thus starch has the higher energy value accordingly. The following values were derived by Atwater ${ }^{1}$ as the heats of combustion of the three classes of nutrients as they occur in foods making up the average U.S. mixed diet.

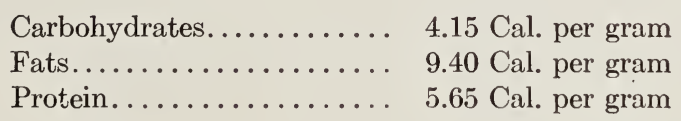

These figures provide a basis for computing the gross energy values of foods from their chemical composition. They also serve to explain the differences in gross energy among various feed stuffs exemplified in Table XVII. Fat content is of special importance because of its high heat of combustion. The difference between the values for the soybean, an oil-bearing seed, and for the cereal grains which contain only about one-fifth as much fat, is illustrative of this.

228. Metabolizable Energy.-Not all of the gross energy as determined in the bomb calorimeter is useful to the body. A part of it escapes in the undigested portion and as combustible

${ }^{1}$ Atwater, Wilbur Olin, Discussion of the terms digestibility, availability, and fuel value, 12th Annual Report of Storrs Agr. Exp. Sta., 1899, 69-110. 
gases. Though the latter are readily burned giving rise to heat which is included in gross energy, their energy is not useful to the body. A further portion of the gross energy escapes unused because, in the case of protein, the complete oxidation which gives rise to this energy value does not take place in the body. Whereas the end products of protein oxidation in the calorimeter are carbon dioxide, water, and nitrogen, catabolism in the body results in urea and other incompletely oxidized nitrogenous end products which are excreted in the urine.

Table XVIII.-Metabolizable Energy of Feeds for Sheep

\begin{tabular}{|c|c|c|c|c|c|c|}
\hline \multirow{3}{*}{ Feed } & \multirow{3}{*}{$\begin{array}{l}\text { Dry matter } \\
\text { eaten per } \\
\text { day per } \\
\text { head, kg. }\end{array}$} & \multicolumn{5}{|c|}{ Energy per kg. of dry matter, Therms } \\
\hline & & \multirow{2}{*}{$\begin{array}{l}\text { Intake } \\
\text { in } \\
\text { food }\end{array}$} & \multicolumn{3}{|c|}{ Losses } & \multirow{2}{*}{$\begin{array}{l}\text { Metab- } \\
\text { oliz- } \\
\text { able }\end{array}$} \\
\hline & & & Feces & Urine & Methane & \\
\hline Soybean. . & 0.795 & 4.333 & 2.033 & 0.196 & 0.208 & 1.896 \\
\hline Soybean straw... & 0.674 & 4.345 & 2.676 & 0.042 & 0.229 & 1.398 \\
\hline
\end{tabular}

A determination of the heats of combustion of the feces and urine ${ }^{1}$ and a measurement or calculation of the calorific value of any combustible gases produced in the digestive tract furnish data as to the part of the ingested gross energy which is unavailable to the body. The sum of these losses subtracted from the gross energy gives what is called metabolizable energy - the portion of the total which is actually capable of transformation within the body. There are small amounts of energy which escape as perspiration, epidermal scales, and shed hair. If accounted for, they should be subtracted in arriving at metabolizable energy, but they are so small that no significant error is ordinarily involved in neglecting them.

An illustration of the data involved in the determination of metabolizable energy is given in Table XVIII, comprising figures obtained with sheep by Hamilton, Mitchell, and Kammlade. ${ }^{2}$ It is noted that by far the largest part of the losses is that which occurs in the feces as a result of lack of digestion. This illustrates

1 The gross energy of urine can also be roughly calculated from its carbon content.

${ }^{2}$ Hamilton, T. S., H. H. Mitchell, and W. G. Kammlade, The digestibility and metabolizable energy of soybean products for sheep, Ill. Agr. Expt. Sta. Bull. 303, 1928. 
the fact that metabolizable energy takes account of the same losses, for the most part, as do total digestible nutrients. It does represent a more accurate measure since further losses are accounted for. The much larger fecal loss for the straw is the primary factor causing its lower metabolizable energy, corresponding to its lower digestibility. The straw has a smaller urinary loss than does the hay because of its lower content of protein, the nutrient which is less completely oxidized in metabolism than in the bomb. The methane losses are similar for the two feeds.

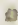

The drawback of the use of the metabolizable-energy measure experimentally and for the development of values for. feedstuffs for use in practice has been the requirement that the animal must be placed in a respiration chamber (Sec. 222) to collect and measure the combustible gases. Recent studies, however, have indicated that these gases can be computed fairly accurately in the case of cattle from the digestible organic material of the feed or from the total dry matter in the case of roughages and of mixed rations. The formulas that are used and the correspondence of the results with experimentally determined values are presented and discussed in the paper by Forbes and Thacker. ${ }^{1}$ The formulas for the calculation from dry matter of the ration, as proposed by Kriss, are as follows:

$$
\begin{array}{ll}
\text { Roughage........ } & y=0.0198 x+9 \\
\text { Mixed rations..... } & y=0.0225 x+18
\end{array}
$$

in which $y$ is the methane in grams produced daily and $x$ is the grams of total dry matter consumed daily.

229. Physiological Fuel Values. - These are calorific values for nutrients as originally set forth by Atwater for use in human nutrition to calculate the portion of the gross energy which is available for transformation in the body, a calculation which resulted in figures having a similar significance as metabolizable energy. Account was taken of losses in digestion on the basis of the following average figures for digestibility of a mixed diet: carbohydrates, 98 per cent; fats, 95 per cent; protein, 92 per cent. The figures for gross energy were multiplied hy these coefficientis and in the case of protein a subtraction of 1.25 ( $a$ al. per gram was

1 Forbes, E. B., and E. J. Тнаскеn, Determinations of metabolizable energy of feeding stuffs for cattle, J. Animal sici., 2, 226-230, 1943. 
made for the energy lost in the urine. Thus the average physiological fuel values became:

$$
\begin{aligned}
& \text { Carbohydrates...... } 4.15 \times 98 \%=4 \text { Cal. per gram } \\
& \text { Fats............ } 9.4 \times 95 \%=9 \text { Cal. per gram } \\
& \text { Protein.... } 5.65 \times 92 \%-1.25=4 \text { Cal. per gram }
\end{aligned}
$$

The physiological fuel values shown above are the figures commonly applied to data for the chemical analysis of human foods to arrive at their fuel or calorific value as set forth in tables used in computing diets or comparing foods. The analysis of foods to provide data for such a table was one of the important contributions of Atwater. ${ }^{1}$ The table now in use in this country is the one compiled by the Bureau of Human Nutrition and Home Economics and the Food and Nutrition Board of the National Research Council. $^{2}$

The applicability of these average calorific values to various foods and diets has been reviewed by the writer. ${ }^{3}$ They are not applicable to animal feeds and rations because the digestible figures on which they are based are too high.

230. Heat Loss.- In addition to the losses which are subtracted in obtaining metabolizable energy, the energy balance must take account of a further loss, viz., that energy escaping in the form of heat. In every cell of a living organism, chemical reactions are constantly occurring as an essential accompaniment and manifestation of life processes. Most of these reactions are oxidative in nature and produce heat. There results a continual outgo of heat from the body in amounts which represent a considerable fraction of the total income of chemical energy. The heat that is eliminated from the body may constitute 25 per cent or more of the gross calorie intake. It is considered, therefore, of large importance in nutrition both from the standpoint of the economy of food utilization and of body-temperature relations.

In all warm-blooded animals, the maintenance of a constant

1 Atwater, W. O., and A. P. Bryant, The chemical composition of American food materials, U.S. Dept. Agr. Office of Experiment Stations Bull. 28, rev. ed., 1906.

${ }^{2}$ Anonymous, Tables of food composition in terms of eleven nutrients, U.S. Dept. Agr. Misc. Pub. 572, 1945.

3 Maynard, Leonard A., The Atwater system of calculating the caloric value of diets, J. Nutrition, 28, 443-452, 1944. 
body temperature is a factor affecting heat production and heat outgo. Since the temperature of the body is normally above its environment, the heat constantly being produced serves in the maintenance of this temperature. The environmental temperature and the amount of heat being produced within the body are the factors which determine the extent to which this heat must be conserved. The amount which is allowed to escape from the body is subject to control which is referred to as physical regulation. This control is brought about by an adjustment of the blood flow to the skin and by the perspiration mechanism. If the conditions call for the dissipation of body heat, the blood flow to the surface is increased as a result of a dilation of the capillaries, which facilitates the escape of heat by radiation, and the pores are opened, which allows for a loss of heat through evaporation. These processes are reversed when there is need for the conservation of body heat.

The effects of a low environmental temperature may be combated also by chemical regulation, involving the increased oxidation of body substance and resulting in an increased heat production. Shivering is an involuntary form of muscular activity, the function of which appears to be to increase heat production when physical regulation proves insufficient. The environmental temperature at which physical regulation proves insufficient to maintain body temperature, and the point, therefore, at which chemical regulation must come into play, is called the critical temperature. As determined for the quict-fasting condition, the following values have been reported: rat, $28^{\circ} \mathrm{C}$.; mouse 29 to $30^{\circ} \mathrm{C}$.; chick, $17^{\circ} \mathrm{C}$.; guinea pig, 32 to $33^{\circ} \mathrm{C}$.; rabbit, 27 to $28^{\circ} \mathrm{C}$; hog, $21^{\circ} \mathrm{C}$. These values are modified by humidity and other factors. Removing the hair coat, as in shearing, raises them and so does exposure to wind. Increasing fatness tends to lower the critical temperature of the individual by increasing the insulating layer under the skin.

As the environmental temperature is raised above the critical, physical regulation operates without any increase in metabolism until this regulation becomes insufficient to cool the body. At this point a supernormal body temperature ensues, referred to as the hyperlhermal rise. This in turn results in an increased metabolism. The range of temperature between the critical and the point of hyperthermal rise is referred to as the range of thermal 
neutrality, and it is in this range that basal metabolism studies are made (Sec. 247).

By using the same principle that is employed in measuring the heat produced by burning a feed in a bomb calorimeter, the heat loss resulting from body oxidation processes may be measured by enclosing the animal in a specially constructed chamber called an animal calorimeter. Such an apparatus for use with pigs is described by Deighton. ${ }^{1}$

231. Respiration Calorimeter.-The direct measurement of heat loss can also be carried out in a respiration calorimeter which combines the features of a respiration chamber and a calorimeter. Such an apparatus makes possible an accounting for the income of feed, water, and oxygen and the outgo of the solid, liquid, and gaseous excreta and of the heat eliminated. In the lactating animal, milk outgo can also be accounted for. Shortly after Atwater and his associates perfected their respiration calorimeter for use with man, Armsby ${ }^{2}$ built a similar one for experiments with cows at Pennsylvania State College, introducing certain modifications required for use with animals. This calorimeter is still in active service at the Institute of Animal Nutrition of the College. The following brief description of it is taken from a bulletin by Braman. ${ }^{3}$

A horizontal cross section of the respiration calorimeter is shown in Fig. 30, and a view of the interior is given in Fig. 31. The three walls, with the air spaces in between, provide the special construction which prevents the chamber from gaining or

${ }^{1}$ Deighton, Thomas, A new calorimeter for use with young farm animals, J. Agr. Sci., 16, 376-382, 1926.

${ }^{2}$ Henry Prentiss Armsby (1853-1921), following periods of service at the New Jersey, Connecticut, and Wisconsin Experiment Stations, became director of the newly established Pennsylvania Experiment Station at State College in 1887. In 1907 the Institute of Animal Nutrition was established at this institution with Armsby as director, and here he served until his death, winning lasting fame for himself and his Institute. During his postgraduate study at Leipzig, he became interested in the respiration experiments. being carried out by Kuhn and others at Möckern, and this resulted in his construction of a respiration calorimeter for farm animals and in the inauguration of his studies of heat production in cattle. These epoch-making studies, which led to the development of the net-energy system of evaluating feeds, are frequently referred to in this book.

${ }^{3}$ Braman, Winfred W., The respiration calorimeter, Pa. Agr. Expt. Sta. Bull. 302, 1933. 
losing heat. This is accomplished by maintaining the temperature in the air spaces the same as in the chamber by means of water pipes for cooling and resistance coils for heating, both of which are located in the air spaces. The necessity for heating or cooling is determined by a large number of thermocouples in the walls of the inner metal chamber and of the wooden chamber next outside. This ccntrol is so delicate that changes as small as $0.01^{\circ} \mathrm{C}$. can be detected and immediately corrected.

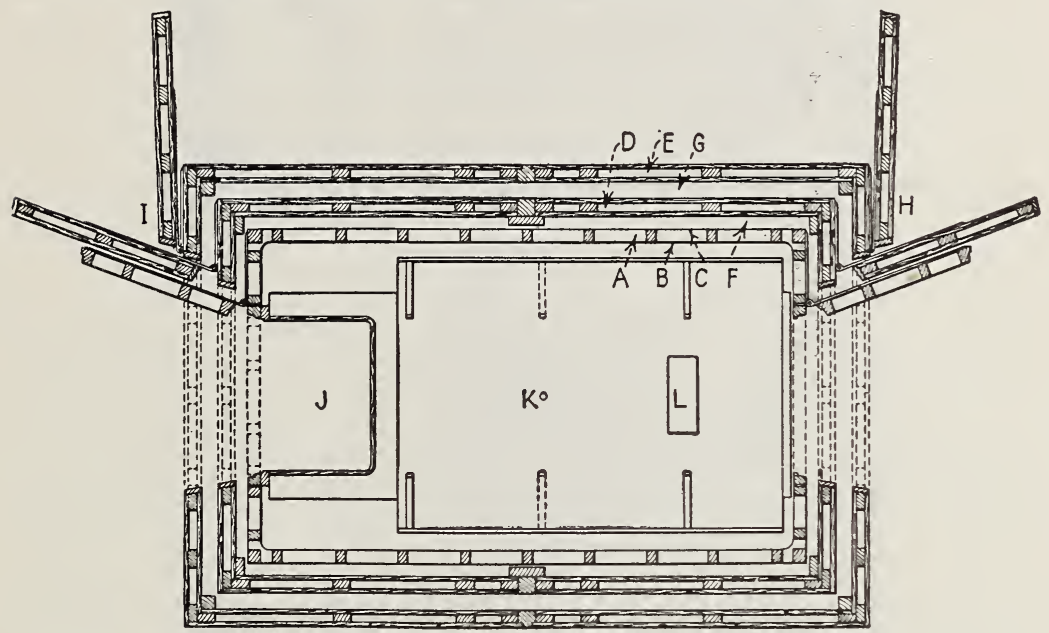

Fig. 30.-Horizontal cross section of the Armsby respiration calorimeter. $A$, double metal wall; $B$, inner wall of copper; $C$, outer wall of zinc; $D$ and $E$, double wooden walls; $F$ and $G$, air spaces; $H$, entrance doors; $I$, feedbox doors; $J$, feedbox; $K$, opening for urine tube; $L$, opening for feces hopper. (Courtesy of E. B. Forbes, Institute of Animal Nutrition.)

The heat lost by the animal is removed as fast as eliminated by cold water flowing through a series of pipes suspended from the ceiling of the chamber. The heat thus removed is translated into calories by recording the difference in temperature between the ingoing and outflowing water and the water volume. This heat plus the latent heat of vaporization of moisture condensed on the heat-absorbing apparatus or carried out in the air current gives the heat loss.

A steady flow of air is drawn in and out of the chamber by a special pump, and its volume is measured by passing it through a meter. The entrance flue is equipped with both heating and cooling facilities to keep the temperature of the incoming air identical with that of the outgoing, thus avoiding the error which would otherwise be introduced in the measurement of the heat lost. 
A continuous sample is drawn from the incoming air for the determination of water and carbon dioxide by absorption and of any methane by combustion. Continuous samples are taken from the outgoing air for the same determinations, and there is also pro-

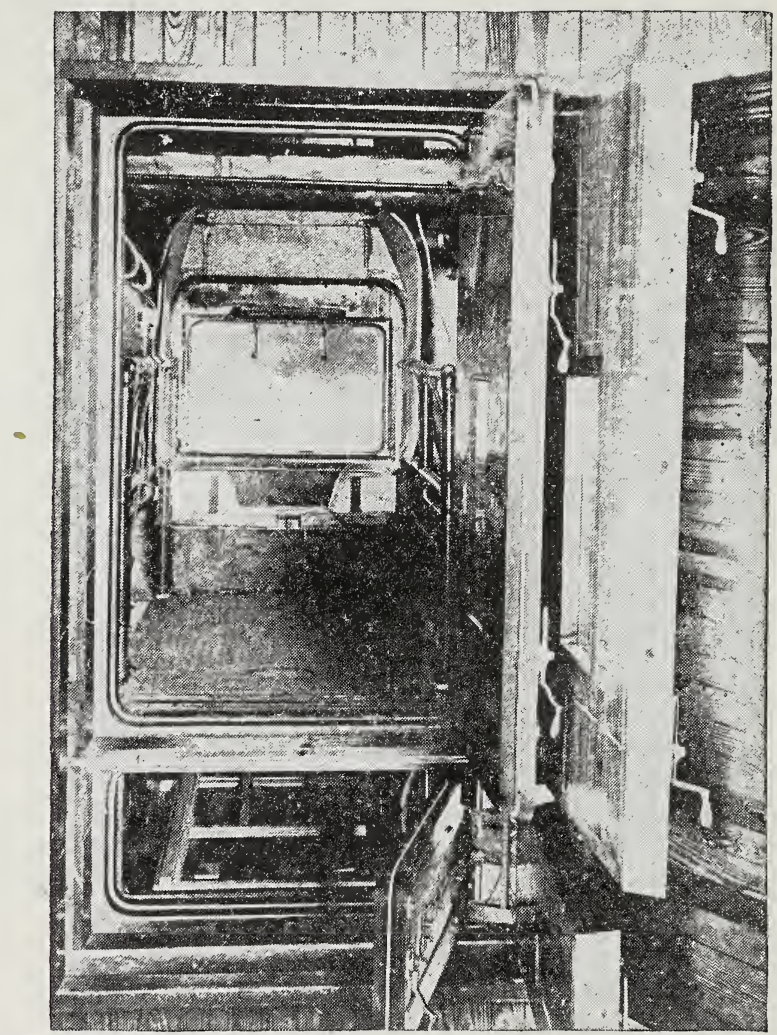

FIG. 31.-Interior of the Armsby respiration calorimeter. (Courtesy of $E$. B. Forbes, Institute of Animal Nutrition.)

vision for analyzing this air for oxygen. These measurements, together with analyses of the chamber air at the beginning and end of the period, provide the data for gaseous exchange.

It is noted in the diagram that there are openings for the discharge of urine and feces. The one for urine is for use with a steer equipped with a harness holding a tube leading to a urine receptacle under the floor. Similarly, there is special equipment for guiding the feces through $L$ into a container underneath. These features provide for the quantitative collection of the 
excreta. In addition to the arrangement for feeding as indicated by the feedbox, there is also provision for watering. There are many other features, such as devices for recording the movement of the animal and for accounting for the proportion of the time spent standing and lying down. For further details of the construction and operation, the student is referred to the descriptive bulletin.

Table XIX.-Daily Energy Balance of a Steer ${ }^{1}$

\begin{tabular}{|c|c|c|}
\hline Items & $\begin{array}{c}\text { Income, } \\
\text { Cal. }\end{array}$ & $\begin{array}{c}\text { Outgo, } \\
\text { Cal. }\end{array}$ \\
\hline $\begin{array}{r}6,988 \mathrm{~g} . \text { timothy hay } \ldots \ldots \ldots \ldots \\
400 \mathrm{~g} . \text { linseed meal. . . . . . }\end{array}$ & $\begin{array}{r}27,727 \\
1,811\end{array}$ & \\
\hline 16,619 g. feces . . . . . . . . . . & $\ldots \ldots$ & 14,243 \\
\hline 4,357 g. urine............. & $\ldots$. & 1,210 \\
\hline 37 g. brushings............ & $\ldots$ & 88 \\
\hline 142 g. methane............. & $\ldots \ldots$ & 1,896 \\
\hline 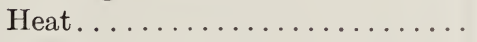 & $\ldots \ldots$ & 11,493 \\
\hline Gain by body ............... & $\ldots \ldots$ & 608 \\
\hline Total. . & 29,538 & 29,538 \\
\hline
\end{tabular}

1 Data from Armsiy, Henry Prentiss, and J. August Fries, The available energy of timothy hay, U.S. Dept. Agr. Bur. An. Ind. Bull. 51, 1903.

A test in the respiration calorimeter is normally preceded by a considerable preliminary period during which the animal receives the same feed intake as that during the test. A digestion trial is commonly carried out during the preliminary period. Of course, the digestion trial, as well as fceding during the test itself, is omitted when fasting metabolism is being studied. An accounting is made for insensible losses from the animal by weighing it at the beginning and end and by taking into account the weights of food, water, and excreta. It is evident that the conduct of a test in the respiration calorimeter requires a high degree of skill. The accuracy of the apparatus itself is amazing. The heat and gaseous products of combustion which are obtained by burning a known amount of alcohol in a special lamp in the chamber are generally found to be within less than 1 per cent of the theoretical values.

An illustration of the data obtained in an experiment carried out in a respiration calorimeter is given in Table XIX. It is noted that an accounting for all energy losises left a balance of 608 Cal. as the net gain to the animal from the feed ingested. 
The striking feature of these data is the large loss of energy as heat, representing approximately 40 per cent of the total intake. The importance of giving attention to heat losses in measuring the usefulness of feeds is thus indicated.

232. Net-energy Values.-In connection with his studies with the respiration calorimeter, Armsby developed his net-energy system of evaluating feeds founded upon a concept not basically different from that underlying Kellner's starch values (Sec. 225). While not agreeing that it was literally "work of digestion" in

Table XX.-Net-energy Values of Feeds for Ruminants ${ }^{1}$ (Therms per $100 \mathrm{lb}$. of Dry Matter)

\begin{tabular}{|c|c|c|c|c|c|}
\hline Feeds & $\begin{array}{c}\text { Gross } \\
\text { energy }\end{array}$ & $\begin{array}{c}\text { Losses } \\
\text { in } \\
\text { excreta }\end{array}$ & $\begin{array}{l}\text { Metabo- } \\
\text { lizable } \\
\text { energy }\end{array}$ & $\begin{array}{c}\text { Heat } \\
\text { incre- } \\
\text { ment }\end{array}$ & $\begin{array}{c}\text { Net } \\
\text { energy }\end{array}$ \\
\hline Timothy hay......... & 204.94 & 120.84 & 84.10 & 35.47 & 48.63 \\
\hline Red clover hay....... & 202.40 & 111.63 & 90.77 & 44.13 & 46.64 \\
\hline Corn stover....... & 196.50 & 107.96 & 88.54 & 48.31 & 40.23 \\
\hline Corn meal. ...... & 201.49 & 50.58 & 150.91 & 58.33 & 92.58 \\
\hline Hominy feed......... & 213.60 & 53.84 & 159.76 & 61.92 & 97.84 \\
\hline Wheat bran.......... & 205.57 & 91.67 & 113.90 & 53.39 & 60.51 \\
\hline
\end{tabular}

1 Data from Armsby, Henry Prentiss, and J. August Fries, Net energy values for ruminants, Pa. Agr. Expt. Sta. Bull. 142, 1916.

its entirety, Armsby recognized that the assimilation of a feed resulted in an energy cost to the organism in addition to those losses accounted for in arriving at metabolizable energy, and that this energy cost could be measured as the heat lost from the body. He therefore measured the heat resulting from the ingestion of a feed at a given level of intake, increased the intake, and, by a second measurement, obtained by difference the heat increment (Sec. 241) corresponding to the amount by which the level of food intake was increased. He then subtracted the heat increment, expressed in terms of a given unit of intake, from the metabolizable energy of the same intake to obtain the net-energy value. In the case of concentrates, it was necessary to add them to a basal roughage ration in measuring their net-energy value with steers. Some of Armsby's values and the data on which they were based are given in Table XX.

Since the direct determination of net-energy values was necessarily slow and expensive, Armsby and Fries developed, from 
respiration calorimeter experiments, factors for computing metabolizable energy values from digestible organic matter. Given the metabolizable energy for a feed, they subtracted the value for its heat increment either directly determined or estimated from the value for a similar feed. In this way they prepared a table of net-energy values for the common feeds. Later studies by Forbes and Kriss ${ }^{1}$ resulted in improved methods of computing these values from Armsby's data and in the publication of a table of revised values.

It is evident that both Kellner and Armsby arrived at essentially the same measure of feed values; the former by calculating the productive value as measured by the gain in fat shown by the carbon-nitrogen balance, the latter by directly accounting for all losses and thus arriving at a value which represented energy gained. In fact, Kellner stated his gains in fat in Calories, and he computed the percentage of metabolizable energy thus stored, but he expressed the energy value of his feeds in terms of matter instead of Calories, because he felt that starch values would be more readily understood in practice. Armsby regarded Kellner's figures as real net-energy values, and he made use of them in preparing his own table. A critical discussion of the usefulness and limitations of these values is presented later (Chap. XI).

233. Indirect Calorimetry.-The measurement of heat loss as just described is referred to as direct calorimetry in contrast to indirect calorimetry which is based on a calculation of the heat production responsible for the loss measured directly. Such a calculation is possible if the complete chemical metabolism is known since every chemical process is related to a definite transformation of energy. Fortunately, it is not necessary to know all the chemical changes, but only the initial and final states, because the sum of all transformations of chemical energy results in a heat production which is independent of any variations in the intermediary processes (Law of Hess). The heat loss can thus be computed either from the data of a nitrogen and carbon balance or from the data of gaseous exchange.

The procedure of the first method, most applicable to animals receiving feed, may be illustrated from the work of Armsby. He used the data of nitrogen-calbon balances to compute the heat

1 Forbes, E. B., and MAx Kriss, Revised net-energy values of feeding stuffs for cattle, J. Agr. Research, 31, 1083-1099, 1925. 
loss in order to compare the values thus obtained with those actually observed in the calorimeter. For example, data obtained in connection with the energy balance listed in Table XIX showed gains of nitrogen and carbon which corresponded to gains of $66.6 \mathrm{~g}$. of protein and $15.2 \mathrm{~g}$. of fat. On the basis that the energy value of each gram of protein stored is $5.7 \mathrm{Cal}$. and of each gram of fat, 9.5 Cal., he calculated that the total energy thus gained was $524 \mathrm{Cal}$. The metabolizable energy was calculated from the data in the table by subtracting all outgo except heat from the total income, giving a figure of $12,101 \mathrm{Cal}$. Subtracting the figure for energy gained as protein and fat, $524 \mathrm{Cal}$, , from the metabolizable energy left a balance of 11,577 Cal., which represented the energy lost as heat, as thus determined by indirect calorimetry. These calculations both illustrate the method of computing the heat loss from the nitrogen-carbon balance, and indicate the accuracy of the method, since the value thus obtained by indirect calorimetry closely approximates the directly determined value of 11,493 Cal. as given in Table XIX.

Instead of obtaining the changes in protein and fat in the body as described in the preceding paragraph, these changes can be directly determined by the slaughter method. This procedure, along with a measure of urine and fecal losses, suffices to arrive at the heat production indirectly, in animals where combustible gases do not figure. This method has been used for the rat and is applicable to the pig.

Heat production may be computed from oxygen consumption by use of the average heat equivalent of a liter of oxygen. It may be more accurately calculated from the determination of both the oxygen consumption and carbon dioxide output, which thus gives the respiratory quotient (R.Q.) and thereby makes possible the use of an exact value as the heat equivalent for the oxygen consumed. Knowing the R.Q., the proportion of fat and carbohydrate being burned, and thus the energy being produced per liter of oxygen consumed at that R.Q., can be computed. This calculation has been made for all respiratory quotients between 1.0 and 0.7 , and the values are available in tabular form (Zuntz and Shumberg). Thus, if the data of a respiration experiment show that 70 liters of oxygen were consumed and that the R.Q. was 0.9 , multiplying this number of liters by 4.924 , the calorific equivalent given in the table for a liter of oxygen at this R.Q., gives 344.7 Cal. as 
the heat production. This is the procedure commonly used in the case of man.

234. Respiration Apparatus for Indirect Calorimetry.-The respiration-calorimeter experiments of Armsby clearly showed the value of heat-loss studies with farm animals, and they also indicated that the indirect methods previously employed could be highly useful. Studies by indirect calorimetry were thereby stimulated in view of the much lower cost of construction and operation of a respiration apparatus than of a calorimeter. In this country modern apparatus have been built and described by Ritzman and Benedict, ${ }^{1}$ by Mitchell, ${ }^{2}$ and by Kleiber. ${ }^{3}$ Though each has its own special features as regards construction and operation, basically they do not differ from the respiration calorimeter with the exception of the absence of the calorimetric feature. It is evident that the construction of an airtight chamber is much simpler than of one which must be heat tight as well. For a detailed description of the construction and operation, the student is referred to the publications cited above. These respiration apparatus have made possible the much more rapid accumulation of data regarding the energy metabolism of various farm animals than would have been possible had such studies been limited to the use of the respiration calorimeter alone. It is generally agreed that the data are highly reliable, closely approximating those obtainable in the calorimeter.

235. Insensible Loss in Weight as a Measure of Heat Elimination.-The loss of body weight which was early referred to as "insensible perspiration" is equal to the difference between the carbon dioxide, water vapor, and methane emitted from the body and the oxygen intake. It can be computed from data as to change in weight and as to food intake and fecal and urinary outgo, as is illustrated by the experiment with cattle by Kiriss." It was early

1 Ritziman, Ernest G., and Francis G. Benedict, Simplified technique and apparatus for measuring energy requirements of cattle, N.II. Agr. Expt. Sta. Bull. 240, 1929.

${ }^{2}$ Mitchels, H. H., et al., The effect of the amount of feed consumed by cattle on the utilization of its energy content, J. Agr. Research, 45, 163-191, 1932.

${ }^{3}$ KLemen, MAx, The California apparatus for respiration trials with large animals, II ilgardia, 9, 1-70, 1935.

${ }^{4}$ Kriss, M$\Lambda x$, The insensible loss in body weight of cattle, J. Agr. Research, 40, 271-281, 1930 . 
recognized that the percentage of water vaporized from the skin and lungs is remarkedly constant under specified conditions. Since the vaporization of water is the principal channel of heat elimination, other than through radiation and conduction, its measurement has been suggested from time to time as an indirect method of obtaining the heat eliminated. This method has been studied with steers by Mitchell and Hamilton ${ }^{1}$ with the conclusion that the heat loss can be estimated in this way with a very small error from a careful determination of the insensible loss over a two-week period under standardized conditions. The procedure involves a preliminary estimate for each animal of the fraction of the heat lost in the vaporization of water under the same conditions which are to be maintained in the subsequent experiment. It also requires a fairly accurate estimate of the respiratory quotients to be expected on the experimental rations.

Despite the fact that various methods of indirect calorimetry have proven useful and that the methods are much more practicable from the cost standpoint, it is recognized that a distinct place still remains for studies by the direct procedure. Such studies are obviously essential as a check on the accuracy of indirect determinations. There are questions as to the applicability of the indirect method under extreme conditions such as are represented by respiratory quotients greater than 1.0 or less than 0.707 which require comparative study by the use of both methods.

236. Usefulness of Energy Studies.-In these days when so much emphasis is being placed upon the more alluring studies of vitamins and minerals, it should not be forgotten that energy metabolism is concerned in every body function and that its study is making equally important, though less spectacular, contributions to our knowledge of the physiology of animal nutrition. First of all, the ration must supply an adequate amount of useful energy, and, thus, a knowledge of energy needs and energy utilization is essential to profitable production. Energy studies are concerned with the determination of relative food values, with the influence of various environmental factors, methods of feeding, and combinations of nutrients upon food utilization, and with the efficiency of various animals as converters of food energy. The

${ }^{1}$ Mitcheli, H. H., and T. S. Hamilton, The estimation of the heat production of cattle from the insensible loss of body weight, J. Agr. Research, 52, 837-852, 1936. 
methods and results of energy studies in these various fields will become evident in later discussions.

237. Advantages and Limitations of the Balance Method.The balance method provides exact information as to metabolic processes and as to the effect of a specific nutrient or ration which cannot be obtained by the more general measures of weight and size, and such studies can be made repeatedly without sacrificing the animal as is required by the slaughter method. It is necessarily an expensive and laborious procedure which must be limited to a few animals and for short periods. The animals must be kept in confinement and subjected to other unnatural conditions.

\section{Selected Literature}

Armsby, Henry P.: Food as body fuel, Pa. Agr. Expt. Sta. Bull. 126, 1913. Atwater, W. O.: Methods and results of investigations on the chemistry and economy of food, U.S. Dept. Agr. Office of Expt. Stations Bull. 21, 1895.

Axelsson, J.: Die Bestimmung des allgemeinen Nährwertes (Energiewertes) der Futtermittel nach der chemischen Zusammensetzung, Tierernähr., 10, 238-248, 1938.

Benedict, Francis G., and Edward L. Fox: A method for the determination of the energy values of foods and excreta, J. Biol. Chem., 66, 783$799,1925$.

Brody, S., and associates: Growth and development. LVIII. Resting energy metabolism and pulmonary ventilation in growing horses, Mo. Agr. Expt. Sta. Res. Bull. 368, 1943.

Coulson, E. J. and J. S. Hughes: Collection and analysis of chicken urine, Poultry Sci., 10, 53-58, 1930.

Deighton, T., and J. C. D. Hutchin'son: Studies on the metabolism of fowls. III. The determination of the comparative nett energy of Sussex ground oats and white maize meal for fattening cockerels, $J$. Agr. Sci., 30, 463484, 1940.

Forbes, E. B., and associates: Conditions affecting the digestibility and the metabolizable energy of feeds for cattle, Pa. Agr. Expt. Sta. Bull. 452 , 1943.

, and R. W. SwIrT: The minimum base value of heat production in animals, P'a. Agr. Expt. Sta. Bull. 415, 1941.

French, Rowland 13.: The use of preservatives to prevent loss of nitrogen from cow excreta during the day of collection, J. Agr. Research, 41, $503-506,1930$.

Kriss, MAx: $\Lambda$ comparison of direct and indirect calorimetry in investigations with cattle, J. Agr. Reseurch, 30, 393-406, 1925.

LEE, R. C.: Relationship between insensible loss of weight and heat production of the rabbit, J. Nutrition, 20, 297-304, 1940. 
[CHAP. X

Mitchell, H. H., and M. A. R. Kelley: Estimated data on the energy, gaseous, and water metabolism of poultry for use in planning the ventilation of poultry houses, J. Agr. Research, 47, 735-748, 1933.

Morey, N. B.: An analysis and comparison of different methods of calculating the energy value of diets, Nutr. Abstracts \& Revs., 6, 1-12, 1936.

RhoAd, Albert O.: The influence of environment temperature on the respiratory rhythm of dairy cattle in the tropics, J. Agr. Sci., 26, 36-44, 1936.

Ritzman, E. G., and F. G. Benedict: The energy metabolism of sheep, N.H. Agr. Expt. Sta. Tech. Bull. 43, 1930.

Rubner, Max: Die Gesetze der Energieverbrauch bei der Ernährung, Franz Deuticke, Leipzig, 1902. 


\section{CHAPTER XI}

\section{MEASURES OF FOOD ENERGY}

The expression food energy is used to denote the value of food for its largest function, viz., to furnish energy for body processes and to form the nonnitrogenous, organic matter of tissues and secretions, functions in which all organic nutrients can take part. Total digestible nutrients, starch values, metabolizable energy, physiological fuel values, and net energy, the determinations of which were discussed in the two preceding chapters, are all different measures of food energy. These measures are used to evaluate feeds and rations in experimental work and in practical feeding operations, and they form the basis of various feeding standards which serve as guides in computing rations for various purposes. Since these measures differ as regards the actual feeding value represented, it is desirable to understand clearly the exact significance of each and to know something of their advantages and limitations for practical use.

238. Total Digestible Nutrients (T.D.N.).-Previous discussion has indicated that, in order to arrive at the actual useful portion of a ration, we must deduct losses in the feces, urine, combustible gases, and heat elimination. It is obvious that the determination of digestibility is only one step in this direction and thus that digestible nutrients must not be considered as the final measure of useful energy because they are subject to several losses in the course of metabolism. The fecal loss, however, is a large one, exceeding the sum of all the other's in many cases. It is a loss which may vary widely among feeds which are alike as regards content of gross energy or total nutrients. Thus it is evident that the determination of digestibility is a highly useful measure, not only because it eliminates an important loss, but also because, by the elimination of a highly variable loss, it places the feeds upon a much more nearly comparable basis as regards their actual physiological value.

Of all the measures of food energy, digestible nutrients are the casiest to determine. This largely accounts for the fact that digestion coefficients are available for all of the common feeds. While 
it is evident that some of them need redetermination, we have far more extensive and more reliable data regarding digestible nutrients than for any other measure. This is an important consideration from the standpoint of their usefulness in practice. Published average digestion coefficients make possible the calculation of the T.D.N. of a given supply of a feed from its specific nutrient content as determined by analysis, rather than relying on figures calculated from average analyses. This is frequently very important in experimental work as well as in the compounding of mixed feeds or rations on a large scale.

Some of the factors that affect the general applicability of average coefficients of digestibility and of T.D.N. values calculated from them have been discussed (Sec. 218). They are not constants but are affected by the plane of nutrition, the make-up of the ration, and by other factors. There is evidence from feeding trials that the currently used average coefficients overrate roughages relative to concentrates, for productive purposes. This is in part explainable by the higher gaseous losses from roughages that are not taken account of in the determination. The roughages, in the mixed rations in question, might also result in a larger heat increment, leaving less net energy for production. These explanations are not in accord, however, with the observation of Kellner, in his determinations of starch values (Sec. 225), that digestible crude fiber had as high a fat-producing power as digestiole starch. Clearly, the questions here involved require further study.

Some of the uncertainties inherent in the T.D.N. measure would be eliminated by determining the digestible energy instead. ${ }^{1}$ This would involve bomb-calorimeter determinations on the feed and feces.

1 This procedure would also eliminate an inconsistency in T.D.N. values as customarily calculated (Sec. 216). The practice of multiplying fat by 2.25 apparently originated from a consideration of the physiological fuel values of Atwater or similar values of Rubner (Sec. 229) which give fats two and one quarter times the energy value of either carbohydrates or protein. It seems to have been overlooked, however, that the value for protein here involved was one from which the portion of the digested energy that is lost in the urine had been subtracted. Thus it would be more exact, in arriving at a value assumed to take account of digestion losses only, to base the relationship on the gross fuel values (Sec. 227). This would involve multiplying the protein by 1.36 as well as the fat by 2.25 , assuming the use of carbohydrates as a base. 
239. Metabolizable Energy.-In taking account of the losses in the urine and combustible gases as well as those in the feces, metabolizable energy represents a step beyond digestible nutrients as a measure of nutritive value. It falls short of being the final measure in that a portion of it is lost as heat not useful to the body, but it is clearly a better measure than digestible nutrients.

Its determination involves additional steps, however. The urine must be collected and its gross energy value determined. More important, the determination of the losses in combustible gases, required in the case of Herbivora, calls for the use of an expensive and complicated apparatus, a respiration chamber, and involves much labor as well as technical skill accordingly. By reason of these limitations, actually determined values are available for only a few feeds. The additional information gained, over that available from the determination of digestible energy, has not been deemed of sufficient importance to justify the large outlay involved.

There are many published figures for metabolizable energy that have been calculated from digestible nutrients. Their value obviously depends on the reliability of the calculation procedures. The urinary loss can be calculated with reasonable accuracy from the digestible protein, after the manner used in arriving at the physiological fuel value for protein. The combustible gases are calculated by formulas such as have been discussed in Sec. 228 . Recent studies have served to strengthen the belief that a reliable calculation is thus possible. The comparability of values, involving the calculation of the gaseous losses by two different procedures, is reported for various experimental rations by Forbes and associates. ${ }^{1}$ The advantages of the use of the metabolizable energy measure are discussed in a report by a committee of the American Society of Animal Production. ${ }^{2}$

It is evident that any of the variable factors which influence digestibility also affect the metabolizable energy value. Mitchell and coworkers, ${ }^{3}$ for example, reported that the metabolizable

1 Fornes, E. B., and associates, Conditions affecting the digestibility and the metabolizable energy of feods for cattle, Pa. State College Bull. 452, 1943.

${ }^{2}$ Mitchen, H. II., The evaluation of feeds on the basis of digestible and metabolizable nutrients, J. Animal Sci., 1, 159-173, 1912.

${ }^{3}$ Mitchels, H. H., and eoworkers, The coffert of the amomt of feed consumed by cattle on the utilization of its energy content, J. Agr. Research, 45, $163-191,1932$. 
energy per kilogram of dry matter of a ration for steers increased progressively from $2661 \mathrm{Cal}$. to $3094 \mathrm{Cal}$. as the level of intake was reduced by stages from full feed to one-fifth of this intake. Digestibility and the percentage of metabolizable energy utilized also increased. Neither can the output of combustible gases be considered a constant per unit quantity of a given feed. Despite these limitations, metabolizable energy is a more useful measure for experimental comparisons and for evaluating the useful energy of feeds than is T.D.N. For animals except Herbivora the values can be arrived at without considering gaseous losses. But it is for Herbivora that some measure of the usefulness of the total food energy ingested is particularly needed. Here the determination and use in practice of metabolizable energy values would appear to rest on decisions as to the reliability of the calculation of the gaseous losses.

Various factors have been used for translating metabolizable energy into T.D.N., and vice versa. The relationship, of course, is not constant but varies with the nature of the ration and, in the case of ruminants, with the fermentation losses. Thus, any factor selected must be considered an approximation only. Brody multiplies pounds T.D.N. by 1814 to arrive at Calories of digestible energy in the case of good mixed rations for ruminants, on the basis that 1 g. of T.D.N. contains 4 Cal. The factor 1616 is commonly used to obtain metabolizable energy.

240. Physiological Fuel Values.-The calorific values obtained by the use of the physiological fuel values (Sec. 229) applied to data on the analysis of foods provide a measure similar in principle to metabolizable energy. They find their most exact application in calculating the energy value of the average mixed United States diet, the purpose for which they were designed. They are not strictly applicable to many individual foods or to mixed diets differing significantly in digestibility from those from which the values were originally derived. For these reasons they are not suitable for evaluating the foods or rations of farm animals. Particularly, they would greatly overvalue the available energy of the rations of Herbivora because of their low digestibility.

\section{NET ENERGY}

The net-energy system, based upon Armsby's net-energy values, conceives of the measurement of that portion of the feed which is 
completely useful to the body. By taking account of all losses in metabolism, net energy, according to this concept, is that portion of the ingested energy which actually appears as a product, viz., milk, meat, work. Theoretically, 1 Therm of feed energy corresponds to 1 Therm actually produced. On this basis it certainly represents a more nearly exact measure than any of the others which fail to account for one or more of the losses always involved. The distinguishing feature of the net-energy system is an accounting for the loss as heat increment of that portion of the metabolizable energy which fails of conversion into body substance or product, a loss which varies significantly from one feed or ration to another. While the discussion that follows leads to the conclusion that the net-energy system does not provide a suitable measure for evaluating feeds and rations in practice, a consideration of the facts that have been learned from its study is important because of their bearing on energy utilization in general.

241. Heat Increment.-The measurement of heat increment, whether carried out in the respiration calorimeter or determined indirectly by one of the methods previously described (Sec. 233), is a procedure which gives highly reliable results for a given set of conditions. The instrumental error involved in its determination is only 1 or 2 per cent. The heat increment of a given feed, however, is subject to several factors of variability according to the conditions under which it is measured, and this fact has an important bearing on the usefulness of the net-energy system as a measure of food energy.

The heat increment of a feed or ration can be measured between any two planes of intake, but determinations at submaintenance levels have a different significance from those determined above maintenance. It is now recognized that the usual purpose of the determination is best served by making maintenance the lower plane. The determination is made in a thermal enviromment at or above the critical temperature and below the point of hyperthermal rise and, thus, above the point below which the oxidation of body substance becomes necessary to keep up body temperature. It is recognized that a heat loss thus measured has a tissuesaving value for an animal in an environment below its critical temperature and thus that the net-energy system may undervalue certain rations for animals maintained sunder cold conditions in practice. It is now agreed that the additional work of digestion 
is a minor factor in heat increment. Differences in muscular activity or tonus play some role, but such differences are largely corrected for in making the measurements. For example, a record is kept of the time the animal spends standing and lying down, and the results are corrected to a standard day of $12 \mathrm{hr}$. of each. The primary cause of differences in heat production lies in variations in the specific dynamic effect which is defined in an exact sense as the heat increment of a specific kind of nutriment.

It has long been recognized that the ingestion of pure, readily absorbable nutrients results in an increased heat production which is the most marked in the case of protein. No simple explanation of the cause of this heat increment finds general acceptance, and it is probable that several factors are involved. The most generally accepted theory at present is that of Rubner. He believed that the heating effect of ingested food was the result of intermediary oxidations and reactions causing the liberation of energy which was only in part available for physiological work, the balance being dissipated as extra heat.

Whatever may be the cause of specific dynamic effect, it is agreed that the summation of such values for the individual nutrients in a feed does not necessarily represent the heat increment of the feed itself, and further that the heat increment of a ration is not necessarily the sum of the values of its feed components. From this it follows that the net-energy values of individual feeds are not strictly additive. The value of the mixture may be greater or less than calculated, depending upon how the heat increments of the individual nutrients and feeds are modified by the combination. For example, Forbes and coworkers ${ }^{1}$ found that, considering the value for a given basal ration as constant, the addition of corn meal to different basal rations resulted in variable figures for the heat increment and thus for the calculated net-energy value of the meal according to the ration with which it was fed. The experiment showed, however, that net energy is not the only measure subject to this variability, for the digestibility and metabolizable energy of the corn differed with the different basal rations.

Another limiting factor in the usefulness of net-energy values is that the heat increment per unit of food increases with level of

${ }^{1}$ Forbes, E. B., and associates, The associative effects of feeds in relation to the utilization of feed energy, J. Agr. Research, 46, 753-770, 1933. 
intake, but not in any simple relationship which allows this factor of variation to be accounted for accurately by calculation. The effect is undoubtedly due to the interplay of several factors which are explainable in various ways according to the theory of specific dynamic action adhered to. The practical result is that for a given food or combination there is a different net-energy value at each point of observation as the plane of nutrition changes.

242. Net-energy Value and Body Function.--Since the heat increment varies with plane of intake, it is to be expected that a given feed will have a different energy value when fed below the maintenance level than above and a different value for growth or fattening than for maintenance alone. It is of greater significance that, at the same level of intake, a given feed has a different netenergy value according to the productive function being supported. For example, the workers at the Pennsylvania Institute of Animal Nutrition have found that 1 Therm of metabolizable energy is equivalent to 0.693 Therm of milk energy but only 0.575 Therm for fattening. It is thus clear that the proportion of the metabolizable energy lost as heat differs according to the body function for which it is being used, and this is understandable in view of the differences in the metabolic processes involved. From the practical standpoint, this means that there can be no one set of netenergy values for our feeds but that there are different values for different purposes, in contrast to digestible nutrients which remain invariable in this respect since they take no account of body processes beyond the digestion stage. This variability of netenergy values according to body function adds to the difficulty of providing the necessary data for making use of the net-energy system in the various operations of feeding practice, but it does not affect the soundness of the system itself.

243. Net Energy and Balance of Nutrients.-In general terms a balanced ration is one which supplies all the nutrients needed for the optimum nutrition of the body function in question in adequate amounts and in proper relationships to each other. It is a ration which is qualitatively and quantitatively complete. Ideally it should support to the maximum the function for which it is balanced, but there should be no excess of any nutrient or of the ration as a whole large enough to interfere with physiological efficiency. This concept of a balanced ration does not necessarily imply that all of the essential nutrients must be present in certain 
fixed proportions. Rather there may be a certain range between the minimum optimum level and the upper level of efficiency within which the proportion of a given nutrient may fluctuate without affecting the balance.

There is evidence that the more nearly balanced the ration the smaller the proportion of it which is dissipated as heat and the greater, therefore, is its net-energy value. A deficiency of one nutrient impairs the efficiency of all others. It has been shown, for example, by Swift and associates, ${ }^{1}$ at the Pennsylvania Institute of Animal Nutrition, in experiments with rats that the addition of 0.24 per cent of cystine to a ration unbalanced with respect to this amino acid resulted in a storage of 10.8 per cent more energy as well as a greater growth in weight and a storage of 24.4 per cent more nitrogen. An additional storage of $40.4 \mathrm{Cal}$. in the course of 14 weeks was accomplished by 29 Cal. less loss as heat, 8.6 Cal. less loss in the feces, and 2.8 less loss in urine.

Studies at the Institute of Animal Nutrition, as well as at the University of Illinois, have also shown that the percentage of total protein has a very definite effect on the heat losses. In the Illinois experiments ${ }^{2}$ it was found with rats that, as the protein level was increased from 4 per cent to 18 per cent, there was a progressive decrease in heat elimination. For example, a ration containing 8 per cent of protein had a heating effect averaging 443 small cal. per gram, compared to only 80 small cal. for the ration containing 18 per cent. Similar results have been reported for chickens. These decreased heat losses with increasing protein level had the practical effect of increasing the net-energy value. This finding is in direct conflict with the prevailing view that increasing the protein content of the diet increases its heating effect because protein has a larger specific dynamic effect than do other nutrients.

The fact that the dynamic effects of nutrients when fed singly are not additive in complete rations is clearly brought out in the recent study by Forbes and Swift. ${ }^{3}$ In addition to the effect of protein level on heat losses as referred to above, experiments have

${ }^{1}$ SwIFr, R. W., and associates, The utilization of energy producing nutriment and protein as affected by individual nutrient deficiencies. I. The effects of cystine deficiency, $J$. Nutrition, 8, 197-219, 1934.

${ }^{2}$ Mitchell, H. H., and T. S. Hamilton, The balancing of rations with respect to protein, Proc. Am. Soc. Animal Production, 1935, pp. 241-252.

${ }^{3}$ Forbes, E. B., and R. W. Swift, Associative dynamic effects of protein, carbohydrate and fat, $J$. Nutrition, 27, 453-468, 1944. 
shown that deficiencies of phosphorus, riboflavin, and other nutrients also increase these losses.

From results such as the preceding, the conclusion has been reached that each improvement in nutritive balance results in a better utilization of metabolizable energy by economizing heat losses and thus increases the net-energy value. Whatever may be the true explanation of specific dynamic effect, the efficiency of the utilization of metabolizable nutrients must depend upon how closely their proportions correspond to those which can be effectively used for the body processes in question, and it seems logical to expect that the poorer the balance the greater the "leftovers" which would be especially subject to dissipation as heat. In fact from one point of view, one may think of heat production as a defense mechanism by means of which excessive concentrations of nutrients are removed. Thus heat increment increases with plane of intake because the concentration of nutrients is augmented owing to a failure of the rate of utilization to keep pace with intake, and it is further increased when there is a lack of balance, because "leftovers" tend to increase the concentration still further. This is most easily visualized according to the Voit theory which conceives of heat production as being due primarily to a plethora of nutrients in the cell, the magnitude of which is governed by both the supply and the rate of utilization. It is recognized that heat production is at a minimum when just the amounts of protein, fat, and carbohydrate required to meet body needs are given in frequent feedings.

Since individual feeds are seldom if ever balanced rations, it is evident that the summation of the net-energy values of the feeds making up a ration is not an accurate measure of the energy value of the ration as a whole and that the values for certain indiridual feeds may be highly misleading as to their effects as constituents of completely balaneed rations. Herein lies another practical limitation of the net-energy system.

244. Inconstancy of Net-energy Values. $-\Lambda$ consideration of these various factors which influence the heat increment has led to the conviction that net-energy values of individual feeds camnot be considered in any sense as constants, that they are so variable as to be of very limited usefulness for arriving at the energy value of rations representing different combinations and fed at different levels. It has come to be recognized that net-energy values have 
their most nearly exact and characteristic meaning when they are determined for the ration as a whole which is completely balanced for the body function in question. The logic of this viewpoint is clear, but its implications in terms of the usefulness of the netenergy system must be recognized. Our knowledge is still too imperfect to decide what is a completely balanced ration in terms of all the qualities which are implied in its definition. Further, the determination of the net-energy values of all of the balanced rations which find use in practice is clearly impossible. To what extent calculations based upon certain typical combinations could be made use of is a question that can be answered only by further study of the net-energy system.

Net-energy values are subject to more and to larger variables than are other measures because they take into account a further loss, the heat increment, a loss which is particularly susceptible to variability. Thus while no measure can be considered a constant, net energy, which is clearly the most nearly exact measure of useful nutritive energy for a stated feed or ration, condition, and function, becomes, by its very exactness for specified conditions, the more difficult to apply as a workable measure to the varied conditions of practice. The many variable.factors which govern the net-energy values of individual feeds have caused authorities working in this field to consider that further determinations of these individual values are not worth while. The values now available, which it is agreed require restudy and revision, are mostly computed ones based primarily upon body increase, and their application to milk production is especially questionable. Data obtained on the preferred basis of balanced rations are too scanty for any practical use. These various considerations lead to the conclusion that the net-energy system does not at present provide a suitable measure of total nutritive energy for practice, though it remains a promising field for further study.

Kleiber ${ }^{1}$ has recently reviewed the various studies on the effects of mineral, vitamin, and protein deficiencies on energy economy. Kriss ${ }^{2}$ has reviewed the net-energy system with particular reference to its use in practice.

1 Kleiber, M., Dietary deficiencies and energy metabolism, Nutrition Abstracts \& Revs., 15, 207-222, 1945.

${ }^{2}$ Kriss, M., Evaluation of feeds on the basis of net available nutrients, J. Animal Sci., 2, 63-79, 1943. 


\section{OTHER MEASURES OF FOOD ENERGY}

Various other methods of measuring food energy are in use, most of which are based on the net-energy concept and thus subject to the limitations previously discussed. The starch equivalents that are widely used in many countries are based on calculations from digestible nutrients, using, with modification in some instances, the factors that Kellner derived from indirect calorimetry (Sec. 233).

Mollgaard's production-equivalent system, which finds use in Denmark, is based upon energy-balance studies with milch cows, and it combines some features of both Kellner's and Armsby's methods. The production unit is the net energy for fattening which will produce 1000 Cal. of milk energy, viz., 837 Cal. in a ration which is properly balanced with respect to protein.

Hansson's food-unit system is based upon results from practical feeding experiments, with $1 \mathrm{~kg}$. of barley as the standard unit. Recently it has been expressed in accordance with the net-energy concept by computations making use of Kellner's starch values. As so computed, one food unit is equivalent to 1.65 Therms net energy for fattening or 2.1 Therms milk energy. These values, as do also those of Møllgaard, recognize the previously mentioned greater net-energy value for milk production than for fattening (Sec. 242).

Fraps' energy-production coefficients ${ }^{1}$ are values derived from Kellner's work which are applied with certain corrections to the various nutrients in feeds to compute their productive encrgy. The values thus obtained are modified for certain feeds in accordance with the results of feeding trials when the latter suggest the computed values to be in error.

Morrison's estimated net-energy values are derived from the results of feeding trials conducted to study the comparative usefulness of feeds for productive purposes. The net-energy value of corn is used as the base.

None of the measures discussed in this section has found any wide use in the United States. Space cannot be taken to give further details regarding their bases or to discuss their advantages

1 Fraps, G. S., Productive energy of feeds calculated from feeding experiments with sheep, Texas Agr. Expt. Sta. Bull. 436, 1931. (See also later papers by this author.) 
and limitations. Papers dealing with them are cited at the end of this chapter. Some of them are briefly discussed by Kriss ${ }^{1}$ in his review.

In view of the limitations of the T.D.N. measure in terms of net feeding value, further studies of the measures which take account of more of the losses are clearly desirable. The superiority of a given method of evaluating energy cannot be established, however, merely from theoretical considerations or by emphasizing the limitations of other measures. Research must definitely show its greater usefulness for general application, both in experimental comparisons and in feeding practice. Such research is greatly needed, and the time and labor involved can be fully justified in view of the importance of arriving at a more useful measure of the largest function of feeds and rations. In the meantime, animals must be fed. No measure of useful food energy can be exact in its general application because of the many variables involved. Any measure, however, which takes account of one or more of the losses in metabolism is more useful than a mere statement of chemical composition.

\section{FOOD-ENERGY VALUES FOR FEEDING STANDARDS}

Feeding standards are tables showing the amounts of the nutrients which should be provided in the rations of different species for different purposes, such as growth, fattening, and lactation. Commonly these standards deal only with the requirements for protein and energy. The protein requirement is generally stated on the basis of the digestible nutrient but the energy requirement is expressed in a variety of ways, making use of the various measures described in this chapter.

245. Bases of Feeding Standards.-In 1810, many years before the nature of the organic nutrients in foods was appreciated, Thaer developed his "hay values" as measures of relative nutritive value. His basic hay value consisted of the sum of the ingredients extractable with water, alcohol, dilute acid, and dilute alkali. Similar determinations made on other feeds were referred to this basic value as the standard. Following the recognition of protein, fat, and carbohydrate as the essential organic nutrients, Grouven made use of analyses for these nutrients to formulate in 1859 the first feeding standard for farm animals.

${ }^{1}$ Loc. cit. 
In 1864 Wolf devised a standard based on digestible nutrients which was derived from results of various feeding trials. His standards were republished annually without fundamental change until modified by Lehmann in 1897. In 1914 an important advance in the accuracy of the standard for dairy cows was made, as a result of many years' study by Haecker ${ }^{1}$ of the University of Minnesota, showing that the nutritive requirements varied not only with the quantity of milk produced but also with its quality, especially its fat content. In the following words Haecker set forth a principle which should be recognized in all studies of nutritive requirements:

In order to determine the actual net nutrients required to produce a given animal product, the composition of the product should be known, as well as the composition and the available nutrients in food which is to be fed for its production, so that the nutrients in the ration might be provided in the proportions needed by the animal. Before a builder bids on a contract, he determines the quantity needed of each of the materials that are to appear in the structure. Without such specifications he would not know how much of each of the different materials would have to be provided.

Since the time of Haecker several different standards, based upon digestible nutrients, have been proposed for farm animals by various American workers. Such is the basis of the Morrison standards which are at present widely used. Both Kellner and Armsby devised standards utilizing the net-energy system and there are also standards by Hansson and by Mollgaard, based on their measures of total nutritive energy. The features of thesc various standards have been excellently set forth by Kriss." The standards used in human nutrition make use of physiological fuel values.

246. Usefulness of Feeding Standards.- Feeding standards are not exact statements of nutritive requirements. Designed to be guides for practice, as well as a basis for teaching, they must allow a factor of safety for individual variability, and their values must be higher than the minimum requirements under optimum conditions. They are not complete statements of nutritive require-

${ }^{1}$ Haеcker, T. L., Investigations in milk-production, M $\mathrm{inn}$. Agr. Expt. sla. Bull. 140, 1914.

${ }^{2}$ Kriss, Max, A comparison of feeding standards for dairy cows, with special reference to energy requirements, $e^{I}$. Nutrition, 4, 141-161, 1931. 
ments because they commonly deal only with protein and energy requirements. The needs for minerals and vitamins and the question of protein quality must also be taken into account. A standard which attempted to cover all of these factors would be a highly complicated one, and, even then, it would not be a complete guide to feeding because other considerations, such as palatability and physical nature of the rations, would still require attention. The fact that feeding standards do not take account of all the factors which comprise a complete and satisfactory ration does not alter their basic usefulness in practice and teaching and even in research.

Complete statements of the nutritional needs of farm animals have recently been set forth in the reports of the Committee on Animal Nutrition of the National Research Council, under the general title, "Nutrient Allowances for Farm Animals." These reports are cited in the selected references for Chap. I.

\section{Selected Literature}

Fraps, G. S., E. C. Carlyle, and J. F. Fudge: Metabolizable energy of some chicken feeds, Tex. Agr. Expt. Sta. Bull. 589, 1940.

Hansson, NILs: Fütterung der Haustiere, ihre theoretischen Grundlagen und ihre wirtschaftliche Durchführung, Steinkopff, Dresden, 1929.

Kriss, MAx: The influence of the plane of nutrition on the manner of heat disposal by cattle, Am. J. Physiol., 116, 262-273, 1936.

- E. B. Forbes, and R. C. Miller: The specific dynamic effects of protein, fat, and carbohydrate as determined with the albino rat at different planes of nutrition, $J$. Nutrition, 8, 509-534, 1934.

MøllgaARd, Holger: Grundzüge der Ernährungsphysiologie der Haustiere, Paul Parey, Berlin, 1931.

Morey, NANCY Booker: An analysis and comparison of different methods of calculating the energy value of diets, Nutrition Abstracts \& Revs., 6, $1-12,1936$.

Ritzman, E. G., and F. G. Benedict: The effect of varying feed levels on the physiological economy of steers, N.H. Agr. Expt. Sta. Tech. Bull. $26,1924$. 


\section{CHAPTER XII}

\section{THE FASTING CATABOLISM. MAINTENANCE}

Whether an animal is being fed for growth, fattening, milk secretion, or other productive function, a substantial part of its food is used for supporting body processes which must go on whether or not any new tissue or product is being formed. This demand for food is referred to as the maintenance requirement, since it comprises the amount needed to keep intact the tissues of an animal which is neither growing, working, nor yielding any product. If this need is not met, tissue breakdown occurs, which is commonly revealed by a loss in weight and which leads to various undesirable consequences. For a considerable part of the human population, the maintenance requirement comprises the principal need for food. While this is much less true for farm animals because they are always fed for productive purposes, maintenance is an important "overhead" of the livestock business. The income is governed by the ability of the animal to consume and utilize feed in addition to its maintenance requirement. Thus the knowledge of this requirement, which the student must have in order to understand the principles underlying nutrition, has a direct practical interest. The starting point of this knowledge is the fasting catabolism.

\section{THE FASTING CATABOLISM}

The animal receiving no food, doing no external work, and yielding no product is nevertheless carrying on a variety of internal processes which are essential to life. These processes include respiration, circulation, maintenance of muscular tonus, manufacture of internal secretions, and several others. In the absence of food, the nutrients required to support these activities must come from the breakdown of body tissue itself. This destruction of body tissue is referred to as the fasting catabolism, and it can be measured in terms of the waste products eliminated through 
the various paths of excretion. Most of the breakdown which occurs is in response to the demand of the fasting organism for energy for its vital processes.

247. Energy Catabolism of Fasting.-The energy consumed in the fasting animal appears as heat and thus can be measured in the respiration calorimeter, or it can be obtained by one of the methods of indirect calorimetry. Its measurement provides a useful basis of reference for other phases of the energy metabolism. In order that the fasting catabolism may be measured at its minimum value, it is necessary that all influences tending to increase heat production above the minimum expenditure compatible with the maintenance of life be eliminated in so far as possible. Such a minimum value is called basal metabolism or basalmetabolic rate. It has its most exact meaning in the case of man, because it is with this species that the conditions which are essential for a true minimum value can most nearly be attained. The conditions for its measurement in man are commonly specified as follows:

1. Good nutritive condition

2. Environmental temperature of approximately $25^{\circ} \mathrm{C}$.

3. Relaxation on bed prior to and during measurement

4. Postabsorptive state

A good nutritive condition implies that the previous diet of the subject has been adequate, especially as regards energy and protein. A poor state of nutrition tends to decrease the heat production during fasting. The temperature of $25^{\circ} \mathrm{C}$. is specified as one which is above the critical, assuring that no tissue breakdown is occurring to keep up the temperature of the body, and as one below the point of hyperthermal rise where the onset of febrile conditions increases heat production. Both of these first two conditions are entirely realizable in the case of animals. The minimum muscular activity assured by the third condition, however, is obviously much less subject to control, particularly in farm animals. In addition to various miscellaneous movements, the animal may be expected to spend a variable portion of the experimental period standing and lying down. The magnitude of the influence of voluntary muscular activity is illustrated by the observations that the basal metabolism of different species and individuals is 10 to 15 per cent greater when they are standing than while they are lying down. In making the measurement, therefore, the heat production is calculated separately for the 
periods of standing and lying and then computed to a standard day of $12 \mathrm{hr}$. of each.

The fourth condition implies a state of fasting in which a long enough time has elapsed since the ingestion of food to make certain that the heat increment due to its digestion and assimilation has been dissipated. Such a condition is readily obtainable in animals with simple stomachs, but not in the case of the ruminant. In this species the anatomy and physiology of the digestive tract result in a prolonged retention of food in the rumen and a correspondingly slow passage through the tract and into the blood stream. The achievement of a truly postabsorptive state cannot be obtained except after such a prolonged period of fasting as may result in other disturbing factors which alter the normal catabolic processes. Thus the measurement of basal metabolism in the ruminant cannot have the exact significance that it does in man.

In the ruminant a minimum value for the methane excretion is one criterion of the establishment of the postabsorptive state. Another criterion of the attainment of a basal condition is a respiratory quotient which indicates that little or no carbohydrate is being burned, a condition that is generally reached after two or three days of fast. On the latter basis the heat eliminated in the next experimental period following the attainment of a metabolism which is characterized by the nonprotein, respiratory quotient of fat $(0.707)$ is frequently referred to as the basal metabolism. Some workers determine what is called a standard metabolism, which is a value obtained under specified conditions as to time after the last feeding. It is preferable from a strict point of view to refer to any value determined on a ruminant as a measure of the fasting catabolism rather than of the basal metabolism. The conditions under which such a value is obtained should be aceurately defined. The term resting metabolism has been used to denote the heat eliminated when an animal is lying at rest, though not strictly in a thermo-neutral environment nor in the postabsorptive state. It is important that the significance of these various terms be not confused.

Determinations of fasting catabolism for a given species provide a basis for studying the factors which affect this function and for comparing the metabolism in different species. They also provide a base line for measuring the effect of any superimposed factor such as muscular work, digestion, and other body activities. 
248. Units of Reference in Fasting Catabolism.-Heat production is obviously related to body size. In making use of determined values it is necessary to have some unit of reference. Rubner developed the concept, commonly referred to as the surface-area law, that the heat given off by all warm-blooded animals is directly proportional to their body surface and that, expressed on this basis, heat production is a constant for all species. Thus it became customary to express fasting catabolism in terms of surface rather than of weight, for example, as Calories per square meter per hour. In view of the difficulties and uncertainties involved in measuring surface area, formulas were devised for computing it from weight, recognizing that surface was proportional to some fractional power of weight. Thus most of the values were really based on weight, though expressed in relation to surface.

It is now recognized that the surface-area theory rests primarily on an empirical basis and that it does not have so general an application as previously thought. While the concept has been and still remains very useful, it is agreed that the various methods of measuring or estimating surface area give such variable results that a statement of heat elimination per unit of surface has a very limited meaning except in terms of the specific method used in obtaining the surface measure. The body surface is not a constant but varies with the position of the body. The fact that the skin is elastic causes its measurement to vary with conditions, whether measured on the live animal or after removal.

In view of these considerations many investigators are returning to the use of weight as the direct unit of reference. Since surface area increases with a fractional power of weight, the metabolic rate can be referred directly to the latter. Different investigators have given figures for this power varying from 0.66 to 0.75 . On the basis of an analysis of a very large number of basal metabolism data of mature animals of different species, ranging in weight from 0.02 to $4000 \mathrm{~kg}$. (mice to elephants) Brody and associates ${ }^{1}$ suggested the power, 0.73. In the case of the human species, however, it remains the general practice to express heat produc-

1 Brody, Samuel, Robert C. Procter, and Ural S. Ashworth, Growth and Development. XXXIV. Basal metabolism, endogenous nitrogen, creatinine and neutral sulphur excretions as functions of body weight, Mo. Agr. Expt. Sta. Research Bull. 220, 1934. 
tion in terms of surface, calculating the latter from a formula which takes account of both weight and height. Since heat production varies as a fractional power of weight, it follows that it decreases per unit of weight during growth, for the smaller animal has relatively more surface.

249. Lability of Fasting Metabolism.-While a properly determined value for basal metabolism is conceived as being a constant, it must be recognized that this is not true in the absolute sense. Differences in the degree of muscle tonus may exist in animals which appear entirely relaxed. The minimum influence of this tonus becomes evident during sleep. Basal metabolism is lowered by undernutrition but increased by emotional stimuli. It decreases with age. Certain internal secretions, notably that of the thyroid gland, augment heat production by increasing the heart rate, the respiration, and, probably, by affecting body oxidations in other ways. Thus variations in the activity of the thyroid influence basal metabolism accordingly. Any marked abnormality of this gland is recognized as pathological, and an altered basal metabolism is expected. The fact that this and certain other pathological conditions are accompanied by characteristic changes in the metabolic rate make the determination of the basal metabolism an important diagnostic agent in the case of various discases in man. The lowering of basal metabolism which results from castration is due presumably to alterations in the endocrine relationships. This lowered basal-energy requirement is reflected in the cheaper feed costs of gains in castrated farm animals.

Some rather large deviations in the fasting catabolism of ruminants, not adequately explainable by the recognized factors of variability, have recently heen noted. In the case of sheep on pasture in Australia, marked variations according to the season of the year have been reported for values obtained after ts hr. of fast. Perhaps a true seasonal factor was involved, or perhaps differences in previous feeding were not eliminated by the short period of fast. Benedict and Ritzman, however, have reported from studies with dairy cows that the fasting metabolism may vary for a given animal as much as 30 to 80 per cent within a period of two months, without any marked change in body weight. Their studios were made under conditions which alosely

1 BentareT, F. G., and E. (i. RrTzMan, Iability of the bisal metabolism of the dairy cow, Proc. Nat. Acad. Sci., 21, 301-30s, 1935. 
approximate the basal condition. These investigators mention the observation of less marked variations in sheep and horses. Large variations in the fasting catabolism may be exceptional rather than usual, but an important field for further study is here presented, because the possibility of extensive variations obviously must limit the general application of determined values.

As illustrative of the fasting metabolism values for animals reported in the literature, the following, expressed in Calories per square meter per $24 \mathrm{hr}$., may be cited: horse (lying), 1719; cow (standard day), 1409; sheep (lying), 1163; pullets, 805; dog, 1150. These figures are averages of values representing in most cases a rather wide range for different individuals.

250. Endogenous Nitrogen Metabolism.-There is a minimum essential nitrogen catabolism incident to the maintenance of the vital processes of the body, even as is the case for energy. This catabolism is measured as the minimum endogenous nitrogen (Sec. 100) on a nitrogen-free, energy-adequate diet. Upon the inauguration of a nitrogen-free diet the urinary nitrogen decreases gradually. After the attainment of a postabsorptive state as regards protein, there remains "deposit protein" (Sec. 98) to be eliminated, at least in part, before the minimum endogenous value is reached. Thus the higher the level of previous nutrition, the larger the reserve of protein and the longer the time to reach the minimum level. It may be reached in a week with a rat previously on a low-protein diet, whereas on a high-protein diet four weeks or longer may be required. The minimum endogenous nitrogen is the maximum reduction of nitrogen waste of which the body is capable. It may represent a balance between destruction and synthesis-the net catabolism.

In order to arrive at a true value for endogenous nitrogen, it is essential that the animal be receiving a diet adequate in energy, because otherwise the output of urinary nitrogen may include some from body protein which has been broken down to furnish energy and thus be in excess of the value representative of the minimum essential nitrogen catabolism. Muscular activity has no appreciable influence on endogenous nitrogen so long as the energy intake is sufficient to cover it, for such activity has little, if any, influence on protein catabolism (Sec. 373).

While the measurement of the minimum endogenous nitrogen metabolism is simple in theory, it is difficult in practice to obtain 
reliable and significant values, particularly with certain species. Not only is a variable and, frequently, a long time required to arrive at what may, by reason of its constancy, be considered a minimum value; but it is difficult, if not impossible, to get most animals to eat a sufficient amount of a nitrogen-free diet for any extended period. Any marked failure of adequate consumption destroys the significance of the results.

\section{Relation of Endogenous Nitrogen to Energy Catabolism.} Like basal metabolism, endogenous nitrogen metabolism is a function of body size. Since this is true and since both represent the minimum catabolism essential to life, one would expect a relationship between them. That a relationship actually exists was first proved by Terroine and Sorg-Matter. ${ }^{1}$ In this and later studies from Terroine's laboratory, it was found that the ratio of endogenous nitrogen to basal matabolism was nearly the same for mice, rats, pigeons, chickens, rabbits, and pigs and that varying the environmental temperature from $0^{\circ}$ to $30^{\circ} \mathrm{C}$. did not change it. This work resulted in the conclusion that the law of constant relationship of minimum nitrogen and energy output holds for all warm-blooded animals irrespective of body weight or age.

In most of his studies, Terroine included the metabolic nitrogen of the feces of his nitrogen-free diets as a part of the endogenous whole. If the previously discussed view (Sec. 96) that the metabolic nitrogen is a function of the digestive process primarily is accepted, the ratio may be more appropriately calculated on the basis of the urinary nitrogen only, considering that the latter is more truly representative of the same vital processes which are responsible for the encrgy catabolism. Using this basis, Smuts ${ }^{2}$ has confirmed the work of Terroine as to the approximate constancy of the ratio among different species. Additional evidence is also furnished by the recent work of Brody and associates ${ }^{3}$ who further confirmed the relationship by showing that endogenous

1 Terroine, F. F., and Helène Sorg-Matter, Loi quantitative de la dépense azotée minima des homéothermes: validité intraspécifique, Arch. intern. physiol., 29, 121-132, 1927.

${ }^{2}$ SmuTs, D. B., The relation between the basal metabolism and the endogenous nitrogen metabolism, with particular reference to the estimation of the maintenance requirement of protein, J. Nutrition, 9, 403-433, 1935. (See later papers under "Selected Literature.")

${ }^{3}$ Bhody, Procter, and Asirworth, loc. cit. 
nitrogen is proportional to practically the same power of live weight as is basal metabolism.

A study of these various experiments is convincing that a relationship between the energy and nitrogen catabolism of fasting exists. The studies by Smuts indicate a ratio of approximately $2 \mathrm{mg}$. of nitrogen per basal Calorie. The variability of the data reported, however, suggests that further studies are needed to determine the degree to which the ratio may be considered constant, particularly for all ages and species. For example, Bricker ${ }^{1}$ and associates recently reported a ratio of approximately $1.4 \mathrm{mg}$. of nitrogen per basal Calorie in two women subjects. The same difficulties previously mentioned for the determination of a significant value for the minimum endogenous nitrogen obviously apply to the determination of the ratio. Since the measurement of the energy catabolism is subject to fewer uncertainties than is the case for nitrogen, the establishment of a reliable and generally applicable figure for the ratio would be a distinct advantage in that it would permit the calculation of the value for endogenous nitrogen from the more easily determined energy value.

252. Mineral Catabolism in Fasting.-From the discussion in Chap. VII of the functions of mineral elements, it is evident that an active mineral metabolism continues during fasting. Differing from organic constituents of the body, however, catabolized minerals may be reutilized instead of being excreted. For example, although the red cells of the blood are constantly being destroyed, the catabolized iron is available for the resynthesis of hemoglobin.

There is, nevertheless, a constant excretion of mineral elements during fasting as is evident from the study reported by Benedict. ${ }^{2}$ He measured the urinary excretion of certain minerals by a man during a fast of 31 days. The outputs gradually decreased during the early days and then reached values which tended to become constant. The figures obtained for the last day's output, expressed in grams, were as follows: chlorine, 0.13 ; phosphorus, 0.58; sulfur, 0.49; calcium, 0.138; magnesium, 0.052; potassium, 0.606; sodium, 0.053. The relatively large excretions of

1 Bricker, M., H. H. Mitchell, and G. M. Kinsman, The protein requirements of adult human subjects in terms of the protein contained in individual foods and food combinations, $J$. Nutrition, 30, 269-283, 1945.

2 Benedict, Francis G., A study of prolonged fasting, Carnegie Inst. Wash., Pub. 203, 247-291, 1915. 
phosphorus and especially of sulfur doubtless were due in part to the breakdown of protein containing these elements as reflected by the endogenous nitrogen catabolism. This fact suggests that the data cannot be considered to indicate the catabolism of mineral fasting alone. Had there been an adequate intake of energy and protein, certainly less sulfur- and phosphorus-containing protein would have been broken down. The large output of potassium in contrast to the low excretions of sodium, calcium, and chlorine is less readily explainable. These data from Benedict do not measure the total excretion of all the minerals considered since the feces are an important path of outgo for some of them.

\section{MAINTENANCE REQUIREMENTS}

The term requirement implies an exactness which it does not have, as frequently employed, and which it cannot have when used in feeding standards for practice. Strictly speaking, it is the minimum amount of a given nutrient needed to promote a given body function to the optimum in a ration adequate in all other respects; i.e., a perfectly balanced ration. Such a minimum value will not be the same for any two individuals, and thus, for this reason alone, any determined individual value or any average of such values must be increased as a practical recommendation in order that the optimum performance of all may be assured. Further, perfectly balanced rations cannot be guarantecd in practice. For these and other reasons, the intakes specified in feeding standards must be higher than the minimum values experimentally determined under specific conditions.

Recognizing this fact, the Food and Nutrition Board of the National Research Council adopted the term allowance for use in human dietary standards, following a suggestion originally made by Sherman. The Committee on Animal Nutrition of the Council has also adopted this term in setting forth the nutritional needs of farm animals. These recommended allowances, in the case of both man and animals, are intended to provide intakes sufficiently liberal to insure adecquate nutrition for all individuals, under practical conditions. 'This is the sense in which the term allowance is used in this text. In recommending allowances for practical feeding operations, however, it is sometimes desirable to take economic factors into account. Thus, recommendations may 
vary somewhat according to the rate of gain or level of milk production that seems the most economical in terms of current feed costs and market price of the product.

The term minimum requirement as employed in this text denotes an experimental average minimum value, a figure that is not suitable, however, as a practical recommendation. When the term requirement is used without qualification, it has a general and thus indefinite meaning. This usage cannot be avoided easily because of the variable ways in which the term is employed in the literature on which the following discussions are based. The terms minimum requirement and allowance are introduced, however, where needed to clarify the meaning. In all cases the figure given refers to a day's need.

Though not directly applicable to practice, the determination of the exact, minimum requirement is highly useful because it provides a base line for studying the influence of factors which increase it in practice and thus for arriving at safe and yet economical recommendations as guides for feeding operations.

253. The Maintenance Need for Food Energy.-The energy requirement for maintenance is the minimum amount needed to keep the animal in energy equilibrium, i.e., to prevent any loss from its tissues. Thus an intake sufficient to offset the loss represented by the fasting catabolism would be the requirement under the conditions specified for measuring the latter. Expressed as net energy, it would be represented by the fasting catabolism itself, but, expressed as any other measure of food energy, it would obviously be larger, since no other measure represents energy which is completely utilizable for the prevention of tissue breakdown. For example, in translating the fasting catabolism into metabolizable energy, it is necessary to choose a value for the latter which includes the fasting value plus the heat increment resulting from the food ingested.

254. Basal Metabolism as a Measure of Energy Maintenance. Under conditions of practice, however, an intake of food energy sufficient to balance the fasting catabolism is not an adequate maintenance value because the animal is never so restricted in its activity as represented by the standard, confined conditions which are specified for the determination of the basal value. At the present time there are no adequate experimental data for deciding what this activity factor should be. Clearly, it must vary for 
different animals and conditions, and any value selected for general use needs to be high enough to cover the extreme cases in order to arrive at a maintenance figure which would be adequate under all conditions of practice. The same principle applies, however, to the formulation of any generalized feeding standard. Mitchell and coworkers ${ }^{1}$ increased the basal metabolism values determined on chickens of different ages by 50 per cent to obtain their minimum requirements in terms of net energy, on the basis that the added 50 per cent should cover the activity increment. Mitchell tentatively suggests the same percentage figure for arriving at the maintenance requirement of pigs, and 25 per cent as the increment to be used for sheep and cattle.

Brody and coworkers ${ }^{2}$ have published a set of maintenance values calculated from basal metabolism data and expressed in terms of total digestible nutrients. From a large number of data in the literature on the basal metabolism, they arrived at the following equation as applicable to all mammals:

\section{Basal metabolism (in Calories) $=70.5 M^{0.734}$}

$M$ is weight in kilograms. From a consideration of data of feeding trials, they decided that maintenance needs would be satisfied by providing an intake of total digestible nutrients equal to twice the basal metabolism. Hereby provision was made for both the activity factor and the losses undergone by digested nutrients in metabolism. Thus they multiplied the basal metabolism values for different weights by two to obtain the maintenance requirements as digestible energy, which were in turn translated into pounds T.D.N. In a later publication Brody and Procter gave the following formula for calculating the maintenance requirement directly in terms of digestible nutrients:

\section{Digestible nutrients $=.05 .3 \mathrm{M} .73$}

Such calculations assume that the energy expended in activity is proportional to the same power of body weight as is basal metabolism. There are no reliable data on this point, and many authorities are doubtful as to the validity of the assumption.

${ }^{1}$ Mitchell, I. H., L. E. Card, and T. S. Hamilton, The minimum nutritive requirements of single comb white leghom chickens, Proc. 4th World's I'oultry Congress, Sec. B, Nutrition and Rearing, Paper 49, 301-306, 1930.

${ }^{2}$ Brody, Procter, and $\Lambda$ shworth, loc. cit. 
These two examples illustrate how basal metabolism data can be used to arrive at the maintenance requirement. The general procedure is theoretically sound. Because of the lability of the fasting catabolism and the uncertainty as to the expenditure which should be allowed for activity, however, values so obtained need to be checked in practical feeding trials to test their reliability as bases for maintenance allowances.

255. Determination of Maintenance Needs from Feeding Trials.-The maintenance values of feeding standards now in common use have been arrived at by feeding trials. In its simplest form this method involves the determination of the amount cf food required to hold adult animals at constant weight. The inclusion of a digestion trial in the course of the experimental period allows the expression of the requirement in terms of total digestible nutrients, or the latter may be calculated from the average coefficients. It is also possible, of course, to calculate the results to metabolizable energy. In such an experiment, in which live weight is the sole criterion, the importance of accurate and representative data for this measure is clear. If the experiment is successful in maintaining the weight substantially constant over an extended period, a fairly accurate measure of the maintenance requirement is obtainable and a measure which is directly applicable to the conditions of practice. Allowances can be made for changes in live weight by estimating the food equivalent of the losses or gains and correcting the observed intakes accordingly. The figures proposed for this purpose by Knott and associates ${ }^{1}$ are as follows:

$$
\begin{aligned}
& \text { Pounds gained } \times 3.53=\text { T.D.N. required for gain } \\
& \text { Pounds lost } \quad \times 2.73=\text { T.D.N. equivalent to loss }
\end{aligned}
$$

Such corrections can be only approximate at best because of a lack of knowledge of the kind of tissue gained or lost. As an extreme example, the change in weight might be due entirely to water, which of course would have no food equivalent at all. It is clear that the larger the corrections which have to be applied the less significant become the results.

The preceding considerations indicate the basis of a more general criticism of the live-weight method, viz., that constancy of

${ }^{1}$ Knotr, J. C., R. E. Hodgson, and E. V. Ellington, Methods of measuring pasture yields with dairy cattle, Wash. Agr. Expt. Sta. Bull. 295, 1934. 
weight does not necessarily imply the maintenance of the integrity of the body tissues or a constancy of energy content. In the case of a young animal, for example, in spite of a constant weight, an increase in protein and minerals may take place, representing a growth the energy for which is furnished in part by a catabolism of body fat. This uncertain feature of the feedingtrial method can be eliminated by including a slaughter test, as is illustrated by the work of Mitchell and coworkers ${ }^{1}$ with lambs. In this experiment a check group was slaughtered at the start, and the experimental group was slaughtered at the close of the period during which the food intake for maintenance was determined. A comparison of the slaughter data for the two lots showed that the experimental lot actually gained in energy and a corresponding deduction was accordingly made in the observed food intakes in arriving at the maintenance requirement. The experiment included a digestion and metabolism trial which enabled the expression of the results both as total digestible nutrients and as metabolizable energy. This method has also been used in studies with swine.

The inclusion of the slaughter procedure adds much to the accuracy of the results, but it also adds greatly to the cost of the determination and is not practicable for all classes of stock.

256. The Determination of Energy Equilibrium.-The use of a respiration apparatus or respiration calorimeter makes possible the measurement of the effectiveness of a given ration for the maintenance of tissue integrity without slaughter of the animals. This procedure was early used by Kellner, Armsby, and others as a basis for obtaining the minimum requirement. It involves the determination of the energy balance with a ration which is just adequate to maintain weight. It cannot be expected that any such ration will result in exact energy equilibrium, but the procedures furnish specific data as to any tissue gains or losses, and the feed energy intake, whether expressed as digestible, metabolizable, or net, can be eorrected aceordingly to arrive at the exact maintenance requirement. Kriss ${ }^{2}$ has cited findings of

1 Mitcheld, H. H., W. G. Kammlade, and T. S. Hamidon, A technical study of the maintenance and fattening of lambs and their utilization of a ration of alfalfa hay and corn, $I l l . A g r$. Expt. Sta. Bull. 31., 1928.

${ }^{2}$ Kriss, MAx, $\Lambda$ comparison of feeding stamblards for dairy cows, with special reference to energy requirements, $J$. Nutrition, 4, 141-161, 1931. 
the Institute of Animal Nutrition that the average heat production of the seven cows in energy equilibrium on a normal mixed ration was 8.487 Therms of metabolizable energy per $1000 \mathrm{lb}$. live weight. This maintenance requirement was translated into digestible nutrients by dividing by the factor 1.616 (1 lb. total digestible nutrients was considered equivalent to 1.616 Therms metabolizable energy).

The energy-equilibrium method of determining the maintenance requirement is recognized in the Report of the Conference on Energy Metabolism ${ }^{1}$ in the following words:

The standard physiologic maintenance requirement of an animal for net, energy is that quantity necessary for the maintenance of energy equilibrium under ideal conditions, computed to a day of 12 hours standing and 12 hours lying. The standard conditions of environment are as in the respiration calorimeter or chamber, with the air temperature neither below the critical nor above the point of hyperthermal rise. The economic maintenance requirement must include an additional quota of energy sufficient to cover the energy expenditure in muscular activity under the particular conditions prevailing.

Forbes and Kriss recognized the need for this additional quota in connection with their standard ${ }^{2}$ for dairy cows when stating that their values determined in the respiration calorimeter would presumably need revision upward to be applicable in practice. Certainly this would be true according to the allowance concept.

Some maintenance values obtained for different species by the various procedures previously discussed are given in Table XXI. Even when expressed in the same units, these values are not strictly comparable because some of them are minimum requirements while others are designed to be allowances for practice, as is evident from a consideration of the methods used. They serve, however, to indicate the relative magnitude of the requirements as expressed in different ways and as arrived at by different procedures. It is noted that the values are given in terms of specific body weights. The original publications list a series of corresponding values for various weights or indicate how they may be obtained.

${ }^{1}$ Report of the Conference on Energy Metabolism, held at State College, Pa., June 14-15, 1935, under the auspices of The Committee on Animal Nutrition of the National Research Council, Washington, D.C.

${ }^{2}$ KrISS, op. cit. 
Current feeding standards for dairy cows utilize the maintenance value of approximately $8 \mathrm{lb}$. T.D.N. per $1000 \mathrm{lb}$. body weight, proposed by Haecker over 40 years ago on the basis of feeding trials. This same allowance-weight relationship has also been used for calculating the maintenance component of the over-all needs of other species. But authorities differ as to whether,

Table XXI.-Some Maintenance Values Obtained by Various METHODS

\begin{tabular}{|c|c|c|c|c|c|}
\hline Method & Species & $\begin{array}{c}\text { Body } \\
\text { weight, } \\
\text { lb. }\end{array}$ & $\begin{array}{c}\text { Total } \\
\text { digestible } \\
\text { nutrients, } \\
\text { lb. }\end{array}$ & $\begin{array}{l}\text { Metabolizable } \\
\text { energy, Therms }\end{array}$ & $\begin{array}{l}\text { Net } \\
\text { energy, } \\
\text { Therms }\end{array}$ \\
\hline Fasting metabolism & $\begin{array}{l}\text { All } \\
\text { Horse } \\
\text { Pullet }\end{array}$ & $\begin{array}{r}1000 \\
1000 \\
4\end{array}$ & 6.75 (B) & & $\begin{array}{l}4.08(\mathrm{ZH}) \\
0.141(\mathrm{MCH})\end{array}$ \\
\hline Energy balance & $\begin{array}{l}\text { Dairy cow } \\
\text { Steer } \\
\text { Sheep } \\
\text { Horse }\end{array}$ & $\begin{array}{r}1000 \\
1000 \\
100 \\
1000\end{array}$ & $5.51(\mathrm{FK})$ & $\begin{array}{l}8.487(\mathrm{FK}) \\
1.32(\mathrm{~A}) \\
11.9-13.1(\mathrm{ZH})\end{array}$ & $\begin{array}{l}5.5(\mathrm{C}) \\
6.0(\mathrm{~A}) \\
0.72(\mathrm{~A})\end{array}$ \\
\hline Live weight & $\begin{array}{l}\text { Dairy cow } \\
\text { Dairy cow } \\
\text { Dairy cow } \\
\text { Sheep }\end{array}$ & $\begin{array}{r}1000 \\
1000 \\
1000 \\
100\end{array}$ & $\begin{array}{l}6.48(\mathrm{H}) \\
5.97(\mathrm{FK}) \\
7.925(\mathrm{Ha})\end{array}$ & $1.37(\mathrm{~A})$ & $0.79(\mathrm{~A})$ \\
\hline $\begin{array}{l}\text { Live weight and } \\
\text { slaughter }\end{array}$ & $\begin{array}{l}\text { Beef cow } \\
\text { Sheep } \\
\text { Pig }\end{array}$ & $\begin{array}{r}1000 \\
100 \\
100\end{array}$ & & $\begin{array}{c}12.92 \text { (TMH) } \\
1.64(\mathrm{MKH}) \\
1.86(\mathrm{MH})\end{array}$ & \\
\hline
\end{tabular}

The letters given in parentheses refer to the investigators as follows: A, Armsby; B, Brody; C, Cochrane, Fries, and Braman; FK, Forbes and Kriss; H, Hills; Ha, Haecker; MCH, Mitchell, Card, and Hamilton; MH, Mitchell and Hamilton; MKH, Mitchell, Kammlade, and Hamilton; TMH, Trowbridge, Moulton, and Haigh; ZH, Zuntz and Hagemann. Their publications have been previously cited or are to be found at the end of the chapter.

in arriving at values for various weights, the allowance should be figured as being directly proportional to weight or as related to some fractional power of it. From a statistical study of data for dairy cows Gaines ${ }^{1}$ has concluded that working maintenance, i.e., maintenance under practical conditions, is more nearly directly proportional to weight than to the 0.7 power thereof. It seems clear that such maintenance needs cannot be directly proportional to weight because a large component of these needs, namely the basal metabolism, appears to be proportional to approximately

${ }^{1}$ Garnes, W. I., Working maintenance as a function of live weight of dairy cows, and its bearing on an energy-size index of lactation, J. Dairy Sci., 20, 583-598, 1937. 
the 0.7 power of weight. Morrison ${ }^{1}$ has adopted the compromise value of the 0.87 power in his feeding standards. The arguments in favor of the 0.7 power, as well as of the opposing views, have been reviewed by Brody. ${ }^{2}$ This is an important question which needs further study, not only in calculations from metabolism data (Sec. 255), but also in the case of feeding-trial results as well, for the observed data cover only a few weights, and the allowances for other weights must be arrived at by some system of calculation.

257. The Protein Requirement for Maintenance.-The discussion in Chap. VI has shown that the need of the body for nitrogenous food, which we commonly refer to as a protein requirement, is actually a need for the building stones of protein, viz., the amino acids. It was also brought out in that chapter that the figures for the protein content of foods are conventional values, calculated from nitrogen content, and thus that they include both proteins and other nitrogenous compounds calculated to a protein basis. Despite these limitations, we express the nitrogen phase of nutrition on a protein basis because it is simpler to do so, and because our knowledge is insufficient for a more exact expression. No serious disadvantage is here involved provided the limitations are kept in mind.

A separate figure for a maintenance allowance is commonly utilized in feeding standards only in the case of the dairy cow. The protein need of the horse is essentially a maintenance requirement, however, because work does not involve the catabolism of protein. Maintenance values for all species are useful, nevertheless, as a base line for arriving at the over-all need during production. A stated requirement assumes that the ration is adequate in energy content so that protein need be utilized only for its specific purpose.

258. Biological Value and Protein Requirement.-While the nitrogen requirement of the body for a given function may be absolutely fixed, the amount of digested food protein which will satisfy this requirement is variable according to its amino-acid make-up, at least in the case of nonruminants. No protein

${ }^{1}$ Morrison, F. B., Feeds and feeding, 20th ed., The Morrison Publishing Company, Ithaca, N.Y., 1936.

${ }^{2}$ Brody, S., Bioenergeties and growth, Chap. 15, Reinhold Publishing Corporation, New York, 1945. 
combination has a 100 per cent biological value, even though its amino-acid mixture exactly corresponds to what is needed, because some deaminization and oxidation always occur. This breakdown tends to increase with the level of intake. Thus there can be no fixed minimum value for protein requirement for any body function, except in terms of a specific protein or combination, and any allowance which is made the basis of a general feeding standard, applicable to any and all combinations of feeds, must be high enough to be adequate with the ration of poorest biological value. Therefore, though specific minimum requirements are important experimentally, a protein allowance for general application must be a value which can be counted upon to be adequate without being unnecessarily high, rather than a minimum figure. Lower figures can be used for specific combinations which have been studied or for which some estimate of their biological value can be formed.

The constant loss of nitrogen which occurs on a nitrogen-free, energy-adequate diet bears witness to the body's need for nitrogenous food to maintain the integrity of its tissues. This endogenous nitrogen comes, at least in part, from simpler nitrogenous compounds than tissue proteins. Thus the requirements for maintenance are somewhat different from those of growth, and may be of a simpler order. It seems probable that a part of the maintenance requirement is for relatively simple body constituents which can be supplied by incomplete proteins, but that complete maintenance involves also the synthesis of proteins needed for such purposes as the secretion of digestive juices and hormones and that dietary protein containing all of the essential amino acids is here demanded. Thus the quality or biological value of the nitrogen intake is important in maintenance as well as for growth, though probably not to the same degree. Actually we have little specific information on these questions in the case of farm animals. In fact such information is of little practical importance because these animals are nearly always being fed for productive purposes, and thus the qualitative protein needs for the latter govern the entire intake. For this reason these needs, in the case of the different species, are dealt with in the following chapters.

259. Estimation of Protein Requirement from Endogenous Nitrogen. The endogenous nitrogen can be used as a measure for 
the body nitrogen which the food protein must spare in protein maintenance, provided certain assumptions are made as to the losses in metabolism. Various workers have proposed figures for the minimum requirement on this basis. Mitchell ${ }^{1}$ came to the conclusion that an endogenous nitrogen value of $0.03 \mathrm{~g}$. per kilogram body weight daily was a fair figure to apply to all species. Considering that commonly fed rations should have a biological value of at least 50 per cent in meeting this endogenous loss, he suggested a minimum requirement of $0.06 \mathrm{~g}$. of digestible nitrogen per kilogram, or approximately $0.4 \mathrm{lb}$. digestible protein per $1000 \mathrm{lb}$. live weight.

As a result of studies of the relation of endogenous nitrogen to basal metabolism Smuts ${ }^{2}$ working in Mitchell's laboratory has suggested an estimation of the maintenance requirement on this basis. Using Brody's equation (Sec. 254) for the relation of basal metabolism to body weight and considering that $2 \mathrm{mg}$. of nitrogen or $12.5 \mathrm{mg}$. of protein is required per Calorie of basal heat, he proposed the following formula for calculating the protein requirement:

$$
P=0.88 M^{0.734}
$$

where $P$ is the day's protein requirement expressed in grams and $M$ the body weight in kilograms. Such a value obviously refers to protein actually utilized in the replacement of endogenous nitrogen and must, therefore, be increased to allow for wastage in metabolism. Considering that the protein of commonly fed rations should have a biological value of at least 50, the minimum requirement was obtained by doubling the value calculated from the formula. This method is based on the viewpoint that the requirement is proportional to a power of weight. For a 1000-lb. animal, it figures out as $0.35 \mathrm{lb}$. of digestible protein. Differing from the situation with respect to energy needs, activity does not require consideration in calculating a protein requirement from the basic nitrogen excretion because activity does not significantly increase protein metabolism. While it is agreed that endogenous nitrogen provides the basic value for arriving at the maintenance need for protein, the uncertainties as to the correctness of present

1 Mrtchell, H. H., The minimum protein requirements of cattle, Natl. Research Council Bull. 67, 1929.

${ }^{2}$ Smuts, loc. cit. 
values, viz., as to whether they are actually minimum values and particularly as to whether they represent the actual catabolism under maintenance conditions, suggest that any figure so arrived at must be thoroughly tested in practice before it can be accepted as a recommended allowance. The same reservation applies to calculations based on the ratio of endogenous nitrogen to basal metabolism. Such a ratio can be only as reliable as the endogenous nitrogen value, and present data on the ratio are by no means uniform. A further reason for testing such calculated values in practice is that they are much lower than those determined from feeding trials, as is discussed later.

The studies of endogenous nitrogen have taught us that the maintenance requirement for protein is not directly proportional to weight but to a fractional power thereof. This concept is now being adopted in feeding standards for animals.

260. Nitrogen-balance Data as a Measure of Protein Maintenance.-The minimum protein intake in a ration otherwise complete, which will keep an animal in nitrogen equilibrium, is an exact measure of the requirement for the protein mixture in question. The minimum intake essential for equilibrium must be determined because in the adult animal in good nutritive condition there is no marked storage (Sec. 98) and thus an unnecessarily high intake tends to result in equilibrium also. The value obtained in a nitrogen-balance study of a specific food or ration is not a safe general recommendation because of differences in protein quality, and also because of the uncertainty as to whether such a value obtained over the short experimental period commonly involved can be considered the optimum for continuous feeding. The nitrogen-balance method is illustrated by the study of Hegsted ${ }^{1}$ and associates with adult men. In studies with 26 subjects it was found that a $70-\mathrm{kg}$. man required 30 to $40 \mathrm{~g}$. protein, depending on his height, to maintain nitrogen equilibrium on a diet in which the protein came solely from foods of plant origin. The needed intake was apparently 17 per cent less where onethird of the protein was supplied as meat. It was also found that the protein requirement was more closely related to surface than to weight. 'The authors agree, of course, that the allowance for practice should be higher than the figures experimentally obtained.

1 Hegsteo, D. M., and associates, Protein requirement of adults, J. Lab. Clin. Med., 31, 261-281, 1946. 
From nitrogen-balance studies with the horse, Nitsche ${ }^{1}$ has reported that an intake of $42 \mathrm{~g}$. digestible protein per $100 \mathrm{~kg}$. live weight resulted in equilibrium.

261. Determination of Protein Maintenance from Feeding Trials. - The protein requirements which are used in most of the feeding standards at the present time are based upon the results of feeding trials, representing intakes, in rations considered otherwise satisfactory, which were found adequate for keeping the animals in good condition without loss of weight. Scientifically, the maintenance of weight and condition is no certain measure of the integrity of the nitrogenous tissue, or of the minimum requirement for this purpose, but the rations which prove satisfactory for such maintenance over extended periods are considered to supply an amount of protein which is at least adequate. It is evident that the inclusion of slaughter data in feeding trials provides for a more accurate measure of protein requirement than do observations on weight and condition alone.

Since protein maintenance allowances for farm animals find their principal use in practice for dairy cows, most of the feeding trials designed to determine them have been carried out with this species. From an extensive study of the data from these trials carried out prior to 1917, Armsby came to the conclusion that an intake of $0.6 \mathrm{lb}$. of digestible protein per $1000 \mathrm{lb}$. live weight was an adequate allowance. While some of the later trials by other investigators have resulted in somewhat higher values, the most extensive study of all, by Hills, ${ }^{2}$ resulted in the conclusion that the Armsby figure provides a sufficient intake. Morrison has adopted this figure as the minimum allowance in his standard. It is also the figure proposed in the recommended nutrient allowances of the National Research Council. Some authorities use $7 / 8$, while others use $3 / 4$, as the power of weight in calculating the value per $1000 \mathrm{lb}$. to other weights.

This value of $0.6 \mathrm{lb}$. per $1000 \mathrm{lb}$. is one-third or more higher than the previously mentioned figures suggested by data obtained from measurements of the endogenous nitrogen and basal metabo-

1 Nitsche, Herbert, Eiweiss-minimum-bestimmung bei Arbeitspferden in Ruhe, Landw. Jahrb., 82, 429-438, 1936.

${ }^{2}$ Hills, J. L., C. L. Beach, A. A. Borland, R. M. Washburn, G. F. E. Story, and C. H. Jones, The protein requirements of dairy cows, Vt. Agr. Expt. Sta. Bull. 225, 1922. 
lism. While it may be unnecessarily high, at least with certain rations, a sound recommendation for general practice must allow a sufficient margin of safety to meet the needs of all individuals. Further, the minimum intake which is adequate in terms of the specific functions of protein may not be the optimum from the standpoint of the most efficient utilization of the ration as a whole (Sec. 243). For these reasons the allowance of $0.6 \mathrm{lb}$. per $1000 \mathrm{lb}$. body weight is considered a safer guide for practice at present than the lower values which have been proposed.

262. Does the Protein Requirement for Maintenance Remain Constant during Production?-The Folin theory (Sec. 100) postulates a constant endogenous catabolism of nitrogen independent of the total protein catabolism, and the theory implies that there is a constant requirement to meet this loss, irrespective of the protein metabolism which may be taking place for the support of other body functions. For example, the feeding of protein to meet the needs of such a function as growth does not alter the amount required for maintenance where the latter alone is involved. Many do not agree with this concept, basing their objection on the view that the maintenance requirement is for certain amino acids only and that on a nitrogen-free diet the catabolism of body nitrogen compounds to furnish the acids needed results in "leftovers" which are wasted. It is argued that during protein ingestion, on the other hand, this wastage is decreased.

The questions here involved are of minor importance from the standpoint of feeding practice. It may be agreed that amino acids which are unsuitable or unneeded for a given productive function may serve in maintenance and thus lessen the specific intake for this purpose, but whether the gain here should be subtracted from the maintenance requirement or from the production requirement is a matter of bookkeeping.

263. Mineral and Vitamin Needs for Maintenance.-The discussion in Chap. VII has shown that many of the mineral elements undergo a very active metabolism in eonnection with various processes which are essential for the normal functioning of the body in maintenance. Differing from the energy and protein metabolism, however, they are not necessarily used up and excreted in the process. Chlorine which is secreted in the gastric juice to provide for the digestion which is essential to life can be 
reabsorbed from the digestive tract and reutilized. The ironcontaining red cells are being constantly destroyed but the iron so catabolized can be used again for hemoglobin synthesis. While both sodium and chlorine perform many functions in maintenance, experiments have repeatedly shown that on a salt-free diet the excretion of these elements nearly ceases. That there always is some loss of mineral elements during maintenance is suggested by the data given for the fasting catabolism (Sec. 252). The extent to which a given mineral is excreted and to which, therefore, it is required in the maintenance ration is doubtless governed by variable factors such as body activity, nature of the mineral relations in the diet, and others. These variables suggest that there can be no fixed minimum requirement.

Of the thirteen mineral elements that are essential for normal body function, it is recognized that only a few are ever sufficiently likely to be lacking in the commonly fed rations to merit attention as regards their requirements. Little study of the maintenance requirements of farm animals for even these few has been made, because these animals are fed primarily for productive purposes. Thus there is little or no advantage in attempting to distinguish the relatively small maintenance requirements from the total amounts needed which are discussed in the following chapter.

On the basis of our knowledge of the specific functions performed by the various vitamins, their importance during maintenance as well as for productive purposes is clear. In the case of farm animals, however, no separate consideration of their needs for maintenance is of value, and thus their quantitative requirements are discussed in the chapters to follow.

\section{Selected Literature}

Brody, S., and H. H. Kibler: Growth and development. LIX. Resting energy metabolism and pulmonary ventilation in growing swine, $M o$. Agr. Expt. Sta. Research Bull. 380, 1944.

Cochrane, Donald C., J. August Fries, and Winfred W. Braman: The maintenance requirement of dry cows, J. Agr. Research, 31, 1055-1082, 1925.

Dukes, H. H.: Studies on the energy metabolism of the hen, J. Nutrition, 14, 341-354, 1937.

Forbes, E. B., J. August Fries, and Max Kriss: The maintenance requirement of cattle for protein, as indicated by the fasting katabolism of dry cows, J. Dairy Sci., 9, 15-27, 1926. 
Gaines, W. L.: Liveweight versus metabolic size in dairy cows and goats, J. Dairy Sci., 29, 259-272, 1946.

Hills, J. L.: The maintenance requirements of dairy cattle, Vt. Agr. Expt. Sta. Bull. 226, 1922.

Horst, Kathryn, Lafayette B. Mendel, and Francis G. Benedict: The influence of previous diet, growth and age upon the basal metabolism of the rat, J. Nutrition, 8, 139-162, 1934.

Mitchell, H. H., W. G. Kammlade, and T. S. Hamilton: Relative energy value of alfalfa, clover, and timothy hay for the maintenance of sheep, Ill. Agr. Expt. Sta. Bull. 317, 1928.

Morris, S., and S. C. RAY: CXLIX. The fasting metabolism of ruminants, Biochem. J., 33, 1217-1230, 1939.

RHoAD, A. O.: The influence of environmental temperature on the respiratory rhythm of dairy cattle in the tropics, J. Agr. Sci., 26, 36-44, 1936.

Ritzman, E. G., and Francis G. Benedict: The heat production of sheep under varying conditions, N.H. Agr. Expt. Sta. Tech. Bull. 45, 1931.

- Nicholas F. Colovos, and Francis G. Benedict: The heat production of the sheep and the pig before and after castration. N.H. Agr. Expt. Sta. Tech. Bull. 64, 1936.

Smuts, D. B., and J. S. C. MaraIs: The endogenous nitrogen metabolism of young sheep, with reference to the estimation of the maintenance requirement of sheep, Onderstepoort J. Vet. Sci. Animal Ind., 13, 219-225, 1939.

DuToit, B. A., and D. B. Smuts: The endogenous nitrogen metabolism of pigs with special reference to the maintenance protein requirement, Onderstepoort J. Vet. Sci. Animal Ind., 16, 169-179, 1941.

Trowbridge, P. F., C. R. Moulton, and L. D. Haigh: The maintenance requirement of cattle as influenced by condition, plane of nutrition, age, season, time on maintenance, type and size of animal, Mo. Agr. Expt. Sta. Research Bull. 18, 1915.

Tyler, C., and J. S. Wrllcox: The calcium requirements of poultry with particular reference to their needs for maintenance, J. Agr. Sci., 32, 6269, 1942. 


\section{CHAPTER XIII}

\section{GROWTH}

Growth is such a universal phenomenon that it commonly incites little curiosity in the layman; but when the physiologist faces the question, "what is growth?," he is overwhelmed by its complexities. The fertilization of a single cell starts a multiplication and a differentiation which become highly varied in kind and rate in the differentiated cells, yet remain coordinated and culminate in the adult. There is no complete explanation as to why the process starts, or how it is coordinated during its course, or why it stops at the definite point which characterizes adult development. As expressed by Rubner: ${ }^{1}$

Throughout the animate kingdom, from the simplest microorganisms to the most complexly organized beings, that inexhaustible power of growth which ever since the genesis of the first protoplasm in the infinite past has created the structure of the fossil remains of former ages as well as our own existence- this capacity to grow, has remained as the rost remarkable phenomenon of nature, the supreme riddle of life.

Despite the complexities involved, physiological studies have produced a large body of information regarding the major processes of growth and some knowledge of these facts is obviously essential for an understanding of the nutritive requirements involved and as to how they can be met.

\section{THE PHYSIOLOGY OF GROWTH}

264. The Nature of Growth.-Clearly a process as complex as growth cannot be simply defined. It is much more than an increase in size. Schloss ${ }^{2}$ defines growth as a "correlated increase

1 Rubner, Max, Das Problem der Lebensdauer und seine Beziehung zum Wachstum, p. 81, R. Oldenbourg, Munich, 1908. Translation given in: Mendel, Lafayette, B., Abnormalities of growth, Am. J. Med. Sci., 153, $1-20,1917$.

${ }^{2}$ Schloss, Ernst, Pathologie des Wachstums, p. 4, S. Karger, Berlin, 1911. 
in mass of the body in definite intervals of time, in a way characteristic of the species." This brief statement is excellent because it has very broad implications. It implies that, subject to individual variability, there is a characteristic rate of growth for each species and a characteristic adult size and development. . It is considered that the maximum size and development are fixed by heredity. Nutrition is an essential factor determining whether this maximum will be reached, and an optimum nutritional regime is one which enables the organism to take full advantage of its heredity. According to the basic concept, however, the maximum development fixed by heredity cannot be exceeded through nutrition or by any other means, in the normal organism. The definition by Schloss also implies that in the growth of the organism as a whole there must be a complete and coordinated growth of all its parts. This simply stated characteristic involves a multitude of interrelated processes which are very imperfectly understood at the present time.

Optimum growth should result in an adult organism capable of optimum performance throughout its normal life. This is an extension to the life span as a whole of the previous statement that an optimum development is one which enables the organism to take full advantage of its heredity. Here again we are ignorant of many of the factors concerned, but it is evident that optimum growth in this sense includes much more than the rate of increase of weight and size.

True growth involves an increase in the structural tissues such as muscle and bone, and also in the organs. It should be distinguished from the increase that results from fat deposition in the reserve tissues. Thus growth is characterized primarily by an increase in protein, mincral matter, and water. From the nutritional standpoint, it involves in addition a large intake of energyproducing nutrients to support the growth processes, and an adequate supply of the various vitamins concerned is also required. A minute amount of lipid material goes into the structure of each cell, but this does not represent a specific dietary recpuirement with the exception of the essential fatty acids (Sec. 77), in view of the synthesis of lipid from carbohydrate.

265. The Cell, the Unit of Growth.- ( Erowth takes place both by means of an increase in the number of cells, hyperplasia, and also through an increase in their size, hypertrophy. In early 
embryonic life both processes occur in the case of all cells. In the adult three types of cells are differentiated: the permanent cells, such as those in the nerves, which ceased to divide early in prenatal life and whose number has remained fixed thereafter; the stable cells, including those of most organs, which continued to divide for a variable but major part of the growth period but which have become fixed in the adult; the labile cells, composing the epithelial and epidermal tissues, which continue to divide throughout life, the process in the adult being limited to the replacement of cells worn out. All of these three types of cells undergo hypertrophy during growth and some of them may increase in size thereafter in accordance with special physiological demands. For example, the increased muscular development which can be brought about through exercise involves a hypertrophy. The cells of the adult kidney can undergo enlargement if an increased burden is placed on this organ. It seems probable that the ability of the cells of the adult organism to hypertrophy becomes less with age.

266. The Course of Growth of the Body as a Whole.-Conception is the starting point of growth. The discussion in the present chapter deals with postnatal growth since it is more convenient to discuss intra-uterine growth as reproduction (Chap. XIV), but it should be remembered that the character of the latter has important bearings on the course of growth after birth. The evident vigor of the newborn, their content of certain nutrient reserves, and other qualities are influenced by the intra-uterine nutrition. This fact is reflected in the recognized desirability of considering the diet of the mother, and other factors affecting intra-uterine development, when selecting animals for many types of growth experiments. The percentage of the total growth period which is spent in utero differs in different species and this also has a bearing on the nutritional and other factors concerned in postnatal development. The longer the portion of the total period spent in utero the more advanced are the young at birth. The rat is born with its eyes closed, has no hair, does not gain the use of its legs for a considerable period, and must be nourished for a relatively long period solely by its mother's milk. In contrast, the guinea pig has a full coat of hair, its eyes are open at birth, and, within a few hours, it is running around nibbling leafy material. The calf, lamb, and foal resemble the guinea pig as 
regards their stage of development at birth, while the pig and the human baby are more like the rat.

In the various species the time that is normally spent in growth bears a rather definite relation to the length of life. The data in Table XXII, calculated by Brody and associates, ${ }^{1}$ give the age, in months from conception, at which definite percentages of the mature weight are achieved in the different species. While these figures would doubtless be modified if calculated from the more recent data on growth rates, they present a useful picture for comparative purposes.

Table XXII.-Equivalence of Growth Age

\begin{tabular}{|c|c|c|c|c|c|}
\hline \multirow{2}{*}{ Species } & \multicolumn{5}{|c|}{ Percentage of mature weight } \\
\hline & $10 \%$ & $30 \%$ & $50 \%$ & $80 \%$ & $98 \%$ \\
\hline Holstein cow... & $\begin{array}{c}\text { Months } \\
10.6\end{array}$ & $\begin{array}{c}\text { Months } \\
16.0\end{array}$ & $\begin{array}{c}\text { Months } \\
23.4\end{array}$ & $\begin{array}{c}\text { Months } \\
43.3\end{array}$ & $\begin{array}{c}\text { Months } \\
93.2\end{array}$ \\
\hline Duroc-Jersey sow ....... & 5.9 & 10.1 & 15.7 & 31.0 & 67.3 \\
\hline Suffolk ewe....... & 5.3 & 6.7 & 8.6 & 13.7 & $26 . \tilde{5}$ \\
\hline Guinea pig, male. . . & 2.8 & 3.9 & 5.3 & 9.3 & 18.9 \\
\hline White rat, male....... & 2.1 & 2.8 & 3.6 & 5.9 & 11.7 \\
\hline White mouse, male.... & 1.1 & 1.3 & 1.8 & 2.8 & 5.6 \\
\hline
\end{tabular}

The rate of growth is not constant nor does its entire course follow any simple mathematical expression. There are periods of acceleration and of retardation. The observation of these periodic changes in rate of growth early led to the view that growth takes place in cycles. Robertson, ${ }^{2}$ from a mathematical analysis of growth curves, came to the conclusion that in higher animals and man there are at least three definite growth cycles, of which the first is passed partially or wholly in utero. Robertson's views have been repeatedly challenged, but it is agreed that acceleration and retardation oceur. In the human, for example, the curve of growth is characterized by a decreasing rate during childhood, an acceleration during adolescence, and a decreasing rate thercafter.

1 Brody, Samuel, Cingster D. Sparrow, and IIudson H. Kimler, Time relations of growth. 11. The equivalence of age in mammals estimated on the basis of their growth constants, J. Cen. Physiol., 9, 285-308, 1925.

${ }^{2}$ Romentson, 'T'. Bransword, 'The chemical basis of growth and senescence, J. B. Lippincott ('ompany. Philadelphia, 1923. 
267. The Growth of Parts. - The growth of the body as a whole is a resultant of the simultaneous growth of its parts for which the individual rates are widely variable. The skeleton increases as a percentage of the total body weight for a short period after birth and then decreases on this relative basis. This means that skeletal development tends to precede muscle growth. The musculature increases as a percentage of body weight during growth, provided there is no marked fat deposition. There is always

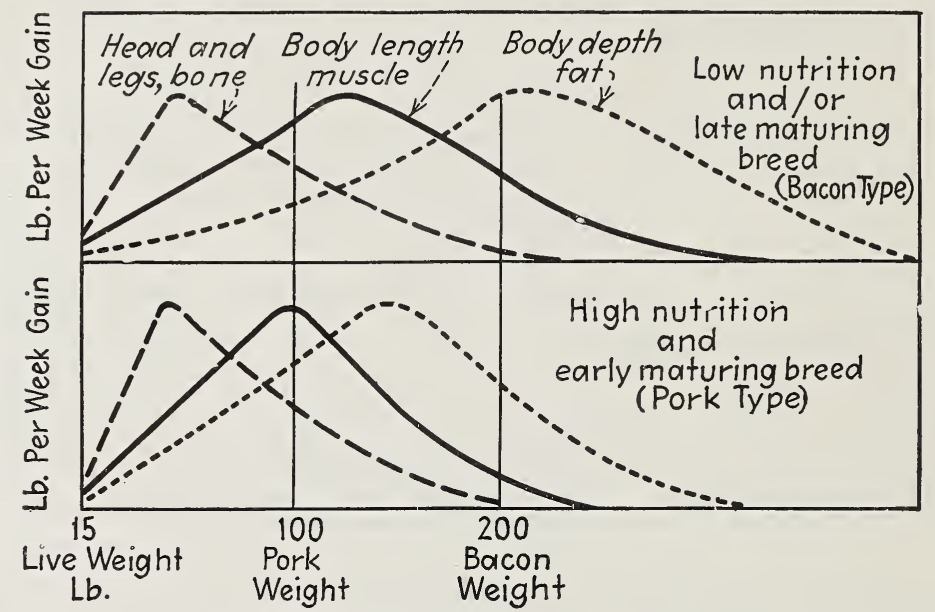

Fig. 32.- Rates of growth of parts. The curves portray the rates of growth for the parts considered. It is noted in both charts that the rate of growth for the head and legs reaches its maximum earlier than the rate for body length, and that the maximum for the latter is followed in turn by that for body depth. These three curves are considered to represent respectively: bone growth, muscle growth, and fat deposition. All of these processes occur earlier where the plane of nutrition is higher and earlier in the lard type of hog than the bacon type. (Courtesy of John Hammond, University of Cambridge.)

some deposition of fat which becomes greater as maturity approaches. The head of the human baby is 25 per cent of its body size at birth, but only 7 to 8 per cent at maturity. These different growth rates for the various parts of the body explain the changes in conformation which take place as growth proceeds. Based upon his extensive studies, Hammond ${ }^{1}$ has prepared the diagram shown in Fig. 32, illustrating how changes in body form

1 Hammond, John, Pigs for pork and pigs for bacon, J. Roy. Agr. Soc., 93, 1-15, 1932. 
and composition in hogs are brought about by differences in the time and rate of growth of different parts and tissues. Markedly different rates are exhibited by certain organs. The brain reaches adult size early in the growth period. The thymus increases to puberty and then decreases. The suprarenals actually lose weight for a time after birth, but this loss is balanced by an accelerated development toward the end of the growth period.

268. Measures of Growth.-The growth of the body as a whole is most commonly measured as an increase in weight. Size measures, such as height, and various other body dimensions are also frequently employed. A combination of both weight and size measures is much more useful than either alone. An animal may increase in weight through the deposition of fat without any increase in the structural tissues and organs which characterize growth. An animal which is receiving insufficient protein and energy, to permit of the growth of its muscles and organs, may still show an increase in size due to skeletal growth.

The increase in mass of the body as a whole may be expressed absolutely, as in grams per day, or it may be expressed as a percentage of the mass at the start. The absolute measure is the one most commonly employed in growth experiments, but the relative measure, which records the percentage increase, gives a more useful picture in many instances. The latter measure is plotted on semilogarithmic coordinate paper as is shown in Fig. 33. These curves illustrate the usefulness of the measure in comparing the growth rates of species of widely different size. Clearly the absolute increases in weight would be useless for such comparison.

Increases in weight and size are highly useful measures of growth but they are obviously incomplete. They do not show the nature of the tissue formed, nor are they suitable measures of coordinated development. The amounts of the true growth tissue, viz., protein and the skeletal minerals can be obtained by a balance experiment or by the slaughter procedure. The latter must be employed to record the growth of organs and other parts which provide measures of coordinated growth.

269. "Normal Growth." - In nutrition studies much use is made of "normal" growth data as illustrated by height-weight. tables for childen, and by curves for increase in weight and size for farm animals such as those presented by Moulton and asso- 
ciates. $^{1}$ These data are useful for comparative purposes, but their limitations must be realized. They are averages of the increases found for a group of individuals for which the nutritive and other factors were considered to be adequate to produce a satisfactory adult. Since only the growth of the whole is measured, it cannot be said that the growth is coordinated or complete

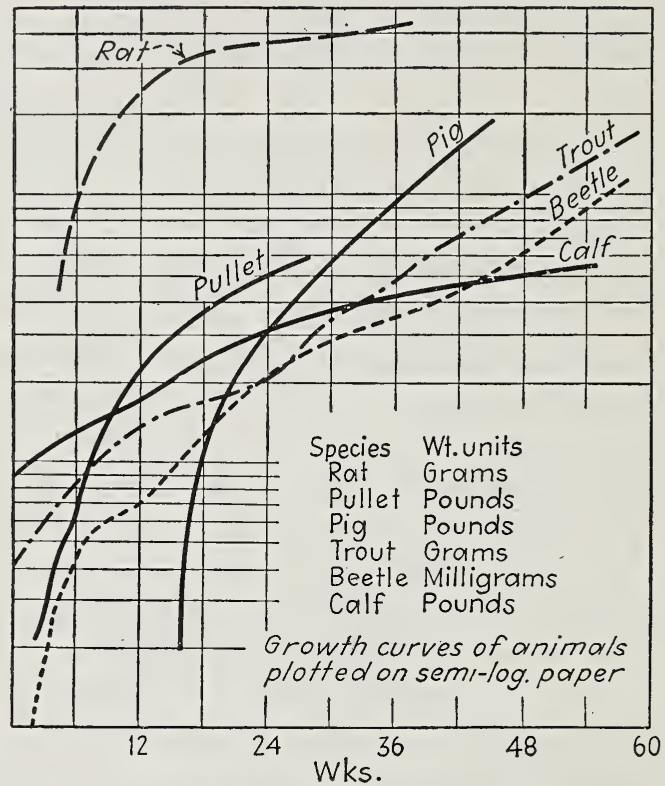

FIG. 33.-Growth of various species plotted on semilogarithmic coordinates. (Courtesy of C. M. McCay, Cornell University.)

in all its aspects. It is unsafe to assume that this use of the term normal implies an optimum development.

270. Internal Secretions and Growth.-The striking abnormalities of growth which result when certain organs of internal secretion fail to function normally bear witness to the vital role of these secretions in controlling and coordinating the growth processes and furnish a further illustration of their complexity. In view of the influence that the thyroid secretion has upon metabolic rate one would expect this secretion to affect the character of growth. Such is the case. An overactive gland speeds up metabolism and steps up the requirements of all nutrients, increasing the growth

${ }^{1}$ Moulton, C. R., and associates, Normal growth of domestic animals, Mo. Agr. Expt. Sta. Research Bull. 62, 1923. 
rate in some species. Thyroidectomy, on the other hand, stunts growth of the body as a whole and causes a relative overgrowth of certain parts. It has been reported that partial thyroidectomy causes hogs and beef cattle to fatten more readily. A similar effect has been noted from the feeding of substances which suppress thyroid activity. The practical significance of these findings remains to be demonstrated.

The overproduction of a secretion from the anterior lobe of the pituitary results in gigantism. There is an excessive skeletal growth which produces a giant in stature, but a weakling physically because other growth processes do not keep pace. When the pituitary gland is underactive, the individual is small and infantile in appearance. Other internal secretions also play roles in growth, and there are definite interrelations in the functions of certain of the endocrine glands in the coordinating of the processes which combine to produce normal development, physical and mental.

271. Retardation of Growth.-The severe retardation or arrest of growth which results from a failure of glandular secretions is fortunately comparatively rare. Much more common are the lesser retardations which are caused by undernutrition, either in calories or in some specific essential nutrient. The nature and extent of the effect on growth are dependent upon the character and severity of the deficiency and upon the period involved. A deficiency of energy, for example, will immediately check growth in mass, while a lack of calcium may not, since its primary effect is upon bone structure rather than its size. A deficiency of certain other nutrients, such as phosphorus or vitamin $B$, exerts an indirect influence on increase in size by decreasing appetite, as well as causing direct physiological effects.

The influence of varying degrees of undernutrition on the growth process has been the object of much study. One of the pioneer studies was that of Waters ${ }^{1}$ in which steers were placed on a ration which permitted no gain in weight, and the resulting changes in conformation were observed. Though the weight, remained stationary, growth was not entirely inhibited, for the stecrs increased in length and height; but they became exceed-

${ }^{1}$ Waters, H. J., The eapacity of animals to grow under adverse conditions, Proc. Soc. Promotion Agr. Sci. (29th ann. meeting), 1908, pp. 71-96; How an animal grows. The influence of nutrition on the size and form of animals, Kan. State Board Agr. Rept. 113, 59-85, 1910. 
ingly thin because of a depletion of their fat reserves. Many experiments with laboratory animals, notably those by Osborne and Mendel ${ }^{1}$ have shown that, following a period of retardation, growth in weight can be resumed at a more rapid rate than normally exhibited at any time during life. There is no adequate explanation of this. In stunting, cells may be depleted yet remain in outline, capable of being filled in later without complete rebuilding. The rapid increase in weight which follows retardation may be to a considerable extent a replacement of lost fat and this process may take place more rapidly than true growth. The actual suppression of growth may be less than the weight measures indicate. Cellular development may proceed in important ways and yet not be reflected in any increase in weight.

The major interest in the effects of growth retardation lies in the question of its influence on ultimate body size and development. Does any prolonged or severe retardation permanently harm any tissues or functions? The view is commonly expressed that any marked retardation is definitely undesirable. This may be true, but experiments have shown that underfeeding may prolong the growth period without affecting the ultimate size. The previously mentioned, severe treatment to which steers were subjected by Waters did not result in any permanent stunting, according to later reports from the Missouri Experiment Station where the study was carried out. Of greater interest is the established fact that the growth impulse may be exercised in an important way long after the time of life at which growth is normally completed. As an extreme example McCay and associates ${ }^{2}$ have shown that rats held undersized by calorie restriction beyond the average life span for the species were able to resume growth on ad libitum feeding. This growth was reflected in organ development as well as in weight, but those severely retarded animals never reached full body size.

272. Accelerated Growth Performance.-Mendel and Hubbell ${ }^{3}$

1 Osborne, Thomas B., and Lafayette B. Mendel, The resumption of growth after long-continued failure to grow, J. Biol. Chem., 23, 439-454, 1915.

${ }^{2}$ McCay, C. M., Mary F. Crowell, and L. A. Maynard, The effect of retarded growth upon the length of life span and upon the ultimate body size, J. Nutrition, 10, 63-79, 1935.

${ }^{3}$ Mendel, Lafayette B., and Rebecca B. Hubbell, The relation of the rate of growth to diet. III. A comparison of stock rations used in the 
have reported a very interesting study of the growth of the rat during three periods in the history of the inbred colony of the Connecticut Agricultural Experiment Station. A gradual increase in growth rate occurred during the 25 years studied, and the animals were found to be markedly larger as adults accordingly. Improvements in the nutritional regime was considered to be largely responsible for these developments. Similar data have been reported for man. There are several studies, such as those published by Appleton, ${ }^{1}$ showing that Orientals grow more rapidly and to a larger size in a Western environment. Various factors, such as sanitary conditions and climate as well as nutrition, are doubtless concerned. There are convincing data from selected groups in this country and elsewhere that a physical evolution is occurring whereby children are growing to be taller and heavier than their parents. Better and more abundant food is listed as one of the causes.

These various results do not necessarily mean that the development fixed by heredity is actually being exceeded. Rather, they may mean that we are merely learning how to take fuller advantages of the hereditary capacity to grow and that the attainment of the maximum possible development lies in the future.

273. Effect of Growth Rate on Feed Efficiency and Carcass Quality.-From the standpoint of animal production we are particularly interested in the influence of the growth rate on feed economy and on the final product. Following his initial study previously mentioned, Waters planned an extensive series of experiments dealing with the effect of nutritional plane and of age on the efficiency of food utilization and on body development and composition. These experiments were carried out at the Missouri Agricultural Experiment Station and the results have been reported in a classical series of papers. ${ }^{2}$ The data clearly show that the higher planes of nutrition proved more efficient from the standpoint of energy recovery and the production of breeding colony at the Comnecticut $\Lambda$ gricultural Wxperiment Station, $J . N u$ trition, 10, 557-563, 1935 .

1 Appleton, Vivis B., Growth of Chinese ehildren in Hawaii and in China, Am. J. Phys. Anthrop., 10, 237-252, 1927; Growth of Kiwngtung (hinese in Hawaii, ibid., 11, 473-500), 1928.

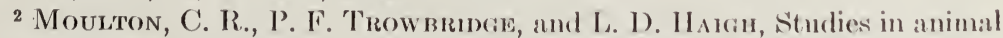
nutrition. HI. Changes in chemical composition on different planes of nutrition, Mo. Agr. Expl. Sla. Research Bull. 55, 1922; and earlier papers here cited. 
edible meat. The papers contain a wealth of data on carcass composition as influenced by different levels of nutrition. The large body of data presented has recently been analyzed and evaluated by Watson ${ }^{1}$ as a basis for determining wartime food policies in England. His analysis brings out clearly the increased physiological efficiency resulting from high nutritional planes of intake. Guilbert and coworkers ${ }^{2}$ have published an important study demonstrating the superior results obtained through continuous growth in steers, brought about by supplementing the range

Table XXIII.-Variation in Percentage Composition of Carcass as Influenced by Plane of Nutrition (McMeekan)

\begin{tabular}{|c|c|c|c|c|}
\hline \multirow{2}{*}{ Plane of Nutrition } & \multirow{2}{*}{$\begin{array}{l}\text { Live weight, } \\
\text { lb. }\end{array}$} & \multicolumn{3}{|c|}{ Percentage composition of carcass } \\
\hline & & Bone & Muscle & Fat \\
\hline High-high. . & 200 & 11 & 40 & 38 \\
\hline Low-low..... & 200 & 12 & 49 & 27 \\
\hline High-low. . . . . . . . . . . . & 200 & 11 & 45 & 33 \\
\hline Low-high............. & 200 & 10 & 36 & 44 \\
\hline
\end{tabular}

feed during the dry season, as compared with the interrupted growth which otherwise resulted.

The outstanding studies by McMeekan of New Zealand, ${ }^{3}$ carried out under the direction of Hammond at the University of Cambridge, have demonstrated how the plane of nutrition can be adjusted in relation to the growth rate of the different parts, as illustrated in Fig. 32, to influence the composition of the carcass at market weight. One group of animals designated "high-high" was kept on a high plane of nutrition through a slaughter weight of $200 \mathrm{lb}$. at 180 days. Another group "low-low" was fed on a low plane to the same weight, 300 days being required. The third group "high-low" first were fed at a high and then at a low plane of nutrition, reaching $200 \mathrm{lb}$. at 240 days. The fourth group "low-high" received the reverse treatment. The results in terms of carcass composition are shown in Table XXIII.

1 Watson, D. M. S., Beef cattle in peace and war, Empire J. Expt. Agr., 11, 191-228, 1943.

${ }^{2}$ Guilbert, H. R., and coworkers, The importance of continuous growth in beef cattle, Calif. Agr. Expt. Sta. Bull. 688, 1944.

${ }^{3}$ McMeenan, C. P., Growth and development in the pig with particular reference to carcass quality, J. Agr. Sci., 30, 276-343, 387-436, 511-569, 1940; 31, 1-49, 1941. 
The high-low system produced the best bacon type, as a result of the heavy feeding during the period of maximum bone and muscle formation and the limited feeding when fat deposition normally predominates. The reverse feeding system produced a hog with the characteristics of the early maturing, lard type. The low-low group had too large a portion of bone, poor development of loin and hindquarter, and too little fat. These papers contain a tremendous store of unique and valuable data on the growth of individual bones, muscle, and other tissues, as influenced by dietary regimes.

274. Rate of Growth and Productive Life.-Clearly the recent studies in nutrition have resulted in practices that have markedly increased the growth rate as measured by weight and size. It is the general belief that this is a desirable development in terms of the life span as a whole. This belief is supported by an extensive series of experiments by Sherman showing that diets which produced a more rapid rate of growth also resulted in a longer life. On the other hand, McCay's studies have clearly shown that rats whose growth is severely retarded in early life, by calorie restriction only, have a longer life span than those which grow rapidly under ad libitum feeding. While these experiments involved a too severe retardation to have any direct application to practice, they do serve to indicate the need for further investigations of the nutritional factors involved in length of life. Of real practical significance, McCay found that with animals which had grown normally and continued to receive an ad libitum diet until middle age, calorie restriction thereafter resulted in a longer life.

These experiments serve to emphasize the fact that growth should be looked at primarily as a preparation for life. In man we are interested in a healthy, productive life in which the infirmities of old age are postponed as long as possible. In breeding stock and in animals kept for milk and egg production lifetime performance is the final measure of the success achieved in rearing these animals. The possibility must be considered to exist, particularly sinee there may be nutritional factors still unknown, that, from the standpoint of produetive life, there are limitations in a system of rearing which relies upon a rapid increase in weight and size as the primary measure of success. However much one may doubt this possibility, it cannot be said with certainty 
that all the factors for growth are optimum until their influence on lifetime performance has been studied as thoroughly as their effects during the growth period itself.

\section{ENERGY REQUIREMENTS FOR GROWTH}

Previous discussions have shown that the rate and character of the body increase vary with age, as well as with species. It is evident, therefore, that a feeding standard for growth must be different for each species and must consist of a series of values corresponding to the different ages and body weights representing the growth period. Such a detailed presentation for all species is beyond the scope of a text dealing with the principles of nutrition. Rather, the physiological bases of the requirements will be considered, typical procedures for arriving at specific values will be outlined, and reference will be made to sources of detailed information for the different species which have been studied.

The total requirement for a given nutrient during growth must include the amount needed for maintenance as well as the amount required for the new tissue formed. The values given in feeding standards represent these combined requirements. Of the various nutrient needs for growth, the requirement for energy is by far the largest and primarily governs the total food allowance. It is, therefore, advantageous to discuss this requirement first.

275. Factors Governing the Energy Requirement for Growth.The maintenance component of the total energy requirement during growth increases regularly with body size, but the additional demand for the growth itself varies with the rate and with the composition of the tissue formed. Per unit of body weight, the amount of energy represented by the growth tissue formed decreases with age, reflecting the declining rate of body increase measured on a percentage basis (Sec. 268). But the amount of energy stored per unit of body increase becomes larger with age because of its lower water and higher fat content. While the true growth tissue contains only a trace of fat, a certain amount of fat deposition is an inevitable accompaniment of growth, and in practice a considerable amount of fattening is an integral part of growing animals for meat. Since fat contains much more energy than does protein, it is evident that the energy requirement per unit of body gain increases in accordance with its fat content. 
In fact, if the fattening is very rapid, the normal trend of decrease in energy stored per unit of body weight may not occur. In feeding standards for meat animals, no separate statement is made of the requirements for growth proper and for the fattening which concurrently takes place, but a distinction may be made according to the amount of fattening desired.

Except under conditions where very rapid fattening is sought, the maintenance component of the total growth requirement always markedly exceeds the portion required for the formation of new tissue. Thus the faster the growth rate the lower the total requirement per amount of gain tends to be, but this tendency may be partially counterbalanced by the decreasing efficiency of food utilization as the intake is increased.

Since balanced rations (Sec. 243) involve less wastage as heat loss, they have the practical effect of decreasing the total feed required per unit of gain. The economy of balancing the hog ration with respect to protein has been shown by Ellis and Hankins ${ }^{1}$ in studies involving three levels of protein intake. The higher the level, the more economical were the gains in terms of total feed required. The differences were most marked during the early part of the growth period. Similar data have been obtained with chickens.

276. Energy Requirements from Metabolism and Slaughter Data.-The net-energy requirement for growth may be considered to be the sum of the energy of the tissue formed, plus the basal metabolism increased by an activity factor (Sec. 254). Mitchell, of the University of Illinois, has applied this general procedure to various species of farm animals. By special permission his unpublished data for Holstein heifers are reproduced in Table XXIV. The footnotes at the bottom of the table explain how the various values are obtained. The over-all compilation seems theoretically sound. The resulting values for T.D.N. are considerably higher at the lower body weights than those obtained from feeding trials (Table XXV). Mitchell has made similar eompilations for other species. The data obtained are certainly worthy of a controlled test in comparison with those now set forth in feeding standards and based on feeding trials.

1 ELLAs, N. R, and O. G. HANKins, The influence of the protein content of the ration on the growth and fattening of hogs forl at a moderately restricted level, Proc. Am. Soc. Animal Production, 1935, M). 107-111. 


\title{
277. Energy Requirements Obtained from Feeding Trials.-
} The data contained in the currently used feeding standards for

\author{
Table XXIV.-Energy Requirements of Growing Holstein \\ HeIFERS
}

(Calculated by H. H. Mitchell, University of Illinois)

\begin{tabular}{|c|c|c|c|c|c|c|c|}
\hline \multirow[b]{2}{*}{$\begin{array}{l}\text { Body } \\
\text { weight, } \\
\text { lb. }\end{array}$} & \multirow[b]{2}{*}{$\begin{array}{c}\text { Age,* } \\
\text { mo. }\end{array}$} & \multirow[b]{2}{*}{$\begin{array}{c}\text { Daily } \\
\text { gain, } \dagger \\
\text { lb. }\end{array}$} & \multicolumn{3}{|c|}{ Net Energy } & \multirow{2}{*}{$\begin{array}{c}\text { Total } \\
\text { metabo- } \\
\text { lizable } \\
\text { energy, } \uparrow \\
\text { Cal. }\end{array}$} & \multirow[b]{2}{*}{$\begin{array}{c}\text { T.D.N., }{ }^{* *} \\
\text { lb. }\end{array}$} \\
\hline & & & $\begin{array}{c}\text { Basal } \\
\text { metabo- } \\
\text { lism, } \ddagger \\
\text { Cal. }\end{array}$ & $\begin{array}{c}\text { Activity, } \S \\
\text { Cal. }\end{array}$ & $\begin{array}{c}\text { Growth, II } \\
\text { Cal. }\end{array}$ & & \\
\hline 150 & 2.2 & 2.08 & 2151 & 968 & 1970 & 7914 & 4.90 \\
\hline 200 & 3.0 & 2.02 & 2230 & 1003 & 1955 & 8052 & 4.98 \\
\hline 400 & 6.6 & 1.76 & 4241 & 1908 & 1864 & 12089 & 7.48 \\
\hline 600 & 10.6 & 1.52 & 5233 & 2355 & 1814 & 14073 & 8.71 \\
\hline 800 & 15.4 & 1.26 & 5976 & 2689 & 1759 & 15527 & 9.61 \\
\hline 1000 & 21.3 & 1.01 & 6640 & 2988 & 1746 & 16890 & 10.45 \\
\hline 1200 & 28.9 & .76 & 7304 & 3287 & 1884 & 18516 & 11.46 \\
\hline
\end{tabular}

* Growth data for Holstein heifers are taken from Espe, Cannon, and Hansen, Iowa Agr. Expt. Sta. Research Bull. 154, 1932. The growth equation describing the data is: $\mathrm{W}_{1 \mathrm{~b} .}=1800$ $-2560 \mathrm{e}^{-.0378 t} \mathrm{mo}$. This covers only the period to first calving, after which growth is retarded markedly by successive lactation periods.

$\dagger$ Obtained by differentiation of the growth curve: $\frac{\mathrm{dw}}{\mathrm{dt}}=3.29 \mathrm{e}^{-.0378 \mathrm{t}}$ (lb. per day).

$\ddagger$ Brody's equation for Holstein heifers (Mo. Agr. Expt. Sta. Research Bull. 166): $\frac{\mathrm{AQ}}{\mathrm{m}}=$ $28 \mathrm{e}^{-.0045 \mathrm{~m}}+11 ; \mathrm{Q}$ in Cal., $\mathrm{m}$ in $\mathrm{kg}$.

$\S$ From a comparison of the net-energy intake for maintenance and the estimated basal metabolism of dairy cows kept under herd conditions (see Mo. Agr. Expt. Sta. Bull. 222), it was shown that the activity of the cow expressed in calories required averages about 45 per cent of her basal expenditures of energy. Application of this average to calves of all ages implies a greater activity of the younger calf, because activity expenditures vary with body weight, and the ratio of surface area to body weight increases, the smaller the animal.

$\|$ These values are taken from the analysis of the changes in composition of growing beef calves (group II Missouri steers; see Mo. Research Bull. 55) given in Natl. Research Council Bull. 67. They have been applied to dairy calves by assuming that at equivalent ages, in the Brody sense, growing cattle of all breeds put on gains of the same chemical composition.

If Assuming the availability of metabolizable energy, in a good mixed ration, to be 69.5 per cent for maintenance (basal + activity) and 57.5 per cent for body gain. See recent publications from the Institute of Animal Nutrition, Pennsylvania State College.

** Assuming that there are 1.616 Therms of metabolizable energy per pound of total digestible nutrients in a good mixed ration (see Proc. Am. Soc. Animal Production, 1931, pp. 113-126).

farm animals are based primarily on the results of feeding trials. In the more critically conducted trials different groups of animals have been fed throughout the growth period at different levels of energy intake to ascertain the level that would produce normal growth and development without being unnecessarily high. A 
feeding trial enables the statement of the requirement in terms of specific feeds or in terms of any desired measure of the energy required, by the inclusion of appropriate procedures. Most commonly the data obtained with farm animals are expressed as total digestible nutrients, either by including digestion trials or by the use of average coefficients of digestibility (Sec. 216).

The feeding-trial method of determining the energy requirements for growth is illustrated by the studies of Eckles and Gullickson ${ }^{1}$ with Holstein and Jersey cattle, based upon data for 50 animals divided among three levels of energy feeding. The intakes of those which were considered to have made a normal growth, as measured by weight, were then averaged to provide the data selected to represent the requirements. These estimated requirements are given in Table XXV.

Table XXV.-Total Digestible Nutrients in Pounds Required by Growing Dairy Cattle

\begin{tabular}{c|c||c|c}
\hline Body weight & $\begin{array}{c}\text { Total digestible } \\
\text { nutrients }\end{array}$ & Body weight & $\begin{array}{c}\text { Total digestible } \\
\text { nutrients }\end{array}$ \\
\hline 100 & 2.32 & 450 & 6.77 \\
150 & 3.36 & 500 & 7.06 \\
200 & 4.23 & 550 & 7.34 \\
250 & 4.96 & 600 & 7.65 \\
300 & 5.55 & 650 & 7.96 \\
350 & 6.03 & 700 & 8.26 \\
400 & 6.44 & 750 & 8.56 \\
\hline
\end{tabular}

Actually, the feeding trials in which any attempt has been made to determine the minimum intakes of energy required for growth are very few. Most of them have involved ad libitum feeding, and the results are expressed in terms of feed required per $100 \mathrm{lb}$. gain. Undoubtedly these results do not represent the minimum requirements in many cases, particularly where unbalanced rations were used. Any allowance for practice, however, must allow a margin of safety for, if the values selected just meet the requirement determined as an average of the data obtained with a groups of animals, half of them may be underfed with such an allowance.

1 Eckles, C. II, and T. W. Guldickson, Nutrient requirements for normal growth of dairy cattle, J. Agr. Research, 42, 603-616, 1931. 


\section{THE PROTEIN REQUIREMENTS FOR GROWTH}

Aside from water, the body increase during growth consists very largely of protein. The theoretical minimum protein requirement is the amount actually stored in the body. But this is far below the actual requirement because of the wastage in digestion and metabolism. The loss in digestion can be taken account of by stating the requirement in terms of digestible protein, and data on digestibility are available for all of the common feeds. The wastage in metabolism is much less readily assessed. It is governed primarily by the efficiency with which the digested protein supplies the amino acids required for the construction of body tissue, a measure which constitutes the biological value of the food protein. The wastage here concerned is a large and variable one; and a consideration of the data available on the biological value of different protein sources for growth is a logical starting point for a discussion of the protein requirement.

278. The Determination of Biological Value.-The protein efficiency or biological value of a given feed is measured as the percentage of the intake which is actually utilized in the body. It is sometimes expressed as the percentage of the total intake that is stored. Here losses in digestion as well as in metabolism are taken into account. The biological value, properly speaking, takes account of metabolic losses only and thus should be computed on the basis of the digested protein. This procedure measures the efficiency of the absorbed protein in supplying the amino acids needed for the synthesis of body protein, thus arriving at a figure for biological value which constitutes the more exact and preferred usage of the term. The calculation is made most simply as follows:

$$
\frac{\mathrm{N} \text { intake }-(\text { fecal } \mathrm{N}+\text { urinary } \mathrm{N}) \times 100}{\mathrm{~N} \text { intake }- \text { fecal } \mathrm{N}}=\text { biological value }
$$

It is evident that the data for such a calculation can be obtained from a nitrogen-balance experiment. The level of protein fed must be high enough so that marked growth will actually result as indicated by the positive balance; yet it must not be in excess of the amount needed to cause maximum growth, because an intake above this would be catabolized and excreted and thus give a biological value lower than the true one. There must be a suffi- 
cient intake of nonnitrogenous food so that the protein will not be needed as a source of energy. Other nutrients must be supplied adequately also.

279. The Thomas-Mitchell Method.-The formula previously given measures the biological value of protein for growth purposes only: A more useful measure is one that takes account of maintenance as well. This can be accomplished by considering the metabolic and endogenous losses separately from the total fecal and urinary excretions. A method for this purpose was originated in 1909 by Karl Thomas ${ }^{1}$ of Leipzig who first used the term, biological value. In so doing he had amino-acid make-up in mind. It is interesting to note that Thomas developed this concept and a method for its measurement prior to the work of Osborne and Mendel which inaugurated the modern studies of protein quality. The Thomas method has been modified and popularized by Mitchell ${ }^{2}$ who has conducted a very large number of studies with it. The method is best explained by a consideration of the formula which Mitchell uses in calculating the value obtained:

$\frac{N \text { intake }-(\text { fecal } N-\text { metabolic } N)-(\text { urinary } N-\text { endogenous } N)}{N \text { intake }-(\text { fecal } N-\text { metabolic } N)} \times 100$

The feature of this formula, distinguishing it from the previous one, is its recognition of the fact that endogenous and metabolic nitrogen represent fractions which have actually been utilized by the body even though they appear as excretions. Thus, in the numerator, the fecal loss subtracted from the total intake is limited to the part actually undigested, and the urinary loss is reduced by its endogenous fraction before being subtracted. The numerator, therefore, represents the total nitrogen utilized, including the part used in maintenance as well as that built into growth tissue. Since in the denominator also, the metabolic nitrogen is subtracted from the total fecal output, the biological value computed is the percentage of the actually digested nitrogen

1 Thomas, KarL, Uber die biologische Wertigkeit der stickstoff Substanzen in verschiedenen Nährungsmittel, Arch. Anat. Physiol., Physiol. Abt., 1909, pp. 219-302.

${ }^{2}$ Mitchels, H. H., $\Lambda$ method of determining the biological value of protein, J. Biol. Chem., 58, 873-903, 1924. Mitchill, H. H., Wise Burmougus, and Jesse R. BEADuens, The significance and acruracy of biological values of proteins computed from nitrogen metabolism datit, J. Nutrition, 11, 257$274,1936$. 
that is utilized. In excluding the metabolic and endogenous nitrogen from the losses it becomes a measure of the efficiency of the protein for the combined functions of growth and maintenance.

In principle the Thomas-Mitchell method is certainly an exact one for evaluating proteins, but the procedure used in carrying it out involves certain uncertainties and difficulties. The values for metabolic and endogenous nitrogen cannot be determined while the protein is under study, but must be calculated from values obtained in separate periods when the animals are receiving a nitrogen-free diet. A frequent difficulty here, particularly with certain species, is that some individuals will not eat enough of the nitrogen-free diet to supply their energy needs, and thus true endogenous nitrogen values are not obtained. To obviate this difficulty a small amount of protein, such as egg or milk, which is considered to be utilized to an approximately complete degree both in digestion and metabolism, can be included in the ration. The method assumes that the same output of endogenous and metabolic nitrogen occurs during the protein test itself as during the nitrogen-free period. Thus the method assumes the applicability of the Folin theory, the recent criticisms of which have been previously discussed (Sec. 100). The reliability of the metabolic fecal-nitrogen values has also been questioned in a recent study by Bosshardt and Barnes. ${ }^{1}$ Despite these limitations the method still appears to be a useful one. A detailed and current discussion of the general procedure and of its practical applications, compared with other methods, has been presented by Mitchell. ${ }^{2}$

The data presented in Table XXVI, taken from a publication by Mitchell, ${ }^{3}$ illustrate the nature of the results obtained by the Thomas-Mitchell procedure. These figures reveal the wide differences which exist in the efficiency of various proteins, as measured by the rat, and they illustrate the extensiveness of the role that biological value can play in governing the amount of dietary protein required.

1 Bosshardt, D. K., and R. H. Barnes, The determination of metabolic fecal nitrogen and protein digestibility, J. Nutrition, 31, 13-21, 1946.

2 Mitchell, H. H., Biological methods of measuring the protein value of feeds, J. Animal Sci., 2, 263-277, 1943.

${ }^{3}$ Mitchell, H. H., The protein values of foods in nutriticn, J. Home Econ., 19, 122-131, 1927. 
The biological values given in Table XXVI were determined by introducing the food in question into the basal diet in such amounts as would provide a protein level lying between 8 and 10 per cent. In addition to avoiding too high levels, it is necessary to hold to approximately the same level where the data obtained with different foods are to be compared. This is because biological value decreases with increase in protein level. This

Table XXVI.-Brologrcal Value of the Proteins of Human Foods

\begin{tabular}{|c|c|c|c|}
\hline Food & $\begin{array}{l}\text { Biological } \\
\text { value of } \\
\text { protein, } \%\end{array}$ & Food & $\begin{array}{c}\text { Biological } \\
\text { value of } \\
\text { protein, \% }\end{array}$ \\
\hline Whole egg.......... & 94 & Whole wheat........ & 67 \\
\hline Milk.............. & 85 & Potato............ & 67 \\
\hline Egg white.......... & 83 & Rolled oats......... & 65 \\
\hline Beef liver........... & 77 & Whole corn. ........ & 60 \\
\hline Beef heart........... & 74 & Wheat flour......... & 52 \\
\hline Beef round.......... & 69 & Navy beans (cooked).. & 38 \\
\hline
\end{tabular}

fact also indicates that determined values are more useful for comparative purposes than as absolute measures applicable to practice where different diets may vary markedly as to protein level.

280. The Supplementary Relations among Proteins.-Another reason why figures, such as those given in the preceding table, are more useful as relative measures than as absolute values to be used in selecting diets lies in the fact that when two protein sources are combined the resulting value is not necessarily the mean of the individual values. The explanation here is that certain proteins mutually supplement each other so that the resulting amino-acid mixture has a biological value superior to that of either protein when fed alone. This is strikingly illustrated by the studies of Mitchell and Kick ${ }^{1}$ with corn and tankage, long known to represent an effective combination for the growth of swine. Using eight growing pigs the average biological values were: corn, 54; tankage, 42 ; the combination (2:1), 61. Though an animal product, tankage consists of tissues which by themselves furnish a very inefficient amino-acid mixture, but it sup-

${ }^{1}$ Miтcheld, Н. Н., and С. Н. Kiск, The supplementary relation between the proteins of corn and of tankage determined by metabolism experiments on swine, J. Agr. Research, 35, 857-864, 1927. 
plies certain amino acids in which corn is deficient and the latter performs a similar service for tankage.

The different protein efficiencies which result when corn is combined with other feeds are illustrated by the data shown below taken from an extensive experiment by Hart and Steenbock ${ }^{1}$ with growing pigs.

These data also show the differences in values obtained by two methods of calculating the efficiency. The percentage retention is always larger when computed on the basis of the absorbed nitrogen than on the basis of the total fed because of the loss in digestion. The lower the digestibility of the ration the greater the difference between the values calculated by the two methods.

\begin{tabular}{c|c|c}
\hline Ration & $\begin{array}{c}\text { Percentage of } \\
\text { total nitrogen } \\
\text { retained }\end{array}$ & $\begin{array}{c}\text { Percentage of } \\
\text { absorbed nitro- } \\
\text { gen retained }\end{array}$ \\
\hline Corn and alfalfa....... & 31.7 & 47.3 \\
Corn and tankage..... & 40.3 & 56.7 \\
Corn and milk....... & 61.7 & 71.4 \\
\hline
\end{tabular}

The experiments just cited also illustrate the fact that the most useful data for biological value are those obtained with specific combinations used in practice, since single feeds seldom provide the entire ration. Much useful information has thus been obtained as to the relative value of various protein supplements for swine feeding and, to a lesser extent, for other species. With rations which usually include several feeds and draw on a wide range of sources, such as those for dairy cattle and for man, studies of specific combinations have less application.

281. Biological Values for Different Species.-Most of the data for biological values have been obtained with rats. Several studies have been made with pigs and a few with sheep and cattle. The question as to the extent to which the values obtained with one species apply to another is an important one from the standpoint of their general usefulness, particularly in view of the special suitability of the rat for determining these values. There are several experiments, such as those of Schneider ${ }^{2}$ with fish meals,

${ }^{1}$ Hart, E. B., and H. Steenbock, Maintenance and production value of some protein mixtures, J. Biol. Chem., 38, 267-285, 1919.

${ }^{2}$ Schneider, Burch H., Nitrogen-balance studies with various fish meals, J. Agr. Research, 44, 723-732, 1932. 
indicating that the values obtained with rats tend to hold for pigs also. Chickens also appear to respond similarly to rats. The discussion in Sec. 88, however, has shown that the qualitative amino-acid needs of rats and chicks are not identical. Thus a diet could be devised, from purified nutrients at least, which would have a maximum biological value for rats and yet would not even maintain a chick. There is also evidence that there are quantitative differences among species in the relative amounts of the amino acids required in common. For these reasons interpretations from one species to another must be made with reserve.

Rats are not suitable as test animals for roughages or for the mixed rations of Herbivora because of limitations as to their digestibility. Further, one would expect the amino-acid make-up of the ration as fed to be of less importance in the case of ruminants because of microbiological synthesis. The studies thus far made with ruminants have failed to reveal any large differences in biological value for growth among commonly used feeds or rations. Such has been true in the case of extensive trials with sheep at Cornell University. These studies, carried out by the ThomasMitchell procedure, for the most part have not revealed significant differences among feeds that have been found to differ widely in biological value for rats.

Evidence from rat experiments that the proteins of leaf and seed tend to supplement each other is responsible for the suggestion that rations containing legume hay should have a higher biological value than those based upon grass hay. No evidence for this viewpoint has been obtained in critically conducted experiments.

It remains to be proved that any large variations in biological value exist among the combinations of feeds which make up the usual rations of Herbivora. Large differences are unlikely for several reasons. The studies which have been made of plant products with rats have revealed few cases showing large variations, in contrast to the results obtained with and without the inclusion of the better animal sources. A ration of roughage and mixed roncentrates provides a wide varicty of proteins and thus a greater likelihood of supplementary action (Sec. 280). Furthermore, the protein mixture as fed is of less importance with Herbivora because of protein synthesis in the digestive tract. Further studies, however, of the protein efficiency of rations for Herbivora by critical procedures are clearly worth while. 
282. Protein Efficiency as Measured by Feeding Trials.-The nitrogen-balance method of measuring protein efficiency, as described in Sec. 279, gives precise information under the conditions imposed, but it is obviously not adapted to long-time studies nor applicable to all rations fed in practice to farm animals. Feeding trials of various types are thus also employed. Here a measure of the protein stored, comparable to that of a nitrogen balance, can be obtained by a slaughter check (Sec. 209). But more commonly, gain in weight is used as the sole criterion, which is not a very reliable measure of the gain in protein tissue. With both procedures the rations under comparison are sometimes fed ad libitum and the results expressed in terms of gain per unit of protein intake and sometimes equalized by paired feeding. There are limitations which should be recognized in all of these methods.

In Sec. 207 reference was made to Osborne and Mendel's critical studies of ad libitum vs. various systems of controlled feeding as techniques of measuring protein efficiency in terms of body gain. In a later publication ${ }^{1}$ they revealed the limitations of making the comparison at a single protein-intake level because different proteins differed as to the level at which they showed their maximum efficiency. Mitchell ${ }^{2}$ has critically reviewed the advantages and limitations of various feeding-trial procedures for determining protein efficiency and Barnes and coworkers ${ }^{3}$ have very recently reported a comparative study with rats of various methods. The viewpoints expressed in these two papers are largely in agreement though differing somewhat in emphasis. While Mitchell believed that ad libitum feeding has no place as an exact measure of protein efficiency, Barnes and coworkers have shown that there are pitfalls in paired feeding also. These papers should be read by students of protein nutrition as a basis for critically evaluating experimental work in this field, as well as for planning any ex-

1 Osborne, Thomas B., Lafayette B. Mendel, and Edna L. Ferry, A method of expressing numerically the growth-promoting value of proteins, J. Biol. Chem., 37, 223-229, 1919.

${ }^{2}$ Mitcheli, H. H., Biological methods of measuring the protein values of feeds, J. Animal Sci., 2, 263-277, 1943. Determination of the nutritive value of the proteins of food products, Ind. and Eng. Chem. Anal. Ed., 16, 696-700, 1944.

3 Barnes, Richard H., and coworkers, The measurement of the growth promoting quality of dietary protein, Cereal Chem., 22, 273-286, 1945. 
periments of their own. Some of the limitations discussed apply to the Thomas-Mitchell procedure as well as to feeding trials.

There is no single procedure for determining protein efficiency or biological value which is free from limitations nor any single procedure which is best for all purposes. One method may provide more reliable and specific basic scientific information yet be less suitable than another for the solution of animal feeding problems in practice. The critical investigator can find, however, a method useful for his purpose which will yield reliable results if they are properly interpreted. Quantitative knowledge regarding aminoacid requirements and the perfection of methods for determining the amino-acid content of feeds - a field in which much progress has already been made in the case of poultry, as indicated by the work of Almquist ${ }^{1}$ - may eventually eliminate the need for biological studies. But the application of such information must be checked by feeding trials, at least until it is shown that despite losses in digestion and metabolism the amino acids presented to the tissues are in the same quantitative relations as existed in the feed.

283. Comparative Biological Value of Various Foods.- On the basis of the studies with rats and the much fewer ones which have been made with pigs and chicks, certain generalizations have been made regarding the comparative biological value of individual foods and combinations. Animal products as a class are superior to vegetable foods. At the top stand milk and eggs, followed by liver, kidney, and other glandular organs. Muscle meat ranks somewhat lower but is above most seeds and other vegetable products. Certain animal tissues, however, such as blood, connective tissue, and others, rank well below the sceds, and this fact explains the low value for tankage. Most of the whole seeds do not show wide differences from each other but some, such as soybeans and peanuts, are distinctly superior. The cereal seeds have higher values than the flours made from them. Thus milling by-products tend to be higher than whole seeds or their flours.

These generalizations cover the field very incompletely, their application varies according to species, and there are other reasons why they must be accepted with reserve. Most of the studies on which they are based were made with the food products as a whole and not with their proteins alone. It is now recognized that the

1 AlmoUist, H. J., Effective use of proteins in the nutrition of the chick, Trans. Am. Assn. Cereal Chemists, 3, 158-168, 1945. 
presence of vitamins, unknown and thus not taken into account at the time the studies were made, contributed to the superior results in some cases. We can still speak with confidence regarding the nutritional superiority of certain protein foods, but we are less sure than formerly that the superiority is owing to protein biological value alone. In fact, we know in some cases that this is not true. Current research is serving to clarify our ideas here. The issues involved are set forth in the review by Mitchell. ${ }^{1}$

Since individual feeds are seldom used as the sole source of protein, the values for combinations of them are of more practical importance. Combinations of vegetable and animal products generally provide effective mixtures, and, when seeds are supplemented with 10 to 15 per cent of one of the better animal products, the combination is nearly as good as the animal source alone. In the case of corn and tankage, it is better. In general, seeds and their products do not supplement each other, but a combination of soybeans or peanuts with cereal seeds is an exception. For swine and chicks milk is a better supplement to cereal grains than is meat scraps or tankage. Soybean-oil meal has been found as good as the slaughter-house by-products and certain fish meals have proven superior. There is no basis for making any statements regarding the combinations commonly used for Herbivora.

284. Effect of Heat on Biological Value.-The marked changes that proteins undergo as a result of being heated can affect their nutritive efficiency. A fish meal that is flame-dried has a markedly lower digestibility and biological value than when the same product is vacuum-dried at a lower temperature. The toasting of bread lowers the biological value of its protein. The same has been found true for other plant and animal products. A reverse result occurs in the case of soybean protein, however. In studies with rats and chicks it has been found that the heating of soybeans improves their biological value by making the sulfur-containing amino acids more available, apparently by destroying an antienzyme. Thus for chickens and pigs the protein of soybean meal that has been heated in the process of oil extraction, or subsequent thereto, is of higher nutritive value than that of the raw beans. This has been found not to be true in the case of sheep and probably is not true for other ruminants.

${ }^{1}$ Mitchell, H. H., Is animal protein an essential constituent of swine and poultry rations? Natl. Research Council Report 117, 1943. 
285. Factors Governing Protein Needs.-As commonly stated in feeding standards, the protein requirement for growth includes the amount needed for maintenance as well. The maintenance component increases with body size, but the demand per unit of new tissue formed decreases with age and body size because of the decreasing protein content of this tissue. While the total daily requirement increases with age and size, it decreases per unit of weight and in relation to the energy requirement. For example, according to the average values of the Morrison standard, a $50-\mathrm{lb}$. lamb requires $0.175 \mathrm{lb}$. of digestible protein daily in a ration having a nutritive ratio of $1: 6.75$, while a lamb weighing twice as much needs $0.26 \mathrm{lb}$. with a ratio of $1: 7.75$. Standards for children, expressed as grams per kilogram of body weight, decrease from $3.5 \mathrm{~g}$. during the first year to $1 \mathrm{~g}$. near maturity.

In view of the factor of biological value, it is evident that there can be no fixed minimum requirement except in terms of specific food sources. The fact that biological value decreases with level of intake has the effect of increasing the requirement per unit of tissue gained as the growth rate is increased. The previously discussed evidence (Sec. 243) that, within rather wide limits, the wastage of energy in metabolism is decreased as the level of protein is raised suggests that the most efficient level of intake may be higher than the amount needed for its specific function as protein. All of these considerations suggest higher allowances in practice than certain minimum values which have been determined for specific combinations.

286. Estimation of Protein Requirement from Metabolism and Slaughter Data.-The protein requirement can be estimated as a sum of the amount needed for maintenance plus that of the growth tissue formed, with an allowance for losses in metabolism. This is the procedure used by Mitchell, as illustrated in Table XXVII, representing unpublished data reproduced with his permission. The calculation is similar in principle to that for the energy requirements set forth in Table XXIV and is based on the same growth data. The maintenance figures are calculated endogenous nitrogen values. These values plus the protein gained, as estimated from the slaughter data, give the total net requirements that are translated into intakes of digestible crude protein by assuming a 50 per cent biological value. The calculation seems theoretically sound, subject to the assumptions made, but 
the decreasing total requirements with age represent a sharp reverse of the trend of data obtained from feeding trials, as is discussed later (Sec. 287).

Table XXVII.-Protein Requirements of Growing Holstein HeIFERS

(Calculated by H. H. Mitchell, University of Illinois)

\begin{tabular}{|c|c|c|c|c|c|c|}
\hline \multirow{2}{*}{$\begin{array}{c}\text { Body } \\
\text { weight, } \\
\text { lb. }\end{array}$} & \multirow{2}{*}{$\begin{array}{l}\text { Age,* } \\
\text { mo. }\end{array}$} & \multirow{2}{*}{$\begin{array}{l}\text { Daily } \\
\text { gain,* } \\
\text { lb. }\end{array}$} & \multicolumn{3}{|c|}{ Net Protein } & \multirow{2}{*}{$\begin{array}{l}\text { Digestible } \\
\text { crude pro- } \\
\text { tein, } \ddagger \text { lb. }\end{array}$} \\
\hline & & & $\begin{array}{l}\text { Maintenance, } \dagger \\
\text { gm. }\end{array}$ & $\begin{array}{c}\text { Growth, }{ }^{*} \\
\text { gm. }\end{array}$ & $\begin{array}{l}\text { Total, } \\
\text { gm. }\end{array}$ & \\
\hline 150 & 2.2 & 2.08 & 27 & 202 & 229 & 1.01 \\
\hline 200 & 3.0 & 2.02 & 28 & 191 & 219 & .97 \\
\hline 400 & 6.6 & 1.76 & 53 & 154 & 207 & .91 \\
\hline 600 & 10.6 & 1.52 & 65 & 118 & 183 & .81 \\
\hline 800 & 15.4 & 1.26 & 75 & 86.0 & 161 & .71 \\
\hline 1000 & 21.3 & 1.01 & 83 & 56.5 & 139 & .61 \\
\hline 1200 & 28.9 & .76 & 91 & 30.4 & 121 & .53 \\
\hline
\end{tabular}

* See corresponding notes under Table XXIV.

† Estimated at $12.5 \mathrm{gm}$. of protein per $1000 \mathrm{Cal}$. of basal heat (Smuts, J. Nutrition, 9, pp. 403-433, 1935).

$\ddagger$ Assuming a biological value of protein of 50 .

The nitrogen-balance method can be used to measure the actual requirement in terms of a specific food or ration by determining the lowest level of intake which will give the maximum total retention. In view of the changes with age, the procedure must be carried out at various stages of the growth period in order to provide the data required. Thus, the method is very laborious and time-consuming. Mitchell and Hamilton ${ }^{1}$ have made a brief report of an extensive experiment with pigs, carried out by the paired-feeding technique, in which the nitrogen retained was used as a measure of the protein requirement. On this basis a ration containing 15 per cent of protein proved superior to those containing lower levels, for pigs weighing from 130 to $186 \mathrm{lb}$. as well as for younger pigs. A ration supplying 18 per cent of protein caused a larger retention than one furnishing 15 per cent for pigs weighing from 42 to $70 \mathrm{lb}$, , but not for those weighing $140 \mathrm{lb}$. or more. Digestibility data were obtained as were also

${ }^{1}$ Mitchell, H. H., and T. S. Hamilton, The balancing of rations with respect to protein, Proc. Am. Soc. Animal Production, 1935, pp. 241-252. 
growth records which checked the nitrogen-balance results. It was concluded that pigs weighing from 40 to $100 \mathrm{lb}$. require a ration containing more than 17 per cent of total protein, corresponding to 15.4 per cent of the digestible nutrient; but that, for higher weights, a total figure of 15 per cent, corresponding to 12 per cent digestible protein, is sufficient.

287. Protein Requirement from Feeding Trials.-In the feeding-trial method of measuring the protein requirement different levels are fed to find the minimum one which will give a maximum rate of growth. The inclusion of slaughter tests to show the nature of the increase made provides valuable additional data which are obtainable in the case of meat animals. The studies with chicks by Norris and Heuser, ${ }^{1}$ in which rations containing different percentages of protein were prepared by varying the amount of meat scrap included, illustrate the feeding-trial method. Levels varying from approximately 13 to 21 per cent were compared. The requirement was found to be higher than 18.58 per cent for the first eight weeks, whereas a level of 15 to 16 per cent was adequate thereafter. The birds were fed ad libitum, and the highest level of protein intake gave the largest gain per gram of feed during the first eight weeks, as well as the greatest total gain. The gain per gram of protein decreased with the level of intake as was to be expected.

In 1917 a cooperative study of the protein requirements for the growth of cattle was undertaken under the auspices of the National Research Council, directed by Armsby who had worked out the detailed plan much earlier but met with no success in interesting experiment stations to cooperate. From 1918 to 1923 studies were carried out at seven different stations and the data obtained have been summarized in two bulletins of the council.? The plan, involving both growth and nitrogen-balance studies, was not fully carried out at any station and many modifications were made in its procedures. Thus suceess was not achieved in producing a large body of data which could be summarized as a

1 Nornss, I. C., and C. F. Heuser, The relation of the protein requirement of chicks to the rate of growth. I. The quantity of protein required by chicks during early growth, Poultry Sci., 9, 378-392, 1930.

${ }^{2}$ Anmsвr, H. P., Cooperative experiments upon the protein requirements for the growth of rattle, Natl. Research Conncil Bull. 12, 1921. Fовнвs, Fs. B., Cooperative experiments upon the protein requirements for the growth of cattle, ibid., 42, 1924. 
unit to answer the question under investigation. At the close of the second bulletin a summary is presented of selected data, giving the minimum protein intakes of animals, six months of age and older at the start, which made gains considered to be normal over an experimental period ranging from 150 to 400 days for different individuals. These intakes varied from 1.17 to $1.69 \mathrm{lb}$. per $1000 \mathrm{lb}$. live weight. The data actually obtained from these cooperative experiments are of limited value, but the excellent plan of Armsby and the experience gained with it remain as very valuable guides for further studies.

While feeding trials have shown, as is to be expected from the nature of the tissue formed, that the protein needs decrease relative to energy needs as growth proceeds, few critical studies have been made of the differential quantitative requirements at different stages. Most of the experiments, especially those with cattle and sheep, have compared different percentages of the total ration or different intakes per unit of live weight for the growth period as a whole. Thus, whatever level is selected as adequate on one of these bases, it automatically specifies an increasing daily intake as weight and total feed consumption increases. This implies that the increasing maintenance needs must overbalance the decreasing needs for the formation of new tissue. The data calculated by Mitchell for cattle and.sheep, as illustrated in Sec. 286, challenge this view in the case of these species in that they indicate an actual decline in the daily requirement over the growth period. Even though not considered applicable to practice, feeding trials designed to establish the minimum levels of protein intake needed at different stages of the growth cycle would be helpful to clear up the marked discrepancy exhibited by the data from the two procedures of arriving at body needs.

In any experiment set up to study the protein requirement, provision cannot be made for keeping the biological value constant. Varying amounts of different sources of protein must be used, except where the purified-diet method is employed, and, even in the latter case, the values will vary with the level tested. This is not a serious limitation from the standpoint of arriving at reliable figures for practice, provided the feeds are properly selected. In the experiments previously cited, the shifts in the combinations of the ingredients were those that would normally be made in good feeding practice where a change in protein intake 
is desired. In the case of the studies with the pigs and chickens, the rations providing the minimum protein which gave the best results contained protein mixtures known to have good biological values for the species. The requirements suggested by these results should apply to the rations recommended to represent good feeding practice. They might prove inadequate for less efficient combinations.

288. Methods of Stating the Protein Allowance.-In the previously cited studies, the protein needs have been expressed in different ways. The allowance should be stated as digestible protein for those species for which digestibility data are available. Stating it as the pounds required per head per day for different body weights provided an exact basis for modifying the intake in accordance with the decreasing requirement per unit of body weight. Since the total food intake for growth is governed primarily by the energy needs, stating the protein needs in relation to the energy intake has certain advantages. The nutritive ratio provides a means of doing this where digestibility data are available. A similar relationship is provided in dietary standards for man by the statement that the intake of protein calories should be 10 to 15 per cent of the total calories, using the factors employed in calculating physiological fuel values (Sec. 229). Having specified the relation between encrgy and protein for a given age and selected the ration accordingly, the only intake figure needed is for the total food intake which will supply the energy needs. This same procedure applies where the protein allowance is stated as a percentage of the total ration, but the latter statement, though simple, is a less exact method because digestibility is not taken into account. It is most suitable for stating the requirements of those species, such as pigs and rhickens, which are normally fed rations of rather high digestibility and thus not susceptible to wide variations in this respect. In contrast, the method is not applicable in the case of the Herbivora, because of the large differences in digestibility of the feeds which may make up their rations. The method loses its simplicity, anyway, when two or more components of the ration, such as grain, hay, and silage, are fed separately.

289. Wool Production. - Since the wool fiber is practically pure protein, a substantial amount of food protein is required for its production. Thus the protein requirements for sheep are 
somewhat higher than for cattle at the same stage of maturity. A deficiency of this nutrient or of energy results in a lighter fleece of poorer quality. The fact that wool is especially rich in cystine early stimulated studies to ascertain whether commonly fed rations could be improved by the addition of this amino acid, with generally negative results. Such results are no longer surprising in view of the finding that cystine is not an essential amino acid for any species thus far studied, and in view of the synthetic activity in the rumen. On the other hand, studies with rats have shown that with a diet deficient in the sulfur-containing amino acids, the addition of methionine produces more hair and hair richer in cystine.

\section{CALCIUM, PHOSPHORUS, AND VITAMIN D}

The general functions of the mineral elements and vitamins required by the body have been discussed in Chaps. VII and VIII. As a result of many studies, fairly reliable data for several species are available on their quantitative requirements for growth of those which particularly need attention to insure that the ration selected will contain an adequate supply. The calcium, phosphorus, and vitamin $\mathrm{D}$ needs for growth have been extensively studied in farm animals, not only because of their individual importance but also because of their interrelations in metabolism. They are best discussed together.

Vitamin D is essential for the growth of all species of higher animals in so far as studied, but there are marked species differences as regards quantitative needs. There are also species differences with respect to the requirements for calcium and phosphorus, depending upon the rate of growth and other factors. In every case the interrelations between the three nutrients are such that a minimum requirement for a given one cannot be specified except in terms of rather definite amounts of the other two also. Failure to recognize this fact in many of the experiments, designed to determine requirements, limits the usefulness of the data obtained. Since the intakes in diets consisting of natural feeds cannot, at best, be adjusted exactly to the optimum relations which make possible a minimum requirement, recommendations in practice must specify more liberal allowances accordingly. 
By far the principal needs for calcium, phosphorus, and vitamin $\mathrm{D}$ during growth are for the formation of the skeleton, and thus they may be termed the bone-forming nutrients. Phosphorus plays an important role also in the growth of the soft tissues, as is evident from its occurrence in important amounts elsewhere in the body than in the bones (Sec. 108). In addition, this element exerts an indirect effect on growth because of its relation to appetite. To a lesser extent this is true also for calcium and vitamin $\mathrm{D}$.

290. Measures of Skeletal Growth.--The development of the skeleton cannot be measured by increase in weight, nor can its adequacy be determined by dimensional measures of the body or even of the bones themselves. Size of bone is governed largely by inheritance and a large bone may be a very weak one if the nutrition has not been adequate. Severe nutritive deficiencies during growth manifest themselves in misshapen bones as in severe rickets, but mild deficiencies may have serious consequences without any evident early symptoms. There may be later deformities or fractures or a breakdown of the teeth, as a result of prolonged periods of mild deficiency. Even though these evident symptoms never occur, the bone development may still be inadequate, particularly as regards its content of calcium and phosphorus reserves which are normally called upon during reproduction and especially during lactation (Sec. 353).

The real measure of the adequacy of skeletal development is the density and strength of the bones formed as conditioned by their content of calcium and phosphorus and their histological structure. Thus the requirements for the bone-forming nutrients can be determined by slaughter experiments in which representative bones are analyzed for calcium and phosphorus or studied histologically. The measurement of density and hardness and the determination of breaking strength are useful supplementary measures. Since the ash of bone consists almost entirely of calcium and phosphorus and since this remains true no matter what the quality of the bones, the determination of the ash is more commonly used as the measure of the adequacy of bone nutrition than the more time-consuming analyses for calcium and phosphorus. The progress of bone development ean be followed quantitatively in the living animal by calcium and phosphorus balances. Useful supplementary measures of the state 
of the nutrition of both elements are their levels in the blood, blood phosphatase, and X-ray photographs.

291. Optimum Bone Development.-In the discussion of bone growth in Chap VII, it was pointed out that calcium and phosphorus are deposited in the bone as reserve material as well as constituents of the structural portion itself. Presumably the building of the latter has first call on the bone-forming nutrients, but where the intakes are large enough deposition in the trabeculae doubtless occurs also. In the case of animals grown for slaughter, the state of the reserves would seem to be of minor importance, but other considerations enter for those being reared for breeding and milk production.

In an interesting study of skeletal development in the rat, Outhouse and Mendel ${ }^{1}$ found that an increased rate of body growth, caused by a diet richer in various nutritive factors including calcium, was accompanied by an increased rate of calcification compared to that in the slower growing animals. When the latter reached the same mature body weight, however, there were no differences between the two groups as regards the ash content of the bones. Thus it is suggested that, if bone development keeps pace with body growth, the end result is satisfactory, even though the rate of calcification is not at its maximum. Such is not the case if the calcification lags markedly behind body growth. Sherman and Booher ${ }^{2}$ have reported that as diets containing increasing levels of calcium are employed, not only is maturity reached earlier, but an increased storage of calcium per unit of body weight also results. They consider that the diet which causes the maximum rate of retention should be considered optimum until the normal store at maturity, including reserves, is attained. There are special reasons for believing that this is true in the case of animals which are to become milking cows, and in fact for all breeding females, because of the desirability of providing them with liberal reserves before they are subjected to gestation and lactation. This must be accomplished by a ration which will cause a rapid rate of calcification throughout

1 Outhouse, Julia, and Lafayette B. Mendel, The rate of growth. I. Its influence on the skeletal development of the albino rat, J. Exptl. Zool., 64, 257-285, 1933.

${ }^{2}$ Sherman, H. C. and L. E. Booher, The calcium content of the body in relation to that of the food, J. Biol. Chem., 93, 93-103, 1931. 
the growth period, or else the time of breeding must be delayed accordingly.

While, within rather wide limits, increasing the bone-building nutrients in the ration results in an increased storage in the bones, the percentage retention falls off markedly at the higher intake levels. This suggests that, as the limit of the capacity for the deposition of reserves is approached, the process becomes increasingly less efficient. If a maximum rate of calcification is considered to be optimum, a high intake in proportion to the amount stored must be supplied. There is no present reason to believe that calcification can be overdone during growth, except by massive doses of vitamin D (Sec. 168), nor is there evidence that excretory or other functions are unduly burdened by the ingestion of amounts of calcium and phosphorus which are large compared to the amounts stored.

292. Calcium and Phosphorus Requirements Measured by Balance Studies.-The generally recommended intakes of calcium and phosphorus for children are based upon balance studies by Sherman and Hawley, ${ }^{1}$ involving periodic determinations on 21 individuals varying in age from three to thirteen years. The amounts of calcium stored were markedly greater when $1000 \mathrm{~g}$. of milk were fed daily than when the intake was $750 \mathrm{~g}$., from which it was concluded that children should receive an average daily intake of at least a gram of calcium to provide maximum storage. These results provided the basis of Sherman's recommendation that the child should receive a quart of milk a day to insure optimum intakes of the bone-forming minerals. His experiments were made before the importance of vitamin D was understood, but he has later pointed out that the children under study were in the sunshine much of the time before and during the experiments and thus that the vitamin was actually supplied.

Archibald and Bennett ${ }^{2}$ have used the balance method in studying the phosphorus requirements of dairy heifers. Some of their data, representing summarized values for the trials noted, are presented in Table XXVIII.

It is noted that the amounts of phosphorus retained were larger

1 Sherman, H. C., and Entru Hawary, Calcium and phosphorus metabolism in (hildhood, J. Biol. Chem., 53, 375-399, 1922.

${ }^{2}$ Ancmizald), J. G., and E. Bunnwit, The phosphorus requirements of dairy heifers, J. Agr. Rescurch, 51, 83-96, 1935. 
for the high-phosphorus ration for each group. The difference is nearly 40 per cent for the calves, a large figure which was shown statistically to be clearly significant. It is thus demonstrated that calves under 1 year of age require considerably more than $1.8 \mathrm{~g}$. of phosphorus daily per $100 \mathrm{lb}$. live weight. Whether the intake should be as high as $3.25 \mathrm{~g}$. or even higher cannot be stated without further comparisons. While not statistically significant, the differences shown by the amounts retained as yearlings and

Table XXVIII.-Phosphorus Balances with Dairy Heifers

\begin{tabular}{|c|c|c|c|}
\hline Ration and period & $\begin{array}{l}\text { Daily } P \\
\text { intake per } \\
100 \text { lb. live } \\
\text { weight, g. }\end{array}$ & $\begin{array}{l}\text { Daily P re- } \\
\text { tained per } \\
100 \mathrm{lb} \text {. live } \\
\text { weight, g. }\end{array}$ & $\begin{array}{c}\text { Percentage } \\
\text { of intake } \\
\text { retained, } \\
\%\end{array}$ \\
\hline $\begin{array}{l}\text { High-phosphorus ration: } \\
\text { As calves, } 16 \text { trials. . . . . . . . } \\
\text { As yearlings, } 21 \text { trials. . . . . } \\
\text { As } 2 \text {-year-olds, } 5 \text { trials. . . . . }\end{array}$ & $\begin{array}{l}3.25 \\
2.49 \\
2.49\end{array}$ & $\begin{array}{l}1.01 \\
0.61 \\
0.37\end{array}$ & $\begin{array}{l}31.08 \\
24.50 \\
14.86\end{array}$ \\
\hline $\begin{array}{l}\text { Average (weighted)........ } \\
\text { Low-phosphorus ration: } \\
\text { As calves, } 17 \text { trials ......... } \\
\text { As yearlings, } 13 \text { trials....... } \\
\text { As } 2 \text {-year-olds, } 5 \text { trials....... }\end{array}$ & $\begin{array}{l}2.73 \\
1.80 \\
1.68 \\
1.18\end{array}$ & $\begin{array}{l}0.73 \\
0.73 \\
0.54 \\
0.32\end{array}$ & $\begin{array}{l}40.56 \\
32.14 \\
27.12\end{array}$ \\
\hline Average (weighted)........ & 1.67 & 0.60 & 35.93 \\
\hline
\end{tabular}

two-year-olds suggest that the intakes on the low-phosphorus ration were inadequate for maximum retention for these ages also. The data for percentage retained reveal the expected lower efficiency of utilization which occurs with higher intakes even though the total retention is greater. In the one case where the intakes were identical (high-phosphorus group, yearlings and two-year-olds) the declining rate of retention with age is revealed.

293. Calcium and Phosphorus Requirements from Growth and Bone Data.-Aubel, Hughes, and Lienhardt ${ }^{1}$ have compared rations containing various levels of phosphorus for pigs receiving ample D, using growth, blood, and bone analyses and breaking strength as measures. They have concluded that the level should

${ }^{1}$ Aubel, C. E., J. S. Hughes, and H. F. Lienhardt, Phosphorus requirements in the rations of growing pigs, Kans. Agr. Expt. Sta. Tech. Bull. 41, 1936. 
be between 0.27 and 0.3 per cent of the total food intake for the growth period as a whole. This percentage level corresponds to a daily intake of $6.5 \mathrm{~g}$. per $100 \mathrm{lb}$. live weight for 50-lb. pigs and 4 g. per $100 \mathrm{lb}$. for 200-lb. pigs. The data obtained for bone composition are illustrated by the following figures from one period of their first experiment:

\begin{tabular}{|c|c|c|c|}
\hline Constituent & $\begin{array}{c}\text { Lot } \\
\text { I }\end{array}$ & $\begin{array}{l}\text { Lot } \\
\text { II }\end{array}$ & $\begin{array}{l}\text { Lot } \\
\text { III }\end{array}$ \\
\hline Calcium in feed, per cent.... & 0.77 & 0.78 & 0.77 \\
\hline Phosphorus in feed, per cent........ & 0.18 & 0.33 & 0.59 \\
\hline Ash in femur and humerus, per cent...... & 48.14 & 57.35 & 59.64 \\
\hline Calcium in femur and humerus, per cent....... & 18.35 & 21.93 & 22.70 \\
\hline Phosphorus in femur and humerus, per cent.... & 8.69 & 10.58 & 10.82 \\
\hline
\end{tabular}

It is noted that the calcium was held constant in all lots at a level which was certainly adequate, while the phosphorus was varied. Such a scheme unavoidably involves a variation in the ratio between the two elements. The ratio of 4.4:1 existing for the ration fed Lot I may have been in part responsible for the poorer bone development, but the ample amount of vitamin $\mathrm{D}$ supplied in each ration would tend to overcome any such effect. The data for ash, calcium, and phosphorus clearly reveal the superiority of the intermediate level over the lower one. While the data for the highest level are still better, the differences are small. For the experiment as a whole, the bone analyses and other measures employed failed to show significant differences in favor of the highest phosphorus level.

Aubel, Hughes, and Peterson ${ }^{1}$ have reported a similarly conducted study of the calcium requirements of pigs. They found a level of 0.25 per cent in the ration was insufficient but that a level of 0.41 per cent was definitely adequate.

294. Calcium and Phosphorus Requirements as Measured by Blood Data.--Inadequate bone nutrition is reflected in a lowering of the blood level of ealeium or phosphorus or both. The blood picture varies according to the specific deficiency concerned and also according to the species. A rapid rate of body growth which is accompanied by normal levels of calcium and phosphorus in the

' Auber, C. F., J.S. Hugmes, and W. J. Pertison, Calcium requirements of growing pigs, J. Agr. Research, 62, 531-542, 1941. 
blood is highly indicative of adequate skeletal development, and these measures are frequently employed to determine the actual requirements for the minerals.

Huffman and associates ${ }^{1}$ have used this procedure for studying the phosphorus requirements of dairy cows, resulting in the following conclusions as regards growth requirements. A ration containing 0.2 per cent of phosphorus caused a lowering of the blood phosphorus of calves, which persisted up to eighteen months of age. Intakes of 5.7 to $9.9 \mathrm{~g}$. of phosphorus per day were inadequate where the calcium-phosphorus ratio was $4: 1$ or wider. An intake of $10.3 \mathrm{~g}$. daily sufficed from three to six months of age. Ten to $12 \mathrm{~g}$. daily were adequate from eighteen months to first calving. Similar studies by these Michigan workers have led to the conclusion that an intake of 6 to $12 \mathrm{~g}$. of calcium daily from birth to two years of age is sufficient for the growth of calves.

Beeson and associates ${ }^{2}$ compared different levels of phosphorus intake for fattening lambs in terms of growth, efficiency of feed utilization, and blood phosphorus level. They concluded that the need should be set at $2.40 \mathrm{~g}$. per $100 \mathrm{lb}$. of live weight and that the ration, on a dry basis, should contain 0.17 per cent or more of the element.

\section{Estimation of Calcium and Phosphorus Requirements} from Metabolism and Slaughter Data.-Using a procedure similar to that detailed for energy and protein in Secs. 276 and 286, Mitchell has estimated the calcium and phosphorus requirements on the basis of calculated maintenance values, storage during growth as shown by carcass analyses, and percentage retention data. The detailed procedures are set forth in a publication of the National Research Council. ${ }^{3}$ As was noted in the case of Mitchell's data for protein, this procedure results in relatively higher estimated requirements early in growth and relatively lower ones later than those reported from studies using other methods. These other studies, however, actually provide few data applying

${ }^{1}$ Huffman, C. F., and associates, Phosphorus requirement of dairy cattle when alfalfa furnishes the principal source of protein, Mich. Agr. Expt. Sta. Tech. Bull. 134, 1933.

${ }^{2}$ Beeson, W. M., and associates, The phosphorus requirement for fattening lambs, J. Animal Sci., 3, 63-70, 1944.

${ }^{3}$ Mitchell, H. H., and F. J. McClure, Mineral nutrition of farm animals, Natl. Research Council Bull. 99, 1937. 
to specific stages of the growth cycle. It is clearly evident that further experiments are here needed.

\section{Calcium and Phosphorus Requirements as a Percentage} of the Total Ration.-The number of experiments which have dealt with the question of the calcium and phosphorus requirements for growth of the different species by one or another of the methods previously described are large indeed. But the data as a whole are incomplete and in many cases so variable that it is very hazardous to draw conclusions from them as to what the actual requirements are for a given species over its entire growth period. It is agreed that the requirements decrease with age per unit of body weight and also per unit of dry-matter intake. The calcium requirements markedly exceed those for phosphorus at the start, but the difference here becomes much less as maturity is approached.

Allowances for practice may be conveniently expressed as percentages of the dry matter of the ration, from which the intakes per day can be calculated by a consideration of the amounts of dry matter fed at different ages.

The following figures are proposed as intakes which should be adequate, based on a study of what appear to be the more reliable of the many experiments conducted. The figures are given as a range, the highest representing the requirement at weaning (or hatching) and the lowest the value to which the percentage may gradually fall during the course of growth. The average for a given range would not be optimum for the first part of growth, but continuing the maximum intake proposed throughout the growth period is clearly unnecessary.

\begin{tabular}{|c|c|c|}
\hline Species & $\begin{array}{l}\text { Calcium in } \\
\text { dry matter, } \\
\text { per cent }\end{array}$ & $\begin{array}{l}\text { Phosphorus in } \\
\text { dry matter, } \\
\text { per cent }\end{array}$ \\
\hline Chicken..... & 1.0 to 0.50 & 0.60 to 0.40 \\
\hline Pig..... & 0.60 to 0.30 & 0.40 to 0.25 \\
\hline Calf.... & 0.40 to 0.20 & 0.35 to 0.20 \\
\hline Tamb. . . & 0.25 to 0.20 & 0.20 to 0.18 \\
\hline
\end{tabular}

These datat assume that vitamin I) is supplied in aceordanee with the needs of the species in question. It should be remembered that the figures would be approximately 10 per cont higher on the 
basis of the air-dry ration. There is little information available for colts, but their requirements are evidently closer to those of lambs than of cattle.

297. The Requirements for Vitamin D.-The growth requirements for this vitamin are measured by bone studies involving either periodic $\mathrm{X}$ rays in the living animal, or slaughter and bone analysis and measurement, or both. Blood phosphorus, calcium,

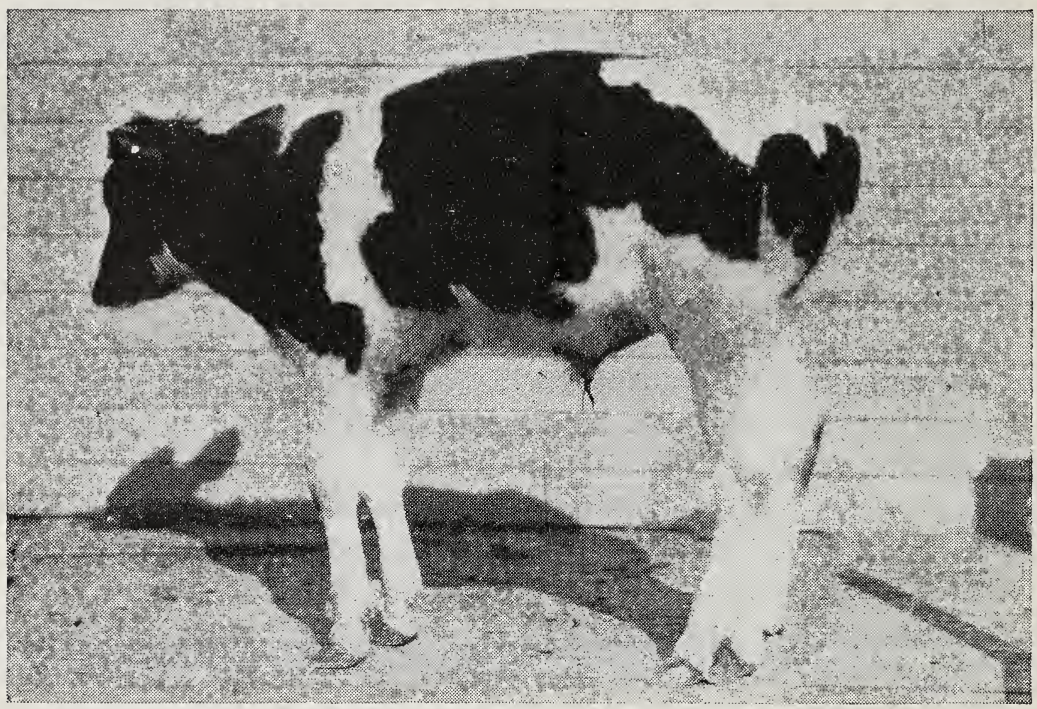

FIG. 34.- Severe rickets produced on a ration lacking in vitamin D. Note humped back, enlarged joints, and buckling of front legs. (Courtesy of S. I. Bechdel, Pennsylvania State College.)

and phosphatase are useful supplementary measures. The full metabolic requirements can be determined only where the sunlight factor is excluded. In translating the results into practice, however, the actual dietary requirements become very low or nil for animals sufficiently exposed to sunlight.

Bechdel and associates ${ }^{1}$ have reported a comprehensive study with dairy calves which well illustrates the experimental procedure required. Using a basal ration adequate in other nutrients but selected to be as low as possible in vitamin D, different groups of calves received different levels of the vitamin, as irradiated yeast

${ }^{1}$ Bechdel, S. I., and associates, The vitamin D requirement of dairy calves, Pa. Agr. Expt. Sta. Bull. 364, 1938. 
or cod-liver-oil concentrate, after the first month until they were six months of age or older. From birth they were kept out of direct sunlight (first experiment) or in the dark (second experiment). The observations included growth rate, physical condition, periodic $\mathrm{X}$ rays and blood studies, and chemical analysis and line-test studies of the bones on slaughter. On the basis of their results the investigators concluded that the minimum requirement of the vitamin is approximately 300 U.S.P. units per day per $100 \mathrm{lb}$. live weight. Since the experimental calves grew slowly, it remains uncertain whether this level is adequate for rapid growth.

On the basis of limited evidence the requirements of lambs and beef calves are considered to be of the same order as found by the Pennsylvania workers for dairy calves. The needs of pigs are markedly less, but those of chicks markedly greater. Exact data are available for the latter, based on several carefully controlled studies. The N.R.C. recommended allowance is 180 A.O.A.C. units per pound of feed. The allowance for turkey poults is set at double this figure.

298. Meeting the Requirements for Bone-forming Nutrients in Practice.-Nursing young never suffer from a deficiency of calcium or phosphorus and neither does the dairy calf reared on a liberal supply of skim milk. Herbivorous animals will receive ample calcium if their roughage is one-half or more legume hay, but where grass hay is the sole roughage and particularly where it is not consumed liberally, a calcium supplement should be included unless the hay is known to contain 0.5 per cent or more of this element. No concentrate mixture is rich in calcium, but a liberally fed mixture which contains 25 per cent or more of some phosphorus-rich feed, such as wheat bran or one of the oil meals, will take care of the needs for the latter element, unless the roughage is unusually low in it. Roughage alone will not suffice. Under some conditions of practice, it is more economical to make up the deficiency in the roughage and cereal-grain ration by adding bone meal rather than a high-phosphorus concentrate, as has been shown by the experiments of Maynard and associates. ${ }^{1}$

Whether or not herbivorous animals on pasture will receive enough bone-forming minerals depends upon the nature of the

${ }^{1}$ Maynard, E. J., J. E. Greaves, and H. Н. Sмith, Phosphorus supplements improve sugar-beet by-product rations for cattle, Utah Agr. Expt. Sta. Bull. 265, 1936. 
soil and the resulting calcium and phosphorus content of the forage. In the absence of specific information in these respects, giving the grazing animals access to bone meal is a desirable procedure. These various provisions for insuring adequate minerals in the rations of Herbivora require more attention in the case of calves than in the case of lambs and colts, because of the lower requirements of the latter. For a given species, the provisions demand less attention with advancing age because of the decreasing requirements.

If pigs are being fed corn or other cereal grain with the additional protein required furnished as tankage or fish meal, they will receive sufficient calcium and phosphorus. Where a vegetableprotein concentrate is used instead, additional calcium is required, and it can be supplied as a mineral supplement. Where a milk by-product is the protein concentrate, it must be liberally fed to meet the calcium requirements.

Animals which are outdoors in summer will always receive plenty of vitamin $\mathrm{D}$, but, in winter, the sunlight is an uncertain source in the northern latitudes even though the weather allows the animals to be outside much of the time, because of the generally less sunlight and its lower efficiency (Sec. 167). Whole milk cannot be relied upon to supply the vitamin D requirements of the calf and skim milk is certainly deficient. It takes only a small amount of sunlight to be effective, however. Johnson and Palmer ${ }^{1}$ report, for example, that rickets was cured in pigs exposed to January sunshine in Minnesota for an average of $45 \mathrm{~min}$. per pig per day for two weeks.

A real problem occurs with the dairy calf during the early weeks of life, the time when bone formation is normally most rapid because the calf is usually kept inside and is eating little or no roughage. A vitamin D supplement is called for at this time. Later, with good roughage, it is not needed. As little as $1 \mathrm{lb}$. a day of good-quality sun-cured legume hay will supply the needs of the young calf. Similarly, 5 to 10 per cent of such hay in the ration of growing pigs will take care of their needs when sunlight is not available.

In general, it is preferable feeding practice to supply the mineral

1 Johnson, D. W., and L. S. Palmer, Meeting the vitamin D requirement of pigs with alfalfa hay and winter sunshine, $J$. Agr. Research, 63, 639-648, 1941. 
and vitamin needs of farm animals, in so far as possible, by an appropriate selection of the natural feeds rather than by resorting to special supplements.

\section{OTHER MINERALS}

299. Iron.-There are no quantitative data as to the iron requirements for the growth of farm animals, but several studies with children indicate than an intake of approximately $0.4 \mathrm{mg}$. per kilogram is adequate when a highly available source is employed (Sec. 127). An intake of this magnitude and more is supplied by the usual rations of farm animals, and there appears to be no practical problem as regards their iron requirements except in very special situations. The trace of copper that is needed for iron assimilation is also abundantly supplied by the commonly fed rations.

While a deficiency of iron in the soil and thus in the herbage has been reported from two or three areas in the world, the only common case of iron deficiency is that represented by the anemia which frequently occurs in suckling pigs. Owing to the labored breathing which is always characteristic of severe cases, this trouble was known as thumps long before it was discovered to be due to a lack of sufficient iron for blood formation. The trouble is most frequent in litters farrowed in late fall or early spring and kept inside without access to soil or forage. Anemic pigs are listless and flabby, their skin becomes wrinkled and their coats have an unhealthy appearance. As the disease progresses, the skin and mucous membranes beeome pale, and the animals become thin and weak. In advanced stages, the breathing is labored, and the pigs may have a swollen appearance, especially around the head and shoulders. This anemia can be prevented, or cured in its early stages by drenching the sucklings with a saturated solution of ferrous sulfate or other soluble iron salt. The weekly dosage is $1 / 3$ teaspoonful for pigs under one week of age, up to 1 teaspoonful at four weeks. As an alternative procedure the iron solution can be swabbed daily on the udder of the sow. Whichever method is employed the commercial iron salt used will contain enough copper as an impurity to meet the need for this element.

This nutritional anemia in pigs and the recognized defieiency of iron and copper in the milk of all species have led to the suggestion 
that all mammals should have supplements of these minerals during the suckling period. Such is not the case. While this anemia has been produced experimentally in calves and lambs, it does not occur in practice because these species begin to supplement their milk diet with other foods relatively earlier than does the pig. The store of iron with which they are born suffices until their needs are met adequately by grain and hay.

300. Other Minerals. - While it is recognized as desirable to add salt to the rations of all farm animals, very little information is available as to the exact requirements for its component minerals. South African workers have concluded that for growing cattle the daily requirements are only $1.5 \mathrm{~g}$. of sodium and $5 \mathrm{~g}$. of chlorine. The practice of allowing salt ad libitum to farm stock undoubtedly results in an intake in excess of requirements. There is no harm in this ordinarily, but certain species may be injured by overeating when salt is offered ad libitum after a long period of deprivation. Since salt increases the palatability of rations an intake in excess of the minimum physiological requirements is desirable from this standpoint. When it is fed free choice, the nature of the ration is a large factor governing the intake, and this may be in part a response to a variation in physiological need according to the mineral and other relations in the ration fed.

There are practically no specific data as to the iodine requirements for the growth of farm animals. Previous discussion has indicated that there is little definite evidence that commonly fed rations will be benefited by an addition of this element (Sec. 135). The possibility has also been noted that additional iodine may be needed for growth, as well as for reproduction (Sec. 135), to supplement rations fed in goitrous areas. The experiments of Malan and associates ${ }^{1}$ showing that growing lambs may be harmed by low intakes of supplementary iodine have caused them to conclude that the use of such a supplement is to be discouraged unless a known deficiency exists. Other experiments testify to the correctness of this viewpoint.

Little, if anything, is known about the requirements of farm animals for the several other inorganic elements which are recog-

${ }^{1}$ Malan, A. I., P. J. DU ToIt, and J. W. Groenewald, Studies in mineral metabolism. XXXIII. Iodine in the nutrition of sheep, Onderstepoort $J$. Vet. Sci., 5, 189-200, 1935. 
nized as essential for growth on the basis of experiments with laboratory animals. A discussion of the limited information available has been given in Chap. VII, and presumptive evidence has been presented that commonly fed rations are seldom if ever deficient in them.

\section{VITAMIN A}

All higher animals, in so far as they have been studied, require vitamin $\mathrm{A}$ for growth, and there is a considerable amount of

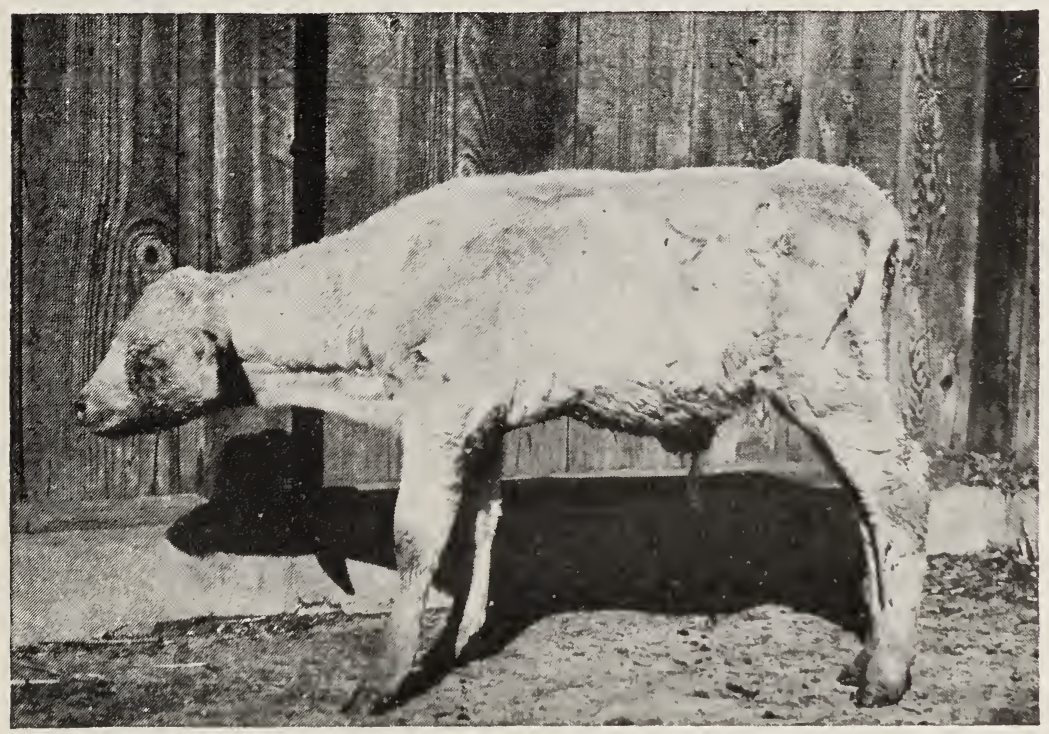

Fig. 35.-Three-month-old steer in moribund condition from vitamin-A deficiency. (Courtesy of G. H. Hart, University of California.)

information as to their quantitative requirements. In addition to the failure of growth there are various other characteristic deficiency symptoms which differ somewhat with the species (Sec. 156).

301. Vitamin Requirement of Different Species.-The need of vitamin $\Lambda$ by calves was first shown by Jones, Eckles, and Palmer in 1926. Later studies have added greatly to the knowledge of the specific physiological effects and of the requirements. While the early studies by Cuilbert and Hart ${ }^{1}$ showed that 1.5

1 Gumber'T, H. R., and (A. H. HaR'T, Minimum vitamin A requirements with particular reference to cattle, $J$. Nutrition, 10, 409-427, 1935. 
mg. of carotene per $100 \mathrm{lb}$. body weight was sufficient to prevent night blindness in calves, their later studies and those of others indicated that much higher intakes were needed to insure maximum growth, some storage of the vitamin, and normal reproduction. On the basis of these various studies the N.R.C. allowance for the growth of calves has been set at $6 \mathrm{mg}$. per $100 \mathrm{lb}$. body weight. Guilbert, Howell, and Hart ${ }^{1}$ obtained evidence that the requirements of sheep, swine, and horses were similar to those of cattle per unit of body weight. Thus the recommended allowance of carotene for lambs has been set at the same figure as for calves. It seems best to express their needs as carotene since this is the form in which the vitamin is present in their feed supply. Lewis and Wilson ${ }^{2}$ have reported that a much higher intake than that recommended above is required to provide a maximum concentration in the blood and substantial liver storage.

The N.R.C. recommended allowance of vitamin A for the growth of pigs is $2600 \mathrm{I}$.U. per $100 \mathrm{lb}$. body weight. The level for chickens has been set at over twice this figure.

A comparison of the preceding recommended allowance for calves and lambs with the data for the carotene content of roughages in Table XIII makes it clear that their needs can readily be met even from hay of rather poor quality if readily consumed. As little as $1 / 2 \mathrm{lb}$. of bright green, leafy legume hay will supply the allowance for a 300-lb. calf. Nursing lambs and calves will get plenty from milk if their mothers are being properly fed. The dairy calf that is transferred soon after birth to skim milk or a special concentrate mixture ("calf starter") presents a special problem. The newborn calf has only a small store of the vitamin at birth. Here it is greatly benefited by receiving the colostrum, which is especially rich in the vitamin unless the cow has been on a ration low in it for a considerable time. It seems probable that calves that are transferred from whole milk soon after birth and are slow in starting to eat hay or receive hay of poor quality would be benefited by supplementary vitamin A during these early weeks of life. It has been claimed that such supplementary

${ }^{1}$ Guilbert, H. R., C. E. Howell, and G. H. Hart, Minimum vitamin A and carotene requirements of mammalian species, $J$. Nutrition, 19, 91-103, 1940.

${ }^{2}$ Lewis, J. M., and Logan T. Wilson, Vitamin A requirements in calves, J. Nutrition, 30, 467-475, 1945. 
feeding will markedly lower the incidence of scours, but the evidence here is not clear. Experiments have shown that feeding large amounts of the vitamin will by no means eliminate this trouble nor cure cases which have developed.

Concentrate mixtures supply very little vitamin $A$, with the exception that yellow corn can provide a substantial amount if its activity has not been depleted in storage. The needs of pigs can be met readily, however, by including 5 to 10 per cent of green, leafy alfalfa hay, a provision which will take care of vitamin D needs also. Fresh, leafy forage crops supply the factor in abundance.

\section{VITAMIN B GROUP}

The information presented in Chap. VIII has indicated that, at least so far as we know at present, cows and sheep have no dietary needs for the vitamins of the B group because of rumen synthesis. Thus the following discussion is limited primarily to pigs and poultry.

302. Thiamine.-The need for thiamine is most exactly expressed as a function of food intake because of its role in energy metabolism. On this basis the requirements of all species are similar--roughly $1 \mu \mathrm{g}$. per gram of feed, as a minimum value. The N.R.C. allowance for chickens is stated to be $0.9 \mathrm{mg}$. per pound of feed. U.S. Department of Agriculture workers have found that an intake of approximately 0.45 to $0.55 \mathrm{mg}$. per pound of feed is adequate for maximum growth and the maintenance of health in pigs. The N.R.C. allowance for pigs is set at $2.5 \mathrm{mg}$. per $100 \mathrm{lb}$. body weight, a level designed to be somewhat higher than experimentally determined values and corresponding rather closely with the allowance for poultry.

Thiamine deficiency is not encountered in either pigs or chickens in practice because their customary rations contain large proportions of whole grains and milling by-products rich in the vitamin.

303. Riboflavin.-The riboflavin needs of chicks have been extensively studied because their rations commonly require special supplements, particularly during the early weeks. The N.R.C. allowance is set at $1.6 \mathrm{mg}$. per pound of feed during the first eight weeks and at $0.9 \mathrm{mg}$. thereafter during growth. The needs are higher for turkey poults. Less specific information is available 
for pigs. Studies by Hughes placed the minimum requirement between 1 and $3 \mathrm{mg}$. per $100 \mathrm{lb}$. live weight. The N.R.C. allowance is $3.8 \mathrm{mg}$. Whether special attention needs to be given to riboflavin in selecting rations for pigs has not been established. Dairy by-products are excellent sources. So also is alfalfa meal.

304. Nicotinic Acid.- Using a purified diet, Hughes ${ }^{1}$ found that the minimum amount of nicotinic acid needed for normal growth and to prevent the onset of physical symptoms in pigs was between 5 and $10 \mathrm{mg}$. per $100 \mathrm{lb}$. live weight daily. The N.R.C. recommended allowance ranges from $7 \mathrm{mg}$. for a $60-\mathrm{lb}$. pig to $21 \mathrm{mg}$. at $250 \mathrm{lb}$. The allowance for chicks is set at $8 \mathrm{mg}$. per pound of feed. So far as is known at present, the nicotinic acid needs of pigs and poultry can be readily met by commonly fed rations without resort to special sources.

It has been reported that nicotinic acid is needed in the diet of the newborn calf since the rumen is undeveloped at birth, and that the supplementary feeding of the vitamin at this time will help prevent scours. The latter observation has not been confirmed. It seems a reasonable assumption that any needs for the B-vitamins in the very young calf must be met from sources other than rumen synthesis. But there is no evidence at present to indicate that any special supplements to the usual diet are called for to meet any needs that may exist.

305. Other B-Factors.-Various experiments, some of which are cited at the close of this chapter, have produced data as to the quantitative needs for other B-factors by the pig and chick. The recommended allowances, as set forth by the National Research Council, are as follows:

\begin{tabular}{|c|c|c|}
\hline & $\begin{array}{l}\text { Starting chicks, } \\
\text { per pound } \\
\text { feed }\end{array}$ & $\begin{array}{l}\text { Pigs, } \\
\text { per } 100 \mathrm{lb} . \\
\text { live weight }\end{array}$ \\
\hline $\begin{array}{l}\text { Pantothenic acid, mg. } \ldots \ldots \ldots \\
\text { Pyridoxine, mg. } . \ldots \ldots \ldots \ldots \\
\text { Biotin, mg. } \ldots \ldots \ldots \ldots \ldots \\
\text { Choline, g. } \ldots \ldots \ldots \ldots \ldots \\
\text {. } \ldots \ldots \ldots\end{array}$ & $\begin{array}{l}5.0 \\
1.6 \\
0.045 \\
0.7\end{array}$ & $\begin{array}{l}18.5^{*} \\
3.0^{*} \\
\ldots \\
\cdots\end{array}$ \\
\hline
\end{tabular}

* No figures given for higher weights.

${ }^{1}$ Hughes, E. H., The minimum requirement of nicotinic acid for the growing pig, J. Animal Sci., 2, 23-26, 1943. 
Deficiencies resulting from these vitamins have not been definitely identified in growing chicks or pigs in practice. The usual feed supplies are rich in terms of recognized needs.

It is to be expected that further research will modify and extend present knowledge regarding the quantitative needs of animals for the various vitamins, particularly the more recently discovered factors. Current publications should be followed accordingly.

\section{Selected Literature}

Aron, H.: Nutrition and growth, Philippine J. Sci., ser. B, 6, 1-52, 1911.

BLACK, W. H., and associates: Effects of phosphorus supplements on cattle grazing on range deficient in this mineral, U.S. Dept. Agr. Tech. Bull.856, 1943.

Boyer, P. D., and associates: Vitamin A and carotene requirements for the maintenance of adequate blood plasma vitamin A in the dairy calf, $J$. Dairy Sci., 25, 433-440, 1942.

Duncan, C. W., and C. F. Huffman: Vitamin D studies in cattle. III. Influence of solar ultraviolet radiation upon the blood chemistry and mineral metabolism of dairy calves, J. Dairy Sci., 19, 291-303, 1936.

Ellis, N. R., and L. L. Madsen: The thiamine requirement of pigs as related to the fat content of the diet, J. Nutrition, 27, 253-262, 1914.

Gullickson, T. W., and J. B. Fiтch: Effect of adding cod liver oil to the rations of dairy calves, J. Dairy Sci., 27, 331-335, 1914.

Halpin, J. G., C. E. Holmes, and E. B. Hart: Salt requirements of poultry, Poultry Sci., 14, 99-103, 1936.

Hammond, John, and A. B. Appleton: Growth and development of mutton qualities in sheep, Oliver and Boyd, Edinburgh, 1932.

Harris, Lorin E., and associates: The calcium requirement of growing foxes, Cornell Vet., 35, 9-22, 1945.

Herman, H. A.: Growth and development of dairy calves on a milk diet, Mo. Agr. Expt. Sta. Research Bull., 245, 1936.

Hogan, A. G.: Retarded growth and mature size of beef steers, Mo. Agr. Expt. Sta. Research Bull. 123, 1929.

Hughes, E. H.: The minimum requirement of riboflavin for the growing pig, J. Nutrition, 20, 233-238, 1940.

JACKson, C. M.: Recovery in rats upon refeeding after prolonged suppression of growth by dietary deficiency of protein, Am. J. Anat., 58, 179-191, 1936.

Kempster, H. I., and Jesse E. PArker: The normal growth of chickens under normal conditions, Mo. Agr. Expt. Sta. Research Bull. 247, 1936.

Lusi, JAY L., J. M. Jones, W. H. DAmeron, and O. I. CArpenter: Normal growth of range cattle, Texas Agr. Expt. Sta. Bull. 409, 1930.

McCAY, C. M., and associates: Retarded growth, life span, ultimate body size and age changes in the albino rat after feeding diets restricted in calories, J. Nutrition, 18, 1-13, 1939. 
Mrluer, J. I., and F. B. Morrison: The influence of feeding low-nitrogen rations on the reliability of biological values, J. Agr. Research, 65, 429$451,1942$.

- Effect of heat treatment and oil extraction on the utilization of and digestibility of soybean protein by lambs, J. Agr. Research, 68, 35-48, 1944.

Norris, L. C., L. J. Elmore, R. C. Ringrose, and Gardiner Bump: The protein requirements of ringnecked pheasant chicks, Poultry Sci., 15, 454-459, 1936.

Norton, C. L., and associates: Controlled experiments on the value of supplementary vitamins for young calves, J. Dairy Sci., 29, 231-238, 1946.

Palmer, L. S., and associates: The effect of rations deficient in phosphorus and protein on ovulation, estrous, and reproduction of dairy heifers, J. Dairy Sci., 24, 199-210, 1941.

Record, P. R., R. M. Betrke, and O. H. M. Wilder: The vitamin A requirements of chicks and observations on the comparative efficiency of carotene and vitamin A, Poultry Sci., 16, 25-33, 1937.

Reimers, J. H. W. T., and L. H. Bartel: The retention of protein by growing pigs, J. Agr. Sci., 25, 397-418, 1935.

Ritzman, E. G., and N. F. Colovos: Physiological requirements and utilization of protein and energy by growing dairy cattle, N.H.Agr. Expt. Sta. Tech. Bull. 80, 1943.

Robertson, Don D., and DaN D. Baker: Histological differences in the muscles of full, half and rough fed steers, Mo. Agr. Expt. Sta. Research Bull. 200, 1933.

Rupel, I. W., G. Bohstedt, and E. B. Hart: Vitamin D in the nutrition of the dairy calf, Wis. Agr. Expt. Sta. Research Bull. 115, 1933.

Savage, E. S., and C. M. McCAY: The nutrition of calves; a review, J. Dairy Sci., 25, 595-650, 1942.

Schultze, A. B., and C. W. Turner: The determination of the rate of thyroxine secretion by certain domestic animals, Mo. Agr. Expt. Sta. Research Bull. 392, 1945.

Sherman, H. C., H. L. Campbell, and C. S. Lanford: Experiments on the relation of nutrition to the composition of the body and the length of life, Proc. Natl. Acad. Sci., 25, 16-20, 1939.

SuINGer, S. J., and associates: The use of a hoof and horn meal to replace animal and vegetable protein in rations for growing chicks, Poultry Sci., 23, 431-436, 1944.

WEBER, A. D., and associates: Calcium in the nutrition of the fattening calf, Kans. Agr. Expt. Sta. Tech. Bull. 51, 1940.

Wilgus, H. S., Jr., and D. V. ZANDER: The quantity of animal protein required to supplement soybean-oil meal for growth, Poultry Sci., 24, 4145, 1945. 


\section{CHAPTER XIV REPRODUCTION}

While it has long been appreciated that regular and normal reproduction is the essential basis of a successful animal industry, including commercial milk production, it is only within comparatively recent years that the various aspects of this primary physiological function have received detailed study. With the recognition of infectious abortion as a major cause of reproductive troubles, concentration on the disease aspects was a natural development with the result that other phases were in part neglected. It is now appreciated, however, that the reproductive function is conditioned by a long series of distinct but interrelated physiological events in which the body as a whole, as well as the sex organs, is concerned and that important, though less obvious causes of failure, reside in abnormalities which are not the result of infectious disease. The economic importance of these less obvious causes has been stressed by Marshall and Hammond ${ }^{1}$ as follows:

Low fertility and sterility of a temporary nature, because of their prevalence, are the cause of much greater loss to the breeding industry than infertility of a more permanent kind which oecurs less frequently, although the latter, because of its striking effects, generally attracts most attention.

It is self-evident that nutrition must play at least a general role in the development and functioning of the organs of reproduction, but its significance is much larger than this. Recent discoveries have shown that specific nutrients have specific functions in the various events which comprise the reproductive cycle. To understand these functions some knowledge of the physiology of reproduction is required. This discussion which immediately follows deals with mammalian reproduction and its nutritive

1 Marshald, F. H. $\Lambda$., and John Hammond, Fertility and animal breeding, 6th ed., Ministry Agr. Fish. Bull. 39, 1945. 
requirements. At the close of this chapter the avian process is considered from the standpoint of the nutritive needs for egg production.

\section{PHYSIOLOGY OF REPRODUCTION}

The sexual organs reach their full development and become functional at an age which varies with the species, the breed, and the nutrition of the individual. The development of these organs is a rather gradual process controlled by a secretion from the pituitary, the gland which also secretes a substance controlling body growth (Sec. 270). Apparently the gland cannot provide both secretions at a maximum at the same time, and thus the development of the sex organs proceeds more rapidly as the rate of growth declines. These organs become functional before body growth is completed. If their ability to function is immediately utilized, there may be an unfavorable effect on body development because of an undue diversion of the secretions of the pituitary from body growth to sexual activity. The lactation which follows premature breeding is one of the chief causes of the arrest of growth in the female. If the male is subjected to heavy service too early his growth and vigor are likewise impaired. Herein lies an explanation of the deleterious effects on growth and development which are recognized to occur in practice from premature breeding.

306. Ovulation and Fertilization.-Sexual maturity in the male is characterized by the full development of the testicles and the production of viable sperm which become motile when mixed with the secretions of certain accessory organs. In the female the functional development of the ovary is followed by a recurring cycle of events, an early stage of which is characterized by the onset of heat, or estrus. The ovary contains a large number of minute eggs, each enclosed in a Graafian follicle. As the animal comes in heat one or more of these follicles enlarge, the egg is matured and liberated and then passes down the Fallopian tubes or oviducts to the uterus. It is during this passage that fertilization usually occurs provided the animal has been served during the heat period. With the shedding of the egg, the cavity of the Graafian follicle becomes filled with the corpus luteum or yellow body. While this yellow body is present no more follicles are ripened and thus no more eggs are matured. If fertilization has 
occurred, the corpus luteum normally persists during the ensuing pregnancy, and thus no new fertilization can take place until its termination. If pregnancy does not occur the corpus luteum usually degenerates after a brief period, allowing a new follicle to mature as the start of a new cycle. Sometimes the yellow body persists without pregnancy, which is one of the causes of delayed breeding.

The ovarian changes of the estrus period are accompanied by cyclic changes in the epithelial lining of the vagina. A study of these changes in the rat and guinea pig by the vaginal smear technique ${ }^{1}$ has proved very useful as an indicator of the regularity of estrus and of the ovarian processes involved, as influenced by various nutritional and other factors. Less well-defined cyclic, vaginal changes have been noted also in the cow, sow, and bitch. Little is known regarding them in the ewe and mare.

An excellent description of the rolc of hormones in reproduction has been given by Asdell and Smith. ${ }^{2}$ A more detailed technical presentation is to be found in the review by Hammond. ${ }^{3}$

307. Fetal Growth.-The fertilized egg is nourished for a short time by secretions from glands of the uterus, and, during this time, it develops the placenta by which it becomes attached to the uterine walls. Following this implantation, it receives its nourishment from the maternal blood through its placenta and umbilical cord. The blood vessels are among the first permanent structures in the embryo, providing for the circulation of nutrients and the removal of waste products through interchange with the maternal blood. This interchange, including the oxygenation of the fetal blood, occurs in capillaries in the placenta. While the fetus receives most of its nutrients preformed, it certainly carries on some synthetic functions in connection with its growth.

Expressed arithmetically, the growth of the fetus takes place at an increasing rate throughout the gestation period. More than half of the period elapses before the weight of the fetus equals that of its membranes, whereas, at term, the placenta

1 Stockard, Charhes R., and George N. Papanicolaou, The existence of a typical oestrous cycle in the guinea-pig-with a study of its histological and physiological changes, Am. J. Anat., 22, 225-265, 1917.

${ }^{2}$ Aspell, S. $\Lambda$., and W. A. Smitu, The hormone basis of animal health and reproduction, Agr. Educ. Magazine, 13, 124-138, 1941.

${ }^{3}$ Hammonis, John, Fertility in mammals and birds, Biol. Revs., 16, 165-190, 1941. 
make up only about 20 per cent of the total weight of the products of conception. Most of the growth takes place in the last third of the gestation period, as is illustrated by the curves in Fig. 36 taken from the studies of Mitchell and associates ${ }^{1}$ with swine. These workers slaughtered pregnant gilts in groups of one to three at weekly intervals from the fifth to the sixteenth week of gestation and determined the nutrients stored in the fetus and the placenta. The data were corrected to a standard litter of eight and treated mathematically to provide curves showing the increase in nutrient storage over the gestation period.

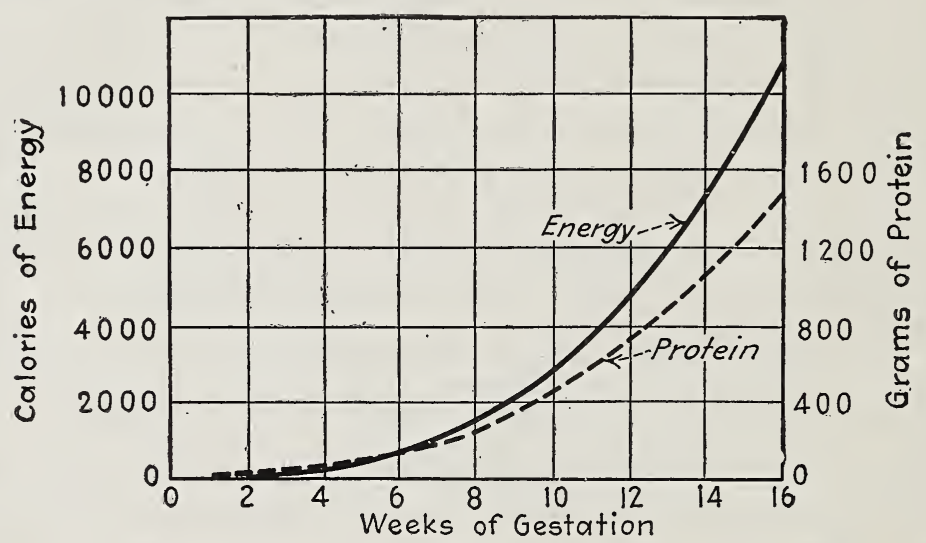

FIG. 36.-Gross energy and protein in products of conception at different stages of gestation-sow. (Mitchell, Carroll, Hamilton, and Hunt.)

It is evident from Fig. 36 that approximately half of the protein and more than half of the energy storage occurs in the last quarter of pregnancy. Additional data showed that even larger proportions of the calcium and phosphorus are stored toward the end of the period. In accordance with the general picture in growing organisms, the percentage of water in the fetus decreases with age. On a dry-matter basis, protein makes up about twothirds of the products of conception, a figure which shows little change over the gestation period. Neither do the percentages of fat or iron change markedly, but the calcium and phosphorus contents make up an increasing percentage with age. It is, therefore, clear that the quantitative demands for nutritive

${ }^{1}$ Mitchell, H. H., W. E. Carroll, T. S. Hamilton, and G. E. Hunt, Food requirements of pregnancy in swine, Ill. Agr. Expt. Sta. Bull. 375, 1931. 
material are small in early pregnancy and that they progressively increase to become several times as large toward the close of the period.

In multiparous animals, the larger the number of fetuses the smaller the individuals tend to be, owing to crowding, and there is frequently a marked difference in size among the individuals of a litter. In animals which may give birth to one or more young, multiple births do not produce so large individuals as do single births.

For each species there is a certain duration of pregnancy which is recognized as normal. Its termination is associated with the degeneration of the corpus luteum and is probably under the influence of both nervous and endocrine factors. The delivery of young is followed by the expulsion of the placenta or afterbirth.

\section{NUTRITIVE REQUIREMENTS}

Nutritional factors play vital roles in the various physiological events which occur in the attainment of sexual maturity and in the course of the reproductive process. Undernutrition delays puberty in both the male and female, and it may cause retrogressive changes in the sex organs after they are fully developed. It is a well-recognized fact that half-starved animals are relatively infertile. If the severely undernourished animal becomes pregnant, the drain on her body by the developing young may result in permanent damage. The death of the fetus in utero or the birth of a weak animal, perhaps prematurely, may also occur. In the male, undernutrition decreases the number and vigor of the sperm.

The practical importance of adequate nutrition during gestation has been demonstrated with various species. For example, the results of the seven-year study by Miller, Hart, and Cole ${ }^{1}$ indicate clearly that to produce a satisfactory lamb crop, rations low in protein, phosphorus, and vitamin $\Lambda$, as well as in encrgy, must be avoided. The striking differences that can result from good in contrast to poor nutrition in the case of human reproduction are illustrated by the studies of Burke and associates." Recent

1 Minler, R. F., G. H. HART, and H. II. Cole, Fertility in sheep as affected by nutrition during the breeding season and pregnancy, Calif. Expl. Sta. Bull. $672,1942$.

${ }^{2}$ Burкe, B. S., and associates, Nutrition studies during pregnancy, $A m . J$. Obstel. Gynecol., 46, 38-52, 19.13. 
experiments, such as those conducted by Ross and associates ${ }^{1}$ with swine, have shown that various congenital malformations can be produced by dietary deficiencies, making it clear that heredity is not the only cause of the cases which are met in practice.

A condition of extreme fatness is also deleterious to reproduction. The ovaries may become so infiltrated with fat as to hinder the development of the follicles, with a consequent irregularity or cessation of estrus which results in delay or failure in breeding. There may be also such an excessive amount of fat in the reproductive tract that, even if the egg is matured and fertilized, it may fail to reach the uterus and become implanted properly. Extreme fatness also interferes with the production of fertile sperms in the male and lessens his desire to mate. It is recognized that "show" condition is associated with low fertility in both sexes.

While the nutritive intake is qualitatively of equal importance in both sexes, obviously the quantitative requirements are vastly greater for the female. Thus most of the following discussion deals with the needs of the mother. Her nutrition must have the double object of producing normal offspring and of protecting her own tissues, for on an inadequate ration the mother sacrifices her bones and other tissues to nourish her fetus.

As is indicated by the curves in Fig. 36, the last quarter of the gestation period is the time of critical importance. It has been clearly proven that a system of feeding that takes full account of the increased needs at this time is much more effective than one that supplies the same amount of feed over the period as a whole but at the same intake level throughout. The beneficial effects of meeting fully the current needs toward the end of the period are reflected not only in more vigorous young but also in a higher potential level of milk secretion by the mother. It is during the last part of the period of gestation that the formation of secretory cells in the udder is most active (Sec. 325). Inadequate nutrition at this time limits this process and thus lessens the milk-secreting capacity that is developed.

3C8. Energy Requirements.-While the effects of general undernutrition previously mentioned are undoubtedly the result

${ }^{1}$ Ross, O. B., and associates, Congenital malformations, syndactylism, talipes and paralysis agitans of nutritional origin in swine, $J$. Animal Sci., 3, 406-414, 1944. 
of more than one deficiency, it is evident that the energy supply is an important factor. Experiments with rats have shown that a deficiency of energy alone results in a delay in the opening of the vagina, a prolongation of the period between this event and the first estrus, and an irregularity or cessation of the estrus cycle. The studies by Asdell and Crowell ${ }^{1}$ showing these effects included observations on sexually mature rats which were held at constant weight far below normal size, by energy restriction. Under these conditions, the cycles were highly irregular. When the animals were given an increment of energy sufficient to cause some growth, regular cycles occurred until the animals reached a weight where growth ceased because the total energy intake was needed for maintenance. Here sexual activity ceased also. Thus it was shown that neither growth nor sexual activity takes precedence over the other.

The energy requirement for reproduction consists of the energy stored in the new tissue formed plus the energy expended in the process. The tissues formed include the fetus and its membranes, the enlargement of the uterus, and the mammary development (Sec. 325). The energy content of these tissues at different stages provides the basic figures for estimating the nutritive requirements over the gestation period. Mitchell and associates ${ }^{2}$ in their studies, previously cited, with swine, computed the daily increase in energy and other nutrients in the products of conception. These data are reproduced in Table XXIX. It is noted that the energy storage is very small during the early weeks. While 272 Cal. are stored daily during the last week, computation shows that the average daily deposition for the period as a whole is only $104 \mathrm{Cal}$. No data are available for estimating the energy stored in the mammary growth, but, except in a first pregnancy, it should not exceed 10 per cent of that in the uterine products. On this basis a daily intake of 115 (al. could be considered as the net-energy requirement for reproduction in a sow producing a litter of eight pigs. That these calculations are only approximations is clear, but the final value obtained is uscful for comparison with the estimated net-energy recquirement for maintenance.

1 Asdeld, S. A., and MARY F. CRownd, The effect of retarded growth upon the sexual development of rats, $J$. Nutrition, 10, 13-24, 1935.

2 Mitchell, Carroli, Паmitón, and Hunt, loc. cit. 
The gilts studied by Mitchell weighed around $200 \mathrm{lb}$. Armsby gives the net-energy requirement for maintenance of a pig of this weight as 1.99 Therms. Even on the basis of this figure, which is probably too low, the average daily need for reproduction itself adds only 6 per cent to the maintenance requirement and less than 15 per cent during the last week of gestation when the

Table XXIX.-Computed Daily Rate of Increase in Weight and Energy Content, and Computed Daily Deposition of Nutrients in the Uteri of Pregnant Gilts

\begin{tabular}{r|c|c|c|c|c|c|c}
\hline $\begin{array}{c}\text { Week } \\
\text { of ges- } \\
\text { tation }\end{array}$ & $\begin{array}{c}\text { Total } \\
\text { weight, } \\
\text { g. }\end{array}$ & $\begin{array}{c}\text { Gross } \\
\text { energy, } \\
\text { Cal. }\end{array}$ & $\begin{array}{c}\text { Crude } \\
\text { protein, } \\
\text { g. }\end{array}$ & $\begin{array}{c}\text { Ash, } \\
\text { g. }\end{array}$ & $\begin{array}{c}\text { Cal- } \\
\text { cium, } \\
\text { g. }\end{array}$ & $\begin{array}{c}\text { Phos- } \\
\text { phorus, } \\
\text { g. }\end{array}$ & $\begin{array}{c}\text { Iron, } \\
\text { mg. }\end{array}$ \\
\cline { 1 - 2 } 1 & 27 & 1.6 & 0.54 & 0.028 & 0.0001 & 0.0011 & 0.28 \\
2 & 49 & 5.9 & 1.5 & 0.126 & 0.0018 & 0.0074 & 0.71 \\
3 & 71 & 12.5 & 2.7 & 0.30 & 0.0081 & 0.022 & 1.24 \\
4 & 91 & 21 & 4.2 & 0.57 & 0.024 & 0.048 & 1.84 \\
5 & 111 & 32 & 5.9 & 0.93 & 0.055 & 0.087 & 2.50 \\
6 & 131 & 45 & 7.7 & 1.38 & 0.109 & 0.142 & 3.2 \\
7 & 150 & 59 & 9.6 & 1.93 & 0.194 & 0.215 & 4.0 \\
8 & 169 & 76 & 11.8 & 2.6 & 0.32 & 0.31 & 4.8 \\
9 & 187 & 94 & 14 & 3.3 & 0.50 & 0.42 & 5.6 \\
10 & 205 & 115 & 16 & 4.3 & 0.74 & 0.56 & 6.5 \\
11 & 224 & 137 & 19 & 5.2 & 1.05 & 0.72 & 7.4 \\
12 & 242 & 160 & 21 & 6.2 & 1.46 & 0.91 & 8.3 \\
13 & 259 & 186 & 24 & 7.4 & 1.97 & 1.13 & 9.2 \\
14 & 277 & 213 & 27 & 8.7 & 2.60 & 1.38 & 10.2 \\
15 & 294 & 242 & 30 & 10.1 & 3.37 & 1.67 & 11.2 \\
16 & 312 & 272 & 33 & 11.7 & 4.29 & 1.98 & 12.3 \\
\hline
\end{tabular}

demand is greatest. Approximately the same relations should hold for the requirements in terms of digestible nutrients. The preceding calculations are useful to show that even for the sow, in which multiple birth involves a relatively higher reproductive performance than for other farm mammals, the additional energy needs above maintenance are very small until the last part of the gestation period. The data are not particularly useful, however, for arriving at allowances for practice because of other factors involved. Animals are usually bred before they have reached their full growth, and, thus, allowances during gestation must take account of growth needs as well. Mature animals frequently begin their gestation in rather poor flesh because of the previous lactation and need additional feed accordingly. Thus, in practice 
most pregnant animals must be given a sufficient energy allowance to enable them to gain some weight during the period as a whole, with special attention given to the last quarter when the specific needs are substantial. The aim should be to have the animals in good flesh at parturition without being too fat.

309. Fat Metabolism in Reproduction.-A specific requirement for fat for reproduction in the rat was reported by Burr and Burr (Sec. 77) who found that, on a fat-free diet, ovulation became irregular or ceased entirely, a disturbance which could be corrected by adding an appropriate fat. The males deprived of food fat showed a lack of sex interest and, with few exceptions, would not mate. It is probable that, if any such need for fat exists for farm animals, it is always taken care of in practical rations, since these rations of natural foods are never free from this nutrient nor from the specific fatty acids which Burr and Burr have found essential.

310. Protein Requirement.-When the protein intake is deficient, the estrus cycle is upset. Since the dry matter of the products of conception consists largely of protein, it is evident that there is a substantial requirement for this nutrient, and it is also clear from various experiments that, for hogs and poultry, the quality of the protein ingested is of equal importance here as in growth. The data in Table XXIX show that the quantitative need does not become of large importance until the last half of pregnancy during which the daily storage increases rapidly. The average daily figure for the gestation period as computed from these data is approximately $14 \mathrm{~g}$. Assuming that this should be increased to $16 \mathrm{~g}$. to include the mammary development and that the digestible protein fed has a biological value of 50 per eent, the average daily requirement for the sow producing a litter of eight would be $32 \mathrm{~g}$. Similarly computed, the figure for the last week of gestation would be approximately $70 \mathrm{~g}$. Aceording to Brody's estimate ${ }^{1}$ from endogenous nitrogen a 200-lb. animal shoukl receive approximately $100 \mathrm{~g}$. of protein daily for maintenance. On this basis the pregnant sow requires an average increment of 32 per cent throughout gestation, the requirement being over

1 Bhony, Samuel, Robent (․ Procten, and Jhal s. Ismwontr, Growth and Development. XXXIV. Basial metabolism, endogenous nitrogen, creatinine and neutral sulphur excretions as functions of body weight, Mo. Agr. Lxpt. Sta. Research Bull. 220, 1931. 
twice this at the close of the period. Similar calculations for the cow, based on meager data, indicate that the average daily gestation demand increases the maintenance requirement by 17 per cent, with a figure of 40 per cent at the end of the period. These calculations show that pregnancy increases the need for protein much more than for energy. This means that the ration fed during gestation should have a narrower nutritive ratio than is required for maintenance alone.

Studies with different species have shown that the pregnant animal has a considerable capacity to store protein in its own body as well as in the products of conception. This has been demonstrated for women by Hunscher and associates. ${ }^{1}$ They measured the total nitrogen retained by intermittent balance studies over the period of gestation, and the nitrogen in the fetus and adnexa was calculated from reported analyses. The data thus obtained revealed a marked retention in excess of that required for fetal development. Their data showed that following parturition the mother was in negative nitrogen balance during the first two weeks of lactation despite a liberal protein intake. Similar findings have been reported for cows and other species. These various observations emphasize the importance of a protein intake during gestation, in excess of the minimum requirements for maintenance and fetal growth, to take full advantage of the capacity of the maternal organism to store reserves for the period immediately following parturition when the food supply may be incapable of meeting the demands for lactation. All these considerations emphasize the importance of liberal protein intakes for pregnant animals. Toward the end of the gestation period the daily allowance, even for mature animals, should be larger than at any time during their previous growth.

311. Effects of Calcium and Phosphorus Deficiencies.-The observations in the phosphorus-deficient areas (Sec. 103) throughout the world are in agreement that reproductive troubles are very common and that they have caused very large losses in the animal industry. Conclusive proof for cows is furnished by the extensive studies of Theiler and associates ${ }^{2}$ carried out in the

${ }^{1}$ Hunscher, Helen A., Eva Donelson, Betty Nims, Fanny Kenyon, and ICIE G. MACY, Metabolism of women during the reproductive cycle. v. Nitrogen utilization, J. Biol. Chem., 99, 507-520, 1933.

${ }^{2}$ Theiler, A., H. H. Green, and P. J. DU Toit, Studies in mineral metab- 
phosphorus-deficient area in South Africa. The studies included observations on 200 animals over a period of two years. In groups in which the phosphorus-deficient pasture was supplemented by bone meal or other phosphorus sources, the calf crop was approximately 80 per cent in contrast to a figure of approximately 51 per cent in the control group. Similar evidence has been presented from various areas in the United States. The most frequently observed specific trouble is irregularity or cessation of estrus, corresponding to the commonly reported finding in rats.

It is becoming apparent, however, that other deficiencies, such as lack of vitamin $\mathrm{A}$ or of protein, are also concerned in some of the reproduction troubles in phosphorus-deficient areas.

Calcium deficiency can also upset reproduction. In severe deficiency failure to mate is common and, if mating occurs, few viable young are born. Intra-uterine death occurs in rats and pigs, probably because of a lack of tone of the uterine muscle. Calcium deficiency is much less an area problem than is the case for phosphorus.

Though of primary importance, regularity of breeding and normal pregnancy and parturition do not constitute complete proof that the calcium and phosphorus nutrition is adequate for reproduction. Despite a normal birth there may be pathological changes in the osseous system of the newborn as a result of mineral deficiency in the diet of the mother. Of equal importance, the mother's bones may be depleted to supply the minerals in the skeleton of the fetus. This has been shown to occur in various species of animals fed rations low in calcium and phosphorus. To the extent that it involves only the reserves of the minerals in the bones, no structural injury is caused, but, since in the lactation to follow, the demand for these minerals is so large that losses from the bones cannot be prevented despite the most liberal nutrition (Sec. 353), it is clearly desirable to husband the reserve in the bones during gestation. It has been shown with sheep by Fraser and associates ${ }^{1}$ and with swine by Evans ${ }^{2}$

olism. III. Breeding of cattle on phosphorus deficient pasture, J. Agr. Sci., 18, 369-371, 1928; Phosphorus in the live stock industry, J. Dcpt. Agr., Union S. Africa, 8, 460-504, 1924.

1 Fraser, A. H. H., W. Godden, and W. Thomson, The effect of a calciumdeficient diet on pregnant ewes, Vet. J., 89, 408-411, 1933.

2 Evans, R. E., Protein and mineral metabolism in pregnant sows on a normal or high calcium diet, compared with a calcium-deficient diet, $J$. Ayr. Sci., 19, 752-798, 1929. 
that losses from the bones which occur on a deficient ration can be prevented, by increasing the intakes of the bone-forming minerals. Similar findings have been reported from studies with women and with rats. Severe or continued depletion of the bones results in osteomalacia (Sec. 113).

The fact that the mother's bones can be sacrificed in the interests of the fetus provides a means of protecting the offspring of a first pregnancy from serious skeletal defects. X-ray studies have shown that calcification is best in infants from mothers showing the highest retentions of calcium and phosphorus during pregnancy. In a study with sows fed a ration deficient in calcium, Davidson ${ }^{1}$ found that a calcium-deficient ration did not produce an immediate effect because of the store in the maternal body. In successive farrowings there was an increase in the number of pigs born weak or dead and a decrease in the number reared to weaning. There was a serious reduction and eventual failure of the milk supply. Several investigators have reported fetal rickets, gross hypoplasia of the enamel, and defective dentine in infants from mothers undernourished in bone-forming minerals during pregnancy.

312. Calcium and Phosphorus Requirements.-In addition to providing for the growing fetus, the calcium and phosphorus intakes during gestation must be sufficient to meet the maintenance requirement of the mother and also to build up reserves in her bones in so far as this is possible. Data as to the amounts of these minerals present in the products of conception at birth are of limited value in arriving at the actual intake needs for several reasons. For most species there is a lack of information as to the maintenance requirement, and there is no reliable figure as to the percentage retention which can be assumed where it is desired to insure storage in the mother's bones to the fullest extent that it is possible, as well as in the fetus. The efficiency of utilization is recognized to be low under these conditions. Further, the daily requirement for fetal growth cannot be based upon the average storage in products of conception, for almost all of this storage takes place in the last half of gestation and especially in the last fifth. This fact is clearly brought out in Table XXIX. The

${ }^{1}$ Davidson, H. R., Reproductive disturbances caused by feeding proteindeficient and calcium-deficient rations to breeding pigs, J. Agr. Sci., 20, 233-264, 1930. 
intake chosen for the period as a whole must be that which will be optimum for the last days of gestation, or provision must be made for increasing a lower initial intake in accordance with increasing storage.

While extensive data are available for rats, few studies have been made with farm animals providing information as to the minimum intakes of calcium and phosphorus which can be relied upon to be optimum over the gestation period alone. In a very extensive balance experiment with swine, Evans ${ }^{1}$ compared intakes of approximately 0.6 and 0.04 per cent of calcium in a basal ration adequate in other nutrients including vitamin $D$. On the low level of intake only $15 \mathrm{~g}$. of calcium was retained

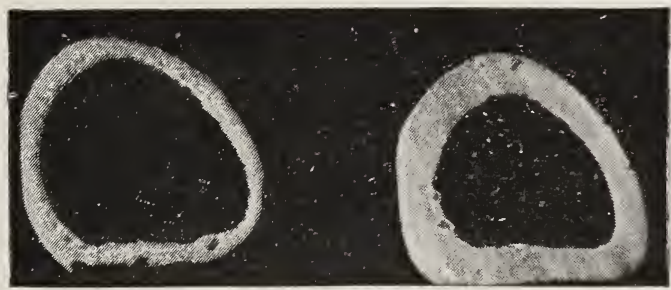

Fig. 37.-Cross section of metacarpal bones. The bone on the left was taken from a gilt on a low-calcium ration. Note the thin-walled, spongy, porous condition compared to the bone on the right produced on an adequate ration. The poor bone contained only half as much calcium. (Courtesy of A. G. Hogan, University of Missouri.)

during gestation although five times this amount was found in the products of conception at the close. A large depletion of the sow's skeleton therefore occurred. There was a lack of milk secretion following farrowing. The high level resulted in a storage in gestation greatly in excess of the demand for fetal growth, demonstrating the ability of the maternal organism to build up her reserves when the dietary supply is sufficiently large. From records of the number of pigs farrowed and weaned and from studies of the bones of the mothers, Hogan ${ }^{2}$ has suggested that the ration of brood sows should not contain less than 0.4 per cent of calcium. The striking effect of an inadequate supply on the bones of the gilt, noted by Hogan, is shown in Fig. 37. Probably 0.3 per cent of calcium will provide an adequate supply for

1 Evans, loc, cit.

${ }^{2}$ Hogan, A. G., The calcium requirement of brood sows, Mo. Agr. Expt. Sta. Research Bull. 167, 1932. 
the mature pregnant sow up to the middle of gestation, but then it must be increased, and the ration should contain at least 0.5 per cent at the close. Gilts need larger amounts in view of their growth requirements. Somewhat less phosphorus than calcium is needed. The N.R.C. allowances call for $16 \mathrm{~g}$. of calcium and $11 \mathrm{~g}$. of phosphorus daily.

In terms of body size, pregnant cows have a lower requirement for bone-forming minerals than do swine. Beef cows should have 0.2 per cent of calcium and 0.18 per cent of phosphorus in their rations, on a 90 per cent dry-matter basis, according to the N.R.C. allowances. These percentages correspond to around $20 \mathrm{~g}$. of calcium and $16 \mathrm{~g}$. of phosphorus daily. For dairy cows the figures specified for the two elements are $22 \mathrm{~g}$. and $17 \mathrm{~g}$. respectively. Beyond the first gestation the needs overlap with the larger ones for lactation, as is discussed later (Sec. 355).

For ewes, Riches and Godden ${ }^{1}$ found that the average daily storage in the lamb and its membranes was $0.6 \mathrm{~g}$. of calcium. On an intake which supplied double this amount daily the calcium balance was negative. An intake of $6 \mathrm{~g}$. daily was certainly adequate. The N.R.C. allowances for bred ewes specify 0.2 per cent of calcium (approximately $3.3 \mathrm{~g}$. daily) and 0.16 per cent of phosphorus (approximately $2.6 \mathrm{~g}$. daily) on a 90 per cent drymatter basis during the first 100 days. During the last six weeks the figures are increased to 0.24 per cent and 0.18 per cent of the two elements respectively.

313. Vitamin D.-This vitamin is needed during fetal growth as well as during body growth to insure adequate calcium and phosphorus assimilation. In the case of rats, most studies have reported an increased calcium and phosphorus retention during pregnancy and an increased content of the minerals and of the vitamin in the newborn, where liberal intakes of the factor have been provided. Several studies have been carried out with women. In some cases the calcium and phosphorus balances have been improved by additions of the vitamin, in others not. It is generally agreed that the newborn infant from a mother who has received a liberal intake of the antirachitic factor is less susceptible to rickets, because of the storage of the vitamin in the fetus. This

${ }^{1}$ Cited in Garry, R. C., and D. Stiven, A review of recent work on dietary requirements in pregnancy and lactation, with an attempt to assess human requirements, Nutrition Abs. Rev., 5, 855-887, 1936. 
storage is not sufficient to have any prolonged antirachitic effect in the offspring. It is clear that the vitamin is needed for normal reproduction in farm animals, but rigid experimental conditions are required to demonstrate this need. By keeping cows out of the light for a long period and by using a ration in which molasses beet pulp replaced hay, Wallis ${ }^{1}$ was able to produce deficiency symptoms in the course of lactation, followed by the birth of rachitic calves. Under conditions of practice, sunlight or the kind of ration that is satisfactory for growth will take care of the vitamin $\mathrm{D}$ requirements of cows and other animals during reproduction.

314. Iron.-The studies by Mitchell showed that the sow producing a litter of eight stored $580 \mathrm{mg}$. of iron in the products of conception. During the last week of pregnancy, the daily storage was $12.3 \mathrm{mg}$. (Table XXIX), and the average figure for the period as a whole was $5.5 \mathrm{mg}$. Even the latter figure is greatly in excess of the maintenance requirement. Studies with women have also indicated that the demands for fetal growth are much greater than those for maintenance. It is probable that, for all species, the maintenance requirement must be increased two or three times to cover the needs of the gestation.

If the intake during pregnancy is deficient, the needs of the fetus are supplied from the mother's rescrves in her liver and spleen, but, if the deficiency is extreme, the amount stored in the newborn will be less. This has been shown in rats by Lintzel and Radeff. ${ }^{2}$ Pregnant rats, receiving a normal ration containing $11 \mathrm{mg}$. of iron per $100 \mathrm{~g}$., produced litters in which the average iron content of the individuals was approximately $0.25 \mathrm{mg}$. This storage figure was reduced by one-quarter to one-half when the mother's diet was nearly iron-free. 'The mother's reserves were largely depleted and hemoglobin iron was lowered. While the normal picture in the mother and young was restored by iron addition, the amount of iron stored in the young by the ration containing $11 \mathrm{mg}$. was not increased by doubling the dietary level.

${ }^{1}$ Waluss, G. C., Some effects of a vitamin D deficiency on mature dairy cows, J. Dairy Sci., 21, 315-333, 1938.

${ }^{2}$ Lintzes, W., and 'T. RADrfi, Über den Eisengehalt und Eisenansatz neugeborener und saugender 'Tiere (nach Versuchen an Kaninchen, Meerschweinchen, Ratte, Hund, Katze, Schwein, Ziege, Rind), Archiv. Tierernähr. Tierzuchl., 6, 313-358, 1931. 
Despite the very large increase in the iron requirement which accompanies pregnancy, there is no evidence that a practical rroblem is here presented in the case of farm animals. In terms of the need, the commonly used feeds are rich (Sec. 127). It seems very unlikely that any deficiency exists, but the question may deserve critical study in swine in view of the common occurrence of anemia in the suckling young. Doubtless this trouble can occur even though the physiological capacity to store iron in the fetus is reached, but there may be dietary situations where the maximum storage does not take place.

315. Iodine.-The occurrence of goiter in farm animals as a result of a deficiency in the diet of the mother during gestation has been discussed (Sec. 133). In areas where the trouble occurs, the most practicable way of supplying the need for iodine is through the use of iodized salt.

A National Research Council report by Griem and associates ${ }^{1}$ suggests that 1 per cent of stabilized iodized salt (containing .0076 per cent iodine) in the grain portion of the rations of horses, sheep, and cattle, and 0.5 per cent of the salt in the entire rations of swine and chickens is adequate. These levels appear very liberal in the case of cows but may be borderline with respect to chickens and hogs. The later published N.R.C. allowance for swine is $0.2 \mathrm{mg}$. of iodine per $1000 \mathrm{lb}$. body weight, which is considerably in excess of the level that would be provided by the 0.5 per cent of salt mentioned above. The N.R.C. allowance for poultry is placed at $0.5 \mathrm{mg}$. of iodine per pound of feed, a level that is nearly three times that which would be supplied by the earlier figure of 0.5 per cent of the iodized salt. This large allowance was established during wartime to offset the goitrogenic effect (Sec. 133) of the large amount of soybean-oil meal being included in rations. Particularly since iodized salt is an expensive ingredient, further studies appear to be needed to establish more definitely the minimum amounts which can be relied upon to protect hens from goiter troubles.

Where goiter troubles in mammals have been experienced, feeding iodized salt during the last three-quarters of the gestation period only has given protection. The question as to the need for supplementary iodine at other periods in the life of the animal and

${ }^{1}$ Griem, W. B., and associates, Iodine, its necessity and stabilization, Natl. Research Council Reprint and Circ. Series No. 111, 1942. 
in areas where goiter troubles are not evident has been discussed (Sec. 135).

The information available for other minerals, such as manganese, which are known to play a significant role in reproduction has been discussed in Chap. VII.

316. Vitamin A.-In all species, in so far as studied, the reproductive process is dependent upon an adequate supply of vitamin $\mathrm{A}$. This is true for both sexes. In the male, a deficiency of the vitamin causes a very rapid degeneration of the germinal epithelium of the testes with a resultant loss of fertility. In the female there may be, in the first place, a cessation or irregularity of estrus. This disturbance of the cycle is accompanied by a cornification of the vaginal epithelium which can be detected in the rat by the smear technique (Sec. 306) thus providing a means of early diagnosis. The extent of the deficiency determines whether there is a complete failure to breed or whether, after a delay, estrus occurs. If fertilization actually takes place, an injury to the placenta may occur which results in fetal death and resorption, or in an abortion. In certain instances the gestation is prolonged and terminates in a difficult parturition. In fact, reproductive failure more commonly results from placental injury than from cornification.

The symptoms which occur differ somewhat according to the severity of the deficiency and some may be more prominent in one species than another. In cattle, Hart and Guilbert ${ }^{1}$ have reported the birth of dead or weak calves with frequent retention of the placenta, a condition which simulates infectious abortion. Severe diarrhea resembling white scours was present in the weak, newborn calves. These results occurred in animals, negative to the blood test for abortion, which had been maintained for an extended period on dried-up range. Following a failure during gestation, the animals commonly did not come in heat again until they had access to green feed. The disastrous results which occur in dairy cows from the continuous feeding of low-grade timothy hay in contrast to the performance on high-quality alfalfa have been clearly shown by the work of Meigs and Converse. ${ }^{2}$ Later

${ }^{1}$ HART, G. H., and II. R. Guilbert, Vitamin-A deficiency as related to reproduction in range cattle, Calif. Agr. Expt. Sta. Bull. 560, 1933.

2 Meigs, Enward B., and H. 'T. Converse, Some effects of different kinds of hay in the ration on the performance of dairy cows, J. Dairy Sci., 16, 317- 
studies by these workers found vitamin A to be the factor concerned.

In sows a disturbance of the estrus cycle and the farrowing of premature, weak, or dead pigs have been reported by Hughes and associates ${ }^{1}$ (Fig. 38). In sheep the lambs die in utero or soon after birth. In a study by Miller and associates ${ }^{2}$ with ewes depleted to night blindness, 65 per cent of them conceived,

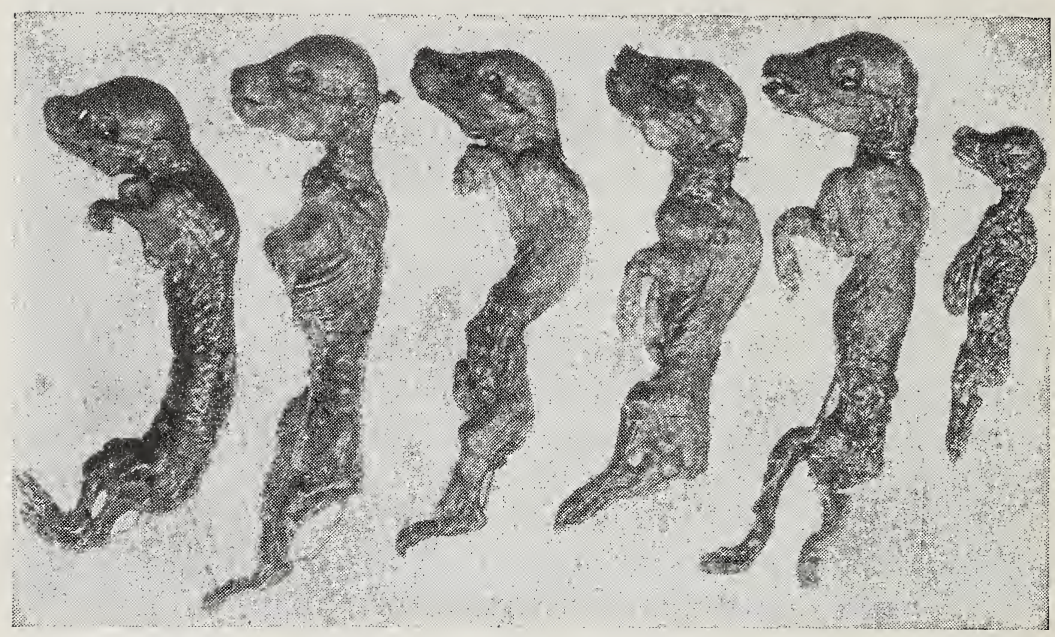

FIG. 38.-Fetuses removed from sow in advanced vitamin A deficiency. These fetuses were obtained on a post-mortem examination 81 days after the sow was due to farrow. They reveal advanced stages of resorption. (Kans. Agr. Expt. Sta. Tech. Bull. 23, courtesy of the authors.)

but every lamb was born dead or died within $48 \mathrm{hr}$. Animals which fail in reproduction because of a deficiency of vitamin A may or may not show the eye, nerve, and other symptoms which commonly occur during growth, depending upon the severity of the deficiency. Intakes which are sufficient to prevent eye symptoms may cause disaster during gestation. This indicates that the needs for reproduction are greater than for maintenance.

328, 1933; The vitamin requirements for reproduction and lactation under practical conditions, ibid., 19, 438, 1936.

${ }^{1}$ Hughes, J. S., C. E. Aubel, and H. F. Leinhardt, The importance of vitamin A and vitamin $\mathrm{C}$ in the ration of swine, Kans. Agr. Expt. Sta. Tech. Bull. 23, 1928.

2 Miller, R. F., G. H. Hart, and H. H. Cole, Fertility in sheep as affected by nutrition during the breeding season and pregnancy, Calif. Expt. Sta. Bull. 672, 1942. 
The N.R.C. allowances for reproduction are as follows: beef cows, 55 to $65 \mathrm{mg}$. carotene; dairy cows, $60 \mathrm{mg}$. carotene with $30 \mathrm{mg}$. extra during the last 6 to 12 weeks of gestation; ewes, 6 to $8 \mathrm{mg}$. carotene; sows, $13,000 \mathrm{I}$.U. vitamin A. There is no problem in meeting these needs in the case of cattle and sheep if reasonably good roughage is available, as is evident from a consideration of the data in Table XIII. Similarly, the needs of sows can be met by the liberal inclusion of bright green alfalfa in the grain mixture when they are not on good pasture. Here yellow corn can make a substantial contribution unless its vitamin value has been depleted in storage.

Fortunately, the ability of animals to store vitamin A protects them from reproductive failure during short periods on feed deficient in this factor. The most liberal intakes during gestation, however, do not result in any marked storage in the newborn.

\section{OTHER VITAMINS}

Very little information is available regarding the specific needs of farm animals for the various other vitamins during reproduction.

317. Vitamin E.-While this vitamin was discovered because a lack of it resulted in reproductive failure, early ideas as to its practical importance in the rations of farm animals have proved to be ill-founded, as has been previously discussed (Sec. 169). It seems clear that any special needs for reproduction are readily met by commonly fed rations which are otherwise satisfactory.

318. B-Factors. - It may be presumed that the requirements of nonruminants for the various B-vitamins are stepped up during the latter part of gestation when the energy metabolism significantly increases. There is no hasis, however, for quantitative statements in the case of farm animals. The allowances during the latter part of the growth period should probably suffice. Providing them should present no practical problem. In this connection it should be noted, however, that some recent reproduction studies with sows, such as those by the Wisconsin workers ${ }^{1}$ and by Fairbanks and associates, ${ }^{2}$ indicate that rertain commonly

1 Ross, O. B., and associates, loc. cit.; Cunus, 'T. J., and associates, Further observations on the dietary insufficieney of a corn-soybean ration for reproduction in swine, $J$, A nimal s'ci., 3, $115-121,1911$.

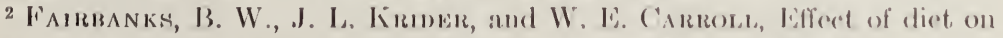
gestation-lactation performance of sows, J. Animal sici, 4, 110-119, 1915. 
fed rations may have unrecognized deficiencies, possibly belonging in the B group. This is an important field for further study.

319. Vitamin C.-Mention has been made in Sec. 201 of some observations with farm animals not considered to require vitamin $\mathrm{C}$ in their rations, indicating that the body synthesis of the vitamin may not always be adequate for best reproduction performance. On the basis of his studies in this field Phillips ${ }^{1}$ has recommended the feeding of vitamin $\mathrm{C}$ to horses and swine and its injection into cattle. Further studies appear to be required to establish the need and usefulness of such procedures. Papers dealing with the evidence to date are cited at the end of this chapter.

\section{NUTRITION AND DISEASES OF REPRODUCTION}

By far the most important reproductive losses in farm animals, particularly in dairy cattle, are those which are due to infectious disease, notably abortion. While it is well recognized that undernutrition may make animals more susceptible to certain diseases, this phase of nutrition has been overemphasized in connection with reproduction. This idea was specifically tested for infectious abortion by Hart and associates ${ }^{2}$ in a very comprehensive experiment. Cows receiving high levels of intake of calcium, phosphorus, vitamin $\mathrm{D}$, and iodine proved no more resistant to the infection than animals whose nutrition was borderline in these respects.

\section{EGG PRODUCTION}

Differing from mammals which nourish the embryo inside their bodies, give birth to living young, and nurse them, birds produce eggs which contain sufficient nutrients for the embryo to develop outside the body and no preformed food is required after hatching. In the hen the egg-formation phase of reproduction has been extended into a continuous process, aside from the moulting period, whereby egg production has become a tremendous industry as a source of human food, as well as serving in the propagation of the species.

1 Phillips, Paul, Nutrition and reproduction of farm animals, Natl. Research Council Reprint and Circ. Series No. 112, 1942.

${ }^{2}$ Hart, E. B., F. B. Hadley, and G. C. Humphrey, The relation of nutrition to contagious cattle abortion, Wisc. Agr. Expt. Sta. Research Bull.112, 1932. 
The egg of the hen is made up approximately as follows: yolk, 31 per cent; albumen or white, 59 per cent; and shell, 10 per cent. The development of the egg starts in the ovary where the yolk portion is formed. Here there are many ova, each enclosed in a follicle. The yolk is deposited in concentric layers and when the process is completed the follicle bursts, and the yolk, surrounded by a membrane, passes into the oviduct. Here the albumen is put on and finally the shell, each process requiring several hours. During its passage through the oviduct, the developing egg is fertilized if sperm are present. After shell formation is completed, the egg passes out through the vent. Under proper temperature conditions, the fertilized egg develops into the chick in twenty-one days. The reproductive process in the cock is similar to that in mammals.

320. Nutritive Requirements for Egg Production.-The hen ranks with the dairy cow in her productive performance. In a year she may produce up to four times as much dry matter as is contained in her body. Clearly an intensive metabolism and very large nutritive requirements are involved. The egg has the following approximate composition: water, 66 per cent; protein, 13 per cent; fat, 10.5 per cent; ash, 10.5 per cent. These figures reveal the fact that, in addition to the energy requirement, there are large demands for protein and especially for mineral matter. There are also important requirements for various vitamins. Besides the large nutritive demands for the formation of the egg as such, there are additional requirements for the production of an egg that will hatch and yicld a strong chick. The magnitude and complexity of the demands for the intensive egg production which characterizes the modern commercial practice have made its nutrition a specialized field, which can be discussed only briefly here.

The adequacy of the prolein content of the ration is mcasured in terms of the number of eggs produced, their size, and the maintenance of the body weight of the bird. Aceording to several studies, these requirements can be met satisfactorily when the ration contains 15 to 16 per cent of protein, provided it is of high biologieal value. The N.R.C. allowane calls for 15 per cent. Protein of the proper quality is provided in practies by including those products, such as skim milk, fish meal, meat seraps, soybean meal, and others, which in eombination with cercals and their by-products furnish efficient protein mixtures (Sec. 28:3). 
321. Calcium, Phosphorus and Vitamin D.-The average egg contains approximately $2 \mathrm{~g}$. of calcium and $0.12 \mathrm{~g}$. of phosphorus. Nearly all of the calcium is in the shell which consists very largely of calcium carbonate, while the phosphorus is concentrated in the yolk, principally combined with protein. Owing to this need for shell formation, the calcium requirement of the laying hen is several times that for any other species per unit weight. The intensity of the metabolism involved is reflected in a doubling of the level in the blood serum during the laying period. A 4-lb. hen which lays an egg daily requires for its eggs alone twice as much calcium as the child, many times the hen's size, needs for growth. A deficiency of the element results in thinner shells, a marked depletion of the bones of the hen, and a lowering of egg production. The same effect on the hen and upon her production occurs from a lack of phosphorus. Though this element is needed in much smaller amounts than is calcium, no mammal has as high a requirement, per unit weight, for any purpose.

Some mobilization of calcium and phosphorus from the bones during heavy egg production appears to be a normal physiological process even as is the case for lactation (Sec. 353). This fact emphasizes the importance of building up the reserves in the growing chick and of continuing a high level of feeding at all times in the case of the hen, for the depleted bones must be restored during the period when production falls off or ceases.

The N.R.C. allowances call for 2.25 per cent of calcium, including that fed free choice, and 0.75 per cent of phosphorus in the ration as a whole. The vitamin $\mathrm{D}$ allowance is 450 A.O.A.C. units per pound of feed.

322. Other Minerals. - The iron requirement of the laying hen is very large in proportion to her maintenance need, as is evident from the fact that the average egg contains $1.1 \mathrm{mg}$. of this element. There have been unconfirmed reports of anemia in the laying hen. The iron requirement appears to be approximately 0.9 mg. per pound of feed. This amount should be more than supplied by commonly fed rations that are satisfactory in other respects.

The N.R.C. allowances for laying and breeding hens call for $15 \mathrm{mg}$. of manganese per pound of feed, a level that is best assured by some supplementary addition of a manganese salt. There is no evidence at present that commonly fed rations are deficient in other minerals, assuming that common salt is included. 
323. Other Vitamins. - The laying hen has very large requirements for the various vitamins, including the needs to produce eggs that will hatch. The N.R.C. allowances are as follows:

Amount per pound of feed

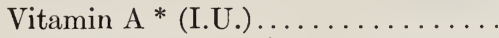

3300

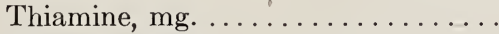

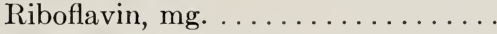

Pantothenic acid, mg. . . . . . . . . .

Nicotinic acid................

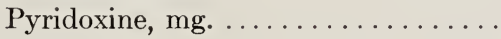

Biotin, mg. ................

Choline, mg. ...............

7.0

0.07

* May be either fish-oil vitamin A or provitamin A from vegetable sources.

† Unknown.

The investigations on which these values are based are cited in the N.R.C. report. ${ }^{1}$

324. Effect of Ration on Nutritive Value of Eggs.-While the mineral content of eggs, except for iodine, is not influenced by the nature of the diet, there are marked effects in the case of several of the vitamins. This is particularly true of vitamin $A$ and vitamin $\mathrm{D}$. The kind of ration which will result in the best production and hatchability is also the kind that provides eggs of the highest nutritive value for human consumption. This general subject has been excellently reviewed by Cruickshank. ${ }^{2}$

\section{Selected Literature}

Asdell, S. A.: Some practical applications of endocrinology to animal husbandry, Proc. Am. Soc. Animal Production, 1935, pp. 235-237.

Davis, G. K., and C. L. Cole: The relation of ascorbic acid to breeding performance in horses, J. Animal Sci., 2, 53-5S, 1943.

Evans, Herbert M.: The effect of inalequate vitamin B upon sexual physiology in the male, J. Nutrition, 1, 1-21, 1928.

Hammond, Jonn: Factors producing sterility, with special reference to genetic causes, Proc. Roy. Soc. Med., 26, 1183-1186, 1933.

: Physiological factors affecting birth weight, Proc. Nutr. Soc., 2, S-14, 1943.

1 Cravens, W. W., and associates, Recommended nutrient allowances domestic animals, No. 1: Poultry, Natl. Research Council, 194.

2 ('rucksmank, E. M., The effect of diet on the chemical romposition, nutritive value and hatchability of the egg, Nutrition Abstracts \& Revs., 10, 645-659, 1941. 
LAsley, J. F., and R. Bogart: Some factors influencing reproductive efficiency of range cattle under artificial and natural breeding conditions, Mo. Agr. Expt. Sta. Research Bull. 376, 1943.

Meyer, Roland K.: Hormones in reproduction, Ann. Rev. Physiol., 7, 567598, 1945.

Morgan, C. L., and associates: The study of calcium metabolism in the laying hen by the comparative slaughter method, Poultry Sci., 21, 212-215, 1942.

Muriel, D., D. Boelter, and D. M. Greenberg: Effect of severe calcium deficiency on pregnancy and lactation in the rat, J. Nutrition, 26, 105-121, 1943.

Rasmussen, R. A., C. L. Cole, and Marian J. Miller: Carotene, vitamin A, and ascorbic acid in mare's plasma, J. Animal Sci., 3, 346-350, 1944.

Ross, O. Burr, and associates: Congenital malformations, syndactylism, talipes, and paralysis agitans of nutritional origin in swine, J. Animal Sci., 3, 406-414, 1944.

Roux, Lucien L.: Sex physiology of sheep, Onderstepoort J. Vet. Sci. Animal Ind., 6, 465-717, 1936.

Russell, Walter C., and M. W. TAylor: The relation between the vitamin $\mathrm{A}$ and $\mathrm{D}$ intake by the hen and the output in eggs, $J$. Nutrition, 10, 613-623, 1935.

Shrewsbury, C. L., Claude Harper, and F. N. Andrews: Nutritive requirements of breeding ewes for maintenance, lactation and growth, $J$. Animal Sci., 5, 47-54, 1946.

Tyler, C., and J. S. Wilscox: Calcium and phosphorus balances with laying birds, J. Agr. Sci., 32, 43-61, 1942.

Warkany, J., and Elizabeth Schraffenberger: Congenital malformations induced in rats by maternal nutritional deficiency. VI. The preventive factor, J. Nutrition, 27, 477-484, 1944.

Welch, Howard: Goiter in farm animals, Mont. Agr. Expt. Sta. Bull. 214, 1928.

Winters, Laurence M., and George Feuffel: Studies on the physiology of reproduction in sheep. IV. Fetal development, Minn. Agr. Expt. Sta. Tech. Bull. 118, 1936. 


\section{CHAPTER XV}

\section{LACTATION}

A 1200 -lb. cow producing $10,000 \mathrm{lb}$. of milk in a year secretes in this milk approximately two and one-half times as much dry matter as is present in her entire body. There are records of cows which have produced in the year's milk over five times the organic matter of their own bodies, and of cows which over a life time have secreted organic matter equivalent to thirty-five times that present in their own tissues. While less subject to direct measurement, it is apparent that milk secretion in the sow nursing a large litter also represents a noteworthy physiological performance. The studies of Macy and coworkers ${ }^{1}$ show that the human organism is capable of producing an astonishing output of milk. It is clear that the metabolism of lactation is tremendous. While this metabolism includes many processes such as the digestion, absorption, circulation, and mobilization of nutrients, it particularly involves the functioning of the mammary glands. As an introduction to a consideration of nutritional requirements for lactation an understanding of the physiological processes concerned is essential.

325. The Mammary Glands.-The glands usually occur in pairs, the number of pairs varying with the species. They are modified cutaneous glands which make their appearance early in embryonic life but reach their full development only after a normal parturition. So far as is known they have no function other than milk secretion; for they can be removed at any stage of the life cycle without any observable harmful effect from their absence. A diagram showing the structure of the functioning udder is presented in Fig. 39.

The glands are present in a rudimentary form at birth and undergo little development until puberty, at which time a marked growth occurs. Thereafter there are periodic changes which are correlated with the ovarian cycle. Histological studies show that

1 Macy, Icue G., and associates, Human milk flow, Am. J. Diseases Children, 39, 1186-1204, 1930. 
at each estrus there is some duct growth in the gland, and an occasional secreting cell may be formed, which explains the fact that a watery secretion has been obtained before pregnancy. With the onset of gestation, there is a large increase in growth which involves the production of ducts, alveoli, and secreting cells. A secretory activity thus develops which results in an accumulation in the gland of products making up the colostrum.

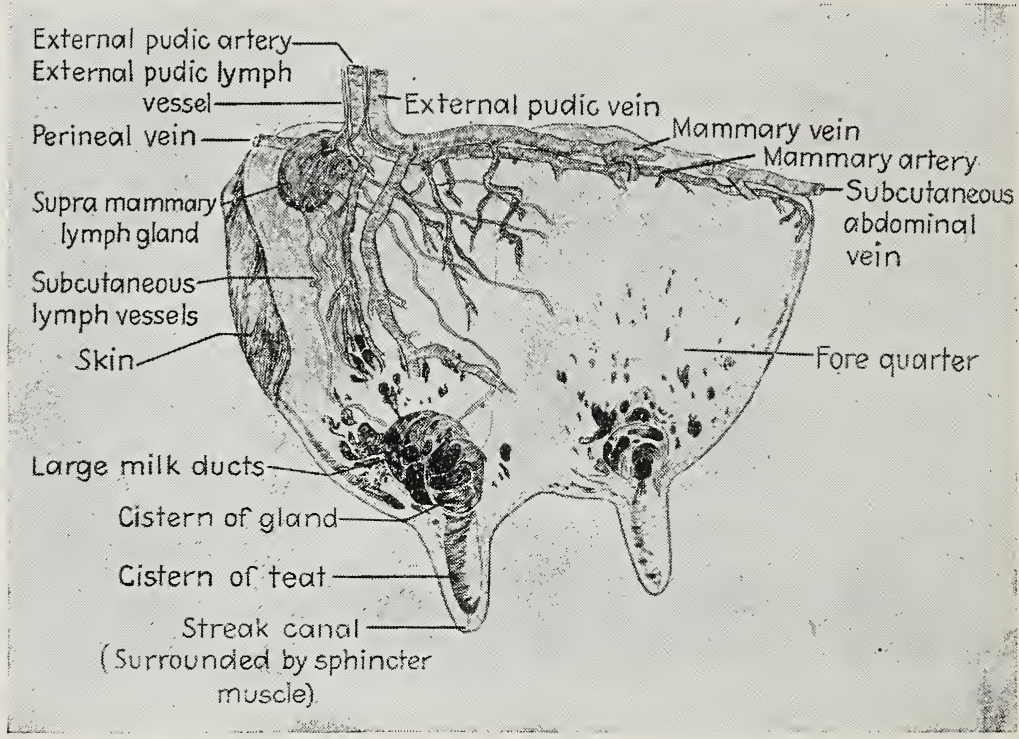

FIG. 39.-Cross section of functioning udder. (Furnished through the courtesy of C. W. Turner, University of Missouri.)

With the withdrawal of the secretion following parturition, its quantity gradually rises for a period which varies in different species, and then gradually falls until lactation ceases. As cessation occurs, the gland shrinks enormously, owing to a decrease in size of the alveoli and ducts, and remains quiescent until another pregnancy starts a renewed growth and secretion.

326. Hormonal Control. - The physiological mechanism controlling these various events is incompletely understood, but it is recognized that the activities of the ovary, uterus, and mammary gland are interrelated. It is now accepted that the essential stimulus for the growth and functioning of the gland is hormonal rather than nervous, and the present evidence indicates that at 
least three hormones are concerned. Each one has a specific function, and the three act in a definite sequence. Estradiol, a hormone from the Graafian follicle, first causes a duct development. Next progesterone from the corpus luteum is responsible for the growth of the alveoli. Finally lactogen (prolactin) from the pituitary gland brings about the secretory activity. As worked out primarily in the rabbit, it seems to be agreed that this represents the general picture. There is much uncertainty and lack of agreement regarding some of the details. There are doubtless some variations among the different species with respect to the relative amounts of the three hormones required to produce the effect and perhaps also as regards their mode of action.

The pituitary hormone is essential for the continuance of the secretory activity, but it is not primarily responsible for the changes in the volume of secretion that occur with advancing lactation. The gradual decline in activity which occurs is due probably to a natural aging of the gland. The secreting cells which were built up during the previous pregnancy gradually cease to function, and little or no new growth takes place. For a detailed statement of the present ideas with respect to the role of the hormones in the development and functioning of the mammary gland, the student is referred to the review by Petersen. ${ }^{1}$

327. Thyroid Gland and Milk Secretion.-Since the secretion of the thyroid gland is a general regulator of metabolism, one would expect it to play a role in lactation. Over 20 years ago evidence was produced that the removal of the gland caused a decline in milk secretion, and this evidence has been confirmed and made more convincing by later studies. Conversely, the administration of thyroxin or of dried thyroid gland to cows stimulates lactation during the period of decline, and increases the fat percentage. Since the effects disappear as soon as injection ceases and since the feeding of thyroxin did not prove particularly effective, the finding seemed to have no practical application. Later studies, however, developed a plentiful source of a product possessing thyroid activity when fed by mouth, namely, iodinated casein. Research with this material has been very active during the past five years.

Actually, this development goes back to 1914 when Morse

1 Petersen, W. E., Lactation, Physiol. Revs., 21, 340-371, 1944. 
showed that iodinated protein would accelerate the metamorphosis of tadpoles. The intervening studies have been reviewed by Reinecke and Turner ${ }^{1}$ who developed an improved method for producing an iodinated casein of high biological activity. In later studies the Missouri workers and several others have shown that the feeding of this or similar products results in significant and sustained increases in milk yield and even larger effects on fat yield, in cows in midlactation. Metabolism is speeded up, and so increased feed must be consumed to avoid loss of weight. An increased pulse rate, elevated body temperature, and hyperirritability are other undesirable effects that may result. The secretion tends to increase with the level of intake of the protein compound, but so also do the undesirable effects. For example, Blaxter, of the National Institute for Research in Dairying in England, has reported that an increased milk production of 35 per cent and of fat production of 54 per cent were accompanied by an increase of 30 per cent in the resting heart rate and of 34 per cent in the respiration rate, with a 9 per cent loss in body weight. By keeping the intake of the protein compound low and regulating it to the individual, the undesirable physiological effects can be largely eliminated, but of course, the maximum increase in milk yield is not obtained. No observations have been made as to whether, despite the elimination of the undesirable current physiological effects, the performance in succeeding lactations may be unfavorably influenced. The status of the current information is typified by the results presented in two papers by Blaxter ${ }^{2}$ which form a part of a series of reports of a wartime project on iodinated casein, sponsored by the Agricultural Research Council of Great Britain.

328. Induction of Lactation by Synthetic Estrogens.-Following an initial finding by DeFremery in Holland that udder growth could be induced in virgin goats by anointing the udder with a salve containing estradiol benzoate, Folley and associates in England found that use of an ointment containing diethylstil-

${ }^{1}$ Reinecke, E. P., and C. W. Turner, Formation in vitro of highly active thyroproteins, their biologic assay and practical use, Mo. Agr. Expt. Sta. Research Bull. 355, 1942.

${ }^{2}$ Blaxter, K. L., The effect of iodinated protein feeding on the lactating cow. I. The effects of preparations of low activity and of iodinated ardein, J. Endocrinol., 4, 237-265, 1945; II. The effects of iodinated casein, ibid., 4, 266-299, 1945. 
bestrol, a synthetic estrogen, caused udder development and a secretion of milk as well.

Reports of other workers followed, describing the induction of lactation in cows by injection or inunction, or both, of the synthetic estrogens. Next it was shown by Folley and associates and by Hammond and Day ${ }^{1}$ that the subcutaneous implantation of tablets of stilbestrol or hexestrol was a simple and more effective procedure. Hammond and Day have reported on the treatment of 140 cows and heifers that had failed to get in calf. While the treatment was not successful in every case, and while sometimes the volume of secretion was low, many animals produced commer-

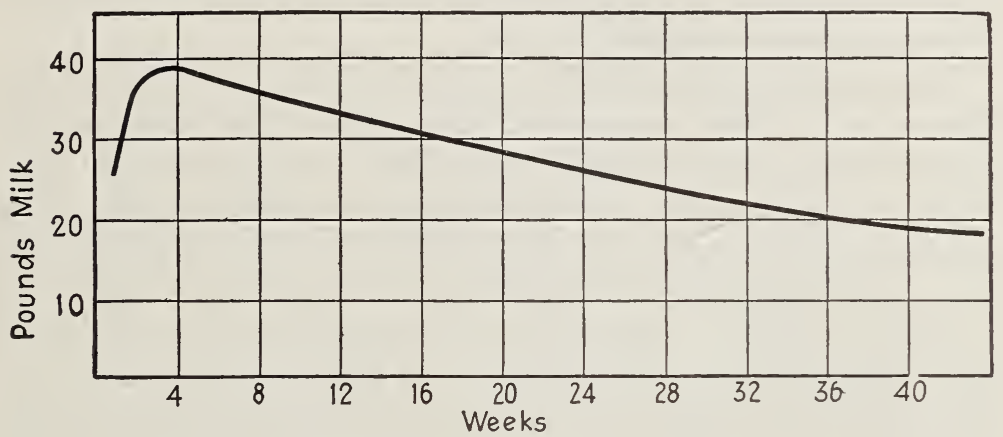

FIG. 40.-Lactation curve of the cow (not pregnant).

cial yields -2600 to $6600 \mathrm{lb}$. over periods of 40 to 64 weeks. A total of over 130 tons of milk resulted. A later report by Day and Hammond states that of the cows thus treated with the estrogens because of failure to breed, 70 per cent of those anatomically normal got in calf following the induced lactation. This wartime development in England appears to hold real promise ats a means of restoring to usefulness animals which before becoming sterile had proven their value as breeders or producers. The milk from the cows in which lactation is incluced has initially a colostral nature, but its composition changes to that characteristic of normal milk as the secretion increases. When the output reaches $5 \mathrm{lb}$. per day, the composition is always normal.

329. The Course of Milk Secretion.-The normal ketation curve for the cow is shown in Fin. 40. The time involved in

1 HАmmono, J., Jr., and F. 'T. DАr, Oestrogen treatment of cattle: Indued lactation and other effects, J. Endocrinol., 4, 53-82, 194. 
reaching the peak depends upon inherited factors and upon the condition of the cow prior to calving and how she is fed and managed thereafter. The rise in secretion following parturition does not run parallel with increased food intakes, and it extends over a much longer time than can be accounted for as the recovery period from the strain of calving. It may be caused by the gradual removal of the accumulated products enabling the cells to reach their maximum rate. However, the current nutrition of the animals is a secondary factor in milk secretion at the start of the lactation period, because the impulse to secrete is so strong at this time that the animal readily draws on her own reserves. Her previous nutrition which determines the status of her reserves at calving is thus concerned.

Following the peak, there is a regular decline in yield such that the curve is of the descending exponential type, each month's yield being a constant percentage of that of the preceding month. Persistency is the term used to denote the measure of this rate of decline, which varies with the individual and in different lactations, and which is accelerated at the twenty-second week after a new conception. The onset of a new pregnancy is thus the determining factor in the length of the lactation of the cow, both because of this accelerated decline and because of the necessity of giving her a rest period before another lactation. The fact that many cows will continue to secrete some milk right up to parturition, if milked regularly, shows that there is no physiological mechanism for absolutely stopping the process before this event. Cows which remain unbred may continue to secrete milk at a decreasing rate for two or three years or even longer.

Failure to remove the milk regularly and completely from the gland lessens its activity and brings about cessation, a fact which finds practical application in the drying off of animals. The onset of a new pregnancy during lactation results, after a period, in a more rapid decline in the secretion than otherwise occurs. In animals nursing young, lactation is usually artificially terminated at weaning, since failure to remove the secretion stops the process. Underfeeding during the declining period of secretion has an immediate effect in lowering the output, in contrast to its lesser influence at the start of lactation, but no system of feeding will counteract in any way the normal decline.

The lactation curve of the goat is similar to that of the cow and 
milk secretion studies with sheep indicate a similar one for this species also. In the case of women, however, the peak is reached much later, or there is a plateau instead of a peak. The increase after parturition may continue to the twenty-eighth week, and the secretion may persist at or near its maximum level to the fortieth week.

With lactations of substantially equal length, the yield of the cow increases for the first four or five, on the average. The

Table XXX.-Percentage Composition of Milk of Different Species ${ }^{1}$

\begin{tabular}{|c|c|c|c|c|c|c|c|c|c|}
\hline Species & Water & $\begin{array}{l}\text { Pro- } \\
\text { tein }\end{array}$ & Fat & $\begin{array}{l}\text { Lac- } \\
\text { tose }\end{array}$ & Ash & $\begin{array}{l}\text { Cal- } \\
\text { cium }\end{array}$ & $\begin{array}{c}\text { Phos- } \\
\text { pho- } \\
\text { rus }\end{array}$ & $\begin{array}{c}\text { Calo- } \\
\text { ries }\end{array}$ & Authority \\
\hline Cow.... & 87.2 & 3.5 & 3.7 & 4.9 & 0.72 & 0.121 & 0.095 & 74 & \\
\hline Sheep... & 82.7 & 5.5 & 6.4 & 4.7 & 0.92 & 0.201 & 0.168 & 109 & Trautmann and Kirchhof \\
\hline Goat... & 86.5 & 3.6 & 4.0 & 5.1 & 0.81 & 0.131 & 0.104 & 79 & \\
\hline Mare... & 89.0 & 2.7 & 1.6 & 6.1 & 0.51 & $\ldots \ldots$ & $\ldots \ldots$ & 54 & Linton \\
\hline Sow.... & 82.0 & 6.2 & 6.8 & $\ldots$ & 0.96 & 0.252 & 0.151 & 113 & Hughes and Hart \\
\hline Woman. & 87.5 & 1.0 & 4.4 & 7.0 & 0.21 & 0.035 & 0.013 & 70 & Nacy et al. \\
\hline Bitch... & 75.4 & 11.2 & 9.6 & 3.1 & 0.73 & $\ldots \ldots$ & $\ldots \ldots$ & 163 & Morris \\
\hline
\end{tabular}

1 The data for the cow and goat were computed by the writer. The publications from which the other data were taken are cited at the end of the chapter. The data for human milk are expressed as grams per $100 \mathrm{ml}$. With the exception of this milk, the data for calorie content were calculated by the writer.

growth of the animal as a whole is a factor during the first three lactations, and there is markedly greater hypertrophy of the gland during the second pregnancy than during the first, with smaller increases in succeeding pregnancies. Persistency decreases in succeeding lactations. Since this is true it is apparent that the higher yields which are obtained in succeeding lactations must be due to a greater secretion during the first part of the lactation. Expressed another way, it may be said that the level, at which secretion begins, increases to maturity but that the total yield for the lactation is not proportional to this rise because of a declining persistency factor.

The longer the dry period the greater the persistency in the next lactation. Shortening the dry period before a second lactation lowers yield to a much greater extent than shortening it before a later lactation. This is readily explainable on the basis of the greater growth of body and gland that takes place before 
the second lactation than later. The importance of an adequate dry period to build up nutrient reserves is well understood.

330. Milk of Different Species.-The chemical composition of the milk of the various species is presented in Table XXX. It should be emphasized that the figures for individual animals may vary widely from these average values. This is certainly true for cows of different breeds and for individuals within the breed as is discussed later (Sec. 342). Doubtless the variations have become greatly accentuated in this species as a result of breeding operations, but they must be expected to occur to a certain extent in all species. The data presented in the table are useful, nevertheless, to indicate the nutrients involved in milk secretion and to bring out certain differences which exist among the species. It is noted that the milk of the sow and ewe contains considerably more dry matter than the milk of any of the other species of farm animals and that this is reflected in a higher energy value and ash content. Particularly noteworthy is the much higher content of calcium and phosphorus. Clearly per unit of product, the nutritive requirements for milk secretion in the sow and ewe are markedly greater than in the cow, goat, or mare. It is also interesting to note that the least variable constituent for all species is lactose. The same is true among individuals and also for different samples from the same individual, as is brought out in later discussions for the cow.

\section{THE SECRETION OF THE MILK CONSTITUENTS}

331. The Composition of Blood and Milk.-Most of the organic constituents of milk arise from specific synthetic processes of the mammary gland, representing products which are not found elsewhere in nature. As an aid to a consideration of the physiology involved and the chemical changes which take place there are presented side by side, in Table XXXI, data as to the composition of the milk and of the blood plasma of the cow. The different milk constituents are listed opposite the respective blood constituents from which they are believed to be derived at least in part. Several other constituents not shown in the table are present in both fluids, such as urea and other nonprotein-nitrogen compounds, pigments, free cholesterol, and various mineral elements. A study of the figures in the table makes it evident that milk has a 
very different composition, both quantitatively and qualitatively, from the blood plasma from which it is made; but the two fluids have one characteristic in common-they are isotonic.

Certain milk constituents, including lactose, casein, and some of the fatty acids are clearly synthetic products of the gland, while others such as the minerals and urea, pass directly from the blood

Table XXXI.-Comparative Composition of Blood Plasma and Milk OF THE Cow

\begin{tabular}{|c|c|c|c|}
\hline \multicolumn{2}{|l|}{ Blood plasma } & \multicolumn{2}{|l|}{ Milk } \\
\hline Composition & Per cent & Composition & Per cent \\
\hline Water............... & 91.0 & Water............... & 87.0 \\
\hline Glucose ............. & 0.05 & Lactose. . . . . . . . . . & 4.90 \\
\hline Serum albumin ........ & 3.20 & Lactalbumin.......... & 0.52 \\
\hline Serum globulin. . . . . . . & 4.40 & Lactoglobulin......... & 0.05 \\
\hline Amino acids.......... & 0.003 & Casein............. & 2.90 \\
\hline Neutral fat........... & 0.06 & Neutral fat.......... & 3.70 \\
\hline Phospholipids.......... . & 0.24 & Phospholipids.... . . . . . & 0.04 \\
\hline Cholesterol ester. ....... & 0.17 & Cholesterol ester. . . . . . & trace? \\
\hline Calcium............ & 0.009 & Calcium........... & 0.12 \\
\hline Phosphorus........... & 0.011 & Phosphorus.......... & 0.10 \\
\hline Sodium............. & 0.34 & Sodium............ & 0.05 \\
\hline Potassium............ & 0.03 & Potassium........... & 0.15 \\
\hline Chlorine............. & 0.35 & Chlorine. . . . . . . . . . & 0.11 \\
\hline Citric acid . . . . . . . . & trace & Citric acid . . . . . . . & 0.20 \\
\hline
\end{tabular}

stream. It is probable that the albumin and globulin of milk, and its cholesterol also, arise directly from the blood. It may be debated as to what ones of these constituents, which come in unchanged, are there by design and what ones represent accidental though constant filtrations. Urea would seem to be in the latter class, although it may be in part a product of gland metabolism.

The milk of the individual cow tends to be of constant composition, but there are periodic fluctuations, notably of fat, and there are characteristic changes over the course of the lactation. With the normal decline in yield the percentage of fat rises, and so does the protein to a lesser degree. In contrast, the lactose declines slightly, and, for the maintenance of osmotic relations, its decline is balanced by a rise in chlorides. These same changes tend to 
occur when the yield is subjected to an abnormal drop as the result of sickness, "off-feed," or other disturbing factors. Overman and coworkers ${ }^{1}$ have published very extensive data on the composition of the milk of different breeds of cows over the lactation period. Their study shows that as the percentage of fat increases, the percentage of protein, ash, and total solids tends to increase and that the percentage of lactose tends to decrease. The composition of human milk is apparently more variable than that of the cow.

332. Mechanism of Milk Secretion.-A complex series of reactions are involved in the secretion process, viz., the passage of blood constituents into the cells, the synthesis of secretory granules and their later breakdown, the transfer of water to dissolve the granules, and the passage of the product into the ducts. Many explanations have been proposed for the physical changes concerned but none of them are entirely satisfactory. A discussion of milk secretion in terms of physicochemical phenomena is given by Blackwood and Stirling. ${ }^{2}$

Histological evidence has disproved the earlier view that the cells are completely destroyed in the process of secretion, the granules forming the lactose and fat, and the nuclei forming the protein of milk. At present some workers adhere to the theory of Heidenhain that there is a partial disintegration of the cell whereby the constituents escape, while others believe that a true secretion is involved. There is histological evidence for both explanations. The most rapid rate of secretion occurs after milking, and there is a gradual decline with time until the product is again removed. This decline is due to the increasing pressure in the udder, as indicated by the work of Swett and associates ${ }^{3}$ and by later investigations. This declining rate of secretion with the accumulation of milk in the udder is the probable explanation of the fact that larger daily yields are obtained from high producers by more frequent milking. Conversely, milk pressure

1 Overman, O. R., F. P. Sanmann, and K. E. Wright, Studies of the composition of milk, Ill. Agr. Expt. Sta. Bull. 325, 1929.

${ }^{2}$ Blackwood, Janet Henderson, and John Dempster Stirling, The absorption of milk precursors by the mammary gland. V. Physicochemical aspects of milk secretion, Biochem. J., 26, 1127-1137, 1932.

${ }^{3}$ Swett, W. W., Fred W. Miller, R. R. Graves, and G. T. Creeech, Quality, size, capacity, gross anatomy, and histology of cow udders in relation to milk production, J. Agr. Research, 45, 577-607, 1932. 
is the responsible agent for stopping the secretion when milk is left in the udder as a means of drying off the cow.

When the milking act is initiated, a small quantity of milk can be immediately removed, then there is a lag period followed by a large inflow of milk into the cistern of the udder. One says that the cow "has let down" her milk. This is believed to be a reflex action as a result of the stimulation of the teat in the act of milking or suckling. The explanation most widely accepted at present is that the stimulation of the sensory nerves in the skin and teats results in the secretion of the oxytocic principle of the posterior hypophysis which, in turn, causes a contraction of the musculature of the gland whereby the milk is forced out of the alveoli and ducts.

As previous discussion indicates, milk secretion is a continuous process, contrary to the former view that most of the milk is secreted at the time of milking. It was formerly thought that the udder of the high-producing cow could hold only a fraction of the milk obtained at a given milking. Experiments by Swett and associates ${ }^{1}$ and by others, in which udders have been milked after removal from the body, have disproved this idea.

333. Blood Changes in Relation to Secretion.-A useful method for the study of milk secretion is the analysis of the blood before and after passing the gland. Data obtained in this way have provided important information as to the blood precursors of the milk constituents, but they cannot establish quantitative relations between blood changes and the constituents secreted, because no one has been able to measure the blood volume passing through the gland. In view of the many outgoing paths, including the lymphatics, such a measure appears impossible. Further, milk secretion is very easily disturbed by external conditions, and, therefore, it is very doubtful whether quantitative data of value could be obtained in an animal disturbed by drawing of blood samples and by the measure of the volume flowing through the gland.

334. The Secretion of Lactose.-It is generally accepted that glucose is the principal blood precursor of lactose. Kaufmann and Magne ${ }^{2}$ took samples simultaneously from the jugular and mam-

1 Swett, Miller, Graves, and Creech, loc. cit.

${ }^{2}$ Kaufmann, M., and H. Magne, Sur la consommation du glucose du sang par le tissu de la glande mammaire, Compt. rend. acad. sci., 143, 779$782,1906$. 
mary veins of a milking cow and found that the mammary blood contained 18 per cent less glucose, whereas similar samples from a dry cow showed no difference. Considering the jugular blood as representative of the supply of the gland, they suggested that the lactose of milk was made from the glucose of the blood. Some-what later Foa obtained, by perfusion experiments, specific evidence that the gland can use glucose to make lactose. The finding of Kaufmann and Magne has been repeatedly confirmed, notably by Blackwood and Stirling ${ }^{1}$ who refined the procedure by comparing arterial blood with mammary-vein blood and by determining the changes in true sugar as distinguished from total reducing substances.

It has been assumed that the transformation of glucose into lactose involves first the formation of galactose from glucose and then the union of galactose with another molecule of glucose. But, from the standpoint of the chemist, the stereochemical transformation of glucose to galactose is difficult to understand. Many attempts to find, in glandular tissue, enzymes that would cause this change and combine the two sugars have given negative results.

During lactation the glucose content of the blood is lower than when the gland is not functioning. This has raised the question as to whether the glucose level of the blood is a controlling factor in milk secretion. Injections of lactose, glucose, and other sugars have not furnished any consistent evidence that the volume of secretion or its percentage of lactose can be increased thereby. Several investigators have shown that the lowering of blood sugar which results from the injection of insulin or phlorizin is accompanied by a lower milk yield. This does not prove that the change in milk was the direct result of the change in blood sugar. A decrease in lactose percentage has been reported from some of these experiments and interpreted to be a direct result of a lowering of its precursor. Other explanations are possible. At the present time the various experimental data furnish no reliable evidence that either the amount of milk secretion or its lactose content is influenced by the level of blood glucose. There is no evidence that the lactose percentage is influenced by diet.

${ }^{1}$ Blackwood, Janet Henderson, and John Dempster Stirling, The absorption of milk precursors by the mammary gland. II. The relation of blood-sugar absorption to lactose secretion, Biochem. J., 26, 362-368, 1932. 
335. The Secretion of Fat.-The lipids of milk consist of neutral fats or triglycerides, phospholipids, cholesterol esters, and free cholesterol. Differing from fat found in other animal products or in plants, milk fat contains a considerable amount of glycerides of short-chain fatty acids (Table VII). The formation of these acids represents a synthetic action by the gland. The distribution of the fatty acids in milk can be modified somewhat by the nature of the diet even as is the case for depot fat, but not sufficiently to alter the specific character of milk fat. While either fat or carbohydrate, and presumably protein also, may serve as the food source of milk fat, fat itself is apparently the preferred source when there is an adequate supply in the diet. Carbohydrates and protein must first be changed into fat before they are used by the gland, for the milk fat is made from blood lipids.

The question as to what lipid fraction in the blood is used by the gland has long been a subject of study. In the blood plasma of the lactating cow about 15 per cent of the fatty acids are present as neutral fats, the balance being about equally divided between phospholipid and cholesterol ester. On the basis of studies by Lintzel ${ }^{1}$ with goats, by Maynard and associates ${ }^{2}$ with cows, and by others, it is now accepted that the neutral fat fraction of the blood furnishes the fatty acids from which milk fat is formed.

While depot fats can be called upon to furnish the precursor of milk fat, it is possible that with an adequate supply in the ration they play little role in the process. At the start of lactation the cow unquestionably makes use of her reserves for milk production but whether these reserves are used specifically to make fat or to furnish energy cannot be stated. Experiments by Petersen and associates ${ }^{3}$ indicate that in the process of milk secretion, a fat intermediate in character between body fat and milk fat is first deposited in the glandular tissue and then further modified to form the milk fat itself. While it is evident that the lower-carbon fatty acids of milk are manufactured in the gland, since they do

1 Lintzel, WolfasNa, Untersuchungen über den Chemismus der Milchfettbildung in $\Lambda$ bhangigkeit von der Fütterung, Z. Zucht. Riche B, Tierzucht. u. Zuchtungsbiol., 29, 219-242, 1934.

${ }^{2}$ Maynatid, I. A., and associates, Studies of the blood precursor of milk fat, Cornell Univ. Agr. Expt. Sta. Memoir 211, 1938.

${ }^{3}$ Petersen, W. E., L. S. Palmer, and C. H. Eckles, The synthesis and secretion of milk fat. III. A study of the activity of the perfused surviving gland. With special reference to the fat, Am. J. Physiol., 90, 592-599, 1929. 
not occur in the blood stream, the mechanism involved is uncertain. There is some evidence for the view that they are formed from the breakdown of oleic triglycerides.

336. Variation in the Secretion of Fat.-Fat is the most variable constituent of milk. In addition to its variation among breeds and individuals, its percentage in the milk of a given animal varies from milking to milking, from quarter to quarter, and increases progressively during the milking process. In a study with a Guernsey cow, Van Slyke found that the first fraction drawn, consisting of about 18 per cent of the whole, contained only 1 per cent of fat, whereas the final fraction of 30 per cent contained 10 per cent of fat. It is very difficult to find an explanation for these large variations. Hammond ${ }^{1}$ has set forth important evidence that differences in fat percentage are caused by milk pressure, through the inhibition of the actual secretory process and through its effect on the ease with which the fat globules pass down the ducts to the cistern. He states that changes in the chemical composition of milk occur as the rate of secretion varies.

Periodic changes in fat percentage are inversely correlated with milk yield. A lowering of yield which results from an abrupt change in conditions, such as weather, surroundings, or even a change in the milker, is frequently accompanied by a rise in fat content. The sharply lowered yield which results during a period of "off-feed" is generally accompanied by a rise in fat percentage. This inverse relationship is also shown in the course of the lactation, for as the decline in yield progresses following the peak the percentage of fat tends to rise.

There is a marked seasonal variation in the percentage of fat, the maximum occurring in winter and the minimum, in summer. That environmental temperature is the primary cause of this variation is indicated by controlled studies in which it has been shown that within certain limits fat percentage increases regularly with drop in temperature. From one lactation to another there is no consistent change in fat percentage. While an increase in milk yield may be expected during the first four or five lactations, a cow which has a low fat test as a heifer will not better it materially in succeeding years.

${ }^{1}$ Hammond, John, The physiology of milk and butterfat secretion, Vet. Record, 16, 519-537, 1936. 
Maynard and coworkers ${ }^{1}$ have made extensive studies of the possible relation between the level of blood lipids and the milkfat percentage. Their comparative studies of the blood and milk from milking to milking, from day to day, and from week to week have revealed no changes in the blood which were correlated in any way with the large variations which frequently occurred in milk-fat percentage. A ration which resulted in a marked decrease in the concentration of the blood lipids did not produce any corresponding changes in the milk fat. Their studies showing that, over the lactation cycle as a whole, the level of blood
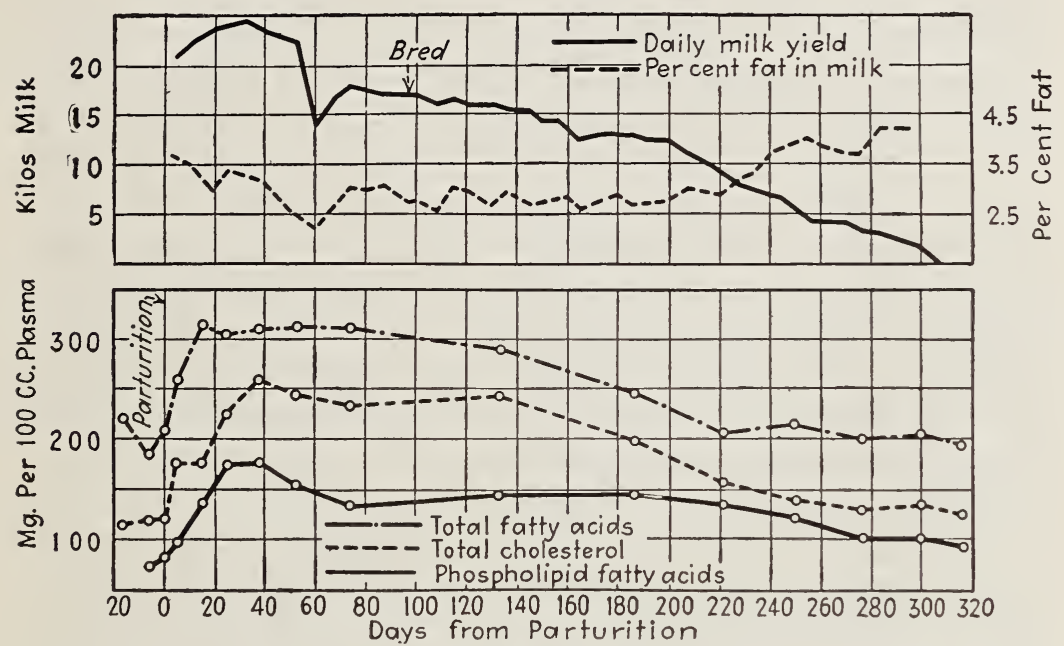

Fig. 41.-The blood-lipid levels during the lactation cycle in relation to the changes in milk yield and in fat percentage. (Maynard, Harrison, and M/cCay.)

lipids tends to follow the course of milk and fat yield rather than the fat percentage are illustrated in Fig. 41. Specifically, it may be noted that, though the fat percentage rises markedly toward the end of the lactation, the blood lipid levels tend to fall rather than otherwise. While a declining food and fat intake

${ }^{1}$ Poncher, Ch., and I. Maynard, La graisse du sang et la graisse du lait pendant la lactation, Le lait, 10, 601-613; 765-782, 1930. Marnard, L. A., E. S. Harmison, and C. M. MCCAY, The changes in the total fatty acids, phospholipid fatty acids, and cholesterol of the blood during the lactation cycle, J. Biol. Chem., 92, 263-272, 1931. MAYnans), L. A., and C. M. MCCAY, The influence of a low-fat diet upon fat metabolism during lactation, $J . N u$ trition, 2, 67-81, 1929. 
undoubtedly operates to cause a drop in blood-lipid level, the investigators found that there was a response in blood lipids with change in milk yield when the food intake was held constant.

Though the distribution of the fatty acids in milk fat can be modified by diet, there is no reliable evidence that the fat percentage can be altered significantly over any extended period by any of the commonly used feeds. The feeding of butter to a cow has been shown to raise the fat percentage, at least over a brief period. The explanation may lie in the fact that the gland is thus presented with the same fatty-acid mixture as is found in its secretion. There are several reports of positive effects with various feeds of vegetable origin, and there are an equal number of reports to the contrary with the same feeds. Failure to take adequate account of the many nondietary factors which cause the fat percentage to vary is doubtless responsible for the contradictory results obtained. Among the many feeds which have been claimed by various workers to raise the fat percentage, highfat press cakes of copra, the palm kernel, the babassu nut, and soybeans are the only ones for which the evidence seems at all consistent. The increases reported are in general small, and they have not been found to occur in all the animals studied or with all rations in which the feeds were included. They may, however, represent a real effect.

While repeated efforts to increase the fat percentage in milk have generally failed, cod-liver oil exerts a marked effect in lowering it. This peculiar response was first observed by Golding and associates ${ }^{1}$ in connection with studies of the influence of the oil on the vitamin content of the milk. It has since been confirmed in several laboratories. Feeding as small amounts as 2 oz. per day has caused a lowering, but larger and more consistent effects are observed with intakes of 4 to 6 oz. A 30 per cent decrease in the fat level has been noted. The specific factor in the oil which is responsible is found in the saponifiable fraction, but it has not been identified. The deleterious effect of the oil is eliminated by hydrogenation. Limited study suggests that this property of lowering the fat percentage is not shared by fish oils generally. Clearly vegetable oils do not exert the effect.

1 Golding, John, Katharine Marjorie Soames, and Sylvester Solomon ZILva, The influence of the cow's diet on the fat-soluble vitamins of winter milk, Biochem. J., 20, 1306-1319, 1926. 
337. The Secretion of Protein.-The very small amount of globulin which is present in milk is identical with globulin of blood plasma and is considered by most workers to represent merely a filtration product. Many workers also believe that lactalbumin is identical with the albumin of blood and that its origin in the milk is similar to that of the globulin. Casein, which makes up nearly 90 per cent of the milk protein, is clearly a synthetic product. Studies first carried out by Cary ${ }^{1}$ and later confirmed by other workers, showing that the amino-acid content of the blood plasma suffers a drop in passing the gland, furnished evidence that casein is made from amino acids, as is true for body proteins in general. Later studies, however, have convincingly shown that the quantity of amino acids removed by the gland is far too small to account for the amount of casein formed. Recent evidence favors blood globulin as the principal precursor.

338. The Secretion of the Mineral Elements.-The data presented in Table XXXI show that milk contains the same minerals as are present in blood plasma but that the quantitative relations are very different. How the gland selectively secretes its minerals presents a physicochemical problem which remains largely unexplained.

For a given animal, the principal mineral constituents normally show little variation, either periodically or over the lactation as a whole. This is brought out by the extensive mineral-balance studies of Forbes and coworkers. ${ }^{2}$ Neither diet nor blood changes have any influence on the calcium, phosphorus, or iron content of milk. The small amount of iodine present in milk can be increased, however, by adding an iodine compound to the ration (Sec. 137). There are recent reports that the small amounts of manganese, zinc, copper, and boron can also be influenced by their content in the ration. ( itrates of the electropositive minerals make up 30 per cent of the milk ash. The role of citric acid in milk is only partially understood, and nothing is known regarding its secretion.

1 CAry, C. $\Lambda .$, Amino acids of the blood as the precursors of milk proteins, J. Biol. Chem., 43, 477-489, 1920.

${ }^{2}$ Fonbes, Ennest B., and associates, The mineral requirements of milk prokuction: the ammal rycle of mineral and nitrogen metabolism of the mileh cow as affected by alfalfa hay, timothy hay, bone flour and ground limestone, Pa. Ayr. Expt. Sta. T'ech. Bull. 319, 1935. 
339. Pigments.-Milk contains both fat-soluble and watersoluble pigments. Of the fat-soluble, carotenoid group of pigments, which are synthesized by plants but not by animals, carotene is the principal one found in the milk of the cow. Chlorophyll is destroyed in the digestive tract, and this is presumably true to a certain extent also for xanthophyll, only a small amount of which gets into the milk. The occurrence of carotene in milk is limited primarily to the bovine species. The milk of the sheep, goat, and camel has little or none, and women's milk is nearly colorless. The reason for these breed and species differences is not known, but when there is no pigment in the milk the blood plasma is also free. The principal water-soluble pigment of milk is riboflavin, also known as lactoflavin. Since carotene is the precursor of vitamin $\mathrm{A}$, and since riboflavin is also a vitamin, the factors which govern their secretion in milk are best discussed later where the vitamin requirements for lactation are considered.

340. The Nature of Colostrum.-The first product from the mammary gland following parturition, the colostrum, is richer in total solids and total ash and much richer in protein, but lower in lactose than normal milk. The proteins, which make up approximately 17 per cent of the product in the case of the cow, consist principally of globulin and albumin, in marked contrast to their very low content in normal milk. Colostrum is rich in antibodies which apparently immunize the newborn temporarily against certain diseases, and it has a laxative action. In the course of the first few days of the lactation, it gradually assumes the composition of normal milk.

Formerly it was considered that colostrum was a special secretion of parturition designed as a more suitable food for the newborn than milk itself, but it is now recognized that this special product can be obtained weeks prior to parturition by manipulating the gland and that secretory activity can be stimulated at this time. As a result the colostrum gradually assumes the character of normal milk, even as it does after parturition, and if the milking is continued uninterrupted through parturition, no further change in the character of the secretion occurs. While accepting these facts, many still believe that colostrum is a special product resulting from the secretion of large amounts of globulin around the fourth and fifth month of pregnancy, and that this globulin has the specific function of carrying the antibodies. There is con- 
siderable support, however, for the view put forward by Porcher ${ }^{1}$ that colostrum is merely a normal milk which has been modified by the resorption of some of its constituents, notably water, lactose, and salts, as a result of its not being removed from the gland. He showed that a similar product could be obtained by allowing the milk to remain in the gland for an extended period instead of removing it regularly, and he produced other experimental evidence for his explanation.

Colostrum has nutritive values that are of special importance for the newborn, as has been shown particularly by studies of the secretion of the cow. The vitamin A content during the first day after parturition is usually ten to twenty times that of normal milk. This high level is of special value, since the store in the newborn is very limited, to help supply the needs of the early days of life when adequate vitamin A nutrition is of crucial importance (Sec. 301). Colostrum is several times as rich in iron as is normal milk. It is also richer in vitamin $\mathrm{D}$, thiamine, and riboflavin. These facts explain why it is so important for the newborn animal to receive colostrum in the interest of adequate nutrition and health.

341. Abnormal Milk Constituents.-It has been mentioned that some of the normal constituents of milk are apparently merely filtration products. Among those there are substances, such as urea, which represent useless products and which apparently pass into the milk in small amounts instead of being excreted entirely through the usual channels, because the membrane is not a perfect barrier. This fact raises the question as to the extent to which such substances as drugs and other nonnutritive or toxic substances may pass into the milk in health and in disease. This subject has been discusised rery comprehensively by Kolda ${ }^{2}$ with the general conclusion that the healthy gland is highly protective against the passage of foreign substances in harmful concentrations. Neither heavy metak, such as mereury and arsenic, nor volatile organic substances, such as aleohol, ether, and chloroform, pass into the milk in toxic amounts. The same was found true for salicylic aroid, aspirin and related compounds, and for various alkaloids such as morphine, atropine, and

1 Ponchen, ('н., La rétention lactée, Am. fals., 12, 329-343, 1919.

${ }^{2}$ Коцим, J., Du passage des substances médicanenteuses dans le lait, Lo lail, 6, 12-24, 88-102, 180-191, 269-287, 1926. 
quinine. It is recognized, however, that certain essential oils may pass into milk to the extent of causing an odor and taste, and that the poisonous principles of certain plants, such as white snake root and rayless goldenrod, may be secreted in sufficient amounts to render the milk harmful.

In diseases of the udder, particularly those characterized by inflammation, the membrane becomes much more permeable. The milk itself changes in the direction of the composition of blood with a resulting increase in protein and salts and a decrease in lactose. The protein fraction contains more albumin and less casein. With a more permeable gland, the danger from the entrance of harmful foreign substances is greatly increased. In diseases not affecting the udder, the primary effect is on yield of milk rather than upon its composition.

\section{THE ENERGY REQUIREMENT}

In addition to her maintenance requirement, the lactating animal must receive sufficient nutrients to supply those secreted in her milk and to cover the wastage involved in the process. It is obvious that a separate requirement can be stated for lactation only for those animals for which the current milk yield and its composition are known, i.e., for those used in commercial milk production. Thus we have specific knowledge of the nutritive needs for milk secretion only in the case of the dairy cow and goat. The following discussions deal principally with the cow.

342. Variations in Milk Composition.-While the milk of the individual cow tends to remain constant in composition, aside from fluctuations and cyclic changes in fat content, there are wide differences among individuals within a given breed as well as among the breeds themselves. This is shown by some data taken from the studies of Overman and Gaines ${ }^{1}$ and presented in Table XXXII. The complete data given by these workers cover an even wider range of fat percentage. The figures presented serve to illustrate the regular increases in protein and energy content that occur with a rising fat percentage and, in contrast, the nearly constant level of lactose that is maintained.

The data clearly show that the protein and energy requirements for milk production must be based on the composition of the

1 Overman, O. R., and W. L. Garnes, Milk-energy formulas for various breeds of cattle, J. Agr. Research, 46, 1109-1120, 1933. 
milk. Since they increase with fat content, formulas can be devised for computing the protein and energy content from fat percentage. This is very helpful because it is a simple matter by the Babcock test to determine the fat percentage sufficiently frequently to provide the basis for arriving at the nutritive

Table XXXII.-Composition of Holstein and Jersey Milk as Related to Its Fat Content

\begin{tabular}{|c|c|c|c|c|c|c|c|c|}
\hline $\begin{array}{c}\text { Fat-percentage } \\
\text { class }\end{array}$ & $\begin{array}{l}\text { No. of } \\
\text { records }\end{array}$ & $\begin{array}{c}\text { Fat, } \\
\%\end{array}$ & $\begin{array}{c}\text { Pro- } \\
\text { tein, } \\
\%\end{array}$ & $\begin{array}{c}\text { Lac- } \\
\text { tose, } \\
\%\end{array}$ & $\begin{array}{c}\text { Ash, } \\
\%\end{array}$ & $\begin{array}{c}\text { Water, } \\
\%\end{array}$ & $\begin{array}{c}\text { Energy } \\
\text { per kg. } \\
\text { of milk, } \\
\text { Cal. }\end{array}$ & $\begin{array}{c}\text { Pro- } \\
\text { tein } \\
\text { per Cal. } \\
\text { mg. }\end{array}$ \\
\hline \multicolumn{9}{|l|}{ Holsteins: } \\
\hline 2.60 to 2.79 & 8 & 2.709 & 3.055 & 5.000 & 0.656 & 88.58 & 616.4 & 49.6 \\
\hline 2.80 to 2.99 & 25 & 2.890 & 3.012 & 4.928 & 0.666 & 88.51 & 628.6 & 47.9 \\
\hline 3.00 to 3.19 & 40 & 3.104 & 3.169 & 4.846 & 0.672 & 88.21 & 654.1 & 48.4 \\
\hline 3.20 to 3.39 & 47 & 3.289 & 3.276 & 4.884 & 0.671 & 87.88 & 678.6 & 48.3 \\
\hline 3.40 to 3.59 & 42 & 3.488 & 3.388 & 4.853 & 0.688 & 87.58 & 702.9 & 48.2 \\
\hline 3.60 to 3.79 & 35 & 3.674 & 3.361 & 4.866 & 0.672 & 87.43 & 718.5 & 46.8 \\
\hline 3.80 to 3.99 & 29 & 3.874 & 3.502 & 4.863 & 0.681 & 87.08 & 745.2 & 47.0 \\
\hline 4.00 to 4.19 & 11 & 4.078 & 3.734 & 4.858 & 0.694 & 86.64 & 777.2 & 48.0 \\
\hline 4.20 to 4.39 & 13 & 4.313 & 3.967 & 4.722 & 0.697 & 86.30 & 806.4 & 49.2 \\
\hline \multicolumn{9}{|l|}{ Jerseys: } \\
\hline 3.80 to 3.99 & 8 & 3.910 & 3.623 & 4.860 & 0.683 & 86.92 & 755.1 & 48.0 \\
\hline 4.00 to 4.19 & 5 & 4.074 & 3.302 & 4.866 & 0.660 & 87.10 & 752.2 & 43.9 \\
\hline 4.20 to 4.39 & 11 & 4.292 & 3.695 & 5.126 & 0.697 & 86.19 & 806.1 & 45.8 \\
\hline 4.40 to 4.59 & 18 & 4.493 & 3.648 & 5.058 & 0.691 & 86.11 & 819.3 & 44.5 \\
\hline 4.60 to 4.79 & 16 & 4.668 & 3.556 & 5.059 & 0.681 & 86.03 & 830.2 & 42.8 \\
\hline 4.80 to 4.99 & 20 & 4.881 & 3.715 & 5.058 & 0.693 & 85.65 & 859.3 & 43.2 \\
\hline 5.00 to 5.19 & 19 & 5.091 & 3.896 & 4.919 & 0.694 & 85.40 & 883.1 & 44.1 \\
\hline 5.20 to 5.39 & 26 & 5.295 & 3.859 & 5.026 & 0.698 & 85.12 & 904.7 & 42.7 \\
\hline 5.40 to 5.59 & 16 & 5.479 & 3.891 & 4.986 & 0.693 & 84.95 & 921.7 & 42.2 \\
\hline 5.60 to 5.79 & 16 & 5.707 & 4.171 & 4.963 & 0.743 & 84.42 & 959.7 & 43.5 \\
\hline 5.80 to 5.99 & 12 & 5.892 & 4.288 & 4.929 & 0.732 & 84.16 & 981.4 & 43.7 \\
\hline 6.00 to 6.19 & 8 & 6.081 & 4.264 & 4.764 & 0.726 & 84.17 & 990.9 & 43.0 \\
\hline 6.20 to 6.39 & 5 & 6.230 & 4.010 & 4.982 & 0.713 & 84.06 & 999.2 & 40.1 \\
\hline
\end{tabular}

requirements, whereas the determination of protein and energy would be very time-consuming. The relations are somewhat different for the various breeds as is evident from the data for protein per Calorie given in the table. Overman and Gaines devised formulas for various breeds for calculating the energy content from fat percentage. They concluded, however, that, for practical purposes, it was permissible to use a single formula, earlier proposed by Caines, ${ }^{1}$ which could be expressed in terms of

${ }^{1}$ Gaines, W. L., The energy basis of measuring milk yield in dairy cows, Univ. of Ill., Agr. Expt. Sta. Bull. 308, 1928. 
4 per cent milk as follows: 4 per cent milk $=0.4 M+15 F . \quad M$ is the weight of milk and $F$ the weight of fat contained in it. The amount of 4 per cent milk thus obtained is multiplied by its calorific value (750 Cal. per kilogram) giving the energy content per kilogram of the original milk.

Overman and Gaines also give formulas for each breed for computing protein content from energy value. They use the basis of $50 \mathrm{mg}$. of protein per Calorie as an approximate relation applying to all breeds.

343. Estimation of Energy Requirements from Metabolism Studies.-A number of workers who have carried out energybalance studies with dairy cows have estimated the energy requirements for milk production from data as to the energy content of the milk and data as to the percentage of feed energy recovered in its secretion. Kriss ${ }^{1}$ has reviewed the different procedures used by these workers. As an example of the basic feature involved, the recently published method of Forbes and Kriss ${ }^{2}$ may be outlined.

From a consideration of 3 complete energy balances by Kellner and 11 carried out at the Pennsylvania Institute of Animal Nutrition, it was found that the average utilization of metabolizable energy for milk production was 69.3 per cent. Forbes and Kriss used this factor to compute the metabolizable energy requirement per pound of milk for milks of different energy contents. From a study of the data of 77 experiments in the respiration calorimeter, they found that, for the rations employed, the average metabolizable energy per pound of total digestible nutrients was 1.616 Therms. This provided a basis for translating their metabolizable energy requirements into total digestible nutrients. Thus, from a consideration of the relation between fat percentage and energy content in milk, they were able to express the requirements in terms of the commonly used method, viz., total digestible nutrients per pound of milk for different

${ }^{1}$ KrISs, MAX, A comparison of feeding standards for dairy cows, with special reference to energy requirements, $J$. Nutrition, 4, 141-161, 1931.

${ }^{2}$ Forbes, E. B., and Max Kriss, The nutritive requirements of the dairy cow expressed in accord with a new method of application of the net-energy conception. Proc. Am. Soc. Animal Production, 1931, pp. 113-120; The nutritive requirements of the dairy cow expressed in accord with a new method of application of the net-energy conception: a correction, ibid., 1932, pp. 344345 . 
fat percentages. For example, the requirement for $1 \mathrm{lb}$. of 3 per cent milk was stated as $0.251 \mathrm{lb}$. of total digestible nutrients, for 4 per cent milk, $0.30 \mathrm{lb}$, and the like. The writers recognized that their standards as thus suggested might require revision after trial in practice, and they proposed the standards as an illustration of the method of estimation rather than as final recommendations.

344. Energy Requirements as Determined in Feeding Trials.The energy requirements for milk production which are specified in the commonly used standards have been derived principally from feeding trials. The general procedure here has been to record the feed intakes and production of groups of cows differently fed and to select as the requirements those intakes which were found to give the best production over extended periods and, at the same time, maintain the weight of the animal. By the subtraction of a maintenance requirement determined after the cows were dry, or upon other animals, the net intakes required for the milk produced were obtained. Most commonly the resulting data have been expressed as total digestible nutrients, based either upon digestion trials run as a part of the experiment or else calculated by the use of the average coefficients for digestibility.

Haecker, who was the first to recognize that the food requirements must vary in accordance with the composition of the product, began in 1897 a series of investigations of nutrient requirements for milk production which extended over many years. His publication in $1914^{1}$ set forth total-digestible-nutrient requirements in accordance with the milk produced. No later work has been so extensive as that of Haecker, but most of it has suggested somewhat lower values. The latest standard published by Morrison states the requirement per pound of milk of a given fat percentage as a range, the upper figures of which are somewhat lower than those proposed by Haecker.

Overman and Gaines ${ }^{2}$ have pointed out that the neressity of tables giving the energy requirement per pound of milk of various fat contents can be eliminated by first translating the yield into standard 4 per cent milk by their formula and then computing the

${ }^{1}$ HАескен, T. L., Investigations in milk-production, Minn. Agr. Expt. Sla. Bull. 140, 1914.

2 Overman and (iaines, loc. cil. 
requirement in terms of this milk. The N.R.C. allowance is expressed on this simplified basis-namely, as 0.32 lb. T.D.N. per pound of 4 per cent milk (Table XXXIII, p. 429). Overman and Gaines suggest that the total nutritive value of the feeds be expressed in digestible energy and that $200 \mathrm{Cal}$. of this energy be allowed for each 100 Cal. in the milk.

In practice it is frequently found impossible to get the milking cow to consume as much total food during the peak of her lactation as is specified by her energy requirement. An inadequate intake under these conditions does not seem to limit production because the impulse to secrete causes the body reserves to be called upon. This is another reason for liberal feeding during the last part of gestation. The aim throughout lactation should be to prevent any marked loss of body weight, but fattening should be avoided except for the purpose of restoring any large loss which has occurred early in lactation, because milk secretion tends to decline if marked fattening occurs.

345. The Importance of Food Fat in Lactation.-While many experiments have shown that milk fat can be made from carbohydrates, a séries of studies at Cornell University has indicated that a certain minimum level of fat is needed in the ration of the cow for the best milk yield. Some results from the initial experiment are presented in Fig. 42. The ration of higher fat content consisted of hay, silage, and a grain mixture containing 5.8 per cent of fat, while the low-fat ration was the same with the exception that, as a result of extraction, the fat content of the grain mixture was reduced to 0.66 per cent and an isodynamically equivalent amount of starch added. The effects on production from the alternate feeding of these rations are clear.

These initial studies were followed by many others using different combinations of feeds typical of commonly fed rations. Most of them dealt with the comparisons of grain mixtures containing around 2 per cent of fat with those containing 4 to 6 per cent. In a total of 18 different comparisons, more 4 per cent fatcorrected milk was always produced on the concentrate mixture of higher fat content. The milk yield increased with little or no change in its fat percentage. The extensiveness of the tests and the uniformity of the results leave no doubt that the differences observed are highly significant statistically. The results of the first 10 comparisons are summarized in a bulletin by Maynard 
and associates. ${ }^{1}$ Others are given in papers cited at the end of this chapter.

It can be calculated on the basis of these studies that $100 \mathrm{lb}$. of grain mixture, containing 4 per cent fat, produced as much milk on the average as did $104 \mathrm{lb}$. of a similar mixture with only
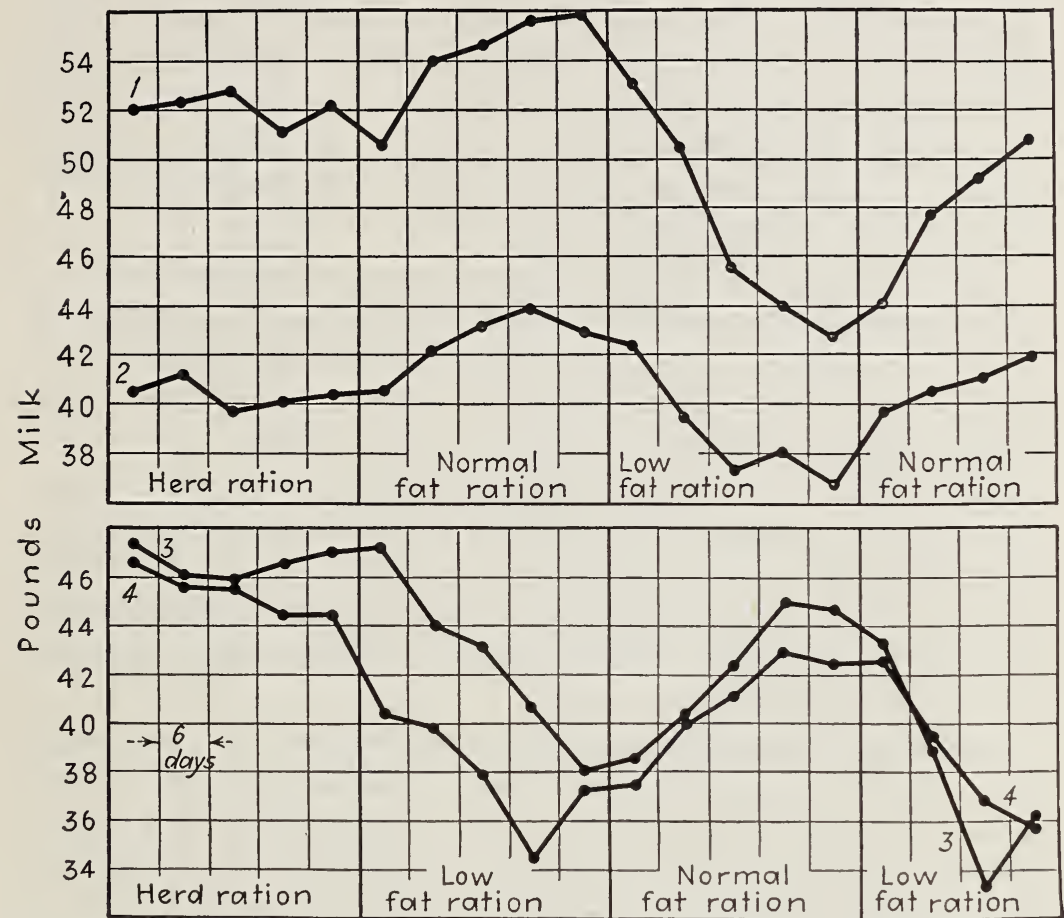

FIG. 42.-The influence of a ration low in fat on milk yield. (Maynard and McCay.)

2 per cent fat. The increased production was considerably greater than could be accounted for by any increased 'T.D.N. content of the higher fat mixture.

Supplementary studies indicated that the beneficial effects of the rations of higher fat content were not the result of an increased intake of fat-soluble vitamins nor of a possible improvement of the digestibility of the ration as a whole. No evidence was obtained that a speeific kind of fat was responsible. 'The probable

${ }^{1}$ MAYNARD, L. A., and associates, III. Further studies of the influence of different levels of fat intake upon milk secretion, Cornell Universily A $\mathrm{gr}$. Expl. Sta. Bull. 753, 1941. 
explanation is that the higher fat intake resulted in a more effective utilization of the digested energy, for milk production. Such an explanation is supported by the recent findings of Forbes and associates ${ }^{1}$ with rats, that increasing the fat level in the diet increases its efficiency by diminishing the heat increment (Sec. 241). This explanation is also suggested by the Cornell findings that the difference in milk production could generally be compensated for by feeding a larger amount of the low-fat grain mixture. Thus, in practice, the question may be purely an economic one as to whether a grain mixture of higher fat content would cost more than the extra feed otherwise required.

The statement is frequently made that an excessive amount of fat in the dairy ration tends to lower milk yield and some evidence for this viewpoint has been obtained by feeding certain oils. It is clear from the Cornell studies, however, that adding oils as such is not a proper method of testing the effects of the fat level in natural feeds. Undoubtedly the herbivorous animal has a lower tolerance for fat than Omnivora, but repeated experiments have failed to find any unfavorable effect from increasing the fat intake of the cow by natural feeds to levels considerably in excess of the amounts secreted in the milk, involving intakes close to a pound per day per $1000 \mathrm{lb}$. live weight.

346. Energy Requirements for Other Species.-In the absence of any measures of the amount of milk being secreted, no attempt is made to specify energy requirements for animals nursing young, separate from their total needs covering maintenance as well. On the basis of feeding trials, standards have been proposed by Morrison to cover the over-all requirements of sows, ewes, mares, and beef cows during lactation. In practice their total feed allowances are regulated in accordance with their apparent needs by giving sufficient amounts to keep them in good flesh during the nursing period. The N.R.C. over-all allowances for sows, ewes, and beef cattle are summarized in Table XXXIII.

\section{THE PROTEIN REQUIREMENT}

The minimum protein requirement for milk production is the amount secreted in the milk plus any catabolized as a specific

${ }^{1}$ Forbes, E. B., and associates, Relation of fat to economy of food utilization. I. By the growing albino rat, J. Nutrition, 31, 203-212, 1946; II. By the mature albino rat, ibid., 213-227. 
accompaniment or result of the secretory process. In translating this minimum value into an actual requirement, account must be taken of the wastage in digestion and metabolism. It is customary to state the requirement for dairy cows in terms of digestible protein, since digestion coefficients are available for all of the common feeds for use in computing a ration which will meet a given requirement on this basis. The wastage in metabolism, however, is much less readily accounted for, since this is dependent upon the quality of the protein in terms of its amino-acid make-up.

347. The Biological Value of Protein for Lactation.-The differences in the biological values of various proteins and combinations

Table XXXIII.-Récommended Nutrient Allowances for

Lactation in Sows, Ewes, Dairy Cows, and Beef Cows

(Committee on Animal Nutrition, National Research Council)

\begin{tabular}{|c|c|c|c|c|}
\hline & $\begin{array}{c}\text { Sows } \\
\text { (per } \\
\text { animal) }\end{array}$ & $\begin{array}{c}\text { Ewes } \\
\text { (per } \\
\text { animal) }\end{array}$ & $\begin{array}{c}\text { Dairy cows } \\
\text { (per lb. milk, } \\
4 \% \text { fat) }\end{array}$ & $\begin{array}{c}\text { Beef cows * } \\
\text { (per animal, } \\
900-1100 \text { lb.) }\end{array}$ \\
\hline Daily feed, lb. ...... & $10-15$ & $4.5-5.0$ & & 28 \\
\hline $\begin{array}{l}\text { Total digestible nu- } \\
\quad \text { trients, } 1 \mathrm{~b} . \ldots \ldots\end{array}$ & $7.5-11.3$ & $2.5-3.0$ & 0.32 & 14 \\
\hline Digestible protein, lb. & $\ldots \ldots$ & $0.27-0.31$ & 0.045 & 1.4 \\
\hline Crude protein, lb. . . . & $1.5-2.3$ & $\ldots$ & ... & $\ldots \ldots$ \\
\hline Carotene, mg. ...... & 40 & $6.0-9.7$ & required & 300 \\
\hline Vitamin A, I.U. . . . . & 26,000 & $\ldots$ & & $\ldots$ \\
\hline Vitamin D, I.U. ..... & 625 & $\ldots$. & required & $\ldots \ldots$ \\
\hline Thiamine, mg. ...... & 6.3 & $\ldots$ & $\ldots \ldots$ & $\ldots$ \\
\hline Calcium, gm. ...... & $27-41$ & $6.1-6.8$ & 1 & 30 \\
\hline Phosphorus, gm. .... & $18-27$ & $4.5-5.0$ & 0.7 & 24 \\
\hline
\end{tabular}

* Figures are for the three or four months after parturition.

of them for growth, which modify the intakes required for this function according to the sources used, have been discussed (Secs. 278, 283). 'That similar differences exist as regards milk secretion is to be expected, since there is no evidence that the mammary gland has special powers for the synthesis of amino acids not possessed by other tissues of the body. In so far as farm animals are concerned, sows are the only ones for which differences in protein quality for lactation have been demonstrated. Here it appears that the kind or combinations of proteins that are efficient for growth are also efficient for milk production.

The evidence that protein quality is of much less importance 
for ruminants and the reasons therefore have been discussed (Sec. 281). Carefully conducted feeding trials with milking cows have failed to reveal differences in efficiency among the protein combinations that show such differences in the case of nonruminants. The nitrogen-balance procedure, which provides the most exact measure of the biological value of protein for growth, cannot be relied upon to produce significant data from lactation studies because there are variables that cannot be controlled. It seems probable that the nature of the protein fed is of some importance in the case of lactating ruminants, but it appears to be a minor consideration in selecting their rations. This is a field in which more critical studies are called for, guided by the information now obtainable by microbiological procedures as to the specific amino-acid make-up of feeds and rations.

348. Protein Requirements as Measured by Feeding Trials.The protein allowances for milking cows recommended by current standards are based primarily on the results of feeding trials. Using combinations of feeds which are recognized to be satisfactory for milk production in other respects, the object has been to determine the protein intake which would certainly prove adequate for maximum production. Long-time feeding trials are essential for this purpose because an animal can keep up its production for an extended period, particularly in the first half of lactation, at the expense of its own tissues.

Haecker, whose long-time, pioneer studies have been referred to (Sec. 344), concluded that, allowing $0.7 \mathrm{lb}$. of digestible protein per $1000 \mathrm{lb}$. live weight for maintenance, an additional intake representing 138 per cent of that secreted in the milk was adequate for satisfactory production and condition. He rejected a lower figure, because he felt that it did not keep the animals in the best condition. In setting up a standard for practice, Haecker increased the figure of 138 per cent to 175 per cent to allow a "factor of safety."

Since the pioneer studies of Haecker, many other experiments have been conducted to determine the protein requirements for milk production. Harrison and Savage ${ }^{1}$ made extensive studies

${ }^{1}$ Harrison, E. S., and E. S. SAVAGE, The effect of different planes of protein intake upon milk production, Cornell Agr. Expt. Sta. Bull. 504, 1932. Harrison, E. S., E. S. Savage, and S. H. Work, The effect of different planes of protein intake upon milk production. II. Further comparisons of 16-, 20-, and 24-per cent mixtures, ibid., 578, 1933. 
in which concentrate mixtures containing $12,16,20$, and 24 per cent of protein were fed with timothy-clover-mixed-hay and corn silage. In two studies extending over two complete lactation periods, the ration containing the 16 per cent protein grain mixture gave as satisfactory results as those containing more protein. It was concluded that, when $0.7 \mathrm{lb}$. per $1000 \mathrm{lb}$. live weight is allowed for maintenance, an additional intake corresponding to 128 per cent of that secreted in the milk, the level supplied by the 16 per cent combination, is adequate. In a later experiment by the alternation system, a ration containing a 12 per cent protein mixture proved definitely inadequate as compared to the higher levels. While no significant differences between the three higher levels were noticeable for any one year, considering the experiments as a whole, the investigators noted a distinct indication of a slightly larger production where the 20 per cent mixture was fed than was the case with the 16 per cent mixture. The ration containing the 20 per cent combination supplied 150 per cent of the protein in the milk, after deducting the allowance for maintenance.

349. Nitrogen-balance Data as Measures of Adequate Protein Nutrition.-The fact that milk production can take place at the expense of body tissue has caused various workers to study the nitrogen balance as a further measure of the adequacy of intakes which were giving satisfactory production. When this has been done, it has generally bcen found that satisfactory production and nitrogen equilibrium can be maintained, at least over short periods, on intakes considerably below those recommended on the basis of feeding trials. An example of the use of the nitrogenbalance method in measuring protein requirement is presented by an experiment by Fries and associates. ${ }^{1}$ Allowing $0.6 \mathrm{lb}$. of protein per $1000 \mathrm{lb}$. live weight for maintenance, various additional levels calculated as percentages of the milk yield were fed in different periods. It was found that the cows were approximately in nitrogen equilibrium when the nitrogen intake above the calculated maintenance was from 111 to 117 per cent of the output in the milk. There was evidence, however, that this intake tended to lower the level of secretion.

When the protein intake is reduced below the recquirement,

1 Fries, J. August, Winfred W. Braman, and Max liriss, On the protein equirement of milk production, J. Dairy Sci., 7, 11-23, 1924. 
there may be a drop in production, or its level may be maintained at the expense of the body and be reflected in a negative balance. Undoubtedly both take place over any long period on an inadequate protein intake. Such was found to be the case in a supplementary study of the ration containing the 12 per cent protein grain mixture used by Harrison and Savage. Clearly nitrogenbalance data alone are not an adequate measure of a satisfactory protein intake for milk production, but they provide useful supplementary information in connection with feeding trials.

Several of the nitrogen-balance studies have furnished some pertinent information relative to the maintenance requirement for protein during lactation. In many instances where positive nitrogen balances have been obtained, subtracting from the intake of digestible protein an allowance of 0.7 or even $0.6 \mathrm{lb}$. for maintenance has left a remainder which is less than the amount of protein found in the milk. Since a conversion efficiency greater than 100 per cent is impossible such a finding must mean that the amount actually used for maintenance was less than calculated. If the customarily used maintenance values are correct for the nonproducing animal, then they must be lower under certain conditions of production. Such findings from short-time balance studies are interesting, but it is unsafe to interpret them as having general application in practice.

350. Protein Allowances for Milking Cows in Practice.-The data of the many experiments dealing with the protein requirements for milk production, a few of which have been cited, are by no means in agreement. Close agreement among experiments conducted under different conditions is hardly to be expected in view of the variables concerned in protein utilization. From a consideration of the many data, the writer believes that, basing the maintenance requirement on an intake of $0.6 \mathrm{lb}$. of digestible protein for a $1000-\mathrm{lb}$. cow, the allowance for production should be at least 125 per cent of that secreted in the milk. This corresponds to the N.R.C. allowance of $0.045 \mathrm{lb}$. of digestible protein per pound of 4 per cent milk (Table XXXIII). It is believed that somewhat higher levels will give superior results under many conditions. Despite the evidence that lower intakes have resulted in excellent production in several experiments, liberal allowances seem wise as general recommendations, because of the indications that they may produce somewhat more milk under many con- 
ditions, because of the lack of certain knowledge as to the extent of the differences in biological value which may occur, and because of the possible effect of liberal intakes in improving energy utilization (Sec. 243). From the standpoint of practice, however, the possible advantage of the higher level of intake may be overbalanced in many situations by the extra cost of high-protein feeds.

The protein content of milks of different fat percentage may be calculated by the relations set forth by Overman and Gaines (Sec. 342) or one may consider the protein percentage increases by 0.42 for each 1 per cent increase in fat, as found in studies at the Ohio Experiment Station.

351. Protein Requirements for Other Species.-There is no basis for estimating the requirements of animals nursing young in terms of their actual lactation performance. Rations having a nutritive ratio of approximately $1: 7$ should contain an adequate proportion of protein, with the exception that a somewhat narrower ratio may be preferable for brood sows. It is noted in Table XXX that the protein-Calorie ratios for the milk of the different species of farm animals are not markedly different. The N.R.C. allowances covering both maintenance and lactation in sows, ewes, and beef cows, are given in Table XXXIII. The ranges are for animals of different size.

\section{THE MINERAL REQUIREMENTS}

Aside from the elements supplied by common salt, the only minerals which require consideration in rations for milk secretion are calcium and phosphorus. The others which occur in milk are generally supplied adequately by the commonly used feeds.

352. Calcium and Phosphorus.-Compounds of calcium and phosphorus make up approximately 50 per cent of the ash of milk and thus its secretion requires a liberal supply of them in the ration. A cow producing $10,000 \mathrm{lb}$. of milk during her lactation secretes in it approximately $12 \mathrm{lb}$. of calcium and $10 \mathrm{lb}$. of phosphorus, and, at the peak of her production, the daily calcium output may exceed $30 \mathrm{~g}$, with a somewhat smaller figure for phosphorus. These figures, however, do not represent the total requirements of the lactating animal because of the needs for maintenance, as well as for the pregnancy which normally occurs 
in the course of the lactation, and because of the fact that there is a large wastage of calcium and phosphorus in metabolism.

353. The Cycle of Calcium and Phosphorus Metabolism.Owing primarily to the pioneer and extensive work of Forbes and associates ${ }^{1}$ begun in 1912 at the Ohio Experiment Station, it has come to be recognized that the natural and significant unit of time in the calcium and phosphorus metabolism of the dairy cow is the annual cycle of lactation and gestation. By means of balance experiments, Forbes found that the most liberal feeding of calcium and phosphorus would commonly not meet the current needs of liberally producing cows during the first part of the lactation but that, toward the end of the lactation and particularly during the dry period, the earlier losses from the body ceased and were replaced by a storage of the elements. A similar cycle has been found to occur in lactating women, and there is evidence that the same is true for the rat and dog. Probably this depletion and restoration of the bone reserves is a common occurrence in all mammals during the lactation cycle.

By continuous balance studies over the entire cycle of lactation and gestation both Ellenberger and coworkers ${ }^{2}$ and Forbes and coworkers ${ }^{3}$ have shown that liberally producing cows may be in negative calcium and phosphorus balance for extended periods early in lactation and still end the cycle with a surplus of the minerals, as a result of storage later in the lactation and during the dry period. Data from one of the Vermont studies are presented in Fig. 43. This chart gives the record of a mature Ayrshire cow from the beginning of lactation over a period of 58 weeks until calving. She was in milk for 47 weeks and produced 11,254 lb. during this period. Her ration consisted of timothy hay, corn silage, and grain during the winter, but during the summer

${ }^{1}$ Forbes, E. B., and F. M. Beegle, The mineral metabolism of the milch cow. I, Ohio Agr. Expt. Sta. Bull. 295, 1916. Forbes, E. B., and associates, The mineral metabolism of the milch cow. II, ibid., 308, 1917. Forbes, E.B., J. O. Halverson, and L. E. Morgan, The mineral metabolism of the milch cow. III, ibid., 330, 1918.

${ }^{2}$ Ellenberger, H. B., J. A. Newlander, and C. H. Jones, Calcium and phosphorus requirements of dairy cows. I. Weekly balances through lactation and gestation periods, Vt. Agr. Expt. Sta. Bull. 331, 1931; Calcium and phosphorus requirements of dairy cows. II. Weekly balances through lactation and gestation periods, ibid., 342, 1932.

${ }^{3}$ Forbes and associates, loc. cit. 
the silage was discontinued and fresh-cut grass was largely substituted for the hay. The average daily intakes of calcium and phosphorus were approximately 45 and $60 \mathrm{~g}$., respectively.

The weekly balances presented in the upper part of the chart, while showing considerable fluctuations, reveal losses of the elements, particularly of calcium, during the early weeks, in contrast to storages which regularly occurred during the last half of the
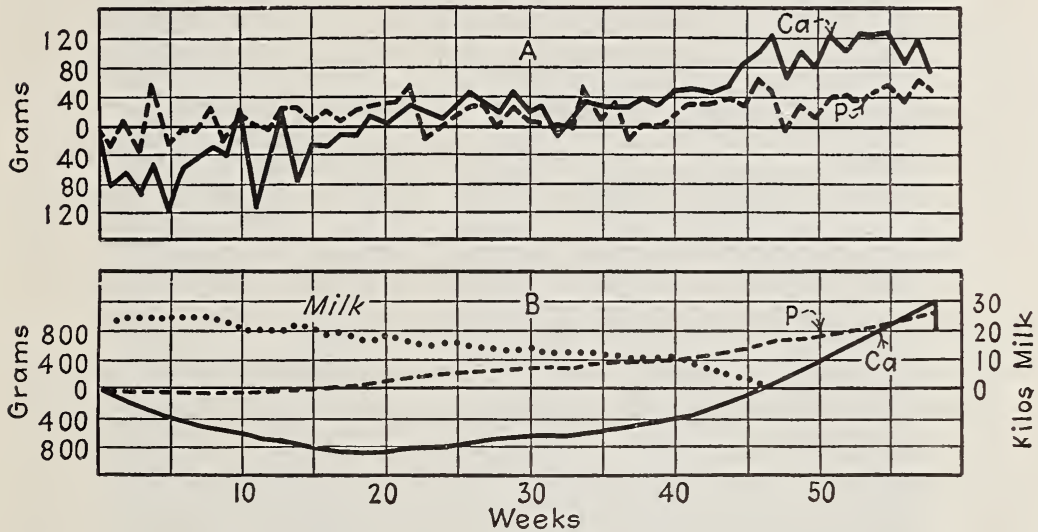

Fig. 43.-Calcium and phosphorus balances throughout the lactation cycle. $A$. Weekly balances of calcium and phosphorus. B. Milk yield and cumulative balances of calcium and phosphorus. (Ellenberger, Newlander, and Jones.)

period. The results over the period as a whole are better shown in the lower part of the chart where the cumulative balances are presented. It is noted that the cow had lost calcium for 20 weeks and did not regain her losses completely until the forty-sixth week, a point which happened to coincide with the close of the lactation. During the following weeks, the calcium store accumulated rapidly. The curve for phosphorus shows a net loss through 12 weeks, followed by a storage which was accelerated as the decline in milk flow became more rapid. The dips in both curves at the end represent a subtraction of the minerals in the calf and placenta. Clearly, negative balances early in lactation do not necessarily mean that the ration is inadequate in calcium and phosphorus for the cycle as a whole, and it would appear that the utilization of reserves early in lactation is a normal process, not harmful to the animal provided the losses are not too great and provided they are fully made good later. 
354. Effects of Calcium and Phosphorus Deficiencies.-If, owing to an inadequate ration, the demands for calcium and phosphorus during lactation are in excess of the reserve supply, or, if the losses are not made good, both the animal and her production eventually suffer. With rations which are extremely low in either of the minerals, the bones may become so impoverished in them as to break, destroying the usefulness of the animal. In less severe situations, the bones may become progressively weakened in succeeding lactations due to incomplete restoration of the losses, and thus it becomes increasingly difficult for the animal to keep up her milk flow. The production may fall off more rapidly than normal in a given lactation, or it may fail to reach previous levels in succeeding lactations. The effect of small deficiencies of calcium and phosphorus may not become evident until after two or three or more years, the essential effect being to shorten the productive life of the animal.

Striking evidence of the effect on production of inadequate calcium and phosphorus nutrition has come from studies in the phosphorus-deficient areas. In South Africa ${ }^{1}$ the feeding of bone meal to cows on deficient pasture increased the milk production by 40 per cent, while in Minnesota ${ }^{2}$ the addition of phosphorus increased the yield by 50 to 146 per cent. It is estimated by the Minnesota authorities that the production losses in phosphorusdeficient areas cost the farmers over a million dollars in the five years prior to the discovery of the cause of the trouble. Similar effects from severe calcium deficiency have been reported from Florida by Becker and coworkers. ${ }^{3}$ Owing to the very low content of this element in the roughages, broken hips and ribs were not an uncommon occurrence in the lactating animals. When the calcium intake was raised by the addition of bone meal the yield, per lactation, increased by 50 per cent, and the cows became more persistent producers. When they were slaughtered at the close of the experiment, tests of the bones revealed an excellent

1 Theiler, Arnold, H. H. Green, and P. J. du Toit, Phosphorus in the live stock industry, J. Dept. Agr., Union S. Africa, 8, 460-504, 1924.

${ }^{2}$ Eckles, C. H., T. W. Gullickson, and L. S. Palmer, Phosphorus deficiency in the rations of cattle, Minn. Agr. Expt. Sta. Tech. Bull. 91, 1932.

${ }^{3}$ Becker, R. B., W. M. Neal, and A. L. Shealy, Effect of calciumdeficient roughages on the milk yield and bone strength of cattle, J. Dairy Sci., 17, 1-i0, 1934. 
state of mineral storage. Depleted bones from an animal on the calcium-deficient ration are shown in Fig. 44.

- To what extent a less severe and thus unnoticed bone depletion may limit milk production and productive life, by reason of rations inadequate in calcium and phosphorus, is unknown. In

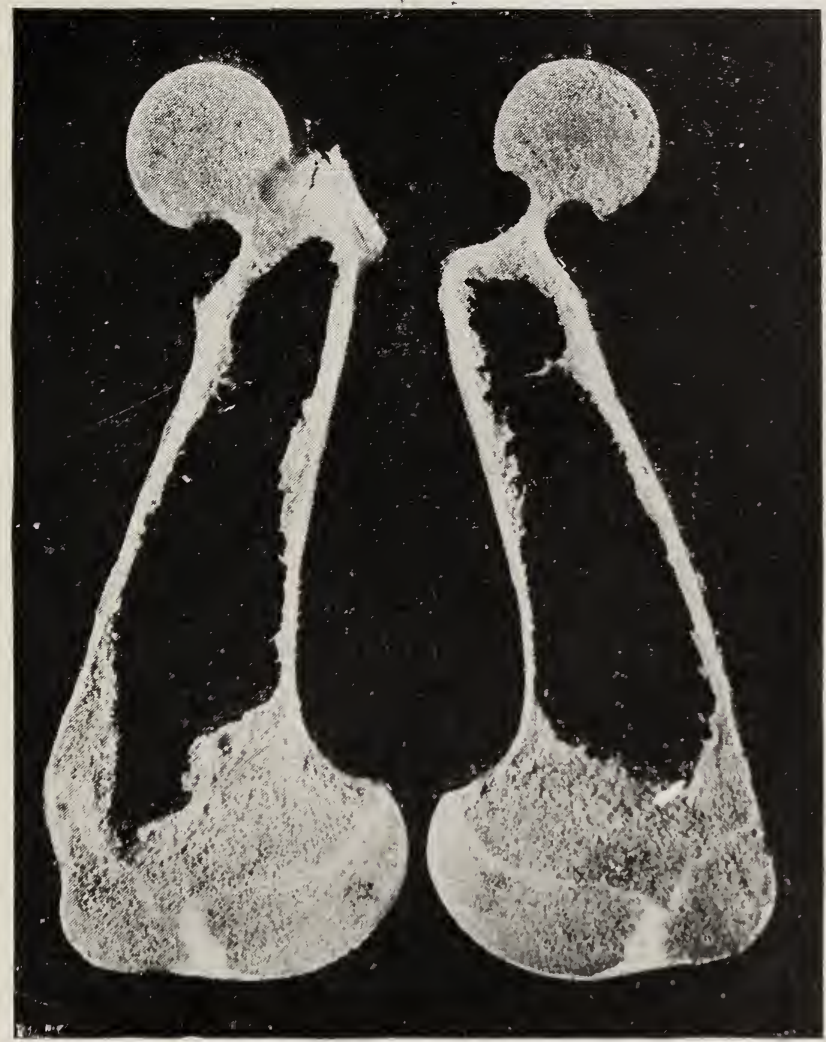

Fra. 44.- Humeri depleted by a ration low in calcium. These bones were taken from a first-calf heifer. (Courtesy of R. B. Becker, Fla. Agri. Expt. Sta.)

fact, it is possible that, even with the best mineral nutrition we know how to provide, productive life may be shortened by failure to meet the physiological demands of extremely high production. Evidence on the question would be very difficult to obtain.

The extent of the losses from the bones which can occur early in lactation without immediate detriment to production or the bones themselves, provided the losses are made good later, depends upon the state of the reserves at the start. It is clear 
that, in considering the entire cycle as a unit, we cannot ignore its various parts. The early losses of calcium and phosphorus can be kept at a minimum by liberal intakes at this time; in fact, some investigators have reported that cows producing from 60 to $80 \mathrm{lb}$. a day have been held in equilibrium either by the use of natural feeds rich in the minerals or by the addition of mineral supplements. While the majority of the experimental results show that such success is unusual, it is desirable to feed the minerals liberally so that excessive losses will certainly be avoided.

355. Calcium and Phosphorus Requirements.-As a basis for estimating the requirements of the dairy cow, there are the annual balances previously discussed, data from slaughter experiments as to the state of the bones after successive lactations and the results of long-time feeding trials. From the Vermont data, it is clear that $45 \mathrm{~g}$. of calcium and $60 \mathrm{~g}$. of phosphorus per day were certainly adequate for a cow producing around 11,000 lb. But they cannot be considered minimum values, especially in the case of phosphorus, in view of the net storages obtained. For a similar production, Forbes and associates, from their annual balances, express the view that a ration containing $39 \mathrm{~g}$. of calcium and $33 \mathrm{~g}$. of phosphorus is adequate. The phosphorus figure rests on the more certain basis. From slaughter experiments, Meigs and coworkers ${ }^{1}$ have reported that $25 \mathrm{~g}$. of calcium was not quite adequate to maintain bones intact in successive lactations in cows producing around $6600 \mathrm{lb}$. of milk annually. In contrast Hart and coworkers ${ }^{2}$ report that the bones of cows producing 10,000 to $12,000 \mathrm{lb}$. annually remained intact up to the fourth lactation on an average daily calcium intake of 25 to $28 \mathrm{~g}$. and a phosphorus intake of $28 \mathrm{~g}$. In this experiment timothy hay ranging from 0.35 to 0.5 per cent calcium was used. The lower value was employed in calculating the calcium figures reported. These calcium and phosphorus intakes could be supplied by rations which contain approximately 0.25 per cent of each of the elements in the dry matter. The figures suggested by Forbes

1 Meigs, Edward B., and associates, The effects on calcium and phosphorus metabolism in dairy cows, of feeding low-calcium rations for long periods, J. Agr. Research, 51, 1-26, 1935.

${ }^{2}$ Hart, E. B., F. B. Hadley, and G. C. Humphrey, The relation of nutrition to contagious cattle abortion, Wis. Agr. Expt. Sta. Research Bull. 112, 1932. 
and coworkers would require around 0.32 per cent of calcium and 0.3 per cent of phosphorus.

It is evident that expressing the requirements as averages for the cycle as a whole does not take account of the greatly varying demands according to the stage of lactation. While it is generally impossible to prevent losses from the bones during the height of secretion, it seems reasonable to provide intakes at this time in accordance with the amounts being secreted. Milk contains approximately $0.5 \mathrm{~g}$. of calcium and $0.4 \mathrm{~g}$. of phosphorus per pound. The intakes specified must allow for the wastage in assimilation, and the total allowances must also cover the needs of maintenance. The data for arriving at these figures are meager. Using $10 \mathrm{~g}$. of phosphorus as the maintenance requirement for a 1000-lb. cow, Huffman and associates ${ }^{1}$ concluded that there should be an additional allowance of $0.75 \mathrm{~g}$. per pound of milk. The latter figure provides nearly double the amount secreted in the milk and this provision seems wise in view of the losses in digestion and metabolism. On the same basis the calcium allowance per pound of milk should be $0.95 \mathrm{~g}$., in addition to an estimated maintenance requirement of $8 \mathrm{~g}$.

On the above basis a $1000-1 b$. cow producing $60 \mathrm{lb}$. of milk at the height of her lactation would require $65 \mathrm{~g}$. of calcium and $55 \mathrm{~g}$. of phosphorus. Huffman and associates concluded that the phosphorus intake should not go below $17 \mathrm{~g}$. even when the cow is dry because of the needs for gestation as well as for maintenance. The same should be true for calcium. Feeding in accordance with the allowances previously mentioned for maintenance and milk, with the $17 \mathrm{~g}$. as the lower limit for either mineral, would provide, in the case of the cow producing $10,000 \mathrm{lb}$., average intakes for the complete cycle close to those found adequate by Forbes and associates. This system of feeding would seem to be a satisfactory way of meeting the calcium and phosphorus requirements of the dairy cow. The N.R.C. allowances of $1 \mathrm{~g}$. of calcium and $0.7 \mathrm{~g}$. of phosphorus per pound of milk are in accord with the above figures.

There is no adequate basis for estimating the calcium and phosphorus needs of lactating ewes, sows, mares, or beef cows.

1 Hurrman, C. F., and associates, Phosphorus requirement of dairy eattle, when alfalfa furnishes the principal souree of protein, Mich. Agr. Lxpt. Sta. Tech. Bull. 134, 1933 
Particular attention is needed in the case of the ewe and sow since their milk is considerably richer in both calcium and phosphorus than is that of other species (Table XXX). The N.R.C. allowances for these species and for beef cattle are set forth in Table XXXIII.

In providing for the needs of lactating animals in practice, account must be taken of the composition of the feeds available, and, in making up the ration, the same principles mentioned in connection with growth (Sec. 298) should apply.

356. Salt.-As is evident in Table XXXI milk contains considerable amounts of both sodium and chlorine. Several studias have shown that milk secretion is decreased by depriving cows of salt, but the specific amount needed cannot be stated (See. 124). In the previously mentioned continuous balance experiments of Forbes and coworkers (Sec. 353) salt was included as 1.5 per cent of the concentrate mixture fed the lactating cows. The intakes, which ranged from 50 to $88 \mathrm{~g}$. daily for different animals, were certainly adequate as shown by the annual balances and probably unnecessarily high. One to two ounces of salt daily should be adequate for milking cows. The addition of 1 per cent of salt to the grain mixture serves the double purpose of providing this needed mineral and increasing the palatability of the mixture. It is a good plan to give the cows free access to salt in addition. By this means those animals which crave more than is provided in the grain mixture can get it and this procedure should certainly be followed when little grain is being fed.

There are no accurate data on the salt requirements of other lactating animals. The common practice of feeding salt ad libitum undoubtedly insures an adequate intake.

\section{THE ROLES OF VITAMINS IN LACTATION}

Vitamins are important in lactation both as essential nutrients for the physiological process involved and as components of the secretion itself.

357. Vitamin A Value of Milk.-The cow on its natural herbivorous ration receives vitamin $\mathrm{A}$ only in the form of carotene. A portion of the carotene ingested is secreted in milk as such and a portion is transformed into vitamin $\mathrm{A}$ and so secreted. The more yellow the milk and butter the larger the amount of carotene 
present, but this is not a true measure of vitamin A value for it gives no information as to the amount of the vitamin present as such. Jersey and Guernsey milk has much more color than Holstein milk because these cows convert a smaller proportion of their carotene intake into the vitamin. Most of the vitamin value of their milk is due to carotene, whereas Holstein milk contains less of the pigment and more of the colorless vitamin. As a result, when the cows are fed the same ration, Holstein butterfat has fully as high a vitamin A value as that from Jerseys or Guernseys despite the marked difference in color. The difference in degree of carotene conversion is also reflected in larger amounts of pigment in the adipose tissue and skin secretions. The extent of the conversion varies among individuals as well as among breeds. Those species which secrete a colorless milk (Sec. 339) make a complete conversion and thus the vitamin value of their fat may be very high though no color is present.

Aside from the contribution which can temporarily be made by the reserves, the vitamin A value of milk is entirely dependent upon the amount present in the feed, and very large variations in the potency may accordingly occur. The amount found in the milk may be several times as great on feeds high in carotene as on feeds which contain very little. Of the natural feeds, pasture results in the richest milk, but nearly as large a potency can be obtained by feeding properly cured alfalfa, dried grass, or corn silage. Much higher potencies are also produced by feeding concentrated sources of the vitamin, notably shark-liver oil.

Despite the large differences in the vitamin A potency of milk according to the nature of the diet, the percentage of the intake that appears in the milk is very small. In the various experiments carried out the percentage recovery has seldom exceeded 3 per cent.

It is evident that the vitamin value of milk can vary widely depending upon the nature of the feed, which commonly reflects the season in which the milk is produced. Dornbush and associates ${ }^{1}$ have reported a study of carotene and vitamin $A$ content of Wisconsin market milk by months throughout the year. The data reveal minima of $3.1 \mu \mathrm{g}$. of carotene and $7.2 \mu \mathrm{g}$. of preformed vitamin A per gram of butterfat, in March and April respectively.

1 Donnbusm, A. C., and associates, The carotene and vitamin A content of market milks, J. Am. Med. Assoc., 114, 1748-1751, 1940. 
The maxima of $9.9 \mu \mathrm{g}$. of carotene and $12.8 \mu \mathrm{g}$. of vitamin A occurred in September. The total vitamin A potency per quart was 1060 I. U. in March and 2005 I.U. in September.

A very comprehensive study of the vitamin A potency of the butter produced throughout the United States, in which the U.S. Department of Agriculture and the experiment stations of 20 states cooperated, has just been completed. Several of the stations have already published their results, and a summary of all the data has been issued by the U.S. Department of Agriculture. ${ }^{1}$ This summary gives the weighted a verages for winter and summer butter as 11,160 I.U. and 17,955 I.U. per pound respectively. The weighted average of the annual production is 15,529 I.U. Winter milk had 1140 I.U. per quart (4 per cent fat basis) and summer milk, 1800 I.U. The average potency of the total annual production was found to be 1530 I.U. per quart. The report points to the fact that much of the summer milk has a potency from 2500 to 3000 I.U. as evidence that much can be accomplished in improving the average level of the annual output by appropriate feeding practices.

358. Vitamin A Requirements.-It is clear that the animal nursing young should receive a liberal intake of vitamin $\mathrm{A}$ in order that its milk may contain an adequate amount for the nutrition of its offspring, at-least until they are able to obtain this vitamin from supplementary foods. This is particularly true because the newborn generally has little reserve of the vitamin in its body even though the mother may have been fed liberally during pregnancy. The latter feeding does provide stores in the body of the mother which will be drawn upon for her milk and which lessen accordingly the necessity of large intakes during lactation. Unless the cow is fed for an extended period on very poor roughage, there should be no practical problem in meeting the needs of the suckling offspring particularly when the calf is given access early to green, leafy roughage. The same should be true for lambs and colts. In the case of pigs, which are dependent solely on their mother's milk for a relatively longer period, the proper feeding of the mother may be of greater importance. Her needs should be met by selecting her ration in accordance with the same principles mentioned in the discussion of reproduction (Sec. 316). The needs of the dairy calf, which is early changed from whole

${ }^{1}$ Anonymous, Vitamin A in butter, U.S. Dept. Agr. Misc. Pub. 571, 1945. 
milk to skim milk or a "calf starter," have been discussed (Sec. 301).

The mature animal requires vitamin $\mathrm{A}$ for various body functions but whether this need increases for the specific function of lactation apart from the demand for secretion in the milk has not been definitely proved. Clearly, the first effect of a deficient diet is a lowering of the vitamin content of the milk. One would expect any eventual effect on production itself to be accompanied by signs of deficiency in the lactating animal. The N.R.C. allowances for lactation, which, in the case of beef cows, ewes, and sows, are considered to provide an adequate level in the milk for the nutrition of the young are set forth in Table XXXIII. No figure is given for dairy cows in this table, but the original report states that the amount specified for reproduction (Sec. 316) should suffice for maximum milk production, though higher intakes would probably increase the level in the milk.

359. Vitamin D. - The early studies of Forbes (Sec. 353), showing that the negative calcium and phosphorus balances of the height of lactation could not be eliminated by increasing the content of these minerals in the ration, were made before vitamin $\mathrm{D}$ was known. With the discovery of its role in the improvement of calcium and phosphorus retention, investigations were undertaken with the expectation that the addition of this vitamin to the ration would do away with the negative balances previously noted. Some initial experiments with goats supported this viewpoint, but more extensive studies with cows gave only negative results. Neither sun-cured hay, cod-liver oil, irradiated yeast, nor any other source of vitamin D, including direct irradiation, was found effective in preventing the losses of calcium and phosphorus which occurred in the liberally producing cow early in lactation, although the vitamin was absorbed and its level in the milk increased. Extensive studies of this question have been reported by Hart and associates. ${ }^{1}$

${ }^{1}$ Hart, E. B., H. Steenbock, E. C. Tent, and C. C. Hemphrey, Dietary factors influencing calcium assimilation. XI. The influence of cod-liver oil on calcium metabolism of milking cows, J. Biol. Chem., 84, 359-365, 1929; XII. A study of the influence of hays eured with varying exposure to sunlight on the calcium metabolism of milking cows, ibicl., 84, 367-376, 1929. HART,

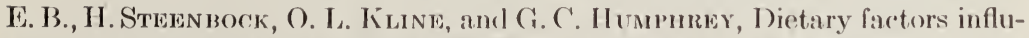
encing calcium assimilation. XIII. The influence of irradiated yeast on the calcium and phosphorus metabolism of milking cows, ibid., 86, 145-155, 1930. 
Wallis ${ }^{1}$ has clearly demonstrated that dairy cows require vitamin $\mathrm{D}$ for lactation. Cows kept out of the sunlight and fed a ration in which molasses beet pulp replaced the hay, and which was otherwise practically devoid of the vitamin, eventually developed striking deficiency symptoms. These experiments cannot be considered to cast doubt, however, on the earlier findings of Hart and associates that under normal conditions of feeding and management supplementary vitamin $\mathrm{D}$ will not materially benefit the calcium and phosphorus metabolism of the milking cow. Wallis has devised a technique, however, that should be used in further studies of the specific needs for vitamin D in lactation.

As shown in Table XXXIII, the N.R.C. allowance for sows has been set at 625 I.U. per animal per day. It is recognized in the table that dairy cows also require the vitamin, but the committee felt that present knowledge was not sufficient to justify any specific figure. The same appears to be true for ewes. On the basis of very limited data, Wallis ${ }^{2}$ suggests 5000 to 6000 I.U. daily as the minimum amount for dairy cows.

The question has not been critically studied in other farm animals. In the case of women, some investigators have reported a marked improvement in the calcium and phosphorus balances of lactation by feeding cod-liver oil, while others have noted little effect. Clearly, neither a uniform nor a complete response can be counted on.

No milk produced from natural feeds is a rich source of vitamin $\mathrm{D}$ in terms of the needs of the growing young. As a result of many studies, there is rather complete information as to the range of vitamin $\mathrm{D}$ content found in the milk of different breeds and under different conditions. For example, the following data were obtained by Bechtel and Hoppert ${ }^{3}$ from a two-year study of the milk of the Guernseys and Jerseys in the Michigan College herd. In tests at monthly intervals, vitamin $\mathrm{D}$ values ranging from 4.8 to 43.8 U.S.P. units per quart were found in Guernsey milk while for Holsteins the range was from 3.1 to 28 units. The

1 Wallis, G. C., Some effects of vitamin D deficiency on mature dairy cows, J. Dairy Sci., 21, 315-333, 1938; Vitamin-D deficiency in dairy cows, S. Dak. Agr. Expt. Sta. Bull. 372, 1944.

${ }^{2}$ W ALlis, loc. cit.

3 Bechtel, H. Ernest, and C. A. Hoppert, A study of the seasonal variation of vitamin D in normal cow's milk, J. Nutrition, 11, 537-549, 1936. 
highest value occurred in the summer and the lowest in winter, and there was a close correlation between the hours of sunshine and the vitamin level, indicating that sunlight was the principal factor involved in the variations. There was little difference in the potencies of the butterfats of the two breeds, thus the Guernsey milk was richer because of its higher fat content.

These variations in potency indicate that the vitamin $\mathrm{D}$ content of milk is under physiological control, but no system of feeding, other than massive intakes of the vitamin, has been found effective in increasing the potency above the normal summer level. Cod-liver-oil concentrates and irradiated ergosterol are more effective, but very large intakes are required to produce a relatively small change in the milk. Feeding cod-liver oil to the human mother will not cure rickets in the suckling infant. Experiments in which the cow has been irradiated have generally failed to increase the vitamin $\mathrm{D}$ content of the milk, but the studies of Campion and associates ${ }^{1}$ have proven that the higher potency of milk produced by cows on pasture is due entirely to the action of sunshine.

360. Vitamin D Milk. - The best milk that can be produced in summer, or on any ration of natural feeds, falls far short of meeting the requirements of children for protection against rickets.

The recognition of this fact and the discovery of methods of enriching milk to the effective level by direct irradiation or by feeding irradiated yeast to the cow has resulted in the production and use of vitamin D milk. This development has received the approval of medical authorities and nutritionists because, despite the knowledge of other effective methods of preventing rickets, the disease persisted unduly. It was felt that if the vitamin were adequately supplied in a product which formed a considerable part of the daily diet of children, a more certain way of insuring the needed intake would be provided.

The standard for vitamin D milk calls for a minimum level of 400 I.U. per quart. 'This level can be obtained either by irradiating. the milk or by feeding irradiated yeast to the cow. Vitamin D milk can also be provided by the direct addition of a cod-liver-oil concentrate, activated ergosterol, or 7-dehydrocholesterol. 'This

1 Campion, John Finard, Kathleen Mary llenry, Stanislaw KaziMERz KON, and JAMEs MAckintosn, The source of vitamin I) in summer milk, Biochem. .J., 31, 81-88, 1937. 
procedure is the one which is now displacing the others in practice because of the greater ease of control in providing the required level. An excellent review of vitamin $D$ milk has been published by Weckel. ${ }^{1}$

361. Thiamine.-The physiological needs for thiamine increase in accordance with the amount of milk secreted because of its role in energy metabolism and because of its content in the milk. These needs present no dietary problem in cattle and sheep because of rumen synthesis. The N.R.C. allowance for sows is set at $6.3 \mathrm{mg}$. per animal per day, a higher level than for growth in view of the larger metabolic performance involved.

In nonruminants the thiamine content of the milk secreted drops when the ration is deficient in the vitamin. There is a low ceiling, however, above which the level cannot be raised no matter how much thiamine is added to the diet. Cow's milk contains 35 to $40 \mu \mathrm{g}$. per $100 \mathrm{ml}$. on the average, a level that is little influenced by the ration. This level is a low one in terms of human needs, for a quart of milk furnishes less than a quarter of the recommended allowance for a moderately active man.

362. Riboflavin.-The story with respect to riboflavin is similar to that for thiamine. Ruminants need no dietary source, but sows do require a supply in their feed. Lack of a basis for estimating the quantitative needs has prevented any statement as to a recommended allowance.

In contrast to thiamine, milk is a rich source of riboflavin. For those species requiring it in the diet, the level in the milk varies markedly according to the feed supply. The nature of the feed does have some influence on the level in cow's milk also. On the average, such milk which has not been exposed to light contains around $200 \mu \mathrm{g}$. per $100 \mathrm{ml}$. Thus, a quart can supply nearly the full recommended allowance for a moderately active man. The milk which reaches the consumer, however, may have a markedly lower value because of exposure to sunlight. Bottled milk has been found to lose as much as three-fourths of its riboflavin in $2 \mathrm{hr}$. in bright sunlight.

363. Other B-Vitamins.- Less is known about the roles of other B-vitamins in lactation. No practical problem is presented in the case of ruminants. While some studies of the lactation needs

${ }^{1}$ WeCKel, K. G., Vitamin D in milk-a review, J. Dairy Sci., 24, 445-462, 1941. 
for these other factors have been carried out with rats, there is no basis for any statement of the requirements for sows. All of these factors are found in milk. Lawrence and associates ${ }^{1}$ have just published a series of studies on the nicotinic acid, biotin, and pantothenic acid contents of cow's milk as influenced by breed, stage of lactation, and season. In an earlier publication ${ }^{2}$ these workers have reviewed data for the various vitamins found in milk and compared them with similar data for human milk.

364. Ascorbic Acid.-In those species requiring vitamin $\mathrm{C}$ in the diet, its level in the milk depends on the dietary supply. Its level in cow's milk is affected somewhat by breed and seasonal influences but not by the ration. Only a small part of the total amount secreted is found in the market milk that reaches the consumer. As drawn from the udder the product contains 2.0 to $2.5 \mathrm{mg}$. per $100 \mathrm{ml}$., practically all in the reduced form. In contrast, Stewart and Sharp ${ }^{3}$ have reported a survey showing that market milk in consumers' homes or retail stores contained $0.58 \mathrm{mg}$. per $100 \mathrm{ml}$. (0.34 mg. in the reduced form and $0.24 \mathrm{mg}$. as dehydroascorbic acid). Thus approximately three-fourths is lost in pasteurization and other marketing operations. Exposure to light is an even more destructive factor in the case of ascorbic acid than of riboflavin. Stewart and Sharp found that reconstituted powdered whole milk had twice as much vitamin $\mathrm{C}$ as the pasteurized fresh product.

\section{Selected Literature}

Archibald, J. G.: Zinc in cows' milk, J. Dairy Sci., 27, 257-261, 1944.

Beck, A. B.: Studies on the copper content of the milk of sheep and of cows, Australian J. Exptl. Biol. Med. Sci., 19, 145-150, 1941.

Bonsma, F. N.: Milk-production studies with sheep, Union S. Africa, Dept. Agr. Forestry Bull. 251, 1944.

Buschmann, Arnold: Untersuchungen über den Eiweissbedarf der Milchkuh und den Einfluss eiweissreicher und eiweissumer Fütterung auf die Menge und Zusammensetzung der Milch, Landw. Vers.-Sta., 101, 1-216, 1923.

${ }^{1}$ Lawrence, J. M., B. L. Herrington, and L. A. Maynard, The nicotinic acid, biotin, and pantothenic acid content of cows' milk, J. Nutrition, 32, $73-91,1946$.

${ }^{2}$ Ian wence, J. M., B. I. II fizizington, and I. A. Maynard, Comparative values of bovine and human milk in infant feeding, Am. J. D)iseases Children, 70, 193-199, 1945.

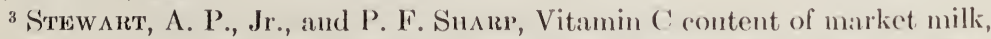
evaporated milk, and powdered whole milk, J. Nutrition, 31, 161-17.1, 1946. 
Buschmann, Arnold: Untersuchungen über die Bedeutung des Fettes im Futter der Milchkuh, Die Tierernähr., 1, 129-178, 1930.

DAY, F. T., and J. HAMmond: Lactation in heifers induced by oestrogen implants, J. Agr. Sci., 35, 150-157, 1945.

Devel, H. J., Jr., and associates: The production of high vitamin A milk by diet, J. Nutrition, 22, 303-313, 1941; The effect of a high vitamin A intake on the blood and milk carotene of Holstein and Guernsey cows, J. Nutrition, 23, 567-579, 1942.

Ely, F., and W. E. Petersen: Factors involved in the ejection of milk, $J$. Dairy Sci., 24, 211-223, 1941.

Espe, D.: Secretion of milk, 3rd ed., Collegiate Press, Inc., Ames, Iowa, 1946.

Folleey, S. J., and F. H. Malpress: The chemical composition of bovine mammary secretions induced by the subcutaneous implantation or oral administration of synthetic oestrogens, J. Endocrin., 4, 37-42, 1944; Artificial induction of lactation in bovines by oral administration of synthetic oestrogens, ibid., 23-36.

Forbes, E. B., and R. W. Swift: The efficiency of utilization of protein in milk production, as indicated by nitrogen balance experiments, $J$. Dairy Sci., 8, 15-27, 1925.

milk energy by the dairy cow, $J$. Nutrition, 5, 395-401, 1932.

HAUGE, S. M., and associates: The vitamin A requirements of dairy cows for production of butterfat of high vitamin A value. III. Availability of carotene in dehydrated alfalfa hay as compared with carotene in oil, J. Dairy Sci., 27, 63-67, 1944.

HiLdith, T. P., and H. JASPERson: The component acids of milk fats of the goat, ewe and mare, Biochem. J., 38, 443-447, 1944.

Hilis, J. L. et al.: The protein requirements of dairy cows, Vt. Agr. Expt. Sta. Bull. 225, 1922.

Hilton, J. H., J. W. Wilbur, and S. M. HAUge: The vitamin A requirements of dairy cows for production of butterfat of high vitamin A value. II. Vitamin A per se, J. Dairy Sci., 27, 57-63, 1944.

Hodson, A. Z.: The nicotinic acid, pantothenic acid, choline and biotin content of fresh, irradiated, evaporated and dry milk, J. Nutrition, 29, 137-142, 1945.

Holmes, A. D., and C. P. Jones: Effect of sunshine upon the ascorbic acid and riboflavin content of milk, J. Nutrition, 19, 201-209, 1945.

- , and associates: The vitamin content of mare's milk, J. Dairy Sci., 29, 163-171, 1946.

Hughes, E. H., and Hugh G. Hart: Production and composition of sow's milk, J. Nutrition, 9, 311-322, 1935.

Hummel, Frances Cope, Helen R. Sternberger, Helen A. Hunscher, and ICIE G. MACY: Metabolism of women during the reproductive cycle. VII. Utilization of inorganic elements (a continuous case study of a multipara), J. Nutrition, 11, 235-255, 1936.

Hunscher, Helen A.: Metabolism of women during the reproductive cycle. II. Calcium and phosphorus utilization in two successive lactation periods, J. Biol. Chem., 86, 37-57, 1930. 
Jordan, W. H., and C. G. Jenter: The source of milk fat, N.Y. (Geneva) Agr. Expt. Sta. Bull. 132, 1897.

- - - and F. D. Fuller: The food source of milk fat; with studies on the nutrition of milch cows, N.Y. (Geneva) Agr. Expt. Sta. Bull. 197, 1901.

Linton, R. G.: The composition of mare's milk, J. Agr. Sci., 21, 669-688, 1931.

Loosli, J. K., L. A. Maynard, and H. L. Lucas: IV. Further studies of the influence of different levels of fat intake upon milk secretion, Cornell Univ. Agr. Expt. Sta. Memoir 265, 1944.

Lucas, H. L., J. K. Looshi, and L. A. Maynard: A study of the effect of dietary fat and fat-soluble vitamins upon milk and fat secretion, Cornell Univ. Agr. Expt. Sta. Memoir 251, 1943.

- and J. K. LoosLI: The effect of fat upon the digestion of nutrients by dairy cows, J. Animal Sci., 3, 3-11, 1944.

McCAy, C. M., and L. A. Maynard: The effect of ingested cod liver oil, shark liver oil, and salmon oil upon the composition of the blood and milk of lactating cows, J. Biol. Cnem., 109, 29-37, 1935.

Maynard, L. A., and E. Rasmussen: The influence of dietary fat on lactation performance in rats, $J$. Nutrition, 23, 385-398, 1942.

Morris, Samuel: The protein requirements of lactation, Nutrition Abstracts \& Revs., 6, 273-280, 1936.

Pearson, P. B., and A. L. Darnell: The thiamine, riboflavin, nicotinic acid and pantothenic acid content of colostrum and milk of the cow and ewe, J. Nutrition, 31, 51-57, 1946.

Porcher, Cн.: La sécrétion lactée, Traite physiol. normale path., 11, 293381, Masson et Cie., Paris, 1927.

Seath, D. M., C. Branton, and A. H. Groth: Effect of feeding iodinated casein on production and health of milking cows, J. Dairy Sci., 28, 509$517,1945$.

Turner, C. W.: The structure of the cow's udder, Mo. Agr. Expt. Sta. Bull. $344,1935$.

: The secretion of milk and the milking process, Mo. Agr. Expt. Sta. Bull. 346, 1935.

Woodward, T. E., R. P. Hotis, and R. R. Graves: Incomplete milking in relation to milk production and udder troubles in dairy cows, U.S. Dept. Agr. Tech. Bull. 522, 1936. 


\section{CHAPTER XVI \\ WORK PRODUCTION}

The previous discussions of nutritive requirements have dealt with the production and maintenance of body tissue and with the formation of products composed of nutrients such as milk and eggs. Body maintenance involves the performance of internal work in respiration, circulation, and other vital processes. It also includes a certain amount of external work represented by the voluntary activity of the animal and assessed as the activity factor (Sec. 254) when maintenance is estimated from basal metabolism. The work performed by the horse, and also by the manual laborer, is so greatly in excess of that which properly belongs to maintenance as to call for a special consideration of its physiology and nutritive requirements. The daily energy requirement of the horse or man at hard work is approximately double the maintenance need, while the maximum work which can be performed during a short period may involve a metabolism ten times as great as at rest.

365. Nutrients Involved in Muscle Activity.-The muscles are the agencies by which mechanical work is performed. In their contraction, nutrients are catabolized. The early physiologists considered that the muscle was broken down in the process, and, since the muscle was known to consist mostly of protein, the assumption arose that protein yielded the energy for the work done. Such was Liebig's view. For many years he taught that work production involved an increased excretion of nitrogenous end-products and, therefore, required an increased intake of protein in accordance with the amount of work performed. Because of his eminence Liebig's views continued to be accepted, though apparently not based upon experimental results, even after Voit showed in 1860 that work could be performed by a dog without increasing the protein catabolism.

In 1866 Fick and Wislicenus ascended a Swiss mountain 6418 ft. high after having abstained from nitrogenous food for $17 \mathrm{hr}$. and measured their urea output before and during the ascent. 
They found no considerable increase in the output while the work was being performed, and their calculations revealed that the total nitrogen excretion could account for only a fraction of the catabolism which must have occurred to furnish the energy needed for the work done. In 1879 Kellner showed that, as long as the total amount of feed of the work horse was ample, the protein catabolism was not increased by work. If, however, the feed was restricted and the work was increased to the point where the animal lost flesh, then a larger nitrogen excretion occurred. Thus it gradually came to be accepted that the muscle is not broken down in work and that its energy is normally supplied by nonnitrogenous food, but that if the food supply is insufficient body protein as well as fat may be drawn on.

366. The Chemistry of Muscle Action.-The knowledge of the nature and sequence of the chemical and thermal changes which take place during muscular activity has been undergoing modification during recent years. Many of the details remain unknown or in dispute. For some time it was believed that creatine phosphate was the primary source of muscle energy, but this role is now ascribed to adenosine triphosphate (adenyl-pyrophosphate). It seems to be agreed that the following events take place. When a muscle is stimulated, adenosine triphosphate breaks down to adenylic acid and phosphoric acid, yielding energy for muscle contraction. Simultancously, the liberated phosphoric acid is utilized in the formation of fructose diphosphate, an intermediate compound in the breakdown of glycogen to lactic acid.

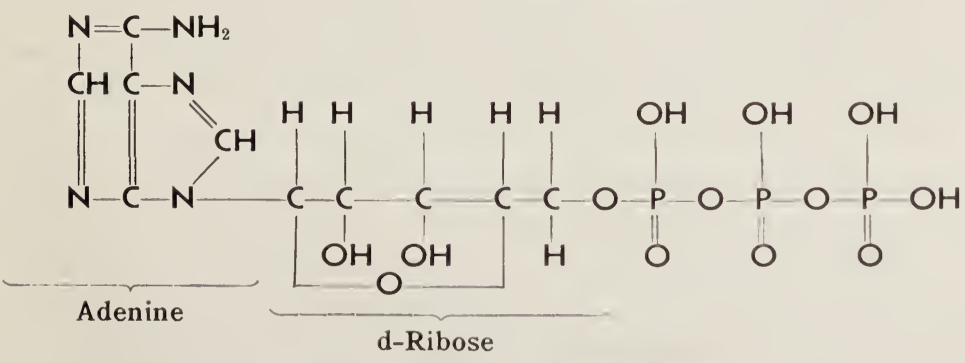

Adenylic acid

Adenosine triphosphate

Adenosine triphosphate $\stackrel{+2 \mathrm{H}_{2} \mathrm{O}}{\longrightarrow}$ Adenylic acid $+2 \mathrm{H}_{3} \mathrm{PO}_{4}+\begin{aligned} & \text { Encrgy for } \\ & \text { muscle con- } \\ & \text { traction }\end{aligned}$ 
Next, phosphocreatine breaks down to creatine and phosphoric acid. This reaction not only supplies the energy but also the phosphoric acid needed for the resynthesis of the adenosine triphosphate.

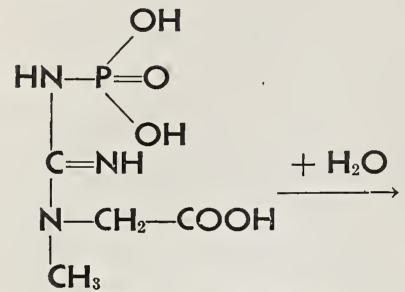

Phosphocreatine

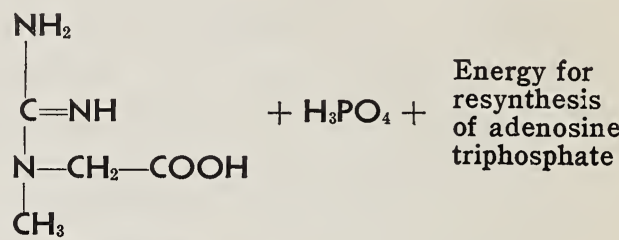

Creatine

The energy for the resynthesis of phosphocreatine is derived from the breakdown of glycogen to lactic acid. During this process the phosphate originally derived from adenosine triphosphate and used for the formation of the fructose diphosphate is transferred to a number of intermediate compounds and finally liberated to recombine with creatine to form phosphocreatine.

Glycogen $\rightarrow$ Lactic acid + Energy for resynthesis of phosphocreatine

Finally, part (about one-fifth) of the lactic acid is oxidized to carbon dioxide and water, and the energy here produced is used to resynthesize the remainder of the lactic acid to glycogen.

Thus, when the original chemical condition of the resting muscle is restored, the net change which has occurred is a loss of a part of the glycogen through the oxidation of lactic acid. It should be noted, however, that this oxidation does not take place until after the contraction occurs. The energy for the contraction is furnished by the anaerobic hydrolysis of adenosine triphosphate. Thus the process is not the same as occurs in the heat engine where the fuel burns before the work is done. Rather, it is analogous to the operation of a storage battery. Contraction takes place as a result of a discharge of energy stored in the muscle. "Charging" occurs during the recovery period with energy obtained by oxidation. The muscle differs from the heat engine in another fundamental respect. The heat produced by the engine provides the energy for the work accomplished, while in the muscle the energy which appears as heat is entirely a waste. Although it is convenient to evaluate foods and body products in terms of 
heat units, it should be remembered that the body is in no sense a heat engine.

The fact that an anaerobic reaction furnishes the immediate energy for muscle contraction and that recovery can occur anaerobically by means of the energy supplied by lactic-acid formation makes it possible for muscle action to take place temporarily without oxygen. The process is stopped by the accumulation of lactic acid. Then oxidation is required to remove the acid and to furnish energy for building up the system so it can start again. The anaerobic mechanism also means that the muscle can temporarily do much more work than represented by the amount of oxygen currently required to accomplish it. When this occurs, the deficit of oxygen is spoken of as the oxygen debt. This provision of nature enables a man or an animal to exert itself eight or ten times as strenuously as would be possible if all of the oxygen had to be supplied currently. A well-trained athlete cannot take in more than about 4 liters of oxygen per minute, yet he can temporarily perform work which would require oxygen at the rate of 30 liters per minute if it were not possible for him to go into oxygen debt. The same picture can be exhibited by the horse.

367. The Fuel of Muscular Activity.-The previously described changes in muscle metabolism are worked out on the basis of carbohydrate as the source of the lactic acid oxidized, for carbohydrate is the primary source of muscular energy. Protein can be utilized by transformation into carbohydrate or its intermediates. There has been much controversy as to how fat is used, and there is still no evidence that it can be utilized directly by the muscle. Carbohydrate is the more efficient source. Gemmill ${ }^{1}$ has recently reviewed the metabolism in muscular activity as influenced by the various sources of energy.

368. Units of Work and Power.-Work done may be measured in foot-pounds; and power, the rate of doing work, may be measured in foot-pounds per second. The development of 1 horsepower (hp.), also a unit of power, necessitates the performance of work at the rate of $33,000 \mathrm{ft}$.-lb. per minute. The work done in moving a body is measured by the product of the force required and the distance the body moves along the line of action of the force. Suppose that a horse must exert a force of $200 \mathrm{lb}$. to pull a

${ }^{1}$ Gemmili, C. L., The fuel for muscular exercise, Physiol. Revs., 22, 32-53, 1942. 
load at a speed of 3 miles per hour ( $264 \mathrm{ft}$. per minute). In pulling the load a distance of $264 \mathrm{ft}$. the horse does $52,800 \mathrm{ft}$.-lb. of work. Since the work is done in 1 minute the power developed is simply $52,800 \mathrm{ft}$.-lb. per minute, and, if this be divided by 33,000 , the result is approximately $1.6 \mathrm{hp}$. One horsepower-hour, also a unit of work, is the energy expended when work is done at the rate of $1 \mathrm{hp}$. for $1 \mathrm{hr}$. It is thus 33,000 times 60 , or $1,980,000$ ft.-lb.

In studying the energy efficiency of work production, it is convenient to translate foot-pounds into Calories. One footpound is equal to $0.000324 \mathrm{Cal}$.

369. Efficiency of Muscle Work.-The mechanical efficiency of the animal machine can be computed even as is true for the heat engine. It represents the percentage of the chemical energy used which can be transformed into useful work. The gross or over-all efficiency is defined by the following equation:

$$
\text { Gross efficiency }=\frac{\text { mechanical work accomplished }}{\text { total energy expended while working }}
$$

It is obvious that only a part of the total energy consumed is actually used for the production of useful work. A portion must serve for the usual processes of maintenance, another portion is dissipated by the increased internal activities, such as circulation and respiration, which are demanded by muscle action, and a further portion is used up in waste movements. Only 40 to 50 per cent of the energy consumed by the muscle is actually transformed into work. The rest appears as heat in connection with the exothermic chemical processes previously mentioned. Thus the maximum gross efficiency which is shown by the man or horse is approximately 25 per cent. This is a high figure, however, compared to the steam or gas engine, according to the following figures from Hill: ${ }^{1}$

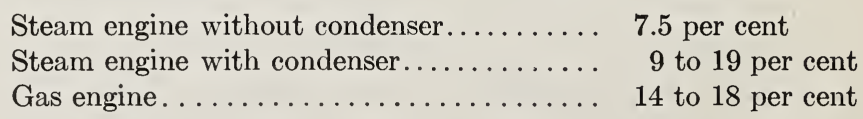

It is a high figure also compared to the tractor which was found to have an efficiency for draft of 13 per cent, in experiments

${ }^{1}$ Hill, A. V., Muscular movements in man, Cornell University Press, Ithaca, N.Y., 1927. 
by Brackett ${ }^{1}$ and associates, but much lower than the 40 per cent figure for the modern Diesel engine.

In comparing the horse and tractor, however, it must be borne in mind that the horse can only work part of the time. Its true efficiency for farm labor is what it can accomplish regularly in a 24-hr. day. Brody and Cunningham ${ }^{2}$ found the all-day efficiency, as measured by metabolism data, of a horse working $8 \mathrm{hr}$. a day to be 14 per cent. Morrison ${ }^{3}$ has arrived at the lower figure of 8.9 per cent, by calculating the amount of work which a 1500-lb. horse could be expected to accomplish daily and the amount of feed which should represent a satisfactory allowance. In comparing the horse with the tractor, Morrison reminds us that the horse uses fuel in a very crude form compared to that of the tractor and that it makes its own repairs. The horse far outclasses the tractor in ability temporarily to exceed its normal load because of its capacity for incurring oxygen debt.

Another measure which is used in studies of work production is the net efficiency. Here the work accomplished is calculated as a percentage of the total energy intake minus that used for maintenance. Such a figure is a truer measure of the muscular efficiency since it eliminates the overhead expenditure of maintaining the body as a whole. Certain questions arise as to just what should be deducted from the gross expenditure. Should the deduction represent merely the metabolism of the resting animal or should certain movements which are normally made by the idle animal and which do not result in useful work be included in the deduction? Such questions are of minor importance if the same basis is used where efficiencies are compared. Brody defines net efficiency by the following equation:

Net efficiency $=\frac{\text { work done }}{\text { total energy used }- \text { energy of standing animal }}$

1 Brackete, F., C. W. Smith, E. B. Iswis, Carlton I. Zink, and C. F. Adams, Nebraska tractor tests, 1930-1934, Nebr. Agr. Expt. Stu. Bull. 292, 1935.

2 Brody, Samuer, and Ricmard Cunningham, Growth and development. XI. Comparison between efficiency of horse, man, and motor, with special reference to size and monetary economy, Mo. Agr. Expt. Sta. Research Bull. $244,1936$.

${ }^{3}$ Mommison, F. B., Feeds and feeding, 20th ed., pp. 128 429, Morrison Publishing Company, Ithaca, N.Y. 
As a comparative measure, net efficiency has the advantage over gross efficiency in being less affected by variations in the intensity and amount of work done over a given period.

370. The Measurement of Energy Expended in Work.-Zuntz was a pioneer in measuring the energy expended by horses in different kinds of work. Using the respiration apparatus which he devised, he was able to arrive at the energy output by indirect calorimetry. He used a tread power which could be set at various inclinations for measuring the work required for different degrees of ascent. Provision was made for driving the power by a steam engine so that locomotion only could be studied. The energy requirements for carrying various loads were measured. By determining the energy output during rest as well as during work, the amount needed in excess of maintenance and the net efficiency were computed. Many of these experiments are reported by Zuntz and Lehmann. ${ }^{1}$

Brody and associates ${ }^{2}$ have conducted somewhat similar studies. Some data taken from one of their experiments are presented in Table XXXIV to illustrate the nature of the results produced. These data were obtained with a Percheron gelding walking at the rate of 2.2 miles per hour. Having measured the draft and the distance traveled in the tread power, the data as to Calories of work accomplished and the horsepower were readily computed using the relationships previously defined (Sec. 368). The energy expense was estimated from the oxygen consumed as measured with a closed-circuit respiration apparatus. The total energy consumption was recorded as the over-all energy. The net-energy expenditure is calculated by subtracting the output during standing from the total measured during walking or working. By adding to the energy of standing, the further amount expended in walking, and subtracting this from the over-all consumption, the absolute energy used in the work of draft is obtained.

These three different energy expenditures provide the bases for computing the three different measures of efficiency with which

1 Zuntz, N., and C. Lehmann, Untersuchungen über den Stoffwechsel des Pferdes bei Ruhe und Arbeit, Landw. Jahrb., 18, 1-156, 1889.

2 Procter, Robert C., Samuel Brody, Mack M. Jones, and D. W. Chittenden, Growth and development. XXXIII. Efficiency of work in horses of different ages and body weights, Mo. Agr. Expt. Sta. Research Bull. 209, 1934. Brody and Cunningham, loc. cit 
the work recorded is accomplished. The over-all efficiency increases with load because the fixed overhead expenditure of maintenance is thus distributed over an increasing output of useful work. In contrast, the absolute efficiency tends to decrease, reflecting the larger wastage as heat which tends to result from increasing the load on the muscle. The net efficiency represents a balance between the trend to an increased efficiency with Table XXXIV.-Energy Consumption and Output by a Work Horse

\begin{tabular}{|c|c|c|c|c|c|c|c|c|c|}
\hline \multirow{2}{*}{ Experiment } & \multirow{2}{*}{$\begin{array}{l}\text { Draft, } \\
\text { lb. }\end{array}$} & \multicolumn{2}{|c|}{$\begin{array}{c}\text { Energy } \\
\text { output, } \\
\text { Cal. per hr. }\end{array}$} & \multicolumn{3}{|c|}{$\begin{array}{l}\text { Energy expense, } \\
\text { Cal. per hr. }\end{array}$} & \multicolumn{3}{|c|}{$\begin{array}{c}\text { Efficiency of } \\
\text { work, } \%\end{array}$} \\
\hline & & $\begin{array}{l}\text { Work } \\
\text { done }\end{array}$ & Hp. & $\begin{array}{l}\text { Over- } \\
\text { all }\end{array}$ & Net & $\begin{array}{l}\text { Abso- } \\
\text { lute }\end{array}$ & $\begin{array}{c}\text { Over- } \\
\text { all }\end{array}$ & Net & $\begin{array}{l}\text { Abso- } \\
\text { lute }\end{array}$ \\
\hline Standing. & 0 & & & 670 & & & & & \\
\hline Walking. & 0 & & & 1607 & 937 & & & & \\
\hline Working. . . . & 125 & 470 & 0.73 & 2908 & 2238 & 1301 & 16.2 & 21.0 & 36.1 \\
\hline Working. . . . & 150 & 564 & 0.88 & 3113 & 2443 & 1506 & 18.1 & 23.1 & 37.5 \\
\hline Working.... & 175 & 658 & 1.03 & 3350 & 2680 & 1743 & 19.6 & 24.6 & 37.8 \\
\hline Working.... & 200 & 752 & 1.17 & 3651 & 2981 & 2044 & 20.6 & 25.2 & 36.8 \\
\hline Working. ... & 225 & 846 & 1.32 & 4031 & 3361 & 2424 & 21.0 & 25.2 & 34.9 \\
\hline Working. . . . & 250 & 941 & 1.47 & 4232 & 3562 & 2625 & 22.2 & 26.4 & 35.8 \\
\hline Working. . & 275 & 1035 & 1.61 & 4650 & 3980 & 3043 & 22.3 & 26.0 & 34.0 \\
\hline Working. . . . & 300 & 1129 & 1.76 & 5008 & 4338 & 3401 & 22.5 & 26.0 & 33.2 \\
\hline Working. ... & 325 & 1223 & 1.91 & 5400 & 4730 & 3793 & 22.6 & 25.9 & 32.2 \\
\hline Working.... & 350 & 1317 & 2.05 & 5651 & 4981 & $40+4$ & 23.3 & 26.4 & 32.6 \\
\hline Working.... & 375 & 1411 & 2.20 & 5752 & 5082 & 4145 & 24.5 & 27.8 & 34.0 \\
\hline Working.... & 400 & 1505 & 2.35 & 6337 & 5667 & 4730 & 23.7 & 26.6 & 31.8 \\
\hline
\end{tabular}

load, which results from eliminating the orerhead of walking, and the opposite trend in absolute efficiency with increasing load. Thus the figures for net efficiency reveal an increase for the lighter loads only.

371. Factors Affecting Work Efficiency.-The previous diseussion indicates that various factors influence the efficiency with which work is done and that they affect the various measures of efficiency in different ways. The practical measure is the over-all efficiency because the horse must be maintained whether it is working or not. 'The net or absolute measure, however, is the more useful for comparing the relative efficiencies with which different kinds of work are aceomplished. Inereasing the speed beyond a certain point decreases the net efficiency with which 
work is done. It is evident that a man uses up much more energy in running $100 \mathrm{yd}$. at top speed than in running it at a trot. Zuntz and associates found that approximately 15 per cent more energy was required by the horse for locomotion at 3.66 miles per hour than at a rate of 2.91 miles. At a trot nearly twice as much energy was expended as at a walk. The horse is most efficient when working at a speed between 2.5 and 3 miles per hour. Though gross efficiency increases with load and speed, a heavy load at low speed is more efficient than a light load at high speed.

Of all the forms of work investigated by Zuntz and associates, the ascent of a moderate grade appeared to be the most efficient on the net basis, but the efficiency decreased as the grade became steeper. Draft up a grade was performed less efficiently than draft alone, and, as the grade increased from 1.5 per cent to 8.5 per cent, the net efficiency decreased from 31.3 to 22.7 per cent.

It is a familiar fact that training increases working efficiency. When the horse or man attempts an unaccustomed task, many unnecessary muscles are brought into play which are not used when skill in performing the work has been acquired. On the other hand, efficiency decreases as the animal becomes fatigued.

According to the studies of Brody and associates, if large and small horses perform work in proportion to their weights, there is no difference in the gross efficiency with which the work is accomplished. From observations that the maximum over-all efficiency of the 1500-lb. horse, the 600-ib. horse, and the 150-lb. man is approximately 25 per cent in each case, Brody concludes that this efficiency is independent of body weight. He also believes that the work-rate capacity is proportional, not to body weight but to the basal metabolism, i.e., body weight raised to the two-thirds power (Sec. 248).

372. Energy Requirements.-The previous discussion of the physiology of muscular work makes it evident that the major requirement is for energy-producing food. This need is most easily visualized as net energy, representing the chemical energy which the body must expend to produce the work in question. This net-energy requirement can be directly measured by respiration experiments such as the one reported in Table XXXIV. As an alternative procedure, the net-energy requirement can be calculated from the energy represented by the work done and by 
the percentage efficiency represented by the work in question. This procedure is illustrated by Armsby ${ }^{1}$ as follows. He cites data showing that a horse, hauling a load having a draft of $100 \mathrm{lb}$. for 20 miles on a level road, would perform mechanical work equivalent to 3421 Cal. Taking the net efficiency of the horse for draft as 31.3 per cent, the calculation thus becomes:

$$
3421 \div 0.313=10,929 \text { Cal. of net energy }
$$

This calculation accounts only for the energy needed for the work of draft itself. The horse expended energy for walking and for maintenance which must be added to that of the draft accomplished in arriving at the total net-energy requirement.

A little thought makes it evident that calculations of this kind have a very limited application to the estimation of the netenergy requirements of horses in practice because of the difficulty of arriving at the amount of work done and the efficiency with which it is performed. Armsby recognized this fact and, in stating the requirements for work production, he limited them to the basis of "full work," "half work," and "one-fourth work." For example, his recommendation to cover both the maintenance and production of a horse at full work was 18.2 Therms of net energy per day per $1000 \mathrm{lb}$. live weight. Armsby recognized that there were no directly determined net-energy values of feeds for work production by the horse. This fact, coupled with the more recent recognition of the variability of such values according to the level of production and the nature of the ration (Sec. 243), has prevented the adoption of the net-energy system in computing rations for horses.

Brody and Cunningham ${ }^{2}$ have derived the following equation for expressing the over-all requirements of the horse in terms of pounds of total digestible nutrients:

$$
\text { T.D.N. }=0.053 M^{0.73}+1.27 \text { (hp.-hr.) }
$$

The first term to the right of the equality sign represents the maintenance requirement in Calories when $M$ is live weight in pounds. The work requirement is obtained by multiplying horsepower-hours by the factor 1.27 , to give the Calories repre-

1 Armsisy, Henry Prentriss, The nutrition of farm animals, p. 564, The Macmillan Company, New York, 1917.

2 Brody and Cunningham, loc, cil. 
senting the work done. One pound of T.D.N. is considered equivalent to $1814 \mathrm{Cal}$. Brody and Cunningham present an alignment chart or nomograph from which the requirements for animals of different weights performing varying amounts of work can be obtained at a glance. Their computed values for different body weights are also set forth in tables in terms both of the horsepower-hours of work done and also of the number of hours worked per day. As an example, the requirement for a 1000-lb. horse working an 8-hr. day is stated as $14.1 \mathrm{lb}$. of total digestible nutrients. Their values are based on an assumed tractive pull of a load equivalent to 10 per cent of the body weight and upon a speed of 2.2 miles per hour.

The energy requirements for the horse can be determined in feeding trials by ascertaining the amount of feed which is needed to maintain the animal in weight and in good working condition while doing a definite amount of work. The feed intake can be expressed as total digestible nutrients, either by running a digestion trial or by using coefficients of digestibility which have been previously determined for the feeds in question. In translating the results into a feeding standard, a difficult problem arises in estimating the amount of work actually performed on a basis which will apply to other conditions. In addition to the factors previously mentioned (Sec. 371) as influencing work efficiency, there are differences in working conditions from day to day which markedly affect the amount of feed required to do a given amount of work. The nature of the roadbed, whether hard, soggy, or icy, is an important example in this connection. Feeding standards are useful to indicate how the feed requirements vary in accordance with amount of work performed, but, in practice, they can serve only as general guides. Having selected a suitable ration, it should be fed in accordance with the amounts needed to keep the horse in good working condition rather than as arbitrarily specified allowances.

373. Protein Requirements.-While it is now accepted, as discussed at the beginning of the chapter, that protein is not the normal fuel of muscular work, some still adhere to the view that protein catabolism is increased during the work even though there is an ample supply of nonnitrogenous nutrients. To many, it is inconceivable that the muscle cells are entirely resistant to wear, and they believe that destruction and renewal must occur. It is 
stated that such a destruction may occur and yet not be reflected in an increased excretion because of a reutilization of the catabolic products. Such a viewpoint is very difficult to prove or disprove. There are experiments in which an increased output of urinary nitrogen has been recorded during work and others in which no such increase has been found. At least some of the positive experiments are inconclusive because of the uncertainty as to whether the intake of nonnitrogenous nutrients was adequate to meet the needs for energy.

Cathcart, ${ }^{1}$ from a review of various experiments of others in conjunction with his own, believes the conclusion to be unmistakable that "muscle activity does increase, if often only in a small degree, the metabolism of protein." From a survey of the evidence Lusk ${ }^{2}$ comes to the opposite conclusion in equally positive terms. These two divergent viewpoints persist although there have been later experiments contributing to the problem. Both agree that there is no basis for believing protein to be the source of muscular energy. Lusk states that large intakes of protein are not essential for the maintenance of physical power, and that, on the other hand, there is no proof of a decreased physical efficiency from large intakes.

From the standpoint of an efficient ration for work production, other considerations appear more important than the question as to whether the protein requirement is actually increased during work. A satisfactory maintenance ration for an idle horse has a nutritive ratio of approximately $1: 10$. During hard work the need for energy is approximately doubled, and the nutritive ratio becomes 1:20 accordingly if the protein intake is not increased. Working horses have been kept in satisfactory condition on even wider ratios than would here result but that such rations are equally efficient in terms of energy utilization has not been shown. Reference has been made to the fact that digestibility is depressed by wide ratios and that, at least in so far as rats and pigs are concerned, such a ration increases the heat losses (Sec. 243). While these questions have not been specifically studied with the horse, indirect evidence suggests that its protein

1 Catucart, E. P., Influence of muscle work on protein metabolism, Physiol. Rev., 5, 225-242, 1925.

${ }^{2}$ Lusk, Granam, The science of nutrition, 4th ed., Chap. XV, IV. B. Saunders Company, Philadelphia, 1928. 
intake should be increased during work although the increase is not specifically needed for muscular activity. Using feeds of a quality which experiments and practice have shown to be desirable in the ration of the work horse, there is no problem in holding the nutritive ratio substantially the same as recommended for maintenance. It is believed that this practice should be followed.

374. Mineral Requirements during Work.-The large increase in the output of sodium and chlorine in the perspiration incident to hard work, particularly during warm weather, has been mentioned (Sec. 124). Thus there is an increased need for salt by the working horse. This need can be taken care of by ad libitum feeding and requires no special attention.

The active phosphorus metabolism which occurs during muscular activity (Sec. 366) has directed attention to the question of an increased requirement for this mineral. During the First World War Emden conducted experiments on German soldiers with acid phosphate drinks, with apparently beneficial results. Their use became popular, accordingly, particularly with athletes. Later studies, however, have increased the skepticism regarding any effect of high-phosphate intake on muscular performance. Harvey and associates ${ }^{1}$ have reported that hard work has no effect on the calcium and phosphorus balance in horses.

Some increase in hemoglobin destruction and resynthesis during hard work is to be expected in view of the greatly increased activity in oxygen transport, but this does not necessarily involve a higher iron requirement because the catabolized iron can be used again. Studies by Caine ${ }^{2}$ revealed no benefit, either in condition or in feed economy, from adding supplements of calcium, phosphorus, and iron to a ration of timothy hay, corn, oats, and salt. The added feed which must be given to supply the energy for work production inevitably means a mineral addition also. If the ration contains the various essential minerals at percentage levels which are adequate for maintenance, it should certainly prove satisfactory in this respect for work production. Brood mares represent a special case calling for attention in accordance with the increased needs for gestation and lactation.

${ }^{1}$ Harvey, A. L., and associates, Effect of work on the calcium and phosphorus retention of Percheron geldings, J. Animal Sci., 2, 103-111, 1943.

${ }^{2}$ Caine, A. B., Feeding and management of horses, Iowa Agr. Expt. Sta. Circ. 130, 1931. 
375. Vitamin Requirements.-There is little evidence that muscular activity has any direct relation to vitamin $\mathrm{A}$ intake and no reason for assuming such a relationship exists. An increased need for thiamine for work production is to be expected, however, in view of its role in carbohydrate metabolism, and experiments have proven that such is the case. To a lesser extent this appears to be an increased need for riboflavin and nicotinic acid, though the experimental evidence is less clear than for thiamine. There is no information available for the other B-vitamins. The nature of the ration of the horse makes it clear that any increased vitamin needs for hard work will be met by any ration that supplies the necessary calories.

Keys ${ }^{1}$ has published an excellent review of the literature dealing with the nutritive requirements for work and the maintenance of physical efficiency.

\section{Selected Literature}

Barborka, C. J., E. E. Foltz, and A. C. Ivy: Relationship between vitamin $\mathrm{B}$ complex intake and work output in trained subjects, J. Am. Med. Assoc., 122, 717-720, 1943.

Benedict, F. G., and E. P. CAтнсаRт: Muscular work: a metabolism study with special reference to the efficiency of the human body as a machine, Carnegie Inst. Wash., Pub. 187, 1913.

with normal individuals of similar height and weight, J. Biol. Chem., 20, 243-252, 1915.

Brody, S., and E. A. Trowbridge: Efficiency of horses, men, and motors, Mo. Agr. Expt. Sta. Bull. 383, 1937.

DARLING, R. C., and associates: Effects of variations in dietary protein on the physical well being of men doing manual work, $J$. Nutrition, 28, 273-281, 1944.

Forbes, W. H.: The effects of hard physical work upon nutritional requirements, Milbank Mem. F'und Quart., 23, 89-96, 1945.

Johnson, R. E., and associates: The effects of a diet deficient in part of the vitamin B complex upon men doing mannal labor, J. Nutrition, 24, 585-596, 1942.

Keys, A., and associates: Absence of rapid deterioration in men doing hard physical work on a restricted intake of vitamins of the $B$ complex, $J$. Nutrition, 27, 485-496, 1944.

Lindsey, J. B., and J. (.. ArchibsL1): The ntilization of feeds by horses, Mass. Agr. Expl. Sta. Bull. 230, 151-159, 1926.

1 Keys, Ances, Physical performance in relation to diet, federation P'roc., 2, $164-187,1943$. 
Mrtchell, H. H., and J. H. Kruger: The effect of muscular work upon the endogenous catabolism of the tissues, J. Biol. Chem., 76, 55-74, 1928.

Morey, N. B.: The energy requirement of farm women, J. Home Econ., 28, 38-44, 1936.

Morris, H. P., L. S. Palmer, and Cornelia Kennedy: Fundamental food requirements for the growth of the rat. VII. An experimental study of inheritance as a factor influencing food utilization in the rat, Minn. Agr. Expt. Sta. Tech. Bull. 92, 1933.

Nitsche, H.: Der Bedarf an Eiweiss bei Arbeitspferden in Ruhe und bei allmählich gesteigerter Arbeit, B. Tierernähr., 11, 214-244, 1939.

Wald, G., L. Brouha, and R. E. Johnson: Experimental human vitamin A deficiency and the ability to perform muscular exercise, Am.J. Physiol., 137, 551-556, 1942. 


\section{LIST OF VISUAL AIDS}

The following list of visual aids can be used to supplement some of the material in this book. This list is a comprehensive rather than a selective list. Therefore, we would suggest that each film be previewed before using as some may contain information that is too advanced while others may contain information that is too elementary.

These films can be obtained from the producer or distributor listed with each title. (The addresses of producers and distributors are given at the end of the bibliography.) In many cases these films and filmstrips can be obtained from your local film library or local film distributor; also, many universities have large film libraries from which they can be borrowed.

The running time (min), whether it is a motion picture (MP) or filmstrip (FS), and whether it is silent (si) or sound (sd) are listed with each title. All those not listed as color (c) are black and white. All of the motion pictures are $16 \mathrm{~mm}$; filmstrips are $35 \mathrm{~mm}$.

Catalysis (EIBF 10min sd MP). Presents several factors which may be responsible for catalytic actions including concentration by absorption, intermediate compound formation, chain reactions, break of reaction chains, poisoning of catalysts and negative catalysts; relation of catalysis to plant and animal life is pointed out.

Colloids (EBF $11 \mathrm{~min}$ sd MP). Defines colloidal state in terms of particle size; factors which prevent particle growth; some effects of coagulation.

Oxidation and Reduction. (EBF $11 \mathrm{~min}$ sel MP). Processes presented by relatively simple experimental materials; methods of investigating problems.

Properties of Waler (Coronet $11 \mathrm{~min}$ sil MP). Composition; boiling under different pressures; distillation; saturation; crystallization.

Foods and Nutrition (EBF $11 \mathrm{~min}$ sd MP). A study of the 465 
metabolic process showing the distribution of carbohydrates, fats and proteins, minerals, vitamins, etc.

Rickets in Calves (Standard Brands 15min si MP). Shows how Vitamin D prevents rickets in calves.

A Better Way (EBF 20min sd c MP). How Delsterol "D," new source of Vitamin D, guards chicks against rickets, promotes growth, aids egg production and hatching.

Vitamin $B_{1}$ (EBF $15 \mathrm{~min}$ si $\left.\mathrm{MP}\right)$. Natural source; effect of deficiencies of the vitamin on pigeons and rats; beriberi; effect of balanced diet.

Mineral Hunger in Livestock (Michigan 55frames FS). Describes abnormalities in farm animals caused by mineral deficiencies; suggests remedies to correct these conditions; explains how even a fine pedigree can't overcome mineral deficiencies in a limited ration due to growth on poor soil.

Fundamentals of Diet (EBF 10min sd MP). Functional classification of food; animal experiments show what happens in diet deficiencies.

Come and Get It (USDA 10min sd MP). Shows importance of feeding livestock in accordance with the work they are doing or the product they are to furnish.

Food and Growth (EBF 15min si MP). Experiment with white rats given coffee, sugar, and milk; effect upon weight and general appearance.

Two Little Rats and How They Grew (Dairy Council 11min sd c MP). Study of a rat-feeding demonstration conducted as a nutrition education experiment.

Endocrine Glands (EBF 11min sd MP). By means of diagramatic drawing and experiments on a goat; points out the effects caused by improper functioning of the glands.

Production of Foods (EBF 11min sd MP). Shows the role of the land in production; the methods employed in the production of plant and animal products; and the relation of animal food production to plant foods.

The Science of Milk Production (Ralston Purina 40min sd MP). How cow functions as "milk factory"; correct diet for cow; importance of proper milking; use of milking machine.

Reproduction among Mammals (EBF 10min sd MP). Tells complete story of embryology, using a domestic pig for an illustration. 
Reproduction in Higher Life Forms (B\&H 10min si MP). Shows reproduction process in fish, reptiles, and mammals.

\section{SOURCES OF FILMS LISTED ABOVE}

B\&H - Bell \& Howell Co., 1801 Larchmont Ave., Chicago 13.

Coronet Instructional Films, Glenview, Ill.

Dairy Council of St. Louis, 4030 Chouteau Ave., St. Louis, Mo. EBF-Encyclopaedia Britannica Films, Inc., 20 N. Wacker Dr., Chicago 6.

Michigan State Board of Control for Vocational Education, Visual Sec., Lansing, Mich.

Ralston Purina Co., Promotion Dept., St. Louis 2, Mo.

Standard Brands, Motion Picture Dept., 595 Madison Ave., New York.

USDA - U. S. Dept. of Agriculture, Motion Picture Dept., Washington, D. C. 



\section{AUTHOR INDEX}

A

Abderhalden, E., 144

Adams, C. F., 455

Adolph, E. F., 32

Albright, F., 124

Allcroft, W. M., 172

Almquist, H. J., 94, 96, 98, 111, 353

Anderson, W. E., 71, 74, 78

Andrews, F. N., 174, 402

Appleton, A. B., 377

Appleton, V. B., 339

Archibald, J. G., 111, 363, 447, 463

Armsby, H. P., 246, 282, 283, 285287, 289, 291, 296, 303, 305, 319, $321,326,357,358,386,459$

Aron, H., 377

Arrhenius, S., 25

Asdell, S. A., 381, 385, 401

Ashworth, U. S., 310, 313, 317, 387

Atwater, W. O., 268, 277, 279, 280, 282, 291, 294

Aub, J. C., 124

Aubel, C. E., 364, 365, 396

Auer, J., 138

Autrey, K. M., 261

Axelsson, J., 261, 291

\section{B}

Babcock, S. M., 2, 34, 35, 141, 142, 423

Baker, D. D., 378

Baker, F., 112

Bandemer, S. L., 174

Barborka, C. J., 463

Barenstein, H. D)., 87

Barnes, L. I., 30

Barnes, R. H., 80, 104, 248, 348, 352

Barrentine, B. F., 172

Bartel, I. H., 378

Batchelder, Is. I., 233

Baudisch, (), 172

Batuer, W., 124
Bauernfeind, J. C., 236

Baumann, E. J., 154

Baumgarten, W., 111

Bay, F., 203

Beach, C. L., 326

Beadle, G. W., 8

Beadles, J. R., 24b, 347

Beath, O. A., 168

Bechdel, S. I., 154, 368

Bechtel, H. E., 444

Beck, A. B., 172, 447

Becker, J. E., 193

Becker, R. B., 127, 436, 437

Beegle, F. M., 160, 434

Beeson, K. C., 115, 173, 366

Bell, J. M., 262

Bellamy, W. D., 235

Benedict, F. G., 268, 269, 271, 276, $289,291,292,306,311,314,315$, 329,463

Benedict, S. R., 138

Bennett, E., 363

Bennetts, H. W., 172

Bentley, W. H., 99

Berry, M. H., 233

Bertrand, G., 159

Bessey, O. A., 237

Bethke, R. M., 235, 378

Bhattacharya, R., 80

Birch, 'T. W., 235

Bird, H. R., 135

Black, A., 196

Black, W. H., 172, 377

Blackwood, J. H., 412, 414

Blaxter, K. I., 406

Block, R. J., 111, 112

Bloor, W. R., 57, 80

Boas, M. A., 223

Boelter, D., 402

Boer, J., 80

Bogart, R., 402

Bohsterlt, G., 101, 163, 262, 378 
Bolling, D., 111

Bonsma, F. N., 447

Booher, L. E., 362

Borland, A. A., 326

Borsook, H., 108

Bosshardt, D. K., 104, 348

Boussingault, J. B., 241, 264

Boutwell, R. K., 80, 131

Bowstead, J. E., 173

Boyd, W. L., 195

Boyer, P. D., 377

Brackett, E., 455

Bradley, W. B., 168

Braman, W. W., 282, 321, 328, 431

Brand, E., 86

Branton, C., 449

Braude, R., 233

Brenemare, W. R., 174

Bricker, M., 314

Briggs, G. M., Jr., 219, 236, 237

Brody, S., 269, 270, 291, 296, 310, $313,317,321,322,324,328,333$, $344,387,455,456,458,460,463$

Brouha, L., 464

Brown, E. F., 80

Brown, J. B., 80

Browne, C. A., 56

Bryant, A. P., 280

Bump, G., 253, 378

Burke, B. S., 383

Burr, G. O., 76, 80, 387

Burr, M. M., 76, 387

Burroughs, E. W., 111, 347

Burroughs, H. S., 111

Buschmann, A., 447, 448

\section{C}

Caine, A. B., 462

Callenbach, E. W., 154

Callow, E. H., 18

Camien, M. N., 111

Campbell, H. L., 378

Campion, J. E., 445

Cannon, C. Y., 261, 344

Cannon, P. R., 111

Cannon, W. B., 33

Card, L. E., 142, 317, 321

Carlström, B., 210
Carlyle, E. C., 306

Carman, G. G., 142

Carpenter, O. L., 377

Carr, F. H., 183

Carroll, W. E., 244, 382, 385, 397

Cary, C. A., 419

Cathcart, E. P., 461, 463

Cheplin, H. A., 56

Chibnall, A. C., 111

Chick, H., 216, 235

Chittenden, D. W., 456

Chittenden, R. H., 110

Chossat, M., 117

Clapp, S. H., 87

Cline, J. K., 210

Cochran, W. G., 261

Cochrane, D. C., 321, 328

Cole, C. L., 401, 402

Cole, H. H., 49, 383, 396

Colovos, N. F., 254, 329, 378

Conley, C. L., 137

Converse, H. T., 395

Cori, C. F., 56

Cori, G. T., 56

Cotter, J. W., 237

Coulson, E. J., 291

Crampton, E. W., 46, 244, 262

Cravens, W. W., 401

Creech, G. T., 412, 413

Crowell, M. F., 7, 338, 385

Cruickshank, E. M., 401

Csonka, F. A., 87

Culbertson, C. C., 152, 234

Cunha, T. J., 224, 397

Cunningham, I. J., 173

Cunningham, R., 455, 456, 459, 460

Curtis, A. C., 112

\section{D}

Dahl, S. J., 79

Dam, H., 204, 206, 234

Dameron, W. H., 377

Daniel, L. J., 235, 236

Darling, R. C., 463

Darnell, A. L., 449

Darrow, R., 253

Davidson, H. R., 390

Davidson, J. A., 174 
Davies, A. W., 188

Davis, G. K., 401

Davis, M., 179, 183

Day, F. T., 407, 448

DeFremery, 406

Deighton, T. A., 282, 291

de LaMare, P. B. D., 81

Deobald, H. J., 134

Deuel, H. J., 448

Donath, W. F., 210

Donelson, E., 388

Dornbush, A. C., 441

Doyle, L. P., 174

Drummond, J. C., 184

Dubnoff, J. W., 108

Duckles, D., 56

Duckworth, J., 127, 234

Duggar, B. M., 37

Dukes, H. H., 328

Duncan, C. W., 136, 137, 377

Dunn, M. S., 87, 111

du Toit, B. A., 329

du Toit, P. J., 114, 372, 388, 436

du Vigneaud, V., 81, 223, 224, 236

\section{$\mathrm{E}$}

Eakin, R. E., 223

Ebbs, J. C., 233

Eckles, C. H., 138, 258, 345, 373, 415, 436

Edgecombe, C. N., 173

Eijkmann, C., 178

Ellenberger, H. B., 434, 435

Ellington, E. V., 318

Ellis, G. H., 47

Ellis, N. R., 18, 72, 73, 78, 135, 237, 343,377

Elmore, I. J., 378

Elvehjem, C. A., 8, 134, 159, 173, 174, $215,218,234,235$

Ely, F., 448

Imden, G., 462

Engle, P., 56

Ensminger, M. E., 224

Ерр⿱ Н., 220

Eppson, H. F., 168

Escher, 'T., 92

Espe, D., 344, 448
Evans, H. M., 203, 205, 401

Evans, R. E., 112, 389, 391

Evans, R. J., 111, 237

Evans, S. T., 172

Ewer, T. K., 234

F

Fairbanks, B. W., 397

Farmer, C. J., 237

Ferguson, W. S., 168

Ferry, E. L., 352

Feuffel, G., 402

Fick, A., 450

Filmer, J. F., 149

Fingerling, G., 101

Fiorito, J. A., 56

Fischer, E., 87

Fitch, J. B., 133, 377

Fitch, L. W. N., 234

Foa, C., 414

Folin, O., 108, 327, 348

Folkers, K., 220

Folley, S. J., 406, 407, 448

Follis, R. H., Jr., 235

Foltz, E. F., 463

Forbes, E. B., 79, 80, 154, 160, 173, $249,255,261,262,279,283,284$, 287, 291, 295, 298, 300, 306, 320, $321,328,357,419,424,428,434$, $438,440,443,448$

Forbes, R. M., 80

Forbes, IV. H., 463

Foster, W. C., 165

Fox, E. L., 276, 291

Franke, K. W., 167

Fraps, G. S., 56, 233, 262, 303, 306

Fraser, A. H. H., 389

French, 1R. 13., 291

Fries, J. A., 285, 286, 321, 328, 431

Frölich, T., 178

Frost, D. V., 236

Fudge, J. F., 306

Fuller, F. I)., 5., 449

Fürth, ()., 56

G

Gaines, W. I., 321, 329, 422, 426, 433

Ciale, E. F', 220 
Gallup, W. D., 262

Garrigus, W. P., 254, 262

Garry, R. C., 392

Gemmill, C. L., 453

Gieseker, L., 56

Gilbert, J. H., 9, 54, 248

Godden, W., 8, 127, 234, 389, 392

Goldberg, S. A., 173

Goldberger, J., 215

Goldblatt, H., 196

Golding, J., 418

Gortner, R. A., 37

Goss, H., 52, 133, 234-236

Graham, R., 81

Grahame, E., 173

Grau, C. R., 94, 111

Graves, R. R., 412, 413, 449

Greaves, J. E., 369

Green, H. H., 114, 172, 388, 436

Greenberg, D. M., 139, 402

Griem, W. B., 394

Griffith, W. H., 66

Grijns, G., 178

Grindley, H. S., 249, 262

Groenewald, J. W., 372

Groth, A. H., 449

Grouven, 48, 304

Guilbert, H. R., 133, 188, 190, 192, $340,373,374,395$

Gullickson, T. W., 195, 345, 377, 436

Gunsalus, I. C., 220, 235

György, P., 314, 220, 229, 236

\section{$\mathrm{H}$}

Haberland, H. F. O., 262

Hadley, F. B., 398, 438

Haecker, T. L., 305, 321, 425, 430

Hagemann, N., 321

Haig, C., 233

Haig, F. M., 235

Haigh, L. D., 69, 321, 329, 339

Haines, W. J., 94

Halnan, E. T., 262

Halpin, J. G., 134, 377

Halverson, J. O., 434

Hamann, C. H., 56

Hamilton, T. S., 50, 247, 249, 278,
$290,300,317,319,321,329,356$, $359,382,385$

Hammond, J. C., 263, 334, 377, 379, 381, 401, 407, 416, 448

Hanawalt, V. M., 81

Hankins, O. G., 343

Hansen, C., 70, 344

Hansson, N., 303, 305, 306

Harley, R., 172

Harper, C., 402

Harris, L. E., 101, 111, 377

Harris, S. A., 220, 224

Harrison, E. S., 417, 430, 432

Hart, E. B., 2, 3, 8, 99, 101, 112, $134,147,159,163,173,174,262$, $350,377,378,398,438,443,444$

Hart, G. H., 181, 188, 373, 374, 383, $395,396,409,448$

Harvey, A. L., 462

Hatfield, J. D., 174

Hauge, S. M., 234, 443

Hawley, E., 363

Hayward, J. W., 262

Hegsted, D. M., 94, 236, 325

Heidenhain, R., 412

Heinemann, W. W., 210

Heller, V. G., 56, 171, 172, 262

Hellström, H., 184

Hendricks, S. B., 119

Hendricks, W. A., 263

Henneberg, W., 45, 269, 271

Henriques, V., 70

Henry, K. M., 80, 173, 445

Herbst, E. J., 234

Herman, H. A., 377

Herrington, B. L., 447

Hess, A. F., 196

Heuser, G. F., 236, 237, 357

Hibbert, H., 45

Higgins, J. W., 80

Hilditch, T. P., 80, 448

Hill, A. V., 454

Hill, E., 56

Hill, F. W., 236

Hill, W. L., 119

Hills, J. L., 321, 326, 329, 448

Hilton, J. H., 234, 448

Hippocrates, 177 
Hjärre, A., 210

Hoagland, R., 80

Hobbs, C. S., 262

Hochberg, M., 235

Hodgson, R. E., 318

Hodson, A. Z., 448

Hogan, A. G., 11, 262, 377, 391

Holman, R. T., 156

Holmes, A. D., 448

Holmes, C. E., 377

Holst, A., 178

Holt, L. E., Jr., 94, 235

Holt, R. L., 128

Hopper, T. H., 18

Hoppert, C. A., 444

Horri, M. J., 87

Horst, K., 329

Hotis, R. P., 449

Hove, E., 173

Howe, P. R., 181

Howell, C. E., 374

Hubbell, R. B., 338

Huffman, C. F., 136, 137, 366, 377, 439

Hughes, E. H., 216, 235, 376, 377, 409, 448

Hughes, J. S., 133, 291, 364, 365, 396

Huldschinsky, K., 196

Hummel, F. C., 448

Hummel, K., 123

Humphrey, G. C., 2, 3, 262, 398, 438,443

Hunscher, II. A., 388, 448

Hunt, G. E., 382, 385

Hutchinson, J. C. D., 291

I

Isbell, H. S., 72

Ivy, A. C., 463

J

Jackson, C. M., 377

Jansen, B. C. P., 80, 210

Jasperson, H., 448

Jenter, C. G., 54, 449

Johnson, D. W., 234, 370

Johnson, J. E., 94

Johnson, R. E., 463, 464
Johnson, S. R., 173

Johnston, M. W., 70

Jones, C. H., 256, 326, 434, 435

Jones, C. P., 448

Jones, D. B., $63,87,89$

Jones, I. R., 373

Jones, J. H., 234

Jones, J. M., 172, 377

Jones, M. M., 456

Jordan, W. H., 54, 449

Jull, M. A., 263

$\mathrm{K}$

Kammlade, W. G., 278, 319, 321, 329

Karns, G. M., 154

Karrer, P. K., 184, 185, 214

Kaucher, M., 80

Kauffman, W. R., 18

Kaufmann, M., 413, 414

Keener, H. A., 173

Kehar, N. O., 174

Keith, M. H., 173

Keith, T. B., 154, 173

Kelley, M. A. R., 292

Kellner, O., 269, 271, 272, 274, 286, 287, 294, 303, 305, 319, 451

Kempster, H. L., 377

Kiendall, E. C., 151

Kennedy, C., 464

Kenyon, F., 388

Keresztesy, J. C., 220

Kieys, $\Lambda ., 463$

Kibler, H. H., 328, 333

Kick, C. H., 349

King, C. G., 228

Kinsman, G. M., 314

Kinter, J. H., 128

Kirchhof, H., 409

Kkeberg, I. J., 172

Kleiber, M., 133, 289, 302

Ḱline, O. L., 262, 443

Knoop, C. E., 231

Knott, J. C., 318

Kioehler, $\Lambda$. E., 56

Kögl, $\mathrm{F}, 223$

Kohler, A., 272

Kohman, E. F., 132

Kolda, J., 421 
Kon, S. K., 173, 237, 445

Krauss, W. E., 234

Krehl, W. A., 218, 219

Krider, J. L., 397

Kriss, M., 279, 287, 289, 291, 302, $304,306,319,321,328,424,431$

Kruger, J. H., 464

Kruse, H. D., 136

Kuhn, G., 184, 185, 214, 220, 269, 271,282

Kummerow, F. A., 81

\section{I}

LaGrange, W. F., 234

Lancaster, R. J., 262

Lanford, C. S., 378

Langtron, W. C., 237

Lantz, E. M., 174

Laplace, P. S., 1

Lardinois, C. C., 234

Lasley, J. F., 402

Lavoisier, A., 1, 267

Lawes, J. B., 9, 54, 248

Lawrence, J. M., 447

Lawrence, R. D., 56

Leathes, J. B., 75

Lee, R. C., 291

Lehmann, C., 305, 456

Leinhardt, H. F., 396

Leitch, I., 8, 36

Lepard, O. L., 171

Lepkovsky, S., 220

Lewis, E. B., 455

Lewis, J. M., 374

Liebig, J., 109, 450

Lienhardt, H. F., 364

Lightfoot, C. C., 137

Lind, 177

Lindley, D. C., 224

Lindsey, J. B., 463

Lines, E., 149

Ling, S. M., 271

Link, K., 206

Linton, R. G., 409, 449

Lintzel, W., 173, 393, 415

Loeb, J., 138

Loofbourow, J. R., 37

Loosli, J. K., 53, 101, 172, 262, 449
Lowry, O. H., 237

Lucas, H. L., 53, 262, 449

Luck, J. M., 112

Lueke, R. W., 217

Lundquist, N. S., 237

Lunin, N., 177

Lush, J. L., 244, 377

Lusk, G., 461

Lyon, C. B., 173

\section{M}

McAnally, R. A., 56

McCance, R. A., 56, 173

McCay, C. M., 7, 8, 74, 173, 336, 338, $341,377,378,417,427,449$

McClendon, J. F., 165

McClure, F. J., 174, 366

McCollum, E. V., 2, 3, 136, 157, $174,179,183,193,199,241$

McComas, E. W., 18

McElroy, L. W., 234-236

McHenry, E. W., 80

McMeekan, C. P., 340

McRoberts, V. F., 262

Mackintosh, J., 445

Macy, I. G., 338, 403, 409, 448

Madden, S. C., 112

Madsen, L. L., 74, 237, 377

Magendie, F., 92, 177, 241

Magne, H., 413, 414

Malan, A. I., 372

Malpress, F. H., 448

Mangold, E., 51

Marais, J. S. C., 329

Marshall, F. H. A., 379

Marston, H. R., 149

Martin, C. J., 235

Mason, K. E., 204, 234

Mather, A. N., 111

Matrone, G., 47

Mattil, K. F., 80,

Mattill, H. A., 203

Maynard, E. J., 369

Maynard, L. A., 8, 46, 47, 53, 74, $172,173,246,253,280,338,415$, $417,426,427,447,449$

Mead, S. W., 52

Meigs, E. B., 395, 438 
Meinke, W. W., 233

Mellanby, E., 193

Melnick, D., 235, 236

Meltzer, S. J., 138

Mendel, L. B., 16, 17, 71, 74, 78, 93, $112,138,179,241,244,245,329$, $330,338,347,352,362$

Meyer, R. K., 402

Michaud, L., 8

Miller, C. O., 18

Miller, E. C., 56

Miller, F. W., 412, 413

Miller, J. I., 378

Miller, M. F., 402

Miller, R. C., 173, 235, 306

Miller, R. F., 383, 396

Minot, A. S., 144

Mitchell, H. H., 8, 18, 50, 101, 103, $109,111,112,131,135,142,163$, $164,174,246,247,249,261,262$, $278,289,290,292,295,300,314$, $317,319,321,324,329,343,344$, $347-349,351,356,358,366,382$, $385,386,393,464$

Moeller, O., 87

Møllgaard, H., 255, 303, 305, 306

Moore, L. A., 233, 237

Moore, T., 184, 188, 233

Morey, N. B., 292, 306, 464

Morgan, L. E., 434

Morgen, C. L., 402

Morris, H. P., 464

Morris, L., 56, 262

Morris, S., 329, 409, 449

Morrison, F. B., 14, 18, 257, 303, 305, $322,326,355,378,425,428,455$

Morrow, K. S., 173

Morse, M., 405

Moulton, C. R., 69, 321, 329, 336, 339

Moxon, A. L., 167, 174

Muriel, D., 402

Murlin, J. R., 81

Murphy, R. R., 144, 154

Murray, I. J., 112

N

Najjar, V. A., 235

Neal, W. M., 127, 436
Nelson, M. T., 196

Newburgh, L. H., 70, 112

Newlander, J. A., 256, 434, 435

Newsom, I. E., 168

Nicholson, L. W., 174

Nierman, J. L., 11

Nims, B., 388

Nitsche, H., 326, 464

Norman, A. G., 56

Norris, L. C., 209, 213, 222, 235, 237, 257, 378

Norton, C. L., 237, 378

O

Olcott, H. S., 87

Olmstead, W. H., 56

Orent, E. R., 136

Orent-Keiles, E., 174

Osborne, T. B., 16, 17, 87, 93, 112 ,

$179,241,244,245,338,347,352$

Oser, B. L., 233, 235

Outhouse, J., 362

Overman, O. R., 412, 422, 426, 433

Overman, R. S., 234

Owen, E. C., 112

\section{$\mathrm{P}$}

Palmer, L. S., 138, 195, 234, 370, 373, $378,415,436,464$

Papanicolaou, G. N., 381

Park, E. A., 112

Parker, J. E., 377

Parks, R. Q., 174

Parsons, H., 223

Patek, A. J., Jr., 233

Patterson, J. M., 80

Patton, A. R., 56, 174

Pavcek, P. I., 234

Pearson, l'. B., 213, 216, 217, 449

Peirce, A. W., 17t

Pekelharing, 178

Pence, J. W., 235

Percival, G. P', 173

Petersen, W. W., 405, 415, 448

Peterson, IV. J., 235, 365

Pettenkofer, M., 267, 269

Phillips, E. F., 56 
Phillips, P. H., 163, 174, 230, 237 398

Phillipson, A. T., 56

Polskin, L. J., 78

Porcher, Ch., 417, 421, 449

Powell, E. B., 53

Prentiss, H., 285, 286

Price, E. A., 183

Procter, F., 52

Procter, R. C., 310, 313, 317, 387, 456

Prout, W., 175

Q

Quakenbush, F. W., 81

$\mathrm{R}$

Radeff, T., 173, 393

Raper, H. S., 75

Rapp, I., 56

Rasmussen, E., 449

Rasmussen, R. A., 402

Ray, S. C., 174,329

Record, P. R., 235, 378

Regnault, H. V., 267, 268

Reimers, J. H., W. T., 378

Reinecke, E. P., 406

Reiset, J., 267, 268

Rettger, L. F., 56

Rhian, M., 167, 237

Rhoad, A. O., 8, 292, 329

Rice, E. E., 112

Riches, J., 392

Riddell, W. H., 133

Ringrose, R. C., 378

Ritzman, E. G., 254, 289, 292, 306, 311, 329, 378

Robertson, D. D., 378

Robertson, T. B., 333

Robinson, C. S., 136

Robinson, W. D., 169

Robison, R., 124

Robison, W. L., 79

Rosa, E. B., 268

Rose, C. S., 236

Rose, W. C., 93-95, 97, 112

Ross, O. R., 384, 397, 402

Rottensten, K. V., 246

Roux, L. L., 402
Rubner, M., 32, 292, 294, 298, 330

Rupel, I. W., 101, 378

Rusk, H. P., 254

Russell, F. C., 114

Russell, W. C., 78, 156, 191, 402

$\mathrm{S}$

Sackville, J. P., 173

St. John, J. L., 111, 237

Salisbury, G. W., 204

Sampson, J., 81

Sanctorius, 264

Sanmann, F. P., 412

Savage, E. S., $378,430,432$

Scarborough, H., 231

Schaible, P. J., 174

Schloss, E., 330, 331

Schmidt, C. L. A., 112

Schmidt, H. S., 213

Schneider, B. H., 103, 112, 350

Schoenheimer, R., 32, 71, 108, 109

Schraffenberger, E., 402

Schultze, A. B., 378

Schultze, M. O., 174

Schutte, D. J., 138

Schweigert, B. S., 237

Seath, D. M., 262, 449

Seekles, L., 169

Sen, K. C., 174

Shankman, S. M., 111

Sharp, P. F., 447

Shaw, A. O., 235

Shaw, J. C., 81

Shealy, A. L., 127, 436

Sheldon, C. C., 80

Sherman, H. C., 315, 362, 363, 378

Sheybani, M. K., 213

Shipley, P. G., 193

Shirley, H. E., 262

Shønheyder, F., 206

Shorland, F. B., 81

Shrewsbury, C. L., 174, 402

Shumburg, 288

Silber, R. H., 236

Simmonds, N., 193

Sinclair, R. D., 173

Singsen, E. P., 131

Sjollema, B., 137, 147, 169 
Slinger, S. J., 378

Slonaker, J. R., 112

Smith, C. W., 455

Smith, H. H., 369

Smith, H. M., 463

Smith, H. V., 174

Smith, J. A. B., 112

Smith, M. C., 174

Smith, W. A., 381

Smuts, D. B., 313, 314, 324, 329, 356

Snedecor, G. W., 262

Snider, G. G., 80

Soames, K. M., 196, 418

Soldner, P. A., 234

Somers, G. F., 37

Sorg-Matter, H., 313

Sparrow, C. D., 333

Spitzer, R. R., 174

Steenbock, H., 2, 3, 81, 183, 196, 200, 262, 350, 443

Stepp, 179

Sternberger, H. R., 448

Stevens, J. R., 220

Stewart, A. P., Jr., 447

Stewart, J., 112

Stirling, J. D., 412, 414

Stirn, F. E., 159

Stiven, D., 392

Stockard, C. R., 381

Stohmann, F., 45, 269

Stokes, J. L., 87, 98

Stone, L., 111

Story, G. F. E., 326

Strong, F. M., 218

Sumner, J. B., 24, 37

Sumulong, M. D., 128

Supplee, G. C., 214

Sure, B., 203

Sutton, 'T. S., 234

Swet, W. W., 412, 413

Swift, R. W., 291, 300, 448

Szent-Gyorgyi, А., 228, 230

\section{$\mathrm{T}$}

T'akaki, 178

Talapatra, S. K., 174

Tash, L. H., 172

Tatum, I\%. L., 237
Taylor, M W., 78, 156, 402

Tepley, L. J., 235

Terroine, E. F., 63, 313

Teut, E. C., 443

Thacker, E. J., 279

Thaer, 304

Theiler, A., 114, 174, 194, 388, 436

Thomas, B. H., 234

Thomas, K., 347, 348, 351, 353

Thompson, R. B., 56

Thomson, J. S., 36

Thomson, W., 127, 234, 389

Titus, H. W., 104, 263

Tolstoi, E., 112

Tonnis, 223

Trautmann, A., 409

Trowbridge, E. A., 463

Trowbridge, P. F., 69, 70, 321, 329, 339

Tufts, E. V., 139

Turner, C. IV., 378, 404, 406, 449

Tyler, C., 329, 402

U

Umbreit, W. W., 235

Underwood, E. J., 148, 149

\section{V}

Van Slyke, L., 416

Vavich, M. G., 237

Vickery, H. B., S6, 87, 112,

Vogt-Moller, P., 203

Voit, ('., 271, 450

von Bunge, (i., 140, 144, 145

von Euler, 13., 18.1, 214

von Euler, H., 184

Voris, L., $4+18$

W

Wachtel, I. W., 17.

Wald, G. I., $46 . t$

Walker, H. А., $7 \mathrm{~S}$

Wallis, G. (., 393, 444

Wang, Y. I., 233

Warkany, J., 102

Warner, 1). 'T', 94

Washhurn, IR. M., 326

Waterman, R. E., 256 
Waters, H. J., 337, 338

Watson, C. J., 263

Watson, D. M. S., 340

Waugh, R. K., 234

Weber, A. D., 378

Weckel, K. G., 446

Weinstock, M., 196

Welch, H., 402

West, E. S., 37

Whipple, G. H., 107, 144

Widdowson, E. M., 173

Wierzuchowski, M., 271

Wilbur, J. W., 448

Wilder, O. H. M., 378

Wilgus, H. S., Jr., 153, 378

Willcox, J. S., 329, 402

Williams, P. S., 154

Williams, R. D., 56

Williams, R. J., 221, 222, 223

Williams, R. R., 210

Willman, J. P., 204

Wilson, D. C., 234

Wilson, L. T., 374

Windaus, A., 197, 210
Winternitz, M. C., 87, 112

Winters, L. M., 402

Wintrobe, M. M., 219, 235, 236

Wislicenus, 450

Wolbach, S. B., 181, 237

Wolfe, E., 305

Womack, M., 97

Woodman, H. E., 112

Woodruff, J. C., 87

Woodward, J. C., 253

Woodward, T. E., 18, 449

Woolley, D. W., 97, 226

Work, S. H., 430

Wright, K. E., 412

Wright, N. C., 52, 112

\section{$\mathrm{Z}$}

Zander, D. V., 378

Zeller, J. H., 78

Zilva, S. S., 418

Zink, C. L., 455

Zscheile, F. P., 234

Zuntz, N., 100, 101, 269, 288, 321, 456,458 


\section{SUBJEGT INDEX}

\section{A}

Acalciosis, 128

Accessory food factors, 178

Acetone bodies, 75

Acetonemia, 75

Acetonuria, 75

Acid, aceto-acetic, 75

alkali-ash value, 170

arachidic, 58, 60

arachidonic, 58, 60

ascorbic (see Vitamin C)

aspartic, 84, 87, 94

butyric, 58

capric, 58

caproic, 58

caprylic, 58

citric, 411

clupanodonic, 58, 59

glutamic, 84, 87, 94

hippuric, 91

hydroxybutyric, 75

hydroxyglutamic, 84, 94

iodogorgoic, 85

ketobutyric, 75

lactic, 55, 452

lauric, 58

lignoceric, 58, 59

linoleic (linolic), 58, 60

as essential nutrient, 76

linolenic, 58, 60

myristic, 58

oleic, 58, 60

oxalic, and calcium metabolism, 131

palmitic, 58, 60

palmitoleic, 58, 59

phytic, 130

pyruvic, 106

stearic, 58, 60

$\Lambda$ cid-alkali-ash value, 170

$\Lambda$ cid-base balance in rations, 170
Acid-forming foods, 170

Acidity, actual, 27

titratable, 27

Acidosis, 75

Acids, saturated, 60

tolerance of body to, 170

unsaturated, 60

Adsorption, 20

Alanine, 83, 87

Aldohexose, 40

Alkali disease, 166

Alkali reserve, 75

Allantoin, 91

"Allowance," definition of, 315

nutrient, 315

Aluminum, 159

Amides, 90

role in protein nutrition, 100,101

Amino acids, 83-86, 92-98, 105

classification of, 83-8j

determination, in feeds, 98

in proteins, 85

essential, 93-96

metabolism of, 105

nonessential, 93-97

percentage in various proteins, 87

and protein quality, 92-97

Anemia, 143-145

hereditary, 144

nutritional, 144-145

in pigs, 371

role of eopper in, 147

role of iron in, 143-145

pernicious or primary, 143

secondiary, 144

\ngstrom unit $(\AA), 29$

Animal body, blood in, 12

gross eomposition of 10

mineral elements in, 11

organic constituents in, 9-11

water in, 9, 10

Anorexia, 209 
Antineuritic factor (see Thiamine)

Antioxidants, 63

Antirachitic factor (see Vitamin D)

Antiscorbutic factor (see Vitamin C)

Aphosphoresis, 128

Arabinose, 39

Arginine, 84, 87, 93, 94

Arsenic, 168

Ash, in bone, 118

determination of, in feeds, 115 significance of, 115

storage in fetal growth, 386

Asparagine, 90

Autoxidation, 62

Avidin, 223

\section{$\mathrm{B}$}

" $\mathrm{B}_{\mathrm{c}}$ conjugate," 226

Balanced ration, 299

influence on net-energy value, 299

Balances, nutritional, 264-291

advantages and limitations of study of, 291

energy, 274-291

example of, 285

of matter, 264-274

mineral, 266

nitrogen, 265

nitrogen-carbon, 271-273

example of, 272

over lactation cycle, 434

Basal metabolism, 308-312

as measure of energy maintenance, 316-318

Base-forming foods, 170

Beeswax, 64

Beriberi, 178, 208, 443

(See also Thiamine)

Biological oxidation-reduction, 23-25

Biological value of protein, for dif-

ferent species, 350

effect of heat on, 354

in growth, 346-354

measured by feeding trials, 352

methods of determining, 346-348

Thomas-Mitchell method for,

347-349

values for various feeds, 353
Biological value of protein, in lactation, 429

in maintenance, 322

supplementary relationships, 349

Biotin, 224-225, 376

chemistry of, 224

in foods, 225

function and deficiency symptoms, 224

species requiring, 224

Blood, calcium in, 120

composition of, 12

composition changes in relation to lactation, 413

glucose in, 53

phosphorus in, 120

sodium in, 139

Blood plasma, composition of, in relation to milk, 410-412

Bone, ash in, 118

chemistry of formation of, 118

composition of, 118

as depot of calcium and phosphorus, $125-127$

growth of, 123-125, 361

longitudinal-section diagram of, 123

malnutrition of, 125-128

phosphatase as factor in deposition, 124

proliferative zone of cartilage, 123

structure of, 118, 123-125

Bone meal, composition of, 134

Boron, 169

Bradycardia, 209

British thermal unit, 274

Buffers, buffer action, 27

Bulk, in concentrate mixture, 51 and laxative effect, 52 in rations, 51

usefulness and limitations of, 52

Butterfat, fatty acids in, 60

(See also Milk)

\section{C}

Calciferol, formula, 198

Calcium, 117-134, 138, 193, 360-371, 388-392, 400, 433-440

absorption of, 121 
Calcium, areas of deficiency, 116, 436

in blood, 120

in bone, 118

deposition of, 123-125, 361-363

diffusible, 120

early studies of, 117

effects of deficiency of, on growth,

125

on lactation, 436

on reproduction, 388-390

excretion, 122

in fasting, 314

in feeds, 128

availability of, $130-132$

interrelations of, with magnesium, 138

with phosphorus and vitamin $\mathrm{D}$, 118,193

metabolism of, in growth, 360363

in lactation, 434

in osteomalacia, 127

in reproduction, 388-390

in rickets, $125-127$

mobilization of, 127

in lactation, 434-435

nondiffusible, 120

requirement of, for egg production, 400

for growth, 363-367, 369

from blood analyses, 365

from bone analyses, 366

in calves, 367

in chickens, 367

in lambs, 367

measured by balance studies, 363

meeting in practice, 369

in pigs, 367

for lactation, 433, 440)

estimation from balance data, 438

estimation from maintenance and milk yield, 43!

for reproduction, 389-391

storage in fetal growth, 386, 389
Calcium, supplements, 133

in tissues, 119

Calcium-phosphorus ratio, in bone, 119

influence on absorption, 122

in rations, 118

Calorie, large, 274

small, 274

Calorimeter, adiabatic, 276

animal, 282

bomb, 275

oxy- (see Oxy-calorimeter)

respiration, 282-286

data obtained with, 285

Calorimetry, direct, 282-286

indirect, 287-289

from nitrogen-carbon balance, 288

from oxygen consumption, 288

by respiration apparatus, 289

from slaughter data, 288

Carbohydrates, 38-56

absorption of, 53

catabolism of, 55

classification of, 38

definition of, 38

gross energy of, 276

metabolism of, 47-56

physiological fuel value of, 277

respiratory quotient of, 270

as structural elements in tissues, 57

Carotenes, 182-186

content of farm feeds, 190-193

destruction of, 186, 187

determination of, 189

formulas for, $18 \tilde{5}$

identification as precursor of vitamin $A, 183-185$

metabolism of, 187-189

secretion in milk, 440-442

storage in body, 188

transformation into vitamin $I$ in body, 184

breed differences among cattle,

18!), 441

(Serealso Vitamin A)

Carr-Price reaction, 183

('atalysis, catalyst, 23 
Cellulose, 43

determination of, 46-47

digestion of, 48

by different species, 50

factors governing, 49

by microorganisms, 48

Cephalins, 65

Cerebrosides, 65

Chemical regulation of body temperature, 281

Chlorine, 141

excretion in fasting, 314

Cholesterol, 66

esters of, 66

as precursor of vitamin D, 197

Choline, 64, 66, 225, 376

Citrin, 230

Citrulline, 84, 94

Cobalt, 149-151

Cocoanut fat, 60

Cod-liver oil, lowering of milk fat percentage by, 418

reference, 189, 199

Coefficients of digestibility, 255 average, 257

Colloidal state of matter, 21

disperse or internal phase of, 22

dispersion medium or external phase of, 22

gelling of, 22

properties of, 22

Colostrum, 420

Combustible gases, 268

formulas for calculating, 279

Complex mineral mixtures, 172

Concentrates, definition of, 15

Copper, 147, 148

Coprosterol, 66

Corn fat, 60

Corpus luteum, 380

Cottonseed fat, 60

Creatine, 92, 452

Creatinine, 92

Critical temperature, 281

Crude fiber, determination of, 45

digestion of, $48-50$

influence on digestibility of other nutrients, 50
Crude fiber, influence on calcium and phosphorus absorption, 122

limitations of method for, 46

Cryptoxanthine, 186

"Curled-toe paralysis," 213

Cystine, 84, 87, 94

in wool production, 360

D

Deaminization, 105, 106

Defluorinated phosphates, 134, 164

Dehydrocholesterol, 197, 198

"Deposit protein," 106, 110

Depot fat, "hardening off," of, 74

Desaturation theory of Leathes and Raper, 75

Dextrin, 43

Dextrose, 40

Diabetes, 56

Diaphysis, 123

Dicalcium phosphate, as mineral supplement, composition of, 134

Digestibility, associative, 259

determination of, 252-256

factors affecting, 258-260

feces collection, automatic devices for, 254

harness and bag for, 254

metabolism cages for, 253

in poultry, 255

use of markers in, 252

influence on, of cooking feed, 260

of grinding and chopping feeds, 259

of level of intake, 258

of protein, enzymatic method for, 256

variability of, in different species, 251

Digestion, of complex polysaccharides, 48-51

of crude fiber, 49

of lipids, 68

of protein, 99

of sugars and starch, 47

Digestion coefficients, 255

average, 257

Digestion trials, 252-256, 259 
Diiodo-tyrosine, 85, 151

Disaccharides, 41,42

Drugs, passage into milk, 421

$\mathrm{E}$

Egg production, 398-401

requirement, for calcium, 400

for iron, 400

for manganese, 400

for phosphorus, 400

for protein, 399

for vitamin A, 401

for vitamin $\mathrm{D}, 400$

for vitamins of B-complex, 401

Eggs, composition of, 399

formation of, 398

Emulsions, 20

Endogenous nitrogen, 108, 312-314, 323-325

constancy of, 312

as a measure of protein maintenance, 325

as measured during fasting, 312

as related to energy catabolism of fasting, 313

Energy, gross, 274-277

values for, 276

metabolizable, 277-279, 295

determination of, 278

for muscle action (work), carbohydrate vs. fat as source, 453

net, 286, 296-302

values for, 286

requirement, for growth, 342-345

computed from metabolism and slaughter data, 343

factors governing, 342

obtained from feeding trials, 344

for lactation, 422-428

determination in feeding trials, 425

estimation from metabolism studies, 424

for maintenance, 314-322

calculated from basal metabolism, 316
Energy, requirement for maintenance, determined as energy equilibrium, 319

determined in feeding trials, 318

values for, 321

for reproduction, 384-387

for work production, $458-460$

allowances in practice, 460

determination by feeding trials, 460

estimation from metabolism studies, $458-460$

storage in fetal growth, 382,386

Energy catabolism of fasting, 308-312 relation to endogenous nitrogen, 313

Energy equilibrium as a measure of maintenance, 319

Energy metabolism, usefulness of studies of, 290

Enzootic ataxia, 147

Enzymes, definition and properties of, 23

Epiphysis, 123

Ergosterol, 67, 197, 201

irradiated, 197, 198, 201

Essential fatty acids, 76

Essential oils, 67

Estradiol, $40 \tilde{5}$

Fstrogens, 406

Ether extract, determination of, 67

F

"Factor U," 226

"Falling disease," 147

Fallopian tubes, 380

Fasting catabolism, 307-315

of energy, 30S-312

lability of, 311

vilues for, 312

of minerals, 314

of nitrogen, 312-314

units of reference in, 310

Fat, in bone, 118

vs. carbohydrate for fat deposition, 78

determination of, 67 
Fat, dynamic state of, 70

as essential nutrient, 76, 77, 387

in feces, 68

formation of, from carbohydrate, 54

from protein, 76

importance, in the diet, 78

in lactation, 426-428

metabolic, 68

metabolism in reproduction, 387

in milk, influence of food on character, 74

peroxide number of, 62

respiratory quotient of, 270

secretion of, in milk, 415-418

lowering by cod-liver oil, 418

relation, of blood lipids to, 417

of ration to, 418

variations in, 416

tolerance, 79

Fat deposition, 69-71

in the hog, 72

influence of character of food fat, 71-73

water relations in, 70

Fat depots, composition of fat in, 69 location of, 69

Fats, 59-64

acid number of, 62

animal vs. vegetable, 77

catabolism of, 75

gross energy of, 276

hydrogenation of, 65

hydrolysis of, 59

iodine number of, 61

melting point of, 61

nature of, in depots, 63

species differences in, 64

oxidation of, 62

physiological fuel value: $\mathrm{of}_{-}, 277$

refractive index of, 62

Reichert-Meissl number of, 62

saponifiable fraction of, 62

saponification number of, 61

solidifying point of, 61

special nutritive value of, 76,78

as structural elements in body, 63 structure of, 59
Fats, subcutaneous, 69

unsaponifiable fraction of, 62

Fatty acids, 58

distribution in individual fats, 60

Feces, collection of, in digestion and metabolism experiments, 253255

nitrogenous products in, 102-104

Feed intakes, controlled, 244

equalized, in paired feeding, 245248

Feed preparation, influence on digestibility, 259

Feed records, group vs. individual, 243

Feeding experiments (see Feeding trials)

Feeding standards, 304-306

Feeding trials, 238-251

feed intake records in, importance of, 238

financial expression of results of, 249

group vs. individual feeding in, 243

with laboratory animals, 240

as measures, of protein efficiency for growth, 352

of energy requirement, for growth, 344

for maintenance, 318

of protein maintenance, 326

of protein requirement for growth, 357-359

paired-feeding method in, 245-248

slaughter data from, 248

use of statistical methods in, 250

Fermentation, in digestive tract, 48

Fertilization, 380

Fetus, growth of, 381-383

nutrients stored in during growth, $382,390,393$

Fluorine, 161-166

cause of mottled enamel, 161

content in foods and mineral supplements, 164

deleterious effect on milk production, 163 
Fluorine, distribution in body, 161 as an essential element, 165 harmful effects on bones and teeth, 161

harmful levels in water, 162 practical aspects of toxicity of, 164

safe and toxic levels of, 163-165

"Folic acid," 226-227

Folin theory of protein catabolism, 108, 109

Food energy, measures of, 293-306 (See also Energy requirements)

Foods, (see Feeds)

Foot-pounds, 453 relation to Calories, 454

Frap's energy-production coefficients, 303

Fructose, 41

Fuel values, physiological, 279, 296 as a measure of energy requirement, 296

Furfural, 44

\section{G}

Gaines formula for 4-per cent milk, 424

Galactose, 41

Gaseous exchange, measurement of, 267

Gigantism, 337

Glucose, 40 transformation of, into fat, 54

Glutamine, 90

Glutathione, 92

Glycerol, 59

Glycine (glycocoll), 83, 87, 94

Glycogen, 43 as reserve in liver and muscles, 53

Glycolipids, 65

Glycosuria, 56

Glycyl-glycine, 87

Goiter, 151-153, 394

Goiter areas, 153

Graafian follicle, 380

"Grass juice factor," 227

"Grasss statggers," 136
"Grass tetany," 136

Growth, 330-378

acceleration of, 338

of bacon type and lard type of hog, 334

biological value of protein for (see Biological value of protein)

of body as a whole, 332

comparison of species, 333

of body parts, 334

calcium requirement for, $363-367$, 369

cell as unit of, 331

cycles of, 333

definition of, 330

energy requirement for, 342-345

fetal, 381-383

general nature of, 330

influence of internal secretions on, 336

iron requirement for, 371

measures of, 325

nicotinic acid requirement for 376

"normal," 335

optimum, 331

phosphorus requirement for, 363367, 369

physiology of, 330-342

protein requirement for, $346-360$

(See also Protein requirement)

rate of, and feed efficiency and carcass quality, 339-341

and longevity, 341

and optimum development, 341 resumption after returdation, 337

retardation of, 337

riboflavin requirement for, 375

salt requirement for, 372

of skeleton, measures of, 361

optimum development of, 362

thiamine requirement for, 375

vitamin $\Lambda$ requirement for, 373 375

vitamin D requirement for, 368 , 369

Guanidine, 92

Gums, 39 


\section{H}

Hansson's food-unit system, 303

"Hay values," 304

Heat, of combustion, 274-277 values for, 276

loss of, by body, 280-282

calculated from insensible loss of weight, 289

direct measurement of, 282-286

indirect measurement of, 287289

relation to body size, 310

Heat increment, 297-299

and level of food intake, 298

measurement of, 297

as a specific dynamic effect, 298

Hemicellulose, 44

Hemoglobin, 143

Hemolysis, 21

"Hemorrhagic sweet clover disease," 206

Hexosans, 39

Hexoses, 39, 40

Histidine, 85, 87, 94

Hormones, 404

(See also Growth)

Horse-power, 453

Hydrogenation, 63

Hydrogen-ion concentration, 25

Hydroxy- $\beta$-carotene, 186

Hydroxyproline, 85, 94

Hyperglycemia, 54

Hyperplasia, 331

Hypertrophy, 331

Hypoglycemia, 54

\section{I}

Inositol, 226

Insensible loss of body weight, 289 as measure of heat loss, 289

International unit, for vitamin A, 189 for vitamin B, 212

for vitamin C, 229

for vitamin D, 199

Interrelationships of animal and human nutrition, 5, 6

Intestinal synthesis of vitamins, 231
Inulin, 43

Invert sugar, 41

Iodinated proteins, 405, 406 influence on milk secretion, 406

Iodine, 151-155, 372 deficiency an area problem, 153 distribution in body, 151 functions of, 151-153 relation to goiter, 151-153 in reproduction, 394 requirement, 154

for growth, 372

supplements, 154

Iodized eggs, 155

Iodized milk, 155

Ionization theory, 25

Iron, 143-146

availability in foods, 146

distribution in the body, 143

requirement, for egg production, 400

for growth, 371

for reproduction, 393

role in hemoglobin formation, 143, 144

storage, in fetal growth, 386

in newborn, 386, 393

Irradiation, of body, 196, 201

of foods, 196

of milk, 201

Isoleucine, 83, 94

Isotopes as "tracers," 31,32

K

Kaufmann-Magne technique, 413

Ketohexose, 40

Ketosis, 75

$\mathrm{L}$

Laboratory animals, usefulness and limitations for nutrition investigations, 240

Isactase, 42

Lactation, 403-449 calcium requirement for, 433-439 curve, 407 energy requirement for, $422-427$ importance of food fat in, 426-428 
Lactation, induction by synthetic estrogens, 406

influence of iodinated protein on, 406

mechanism of, 412

persistency of, 408

phosphorus requirement for, 433439

protein requirement for, 428-433

salt requirement for, 440

secretion, of colostrum, 420

of fat, $415-419$

of lactose, 413

of minerals, 419

of pigments, 420,441

of protein, 419

of riboflavin, 446

of vitamin A, 440-443

of vitamin $\mathrm{B}, 446$

of vitamin $C, 447$

of vitamin D, 443-446

L. Casei factor, 226,227

Lactoflavin, 213

Lactogen, 405

Lactose, 42, 413

influence on calcium and phosphorus absorption, 121

secretion in milk, 413

Lard, 60

Law of mass action, 23

Lechsucht, 147

Lecithin, 64, 65

Leucine, 83, 87, 94

Levulose, 41

Lignin, 44

determination of, 46

digestion of, 48

Limestone, 134, 139

"Line test," 123, 199

Lipase, 68

Lipids, $59-80$

absorption of, 69

classification of, 57

compound, 64-66

definition of, 57

determination of, 67

digestion of, 68

fecal, 68
Lipids, metabolic, in feces, 68

metabolism of, 67-79

(See also Fats)

Liver, glycogenic function of, 53

Longevity, relation of rate of growth to, 7,341

Lysine, 84, 87, 94

\section{M}

Magnesium, 135-139

allowance, 137

in blood, 135

in bone, 118

distribution of, in body, 135, 136

excretion of, 136

in fasting, 314

functions of, 136, 137

interrelationships with calcium and phosphorus, 138, 139

symptoms of deficiency of, 136, 137 tetany, 136

Maintenance requirement, 315-328

definition, 315

for energy, 316

for minerals, 327

for protein, 322-327

constancy of during production, 327,432

for vitamins, 327

Maltase, 42

Maltose, 42

Mammary glands, development of, 403

hormonal control of, 404

structure of, 404

(See also Lactation)

Manganese, 157-159, 400

Mannose, 41

Metabolic nitrogen, 102, 347

Metabolism, basal, 308-311

resting, 309

standard, 309

Metabolism cages, 253

Metabolizable energy, 277-279

determination, example of, 278

is a measure of food energy re(quirement, 295)

Methionine, 84, 87, 94 
Microbiological methods, 86

Microorganisms, role of, in carbohydrate digestion, 48

in protein nutrition, 100

synthetic action in digestive tract, 100

Milk, abnormal constituents in, 421 bitch's, 409

composition for different species, 409,410

course of secretion of, 407

of cow, composition of, 411, 422, 423

relation to blood plasma, 410

relation to blood changes, 413

in udder disease, 422

variations in, 422

fat, 60

influence of food on composition of, 73

(See also Fat)

Gaines formula for 4 per cent, 424 goat's composition of, 409

Holstein, composition as related to fat content, 423

human, composition of, 409

iodized, 155

irradiated, 201, 445

Jersey, composition as related to

fat content, 423

mare's, composition of, 409

relations between fat, protein, and energy in, 423

riboflavin in, 446

secretion of (see Lactation)

sheep's, composition of, 409

sow's, composition of, 409

vitamin A value of, 440

vitamin $\mathrm{B}$ in, 446

vitamin $\mathrm{C}$ in, 447

vitamin $\mathrm{D}$ in, $443-445$

(See also Lactation)

Minerals, 113-173

area deficiencies and excesses of, 114-116

elements essential in nutrition, 113 excretion in fasting, 314

general functions of, 117
Minerals, in milk, 411, 419 and in newborn, 144 requirement for work production, 462

Møllgaard's production-equivalent system, 303

Molybdenum, 168

Monosaccharides, 39-41

Morrison's estimated net-energy values, 303

Muscle contraction, 451-453

nutrients involved in, 450

(See also Work production)

$\mathrm{N}$

Net energy, 286, 296-302

requirement, for growth, 343

for work production, 458

Net-energy values, 286, 296-302

computation of, 286

determination of, 287

inconstancy of, 301

relation, of balance of nutrients to, 299-301

to body function, 299

Niacin (see Nicotinic acid)

Nickel, 169

Nicotinic acid, 215-219

amide, 218

assay, 218

chemistry of, 218

in foods, 218

functions and deficiency symptoms, 216

interrelations with amino-acid metabolism, 218

requirement for growth, 376

species requiring, 216

Night blindness, 180

Nitrite poisoning, 168

Nitrogen, catabolism of fasting, 312314

endogenous, 108

equilibrium, 265

as a measure of protein maintenance, 323

exogenous, 108

fecal, 102-104 
Nitrogen, metabolic, 102, 347 determination of, 102-104 factors governing, 102-104

Nitrogen balance, 265

as a measure of protein maintenance, 323

of protein requirement for growth, 356

studies in lactation, 431

Nitrogen-carbon balance, 271-273

use in indirect calorimetry, 288

Nitrogen-free extract, determination of, 45

Nonprotein-nitrogen compounds, 9092

Norleucine, 83, 94

Nutrition and productive life, $6,7,341$

Nutritional anemia (see Anemia, nutritional)

Nutritive ratio, 258 influence on digestibility, 258

\section{$\mathrm{O}$}

"Oat-hay poisoning," 168

Osmotic pressure, 20

Osteomalacia, 127, 437

Osteoporosis, 128

Ovoflavin, 213

Ovulation, 380

Oxy-calorimeter, 276

Oxygen debt, 453

Oyster shells, 134

\section{$\mathrm{P}$}

Paired-feeding method in feeding experiments, $245-248$

Pantothenic acid, 221-223, 376

chemistry of, 223

in foods, 223

functions and deficiency symptoms, 222

species requiring, 221

Para-amino benzoic acid, 227

Parathyroid gland and calcium metabolism, 120, 127

Pellagra, 215

Pentosans, 44

Pentoses, 36
Peptide linkage, 88

Perosis, 157

Persistency of milk secretion, 408

$\mathrm{pH}$ values, 26

Phenylalanine, 85, 87, 94

Phosphagen, 92

Phosphatase, 124

Phosphocreatine, 92, 452

Phospholipids, 64

Phosphorus, 117-135, 193, 360-371, 388-392, 400, 433-440, 462

absorption of, 121

factors governing, 121

areas of deficiency, 115,436

in blood, 120

in bone, 118

deposition of, 123-125, 361, 362

early studies of, 117

effect, on food utilization, 133

of deficiency, in lactation, 436

in reproduction, 388

excretion, 122

in fasting, 314

in feeds, $128-130$

factors affecting availability, 130

inorganic, factors governing level in blood, 120

interrelations with calcium and vitamin D, 118, 193-195

metabolism, in growth, 360-363

in lactation, 434

in osteomalacia, 127

in reproduction, 390

in rickets, 125

in work production, 451

mobilization of, 127,434

relation to appetite, 132

requirement, for growth, 363-367, 367

in calves, $363,366,367$

in (hickens, 367

in lambs, 366, 367

in man, 363

measured by balance studies, 363

mceting, in practice, 367

obtained from blood analyses, 365 
Phosphorus, requirement, for growth, obtained from bone analyses, 366

in pigs, 364,367

for lactation, 433-440

estimation, from balance data, 438

from maintenance and yield, 439

for reproduction, 389-391

storage of, in fetal growth, 386, 389-391

in lactation, 434

supplements, 133

in tissues, 119

Physical regulation of body temperature, 281

Phytase, 131

Phytin, 130

Phytosterols, 67

Pigments in milk, 420, 441

Plants, by-products as feeds, 16

carbohydrates in, 15

fat in, 15

mineral elements in, 15

nutrient distribution in different parts, 14-17

protein in, 14

Plasma proteins, 106, 107

Polyneuritis, 178, 209

Polypeptides, synthesis in vitro, 87

Polysaccharides, 42-47

Polyuronides, 44

Pork, soft, 71

Potassium, 140, 314

Productive life, influence of growth rate on, 6,341

Progesterone, 405

Prolactin, 405

Proline, 85, 87, 94

Prooxidants, 62

Protein(s), 82-112, 322-328, 382, 387, $427-433,450,460$

absorption of digestion products, 105 apparent digestibility of, 104

biological value of, 93-95, 322, 346354,429

for growth, 346-354
Protein(s), biological value of, for lactation, 429

for maintenance, 322

(See also Biological value)

in bones, 118

catabolism, 107-109

chemical determination of, 90

classification, 82

colloidal behavior of, 88

crude, 90,98

vs. true, 98

elementary composition of, 82

endogenous catabolism of, 108

equivalent, 99

exogenous catabolism of, 108

gross energy of, 276

metabolism, in growth, 346-354

in lactation, 428

in maintenance, 322

in reproduction, 382,387

in work production, $460-462$

minimum vs. optimum intake of, 109-111

physiological fuel value of, 277

in plasma, 106, 107

properties of, 88,89

requirement, for egg production, 399

for growth, 346-354

determined by feeding trials, 357

estimation from slaughter data, 355

factors governing, 355

measured by nitrogen-balance, 356

methods of stating, 359

for lactation, 428-433

allowances for cows in practice, 432

determination in feeding trials, 430

estimation from nitrogen-balance data, 431

relation of biological value to, 429

for maintenance, 322-327

constancy during production; 327,432 
Protein(s), requirement, for maintenance, determined in feeding trials, 326

estimated from endogenous nitrogen, 323

obtained trom nitrogen-balance data, 325

for reproduction, 387

for work production, 460-462

reserve, 106

respiratory quotient of, 270

secretion in milk, 419

storage in fetal growth, 382, 386, 387

structure of, 86-88

supplementary relations in growth, 349

synthesis, in body from amino acids, 105

by microorganisms in digestive tract, $100-102$

transformation into fat, 76

true, 90, 98

Purified diets, 240-243

Pyridoxal, 221

Pyridoxamine, 221

Pyridoxine (see Vitamin $B_{6}$ )

$\mathrm{R}$

Radiation, electromagnetic, 27

absorption of, 30

Raffinose, 42

Rancidity, 62

Range of thermal neutrality, 281

Reaction velocity, 23

Reproduction, 379-402 calciun requirement for, 389-391

effect, of ealcium and phosplorus deficiencies on, 388-390

of general undernutrition on, 383

energy requirement for, 381-387

fat, metabolism in, 387

influence of fathess on, 384

iodine requirement for, 394

iron requirement for, 393

phosphorus requirement for, 38?391
Reproduction, physiology of, 380383 protein requirement for, 387 vitamin A requirement for, 395397

vitamin C requirement for, 398 vitamin $\mathrm{D}$ requirement for, 392 vitamin $\mathrm{E}$ requirement for, 397

(See also Egg production)

"Requirement," definition of, 315 minimum, 316

Respiration apparatus, 267-269

closed-circuit type, 267

open-circuit type, 267

use in indirect calorimetry, 289

Respiratory quotient, 269

use in indirect calorimetry, 288

Riboflavin, 212-215

assay, 215

chemistry of, 213

functions and deficiency symptoms, 212

requirement, for growth, 375

for lactation, 446

secretion in milk, 446

species requiring, 213

Ribose, 39

Rickets, 125-127, 193, 360, 361

blood changes in, 125

in calves, 126

definition of, 125

low-ealcium, 126

low-phosphorus, 126

in pigs, 127

Roughage, definition of 15

sis

Silt, 141, 372, 4.40, 462

repuirement, for growth, 372

for lactation, 4.40)

as related to sweating, 142

for work production, 462

tolerance of body to, 1.42

Saponification of fits, 61

Seurvy, 177, 22S

Selenium, 16 i

Serine, 83, 87, 91

Sex organs, development of, 380 
Silicon, 160

Slaughter data, in feeding trials for maintenance, 319

as measures, of energy requirement for growth, 343

of protein requirement for growth, 355

Slaughter experiments in nutrition in investigations, 248

Slipped tendon, 66

Sodium, 139

absorption and excretion, 140

distribution in body, 139

excretion in fasting, 314

Sodium chloride, 141

Sodium-potassium ratio, 140

Solutions, hypertonic, 21

hypotonic, 21

isotonic, 21

physiological salt, 21

Soybean fat, 60

Specific dynamic effect, 298

Spectra, absorption, 30

of carotene, 184

of vitamin A, 184

Spectrograph, 30

Spectrum, electromagnetic, 28

Spent bone black, 134

Spermaceti, 64

Sphingomyelins, 65

Starch, 43

digestion of, 47

equivalents, 273,303

Starch values of Kellner, 273

Statistical methods in feeding experiments, 250

Sterols, 66

"Stiff-lamb" disease, 204

S. Lactis $R$. factor, 226

Stutzer method for protein, 90

Sucrase, 41

Sucrose, 41

Sugars, $39-42$

configuration of, 40

digestion of, 47

reducing, 40

stereo-isomerism of, 40

(See also Carbohydrates)
Sulfur, 156

compounds of, in wool production, 359

excretion of, in fasting, 314

Sunlight in vitamin D nutrition, 201

Surface-area law, 310

Surface phenomena, 19, 20

Surface tension, 19

Synthetic diets (see Purified diets)

$\mathrm{T}$

Teeth, composition of, 119

Tetany, 120

Therm, 274

Thiamine, 208-212

assay, 211

chemistry of, 210

in foods, 211

functions and deficiency symptoms, 209

requirement, for growth, 375

for lactation, 446

for work production, 463

secretion in milk, 446

species requiring, 209, 210

stability of, 211

unit of, 212

Threonine, 83, 87, 94

Thumps, 371

Thyroxine, 85, 151, 405

Tocopherols, 205

Total digestible nutrients, 256, 293

computation of, 257

for growth, 344

for lactation, 426,429

for maintenance, 321

as a measure of food-energy requirements, 293

for work production, 459

(See also Energy requirements)

Trabeculae, 123

Transamination, 96

Transmethylation, 66

Trisaccharides, 42

Tryptophane, 85, 87, 94

Tyrosine, 85, 87, 94 
U

Udder, development and structure, 403-405

functioning of, 412

(See also Mammary glands)

Ultraviolet light, 28

and vitamin $\mathrm{D}, 196$

Undernutrition, effect on growth, 337

and reproduction, 383

Unit of energy value, 274

U. S. P. unit, for vitamin A, 189 for vitamin D, 199

Units, for vitamin assay (see Vitamins)

of work and power, 453

Urea, 91

as a feed, 101, 102

Uric acid, 91

Uronic acids, 44

\section{V}

Vaginal smear technique, 381

Valine, 83, 87, 94

Vitamin A, 180-193, 373-375, 395$397,440-443$

absorption spectra of, 183

assay, 189

Carr-Price reaction for, 183

chemistry of, 182-186

destruction in feeds, 186-187,

discovery of, 179

effects of deficiency of, 180-182

in cattle, 373

on growth, 373-375

on reproduction, 395-397

on teeth, 182

formula for, 185

in milk, 440

relation of, to infections, 181

requirement, for growth, 373-375

for lactation, 440-443

for reproduction, 395-397

stability of, 186

storage in body, 188

units for, 189

value of feeds, 190-193
Vitamin A, value of feeds, of milk, 440 of plant products, 191-193 relation, of curing process, 191 of stage of maturity, 191

Vitamin $\mathrm{B}\left(\mathrm{B}_{1}\right)$ (see Thiamine)

Vitamin $\mathrm{B}_{\mathrm{c}}, 226$

Vitamin B complex, 208

Vitamin $B_{6}, 219-221,376$

assay, 221

chemistry of, 220

in foods, 221

functions and deficiency symptoms, 220

species requiring, 220

Vitamin C, 228-230, 398, 447

assay, 229

chemistry of, 228

in foods, 229

functions and deficiency symptoms, 228

in milk, 447

species requiring, 228, 229

stability of, 229

Vitamin D, 193-203, 360, 367, 319, $392,443-445$

assay, 199

chemistry of, 197-199

discovery of, 193

in dry roughages, 200

influence of quality and curing, 200

effects of deficiency of, 193-195

enrichment of foods in, 200

by concentrates of the vitamin, 200

by irradiation, 201

in foods, 200,

functions of, 193-195

influence on ralcium and phosphorus metabolism in lactation, 443

interrebtions with ealcium and phosphorus, 118, 19.

milk, 4.5

mocte of action of, 195

multiple nature of, 197, 198

overdosage with, 202 
Vitamin D, as a preventive and cure of rickets, 193

production by ultraviolet light, 196 and radiant energy, 196

requirement, for egg production, 400

for growth, 368, 369

for lactation, 443

meeting in practice, 369

method of measuring, 368

for reproduction, 392

species differences in requirements, 194, 199

stability of, 200

storage in body, 195

and sunlight, 201

unit for, 199

Vitamin $\mathrm{D}_{2}, 198$

Vitamin $\mathrm{D}_{3}, 198$

Vitamin E, 203-206, 397

chemistry of, 205

effects of deficiency of, 203

in foods, 206

requirement, for reproduction, 203, 397

stability of, 205

storage of, 205

Vitamin G, (see Riboflavin)

Vitamin K, 206-208

chemistry of, 207

in feeds, 208

functions and symptoms of deficiency, 206

unit of, 208

Vitamin M, 226

Vitamin P, 230

Vitamins, early studies of, 175-179

fat soluble, 179

history of events leading to discovery, 177-179

synthesis in digestive tract, 231233

water-soluble, 179

in work production, 463

W

Water, alkaline, effect of, 171

balance of, 70
Water, in bone, 118

determination of, 36

factors governing excretion and requirement, 34-36

in fat deposition, 70

metabolic, 33

properties and functions of, 32

requirements, 36

role in body, 32-36

saline, effects of, 171

Waxes, 64

Weende method for crude fiber, 45

Wheat kernel, distribution of nutrients in, 16

Wisconsin experiment with single plants, 2-4

Wool production, 359

Work production, 450-464

absolute energy used in, 456

chemistry of, 451

efficiency of, 454, 457

all-day, 455

comparison with heat engines, 454

effect, of kind of work, 457

of size of horse, 458

of speed, 458

gross, 454

net, 455

energy, expended in, measurement of, 456

requirements for, 458-460

mineral requirements for, 462

nutrients involved in, 450

physiology of, 451-453

protein requirement for, $460-462$

vitamin requirements for, 463

"Working maintenance," 321

\section{$\mathrm{X}$}

X rays, 29

Xerophthalmia, 180

Xylose, 39

\section{$\mathrm{Z}$}

Zinc, 159

Zone of provisional calcification, 123 



\section{Date Due}

\begin{tabular}{|c|c|c|c|}
\hline Ост 16 '51 & 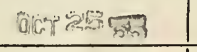 & & \\
\hline $1+912$ & Mov 245 & & \\
\hline Nov 19952 & 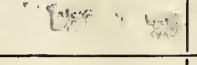 & & \\
\hline $\operatorname{Dec} 42^{15}$ & DeEs C & & \\
\hline Dec19:5? & $.9 g^{90}$ & & \\
\hline $\operatorname{San} 1553^{\circ}$ & - & & \\
\hline Jet $26 \cdot 53$ & FEg & & \\
\hline Nov 3 & $3^{\operatorname{man}} \geq 35$ & & \\
\hline 15 Noy $21 \%$ & 34005 & & \\
\hline Nov30 53 & sescos 962 & & \\
\hline What & $483266^{\circ} 62$ & & \\
\hline 46185253 & Gese $1 P^{2}$ & & \\
\hline oget:ar? & G.SCL OC & 7 & \\
\hline hord 54 & Ifofl 06, & & \\
\hline 0072954 & & Th0 & \\
\hline$\therefore x y$ & & qus comis & \\
\hline$\therefore \mathrm{s} \in \mathrm{m}$ & & $4 x^{4}$ & \\
\hline स⿻y 353 & & 2078 & \\
\hline 5862 & NOV & 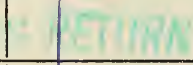 & \\
\hline 067545 & & DUE CAM & pct $16^{\circ} 80$ \\
\hline xwp ? 56 & & 107 08 & AEIUP \\
\hline
\end{tabular}


SF 95 M47 1947 c.1

Maynard, Leonard Amby, 18 Animal nutrition.

$\mathrm{SCI} / \mathrm{TECH}$

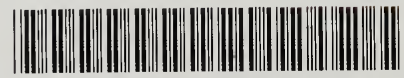

$0 \quad 0004 \quad 4769313$

\section{A37475}

